
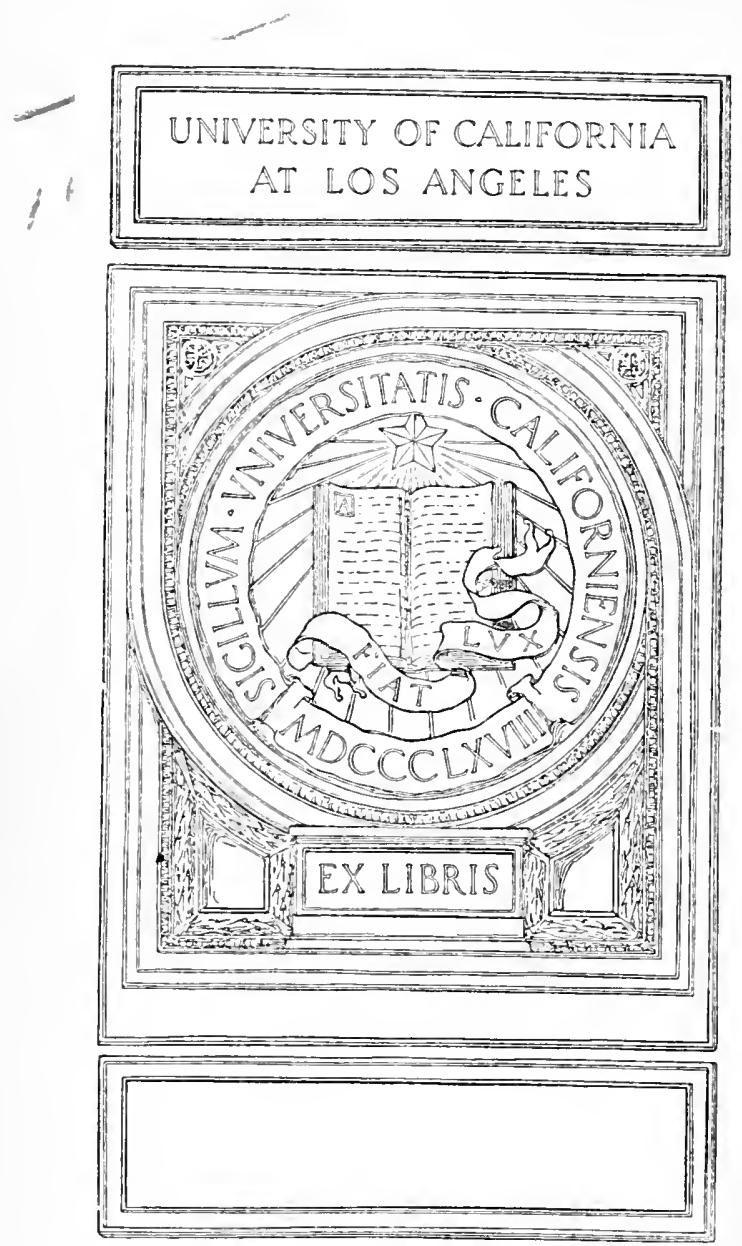
Digitized by the Internet Archive in 2008 with funding from Microsoft Corporation 
、 



\section{THE CAUSE OF BUSINESS DEPRESSIONS}




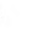

$$
\text { - }
$$




\title{
THE CAUSE OF \\ BUSINESS DEPRESSIONS
}

AS DISCLOSED BY AN ANALYSIS OF THE BASIC PRINCIPLES OF ECONOMIICS

\author{
$\mathrm{BY}$ \\ HUGO BILGRAM \\ IN COLLABORATION WITH \\ LOUIS EDWARD LEVY
}

WITI TWENTY-SIX DIAGRAMS

PIILADELPIIA \& LONDON

J. B. LIPPINCOTT COMPANY

1914 
COIYRIGHT, I 9 I. , BY J. B. LIPPINCOTT COMPANY

FULLISIIED AJIII, I9I4

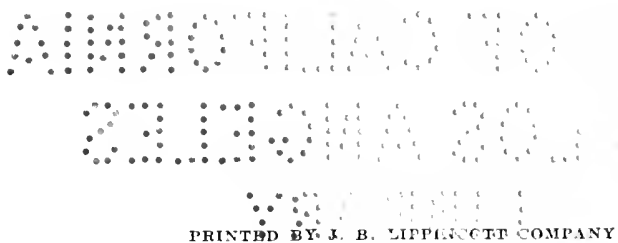

AT THE WASHINGTON SQLARE PRESS

PIILADELPHIA, U. S. A. 


\section{PREFACES}

I

IT is a matter of experience that financial crises and periods of industrial depression continue to recur at successive intervals. As these events bring distress to many of the industrial workers, the question naturally obtrudes itself, is it within the range of possibility to correct this evil? Whether or not this can be done depends on the nature of the eause underlying these business disturbances. If these are the natural outgrowth of industrial progress and commereial development, there can be no hope of avoiding them. If, on the other hand, they are due to some extraneous cause, then there is a possibility of preventing their recurrence and of insuring continued business prosperity. But even then, an effective remedy cannot be pointed out unless that cause is first clearly understood.

It was through a desire to obtain an insight into this problem that $\mathrm{I}$ became interested in the study of political economy, but a careful reading of various works on the subject left me still in the dark. The several explanations of those economic adversities advanced in economic literature appeared to me altogether unsatisfactory.

Convinced that there must be some definite cause for the recurrent periods of business depression, I continued my investigation on basis of those economic propositions which are manifestly true, and, proceeding by methods of purely logical deduction, I was led to conclusions which in many particulars conflict with the currently accepted economic teachings, but which furmish a full and complete explanation of those disturbanees and show them to be the symptoms of a curable economic disorder.

My occupation leaving me but seant leisure in which to put these conclusions in shape for publication, my earlier writings on the subject were but fragmentary and incomplete. Latterly, however, through the sympathetic eo-operation of another stu- 


\section{PREFACES}

dent interested in the same line of investigation, these conclusions have been wrought into the form of the present work, which is presented as a contribution to the discussion on this most important question.

Acknowledgment of my obligation is due not only to my collaborator, but also to the late Herman V. Hetzel for assistance in my earlier studies, and to my son, Oscar H. Bilgram, for valuable counsel in the preparation of this work.

Hugo Bilgram.

\section{II}

The plan of the present work had been outlined and its foundation laid by my collaborator when my interest in its subject-matter led to my joining him in bringing it to its present form. That interest had long before been aroused by the turmoil of contention between labor and capital over their respective shares of their joint products, and between political parties over systems of money, and by my contemplation of the significant fact that these conditions had developed as an accompaniment of the vastly increased productiveness of industry which is so marked a feature of our modern time.

That the existing economic tension, which finds expression in combinations of capital to restrain competition in the market of goods and in combinations of wage-earners to restrain competition in the market of labor, and in the efforts of both classes, each in its own interest, to restrict production, is caused by some distortion in the economic system is evident enough, and that there is imperative need of some effective means of relieving the strain is likewise manifest.

To learn what remedy there might be for these unnatural conditions I had turned, like my collaborator, to the literature of economies, and out of the confusing maze of contradictory teachings on the subject I had found my way to the conclusion that the rancorous discords which make of our modern industrial and commercial life an arena of embittering strife are engendered by defects of our monetary system which give 
to capital an undue advantage over labor. Furthermore, that no tax reform, no social or political reform can remove the cause of the prevailing economic discord, and that nothing but a simple readjustment of our monetary system is needed to that end.

The reasons for our conclusions could not be made plain without such thoroughgoing analysis of the basic principles of political economy as my collaborator had planned, and our joint task has been to present these principles without more technical detail than might be necessary for their demonstration and to point out their application in such manner as would make the subject plain, not only to the specializing student, but to every other intelligent reader as well.

Louis Edward Levy. 



\section{CONTENTS}

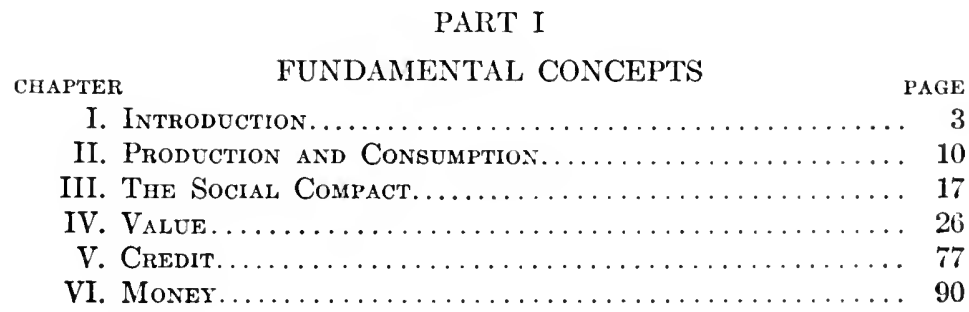

PART II

DISTRIBUTION OF WEALTH

VII. The Process of Apportionment................. 159

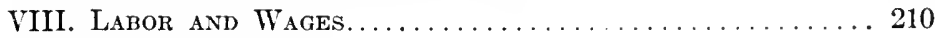

IX. Land and Rent........................... 221

X. Capital Goods and Capital Returns...........240

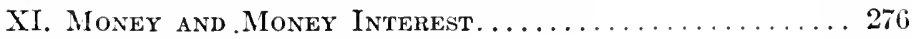

XII. Chance Profits and Losses. . . . . . . . . . . . . . . . 289

PART III

RESTRAINTS ON INDUSTRY

XIII. Monopoly................................ 301

XIV. Monopoly Theory of Interes' $\ldots \ldots \ldots \ldots \ldots \ldots \ldots \ldots . \ldots \ldots 11$

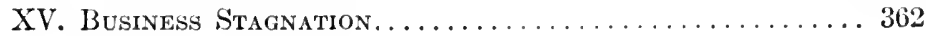

\section{PART IV \\ CONCLUSIONS}

XVI. Currency Reform...................... 38?

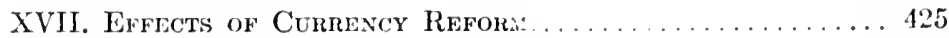

XViII. Old Problems in a New Light................ 456

Appindix. Comments on the United States Banking and Currency Law, Approved December 23, $1913 \ldots \ldots \ldots \ldots \ldots .515$

List of A UTHORS Quoted ......................... 519

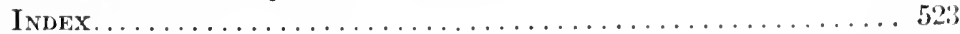

Plates of Diagrams ........................... 533 


\title{
SYNOPSIS
}

\author{
PART I \\ FUNDAMENTAL CONCEPTS
}

PAGE

Chapter I.-Introduction......................... 3

1. Theory as Applied to Economics. 2. Theory and Practice. 3. Induction and Deduction.

4. Plan of Present Investigation.

Chapter II.-Production and Consumption.................

5. Motives of Human Activity. 6. The Process of Developing Utilities.

7. Production. 8. Labor Defined. 9. Labor Embodied in Products. 10. Means of Production. 11. Specialization of Labor. 12. Distribution a Factor in Labor Specialization. 13. Waste Attending Production.

14. Consumption.

Chapter III.-The Social Compact.....................

15. The Elements of Association. 16. Composite Persons.

17. Rights, the Bonds of Association. 18. Legal Rights. 19. Right and Duty. 20. Definition of Equity, 21. The Right of Ownership.

22. The State and its Function.

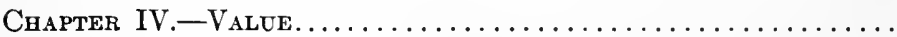

23. Significance of the Term. 24. Distinction between Value and Utility. 25. Definition of Value. 26. Market Value. 27. How Values Are Measured.

28. The Unit of Value. 29. Price. 30. Labor as a Measure of Value. 31. Other Value Units. 32. Expediency of a Composite Unit.

33. The Theory of Value. 34. Supply and Demand Defined.

35. Subjective Valuation. 36. Desire the Impelling Force. 37. Limitation of Demand. 38. Böhm-Bawerk's Illustration. 39. Graphical Representation of Utility. 40. The Question of Quantity. 41. Reluctance the Restraining Force. 42. Graphical Representation of Effort. 43. The Point of Equilibrium. 44. Choice as Regards Production. 45. Choice as Regards Consumption. 46. Advantages of the Graphical Method of Study.

47. Barter. 48. The Buyer's Price Limit. 49. The Seller's Price Limit. 50. Exchange Rate in Barter. 51. Buying and Selling. 
52. The Market. 53. The Common Value Denominator. 54. Appraisement of the Value Unit. 55. Interdependence of Prices. 56. Price Limits Compounded. 57. Relation of Supply and Demand to Price. 58. The Law of Value. 59. Current Price. 60. Normal Price. 61. Cost, the Sellers' Price Limit.

62. Cost and Utility Theories of Value. 63. Both Theories Corollaries of the Same Proposition.

64. Illustrations.

65. Capitalized Values.

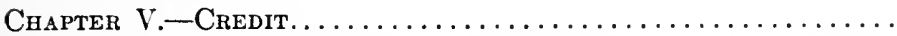

66. The Nature of Credit. 67. The Right of Ownership Analyzed.

68. Credit Defined. 69. Three Forms of Credit. 70. Divergent Conceptions of Credit. 71. "Possession" Versus "Ownership."

72. The Substance of Credit. 73. Superposed Credits. 74. Public Credit.

75. The Value of Credit. 76. Depreciated Credit.

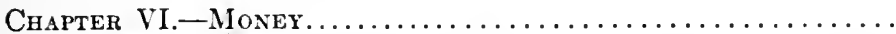

77. Misconceptions Regarding Money. 78. Money not a Value Denominator. 79. "Dollar" does not Mean "Money." 80 . Money not a Store of Value. 81. Money not a Standard of Deferred Payment. 82. Importance of Sharp Definitions.

83. The Function of Money.

84. The Distinctive Feature of Money. 85. Money a Product of Social Compact. 86. Monetary Laws. 87. The Right Conveyed by Moncy. 88 . The Term "Money" in its Broadest Sense.

89. The Theory of Money. 90. Money Analogous to Book Accounts. 91. Creditors and Debtors of the Moncy System. 92. The Issuer of Currency is Debtor.

93. Standard Money. 94. Holder of Standard Money both Creditor and Debtor.

95. Legal-tender Notes. 96. Depreciated Currency. 97. Fiat Money. 98. History of Legal-tender Laws. 99. Legaltender Quality not Essential to Money.

100. Subsidiary Coin.

101. Bank-note Currency. 102. The Real Issuers of Bank Currency. 103. Evolution of Modern Banking.

101. Bank Credit. 105. The Real Issuers of Bank Credit.

106. Subordinate Systems.

107. The Value of Money. 108. The Value of Gold, 109. The Price of Gold. 110. Bimetallism. 111. Composite Value Units. 112. Depreciated Value Unit. 
113. The Seignorage Theory. 114. The Seignorage Theory Untenable.

115. The Volume Theory of the Value of Money. 116. Ricardo's Statement of the Volume Theory. 117. Mill's Argument. 118. Mill's Reasoning Analyzed. 119. Newcomb's Argument. 120. Newcomb's Reasoning Analyzed. 121. Valid Deductions from Newcomb's Equation. 122. The Volume Theory in the Light of History. 123. The Volume Theory Inconsistent with Facts. 124. Seeming Confirmations of the Volume Theory, 125. Minor Incongruities of the Volume Theory.

\section{PART II \\ DISTRIBUTION OF WEALTH}

Chapter VII.-The Process of Apportionment............. 159

126. Statement of the Problem. 127. Modern Industrial Methods.

128. The Factors of Production. 129. What is Capital? 130. Land a Form of Capital. 131. The Three Forms of Capital. 132. Classification of Capital Goods. 133. Active and Idle Capital. 134. Money is always Idle Capital.

135. The Conception of Capital as a "Fund."

136. Classification of Incomes. 137. Wages and Profits. 138. Classification of Profits. 139. Gross Profits of Capital. 140. Gross Business Profits.

141. Composition of Productive Groups. 142. Active Agents. 143. Passive Agents. 144. The Venturer. 145. Composite Agents. 146. The Employer.

147. Competition, the Controlling Force. 148. Direct Effects of Competition. 149. Indirect Effects of Competition. 150. The Law of Value Presupposes Free Competition.

151. Apportionment of Proceeds of Production. 152. The Function of Capital Goods in the Apportionment. 153. The Value of Capital Goods. 154. Apportionment within Groups. 155. Economic Relations of Labor and Capital. 156. Influence of Capital on the Productivity of Labor. 157. Graphical Analysis. 158. Effect of a Varying Interest Rate. 159. Effect of Interest Rate on Wages. 160. Effect of a Varying Wage Rate. 161. Graphical Analysis by Differentiated Function. 162. Final Efficiency of Capital.

Chapter VIII.-Labor and Wages........................

163. The "Wage Fund" Theory. 164. The Wage Theory of Socialism.

165. Three Forms of Wages. 166. Wages Apportioned through Competition. 167. Employers' Wages. 168. Merchants' Wages.

169. Adjustment of Wages. 
Chapter IX.-Land and Rent.

170. Land the Prime Source of Wealth. 171. Land Distinguished from Improvements Thereon.

172. Ricardo's Law of Rent. 173. Graphical Representation of Ricardo's Law. 174. Misinterpretations of Ricardo's Law.

175. The Margin of Cultivation. 176. Cumulative Rent.

177. Intensity of Cultivation. 178. The Point of Diminishing Returns.

179. The Personal Factor in Rent.

180. The Source of Rent.

181. Land Values. 182. The Law of Land Value. 183. Speculative Land Value. 184. Division of the Gross Profits Derived from Land.

185. Summary.

Chapter X.-Capital Goods and Capital Returns.

186. Capital Interest. 187. Distinetion of Capital Interest and Rent. 18S. Distinction of Capital Interest and Money Interest. 189. Current Theories of Interest.

190. Calvin's and Turgot's Explanation of Interest.

191. The Productivity Theory of Interest. 192. Analysis of the Productivity Theory. 193. Interest Ascribed to Nature's Reproductive Powers. 194. Interest Theory of Henry George.

195. Inception of the "Abstinence" Theory of Interest. 196. Senior's Abstinence Theory.

197. Böhm-Bawerk's Theory of Interest. 198. Utility Theory of the Value of Capital Goods. 199. Time Involved in Production with Capital. 200. The Value of Lending. 201. Relation of Money to Merchandise. 202. Money never "Present" Goods. 203. Money never a Means of Production. 204. Calvin's Reasoning. 205. Interest as an Induccment to Production of Capital. 206. Summary.

207. The "Surplus Value" Theory. 208. The Theory Inconsistent with Facts.

Cinapter XI.-Money and Money Interest

209. Interest on Money Joans. 210. Money Interest is Paid for the Use of Money. 211. The Industrial Function of Money.

212. Efficiency of Money. 213. Final Effieiency of Money. 214. Significance of the Phrase "Efficiency of Money."

Chapter XII.-Chance Profits and Losses.................

215. Chance as an Economic Factor.

216. Profits and Losses from Changes in Value. 217. Profity to be Distinguished from Wages. 218. Cambling.

219. The Element of Risk. 220. Insurance. 
221. Economic Inertia. 222. Factors of Economic Inertia. 223. Economic Momentum.

224. The Law of Chance Profits.

PART III

RESTRAINTS ON INDUSTRY

Chapter XIII.-Monopoly.......................... 301

225. Economic Impediments. 226. Monopoly Implies Restraint. 227. Ethics of Monopolies.

228. Ownership a Form of Monopoly. 229. Patent and Copy Rights. 230. Land Ownership. 231. Franchises Depending on the Use of Land. 232. Impersonal Monopolies. 233. "Cornering" the Market.

234. Monopoly Incomes. 235. The Power of Monopoly.

Chapter XiV.-The Monopoly Theory of Interest......... 311

236. Usury Laws. 237. Distinction between Usury and Interest.

238. Money Subject to an Impersonal Monopoly. 239. The Supposed Danger of "Inflation."

240. Interest on Money Due to Competition for Money.

241. Cause of the Inadequacy of Capital. 242. Key to the Theory of Capital Interest. 243. The Missing Link in the Productivity Theory.

244. The Law of Interest. 245. The Barren Circulation of Money. 246. The Growth of Loan Debts. 247. Differentiating the Financial from the Industrial World. 248. The Several Barren Currents. 249. Preparatory Currents. 250. The Volume of Active Funds. 251. The Volume of Loan Debts. 252. The Rate of Interest. 253. A Seeming Contradiction. 254. Effect of the Interest Power of Money. 255. Inevitable Consequence. 256. Effect of Business Failures on Pure Interest.

257. Rate of Capital Interest. 258. Capital Interest an Intramarginal Profit.

259. Currency Laws Examined. 260. Existing Currency Laws Inequitable. 261. Pure Interest a Monopoly Tax. 262. The Power of the Money Monopoly.

263. Service Rendered by the Lender of Money. 264. The Third Item of Gross Interest. 265. Service Rendered by the Capitalist. 266. Abundance of Real Capital.

267. Summary.

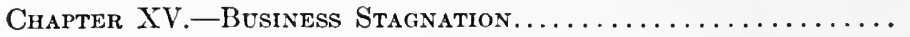
362

268. Involuntary Idleness. 269. Excess of Supply over Demand. 270. Insufficient Supply of Money the Cause. 
; 271. The Cycle of Industrial Activity. 272. First Period. 273. Second Period. 274. Third Period. 275. Fourth Period. 276. Succession of Cause and Effect.

277. Current Explanations of Business Stagnation. 278. Overtrading. 279. Improvident Investments. 2s0. Undue Expansion of Credit. 281. Loss of Confidence. 282. Hoarding of Money. 283. Extravagance. 284. Effect of Tariff on General Business Conditions.

\section{PART IV CONCLUSIONS}

Chapter XVi.-Currency Reform.................... 383

2S5. Essentials of a Sound Currency.

286. The Security of Money. 287. The Issuer's Pledge. 288. The Agent's Pledge. 289. Insurance of Currency. 290. Insurance of Bank Credit. 291. The Natural Limit of the Volume of Currency.

292. Currency Redemption. 293. The Demand for Gold. 294. Can the Monetary Demand for Gold be Reduced? 295. Centralized Redemption. 296. Deferred Redemption. 297. Procuring Gold for Redemption.

298. The Communal Agreement. 299. The Process of Issuing Currency.

300. Money Tokens. 301. The Cost of Issuing Currency.

302. Plan of Currency Reform. 303. Organization of Banks of Issue. 304. Deposit Insurance. 305. Missing or Lost Notes. 306. The Legal-tender Quality. 307. The Function of Banks of Issue. 308. Summary.

309. A Credit Clearing System. 310. Ways and Means of the System. 311. Payment of Individual Balances. 312. Deferred Payments. 313. Issue of Notes. 314. Advantages of the System.

Chapter XViI.--Effects of Currency Reform............ 425

315. Direct Results. 316. Indirect Results.

317. Unfounded Apprehensions. 31S. Natural Indurements to Save. 319. Inducements to Invest Savings. 320. Opposition to Curreney Reform. 321. The Inereasing Cost of Living. 322. A Real Souree of Danger.

- 323. The Land Question. 324. The Right of Land Ownership. 325. Land Laws Examined. 326. Land Ownership a Vested Right. 327. Bearing of Curreney Reform on the Iand Question. 328. $\Lambda$ Concrete Illustration. 329. Land Values Tantamount to a Public Debt. 330. Assessment of I and Values. 331. Exemption of Fixed Improvenents from Taxation. 332. The Tax Rate. 333. Land Tax Ample for I'ublic Needs.

334. Exclusive Rights or Franchises. 
Chapter XVili.-Old Problems in a New Light........... 456

335. Diagnosis of the Economic Disorder.

336. Capital not Productive. 337. The "Almighty" Dollar. 338. The Concentration of Wealth. 339. Efforts to Curb the Concentration of Wealth. 340. Corporation and Bankruptcy Laws.

341. Public Debts.

342. The Strife of Competition. 343. Competition in a Moneyless Community. 344. The Advent of Money. 345. The Real Battle-ground. 346. Significance of the Illustration.

347. The Iron Law of Wages. 348. The Employer's Part in the Process of Apportionment. 349. The Downward Tendency of Wages. 350. Effect of Proposed Currency Reform on Wages.

351. Protective Tariff. 352. Balance of Trade Co-related to Rate of Interest. 353. Advantages of a Tariff.

354. Trade Unions. 355. Labor Legislation. 356. Arbitration of Labor Disputes. 357. Strikes and Boycotts. 358. What Trade Unions Accomplish.

359. The Single Tax. 360. Ethical Status of Land Ownership. 361. Henry George's Theory of Business Fluctuation. 362. Analysis of this Theory. 363. Discrepancy between that Theory and Facts. 364. Single Tax not a Remedy.

365. Socialism. 366. Theory of Socialism. 367. Impracticability of Socialism. 368. Communism.

369. Anarchism. 370. Land Tenure under Anarchism. 371. Theory of Anarchism Regarding Price.

372. Conclusion.

\section{APPENDIX}

Comments on the United States Banking and Currency

Law, Approved December 23, 1913............... 515 


\section{REFERENCES AND CROSS REFERENCES}

THE index at the end of this volume is supplemented by references and cross references inserted in the text. The numbers enclosed in parentheses refer to the serial numbers of the paragraphs.

For illustration, in paragraph 1 will be found the referenee $(43,329)$. Both these numbers have their counterparts in the paragraphs 43 and 329, indicated by the number (1). The statements so marked are co-related. Where there are several cross references in the same two paragraphs, they are distinguished by letters. Thus in paragraph 56 there are two references to paragraph 39 which are marked in paragraph 39 by (56a) and $(56 b)$, and in paragraph 56 by $(39 a)$ and $(39 b)$.

When a reference relates to a subject treated in several consceutive paragraphs, the counter reference in the text referred to is omitted. See, for instance, the mark (36-38) in paragraph 48, which has no counterpart in either of the paragraphs 36,37 or 38 . 


\section{PART I}

\section{FUNDAMENTAL CONCEPTS}





\section{THE CAUSE OF BUSINESS DEPRESSIONS}

\section{CHAPTER I \\ INTRODUCTION}

1. Theory as Applied to Economics.-Almost from the beginning of the modern system of production industrial progress has been attended by economic disturbances which have gradually widened their compass from comparatively localized extent to national and even international proportions. While the need of preventing such disturbances is universally recognized, none of the remedies thus far applied has proved efficacious.

Before such remedy can be prescribed, it is necessary that the cause of the evil be clearly understood. Why is it that in these modern days, when signal advances in seience and the arts have led to improvements in the means and methods of production in every direction, there are times when multitudes of workers find themselves brought to want and privation for lack of the very things. the production of which has been so greatly facilitated? Why is it that "good times," when employment can be had by all who seek it, are periodically succeeded by "hard times," when thousands are thrown out of employment in practically every branch of industry and commerce? Why, in short, are the processes of production and exchange subject to interruptions which are attended by so much misery?

For answer to these questions we must look to the science of economics. But it is frequently said that in this field the rigid treatment which is used in the exact sciences is not applicable, because no given economic condition affects all men alike. This uncertainty, however, cannot aceount for the prevalence of the many opposing views on economic subjects, nor 
for the great divergence of conclusions derived from presumably identical premises. Disagreement among men of affairs on questions like Protection and Free Trade might well arise from a divergence of business interests, but similar discord among students can be accounted for only by errors of reasoning.

Differences in the disposition of men who compose the body social unquestionably introduce a difficulty in the study of economies, but this difficulty cannot be greater than that met with in the theory of chance. An illustration will make this elear.

A marksman firing a large number of shots at a target will find the bullet holes spread over it, clustered thickly near the centre and more widely scattered toward the circumference $(43,329) .^{1}$ If the shots are fired under normal conditions, measurements will show that the geometric centre of all the marks practically coincides with the bull's-eye. If, on the other hand, abnormal conditions prevail, unknown to the marksman, such as a steady cross wind, the geometric centre of the shots will be displaced precisely as much as a single shot would be deflected, had it been aimed true.

Although the presence of constant disturbing factors is not revealed by a single shot, owing to uncertainty in the aim, nevertheless a large number of shots will plainly diselose the existence of extraneous influences. While it is impossible to predict where a single shot will hit, even though all conditions are known, the average location of a large number of shots can be definitely calculated from the velocity of the wind or the intensity of any other known disturbing influence.

So in economic questions it is hopeless to forecast in individual cases what would result from given conditions. The personal differences in men introduces uncertainty, just as the unsteadiness of the hand of the marksman disperses the shots. But this fact does not preclude the possibility of formulating the rules that govern the general trend or average effect of any given cause, however variable its effect may be in in-

\footnotetext{
${ }^{1}$ See note concerning references on page preceding Chapter I.
} 
dividual cases. To determine these rules it is necessary that only the essential factors be taken into consideration, while the merely incidental influences are left out of account, or, as in our illustration, that we distinguish between the steady wind which affects all the bullets alike, and the quivering of the hand which accounts for the scattering (215). By considering only the constant forces and leaving out of account the momentary factors, conclusions can be reached which, while not applicable to every individual case, are yet true as regards the conditions generally. To find general laws, then, is all we can expect to accomplish, and if this is kept in view, there can be no room for disagreement in the deductions obtained from accepted premises.

2. Theory and Practice.-In his endeavor to obtain from surrounding nature with the least exertion all that can make life enjoyable, man has learned to make the powers of nature subservient to his desires. This lias been achieved principally through the advances made in science and the arts. By studying facts, the relation that exists between eause and effect has been found and formulated into "laws," and these make it possible to foresee what must result if certain known causes are at work, and also to show the way to utilize the forces of nature when certain results are desired. Theory based on ascertained facts has been an important factor in the process through which we have obtained mastery over the powers of nature, and since true theory is founded on an accurate unclerstanding of facts, such theory nust be borne out in practice.

It is, however, quite natural that mistakes are occasionally made. When theories are founded on a misinterpretation of facts, or when sound theories are incorrectly applied, the reasoning must lead to faulty conclusions. It thus happens only too often that what is supposed to be true in theory is not confirmed by the facts.

This has thrown more or less doubt on the utility of theoretical deduction, particularly where, in addition, a known cause is found not to produce the same effect in different cases. Failure in the application of theory should, lowever, inspire caution rather than distrust in the efficacy of deductive 
reasoning. The fact that this method has often been misapplied is no reason why it should be rejected in the investigation of phenomena which the inductive method has failed to explain.

There are cases where a certain effect is due to a combination of several different causes. Such cases can be effectively investigated only by considering each of the different causes separately. It is then often found that some one of the causes at work is the predominant factor, and, in order to analyze the conditions, the minor and merely modifying causes are primarily left out of consideration. Conclusions so derived are known as "theoretical" results, and these cannot, of course, be expected to agree more than approximately with the actual facts. If subsequently in any given case the omitted factors are also taken into account, the theoretical result is thereby corrected and is then generally found to be in practical agreement with the facts. Thus the engineer computes the power of a steam engine he is designing by first considering the propelling power of the steam, and from this he deduces the theoretical horse-power. But since this amount is reduced by friction, the loss so incurred must be subtracted from the first result to obtain the effective power.

Discrepancies between theory and practice which are due to incomplete analysis do not prove that the theory is wrong. There are in fact many problems that can be solved only by dealing primarily with the dominant factors of the case and considering the minor factors only so far as they modify the effect of the dominant cause. Most notable of this class of problems are those of economics, and we shall therefore pursue this course in treating the subject before us.

3. Induction and Deduction.-As already noted, the method of deductive reasoning in the study of economics has been held to be unreliable for the reason ihat all men do not react alike to the same impulses. It is therefore assumed that this study must begin with observation of facts and classification of statistics, from which to determine the cause or causes that produce the observed results. In other words, it is held that only inductive reasoning from observed facts can lead to reliable conclusions. 
However valid the conclusions of inductive reasoning may be in some instances, the faet remains that if the methods of deductive reasoning were to be exeluded from the study of eeonomies, this seience would be of no practieal use. Induction is a process of reasoning from effect to cause, neeessary for diseovering laws of nature, while deduction is a process of reasoning from cause to effect, applied in utilizing the knowledge already acquired, either for the purpose of learning what result must follow from given conditions, or what conditions are requisite for the attainment of a desired result. The two methods are complementary. In fact, when through the process of inductive reasoning a law of nature has been discovered, it should stand the test of deductive application to all cases within its province. When Isaac Newton, by observing certain faets, discovered what appeared to him a general law of gravitation and put it to a test by trying to explain the orbital motion of the moon, he found a discrepaney that made him hesitate in aecepting his inference. Many years later, when a new measurement of the earth's diameter diselosed decided inaeeuracies in former measurements, he repeated his computation on the new basis and found that the diserepancy disappeared. Then only did he feel justified in proclaiming his discovery to the world. He did not accept the law whieh the inductive method suggested to his mind before he had verified it by deduetive applieation in a crucial test.

If all theories were similarly tested before their acecptation, the widespread distrust of theory, especially in ceonomics, would never have gained ground. But it appears that in many instances students of economics, legislators, and particularly would-he soeial reformers fail to take this preeantion. Imbued with the notion that economic laws can be discovered only through studying statistics, they rely too mueh on these and base their plans of reform on theories whieh have no other foundation than the mere coineidence of certain facts. 'That opposite theories are often based on the same set of statistics, by merely picking out different sets of coincidenees, shows how easy it is to be misled by methods of induction and how diserepaneies in eeonomie theory are apt to originate. 
Furthermore, in the effort to prove a point, recourse is often had to voluminous quotation from various authorities. This is apt to degenerate into dogmatism, which is out of place in the scientifie treatment of any subject. Parallel quotations are quite in order as serving to show that certain propositions have been propounded before, but not if they are offered as proof of the validity of any proposition. Every demonstration should be conclusive in itself and should not require an appeal to extraneous authority for confirmation. A scientific truth cannot be established by a majority vote.

4. Plan of Present Investigation.-As already stated, the primary object of the present investigation is to learn the cause of financial crises and the attendant business depressions, and its aim is to find a remedy. The subject being clearly within the province of economies, the most promising course is to begin with first principles and consistently to pursue the search, wherever it leads, no matter whether the conelusions agree or conflict with aecepted views. Before entering upon the inquiry we should clearly understand the scope of economics, and the following is a comprehensive statement of the case.

The subject of economics comprises those social relations which arise in the course of the co-operative efforts of men to satisfy their needs and gratify their desires. A clear understanding of these relations is necessary in order properly to determine what laws and conventions will promote the general well-being.

The first part of the present treatise is devoted to laying an adequate foundation for the subsequent investigation. To this end the chief elemental factors, as "right," "ownership," "value," "credit," "money," are sharply defined and the conceptions analyzed.

The second part comprises a study of the processes by which the value of the products of industry is apportioned among the agents of production. The inquiry is directed particularly toward finding what determines the sharing of the produets or their value between the workers, on the one 
hand, and the owners of the material with which they work, including land, on the other.

In the third part follows a study of the principal sociopolitical factors which obstruct economic development. This examination leads to a rccognition of the fundamental cause of business depressions.

The fourth part comprises several chapters, in the first of which the conclusions reached in the preceding chapters are utilized in pointing to ways and means for removing the cause of business depressions. The second is devoted to a consideration of the natural consequences of such a course. 'The elosing chapter contains a review of current economic doctrines in the light of the conclusions derived in our examination.

In the treatment of the subject, which, as already stated, proceeds on lines of deductive reasoning, mathematical methods are utilized wherever found advantageous, but nothing more complex than elementary algebraic formulas and simple analytical diagrams is employed. An earnest effort is made to avoid abstruseness, so that the reader will be able to follow the argument with ease and to pass judgment for himself upon the validity of the conclusions. 


\section{CHAPTER II}

\section{PRODUCTION AND CONSUMPTION}

5. Motives of Human Activity.-Before entering upon the examination of the relations between men arising in the course of their co-operative efforts, a brief survey of the motives of human activity will prepare us better to understand the later investigation. We shall first touch upon the reasons why men exert themselves, and especially why they prefer to work in co-operation. These reasons are independent of the form of social organization; they exist whether individual freedom prevails or whether men are bound together in some socialistic or communistic assoeiation. We are now dealing with the relations that exist between man and nature, and not with those which arise between man and man.

The impulse to exertion springs from human needs and desires. The means through which these needs and desires can be satisfied are furnished by nature, but these are always in such a form that their ntility is not available without human effort. Even wild growing fruit must be gathered. In most eases the labor required is more or less complex, a number of suceessive operations being necessary to prepare the products of nature for man's requirements.

6. The Process of Developing Utilities.-Utility, namely, the eapability of things to satisfy needs or gratify desires (24), is present in the materials furnished by nature in a latent or immature state, and the procedure which makes it available ean aptly be likened to a maturing process. Similarly, products in their more or less advanced stages, as well as in their natural condition, may be termed immatured products. Maturity, in this sense, is not attained until the thing is ready for final use. Sugar, for instance, is generated by a vital process in plants, particularly in sugar-cane, but to obtain sugar for man's purposes the cane must be eultivated and harvested, the juice expressed and evaporated, and the crystals 
so obtained transported to refineries where, by a series of chemical and physical processes, the impurities are removed. But even then the sugar is not an economically mature product. The grocer, in bringing it to his store, performs one of the necessary acts, and a fuither advance is made when the purchaser takes it home. Viewed economically, a pound of sugar in the pantry is more nearly mature than an equal quantity at a grocer's or at a refiner's. And even in the pantry it is not fully matured, for the labor of the cook is required to make it a constituent of the food in which it will be finally applied to its ultimate use.

7. Production.-The process termed "production," by which utilities are developed or matured, not only embraces the vital, the physical, and the chemical changes of the wealthforming material, but also those transfers from place to place and from hand to hand, through which the things are forwarded toward consumption.

Every product of nature has a range of utilities peculiar to itself. Only such utilities as are included in this range can be developed by labor. Utilities cannot be created; they can only be developed where they exist in potential form. Iron can be obtained only from ores containing iron. Sand cannot be twisted into a rope, no matter how much labor may be applied. And in materials possessing capabilitics of the same kind, differences exist by reason of which different amounts of effort are required to make them useful. It takes more labor to obtain copper from ores in the form of oxides than from those containing copper in a native state. The growing of agricultural produce takes more labor on sterile than on fertile soil. Such specific differenees ean be taken into account by considering all these products as being furnished by nature in different stares of maturity, some requiring more, others less labor to develop their utility (180). It thus happens that many products of nature in their native state are as nearly mature as other products to which more or less labor has already been applied. 
8. Labor Defined.-In eeonomie discussion the word "labor" should be understood as denoting all human efforts directed to a useful end. These efforts may be of a manual or of a mental nature. All efforts are labor, in so far as their aim is the development or preservation of utilities, or as they are directed towards satisfying some need or desire. In the meaning of this term are to be included not only the efforts of tillers of the soil, miners, artisans, carriers, but also those of directors of industrial enterprises, merchants and clerks, teachers and preachers, musicians and actors, doctors and lawyers; in short, all services that are in demand. In modem progress everincreasing importance attaches to mental labor, for manual labor is made vastly more effective through the directing effort of mind.

9. Labor Embodied in Products.-As a rule there is a greater or less interval of time between a productive effort and the gratification to be obtained through it. This becomes possible through the capability of matter to retain, at least for a time, the impress of labor applied to it. It may be said that matter absorbs and preserves the labor through which utilities are advanced toward maturity. Such matter, then, becomes the embodiment of labor and the medium through which the services rendered by labor can be conserved and transferred at pleasure from place to place and from one person to another.

The eapacity to absorb and retain the effect of labor is not confined to inanimate things alone, but is also present in the physical and mental attributes of man. The mother teaches the ehild the rudiments of knowledge, the teacher imparts general and speeialized instruction, the diseoverer widens the horizon of our understanding, and the inventor broadens the scope of our capacities. It is by education and training that man is prepared to perform his work, and by practice that his skill is developed.

The term "unproductive labor" is frequently applied to efforts such as dramatic performanees, the rendering of music, delivery of lectures, and so forth. But the only essential difference between these and other productive efforts consists in the difference of time which elapses between the moment of 
production and that of consumption. Although in such eases production and consumption are unavoidably simultaneous, the performance of such labor includes all the features of the process of production. All products of labor being more or less perishable, the distinetion between so-called produetive and unproductive labor is in the last analysis only a matter of time, and the term "unproductive" is therefore a misnomer.

Io. Means of Production.-The modern processes of pro- duction are generally complex and are characterized by the proportionately large amount of labor devoted to the making of things that are not destined to become integral parts of the final product, and which, in fact, serve only as means of completing that final produet. Whether these means of production be tools, machines, factories, railroads, stores, and so forth, they are in themselves ineapable of satisfying ultimate needs or desires. Nevertheless they are produced for that purpose and with that end in view. The making of a trowel is as truly a step toward the building of brick houses as is the making of the brieks; but though the trowel itself is a finished implement, its utility is only potential or immature, for its purpose is the house, which is the thing possessing the ultimate utility. The objeet of making a loom is to produce garments, and the maker of the loom assists in the manufacture of all the cloth that will ever be woven on this machine. In the economie sense, the labor spent in building the loom is absorbed by the cloth as the loom gradually wears out (14, $132,153,197)$.

In the endeavor to increase the effieieney of labor the means and methods of production have been improved and multiplied. $\Lambda$ s a result they have become more and more complex, and an endless variety of ways of aceomplishing the same end have come into use (156a). As a rule, every increase in the efficieney of labor is coincident with greater complexity in the method. It does not follow, however, that every expansion in the means and methods of produetion yields increased advantages. Just here the intelligence and forethought of man heeomes an all-important factor, for even in the effort for betterment exeess is not impossible. Improve- 
ment of appliances, for instance, can be of advantage only if the extra cost of making and maintaining the improvement does not exceed the saving that can be effected thereby. Otherwise the use of such improvement becomes a source of loss (156b).

I I. Specialization of Labor.-In the application of means of production both specialization of industry and co-operation are almost always involved. Long before the invention of labor-saving machines it was recognized that great advantages could be gained by each worker acquiring skill in some one trade and restricting his activity to that specialty. With the introduction of modern appliances the specialization of work, or, as it is more generally called, the division of labor, has been carried into the minutest details of every industry, and this has necessarily been attended by co-operation, so that now in many branches thousands of workmen are employed under one direction. In this way the application of machinery, the specialization of labor, and the aggregation of workers combined bring about the vast increase of productivity which characterizes the present age.

12. Distribution a Factor in Labor Specialization.-There is, however, one factor that in some measure reduces the gain derived from the division of labor. All systems of specialized production necessitate the additional labor of distribution, and this is particularly marked in the modern industrial world. The work of the transporter and of the distributer is indispensable. But the gain from the division of labor far exceeds the cost of this work.

The work of transportation has brought into existence some gigantic organizations, particularly since the advent of the locomotive and the steamship; and the work of distribution requires the labor of countless merchants and tradesmen in collecting the great staple articles in wholesale centres and effecting their distribution to the consumers through retail channels.

A part of the merchant's business is to bring his goods to the notice of the public, which he may do in various ways, generally by exposing them to view or by advertisement. The 
prospective purchasers are thereby informed where certain goods can be obtained. The labor devoted to disseminating this information is manifestly part of the labor of distribution. Simply placing an article in a store where such things are known to be sold imparts to it a share of this labor, and its utility is thus advanced a step nearer to maturity (217).

I3. Waste Attending Production.-There is one more factor that is worth considering at this point. The output of products is often diminished by unavoidable waste as well as by accident. In many branches of industry loss is unavoidable through some part of the products becoming useless in the process of manufacture and distribution (58), and all efforts toward preventing or reducing loss of any kind are on a par with productive labor. In spite of the utmost effort waste will occur, and the best that can be done is to minimize it. But this cannot economically be carried beyond the point where the saving will compensate for the labor involved (219).

14. Consumption.-In the process of production material is prepared for the purpose of meeting human needs. In the process of consumption the products so prepared fulfil this purpose. In common parlance the latter term is generally used only in connection with food and drink, but we must here understand it in a broader sense. Thus not only food, but also clothing, furniture, houses, in short, all products of labor, undergo consumption when they are used to satisfy human wants.

As a rule, every step in the process of consumption brings about a partial or complete destruction of that utility which was developed in the process of production. Food, viewed as an economic product, is totally destroyed when it is eaten Clothes, when worn, deteriorate by degrees until they are finally worn out. Even goods of a more durable nature, such as furniture and houses, cannot stand the wear and tear of use forever. Such examples show that the amount of utility stored up in products is limited and decreases with every act of utilization.

Putting products to use is, however, not the only cause 
of their deterioration. Not only are the elements of nature constantly at work to impair the utility of things by gradual decay, but the danger of accident threatens their existenee. An uninhabited building will in time fall into ruin as surely as one that is occupied, unless kept in repair. An abrupt ending may come to things through various forms of aceident, through fire or water, throngh storm or earthquake. Although most of man's works escape accidental destruction, there are few things which do not succumb to the slow but certain ravages of time.

It is generally within man's power to ward off the inroads of nature by protective means, and also to mend the effects of wear and tear. The process of repairing or of renovating things is nothing more than restoring the utilities which have been partly lost through use or decay.

From the economic viewpoint the means of production, such as tools and machines, possess utility only in a potential or immature form. While being used up in the course of their utilization, they do not satisfy any ultimate desire. Their wearing out has a significance radically different from the using up of matured products in satisfying human needs. In both eases, to be sure, things are destroyed, but in the one case the potential utility of the implements is transferred in a more advanced form to the products that are being made (10), while in the other case mature ntilities disappear. The wearing out of tools is part of the process of production; the using up of mature produets constitutes the process of consumption. Means of production may deteriorate by use or meet with accidental destruction, but they cannot be "consumed."

We have thus far considered only the relations between man and nature and will next take up the relations between man and man, the real subject-matter of political economy. 


\section{CHAPTER III \\ THE SOCIAL COMPACT}

I5. The Elements of Association.-In order to obtain a clear conception of the economic relations existing in society, we must, first of all, make ourselves acquainted with the elements among which economic relations exist.

The individual person is manifestly the primary element, the atom, of the economic organism, and in primitive communities this is perhaps the only economic entity that need be considered. But in modern society, with its complex systems of production and specialization of work involving co-operative effort, we shall have to deal with groups as entities in which the individual is absorbed and his identity practically lost. As atoms combine and form molecules which possess properties peculiar to themselves, so may individuals group themselves into composite bodies which are to be treated as economic persons.

16. Composite Persons.-Such groupings occur in the business world in the form of partnerships composed of sev. eral individuals, of stock companies composed of larger numbers, and of consolidations of such companies in various forms of organization. These combinations assume the character of distinct persons or entities, entering into business relations with individuals or with other composite persons (67). An individual member of a partnership may even do business with the latter, or an individual stockholder with the company in which he holds stock. Since our investigationid refers to general economic rather than to specific business relations, we must go farther and recognize yet other entities consisting of aggregates of individuals. For instance, all men identified with a business organization, such as employer. foremen, bookkeepers and workmen, as well as capitalist and landowner, or stock and bondholders, compose a productive group. Furthermore, when comparing the interests of em- 
ployers with those of the employed, or when examining the economic status of landowners, of capitalists, or of moneylenders, it is necessary to treat such classes as economic entities.

Whenever the external relations of such entities are under discussion, the relations existing between the individuals composing them must be left out of account. And when dealing with internal relations, namely, those among the individual members of a group, these must be examined independently of external relations.

In view of the fact that a single person may be a member of a number of these groups, we have to consider not only economic persons in the form of these groups, but also such as take form through the exercise of scparate economic functions by the same individual. Just as a man may divide his activity by being manager of a business, director of a bank, and treasurer of an association, so a workman may be landlord, if he owns a house which he rents out; capitalist, if he owns shares of railroad stock; money-lender, if he has a deposit in a savings bank. A man's interest in one capacity may indeed be opposed to his interest in another. It is just because one man may at once be employer, workman, capitalist, moneylender, landowner, and what not, that in the investigation of these economic functions and of the relations between any two of them we are to consider each of these functions as represented by a separate economic being, irrespective of the real persons by whom the functions are exereised. We must personify the functions and treat them as though they were individuals $(56,247)$.

I7. Rights, the Bonds of Association.-Economic relations in society exist usually in the form of "rights" and "duties."

Ordinarily the word "right" is used in so many senses that it is necessary sharply to define the meaning in which it is to be used in economics. We hear of moral, of legal, of natural, of inalienable rights, and so forth, each having a different meaning. For illustration, a Jewish merchant considers that he has a moral right to keep his store open on 
Sunday, but he has no legal right to do so where Sunday laws forbid. When we examine the significance of the word "right" thus variously qualified, we reeognize "moral right" as applying to conduet which does not violate what is regarded as good morals, "legal rights" as applying to all that which is in conformity with both common and statutory law, "natural right" as referring to whatever is not contrary to natural law, etc. The idea underlying them all in common is freedom to act within the bounds imposed respectively by dictates of morals, of laws, of nature. The essence of right, then, is absence of restraint, and rights can be coneeived only by contrast witl those restrictions which limit freedom. Thus, travel on private land being forbidden, the use of the lighway becomes a right by contrast. To lay conduits under the streets of a city is forbidden to all except those to whom a special right is given by franchise.

Ethical considerations were no doubt the original motive for regulating individual conduct, and only because men's judgment differed as to what was right or wrong was it neeessary to arrive at conventional agreements and formulate these into law. ${ }^{2}$

It is true, a sense of right and wrong existed cven in primitive socicty before laws were written or eourts established. Rights then existed by dint of common or unwritten law, and when laws came to be formulated and enaeted they were little else than unwritten law put in stated form. In this way legal rights were born of moral rights. The Ten Commandments are among the oldest of our laws, and these have been supplemented by both eeclesiastic and sceular enaetments, so that now our system of law is exeeedingly eomplicated.

"In the use of the term "law" we must guard against possible confusion, as it has two strictly distinct meanings. In the one sense it means rules rearding the rolations between man and man, adopted and enforeed by the body politic; in the other it means rules of nature regarding the relation between eause and effeet. Thus, "enrency laws" have been enacted by the law-making power of govermment, while the "law of rent" has merely been promulgated by its discoverer. 
There have been many instances of the enactment of laws which at a later period were recognized as unjust. Yet the rights created by these laws were accepted as such and enforced by governmental power. Up to a comparatively recent time the right to own a slave was as real as the right to own a horse or a hat, and laws were enforced to that effect. The injustice of such laws is now universally acknowledged. In like manner, laws which to-day are considered right and proper may tomorrow be condemned as improper.

18. Legal Rights.- Since the purpose of the study of economies is to determine what public policy is most conducive to the general welfare of the community, it is only legal rights that concern us here, and among these we can distinguish two categories.

The one class comprises such rights as exist by implication instead of by specification, and which therefore require no statutory definition. Every person has legal right to do that which is not contrary to law. As regards such rights, laws do not say what may be done; they only specify that which may not be done.

The other class comprises such rights as are brought into existence through special exemption, granted to one or more persons, from restraint imposed upon others, that is to say, through grant of special privilege to do what is forbidden generally. Laws ereating such rights specify what may be done, in other words, the extent of the exemption from general restraint.

The difference may be noted by contrasting the general right to drive a team on a public highway with an exclusive right to construct and operate a car line on the same road. The first is a right existing because of the absence of legal interdiction, while the second is a right because legal interdiction is placed on all but those excepted therefrom (226). In the latter class are really embraced other rights than those which are commonly known as franchises or privileges, for the right of ownership, patent and copyrights, the right of creditors and so forth, bear the same characteristics. Such rights are creations of law in the sense that law and the power behind it are requisite to impose restraint of freedom on all but 
the holder or holders of the right, whose freedom is then exceptional or exclusive. Laws of this kind are virtually publie expressions of mutual agreements by which all members of the community are bound to acquiesce in the rights granted by the community to certain of its members and, in case of need, to help in preventing the infringement of such rights. By forbidding and punishing theft and other acts of unjust appropriation, the right of ownership is established. Patent and copy rights exist by virtue of legal protection against unauthorized imitations of inventions, or reproductions of works of art or literature.

It is only rights of the second category which are dependent on legislation, and therefore they are the only ones whieh properly lie within the scope of cconomics.

19. Right and Duty.-As just intimated, such rights can exist only by virtue of a double obligation assumed by the community. In the first plaee, the people agree to give up a certain measure of liberty and to submit to the restraint involved. In the second place, they agree to give the needed protection against infringements of the right when occasion arises. Thus, the lawful right of any individual can subsist only through the obligation or duty of protecting that right assumed by the community.

The performance of that duty is usually delegated to those composing the judicial and executive departments of the state, and the obligation of the people in this comneetion is reduced practically to the payment of those taxes from which the cost of maintaining the protective machinery is derived. Those who pay these taxes are really the ones who afford the protection, the court and police officers being merely their employes.

20. Definition of Equity.-In the sense in which we here use the term "right," it is the correlative of "duty," and the relation of right and duty is akin to that of receiving and giv. ing. Both terms denote the same eondition presented from opposite points of view. A reeognition of this relation will enable us to obtain a clear understauding of what "equity" really means. 
Let us begin with an illustration. The victim of theft can call upon the police and set the whole department in motion to discover the thief, and under like emergency everybody else has the same right. But there can be equity only if all those who have this right share uniformly in the duty of maintaining the protective machinery. Or, take the case of a patent right, where the public agrees to abstain from the unauthorized use of the invention for a certain number of years. The right thus bestowed on the inventor becomes equitable from the fact that he renders an equivalent by fully describing the invention, so that after the expiration of the period of protection anyone versed in the art will be able to utilize it.

Putting it briefly, a compact by which a right is bestowed and a duty imposed is equitable only if those who enjoy the right are burdened with the corresponding or with some equivalent duty, and conversely, if those upon whom the duty devolves are also invested with the corresponding or with some equivalent right. In other words, equity demands that the distribution of the benefits and burdens of right and duty shall be reciprocal, and laws in which this reciprocity is absent or distorted are inequitable $(259,260,325)$. Accordingly, if the right of ownership is to be equitable, the taxes from which the cost of protecting property rights is defrayed must be imposed upon owners without discrimination (228). As an instance of inequitable rights may be mentioned the right to own slaves, now happily abolished. It was the slave's duty to work for the master to the fullest of his ability, while the master's duty was only to feed, clothe and house the slave according to his own discretion. In general, the service rendered by the slave exceeded the service rendered him in return. In this institution reciprocity of right and duty was clearly incomplete.

2I. The Right of Ownership.-By far the most important of all economic rights, and the only one we shall examine in detail at this stage, is the right of ownership, the cormerstone of civilization, upon which practically all other economic rights rest.

A clear conception of the nature of "ownership" can be obtained by contrasting it with "possession." The latter ex- 
presses a merely physical relation of a thing to a person, while the former is deseriptive of an economic relation. Although the owner of a thing is generally its possessor, this is not a necessary condition, inasmuch as he may for a time place it in possession of another witlout relinquishing his ownership (68). In that case he reserves the right of regaining possession at a future time, usually with some compensation for its use. In a certain sense, the owner retains command of the thing. We may accordingly define "ownership" as that economic relation of a thing to its owncr which cxists by virtue of the community protecting the ouner, or those whom he authorizes, in the posscssion of the thing owncd. As stated before, it is due, primarily, to the acquiescence of the members of the eommunity in the undisputed possession or control of that which is an individual's property and, secondarily, to the readiness of the community to prevent others from depriving the individual of that possession $(67,228,324)$.

Where possession is not subject to dispute, as in the case of the fictional Robinson Crusoe, a right of ownership, that is to say, an exclusive right of possession, is not only without signifieance, but actually inconceivable. Possession in sueh case simply does not need to be protected. Ownership is not a natural right, by virtue of which the producer of a thing becomes its owner. This right is invariably a creation of the convention above alluded to. Unless law establishes this right, the produeer of a thing is not its owner. It is true the present laws aim to coneede ownership to the producer, but it has not always been so, and even now this ideal is in eertain respects not fully realized. The produet of a slave belonged to the master. When tithes were eollected, only the product minus the tithes was retained by the producer as his property. Where taxes are eollected on incomes, the producer has not the right of ownership to his entire productions. I and ean be subject to ownership only by virtue of the laws that protect the owner against trespass.

The protection of ownership which the owner of a thing has a right to claim, like that of all other rights, is furnished by the tribunals of law and the social forces back of them. It 
would, however, be practically impossible for a court of law to keep track of what a man produces or earns, or what he buys or otherwise acquires. Certain rules have therefore been adopted to determine the property rights of individuals in case of dispute. According to these rules, possession is accepted as proof of ownership until convincing evidence to the contrary is presented. This principle is tersely expressed by the saying that "possession is nine points of the law."

22. The State and Its Function.-Some power capable of protecting the weak against the strong is manifestly requisite for the maintenance of rights, and this power is exercised by the organization constituting the "state" or "government." Rights can evidently rest secure only when there is a power in control whose authority is paramount.

That statutory laws are the formulation of mutual agreements of the members of the community is sometimes questioned. Most laws have indeed been made before our time and we have had no choice but to submit to them. Even those laws that are made in our day are not made directly by the people; they are either dictated by autocrats or enacted by representatives elected for that purpose. Those who are opposed to any existing law, whether it has come down from our ancestors or has been enacted by contemporary lawmakers, are certainly not willing participants in the agreement. But we must consider, in view of the constantly changing composition of the body politic through the accretion of new members and the dropping out of old ones, that mutual agreements among its members can stand only on condition that all those who are included in the membership shall acquiesce. The only alternative would be to rescind all law and proceed without government. Experience, however, has demonstrated that among men, constituted as they are, such a state of things is impracticable. We have therefore no choice but to adhere to the rule that all inhabitants of a country respect its statutes. These must be enforced, even though the offender be not a citizen.

Laws should, of course, be of such a nature that no reasonable objection can be made to them. If there are laws which 
do not come under this rule, they may be changed or repealed, and invasive conduet not already forbidden ean be forbidden by new laws. It is true that even under representative government this cannot be accomplished by a minority, but if a valid objection to existing laws, or the desirability of new ones, can be elearly demonstrated, the majority will gradually become convineed of this defeet in the statutes, and legislative reform along this line becomes merely a question of time.

Attempts to effect sueh changes by violent means, as by revolutions, have generally led to irrational extremes, and the consequent reaction has restored the old régime with perhaps a few concessions. When reforms are desirable, changes in law should be construetive, not destructive; in other words, faulty laws should be amended and rectified rather than repealed, where repeal would leave the community without judicial power to enforee some neeessary regulation.

Among the attempts to formulate rules for the guidance of law makers, the work of Herbert Speneer oceupies a prominent position. According to his law of equal freedom:

Every man has freedom to do all that lie wills, provided he infringes not the equal freedom of any other man. ${ }^{3}$

This maxim is perhaps more aceurately stated as follows. Every man should have freedom to do as he wills, provided he infringes not the equal freedom of any other man. In other words, laws should interfere only with those acts of men which elearly constitute a breach of equal freedom or an invasion of the rights of others. But even this rule is not a definite guide, beeause opinion may differ as to what constitutes an infringement of equal freedom. There are acts which are considered invasive by some men and not by others. The boyeott is an illustration. When such disagreement prevails, Spencer's rule fails. But it goes withont saying that inequitable laws cannot be in accord with equal frecdom. It is therefore a good rule to make equity the test in deeitling whether any given law should stand or fall.

Spencer, p. 121. See list of authors quoted. 


\section{CHAPTER IV}

\section{VALUE}

23. Significance of the Term.-A thing has "value" if men are willing to give other things in exchange for it, and the more of these other things it can command the greater is its value.

The quantity of goods involved in an exchange is determined by what virtually amounts to an agreement between the parties thereto, and the rate of exchange ruling in each agreement is more or less influenced by the rate at which similar exchanges have been made before.

Value is almost universally considered to designate an attribute of exchangeable goods, but this is true only in a qualified sense. When used in its indefinite sense, the term is descriptive of the power of goods to command other goods in exchange, and this power is not alone dependent on the qualities inherent in the objects of exchange, but likewise on external circumstances. Thus an improvement in the ways of making an article, or even a change in fashion, may cheapen it, although its actual qualities remain the same. There is, however, no objection to regard value as an attribute of things which, in part, depends on external conditions, just as weight is a quality of matter depending on the proximity of the earth, toward which bodies gravitate.

24. Distinction between Value and Utility.-In trying to grasp the meaning of "value," one immediately thinks of "utility," which signifies the capability of things to satisfy men's needs or desires (6). But though value and utility are closely related, they are not identical. For example, air is absolutely indispensable to us, but nevertheless has no value, because it is freely accessible to all, and no conscious effort is necessary to obtain a supply that suffices to sustain life.

Earlier writers have emphasized this distinction by the 
phrases "value in use" and "value in exehange," 4 but "utility" is now universally employed in the sense of "value in use," and the term "value" confined to the idea of "value in exchange " or " market value."

Nevertheless, confusion of the two terms, value and utility, is frequently met with. Thus the statement that "iron is more valuable than gold" is often made, when, evidently, useful is meant. Bishop Whately confounded utility and value when he wrote that "Pearls are not valuable beeause men dive for them, but men dive for them beeause they are valuable." The correct statement would seem to be: Men dive for pearls beeause they are useful, and being useful, they possess value because they cannot be obtained without the effort of the diver.

25. Definition of Value.-It will be observed that the term "value," even if used only in the sense of exchange value, is really applied in two ways, the indefinite and the definite, as may be illustrated by the statements: "This thing possesses value" and "The value of this thing is two dollars." This is analogous to the established use of sueh words as length and weight. When we say that weight is a property of matter, we allude to the tendeney of bodies to fall, but when we say that the weight of a body is two pounds, we compare its downward tendency with that of a standard pound. In the one sense the word designates a quality, in the other a conerete quantity.

The statement that a thing has value may be interpreted that, if it is offered for sale, purehasers will be found willing to give something else in exchange for it. Value, in the indefinite sense, then, is that attribute of things which prompts men to make sacrifice to gain possession of them (40). The term is synonymous with "exchangeability."

The statement that the value of a thing is two dollars informs us that in the market the speeified thing and two dollars will be given one for the other. The exchange shows that the thing and two dollars are equally effective in the market. When applied in its definite sense, the term value denotes the exchange equality of two enumerated quantities. We might,

- Cf. Smith, p. 21. 
accordingly, say: "This thing is economically equal to two dollars," or "The economic equivalent of this thing is two dollars." Value, then, in its definite sense, is synonymous with equivalent. For the phrase "the value of" we may substitute "that which is equal to" or "that which can be obtained for."

This agrees with the use of the term in mathematics. The mathematician finds the value of the unknown quantity of an equation, or inserts numerical values for the literal terms of a formula. In the equation, $A=2$, the number 2 is the value of $A$.

One of the definitions given by MacLeod is as follows:

The value of any economic quantity is any other economic quantity for which it can be exchanged. ${ }^{5}$

This fully covers the case.

It is often said that value means exchange ratio. This, however, is an erroneous conception. Substituting the definition of a word for the word itself should make a statement more clear. But to say that "the exchange ratio of a thing is two dollars" would be without sense.

It is a fundamental principle in mathematics that a concrete numerical quantity is the product of two factors, the number or ratio and the denominator or unit. In the statement that the value of a thing is two dollars, "two" is the ratio that exists between the value of the thing and that of one dollar. The thing is worth twice as much as a dollar. But while, indeed, the number "two" expresses a ratio, the phrase "two dollars" is no more a ratio than is the phrase "two yards." The word "two" and the phrase "two dollars" cannot be substituted for one another. It would be meaningless to say that the value of this thing is two. Nor has anyone ever propounded the doctrine that weight and length are ratios, although in the statement, "The length of this rod is two yards," the number "two" expresses the ratio that exists between the length of the rod and that of a yardstick.

- Macleod, I, p. 223. 
Some eeonomists take pains to warn their readers that "value" is not a thing. This is perfeetly true when used in its indefinite sense. But when used in its definite meaning, that is, when the value of a thing is spoken of, this value is some other thing, say a certain amount of gold. The value, the equivalent, of an abstract quantity ean only be another abstraet quantity. But the value of a conerete quantity must, in the nature of things, be another concrete quantity.

26. Market Value.-A thing can have a definite value or exchange equivalent only while it is being exchanged. Exchange is the sole criterion of value. But on the basis of past experience, more or less eompletely reeorded, the present value of a thing may be estimated, and since exchanges of a like kind are generally made at a more or less uniform rate, a market value may be assigned to staple artieles, and this market value is that which we have in mind when we speak of stability or of fluctuation of values, according as consecutive exchanges are effected at a constant or at a varying rate. The study of the law of value, aecordingly, embraees an investigation of the causes that govern the course of exchange rates. The value of some painting of an old master, or of some relie of antiquity, is of but little importanee in the present inquiry. A law of value ean be of practical use to the stuclent of economies only by its applieation to the study of the distribution of the wealth created by industry.

27. How Values Are Measured.-Comparisons ean be made between things only with regard to such qualities as may be possessed in common by both objects that are being compared. Length may be compared with length, weight witl weight, bulk with bulk. The economic comparison of things must aceordingly be based on a common quality. Each of the things compared must possess exchangcability, or capaeity for meeting a desire for its possession. Fconomic equivalenee does not, however, imply physieal similarity. Just as two objects may be equal in weight, although different in form, size and substanee, so ean two objects be economically equal, that is to say, evenly exchangeable, althongh they are dissimilar in every other respect. Geometric quantities are determined by 
the process of mensuration: physical properties, such as weight, strength, elasticity, are measured by appropriate physical tests ; and in order to measure the value of a thing, we bring it to market and observe its exchangeability.

Economic measurements, when contrasted with physical measurements, possess one distinguishing feature. While in mensuration, in mechanies, and in other like branches the process of measuring quantities consists in comparing length with length, weight with weight, and so forth, the process of measuring value consists in the substitution of each of the two objects of exchange for the other. It is therefore proper to regard each of these objects as the economic equivalent-the value-of the other at the moment of exchange.

28. The Unit of Value.-Although the value of any thing may be expressed in as many different denominations as there are other things for which it may be exchanged, it is currently expressed in terms of a particular commodity selected by convention, a definite quantity of which serves as the unit of value. The value of a coat may be twenty bushels of wheat, or a hundred pounds of meat, or five hundred grains of gold, but according to local usage its value is generally rendered in terms of "dollars" or other value units, which, as we shall presently see, generally means in terms of gold. The advantage of using a conventional unit is so obvious that even in the earlier stages of civilization this method of expressing values was in use. It is true that the selected commodity was not always gold. Within historic times such things as oxen, rice, tobacco, fur skins and silver have served the purpose. But in the course of time the metals gold and silver have proved their superiority for this use, and while in the earlier stages of commercial development silver was chosen as the criterion of market values, gold has supplanted it during the past century in most civilized countries. In different countries different quantities of the selected metal are adopted as the units, known by their respective denominations, such as dollar, pound, mark, frane, florin, peso, and so forth. The present American unit is the dollar, consisting of 25.8 grains of gold $\% / 10$ fine, or 23.22 grains of pure gold. 
29. Price.-When things are offered for sale, the rate at which the merchant is ready to sell them is given in terms of the conventional unit, and the word "price" is used in place of "value." Price, then, expresses the value of a unit quantity of the goods, stated in terms of the adopted value unit.

It is self-evident that the price of the commodity selected for the unit of value will remain stable. By reason of this absence of fluctuation in price the metal selected is known as the "standard commodity." Care must, however, be taken to guard against a misapprehension. It is only the price of the standard commodity that remains fixed, not its value as compared with other things.

In the following pages the dollar is taken as the unit of value and gold as the standard commodity. This is, however, not to be understood as precluding the use of other units of value or standard commodities.

It would seem that these few words should conclude the discussion of this subject. But for some reason there exists a diversity of opinion not warranted by the simplicity of the case. Voluminous controversies have wrought needless confusion and have obseured a really simple problem. $\Lambda$ brief review of some of the proposed methods for measuring values, and a statement of the objections to which they are open, is here in place.

30. Labor as a Measure of Value.-That labor is a factor in the ereation of value has been recognized by early writers on economics who inferred from this that labor is the natural yardstick of value $(63 a, 149)$. Adam Smith asserts that:

Labour is the real measure of the exchangeable value of all commodities."

Were it possible to define a unit of labor so that any one unit would have the same value as every other unit, this would perhaps be the most satisfactory measure of value. But the value of labor lies in its productivity, and productivity is not in proportion either to the duration of labor or to the amomit of physical exertion. There are great differences in anomnt 
and quality of things produced in equal time by different men employed on the same kind of work, and there are still greater differences where the kind of labor differs. We can obtain a conception of the value of labor only by its fruit. Until we learn what the values of the different products of labor are, we have no means of judging the ralue of the different kinds of labor that create them. And if products alone can measure the ralue of labor, labor cannot conversely gauge products. Hence it is impossible to adopt labor as a standard with which to measure the value of things (16t).

If there were no difference in the value of different kinds of labor, and if the productivity of all men engaged in the same kind of work were equal, the labor-hour might very well be used as a unit. This may occasionally be done for the sake of argument, but always with the reservation that all men are supposed to be equally efficient $(32,199)$.

Ricardo follows in the footsteps of Smith when he says (62) :

The exchangeable ralue of all commodities, whether they be manufactured, or the produce of the mines, or the produce of land, is always regulated, not by the less quantity of labour that will suffice for their production under circumstances highly farourable, and exclusively en. joyed by those who have peculiar facilities of production; but by the greater quantity of labour necessarily bestowed on their production by those who have no such facilities; by those who continue to produce them under the most unfavourable circumstances; meaning-by the most uniarourable circumstances, the most unfarourable under which the quantity of produce required, renders it necessary to carry on the production. ${ }^{7}$

This proposition is defective in so far as the expression "quantity of labour" lacks a definite meaning. The "exchangeable value" of a commodity can be expressed in terms of some other commodity, like gold or silver, but not in terms of labor. However, if in Ricardo's proposition "cost of labor" or "cost of production," properly defined and qualified (61), is substituted for "labour." it becomes a correct, though incomplete, statement of the law of value (63b).

${ }^{\tau}$ Ricardo, p. $3 \pi$. 
Karl Marx, in propounding his theory of value as a basis of his scheme of socialism, has recourse to the labor-hour as a measure of value. His error in this respect will be more fully elucidated in Chapter VIII.

3r. Other Value Units.-When the values of two different things, or of the same thing at different times, are to be compared, these values must be expressed in terms of some one value denominator. Nevertheless, there are writers who discuss the subject as though changes of value can be conceived independent of any stated value denominator. Among others, John Stuart Mill asserts that:

All commodities may rise in their money price. But there cannot be a general rise of values. ${ }^{s}$

This statement is valid only if a certain proportionate fraction of the sum-total of all existing commodities is adopted as the unit of value. The sum-total of all wealth, unless its quantity be changed, will then have a fixed and invariable value. Only on this condition is it true that a rise in the value of one thing is balanced by an equal fall in the value of the sum of all other things, so that neither a general rise nor fall of values could ensue.

Other economists, recognizing that the value of our present unit fluctuates in relation to all other things, propose an "invariable" value unit, without, however, specifying how this is to be established. These also, no doubt, have reference to a unit consisting of the sum-total of all wealth, or to a proportionate part thereof. But while such an idealistic unit may very well be adopted in hypothetical examples illustrating an argument $(108,119)$, it cannot be introduced in practice for several reasons.

If a unit consisting of a proportionate part of all existing wealth were adopted, it could not long remain "invariable," in the sense that "there eannot be a general rise of values," since not only the quantity, but also the composition of the wealth in existence, is constantly subject to changes. From time to time new kinds of commoditics, unknown before, appear

- Mlill, 1, p. 540. 
upon the market. It follows that if a unit corresponding to the composition of the wealth of one period were established, it would not correspond with the composition of the wealth of perhaps a decade later. A periodical revision of the unit would therefore be necessary if an idealistic measure of value were to be maintained, and this would evidently not be an invariable unit.

A second difficulty would be met in the attempt to define this unit, so that its composition might be on record. This would require the listing of all forms of wealth, with the statement of the proper amount of each, as they are to figure in the unit, and this is manifestly impossible. Some writers, recognizing this difficulty, have proposed a composite or multiple unit (321), consisting of a definite number of staple articles in definite quantities. The total value of the items is to constitute a standard sum, such as one hundred or one thousand dollars, according to the composition of the list. Of course, by this expedient only an approach to an idealistic unit could be attained.

A third objection, which applies to composite units as well as to the supposed idealistic one, arises from the fact that most goods are produced in different grades of quality (111a). A given list of articles composing the unit would be an unreliable guide, even though an attempt be made strictly to specify the quality of each constituent, and the unit would be correspondingly indefinite. The case is different with gold or silver, the quality of which can be specified with absolute accuracy and tested as closely as it is possible to weigh on precision scales. This homogeneity of the precious metals has been the principal reason for their adoption as standards. A unit composed of commodities of more variable grades might give rise to frequent disputes as to the proper quality and, accordingly, the proper value of the unit.

The fourth objection is a serious stumbling block to the use of either an idealistic or a multiple standard. There is no economic force by which the market value of things generally can become related to a prescribed unit of this kind. The things specified in any arbitrary list would be neither offered 
nor demanded in that particular combination, and in the absence of the "standard commodity" as an article of merchandise, its exchange ratio with any one commodity would never become manifest in the market. The sum of the market values of all the articles specified in the list is supposed to remain unchanged, however each item may change in price; but if the movement of market values should at any time be such that this sum is changed, there is no way in which this condition could automatically react upon prices generally so as to restore the original sum. For gold as well as for silver there is a constant demand, so that the exchange ratio of either of these metals with other things is determined daily (54).

There is still a fifth objection, namely, the difficulty of making the value of money conform to a given composite unit, but discussion on this point must be reserved for a later occasion $(111 b)$.

32. Expediency of a Composite Unit.-Even if these difficulties could be surmounted, it would still be a question whether much could be gained by the introduction of a composite unit. So long as the unit serves merely to indicate the exchange ratios of different commodities, or to compare one amount of wealth with another at any given time, it would be immaterial whether or not the conventional unit is subject to slow changes as compared with the sum of all other things. Changes in the value denominator can work injury only when a debt, expressed in dollars, or whatever the unit may be, is incurred at one time and paid when the unit has changed its value with regard to commodities generally. Let us examine, then, what injury may result through fluctuations in the purchasing power of the value unit.

Owing to the fact that all things are constantly subject to changes in value, their owners must, as a matter of course, assume the risk of such changes. If a uniform change wero to take place in the price of all commodities, the relative values of all forms of wealth, excepting the standard commodity, gold, would remain unchanged, and nobody would either lose or gain except those who hold gold or money and those who hold money claims or owe money debts. $\Lambda$ general rise in prices 
is simply an indication of a fall in the value of gold as compared with all other things, and vice versa. While prices in general rise or fall, the creditors' claims, being in terms of gold, will correspondingly fall or rise in general purchasing power, but the holders of money claims will lose or gain no more on this account than they would have lost or gained had they not loaned the money, but kept it in their possession as such. The owners of other forms of wealth must shoulder similar risks resulting from changes in the value of their holdings. Since gold is the commodity whose value fluctuates from natural causes probably least of all, the importance of protecting creditors against loss from these slight fluctuations is less pressing than is often claimed.

To the advocates of the labor standard of value the composite standard would be scarcely more acceptable than the gold standard. Let us consider, for the sake of argument, the case of a twenty-year bond expressed in terms of a multiple standard, and assume that during the twenty years such progress is made in the industries that the effort required at the beginning of the term to produce the commodities specified in the standard list will at the end be reduced to one-half. Under these conditions the effort of one-half of one day's work of the borrower (30) would pay a debt representing a whole day's work of the lender.

While the gold denominator is not altogether free from objection, no available substitute appears to be preferable.

33. The Theory of Value.-As has been said before, the value of things is ascertained from the rates at which they are exchanged. These rates are not a matter of accident, but are determined by certain existing conditions. The study of these conditions constitutes the most important problem of economics, since upon the process of exchange depends the distribution of wealth.

At first glance the problem appears to present little difficulty. It would seem that the ratio at which any two commodities are exchanged is simply an expression of the relative estimation in which these commodities are held by the parties to the exchange. But on further investigation it becomes 
apparent that the problem is not quite so simple. In the society of to-day, composed of men and women of the most variant tastes and desires, of the most divergent abilities and dispositions, surrounded by the most unequal environments and opportunities, the estimations of any one thing by different persons are very far from equal. Even in the case of food, the most important product of labor, tastes differ widely; and yet more striking differences can be observed in the varying desires for luxuries. While the appreciation of works of art is highly developed in some persons, it is more or less lacking or even totally absent in others. The craving for alcoholic drink or for tobacco becomes irresistible to those who use either habitually, while to others these things are repugnant. Nevertheless, as a rule, and especially for the great staples of production, there is but one market price for all eomers. The prices of things are regulated in some way by the judgment or estimation of all buyers and sellers combined. The question before us is: How do these various evaluations in their combination determine the price of each commodity?

34. Supply and Demand Defined.-The adjustment of values in the market is generally attributed to the interaction of supply and demand. In order to discuss the subject intelligently it is necessary that we arrive at a clear understanding of what these terms really mean.

When we speak of supply and demand, it is with special reference to some particular kind of things or services, and in that sense supply denotes quantity offered for exchange. Hence supply involves an equal demand for other things, generally a demand for money through which those other things are obtainable.

Demand is to be understood as effective demand, that is to say, not merely a desire for things, but a desire accompanied by the ability and readiness to give an equivalent in return, generally in the form of money. Therefore, every demand involves an equal supply, just as every supply involves an equal demand (269).

From this it follows that the total supply of all things and services in a market always equals in value the total effec- 
tive demand for all things and services. It is to be noted, however, that this equality has reference only to the total market, but not to any particular commodity. When we come to consider some one commodity, it will be found that a disparity between supply and demand is not only possible, but is of frequent occurrence.

While by far the greatest number of exchanges are now effected throngh money, we should always bear in mind that money is in reality nothing more than a medium for exchanging one kind of goods for another kind, and that, after all, the fundamental form of exchange is barter. Every buyer is necessarily a seller of that which he gives in payment, and every seller is a buyer of that which he receives in payment (51).

35. Subjective Valuation.-The analysis of the process by which the value of commodities is regulated is, for obvious reasons, to be divided into three stages. The first step will be a study of the relation of the individual to the goods he produces and consumes, in short, of the conditions on which individual estimation depends. This will be followed by an examination of how the respective estimations determine the exchange rate in barter between two individuals. We shall then be prepared for the final step-the deduction of the law of supply and demand, which rules the exchange rate among any number of individuals.

Although values and prices ean be expressed only in terms of something objective, they depend, in the last analysis, on human desires and aversions which are of a purely subjective nature. Production and exchange are really governed by the actions and reactions of these impulses, and it remains for us to find how the gap between the subjective and the objective is bridged.

Production is regulated by two forces, the one impelling, the other restraining, and it is the interaction of these forces that determines subjective valuation.

36. Desire the Impelling Force.-Things which have a capacity for satisfying human wants are for that reason de- 
sired by human beings. Under the impulse of such desire, men labor and strive to gain possession of the things that satisfy wants. After an individual want is satisfied the desire ceases to be an active impulse, but it remains in a passive form which becomes active again with the passing of the gratification.

Whenever some want is only partially satisfied, there remains a desire of some degree still in foree as an impulse to action.

Experience having taught that the gratification of a desire wears away, and that the want will recur with more or less certainty in the future, men are impelled to produce and aceumulate, for future use, stores of things they want. Things that ean be produced but seasonally are aceumulated in quantities that will eover needs until the next season, but of the things that ean be produeed from day to day, only enough to suffice the passing need will be secured, unless there is some reason for aequiring more.

Since an insufficient store of needful things will permit but a partial gratification of the desire for them, the impulse to further aequisition is the greater the more inadequate the store.

37. Limitation of Demand.-The converse is equally true. A housewife, finding two loaves a day ample for her family, would not buy three loaves per day, even though the baker offered the additional loaf at a redueed price. She has no need for the third loaf, because the two loaves which she usually buys are all she wants. Of course, quantity must here be taken in its due relation to time. If the family were to spend the summer in the country where the baker ealls but twice a week, the purchases would have to average seven loaves at eacl call. Thus, when we say that the desire to add to any given store is affected by the possession of a definite quantity of that store for future use, we must keep in view the element of time in that connection (60).

38. Böhm-Bawerk's Illustration.-The eanse of the desire being less when the store is greater has been shown by Böhm-Bawerk to be dne to the diminishing importance of the several uses to which a thing may be put. IIe supposes a lone 
colonist who has just harvested five sacks of grain (39). One sack just suffices to keep him from starvation until the crop of the following year becomes available. The second enables him to supplement his meals so as to remain strong and healthy. With the third he purposes to feed poultry so as to have a variety of food. The fourth he reserves for making liquor, and for the fifth he knows no better use than to feed it to parrots whose antics afford him amusement. Here are enumerated five uses of varying importance. Had the colonist but one sack, he would value it very highly, as his very existence would depend upon it. Were he in possession of two, his desire for more grain would naturally be somewhat less, and every addition would reduce his desire for more in the measure in which each further addition would be of less importance to his existence.

39. Graphical Representation of Utility.-The principle here illustrated applies practically to all commodities. Were a man limited to but a small quantity of any needful thing, this quantity would be highly prized, as it would suffice only for the most urgent needs, and any additional supply would be prized less, inasmuch as it could only be used to satisfy less important needs ( $56 a$ ). 'The estimates thus accorded by an individual to the successive elements of his store, as they would be applicable to satisfy his desires of successively diminishing importance, may be graphically represented by the descending curve $D D^{\prime}$, Fig. 1, the successive elements being laid off on the horizontal axis of abscissas, while the vertical ordinates indicate the intensity of the individual's desire for each corresponding element or unit.

This curve must, of course, be understood as representing, not the physical capacity of the one commodity under consideration to gratify desires, but the varying degree of desire for that commodity in the case of some one individual. It is also to be observed that the curve $D D^{\prime}$ represents not only the unsatisfied or active, but also the satisfied or passive desire for the commodity in question, and that only such portion of the desire which is not covered by the store already on hand will become effective as a desire for more. Hence, if $O q^{\prime}$ is the 
quantity already at command, the desire for the next element to be acquired would be equal to $q^{\prime} d^{\prime}$ or $O p^{\prime}$; or if the quantity on hand should equal the abseissa $O q^{\prime \prime}$, the desire for further acquisition would be represented by the ordinate $q^{\prime \prime} d^{\prime \prime}$ or $O p^{\prime \prime}$.

In the illustration of the colonist (38) the store of grain was adapted for at least four different uses, each of which gratified a different desire. In the mind of the colonist these several uses presented themselves, according to their importance, in deseending progression, the several sacks being reserved, in sueeession, for these several uses. The first two served for plain food neeessary to preserve life and strength. The desire of the next lower importance was met by the third sack, as it provided variety in the fare. The fourth and fifth sacks were reserved for still less important uses, in fact, for luxuries.

If a eommodity is adapted for several different purposes, it would be quite feasible to show in the diagram as many curves as there are independent uses, each curve representing the desire engendered by one of the different utilities. But since the full desire for a thing develops from a sense of all of its various utilities, the desire in its totality should be represented by a single curve. This curve ean be plotted by adding the abseissas of equal ordinates of all the eurves representing the several separate utilities $(53,56 b)$. The same process ean be applied to obtain a representation of the total desire if a new use is found for a thing. Let the eurve $E E^{\prime}$ of Fig. 1 denote the estimate of such a new use, then its geometric addition to the original curve $D D^{\prime}$ will result in the new eurve $D D^{\prime \prime},{ }^{3}$ which will then represent the total desire for the possession of the thing in question.

40. The Question of Quantity.-The desire of an indiridual to aequire more of any given commodity depending, as we have seen, on the amount alrearly at command, and on the relation which his desire bears to his store, represented by the curve $D D^{\prime}$, Fig. 1, this curve will serve to indieate the intensity

- The compounding of the two curves is accomplished ly making, in rach horizontal section, the space $m^{\prime} n^{\prime}$ erjual to $m n$. 
of his desire for more, if the quantity he has on hand is given. Suppose the abscissa $O q^{\prime}$ to represent this amount. The line $q^{\prime} d^{\prime}$ will then divide the desires which can be satisfied from those that cannot, and the ordinate $q^{\prime} d^{\prime}$ measures not only the last of the desires that can be satisfied, but also the first of those desires which will remain unsatisfied, and this, in turn, measures the impulse to further effort toward increasing the store.

This impulse manifests itself by a willingness to make some sacrifice in order to obtain the things desired, either by putting forth the effort to make them or by offering some product of effort in exchange for them (25).

We have now traced the intensity of desire to two factors, of which the one is represented by the curve $D D^{\prime}$ and the other is the quantity at command. Of these the first is a characteristic of the individual whose desire for the commodity in question is represented, and this must be accepted as a fundamental factor. The other, namely, the quantity at command, may vary, but there is a certain quantity which he will accumulate under normal conditions. What is it that delimits this quantity? At what point will he stop accumulating?

41. Reluctance the Restraining Force.-The store of any given commodity that an individual accumulates is, in the nature of things, limited, and, assuming normal conditions, the cause of that limitation is primarily the natural unwillingness of the human being to put forth the necessary effort of production. This reluctance is a restraining force, acting in opposition to the impelling force of desire. Production, then, is regulated by two opposing forces. The desire engendered by the prospective utility of any given product is the incentive, the impelling force to its production, while the diffculty or strain of producing it is the reacting or restraining force.

A commodity can therefore be viewed from two standpoints. To the consumer it represents utility; it offers the means of gratifying some desire. To the producer, on the other hand, it represents a certain amount of effort spent. The desire for a thing and the effort required to get it can 
be compared only in the mind of one and the same person. Everyone who is on the way to obtain anything, whether through production or through exchange, contrasts in his own mind the satisfaction which he can get out of the thing against the labor or sacrifice necessary to get it.

42. Graphical Representation of Effort.-While the impulse to obtain any thing diminishes as the quantity already at command is inereased, the reluetance to produce more of a thing, on the contrary, increases with the amount already produced. The first hours of a day's work fatigue the average workman but little. But as the day wears on, the labor becomes more and more irksome to him and often less efficient. The amount produced in the first hour requires less effort than that produced in the last, and the strain, as conceived by the worker, can be represented graphieally. The ascending curve $S S^{\prime}$, Fig. 2, depicts the relation of the amount already produced to the reactive effect of the strain attending the production of more.

43. The Point of Equilibrium.-Every produeer is also a consumer, for he produces for the purpose of having things to consume. The man who himself consumes that which he produces naturally views his products from both standpoints. He compares the gratification they will yield, or the enjoyment they will bring, with the effort and strain which their production requires. This is also true of him who acquires what he wants in exchange for that which he produces, with this difference, that he gauges the utility of his efforts by the gratification he anticipates, not from the things he makes, but from the things he obtains in exchange for what he makes.

The two opposing forees arising from desire to consume and from disinclination to exert one's self are instinctively felt and intuitively weighed by the individual. By combining in one diagram (Fig. 2) the curves $D D^{\prime}$ and $S S^{\prime}$, the mental contest between his desire for acquiring things and his reluctance to exert himself is lucidly portrayed. It is clearly to be seen at what point the opposing forees come to a balance, 
and to what extent the individua will apply himself to work, supposing him to be free to work as he will.

Suppose, for instance, the diagram to represent the case of a merchant tailor who can complete 6 coats a week if he works 5 hours a day, or 12 coats if he extends his labor to 11 hours. It is here assumed that a doubling of the output requires more than twice the time, so as to include, even in this crude illustration, the effect of increased lassitude and the corresponding decrease of efficiency due to prolonged labor. The increasing disinclination to continue labor is represented by the rise of the curve $S S^{\prime}$. We may now assume that $O q^{\prime}$ represents 6 coats per week, and $O q^{\prime \prime}$ represents 12 coats. By working only 5 hours a day, the worker finds that $q^{\prime}$, the last increment produced, yields to him the gratification $q^{\prime} d^{\prime}$, which, as the diagram shows, overbalances his disinclination $q^{\prime} s^{\prime}$ to continue working. The impelling force exceeds the restraining force. By continuing to produce the next following increments, the worker would obviously gain more in the form of gratification than he would expend in the form of effort, and he will naturally extend his hours of labor. But if he should work 11 hours per day to complete 12 coats per week, represented by $O q^{\prime \prime}$, he would find that in producing the last increment, namely, $q^{\prime \prime}$, the required sacrifice $q^{\prime \prime} s^{\prime \prime}$ would exceed the expected gain $q^{\prime \prime} d^{\prime \prime}$. The restraint would exceed the impclling force. $\mathrm{He}$ will therefore intuitively choose the time of about 9 hours, producing the quantity $O q$, namely, 10 coats per week, since the sacrifice of producing the last increment is equal to the benefit he can derive from it, both being represented by $q a$.

The point $a$, where the two curves intersect, locates the last increment which, under the given circumstances, will be produced. This last increment is the one at which the desire for possession is exactly balanced by the aversion to perform the work required for its production. With the increase of the time of daily labor the restraining force gradually increases, while the impelling force steadily diminishes until, at this point, both forces are equal. So long as the desire for possession, as $q^{\prime} d^{\prime}$, exceeds the dislike for work, as $q^{\prime} s^{\prime}$, the 
time of labor will be prolonged. Only when the degree of the sacrifice, the strain, becomes equal to the expected gratification will the natural limit of work be reached (238).

Of course this result obtains only when the producer is free to ehoose the duration of his labor. When this is precluded by rules of employment, the time of labor will be subject to those rules. But, in general, these rules may be regarded as agreeing fairly well with the time limit which the average workman would ehoose of his own aecord.

The objection may be urged against these diagrams that, as a rule, men do not weigh their likes and dislikes with the nicety here assumed, and may not even be conscious of a graduated mental estimation as shown by the curves. Such indefiniteness of inclination might be indicated in the diagram by the use of curved bands instead of curved lines, the bands to shade off from eentre to edge. The interseetion would then be a field with a somewhat indefinite margin, analogous to our target with its scattered bullet marks (1).

44. Choice as Regards Production.-Before passing from the discussion of the relation of the individual to production and consumption, a few points which have some bearing on our later investigation may profitably be taken up. Among them is the question as to what determines the ehoice of occupation of the individual. The answer to this question differs aceording to the degree in which the facility of exchanging the products of effort is present.

A marooned sailor, for example, who has no opportunity for exchange whatever, first attends to his most imperative needs. He seeks first for fresh water, then for food, then for shelter. After any one of these needs is met, it is eliminated from his endeavors, and the one of next lower importance becomes predominant. During the first few days he can give but little time to the satisfaction of any one need before another claims immediate attention. He must frequently change the direction of his efforts to sustain life. Only after. providing in advance for immediate necessities ean he afford to keep on in any one line of effort and thus reduce the loss of time and energy attending every change of work. 
On the other hand, a man who is living in a populous community and who finds a sufficient demand for some one product to enable him to apply himself to a single occupation naturally chooses that one which, under the circumstances and according to his estimation, yields him the greatest returns for his efforts (61). His choice depends not only on his individual capacity, skill and inclination, but also on the opportunities offered by the presence of natural resources, facilities of transportation, proximity and character of markets, and so forth.

Most men are able to take up more than one kind of occupation, but each man's aptitude for different pursuits varies more or less. For each producer there is, as it were, an occupation of first, another of second, another of third choice, and so forth (149). Some men are capable of applying themselves with almost equal efficiency in more than one direction. To such it makes comparatively little difference which of these pursuits they follow, and a slight change in competitive conditions may cause them to turn from one occupation to another (223). The majority of workers, however, acquire proficiency in only one line. This is not always due to neglect or to inability to learn more than one trade or profession, but, on the contrary, is often a result of special talent or of exceptional opportunity. To such a change of their occupation would be quite disadvantageous.

45. Choice as Regards Consumption.-When a man goes into the market to buy different things that he wants, he apportions his means to the several purchases in accordance with the urgency of his desire for each thing. The mental process by which he reaches a decision is not unlike that by which the marooned sailor determines the succession of his efforts. Guided by past experience, he divides his means so that the quantities of his several purchases will satisfy his corresponding desires to such a degree that the remaining wants are equal.

The case may be illustrated by assuming that all his needs can be met by four different things. Let the curves $D D^{\prime}, E E^{\prime}$, $F F^{\prime}$, and $G G^{\prime}$ (Fig. 3) represent his desires for these things, 
and let the line $h h^{\prime}$ represent the level to which his means enable him to satisfy his wants. The quantities of his purchases will then be $O q, O q^{\prime}$, and $O q^{\prime \prime}$, respeetively. The desires remaining unsatisfied are then measured by $q d, q^{\prime} e$, and $q^{\prime \prime} f$. It will be noted that the level $h h^{\prime}$ is above the highest point of the curve $G G^{\prime}$, which would indicate that under the given circumstances the goods represented by this eurve are beyond his means. Were his income to inerease so that he could more completely satisfy his desires, the line $h h^{\prime}$ would go to a lower level and the goods $G$ would be brought within his reach.

46. Advantages of the Graphical Method of Study.--The many advantages which diagrammatic representation affords in the study of seientific data have led to the application of this method in many fields of investigation. Diagrams not only serve to represent facts in a perspicuous manner, but also to tacilitate the analysis of various subjects, and when designed for the study of one phase of a problem, they are often found applicable to other aspects of the matter. So it is with our diagram (Fig. 2).

Let us take the case of a man who both produces and consumes the amount $O q$. The ordinates of the suecessive elements of the ascending curve $S S^{\prime}$ represent the increasing strain of the effort neeessary for the corresponding increase of production. As work is continued, the total measure of the effort expended is represented in the diagram by the area oqaS.

Similarly, his evaluation of the total satisfaction obtained from eonsuming his eamings is represented by the area $O q a D$, and the net satisfaction derived therefrom equals the difference of these two areas, which, in the diagram, is represented by the threc-sided figure $S a D$. We thus have a graphical representation of the net amount of satisfaction experienced by the worker, quantitatively stated.

Or let us consider the case of a man who produces more than he consunes, saving the remainder for possible emergencies. If he carries on production to the point $q^{\prime \prime}$ (Fig. $t$ ), and consumes only that portion of it represented by $O q^{\prime}$, the 
evaluation of his total effort will correspond with the area $O q^{\prime \prime} s^{\prime \prime} S$, and that of his total satisfaction with the area $O q^{\prime} d^{\prime} D$.

Such illustrations might be further multiplied, but the examples given are a sufficient guide for other possible uses of this method of investigation.

47. Barter.-Our next step is to analyze the process by which exchange rates in simple barter are determined. This occurs when owners of different things come to an agreement to make an exchange. Such agreements are reached after a more or less conscious comparison, by both parties, of the benefit to be derived from the thing obtained with the sacrifice involved in parting with the thing given.

The simplest case is that of two men, removed from markets, who wish to exchange part of the products of their labor. Suppose two settlers, one having cultivated wheat, the other wine, desire to make an exchange. What is the process by which they come to an understanding regarding the rate of exchange?

The curves thus far used for illustrating our line of reasoning represent the degree of an individual's impulse and restraint. So long as we were analyzing the relation of one single individual to production and consumption, only that individual's feeling could be taken into account. It was necessary to leave the comparison of a satisfaction-enjoyment of a utility - with a strain-productive effort - to the judgment of the individual. But now, when we come to examine the likes and dislikes of two persons, these cannot be compared unless we find a way of rendering them in terms of some concrete denominator. And since the contemplated exchange of wheat and wine is a case of simple barter, either of the two commodities can serve as the value denominator.

By selecting a bushel of wheat as the denominator, the desire for wine is to be estimated in terms of wheat. The wine-grower would then be the seller, the wheat-raiser the buyer. The wheat would be the medium of payment-the "money," and the wine the subject of purchase-the "merchandise." 
48. The Buyer's Price Limit.-The problem now before us is to learn how each of the men compares his desire for wine with his desire for wheat. This task would seem to present some difficulty, inasnuch as the desire of each for wine as well as that for wheat differs in degree according to quantity in hand (36-38). How can we compare one variable desire with another?

Suppose that in Fig. 5 the horizontal dimension represents gallons of wine, while the vertical dimension represents the estimate of wine per gallon in terms of wheat, the seale of valuation being marked off in bushels and peeks.

Let us assume the wheat-raiser's desire for wine to be such that, could he obtain no more than one gallon, he would be willing to lose 3 bushels of his store of wheat rather than go without the wine. His valuation of the first gallon is, accordingly, 12 peeks of wheat. But he would not buy 2 gallons at this rate, for his desire for the second gallon is not so great as that for the first, and the additional 3 bushels of wheat which he would have to give up are regarded by him as of more importance than the first 3 bushels of his stock which he was willing to give for the first gallon. For 2 gallons he would not agree to give more than, say, $51 / 2$ bushels, which would make 11 pecks the rate per gallon. The acquisition of each additional gallon of wine would be attended by a reduction of his desire for more, while his relnetance to part with each further bushel of wheat would increase. For 3 gallons he would perhaps refuse to give more than 30 pecks, or 10 peeks per gallon. For 4 gallons he might offer $361 / 2$ peeks, or $91 / 8$ peeks per galion. His valuation of 5 gallons might be 41 pecks, corresponding with a rate of $81 /$, peeks. Thus with each additional gallon to be added to his purchase the price he would be willing to pay per gallon would be redueed, and this reduetion ean be represented by the deseending curve $D D^{\prime}$, which depicts the wheatraiser's desire for the merchandise "wine" expressed in terms of the denominator "wheat." It graphically represents what may be termed the "buyer's price limit," that is, the highest price he would be willing to pay for any one of the suceessive gallons of wine, provided always that this is the rate for the 
entire purchase. It serves to show how much the individual is willing to buy at any given rate. Were this rate equal to $O p^{\prime}$, he would buy the quantity $p^{\prime} d^{\prime}$, that is, 7 gallons. If the price per gallon were lowered to $O p^{\prime \prime}$, his desire for a store of wine would, under the given conditions, increase to the amount $p^{\prime \prime} d^{\prime \prime}$, or 16 gallons.

49. The Seller's Price Limit.-The mental process of comparing wine with wheat on the part of the wine-raiser can be similarly examined. The first gallon that he would sell would be, of course, that one which he could most easily spare and to which he would give the least consideration, while the wheat he would get for it, being the first portion coming into his possession, would be most welcome to him and therefore most highly valued. We may assume that his evaluation of this one gallon of his wine would equal his evaluation of the first $11 / 2$ pecks of wheat, and that he would agree to an exchange at this rate if he could not obtain it on better terms. But this does not imply that he would be willing to give 2 gallons for 3 pecks, for he would naturally be more reluctant to part with the second gallon than with the first, while, at the same time, the second lot of wheat which he obtains would be of less importance to him than the first. He would perhaps be willing to accept $31 / 4$ pecks, which corresponds to a price of $15 / 8$ pecks per gallon. His estimate per gallon would rise as the number of gallons to be parted with increases. All this may be indicated by the curve $S S^{\prime}$ (Fig. 5), which represents the " seller's price limit" in terms of wheat. At a rate equal to $O p^{\prime}$ his offer would amount to $p^{\prime} s^{\prime}$ gallons; at the rate $O p^{\prime \prime}$ his offer would amount to $p^{\prime \prime} s^{\prime \prime}$ gallons.

The curves of the diagram now represent the desire of the purchaser to acquire and the reluctance of the seller to part with the winc, measured in terms of the same concrete denominator, namely, wheat, and this enables us to consider the two men's estimates conjointly.

This example may be taken as the prototype of many similar cases, all of which can be treated in practically the same way. The men may not have the objects of exchange on hand, but may expect to produce them, which would imply 
that the increasing reluctance to put forth greater effort takes the place of the increased reluctance to diminish the store on hand. Or, instead of merely two kinds of goods, a greater number may be included in the problem. One of them may again be chosen as the denominator, but the problem itself, while becoming more complicated, would present no essentially new features. At all events, the case here considered is typical of all direct exchanges of labor's products.

50. Exchange Rate in Barter.-We are now prepared to follow up the process by which the two traders reach an agreement regarding the rate of exchange.

During their negotiations they may at first try to agree upon the price $O p^{\prime}$ (Fig. 5), namely, 7 pecks. At this price the buyer would want to take 7 gallons of wine, as measured by the space $p^{\prime} d^{\prime}$, while the seller would want to sell the greater amount $p^{\prime} s^{\prime}$, namely, 15 gallons. He finds, however, that he cannot persuade his neighbor to increase his purchase except by lowering the proposed price. Had the negotiations initially been based on a price equal to $O p^{\prime \prime}$, or 1 bushel per gallon, the buyer would have been ready to take $p^{\prime \prime} d^{\prime \prime}$, that is, 16 gallons, while the seller would have been unwilling, at that price, to sell more than $p^{\prime \prime} s^{\prime \prime}$, or 11 gallons, and only by agreeing to a higher price is the buyer able to induce the seller to part with a greater quantity. In the first case the negotiations tended toward a lowering of the price, in the second toward a rise. The evident tendeney is toward a price equal to $O p$ or $q a$, namely, 5 pecks. At this price both men will agree upon the quantity measured by the space $O q$, namely, 12 gallons.

This, then, is the natural price under the assumed premises. That price is at the point where the want of the one party for the wine and the want of the other party to the wheat coincide. It is located at the intersection of the curves of the diagram and indicates not only the price, but also the quantity of the exchange.

It is true that traders are perhaps never actually conscious of any such mental process as that above outlined and by which an agreement on the price is finally reached. But how- 
ever the negotiations may proceed, each of the parties intuitively follows his inclinations, and it is these inclinations that have been graphically represented in the diagram.

We have here, of course, left out of account chance factors, such, for instance, as a possible difference in the power of persuasion, or capacity of salesmanship, which may affect the result one way or the other. The proposition is true only as regards the average.

51. Buying and Selling.-In the above illustration wheat has been adopted as the denominator of value, and wine has been treated as the merchandise of which the price was under consideration. What would have been the result if we had chosen wine as the denominator and the means of payment and wheat as the merchandise?

The two men would merely have changed places as buyer and seller. A graphical examination of their respective wants would require the tracing of a curve denoting the winegrower's desire for wheat in terms of wine, and another representing the wheat-grower's reluctance, also in terms of wine, to dispose of his wheat. But, manifestly, we would then have had to deal with quantities that are the exact reciprocals of those considered in the first instance, and the ordinate of the point of intersection of the curves would have been the numerical reciprocal of the corresponding result previously obtained; and since the price of wheat in terms of wine is the reciprocal of the price of wine in terms of wheat, the final conclusion regarding the exchange rate would be identical with that of the first case.

It is thus apparent that it is immaterial which of the two ways is adopted. The terms "buyer" and "seller" are not only correlative, meaning that where there is a buyer there must also be a seller, but they are also reciprocal, meaning that each buyer is also a seller $(34,52)$. Every buyer of one thing is a seller of that which he gives in payment; every seller is a buyer of that which he receives in payment.

52. The Market. - We now enter upon the third and last stage of the study of value, namely, the process by which values are determined in the general market. 
Since it is impossible to compass extended commerce by means of simple barter, recourse has long' ago been had to a process of complex barter through some medium of exchange (83), and instead of one kind of goods being exchanged for another directly, it has become universal practice to give goods or services for money, and then to use the money to procure other goods. The final outeome is, however, nothing more than the exchange of goods for goods.

In barter there ean be no speeific distinction between buying and selling. But where a medium of exchange is used it has become eustomary to apply the term "buying" to the giving of money for goods, and the term "selling" to the giving of goods for money. This distinetion is, however, purely conventional. The law that governs exchange rates is as controlling in sales as it is in barter. It still remains true that the seller of goods is a buyer of money, and the buyer of goods a seller of money. In the last analysis, the terms remain both eorrelative and reeiproeal (51).

The general market may be eonsidered as being composed of numerous market eentres, each of which is again divided into sub-centres. In our present analysis it may be preferable to consider a merely local market. Such a market is supposed to include only a limited number of buyers and sellers. In point of fact, however, in so far as all markets are in communication, praetieally all kinds of merchandise ean be had in any of them.

As regards any one kind of goods, we find in the market a eertain number of individuals seeking to buy them, and a certain number of others offering to sell them. It is the interrelation of these buyers and sellers that we have next to review.

53. The Common Value Denominator.-It has been shown before (39) how evalnations represented by several eurves may be eompounded. But this ean be done only if the evaluations represented by these enrves are expressed in identical terms. When studying an isolated exchange, we were free to adopt as denominator either one of the things to be exchanged. But if our present incuiry were to refer, for instance, to the value of wine, which is desired not only hy 
the farmer, but also by the butcher, the baker, and others, we could not compound the various estimates of wine by the would-be buyers if one estimate were expressed in terms of bushels of wheat, another in terms of pounds of meat, and a third in terms of loaves of bread. It will be necessary to have all these evaluations expressed in terms of the same denominator. This is equally true as regards the evaluations by the would-be sellers. In the actual market this difficulty is met by the use of the conventional unit of value, the dollar, the mark, the franc. The evaluation of the unit, both from the viewpoint of the producer and that of the consumer, becomes so fixed in the mind of each that it serves as a standard by which the value of other things is estimated.

54. Appraisement of the Value Unit.-Each man's estimate of the worth of a dollar is primarily traceable to his experience in the market. A workman learns to know how much of his labor is required to earn a dollar, or how many dollars he can obtain for a week's work. An artisan, by selling his products, obtains a conception of the relation which his efforts bear to the unit of value. Experience also gives an idea of the amount of satisfaction to be derived from a dollar when applied to purchases in the market. In this way the dollar becomes, to all who have to buy or to sell, a standard for measuring both effort and gratification of every kind.

Experience, however, is not the final criterion of the value of the unit. In the last analysis the faculty of the dollarthat is to say, a specified amount of gold-to serve as a measure of effort must be traced to the effort required for the production of the gold of which the dollar consists, and its faculty to serve for measuring gratification must be derived from the capacity of gold to actually gratify desire. Yet, in any given market, there may not be a single person who is mining gold, and perhaps but a few who desire this metal for industrial or other purposes. How, then, can those who neither produce nor actually use this metal obtain a correct estimate of its capacity as a measure for either effort or gratification?

In the case of exchange by barter we had tentatively 
assumed that the seller of goods is the producer, while the buyer is the eonsumer, and that through direct intercourse of producer and eonsumer the value of the goods is determined (58). But, in point of fact, the merchant who sells goods to the consumer is only the last one of a number of those who have contributed their efforts to the production of the thing sold. Producers and consumers are, accordingly, not in that direct contact which we have tentatively assumed. This does not, however, vitiate our eonclusion. In the course of production the goods really pass by way of exchange through quite a number of hands, and it is through these exchanges that an economic contact, so to speak, is established between producer and eonsumer. Those through whose hands the goods pass in the process of exchange obtain a true idea of their value through experience in the market. And through the same kind of experience as that which gives a merchant knowledge of the value of goods in which he deals, though he may be neither producer nor eonsumer of these goods, everybody learns to appraise the dollar both as a measure of effort and of gratification (31).

55. Interdependence of Prices.-Suppose we are to determine the value, in terms of dollars, of a single eommodity, say wine. In order to do so we have to assume that its various evaluations by the farmer, the butcher, or the baker are stated in terms of dollars. As indieated before (47-48), these men ean express their several desires for wine in terms of wheat, meat, or bread, respectively, but in order to express these desires in terms of dollars they must have knowledge of the prices of wheat, meat, or bread expressed in the same terms, for otherwise neither farmer, butcher, nor baker could have a eoneeption of what a dollar is worth. The question at once arises: On what ground can we assume the price of all eommodities other than the one under examination to be known before we have found how the price of any one of them is determined? This question has, accordingly, to be answered.

The conditions under which market prices become established have prevailed for ages. Upon examining the records of the past it is found that the prices of most products, 
especially of staple articles, usually fluctuate, within narrow limits, above and below a mean rate which changes but gradually and which bears a close relation to the effort of producing things. But when a new article is brought into the market, its price does not at once conform to this rule, and is often subject to considerable fluctuations which only gradually subside until the price reaches a comparatively uniform level bearing the normal relation to the effort of production.

This would indicate that prices, of different things in the market are not determined independently, but are the result of a gradual adjustment to prevailing conditions. And the law of value, being an expression of the process of this adjustment, can do no more than state the general conditions under which equilibrium of prices prevails. We are therefore justified in taking the market as we find it and confining our inquiry to the question whether the current price of any given article under given conditions has a tendency to rise, to fall, or to remain stationary. It is therefore quite admissible to assume that the wine-grower, the farmer, the butcher, the baker, and, in short, all possible sellers and buyers of wine, can gauge their estimates of wine and, in fact, of any other commodity, in terms of dollars, the value of which they have learned to estimate by past experience in the market.

56. Price Limits Compounded.-When the price limits of all intending buyers of certain goods in a market are rendered in terms of the same denominator, the dollar, and represented by curves like the curve $D D^{\prime}$ of Fig. 5 , they can be compounded, as previously shown (39b) and represented by a single descending curve. Similarly, an ascending curve is obtained by compounding the price limits of all intending sellers of these goods.

Since the resulting curves would become very much elongated, we must adopt a reduced scale for quantities measured on the horizontal axis, so as to bring the diagram of combined price limits within practicable bounds. In this way we obtain the curves $D D^{\prime}$ and $S S^{\prime}$ of Fig. 6, which depict the combined price limits of all the buyers and all the sellers in 
the market. The significance of these eurves may be further clucidated as follows.

As regards any one community, there can be, at any given time, only a definite quantity within reach of the market. These goods are owned by a number of individuals, some possessing a greater, others a less quantity of them.

The total quantity of these goods may be considered as consisting of a large number of equal integral parts or elements, of which each owner possesses a certain number. Different owners place different estimates on their respective goods and, indeed, each owner attaches a different degree of importance to each of the elementary parts of his store $(39 a)$. Every one of these elementary portions is thus neld at an evaluation of its own.

We could have obtained the eurve $S S^{\prime}$ by supposing all elementary portions of the eommodity within reach of the market-whether held for use ${ }^{10}$ or held for sale-to be spread, figuratively speaking, on the horizontal axis of the diagram (Fig. 6), arranged in a rising order of their evaluations, with the latter marked off as ordinates.

In like manner as we divided the goods supplied into elementary parts we ean, for the purpose of analysis, imagine each supplier of the goods to be divided into as many elementary sellers as there are elementary parts of his goods (16). Each such part would then be owned by one of these elementary sellers who is eorrespondingly located on the curve $S S '$. The first one of them would be willing to sell the part he offer's for a price equal to $O S$, if le conld not obtain more; but he would not sell for less, this being his "price limit" as a seller. The price limit of the seeond is slightly higher, and each following elementary seller's price limit is eonsecutively greater, as indicated by the aseent of the eurve $S S^{\prime}$.

It will be understood from the method of constructing the curve $S S^{\prime \prime}$ that every one of the actual sellers who holds a

${ }^{10}$ It may here be assumed that all owners of things which are not for sale may be indued to sell if the price offered is high enough. 'These things, though not offered for sale, are, accordingly, held at some price limit, whatever that may be. 
number of elementary parts, each at a different price limit, is supposed to consist of the same number of elementary sellers located at various points of the curve.

In the same way as the curve $S S^{\prime}$ represents those who have goods to sell, the curve $D D^{\prime}$ represents those who desire to purchase these goods. Inasmuch as some of the purchasers will buy a greater, others a less quantity, and as the degree of their desire for each part they want is different, we must consider each one of these buyers divided into a number of elementary intending buyers corresponding to the number of parts he desires to buy. Every one of these elementary buyers will then have a definite price limit of his own.

Arranging all elementary buyers in a falling series of their price limits and assigning to each an ordinate equal to his limit, we get a descending curve which is identical with the curve $D D^{\prime}$ of Fig. 6 as previously obtained.

Just as the curve $S S^{\prime}$ represents the sellers' price limit, or, more correctly speaking, the increasing price limits of the consecutively located elementary sellers, so the curve $D D^{\prime}$ depicts the buyers' price limit, or the gradually diminishing price limits of the consecutively placed elementary buyers (62). Every one of the actual buyers of the market is represented by a number of points scattered over the entire curve $D D^{\prime}$.

It is manifest that the buyers' price limit measures desire, which, in turn, is prompted by the utility of the goods. Hence the curve $D D^{\prime}$ represents utility, as estimated by the consecutive elementary buyers, expressed in terms of the conventional value unit.

Similarly, the curve $S S^{\prime}$ represents the varying degree of reluctance of the intending sellers to part with their goods. But this reluctance can be viewed in two ways. When the causes which determine the momentary or current price are in question (59), we must take into account not only the fundamental factors of the case, but also temporary conditions, such as irregularities in the supply or in the demand, from whatever cause. In this case the curve $S S^{\prime}$ must be held to include all goods of a kind within reach of the market. But in study- 
ing the causes that determine normal prices, in examining the conditions under which production is continued uniformly, and under which the price tends to remain unchanged, we can consider only the main fundamental factor, namely, the strain of the effort required to produce the goods for sale. In this case the sellers' price limit is the least price that will induce the sellers to subject themselves to the strain of production. Hence the curve $S S^{\prime}$ in this case represents the strain of effort, and applies not only to things that have already been produced, but also to those that may be produced whenever conditions favor their production (60).

57. Relation of Supply and Demand to Price.-Owing to the inconstancy of human likes and dislikes, as well as to changes in the methods of production, the curves $S S^{\prime}$ and $D D^{\prime}$ are subject to incessant changes. But if we are to study the causes involved in the process by which the value of commodities is determined, we must, at least for the time being, consider these actuating causes as fixed and as definitely known. We are therefore justified in assuming the curves $S S^{\prime}$ and $D D^{\prime}$ as fixed, without regard to possible subsequent changes. On the basis of these premises we must exclude from our present considerations all of those changes in the market which influence the course of these curves.

The conditions represented by the curves $S S^{\prime}$ and $D D^{\prime}$ being assumed, the amount of a given commodity that will be offered for sale depends upon the prevailing price, and the curve $S S^{\prime}$ represents the relation which the market supply bears to that price. All those elementary portions of the commodity of which the price limit is below the prevailing price will be offered for sale, while the remainder will be retained by the owners.

Similarly, the amount demanded in the same market will increase as the price falls and decrease as the price rises, and the rclation which the amount demanded bears to the prevailing price is indicated by the curve $D D^{\prime}$. Of all the desires of various degrees depicted by this curve, those which are equal to or greater than the reluctance to pay the prevailing price will become effective in the market. 
If the prevailing price equals $O p^{\prime}$, the quantity supplied will equal $p^{\prime} s^{\prime}$ and the quantity demanded $p^{\prime} d^{\prime}$. Or if the price were as low as $O p^{\prime \prime}$, the supply would amount to $p^{\prime \prime} s^{\prime \prime}$ and the demand to $p^{\prime \prime} d^{\prime \prime}$. These curves, then, may properly be regarded as curves of supply and of demand, for they depict how those quantities are affected by the prevailing price (62).

58. The Law of Value.- It is manifest that business conditions can be considered as normal only if the amount of goods produced and put upon the market equals the amount sold. The supply will then equal the effective demand. ${ }^{11}$ Whenever more of the goods are supplied than demanded, as would be the ease if the price should equal $O p^{\prime}$ (Fig. 6), the excess remains unsold on the hands of the sellers. In their effort to sell they compete with one another, and the price comes down. This lowering of the price reacts upon the market so that the amount supplied will be reduced and the amount demanded increased, and this process will continue until the quantities supplied and demanded become equal. On the other hand, suppose the amount demanded at any time to exceed the amount supplied, as would be the case if the price equals $O p^{\prime \prime}$. All who are disposed to sell at that low figure will have sold their goods before all buyers are supplied. In their efforts to purchase, the intending buyers will compete against each other, causing a rise of the price, which is eventually followed by an increase of the supply and a decrease of the demand, and this will continue until the quantity supplied and the quantity demanded become equal.

A glance at the diagram shows that equality between the amount supplied and the amount demanded can persist only if the price equals the ordinate $q a$ of the point $a$ at which the two curves intersect. The ordinate $O p$ therefore represents the rate to which the price will tend.

The law of value, or, more properly, the law of price,

"As a matter of fact, the amount of goods brought to market usually slightly exceeds the amount actually sold. In the process of selling a small percentage may perish or otherwise become unsalable (13). The difference due to this cause is here ignored. Its effect on prices will be discussed later (219). 
accordingly involves two propositions: (1) a rising price of any conmodity tends to increase the supply of, and to reduce the demand for, that eommodity, while a falling price has the opposite effect; and (2) an excess of the amount supplied over the amount demauded causes the price to fall, and vice versa. The natural result is that the price of a commodity will aluays tend to that point at which the amount supplicd equals the amount demanded.

It should be observed that the law of value, or, as it is often called, the law of supply and demand, has reference really to the exchange rate of two commodities or sets of commodities. A law of supply and demand is conceivable only if two separate commodities are held in view. In the case of the two settlers we studied the exchange rate of wheat and wine, and when we came to consider the general market for wine we found a way to substitute the standard commodity, gold, for the wheat of the preceding illustration.

Like all economic propositions, the law of value indieates only general tendencies, and departures from the indicated result may oceur in either direction. But whenever such departures do oceur, a tendency to restore normal eonditions at once comes into play.

It may be well to call attention to the faet that we have all along considered the buyer to be the consumer and the seller the producer (54). We have taken into account only the consumers' demand, namely, that which arises direetly from a desire for gratifieation; and only the producers' supply, a supply which, for natural reasons, requires the stimulus of a recompense, and which is regulated by the relation which that recompense bears to the effort $(115,153)$. In the absence of extraneous restraint, desire for gratification and reluctance to exertion are, indeed, the only factors in the determination of value $(63)$.

As intimated above, the eonditions which govern supply and demand undergo change from time to time. For example, production may be made easier through an invention, or the demand may be affected through a change in fashion. The eurves $S S^{\prime \prime}$ and $D D^{\prime}$ will then change their comse, and the 
point of intersection will shift in consequence. According as these influences are of a temporary or of a persistent nature, they have a correspondingly brief or lasting effect on prices.

59. Current Price.-As already stated, the total of all things that are at any given time within compass of the market is always limited (56). Some of these things are for sale at the current price, others are held for a rise, and again others are held for use and are not for sale, except, perhaps, at an unusual price. For the time being, each element of the total supply is held at a definite price limit. There is also a demand composed of a number of elementary demands, each having a certain price limit.

If $O Q$ of Fig. 6 represents the total of any particular kind of goods, the curve $S S^{\prime}$, embracing the seller's' price limits of these goods, cannot go beyond $Q$. The range of price limits of both sellers and buyers being given in the form of the curves $S S^{\prime}$ and $D D^{\prime}$, the tendency of the price is toward the rate $O p$, which equals the ordinate of the point $a$ of intersection.

Both curves of the diagram cut each other in two. The branch $D a$ of the demand curve embraces all the buyers who find goods in the market at a price below their limits and, therefore, at a price acceptable to them. The buyers near the initial point $D$ of the curve find the price materially below that which they would be willing to give rather than go without the goods, while those near the point $a$ find the price but slightly below, or practically equal to, their respective price limits. The intending buyers on the branch $a D^{\prime}$ are those who will not buy, because their desire for the goods, as represented by their price limits, does not come up to the ruling price. We are here speaking of elementary buyers and not of actual persons. If the diagram were, for example, to refer to food products, this conclusion would not mean that high prices would cause any one to go without food. It must be remembered that a real individual, being here assumed as divided into a number of elementary persons, is represented by a number of points distributed over the curve, and the branch $a D^{\prime}$ embraces only those of his desires which, because of the 
high price, remain unsatisfied. A high price may eause some to retrench and, if need be, go on short allowance of food, but not without any.

The branch $S a$ of the curve of supply embraces those sellers who find the market price more or less above their limits and who, therefore, offer their goods for sale, while the section $a S^{\prime}$ represents those who decline to sell, preferring to retain their goods for their own use or for a better market (108).

Only the goods embraced beween $O$ and $q$ will be marketed. The sellers included in the branch $S a$ will dispose of their goods to the buyers included in the branch $D a$. As these exchanges proceed, the buyers included in the branch $D a$ become possessors, like those included in the curve $a S^{\prime}$, and by combining all these possessors and placing them in a rising order of their price limits, in other words, by compounding the curves $D a$ and $a S^{\prime}$, the curve $p S^{\prime \prime}$ is obtained, which embraces all possessors of the goods who will not sell, because they prefer the goods to the price.

At the same time, the elements of the curve $S a$, namely, the sellers who have disposed of their goods, will be in the same class as the intending purchasers who decline to buy because the ruling price exceeds their limits and who eompose the branch $a D^{\prime}$; and by proceeding to combine both classes into one, the curve $p D^{\prime \prime}$ is obtained. This curve, accordingly, embraces all who have none of these goods in their possession. Further exchanges thereupon cease, because the price limits of the possessors exceed those of the intending buyers. The price remains the same as before, namely, $O p$, the point $p$ being now at the junction of the two new curves. The price does not change so long as the respective price limits and the total amount of the goods remain the same.

If there were no subsequent changes, such as will be discussed presently, this would be the end of all buying and selling of the goods in question. Those whose price limits are higher than the prevailing price will remain the owners, and those whose price limits are lower than that price will go without them, the point of division being determined by the quantity of goods within reach. The curves $p S^{\prime \prime}$ and $p D^{\prime \prime}$ show approx- 
imately the condition that prevails with respect to things that cannot be reproduced at all, such as old coins, rare editions of books, and the like.

In a measure, like conditions arise periodically with regard to things of which the production is intermittent, such as farm products. Even though a crop may be a partial failure, the farmers usually have a greater quantity of their products on hand than they need for their own use, and their evaluation of their surplus, gauged on the score of utility to themselves, is materially lower than that of intending buyers. But the total quantity brought to market being below the average, the market conditions are such as presented in Fig. 7 by the curve $R R^{\prime}$, where the distance $O Q^{\prime}$ represents the total quantity in stock. A glance shows the reason for the high prices, measured by $q^{\prime} a^{\prime}$, in years of poor crops. The sale of the goods will then for the time being bring about conditions similar to those depicted in the curves $p S^{\prime \prime}$ and $p D^{\prime \prime}$ of Fig. 6 .

On the other hand, an unusually abundant crop, indicated in Fig. 7 by the curve $T T^{\prime}$, often depresses the market price to a point where it does not pay to transport all the products to market, and farmers have at times allowed part of their crops to rot in the field, or have otherwise destroyed them or put them to an inferior economic use.

In the actual market the buying and selling even of such goods as cannot be reproduced never comes to a complete standstill. There will be changes in the conditions of the market due to the nutations of life, like sporadic changes of fancy, vagaries of fashion, death of owners, the advent of the rising generation, any of which disturb the equilibrium, so that some of these goods reappear from time to time in the market.

6o. Normal Price.-When we come to goods that are consumed by the buyers, while new goods are supplied by the producers, exchanges continue indefinitely. Former buyers, after consuming the goods purchased, reappear as buyers. Former sellers, after replenishing their stock, again appear as possessors and sellers.

The current prices of such products are subject to the 
momentary supply of the goods in question and to the immediate demand. Both supply and demand are constantly influenced by fortuitous conditions apart from those that regulate production and consumption, conditions that give rise to the well-known irregular but mostly inconsiderable fluctuations of market values (278).

But apart from adventitious circumstances, both supply and demand are subject to fundamental conditions which determine average or normal prices. In order to learn what determines the average or normal supply and demand, we have to delve into the ulterior conditions that regulate the continuance of supply and demand, namely, production and consumption, apart from the merely accidental influences that cause at most temporary departures from normal conditions. When the law of normal prices is to be traced, we must ascribe to the curves $S S^{\prime}$ and $D D^{\prime}$ a significance different from that heretofore ascribed to them. The horizontal abscissas must be understood as measuring a stream or current, that is, quantity per unit of time instead of simply quantity (37). The ascending supply curve $S S^{\prime}$ (Fig. 6), then, indicates how production is stimulated by a rising price, while the descending demand curve $D D^{\prime}$ depicts the coincidence of increasing consumption with the falling of the price. Instead of asking at what price a seller is willing to part with his goods, we must inquire what effect price has on the continuance of production. Instead of asking at what price a buyer is willing to purchase, we must inquire what effect price has on continuance of consumption. We have now to deal with dynamic and not with static conditions.

When things are taking their normal course, the rate of production continues uniformly. Only when the market becomes disturbed by some cause of a permanent nature will the production of the goods in question be increased or reduced. At present we shall consider only the normal case, leaving the study of such disturbances for a later stage of our discussion (221). The ordinates of the sncessive elements of the curve S'S" then represent the lowest recompense at which the varions producers continue to produce and supply the market, and 
the curve $D D^{\prime}$ the highest cost at which the different con. sumers continue to consume. The section $S a$ of the supply curve $S S^{\prime}$ represents those producers who, while the price equals $O p$, continue to follow their vocation and keep the market supplied, while the branch $a S^{\prime}$ comprises those who could produce the goods in question, but who find other oceupations more remunerative (56).

When we come to a study of the distribution of wealth, the causes that regulate normal values will alone have to be considered, since the problem deals with the regular course of economic activity apart from merely temporary influences.

6r. Cost, the Sellers' Price Limit.-It is apparent that a man will continue to work in a given occupation only so long as he cannot, with equal effort, earn more in some other direction. He will seek to follow that line of employment in which the efforts he is prepared to put forth receive the highest reward (44).

It is equally evident that the compensation he may be able to obtain for equal exertion in his occupation of second choice determines the lowest recompense he will accept in his chosen occupation before he will abandon it. This, then, is his price limit as a seller of his labor.

When a man works in one direction, he virtually gives up that which he could earn if he applied himself with equal effort to some other occupation. His earning capacity in this latter direction, in his occupation of second choice (215), may therefore quite appropriately be regarded as the cost of his labor, it being that which he sacrifices in producing what he does. It is that which determines labor's price limit (62).

The cost of labor to the worker is, however, not to be confused with the value of labor, that is, the cost of labor to an employer. The value of labor to the employer is equal for equal productivity, while the cost of labor, from the standpoint of the worker, namely, his price limit, is the lowest recompense he will accept before changing the direction of his work.

Different workers naturally have different price limits, which, accordingly, can be represented by the rising curve 
$S S^{\prime}$ of Fig. 6, and the value of their efforts is at the point of intersection of this eurve with the curve $D D^{\prime}$ representing the demand for such services, whatever the price limit of any single worker may be. Workers who can earn nearly as much in their occupation of second choice as they can in their chosen occupation are located at or near the point $a$ of the intersection, while those who are skilled in but one occupation and who can make a change only at a disadvantage, are situated nearer the origin $S$ of the curve.

This view of the case applies particularly to wage earners and to those artisans who do not employ assistants. The cost of producing things becomes more complex where the specialization of labor enters into the problem. Employers of labor must buy their raw materials and supplies, pay wages and cover the regular charges for the use of the land, of the capital goods-namely, appliances and material-and of the money needed in carrying on their business. And if cost is to be considered from their standpoint, there must be added to these items the "cost" of their own labor, namely, their possible earnings in their occupations of second choice. This total cost determines their price limit, for if the income of their business falls below this point, they will endeavor to get into that other line of activity in which they can earn more.

For the same reason that we assume equal products in the same market to command equal prices, we must also postulate that labor which accomplishes equal results commands equal wages, independent of the time or exertion spent in doing the work, and independent of the price limits of the individual workers. The cost of the use of land and of other capital is also assumed to be, in general, proportionate to the advantages these afford to the users.

Let us imagine a number of individuals who are nominally owners of various business enterprises, but who do not take any part whatever in conducting their business, nor furnish any part of either the land or the eapital necessary (144). They have accordingly to employ the manager as well as all other workers, to rent the land required in the business and to horrow the capital needed, all at market rates. All these 
nominal owners are accordingly on the same basis, none contributing in any degree to the success of the business, either by work or by capital, and since all are dependent on the same market for procuring the factors of production, the cost of producing equal quantities of a commodity is normally equal for all. It will be observed that "cost of production" in this sense differs from its colloquial meaning. It includes the market value of all services, those of the organizer and manager and those of the landowner and of the capitalist as well as wages of employes and all other expenses.

The several items constituting cost in this sense are : cost of raw materials, supplies, etc., including depreciation of means of production ; cost of labor, or wages ; cost of the use of land, or rent; cost of the use of capital goods, or capital interest; and cost of the use of money, or money interest. When all factors of production are accounted at their market value, the line $S S^{\prime}$ of Fig. 6, representing cost of production or the sellers' price limit, becomes a horizontal line. It is to be remembered that here, as before, chance variations from normal conditions are to be ignored.

We can therefore conceive the line $S S^{\prime}$ as an ascending curve only if one or another of the items constituting the total cost is not included at its market value. Thus, when the value of labor or the law of competition (148) is under consideration, the line $S S^{\prime}$ must be held as representing cost in which labor is not accounted at its normal market value, but at the lowest point at which different workmen will continue to work before turning from their oceupation to some other, in short, at their price limits. Since the price limits are different for different workers, the line $S S^{\prime}$ then ceases to be horizontal.

So in examining the value of the efforts of managing employers, we must compute the cost of the products of their business from all business outlays, including cost of materials, wages of employes, rent of land and interest of all other capital needed, to which are to be added their price limits as employers, namely, their earning capacities in occupations of second choice.

When we come to study incomes from land (173), the 
sellers' price limit is to be viewed from the standpoint of the landowners. Cost of production is then made up without regard to any recompense for the use of the land, all remaining items being counted in at their full market value.

And when we come to study the earning power of capital goods, that power can be analyzed only by exeluding from "eost" all charges for the use of capital goods $(186,257)$. In this way we obtain cost from the capitalists' standpoint.

In the study of the conditions which determine the net incomes of workmen, of employers, of landowners and of capitalists we have always to eliminate from the total cost the particular item which is under examination. Cost so accounted determines in each ease the "sellers' price limit" (30).

62. Cost and Utility Theories of Value.-We have learned to view the curves $S S^{\prime}$ and $D D^{\prime}$ of Fig. 6 in three different ways. They represent, respeetively, the relation of supply and demand to current price (57), the seller's' and buyers' price limits (56), and effort or cost of production and utility of the product (61). To be sure, these are merely three different aspects of the same functions.

When the two eurves are viewed with regard to effort and utility, they point to conclusions that have a definite bearing on the two most widely accepted theories of value, namely, the labor or cost theory and the utility theory.

The curve $S S^{\prime}$ is drawn to illustrate the inereasing strain of effort of production, which finds its conerete expression in the increasing "cost," as production is carried on under increasingly unfavorable conditions. The ordinate qa of the point $a$ has significance from several points of view. It represents not only the effort required where production is being continued under the most unfavorable cireminstances, but also represents the normal value of the product $(180,257)$. Inasmuch as these two quantities are represented by the same ordinate, they must be equal. It is therefore evident that normal value equals the effort of production where it is being continued under the most unfavorable ciremustances. This is clearly a confirmation of the "labor" theory of value, as 
promulgated by Ricardo (30) and known as the classic theory. Its variant is the "cost" theory.

In this theory two data are assumed to be known, namely, first, the "quantity of produce required," that is, the quantity demanded; and second, the variable effort or cost of supplying the various elements of that quantity. Referring to Fig. 6, these data are the quantity $O q$ and the curve $S S^{\prime}$. It is further assumed that the supply will naturally be adapted to the demand, so that the point $a$ locates the most unfavorable point at which production must be continued to supply the demand. This theory is therefore applicable only when the normal price prevails and the supply has adapted itself to the demand, but is not applicable when the current value differs from the normal value.

The effort expended, or the cost of production, at the point $q$, which is the last element brought into use in order to supply the normal demand, has been denominated the "marginal effort" or "marginal cost," and the most unfavorable point at which produetion is normally continued is called the "margin of production"' (148).

The purport of the curve $D D^{\prime}$ may be similarly analyzed. Viewing this curve as representing utility, the diagram points out that of the entire quantity of the goods brought to market the first element will go to gratify a desire equal to $O D$, the second a desire of a slightly less degree, and so on. All the later elements will cover consecutively less urgent needs, and the last one, at the point $q$, will satisfy the least important of all the desires that can be gratified by the available quantity of the goods $O q$. But the ordinate $q a$ of the last element $q$ of the market supply, which is the measure of that least important desire, represents the price also. This agrees with what is known as the modern, the utility theory of value, which has been so admirably elaborated by Böhm-Bawerk. Aeeording to that writer the value of things is measured by the importance of that concrete want which is least urgent among the wants that are met from the available stock. ${ }^{12}$ 
This theory assumes as known two independent data, namely, first, the "available stock," represented by $O q$ of Fig. 6, and second, the series of possible "wants" which this stock can satisfy and which is represented by the curve $D D^{\prime}$. the least urgent want satisfied by the supply being $q a$. The theory fails to elaborate the conditions which determine the normal supply and is therefore applicable only to current or temporary market value, and incidentally to normal value only when the actual supply happens to equal the normal supply (153).

The importanee of the least want that ean be satisfied by the available stock, in other words, the utility of the last portion of the supply, is known as the "final" or "marginal utility."

\section{Both Theories Corollaries of the Same Proposition.-} We here find eonfirmation of two value theories which are generally regarded as incompatible. At first glance it would indeed appear that only one of them could be correct. If value be a function of effort, how can it be dependent on utility? And if determined by utility, it would seem to be independent of labor or effort. Yet, here we find both theories confirmed. We have arrived at two apparently conflicting conelusions.

But the explanation of this apparent incongruity is not far to seek. In a normal market final or marginal utility and marginal effort or marginal cost are always equal quantities (150). The point $a$ of Fig. 6, where the curves of effort and of utility meet, may be considered from two standpoints. It is that point of the effort eurve $S S^{\prime}$ at whieh the utility eurve $D D^{\prime}$ intersects it. But it is also that point of the utility eurve $D D^{\prime}$ at which the effort curve $S S^{\prime}$ intersects it. Although the curves represent independent functions, the point $a$ is common to both. Although utility and effort are independent concepts, marginal utility is not independent of effort, nor is marginal effort independent of utility. Every attempt to establish either. of the two theories to the exclusion of the other betokens a failure to trace the law of value to its fundamental premises (306).

The statement that value is determined by supply and 
demand would be more deseriptive of the actual facts if rendered in the form that value is determined by cost and utility, conceiving cost to denote reluctance to exertion, the restraining force, and utility to denote desire, the impelling force. As we have seen, value tends to become adjusted to the point where the desire for any given product is balanced by the reluctance to making the effort of producing it $(58,115,123)$.

The labor or cost theory is incomplete in that the "quantity of produce required," -in other words, the quantity demanded, -is assumed as given, while it should really be traced to ulterior factors. A like fault is to be found with the utility theory, which assumes the "available stock," in other words, the quantity supplied, as being given. Both these quantities vary with every change of price, and being thus dependent on price they cannot be regarded as primary factors in the determination of price. In a normal market both are equal to the amount actually produced, and this amount is determined by a balancing process in which the likes and dislikes of all buyers and all sellers come into play. Production proceeds no farther than where desire and reluctance, where impulse and restraint, come to a balance. The primary factors to which value is to be traced are the varions individual evaluations. On the one hand is the diminishing desire for the gratification of consumption, which we have represented by the curve $D D^{\prime}$; on the other the increasing reluctance to makc the effort of production, which we have represented by the curve $S S^{\prime}$. It is only by showing how these forces combine in determining the amount demanded and the amount supplied that the law of value is traced to its fundamental factors. In a normal market these two quantities are equal, as are also final utility and marginal cost, hence both the cost and the utility theory are true as far as they go.

In this respect a possible misapprehension should be guarded against, and an analogy may be helpful to that end. We know that the speed of a steam engine is regulated by its governor. But it is the steam, not the governor, which is the cause of motion; the governor only regulates the speed by controlling the admission of steam. So is utility alone the active principle of value, inasmuch as it engenders the desire 
for things, while the strain of labor, the cost, is that which governs the quantity produeed and so only regulates, but does not engender, the value of the products.

Since the labor or cost theory eannot apply to things that cannot be reproduced-for instance, paintings of old masters - nor to a commodity of which the marginal cost has not beeome equalized with final utility (221), as is the case for a time with things the production of which is facilitated by a new invention, it is final utility alone which determines value in such eases.

The cost theory is applicable only to staple articles and services, and then only under normal conditions of the market. There are eases in which the utility theory is quite inapplieable, the cost theory being the one which alone applies (64).

The notion that labor is a measure of value, as enuneiated by Adam Smith (30a), although correeted by Ricardo, continues to be quoted in the incorreet form, which is to the effeet that the value of things is determined by the amount of labor required in their production (164). This proposition was indeed adopted by Karl Marx as the basis of his theory of value. But, as shown by Rieardo, it is true only for things produced at the margin of production and is aceordingly valid only in a sense so limited that its application as a general economic law leads, as a matter of course, to untenable conclusions.

64. Illustrations. - When applied to speeial eases, the diagram represented in Fig. 6 may lave to be modified so as to adapt it to the conditions of the ease.

When eommodities are of such a nature that they do not admit of indefinite subdivision, the "curves" will assmme a step-like form. Should we desire, for example, to represent the market for horses, the diagram would take the form suggested in Fig. 8, in which each step represents a horse. The conelusion that the "point of intersection" of the two "curves," namely, the stepped lines $S S$ " and $D D$ ', marks the rate toward which the price tends, is as true here as in the case of entinuous curves. However, a glanee at the diagrim plainly shows that the "intersection" is not a point, but the 
short vertical line $a a^{\prime}$, since the two "curves" actually coincide for that distance. Supply and demand will therefore balance, whether the price of horses is equal to $q a$ or to $q a^{\prime}$ or anywhere between. In this case the price is really indeterminate between the points $a$ and $a^{\prime}$.

In the diagram Fig. 8 only a small number of units is shown. As a rule, a large number of units is involved. The step-like elements of the "curves" will then be comparatively small and will virtually disappear in a graphical representation. Continuous curves may therefore be used in practically all cases.

We have seen that a change in the prevailing price of a commodity affects both its supply and its demand, but we have not yet considered the extent to which either is affected. Were we to examine the behavior, in this respect, of a number of commodities, we would find a marked difference among them. A change of a given percentage of price will affect the supply and demand of some commodities more than of others. Furthermore, a like change of prices affects the supply and the demand of many commodities unequally. There are things of which a rise or fall in the price is followed by a considerable change in the supply and no great change in the demand, and there are other things in regard to which the opposite is true. In the case of some things we meet with extreme conditions. There are some commodities for which the amount demanded is almost entirely independent of the price, and there are other things of which the amount supplied remains practically unaffected as the price changes.

As an instance of the first kind we may mention certain drugs. The demand for any one of them is due to the prevalence of the disorder for which it is a specific. A falling price will not appreciably increase the demand, and it would require a considerable rise in the price before even the poorer patients would go without the medicine. There is competition only among those who supply the goods, and since the supply is governed by the cost or effort of production, this cost determines the value. Diagram Fig. 9 applies here and shows that it is the curve $S S^{\prime}$ which in the main decides the ordinate of the point of intersection $(63,153)$. While in ordinary 
cases it is immaterial whether we measure value by marginal utility or by marginal effort, in this case it is the marginal effort which is the predominating factor. However, the quantity demanded is decided principally by the range of utility, represented by the buyers' price limit $D D^{\prime}$.

The other extreme may be illustrated by certain wines which ean be raised only in certain districts. The area of their cultivation cannot be inereased, no matter how high the price may soar. If in a given year a certain number of gallons of such wine is produced and put upon the market, the vintners, guided by past experience, aim to adjust the price as high as possible without losing the chance of selling their entire output, in other words, "as high as the traffie will bear." Were they to make the price too high, they could dispose of only a portion of their produet, and, if too low, the demand would exeeed the supply and they would find that a higher priee eould have been obtained. The diagram Fig. 10 graphically illustrates the case. Value is, then, regulated principally by the range of utility $D D^{\prime}$, while the quantity supplied is determinerl almost entirely by the limited facilities of production, depieted by the sellers' price limit $S S^{\prime}$.

Some writers, Mill among them, treat these extreme cases as though they were subject to independent laws of valne, assigning one law to "freely reprodncible goods" and another to "scareity goods." Our examination, however, shows that this distinction is immaterial, as both eases are obedient to the same law. The difference in the application of the law is simply due to a difference in the conditions peculiar to each ease.

65. Capitalized Values.-Before concluding the present discussion, it is desirable to take notice of a class of values which properly belong to a special eategory. In this we are obliged to anticipate some matters which logieally relate to a later seetion of our investigation; we have to take aceount of the faet that money has the power to command interest.

There are certain kinds of property, ereated by law or by private eontract and not by labor, such as land ownership, franchises, special privileges and anmuities, which lave the 
capacity to yield a continuous or periodic income. Property of this kind, which is in the nature of a right, must be sharply distinguished from the income which it yields. The property itself, the right, not being consumable, cannot be considered to have "utility," and not being the product of labor, it cannot be considered to have "cost." But though devoid of both utility and cost, property of this nature is marketable and therefore possesses value.

This value depends upon conditions different from those which regulate the value of consumable things, this latter being dependent on either final utility or marginal cost, both of which factors are absent in the case of law-created property. It is generally recognized that the bridge between the value of this class of property and the value of consumable things is money, by virtue of its power to command interest. The value of money, namely, its exchange ability with commercial commodities, as well as its interest-commanding quality, will be fully discussed in their proper places. But it is through its interest-bearing quality alone that money can be compared with law-created rights which have the power to render periodic incomes.

It is easy to understand that a right to a perpetual income from any source will normally fetch such a sum of money as is capable of returning an equal net income in the form of interest. In order to find the exchange value of such a right, we must compute, by the well-known process of "capitalizing" the income, the sum of money which, at the prevailing rate of interest, would bring equal returns (181). Thus, an income of $\$ 100$ per year, when the interest rate is five per cent., has a selling value of $\$ 2000$. If the right is not perpetual, but limited to a definite period, its value follows certain rules of computation which are well known.

It is often asserted that a thing can have value only if it is capable of returning an income. But, as we have seen in our foregoing discussion, the value of things produced by labor is not dependent on any income-producing power, so that values determinable by the process of capitalization can have reference only to rights and privileges, but not to things produced by labor (360). 


\section{CHAPTER V}

\section{CREDIT}

66. The Nature of Credit.-The fact that instruments of eredit, such as promissory notes, drafts, certifieates of stoek, and especially paper eurrency, possess exehange value has been variously interpreted. Although men of affairs, like bankers and merchants, who have to deal with credit in praetice, have substantially correct ideas about credit instruments, the theory of eredit remains involved in a maze of academic controversy and in a confusion of conflicting ideas. Before we can proceed to study the subject intelligently, we must find what it is that really constitutes "credit."

Being derived from the Latin word "credere," to believe, "credit" primarily signifies reputation for trustworthiness. The reports of commercial ageneies are information regarding such credit. The term has, however, come to be used in another sense, in which it describes the relation arising when commereial trust has been given, and this is the meaning with which economies has to deal. In this sense "credit" is equivalent to "elaim," usually a elaim to a specified sum of money payable at a speeified future time. When a bookkeeper gives "credit" on his books for value received, he really records the amount the creditor has a right to elaim at some future time. "Credit," then, is the correlative of "debt," just as "creditor"' is the eorrelative of "debtor." The terms "credit" and "debt," accordingly, denote the same relation considered from opposite standpoints. Only in this sense can credit be regarded objectively, that is, as something valuable, as something which ean be bought and sold, or which ean be conveyed by instruments of eredit. In point of fact, eredit instruments are simply acknowledoments of indebtedness.

It is not difficult to see that the right of the creditor is closely related to the right of ownership. In some respects both rights are alike, but how far the similarity goes ean best be learned by first studying in detail the several features which characterize the right of ownership. 
67. The Right of Ownership Analyzed.-Since the right of ownership exists by virtue of the social guarantee to undisputed possession (21), it naturally embraces all rights that such guarantee implies. The owner may use, change, consume or sell that which he owns, unless by doing so he injures others. If the object owned is one that is capable of being utilized for an indefinite period, ownership includes the right to its exclusive use during the entire period of its existence.

The owner of a thing may sell it entirely, or he may sell any portion of his right to it. The latter happens, for instance, when a man rents a house to a tenant. The lease is invariably made for a specified period, which may or may not be extended after the expiration of the term. By leasing a property, the owner really sells a portion of his right to its exclusive use. But it is only the right of possession and use for a specified time that he sells; he retains all other rights. After making such a partial sale, he manifestly is no longer owner in the full sense of the word. It would, instead, be more appropriate to call him "lessor." Commonly, a lessee is not considered joint owner of the leased property, but from a rational standpoint we cannot escape the conclusion that the sum-total of the rights comprised in ownership is actually shared between lessor and lessee, and that the case is really one of joint ownership in a qualified form. A similar relation exists when a librarian loans a book to an applicant, or when the owner of a livery hires out a team to a customer for a specified time. In the following analysis the term "lessor" will be used to denote the owner of anything, the possession of which he has temporarily turned over to another. Although this term is not usually understood as applying to all cases where an owner has temporarily parted with the right of possession in favor of another, there is good reason for giving the term this broad scope. The right of the lessor is clearly a phase of ownership which has an important bearing on the study of credit.

Leasing is, however, only one of the methods by which some part of an owner's rights is conveyed to another person. There are other ways in which the right of ownership may 
be shared by two or more persons. Things may be jointly owned in speeified proportions. This applies partieularly to certain aggregates of things, like stores of goods, manufacturing plants, railroads and the like. Partners share the ownership of such aggregates of things in definite proportions. In stock companies the property is owned in shares by the stockholders. Each partner, each stockholder, is owner of an aliquot part of the whole.

All forms of joint ownership are subjeet to dissolution, either by speeial agreement or under the provisions of law. Partnerships are generally entered into for stated periods. While the agreement is in foree, none of the partners has a right to either use, ehange, consume or sell any portion of the property jointly owned, except for and in behalf of the partnership. Inasmuch as the right of each partner to the possession of his share is for the time surrendered to the partnership, which figures as a separate economic person (16), we must regard each partner as lessor of his respective share rather than as owner. At the expiration of the term of the partnership any one of the members, having eomplied with the neeessary formalities, may insist npon dissolution and the recovery of his portion. If the partners eannot agree upon some other method of division, any one of them can legally insist on the public sale of the property and the sharing of the proceeds.

68. Credit Defined.-The right of the ereditor exists by virtue of law which empowers him to take eertain action in the event of the debtor failing or refusing to pay the debt when it matures. In that event the property of the debtor can be legally seized and sold at public sale, and the proeeeds applied to pay the cost of the legal process and the claim of the creditor, the remainder being returned to the delinquent. Before the debt matures, the right of the creditor is analogous to that of a lessor, since he has no right to demand possession of that to which he has only an ultimate claim; but after the debt falls due, if it be not paid, the creditor can legally insist on the public sale of the property of the debtor and the sharing of the proceeds. 
By comparing this right with that of a partner, it is seen that, with the difference of a few minor details, the right of the creditor is identical with that of a partner or joint owner (210). The main difference appears in the division of the proceeds. Instead of these being divided pro rata among the partners, they are so divided that the creditor obtains the amount due him, while the debtor, who was the reputed owner of the property sold, retains only the remainder.

If it is appropriate to regard partners as joint owners of the property of the partnership, it is manifestly equally appropriate to consider creditor and debtor as joint owners of the possessions of the debtor, the sole difference being that the creditor, instead of owning an aliquot portion of the whole, owns a definite portion equal in value to the amount of his credit. His share is stated in a definite number of dollars, while that of a partner is a stated fraction of the aggregate property of the partnership.

In view of this difference, the process of terminating the joint ownership of debtor and creditor varies in a few particulars from that of dissolving a regular partnership. By his promise to pay a certain sum, the debtor really agrees to dissolve the joint ownership at the time specified by buying the creditor's share, the value of which is stated in the agreement. But if the debtor fails to make this purchase, the creditor can dissolve the joint ownership by selling, through legal process, enough of the debtor's possessions to liquidate the claim.

In view of the creditor's right being virtually a form of joint ownership of the wealth possessed by the debtor, "credit" may be defined as ownership without possession, or, to state it otherwise, joint ownership of wealth to which the debtor has, for the time being, the exclusive right of possession; and conversely, "debt" as possession without ownership, or, possession of wealth which is really owned, at least in part, by the creditor $(21,102,299)$. We must, however, constantly bear in mind that before the debt falls due the creditor is only lessor and not full owner of his share, in other words, that the right of possession is held for a stated time by the debtor. 
According to this reasoning a debtor is only the nominal or reputed owner of those of his possessions whieh are subjeet to seizure for any debt. The creditor owns a share equal to the debt, while the debtor really owns the remainder only. Moreover, a debtor, whose debts equal the value of all his possessions, although nominally owning all, in reality owns no portion of that which he possesses, and furthermore, if the nominal amount of his debts exceeds the value of his possessions, the real value of the corresponding credits is below par, being equal to no more than the actual value of those possessions.

In the event of a third party going surety for a debtor, the amount of wealth subject to seizure is increased and the creditor becomes conditional part owner of the possessions of the surety.

69. Three Forms of Credit.-Ownership can be shared in more than one way. The principal forms of division are (1) between lessor and lessee, (2) among partners or stockholders, and (3) between creditor and debtor. In the first form of division the lessor retains all rights with the exception of possession and use for a specified period, this right being held by the lessee. In the second form the several joint owners share the right in specified proportions, their respective shares being fraetional parts of the value of the aggregate property. In the third form the ereditor owns a certain portion, the value of which is expressed in terms of some commodity or service, usually in terms of the conventional value unit, while the debtor owns the remainder. Partners, however, like ereditors, are really in the position of lessors as long as the partnership) continues or the debt has not matured, and this is true whether the debt is payable on a stated day, or on demand, or at a time otherwise determined.

The term "credit" is generally applied only to the third one of these three forms of divided ownership, but the essential similarity of all three forms is more significant than their actual differenees. Beeause of this essential similarity all forms of ownership without possession are in reality merely different forms of "credit" and are here considered under 
that head. The first and third forms differ only in this: in the first, the identical object of the loan, in the third only an equivalent thereof is to be returned. The lessee of a house must return the identical house leased, the borrower of money need only return an equivalent sum of money. In all other respects debtor and lessee are on the same footing. As regards the second form, a certificate of stock is to all intents and purposes a credit instrument, being an evidence of ownership of wealth in possession of others.

In view of the fact that credit is ownership without possession, and that the property of a debtor is owned by the creditor and the debtor conjointly, it is manifest that the value of this property is likewise divided into two parts, one being owned by the creditor, the other by the debtor. The share owned by the creditor, if expressed in terms of dollars, presents a feature which is worthy of special note. While the value of the entire property, expressed in dollars, may fluctuate, that portion of the property which is owned by the ereditor is not subject to such fluctuation. Barring the elements of discount and risk (76), this share remains at par with the standard of value. Whatever fluctuation may ensue in the value of the property falls on the share owned by the debtor. A rise in the value benefits him alone, just as a fall in value must be borne by him. Credit, therefore, if expressed in dollars, or whatever the conventional unit may be, is a value-magnitude which, though related to and derived from wealth of variable value, is nevertheless stable, at least in the sense in which the value of the standard metal gold is regarded as being stable. This is the fundamental reason why credit is just as well adapted as gold for use as money (88, 95, 115, $125,294)$.

The ownership theory of eredit is by no means new. It is indeed the theory of common law. The creditor who is secured by mortgage is legally a conditional purchaser of the property. The banker, when called upon for a loan, informs himself as to what the property of the applicant would bring at a public sale. He knows that by lending he acquires a 
conditional right to have this property sold, a right which primarily belongs to the owner. Aecording to MaeLeod: thing ${ }^{13}$

Credit is a right of action against a person to pay or to do someand a right of action, in this respect, embraces the right to have the debtor's possessions sold by legal proeess if he fails to pay.

70. Divergent Conceptions of Credit.-Although this ownership eonception of credit is the prevailing one in the practical world and affords a valid basis for further eonclusions, various other definitions of the term "eredit," which are at variance with this idea, are more or less authoritatively propounded.

It is often held that eredit owes its value to wealth to be produced or services to be rendered in the future. This view is apparently corroborated in many ways, for example, in the fact that some credit tokens, like railroad and theatre tiekets, are redeemable in services which, in the nature of things, must be rendered after the tokens are sold. But if the issuer of such tokens fails to redeem them, the holder's final reeourse is to legal proeess, terminating, if need be, in the sale of the delinquent's possessions to the extent of the stated value of the tokens. Not the future service, but the existing possessions of the issuer, constitute the substance of the eredit.

According to another conception, of which MacLeod is the most consistent exponent, credit is a form of wealth, ineluded in the class of "rights," which is created whenever a debt is contracted. After describing how the Royal Bank of Seotland. in the eighteenth century, issued and loaned its notes to customers for whom others became surety, this writer continues:

Now we observe that all these Cash Credits which have produced such marrellous results are purely in the nature of Accommodation Paper. . . Thus we have an enormous mass of exchangeable Property created by the mere will of the Bank and its customers which produced all the solid effects of actual gold and silver, and when it has done its work, it vanishes again into Nothing at the will of the same

${ }^{13}$ Maclsod, I, p. 220. 
persons who called it into existence. Hence we see that the mere will of man has created vast masses of Wealth out of Nothing: and then, having served their purpose, were Decreated into Nothing."

We shall see later (123) that this view, erroneous as it is, is far more prevalent than is generally supposed, especially when applied to those credit instruments which constitute currency. If the owner of a house rents it to a tenant, nobody would say that a second house is thereby created, the owner owning one house and the tenant occupying one, making two. Yet the reasoning of MacLeod and others is tantamount to such an inference. The value of a credit instrument is really the value of that fraction of the possessions of the debtor or his surety which is owned by the creditor. We must be careful not to confuse the nominal with the real, nor possession with ownership.

71. "Possession" Versus “Ownership."-Failure to properly discern between "possession" and "ownership" has given rise to a singular controversy. While most economists hold that the delivery of goods by $A$ to $B$ in exchange for a promissory note is virtually only half an exchange, the other half being effected in the future, namely, when $B$ pays the note, others hold, on the contrary, that an exchange of goods for a promissory note constitutes a complete exchange, the note being an economic quantity of a value equal to the goods delivered. Thus, for instance, MacLeod says :

Now, when a merchant makes a purchase with his Credit, it is not a "loan" of Capital . . . : it is an absolute Sale; just as much as if the purchase had been effected with money.15

It would seem that only one of these views can be correct. But, as a matter of fact, both are correct in their way, for they are taken from different standpoints. If the question of exchange is viewed in a physical aspect, from the standpoint of possession, the delivery of goods by $A$ for a promise of payment by $B$ is undoubtedly an incomplete transaction, or half an exchange. The other half is not even accomplished when the promise is redeemed by the payment of the note, for

"Macleod, 1, p. 402.

10 Ibid., I, p. 288. 
the nltimate exchange, that of goods for goods, is only completed, so far as $A$ is concerned, when he uses the money so received in the purchase of goods. MacLeod's position is, however, correct if the transaction is viewed in its other aspect, namely, from the standpoint of the right of ownership. As soon as $A$ delivers the goods he acquires a elaim against $B$ equal to the value of the delivered goods, and by virtue of that elaim becomes joint owner in $B$ 's possessions. $A$ has simply exchanged his right to the goods delivered for an equal right, as joint owner or joint lessor, to the possessions of $B$. $\mathrm{He}$ is no poorer by aceepting the note-assuming it to be valid -than he would be had he received equivalent payment in money.

72. The Substance of Credit.-A credit, conceived as the correlative of a debt, derives its value from the particular wealth which is subject to seizure and sale if the debt is not paid on time. When a eredit is ereated, or, viewing the transaction from the opposite standpoint, when a debt is contracted, the debtor yields to the ereditor a certain right to his possessions. In the ease of some loans a portion of the wealth of the debtor is actually placed as security in custody of the creditor, who does not, however, thereby acquire the right to use this pledge. The value of such a pledge usually exceeds the value of the loan, and, in ease of non-payment of the debt when due, the creditor may sell this security to reimburse himself. In the ease of a mortgage the creditor obtains the right to attach eertain speeified property, against which the claim is recorded, while the property itself remains in possession of the debtor with the full right to use and even to sell. But if the debtor does sell the property, the right of the creditor to attach and sell it for the debt remains in force. When, however, no part of the debtor's wealth is partieularly specified, then anything nominally owned by him may be attached and therefore eonstitutes that which during the eontinuanee of the debt must be considered as being jointly owned by both debtor and ereditor, but which, for the time, the debtor has the exelusive right to use. The wealth subject to legal claim is the substance of credit. 
This explanation of the source from which eredit derives its value might be questioned on the ground that loans are frequently made where there are no possessions on which to base the value of the corresponding credit, but which yet are ultimately made good through subsequent efforts of the debtor. Such loans, however, are obviously not business transactions in the true sense. They are in the nature of ventures or of acts of consideration or of friendship. Obligations of this nature have usually no definite value, and if they are made good in the end, all that can be said is that the risk assumed by the lender turned out in his favor.

73. Superposed Credits.-When stocks, bonds, warehouse receipts, and the like are given as collateral to secure loans, it would seem, at first glance, that these loans are not secured by actual wealth, since the collaterals are paper. But the value of these collaterals depends on the existence of some concrete wealth in the possession of somebody who does not really own it. The eredit so assured, then, is in the nature of a superposed credit. Credit instruments are fully competent to be used as "security" or "pledges" for further credit. That upon which the elaim is founded may be traced from obligation to obligation, but ultimately the trail must end in some existing concrete wealth to which the elaim applies. While in the case of loans the pledges placed in the hands of the lenders usually consist of paper evidences, like promissory notes, bonds, stocks, and so forth, the material wealth which directly or indirectly underlies these paper evidences is the real, the material security of the loans. Practically our entire monetary system is one vast complex of credit superposed upon eredit $(100,102)$.

74. Public Credit.-The theory that eredit must be founded on tangible property subject to legal seizure is also true when applied to public debts, be they federal, state, or municipal. It is true that no court could issue a writ of attachment against post-offices, warships, or forts, but the resources of a government are not limited to such things. Viewed as a corporate representative of the people, the government renders services to them and receives from them payment for these services in the form of taxes. If a government borrows, it does so be- 
cause the cost of the services performed, ostensibly for the benefit of the people, exceeds the compensation given by the people for the services-in other words, because the taxpayers are nominally getting more than they give. They are the real debtors in the case of public debts. They are paying the interest on these debts and are expected to pay the principal in the end. For non-payment of taxes their property is subject to legal seizure, and since the power of government to impose and collect taxes can be limited only by rebellion, it is evident that the taxable wealth of citizens constitutes the security of public debts.

75. The Value of Credit.-While eredit derives its value from the wealth which secures it, the amount of this value is fixed by the terms or specification of the debt. This specification must needs be rendered in terms of some commodity or service, for debt can be extinguished only by the delivery of some actual wealth or service, the kind and amount of which is stated. This must not be misunderstood. In the course of business routine debts are usually paid by means of credit instruments, like bank notes or ehecks, but by such payment the creditor's claim is not extinguished; it is merely shifted from one debtor to another $(95,341)$.

When debts are expressed in dollars, they are virtually expressed in terms of gold. This does not preclude the fact that some obligations have other denominations. For example, some farming rents are payable in agricultural products. In the produce exchange obligations are contracted for the delivery, on certain dates, of specified quantities of cotton, wheat, or other products. Some instruments, like railroad tickets, are redeemable in services. These obligations do not differ in principle from money debts. The value of all eredit instruments is defined by the terms of the promise of their payment, whether gold or other commodities or services be specified. It also follows that the market value of such credit is subject to the same fluctuations as that of the commodity or service promised.

When prices in general rise, the purchasing power of a eredit expressed in terms of dollars naturally falls in the same 
proportion as the purchasing power of a dollar. The chances of a fall in value are, however, generally speaking, balanced by equal chances of a rise, so that on this score a creditor is just as likely to gain as to lose.

76. Depreciated Credit.-While the nominal value of a credit equals the value of that which is promised, the market value is generally below this amount. There are two elements, namely, charge for the service of lending and the presence of risk, which have the effect of lowering the present value of a credit below its ultimate value $(69,112)$. Ordinarily, a credit has full value only at the moment it falls due, and then only if the promise is promptly fulfilled.

A creditor or lender really sells, for the time of the loan, the right to the use of the thing or things loaned, and, as a matter of course, he receives a consideration in return. This recompense is known as "interest" if the subject of the loan is money, and as "hire" or "rent" if it is something else, such as a motor car, a farm, a house. How this recompense is determined in the market will be discussed further on (252-258).

If the interest on a loan of money is paid in advance, as in the case of a discounted note, the debtor's promise to pay is limited to the amount of the principal, and the value of such a promise before the time of its maturity is obviously the face value less the interest for the unexpired term. But if, on the other hand, the interest remains to be paid, the promise really includes the interest in addition to the principal of the loan. Thus the total sum actually promised in the case of a $\$ 1000$ twenty-year four per cent. bond is $\$ 1800$. Although such a bond may at any time be above par, its value is always less than the amount of principal plus the interest remaining to be paid. Whether interest on a loan is paid in advance or later, the fact remains that the value of a credit at any time is less than the total amount yet to be paid on it. The difference is dependent on the length of its mexpired term and on the current rate of interest. At a later stage of our inquiry (139) we shall see that interest, like hire, comprises several different forms of recompense.

That reduction of the value of a debt below its ultimate 
value which is due to diseount at interest rate is not regarded as depreciation. This term is used to designate a lessening of value owing to risks entailed through one or more of various contingencies. A few of the latter may here briefly be considered.

So far our reasoning has proceeded on the assumption that if a credit is to equal the promised amount, less current discount, it must be secured by wealth fully covering this value. If, however, this is not the case, or if there is some possibility that the security, though adequate at first, may become insuffieient by the time the debt matures, the corresponding eredit will of course be below par.

Another factor which often affects the value of a credit instrument is the integrity or reputation of the debtor. If there is a doubt that a debt, when due, will be promptly paid, the credit instrument will be more or less depreciated below its nominal value (96). On the other hand, a reputation for prompt payment sustains the normal value of credit, and in the case of a debt based on inadequate security the belief that the debtor will sooner or later pay the debt may balanee, at least in part, such depreciation as is due to a present shortcoming of the security.

Ail these and similar factors of risk exert a modifying effect on the fundamental proposition that the market value of a credit equals its face value if the security is adequate or, if it is not adequate, that the market value of the credit is determined by the value of the available security. The gencral repute of the debtor, so universally an element in the value of credit, is for that reason too often mistaken for the essential element, while in reality it is only one feature of the risk factor modifying the fundamental proposition.

Before eoneluding this analysis of the value of credit, allusion should be made to a class of credits, principally represented by legal-tender eurreney, on which the debtor does not pay interest, but which nevertheless are universally accepted without a deduction for diseount (95), and which become depreciated only if the ultimate payment in full becomes questionable. 


\section{CHAPTER VI}

MONEY

77. Misconceptions Regarding Money.-The subject of "money" has becn discussed, extensively and intensively, from the time of the classic philosophers down to the present day. It has bcen studied and analyzed from almost every possible standpoint and presented in endless variety of form. But the various attempts to explain the power which money has had since time immemorial, a power out of all proportion to its economic function, have only tended to involve the subject in irreconcilable contradictions.

Many writers have unduly complicated the subject by introducing into its discussion matter that has no place in it. Instead of presenting a sharp and clear-cut definition of money, they have endeavored to explain, not what it is, but what it does, at the same time ascribing to money a number of functions, most of which are not in reality performed by it. ${ }^{16}$ The cardinal function of money is thereby confused with extraneous matter and is treated as of secondary importance, instead of being made the basis on which the theory of money really rests.

78. Money Not a Value Denominator-Among other things, money is said to be a measure or standard of value, a value denominator. This is in conflict with what we have already said on the matter. We have treated the subject of the value unit (28-32) without the need of referring to money. The fact that some money is made of gold, a metal which, from among other commodities, has become selected as our value denominator, does not justify the substitution of the idea "money" for the idea "gold" in the definition of the value unit "dollar." We cannot say that a dollar consists of 23.22 grains of pure money (115). If it were true that money is the measure of value, then gold could not also be the measure, as these terms are not synonymous, even though they

${ }^{10}$ Cf. Mill, II, pp. 17-24; Perry, pp. 188-276; Walker, pp. 1-23; Conant, 1, pp. 20-21. 
are often used interchangeably in colloquial language. Moreover, not all money is made of gold. Most of it consists of credit which can be commensurate with dollars only if its denomination is in terms of dollars. Confusion is inevitable unless we divest ourselves of the notion that money is a denominator of value. We cannot express the value of things in terms of "money" any more than we can express the height of a steeple in terms of "dry goods."

79. "Dollar" Does Not Mean "Money."-The indiscriminate use of the term "dollar," both in the sense of "value unit" and that of "medium of exchange," is largely responsible for this confusion. It is clear that a dollar note, which merely bears a promise to pay a dollar, cannot actually be a "dollar" (95a), although it is currently regarded as such. In accurate language the word "dollar" should always be confined to the meaning of "value unit."

When speaking of "one hundred apples" we invariably mean one hundred individual fruits, while the phrase "one hundred dollars" does not refer to the number of pieces, but is descriptive of a sum or quantity of money worth one hundred units of value, it matters not whether it be a single one-hundred-dollar note or any number of notes and coins of lower denomination adding up to that amount. Moreover, "dollar" is often used to specify an amount of wealth figured at so many units of value. A man who is "worth" many thousands of dollars may not have at his command a sum of money worth one hundred dollars. A given number of dollars simply designates the number of value units, not the number of pieces of money. The analogy between "dollar" on the one hand, and other units, such as "yard," "pound," or "gallon," on the other, is obvious.

Similarly, the word "cent" designates the one-hundredth part of one dollar and may only at times be used incidentally to denote a "penny." A payment of ten cents may be made with a single dime. A manufacturer, after eompleting a contract for 10,000 picces of a certain article, at the price of ten cents each, would probably refuse to accept payment if the customer were to interpret "cent" as meaning the coin and tender 100,000 "pennies" in payment. 
The terms "dollar," "shilling," “franc," although generally, and for obvious reasons, used in expressing quantities of money, are words which must not be regarded as synonymous with "money" (95b). There is probably no single cause so prolific of error and confusion in the discussion of monetary matters as this failure to sharply distinguish "dollar" from "money." The relation of "dollars" to "money" is analogous to that of "yards" to "dry-goods." Just as we cannot conceive a specific quantity of dry-goods without reference to some yard-stick, so we cannot think of a specific sum of money without reference to some unit of value, such as "dollar." And as "yard" is used for expressing the length of other things, like ropes or fences, so is "dollar" used to express the value of things other than money, like houses or services.

Since "dollar" really means " 23.22 grains of pure gold," a promise to pay so many dollars, if literally interpreted, is a promise to deliver the stated quantity of gold. Indeed, for the elearance of international balances only gold bullion is accepted. If coined gold forms part of the shipment, it is treated as bullion, that is, taken by weight, not by tale. For current commercial transactions, however, this mode of making payments has long been abandoned because of its inconvenience. To avoid the necessity of repeated assaying and weighing, the metals came to be coined and the weight and fineness of the coin guaranteed through the government's stamp. To such coin, but to no other form of money, may the terms "money" and "dollars" be applied with equal propriety. A vague conception of this fact, coupled with a confusion of the ideas "dollar" and "money," is responsible for the notion, often expressed, that nothing but gold coin is "real" or "basic" money (88).

That the unit of value is a conception independent of money can even be shown in history. MacLeod points out that-

there are several passages in the Iliad and Odyssey which show that even while traffic had not advanced beyond barter, such standard of reference was used. We find that various things are frequently estimated as being worth so many oxen. ${ }^{17}$

${ }^{17}$ MacLeod, I, p. 170. 
But we need not go back as far as the time of Homer. In the earlier decades of the nimeteenth century, when in the several states of Germany different units of value were in use, the "Mark fein" was employed in interstate commerce as a unit of account. The "Mark" was at the time the currently adopted unit of weight for silver (about half a pound), and the coins in actual use were appraised by the weight of pure silver they contained (98).

8o. Money Not a Store of Value.-It is also claimed that money is a means of saving or storing wealth. This is not literally true. The man who hoards gold coin does really store away wealth in the shape of gold metal, but the man who hoards bank notes does not thereby store any form of material wealth, for the notes are only bearers of a right to a certain amount of wealth which is actually in possession of others (282).

8I. Money Not a Standard of Deferred Payment.-The assertion that money is a standard of deferred payment, unless intended merely to emphasize the notion that it is a standard of value, is not only groundless, but actually devoid of meaning.

The phrase ean have reference only to promises, either to perform some service, or to deliver something, at some future time. But in every contract the service to be performed, or the thing to be delivered, at some future time, is always specifically described and is by no means always money. When a farmer borrows a bushel of oats from a neighbor, promising to return another bushel a month hence, the standard of deferred payment is oats. Whatever a contract specifies is the standard, and in contracts which promise the payment of a number of dollars, it is the commodity gold, not money, which is the standard of deferred payment. Moreover, anything which is promised to be delivered in the future being a standard of deferred payment in that case, it follows that gold is the standard only where it is specifically or by implication promised to be delivered. The property of being a standard of deferred payment cannot therefore be regarded as being inherent in money. 
82. Importance of Sharp Definitions.-These criticisms may look like hair-splitting. But, as a matter of fact, correct reasoning is impossible unless the words which convey the thought are carefully and sharply defined and used only in the sense of their definitions. The notion that money is a measure of value has led to more than one untenable conclusion. Money need not be produced to provide a value unit; gold has been adopted for this purpose. Nor need money be manufactured to enable men to defer the delivery of a specified amount of wealth, or to accumulate wealth. The latter is done by producing more wealth than is consumed, when accumulation follows as a matter of course. For none of these ends was it necessary to invent or to manufacture money. The only incentive to its production and emission has been the desire to overcome the difficulties experienced in the processes of simple barter (88).

83. The Function of Money.-Simple barter was necessarily the original mode of exchanging things. But although adapted to compass the limited traffic of primitive peoples, barter would be utterly inadequate for the commerce of a more complex society.

Simple barter depends on two distinct coincidences. To begin with, the intending barterers must each have something which the other desires, and, furthermore, the desired things, in order to be exchanged, must be of equal value. The first of these coincidences particularly occurs so rarely that the extensive commerce which goes hand in hand with the specialization of industry would be wholly impossible if we had to depend merely on simple barter.

The use of money obviates these difficulties. The man who has something to exchange need only find a person desiring to obtain it. He will receive in exchange money for which he can in turn obtain such things as he desires from those who may offer them for sale. Thus $A$ may sell a basket to $B$, and, being paid for the same in money, may use it in buying a hat from $C$. He thereby really obtains a hat for his basket. But he delivers the basket to one person and receives the hat 
from another. In short, he need not hunt for a hatter who is in need of a basket. In this way the shorteomings of simple or direct barter are completely met by the process of complex or indirect barter $(52,259)$, a process involving the use of a medium of exchange, money. The use of money enables him to deal with the community at large as a second party; through its mediation he delivers to one member of the community the goods he supplies and receives from another member the goods he demands.

This clearly illustrates the true function of money to be that of a medium of exchange. For no other purpose would it have been necessary to produce money. We should therefore define "money" as any medium of exchange adapted or designed to meet the inadequacy of the method of exchanging things by simple barter. Anything that accomplishes this object is "money", (88).

84. The Distinctive Feature of Money.-Our aim should now be to obtain a clear understanding of what it is that distinguishes money from all other valuable things, namely, its specific quality. At first glance it would appear that this problem is not a difficult one. Cannot everybody tell money from other things? Yet the particular quality which is possessed by money exclusively and which imparts to it its specific power is rarely, if ever, given a thought. What is that particular quality?

This question is not answered by the statement that money is a medium of exchange, for this is not the whole story. We are now trying to find what it is that imparts to money the power to serve as a medium of exchange. If a book is sold for a dollar, there is no question but that each of the two things is given in exchange for the other. The dollar buys the book; the book buys the dollar. Why should the one, but not the other, be considered a medium of exchange?

85. Money a Product of Social Compact.-The one quality whieh is peculiar to money alone is its general acceptability in the market and in the discharge of debts. How does money acquire this specifie quality? It is manifestly due 
solely to a consensus of the members of the community to accept ccrtain valuable things, such as coin and certain forms of credit, as mediums of exchange $(285,298)$. In the course of time this consensus developed into a prevailing tacit agreement which, in the case of legal-tender currency, has found expression in a statutory compact $(93,99)$. This prevailing agreement is that through which gold and certain forms of credit are given the quality of money. It is merely conventional with regard to bank notes and bank checks, and also in intemational conmerce, where bullion is the accepted means for adjusting balances of trade. When serving this office, gold is just as truly merchandise as it is money (315). The relationship between money and merchandise is there exhibited in its true light.

86. Monetary Laws.-When monetary laws were first made, they merely formulated the already existing conventional usage of accepting certain commodities or certain forms of eredit as money. Such laws can of course have sway only within the jurisdiction of the respective authorities, unless by special treaty, as in the case of the Latin Union, some of the legal money of one country is made also legal in another.

Monetary laws may be divided into two categories. They may be mandatory or permissive. The first class comprises the legal-tender laws which prescribe those forms of currency which must be accepted as money (95), while the second class embraces laws which permit and promote the issue of currency which may be accepted as money by those who are willing to do so and which, accordingly, circulates by virtue of a custom amounting to a tacit agreement or consent. Legal-tender currency cannot be refused by a creditor on the plea that he wants gold, while all other forms of currency may be refused and lawful money demanded. In current business transactions this distinction is rarely observed. Both bank notes and checks are usually accepted in payment without hesitation.

87. The Right Conveyed by Money.-The agreement in question, whether it be of a tacit nature or expressed by law, is really an agreement of all who have anything to sell to place their merchandise at the disposal of the bearers of money (93, 
287). These latter ean select anything in the market and obtain exclusive possession upon the delivery of an equivalent amount of money. The merchant concedes in effect that money conveys a right to an equivalent amount of the merchandise he offers for sale. It is true this right cannot be enforced by law, but inasmuch as products obtained through specialized effort cannot be distributed among consumers except through processes of complex barter, it follows that aeceptance of the means of that complex barter, namely, money, in exchange for goods is a matter of necessity. The right conveyed by money is enforced by a power superior to manmade law-by the law of self-interest.

Our conclusion on this matter may now be briefly summarized. By virtue of the general consensus which gives it general acceptability, money conveys an option to any goods exposed for sale, to the extent of the value of the money. This command over the market is not possessed by any other form of wealth.

88. The Term "Money" in its Broadest Sense.-In an exhaustive examination of our present subject we must regard as money all devices used for mediating exchanges. Considered from a purely economic standpoint, the term "money" should include everything that performs the mission of money, no matter whether its domain is of international scope or is limited to national or even to lesser fields. It is tme this view is not shared by the majority of authorities on money, some of whom confine the term strictly to standard coin, others include legal-tender notes, still others bank notes as well, and some writers, particularly among the more advanced school, recognize that bank credit should also be embraced in the term "money." The excluded forms are sometimes termed "money substitutes" (95, 293). There is, however, neither sound economic reason nor any logical necessity for making this distinction (69). Insistence upon it no doubt results from a failure sharply to distinguish the meanings of the two terms, "dollar" and "money" $(79,115)$. The evolution of money has come about through the need of expanding simple into complex barter. The business world needs money for the pur- 
pose of exchange, and absolutely for no other purpose (82). It is indispensable to the business man for the purpose of buying and selling things and services, and of clearing accounts payable by returns from accounts receirable. Whr, then, should only some devices performing this mission be called "money" and not all? The merchant does not care whether he is paid with gold coin, with notes, or with ralid checks. While in a civil suit the court is by law obligated to recognize only lawful currencs: the student of economics is under no such restraint, as the sphere of his research is not limited by legal definitions or br geographical boundaries.

In conformity with our definition (83) We shall apply the term "money," particularly when used in the comprehensire sense of the right convered by it, broadly to all means for mediating exchanges. But when adverting to money systems controlled by legal authority, we shall use the term "currency," especially if the reference is directed or confined to money tokens. In this light, "moner" is related to "currency" as "credit" is related to "credit instrument."

89. The Theory of Money.-In whatever form money may exist, its object is to permit indirect or complex barter. Instead of exchanging goods for goods, the goods are first exchanged for money and then the money for other goods. A member of the community who delivers wealth or renders ans other form of service to another member may thereby be compensated by wealth or service received from a third member. But in this process time elapses between the giving and the receiving, and during the intertal the giver of the service is in possession of money, an instrument attesting that he has given wealth or rendered serrice to the community and is entitled to the return of an equivalent. During that interval the holder of money is evidently a creditor of the communit: $(115,210,211,259)$. Money is not accepted for the purpose of eating. wearing, or otherwise consuming it. In its essence money is credit acquired through rendering a service to the community, a credit constituting a right to receive from the community an equivalent in kind. A piece of money-a money 
token-merely certifies that the holder is entitled to a return for a service rendered by him to the community.

Strictly speaking, this is true only when the money has been obtained in payment for goods or services. Possession of money can be attained in other wars. Thus the statement does not apply to banks when they issue currency which they get, not in return for wealth delivered, but only in return for security deposited, as in the case of United States national banks. They do not part with ownership of the security which they deposit, but only with its possession. Nor is it applicable to banks receiring money on deposit, nor to borrowers of money who obtain it in exchange for mere promises to return an equivalent sum at a future time, for no form of wealth is given in return in either case. Moreover, money may be ob. tained by bequest, by gift or by dishonest means, in any of which cases the money passes into the holder's possession without any goods or other form of service passing in return.

90. Money Analogous to Book Accounts. - The theory of moner, then, is closely parallel to the theory of credit and should be considered accordingly. If there were no moner, any srstem of crediting sellers and debiting buyers would be fully competent to accomplish the work now performed by money (203). It would be immaterial whether these credits are recorded in books or conreyed by credit tokens. The cardinal condition, of course, is that these credits, whaterer their form, shall be accepted at their value in exchange by those who have things or services to sell and that they shall be transferable from those who buy to those who sell.

Suppose that instead of issuing moner we should institute a system of "accounting," by recording all commercial transactions, crediting the sellers and debiting the buyers with the value of the goods or serrices transferred. If it were agreed upon that every credit so recorded shall entitle the creditor to obtain in exchange for it any equivalent merchandise offered for sale, such credit would serve all the purposes of money. The possessor of a recorded credit could thus utilize it to the extent to which the credit entitled him.

This is rirtually the method on which the bank-check 
system is based, a check being an order by the buyer or debtor to transfer, on the books of the bank, a specified amount of his credit to the seller or creditor.

The application of this system to all transactions, even the smallest, would be inconvenient and costly. But we know that credit can be transferred by methods other than book entries, namely, by means of eredit tokens. Our currency system is of this nature. Currency consists of tokens which are passed from hand to hand in the process of transferring credit from the buyer to the seller.

Although the currency and the accounting systems are different in form, they are identical in principle, hence any theory which applies to either system must apply equally to the other. While the currency system is the preferable one for minor transactions generally, the accounting system, on the contrary, is the most convenient method for mediating exchanges on a larger scale, and, since this is the simplest in conception, it will here be made the basis of our further study.

9I. Creditors and Debtors of the Money System.-The reader may have observed that in discussing the accounting system we dealt only with eredits acquired by selling things or services. So far the case is parallel with existing conditions in the use of money, the money being a credit for services rendered. In general, men ean buy only when they have acquired money, presumably by selling goods or services. But there is another side to be considered. Where there are creditors, there must, of course, be debtors. In correct bookkeeping the ledger must always balance. The sum of all credits must be equal to the sum of all debts. So far, in discussing the accounting system, we have considered only creditors. But where are the debtors? If, as a rule, men must sell goods or services before they can buy any, there must be some who can buy goods or services before they need sell any. Who are they?

92. The Issuer of Currency is Debtor.-The same question, when applied to the currency instead of the accounting system, assumes this form. Who are those who obtain goods or services in exchange for money before they have acquired 
money in exchange for goods or services? The answer is obvious. They are those who issue the money and put it into circulation. The issuers are manifestly the debtors in the ease $(105,115,210,259)$. In point of fact, money, in its very essenee, is an acknowledgment of debt (123).

It is plain enough that the right to become debtor to the money system by the issue of money tokens eannot be left to any and everybody uneonditionally. To protect and secure the credit involved, the debtor must be held rigidly to account. Issuers must accordingly be required to furnish seeurity that is practically free from risk, and, moreover, the community must be assured that such seeurity has been furnished. The wealth on which this security is founded is the substance which gives value to the money and which, with one or two exeeptions that shall be diseussed presently, remains in possession of the issuer. The right to eontrol the issue of eurrency has for good reason become a prerogative of government, to which the public looks for assurance of the soundness of the currency (300).

When the government itself becomes the issuer, it is the rule that an amount of gold metal covering a fraction of the face value of the issue is kept on hand for purposes of redemption, while the bulk of the issue is seeured by the credit of the government. As regards such eurreney, the people are creditors as holders and users of this money and debtors as members of the body politic.

According to the nature of the security given and other eonditions of the issue, curreney may be divided into four principal classes, namely, standard money, legal-tender notes, subsidiary coin and notes and other eredit instruments that are not legal-tender. Each class may embrace several systems, and each system has its peculiar features, its own ereditors and debtors. In each of these various systems the issuers are debtors to the amount of the respective issue.

Before we proceed to examine the several systems of currency, it may be in order to warn the reader against the erroneous impression which the term "paper money" is apt to make. Not money, but only money tokens, can be made 
of paper. The paper serves only as the vehicle of a promise and thus becomes an evidence of debt. Not the paper, but the wealth by which the debt is secured, is the real substance of the so-called paper money. The term "credit money" is more descriptive and is less liable to mislead.

93. Standard Money.-Where the coinage of gold is free, any owner of gold may take it to the mint and have it coined. By this process a part of his wealth is converted into money. When he subsequently exchanges the coin for goods in the market, he becomes the issuer of this currency, namely, the one who can and does buy with currency before he must sell to get currency.

In viewing the book-entry credits of our illustration as an analogue of coin currency, we must consider coin as a credit instrument, that is, an instrument conveying a claim to wealth which is in possession of others (260). This is not the view usually taken, but it is the only one from which a clear insight into the subject can be gained, and from which a rational study of the problem involved can proceed. A gold coin differs from a mere disk of gold not only in that its weight and fineness are officially vouched for by the stamp, but in that-and here is the essential difference-the coin obtains through the common consent, expressed in the law of legaltender, a command in the market (85) which the disk in the absence of the prevailing consent would not have, even in the face of the most reliable guarantee of full weight and fineness. The coin invests its bearer with a right to claim, or a power to obtain, in exchange for it any equivalent merchandise exposed for sale, a right which a piece of gold not recognized as money does not convey.

In the ordinary channels of trade, as distinguished from those of banking, gold bullion is not money, but mere merchandise. Merchants do not currently take it in exchange for their wares, since there is no agreement to accept it as currency. But when put in the conventional form of coin, it falls within the agreement through which the gold conveys to the holder an option to become owner of any equivalent mer- 
chandise exposed for sale (87). Those who aecept gold coin in trade have not merely the hope of finding some one willing to accept the piece of gold in trade; they have the assurance that every one who has merchandise to sell will deliver it in exchange for the coin. The command in the market thus conveyed by the eoin is the one typical feature of money. The receiver of coin has no special desire for the metal contained in it, except in so far as it affords assurance that the token actually conveys the value which it designates. As a direct desideratum, as an article of merchandise, the metal of the coin affords an alternative in being a commodity that may be used or sold. The function of the gold in the coin is that of a pledge given by the issuer to assure the payment of the debt that was contracted when the coin was first put into circulation, and which payment is made only when the gold is ultimately put to use as metal. It would be incorrect to assume that the owner of the gold, after having it coined and passed as money, has thereby found a purchaser for his gold $(114,259)$. The merchant who accepts the coin in payment is no more a purchaser of this gold than the banker is the purchaser of bonds which a customer offers as collateral for a loan. He does not want the metal for any other reason than the banker wants the security; he wants a medium of exchange, an instrument conveying an option to any equivalent merchandise which he wants to obtain. Only after this coin is put into a goldsmith's erucible ean the gold assume its normal function as a commodity, and only then will it have found a purchaser. ${ }^{18}$

If we could follow the journey of a coin from the time of its coinage until it is melted down, we would find that the issuer, when using the coin for the first time, obtains goods or services, and thercby ineurs a debt, for the payment of which he gives the gold as collateral security. Everyone through whose hands the eoin subsequently passes first gives and then

${ }^{2 n}$ Objeetion miglit be made to this argument where the melting of coin for its metal is forbidden. But such a regulation cannot, in the nature of things, be enforced. Indeed, if it could not possibly be evaded, eoined metal would be deprived of its value, as its utility would become unavailable. 
receives goods. Only the final owner who melts the coin down, or otherwise uses the metal as such, after giving goods or services, accepts the gold as a merchandise. Thus the last recipient really buys the gold from the first issuer, the collateral having been applied to finally cancel the debt.

94. Holder of Standard Money Both Creditor and Debtor. - The conditions arising from issuing standard coin are, in some respects, peculiar. The security being identical with the denomination of the debt, there is no danger of a fluctuation of its price, and a margin to cover risk is unnecessary (286). The issuer will therefore not insist on an ultimate return of the security, namely, the gold, but will leave it optional with the temporary creditor, the holder of the token, to use the pledge for cancelling the debt if he so chooses. Thus the identity of the issuer, namely, the individual who brought the gold to the mint for coinage and first put the coin into circulation, is lost, and the bearer of the coin becomes himself the custodian of the security, the gold. In a sense he is an agent of the issuer.

In the United States there are two ways of dealing with the pledge. The gold may either be permanently embodied in the token itself, by making this of gold corresponding in weight with the denomination; or the metal may be deposited in the national treasury, there to be held in trust for the bearer of the tokens which are issued in the form of gold certificates. These two forms of currency are virtually identical. The only difference is that in the case of coin the pledge is in possession of the bearer of the token, while in the case of certificates it is in custody of the government. In the latter case the government, in its capacity as trustee of the security, represents the debtor, while the bearer of the certificate is the creditor. In the case of coin, each successive bearer is botl debtor and creditor, debtor as the temporary holder or trustee of the pledge, and creditor as a claimant to merchandise. It should be noted that his credit and his debt, although equal in value, are not identical in character. His credit represents a right to merchandise, while his debt consists in his obligation to deliver the gold when his right to merchandise is made good.

This aspect of the subject is the only one which presents 
to the student a perspieuous view of the salient features of money. It shows in its true light the function whieh the gold in the coin performs. It brings out clearly the prineiple which distinguishes the coin from a mere lump of gold, and points out that the government stamp on the coin imparts to it, not value, but only general acceptability.

The value of such money is manifestly determined by the amount of the gold which is aetually contained in the token if the token is a gold coin, or which ean be obtained on demand if it be a gold certifieate.

95. Legal-tender Notes.-For the purpose of enforeing their aeceptance in payment of debt, eertain notes are by law deelared to be "legal tender." These notes are thereby made legal tender for paying debt, so that a ereditor eannot demand some other money when they are offered $(86,99)$. In the United States only speeie and eertain issues of notes bearing the government's promise to pay dollars are made legal tender.

While legal-tender notes are "money," they are not "dollars." It is clear that a "promise to pay a dollar" cannot itself be a "dollar" (79a). In the striet meaning of the term, a dollar is so and so mueh gold, henee a promise to pay so and so many dollars, if taken literally, ean be discharged only by the delivery of the speeified amount of gold. But in the ordinary course of business payment ean lawfully be made by means of legal-tender notes instead of gold. 'These notes therefore perform the same function in diseharging debt as gold would. They are aetually money, not merely moncy substitutes (88), as they are often designated; but they are substitutes for dollars, that is to say, for gold (69). The very law whieh makes these promises to pay dollars the legal equivalent of dollars has given rise to that perversion of language that allows the term dollars to signify money $(79 b, 115)$. Thus, in place of "a sum of money worth one hundred dollars"' we simply say "one hundred dollars." Colloquially this inexaet expression is aceeptable, as it shortens language. It is only when taken in its literal sense that the phrase becomes misleading, and even then only when false conelusions are derived from its misconstrued meaning. 
In the United States the federal government alone issues legal-tender currency, constituting a non-interest-bearing public debt which, although paying no interest, yet circulates at an undiscounted value equalling the full value of the gold in which it is redeemable ( 76$)$.

When legal-tender notes are applied to the payment of a debt, the creditor is paid only in a legal, but not in an economic sense, for the notes are themselves only promises to pay. Initially the creditor has a claim against a particular debtor, but after he is paid in money he has in its place a claim against the community $(75,341)$ which everyone who has anything to sell is ready to honor with goods or services. $\mathrm{By}$ the payment of money the right of the creditor is not made good, but merely broadened, so as to apply to anything in the market he may choose (102). His claim is finally satisfied only when he receives actual produce of labor.

96. Depreciated Currency.-When adequate provision is made for redeeming the promise to pay dollars, legal-tender notes will naturally be accepted at par with gold. But govemments have not always been able to redeem, or have failed to provide for redemption, and at such times have actually legalized refusal of redemption. In this country, prior to the year 1879, the national issue known as the "greenbacks," nominally promises to pay dollars to bearer on demand, were neither redeemable in specie nor even accepted by the government itself as the equivalent of coin. If a business man issues a promissory note, he is legally obligated to accept it at par on or after its maturity in payment of any debt due him, but governments issuing currency presume to be independent of the rules of common justice, on the old plea that "a sovereign can do no wrong.'

However, although the greenbacks were not honored by the government, the people in general acted on the expectation that, at some future time, the notes would be redeemed, either in silver or in gold. ${ }^{19}$ This expectation of future redemption

10 The United States was on a bimetallic basis at the time these notes were issued. 
gave them a standing, but because of the comparative uncertainty, as well as the delay of redemption, their current value was below their nominal value (76), a eondition which manifested itself in the market by the rise of gold and silver to a premium $(109,112,322)$. The circulation of depreeiated currency in other countries is to be similarly accounted for. In the event of all expectation of ultimate redemption vanishing, as was the ease with the Confederate notes, the value of the notes naturally falls to naught.

When dollars of gold or silver did rise to a premium over the dollar of curreney, this did not indicate that either gold or silver had risen in value, but that the curreney had fallen below parity with the value of its promise. Instead of saying that gold or silver was above par, it should really have been said that the dollar of currency was below par. This misconception arose from the fact that the currently aceepted unit was a unit of lowered value, entailing a general rise of the price level, ineluding, of course, a coincident rise in the price - not in the value-of gold and silver.

Currency notes whieh, however depreeiated, remain in circulation, are not, in the full sense of the term, "irredeemable" or "inconvertible" notes, as they are so generally termed. If there were not a prospect of their being redeemed at some future time, they would have no value and would go out of circulation completely. The above terms, as applied to notes in eireulation, must therefore be understood as implying only a suspension of payment and not a final repudiation.

Depreciation is not an invariable eonsequenee of suspension of speeie payment, partieularly if the issuing authority aeeepts the notes at par with specie. Where the govermment is the issuer, acceptance of the notes in payment of taxes at par with standard eoin $(100,114)$ is a means of maintaining their value.

It would be a mistake to say that such notes are irredeemable. A familiar analogue of such notes is met with in store orders, the issuer of which, while not promising to redeem them in so many dollars, agrees to redeem them in merchandise. They are manifestly credit instruments, redeemable indeed, but only in things other than dollars. Such 
orders, issued by individual storekeepers or by large employers of labor, have circulated within limited fields as currency (106). If money tokens are issued by the government and accepted in payment of taxes, but not otherwise redeemable, they are clearly of the same nature as store orders, for they are accepted by the issuing government in payment for services rendered by the government to the taxpayer and can therefore circulate at par with specie.

Nevertheless, such money is not altogether secure against depreciation. It is manifest that store orders can have value only if the issuer has something for sale which the holders of the orders want to buy, and that without this condition the orders are practically worthless, no matter how much other wealth the issuer may possess. Moreover, if the goods offered by the issuer of the orders are held at exorbitant prices, such orders can be made instruments of extortion. The value of store orders is therefore of an essentially precarious nature, and their use as currency has been forbidden.

Legal-tender notes bearing no effective promise besides that of acceptance in payment of taxes have the same defect. If they are issued in such volume as would overreach the credit of the government, they would depreciate. It cannot, however, be determined just at what point the strain on the public credit would have effect. Money of this kind always possesses an element of uncertainty or indefiniteness, inasmuch as redemption may be evaded by various technicalities. The issue of any currency not directly redeemable in the standard commodity is therefore inexpedient.

97. Fiat Money.-Money tokens bearing no other promise than that of acceptance at face value in payment of taxes cannot have any value unless the unit of that "face value" is related, directly or indirectly, to some standard commodity. Such relation exists if at the same time money which is related to a standard commodity is in general circulation and establishes the accepted unit of value. By being accepted at par with this other money, those tokens are brought into correspondence with the eurrent measure of value. Otherwise "ac- 
ceptance at par" would have no significance (322a), as there would be nothing with which those notes would be at par.

The fact that currency has continued to circulate in the market during periods of suspension of specie payment is the source of a widely prevalent belief that the value of currency is created by the "fiat" of government (322b) through the aet of declaring it legal tender, thus supplying a medium of exchange for which there was a certain demand. But this view cannot be sustained. The issuer, in emitting these notes, obtains in exchange for them valuable things or services. By the believers in fiat money the value so obtained is considered to be a legitimate income of the government, termed "seignorage" (113-114), while in reality it should be regarded as virtually a loan of which the notes are acknowledgments.

History records a number of instances of notes issued under this erroneous impression. Prominent among them are the Continental currency of the American Revolution, and the French assignats and mandats. They circulated for a time under the force of economic momentum, but their worthlessness was sooner or later recognized. This worthlessness was not due to an over-issue, as some economists would have us believe, but to the fact that no provision had been made for their redemption.

98. History of Legal-tender Laws.-Originally, gold and silver, when figuring in exchanges, passed by weight (79). For the purpose of saving the time and trouble of the repeated weighing, coins of these metals were made of certain weights, and by an official stamp their weight and fineness was certified. These coins retained the names of their respective weights, and a pound of silver coins thus certified was known as a pound of money. It was in this way that the denominations drachme, pound, peso, livre, lire, etc., originated.

The exclusive right to coin money was assumed by the state and so became the prerogative of the sovereign. In course of time some rulers made this prerogative of coinage a source of income. Having borrowed money and finding themselves in straits when the time came for paying the debt, they made coins lighter, or of baser composition, than before, but 
continued to apply the term "pound" to the same number of pieces which before the debasement made up a pound of silver (114a). The difference between the nominal and the actual weight afforded an income which was termed "seignorage" (113), the light-weight coin being applied to the payment of the debt contracted when the coin was heavier. By repeatedly employing this process, the coins were ultimately made so light that the "pound of money" contained only a small fraction of a pound of silver. This process was carried much further in France and Italy than in England. ${ }^{20}$

Laws declaring such light-weight coin legal tender for full weight were, of course, necessary to consummate the fraud. Otherwise there would have been no need for legal-tender laws. Thus the law creating legal-tender money was conceived by dishonest sovereigns who used it for defrauding their creditors. Similar misuse of the prerogative of the sovereign power, though not so vicious, has been made whenever the circulation of a depreciated currency has been enforced by legal-tender enactments.

As a matter of course, all reductions of the weight as well as other forms of debasement of the coin were promptly followed by a corresponding fall in the purchasing power of the legal value unit (114b). The terms, pound, lire, livre, peso, lost their original meaning and have since been used to denote the arbitrary unit resulting through the repeated reductions from the original weight of the precious metal in the coin.

After the names of the various units had lost their literal meaning, and especially after gold took the place of silver as a standard of value, laws were, of course, necessary to state precisely what amount of silver or gold should constitute the unit.

99. Legal-tender Quality Not Essential to Money.When notes are in fact redeemable in dollars, there is no need for legal enforcement of their acceptance. The general and unreserved acceptance of national bank notes and of checks in transactions in which formerly only legal tender was

${ }^{30}$ Cf. MacLeod, I, p. 273; Conant, I, p. 138; et al. 
accepted, plainly shows that there is no diserimination in practice between valid legal-tender notes and other valid means of payment, and that legal-tender laws are entirely superfluous for the purpose of giving currency to any sound medium of exchange.

But while legal-tender enactments are not necessary to give acceptability to notes which are known to be redeemable, yet there are some reasons which make such laws desirable. They give expression to the social eompact through which wealth is turned into money (85), and, moreover, they prescribe what is to be regarded as money in an action at law $(95,306)$.

I0o. Subsidiary Coin.-In subsidiary coin the nominal and current value generally exceeds the value of the metal of which the coin is made. This excess of value is attributed by some to the "fiat" of government. Others aver that the limited supply in conjunction with the demand for the coin is that which keeps this money at par. But neither of these assumptions affords the correct explanation. The eontinued cireulation of subsidiary coin, notwithstanding the inferior value of the metal contained in it, is simply due to the fact that this coin is either redeemable in legal money of larger denomination, or, if not so redeemable, is aceepted at par in payment of dues to the issuer, that is to say, of taxes (96). In either case, subsidiary coin represents an indebtedness of the issuer to the holder.

There is no inherent reason why subsidiary coin should be made of such costly metal as silver. When silver was the value denominator and the small coins contained their proportionate share of the metal, there may have been some reason for rnaking fractional coin of silver, since it could then be classed with standard coin not depending for its value on redemption. But now, since the denominator is gold, there is no reason for continuing this practice. Conservatism alone can account for the persistence of a custom that has long since outlived its usefulness. If the value of the metal of which these tokens are made should fall, the issuer must bear 
the loss, just as he would gain in the event of a rise of this value. The fall in the value of silver has, indeed, burdened this govermment with an indebtedness far exceeding the socalled seignorage derived from the issue of under-valued coin. Being redeemable in gold and also accepted at par in payment of taxes, the tokens would circulate in the commercial world at par even if made of alıminum or of some other cheap metal or of paper.

Viewed from an economic standpoint, the silver dollar of to-day should evidently be classed along with subsidiary coin, for the current and nominal value exceeds the value of the metal of which it is made. These coins really represent a public debt, partly secured by the silver they contain and partly by the credit of the government. If they are to be retired, it nunst be by the government.

The silver certificates, based on silver dollars actually deposited and held in the federal treasury, bear the same relation to these coins as gold certificates bear to the gold deposited in the same treasury. The silver certificates illustrate a case of superposed credit (73), for they convey to the holder a right only to other credit instruments, namely, to silver dollars.

ror. Bank-note Currency.-Under this head are comprised all non-legal-tender bank notes issued under provision of law. In the United States the "national bank notes," issued through national banks, are the only notes of this type now in circulation. They bear promises of the respective banks of issue to pay to bearer so and so many dollars on demand. Under present laws these notes are printed by the government at the cost of the banks, and their issue is contingent on a number of conditions of which the principal ones are: (1) that federal bonds be deposited as security in the federal treasury, (2) that a certain tax be paid, (3) that each bank redeem its notes in lawful money on demand, and (4) that a redemption fund of five per cent of the issue be maintained in the federal treasury. There are several additional conditions of minor importance which need not here be enumerated. 
Nominally, bank notes are redeemable in "dollars," that is, in a definite quantity of gold, but since the law places legaltender notes on an equality with gold coin, the banks are free to tender such notes in redemption of their own. Being redeemable in gold or in notes which are redeemable in gold, the value of bank notes is on a par with gold.

I02. The Real Issuers of Bank Currency.-The banks through which these notes go into eireulation would appear, at first sight, to be the issuers of these notes. But, in reality, they are only agents in the process of issue. The actual issuer of a note is any one who in the process of issue becomes debtor of the money system, in other words, the possessor of wealth on which the vahue of the eredit money rests. To realize this fact we need only follow the successive steps by which national bank notes are put into eireulation. The government prints the notes and delivers them to the bank of issue upon deposit of the required security. Then some customer of this bank, say, a manufacturer who is in need of money, borrows from the bank ${ }^{21}$ on deposit of some eredit token-say a promissory note, perhaps supplemented by additional security, be it collateral or endorsement-and is given "eredit" on the books of the bank. Upon drawing on that credit for eash, he receives a corresponding amount of the bank notes. Up to this point the notes have not been used as money, the transactions having been only exchanges of eredit for credit. But now the manufacturer uses the bank notes, say, for buying supplies, or perhaps for paying wages. This is the first exchange of the notes for real products. Only this last transaction, the giving of the notes for goods, results in a condition where ownership and possession of actual wealth are separated (68). The manufaeturer has parted with the money and has the goods; he possesses more wealth than he owns. The former owners of the goods have given up possession of them and obtained money in exchange; they now possess less wealth than they own. Their right to the goods they had for sale has been

${ }^{21}$ For simplifying the argument, a bank's eustomer having some commereial paper cliscounted is here eonsidered a horrower giving the note as collateral. 
converted into a right to goods for sale by others (95). The manufacturer is debtor; the holders of the money are creditors. Nominally the manufacturer is debtor to the bank, but the bank, in turn, is debtor to the bearers of its notes. The bank is manifestly a neutral factor in the chain by which, in the ultimate analysis, the manufacturer is indebted to those who hold the notes; not, however, particularly to those whom he paid with the notes, but, in general, to whosoever may be holder of bank notes, for the social compact, by virtue of which those notes become money, merges and mutualizes all debts and credits of the money system.

In reviewing this process we are led to the following conclusions $(105 a)$ :

1. So long as the bank notes are held by the bank, or are in the hands of the borrower, they are not money in the full sense of the word, but are merely blanks or tokens adapted to become money. Their holder is both debtor and creditor; debtor by reason of the promise to return the notes or their equivalent, and creditor by reason of his possessing the notes.

2 . The notes become currency and are added to the volume of money in circulation when the borrower gives them in exchange for valuable things or services, and whosoever accepts them in exchange for what he supplies becomes creditor of the money system. It is in this transaction that the currency is issued.

3. The notes are nominally the bank's promissory notes. But it is not the bank that is the ultimate debtor. The bank is not in possession of the substance of credit, but only of instruments of credit conveying a right to wealth subject to legal seizure, wealth in possession of the real debtors, the borrowers from the bank. The notes in circulation are instruments of credit secured by other instruments of credit, the ultimate debtors being those who are in possession of the credit substance, the wealth conditionally owned by the holders of the bank notes (73). These possessors of the credit substance are the real debtors of the bank note system; they are the real issuers of the notes $(264,303)$.

The credit instrument furnished by the real issuer, namely, 
the promissory note through which he pledges his property, lies deposited in the bank. The bank, therefore, and not the government, is the custodian of the pledge which conveys the right to the eredit substance. But in order to hold the bank to the proper performance of its function, the government has exacted from the bank another seeurity. The bank is really the government's agent, performing the function of distributing the eurrency, of holding the pledge, and incidentally of acting as insurer of this pledge $(220,289)$.

It is thus seen that the currency so issued is doubly seeured; first, by the borrower's acknowledgment of debt, which forms part of the bank's assets, and second, by the bank's seeurity deposited in the national treasury. We shall term these the issuers' and the agents' pledges $(286,288)$.

Continuing our illustration, we find that in due time the manufacturer pays his note by returning the borrowed money to the bank. If he pays with notes of that bank, they are thereby momentarily retired from cireulation and may be reissued by the same or by other borrowers. But if he uses other means of payment, whether other notes, checks or coin, the security underlying these takes the place of the security he withdraws.

The bank may become a real issuer of its own notes by using them, say, in paying for the services of its own employes. The notes so issued are then still doubly secured, namely, first, by the assets of the bank, and second, by the bank's security held in the national treasury.

The notes of a bank may enter into circulation through a depositor of the bank who is not a borrower and who, therefore, cannot be considered an issuer. The nature of sucl transaction will be explained at a further stage of our examination (105b).

I03. Evolution of Modern Banking.-Before the dawn of the modern era commerce depended chiefly on gold and silver, in the form of bars as well as coin, for means of payment. It became a practice of the goldsmiths who made a business of weighing and testing the precious metals for the merehants to also take these metals and other valuables for safe keeping in their strong boxes. Gradually, goldsmiths loeated in different 
cities became affiliated, so that receipts certifying that gold or silver had been entrusted to any one of them were recognized and redeemed by others, and these certificates came to be used in a limited way as a medium of exchange, passing from hand to hand in payment for goods (293). They were readily accepted, not only because they were fully secured by gold and silver actually held in trust by the issuers, but also because those issuers were known to be responsible through possession of wealth of their own. Our present gold certificates are of the same nature as were the receipts issued by these old-time bankers.

The custodians of these deposits, observing that only a sinall fraction of the metals were called for at any one time by the holders of the receipts, conceived the idea of utilizing some of the gold and silver so held, by lending it out for short terms on promissory notes or other securities. The borrowers generally, instead of taking the metal with them, left it on deposit and accepted certificates of deposit therefor. Thus it came about that the certificates issued and used as money exceeded the amount of metal actually in store, the excess being covered by the pledges of the borrowers, which took the place of the shortage of the metal. But in order always to be ready to redeem the certificates that were currently presented for redemption, it was considered advisable to continue this process no further than the point where the outstanding certificates amounted to about four or five times the actual bullion on hand (322a). The short terms of the loans enabled the bankers promptly to replenish their reserve when it fell below the margin, by collecting or reducing their loans as they fell due.

Let us analyze these conditions. While the reserve fund of bullion amounted to one-quarter of the outstanding certificates, these were covered to the extent of that one-quarter by the deposited metal, and the other three-quarters by the pledges of the borrowers. The outstanding paper was thus fully secured. Inasmuch as the certificates performed all the functions of a medium of exchange, they became the means of utilizing business credits as so much actual money (264). 
One-quarter of the value of this money was therefore based on wealth in the form of precious metal, and the other threefourths was based on credit pledges of the borrowers and was, accordingly, nothing more than monetized credit.

This presents a brief review of the evolution of bank note currency. The continued use of such currency clearly depends upon a faithful compliance with the necessary requirements. But the possibility of deriving large profits from the issue of bank notes led to the abuse of this system, through ignorance or dishonesty. History records numerous instances of such abuse and of the financial disasters that followed; and the so-called "wild-cat banking" in the United States during the middle decades of the nineteenth century may be cited as a notable example (322b). To avoid a recurrence of such irresponsible note issues, the federal government assumed control of the issue of bank notes by according the privilege to banks chartered by it, imposing at the same time an annual tax of ten per cent., virtually prohibitive, on all circulating notes except those issued through national banks.

I04. Bank Credit.-When banks added to their business of money changing and money lending the function of effecting the transmission of payment in the business world, a new medium of exchange, now known as "bank credit," came into existence. The volume of this medium of exehange is now far greater than that of all other forms of currency combined.

Bank eredit is identical in its general nature as well as in the process of its generation with the medium of exchange formed by the certificates issued by the old-time goldsmiths. Differences exist only in some of the details. 'Thus to-day deposits consist of currency, checks, and drafts instead of gold and silver metal, and the deposit banks, instead of issuing certificates, merely enter on their books the deposited sums to the credit of the depositors and anthorize them to draw against this account "checks" or "drafts," which are orders on the bank to pay specified sums of money to designated persons or to their order. Borrowers also, instead of receiving money 
or certificates, have their deposit account credited with the borrowed amount which they are then free to draw upon.

A large portion of the money received from depositors is utilized by the banks in loans. The pledges of the borrowers, as they are added to the resources of the bank, take the place of the money furnished by the depositors and withdrawn by the borrowers. In this way the wealth of the borrowers, represented by those pledges, becomes the largest part of the ultimate basis of the bank credit which is utilized as a medium of exchange. In the last analysis, the borrowing is a process of turning business credit into currency, a process of monetizing credit, and this monetized credit attains wide circulation through a system of interchange, organized to include practically all bahks of the country.

This monetary system has its peculiar features and is particularly distinguished in that the money exists in the form of book account, independent of tokens. As the name "bank credit" implies, the money itself consists of the credit of the various banks, the bulk of whose assets consists of the pledges of borrowers. The real substance of this kind of money is therefore made up principally of the borrowers' business capital, the wealth that sustains their loan pledges. The volume of this money is measured by the amount owed by the debtors of the system to the creditors of the system. Only when some of this credit is being transferred from hand to hand is it put in the form of tokens, namely, bank checks; hence the volume of bank checks which at any moment may be in transit is no criterion of the existing volume of this form of money.

There is, however, a limit beyond which the volume of this money cannot safely be increased. A certain amount of lawful money must be held in reserve to meet the current demands of depositors for cash. Banks established either under the national banking law or under the laws of our several states are forbidden to increase or renew their loans when their reserve is below a certain percentage of the sum of their liabilities to depositors. The ratio necessary for insuring the safety of the system has been indicated by experience, and 
the law merely specifies this ratio as a necessary safeguard. Nominally, the eash reserve which the law prescribes for national banks in eities is 25 per cent., and for country banks 15 per cent. (292), but owing to the legal provision which allows a bank to inelude as part of its reserve such amounts as it has deposited in banks located in certain cities, the average cash reserve in actual money comes down to about one-eighth-or even less-of the total deposits (255). By this system each dollar held in bank, in conjunction with seven dollars' worth of assured business credit, is made to do the work of eight dollars of money. About seven-eighths of the volume of banking power, then, is business credit performing the function of a medium of exchange $(238 a, 281,287)$.

The cash reserve which banks are legally required to maintain, though reduced from the nominal rate by the provision above noted, must eonsist of "lawful money." But the amount of such money is limited, and in the nature of things only a portion of this amount can be retained by banks, the other portion remaining in circulation. The constraint which prevents banks from extending their credit by increasing their loans after their reserve falls below a certain percentage of their deposits inevitably imposes a limit on the expansion of bank credit, in other words, on the nse of assured business credit as a medium of exchange. Under the existing system, the sum-total of all bank credit subject to eheck available in the United States cannot be more than about eight times the sum of money actually remaining in reserve $(238 b, 293)$.

If a deposit and discount bank were to start with no resources except the funds of its depositors, using the incone from discounts to defray its ruming expenses and to cover the average of such losses as are likely to occur, its "bank "redit" would remain just fully eovered by the securities of the borrowers plus the eash reserve. Practically, however, there should be an excess or margin in the bank's assets to cover unforeseen shorteomings of the borrowers' securities, and this is afforded by the net resources of the bank itself, namely, the eapital stoek, plus undivided profits, or "surplus," if such there be. These net resourees are owned by the stockholders, 
whose claims are second to all other claims against the bank's assets (304), and therefore constitute an insurance reserve or margin, without which depositors would scarcely entrust their money to the bank.

Bank checks, viewed as money tokens, are analogous to bank notes, from which they differ only in a few particulars. Apart from the agents' security-the bonds deposited with the government - the two forms of exchange medium are alike in being secured in part by money and in part by business credit; both are redeemable in lawful money by the bank named on their face; and both come within the scope of the general consent which makes them acceptable, at least within their respective spheres, as a medium of exchange. Thus both possess the essential features of credit money.

Their difference extends only to details which, to be sure, are characteristic in their way. The specific features of the bank notes are such as to fit them for general circulation as currency, while the peculiarity of checks is that they are highly convenient means of making, and comparatively safe means of transmitting, payments, especially of larger sums.

Checks differ from bank notes in that they are written and issued by the party who desires to make payment, and are made out for the specific sum to be paid. A check, accordingly, serves generally for one payment only, and, being deposited by the payee in bank, is returned to the bank on which it is drawn for collection or clearance. For this reason it is not adapted for general circulation. Moreover, bank credit transferable through check has no other security than the assets of the particular bank, and has accordingly no other margin of security than the stock and possible surplus of that bank. The government exercises no direct regulation or control over the issue of checks and gives no assurance of their validity, as it virtually does in the case of bank currency which is doubly secured, one of the securities being in custody of the government. If a check is invalid through lack of credit of its issuer, it is returned unpaid to its depositor, who has recourse to the maker of the check. In order to preserve this recourse, each individual or bank through whose hands the check passes 
records such passage by "endorsing", it, and in practice no check is accepted in parment, or redeemed in cash, unless the last endorser is recognized as responsible.

105. The Real Issuer of Bank Credit.-Inasmuch as the system of bank credit subject to check constitutes in itself a distinct monetary system, it necessarily follows that it has its own particular circle of debtors and creditors (92). A brief examination of the case will show that the borrowers from the bank are the debtors of the system, and the depositors of the bank are the creditors, the bank being merely an intermediary agent (288).

The process by which bank credit is established consists in the bank according "eredit" on its books to a borrower on basis of the borrower's obligation to discharge the debt at a future time. If now this borrower, by drawing on the eredit so obtained, buys goods with his check, then his bank credit is used for the first time as a medium of exchange, and when the payee deposits the eheck, the credit so acquired is to him what so much money would be.

The analogy existing between bank credit and bank notes is apparent from the following conclusions which are parallel to those which we have reached with regard to bank notes (102a):

1. Before a borrower who has been given eredit on the books of a bank draws upon it, this bank credit is not yet money in the full sense of the word, but is ready for issue through check. The borrower is yet both debtor and ereditor of this money system; debtor as a borrower from the bank, and creditor by virtue of his deposit account.

2. Bank credit is put into circulation when the borrower uses it in payment, through check, for valuable things or services; this first use of bank credit by the borrower signalizes its issue. The individual who acepts the eheek in payment and deposits it becomes creditor of the system. The bank credit so aequired serves as evirlence that he has given wealth to the community, and it eonveys to him that command of the market which, like the possession of currency, enables him to get from the community an equivalent in return. 
3. While it is nominally the banks which are indebted to the depositors, it is really the borrowers from the bank who are in possession of the credit substance that are the real debtors. The bank merely possesses the instruments through which the credit substance, the real wealth, is pledged. The borrowers, therefore, are the real issuers of the bank credit $(264,287)$, and the depositors are the real creditors of this money system.

Whenever a borrower of a bank pays his loan, the volume of bank credit is thereby reduced; the portion he had issued is retired. Indeed, the process of issuing and retiring of bank credit is going on incessantly. This is one of the incidents of the system, and while it may appear complicated in its details, the system in its general aspect remains simple enough. The borrowers and the depositors of banks are the debtors and the creditors of the system. In case the total of a bank's deposits exceeds the total of its loans, the excess is covered by the bank's reserve and tangible property, and the bank is to that extent debtor of the system. If, on the other hand, the total loans exceed the total deposits, the bank is creditor of the system for the difference.

We can now understand what happens when a depositor who is not a borrower checks out the bank's notes and puts them into circulation (102b). By so doing, this depositor's bank balance is reduced and the volume of bank notes in eirculation is increased. This increase is therefore attended by an equal reduction of the sum total of all bank credits subject to check. There is no increase of the sum total of all available money, but only an increase of bank note circulation and an equal reduction of the total volume of simple bank credit. The transaction is not one of issue, but one of a substitution of one kind of currency for another.

This simply confirms that bank notes are merely bank credit put into a form in which it can be used as a circulating medium of exchange. Being secured through the "agents' pledge," the bonds deposited in the national treasury, the government undertakes to supervise and guarantee the issue of these notes. But as we have already seen, these notes are 
really nothing more than business credit employed as a medium of exchange.

I06. Subordinate Systems.-There are yet other systems of exchange, mostly of a restricted compass, which require passing mention here. According to the premises from which we started, any agreement, expressed or implied, among any number of people, whether only two individuals or many millions, to use certain things or accredited tokens of those things for facilitating the exchange of services or goods, must be considered as establishing a monetary system.

Such a system, for instanee, is that of so-called store orders. It was formerly customary in some places to pay at least a part of workmen's wages in orders upon certain dealers in merchandise. These "store orders," though not redeemable in any form of money, were yet redeemable in merchandise at the specified stores, and for this reason they possessed value (96). They were, of course, not adapted for general circulation, but within the circle in which they did pass they were manifestly a medium of exchange, being in fact a legal-tender in payments due to the designated dealers.

Postage stamps as well as railroad and theatre tiekets may, in a way, be considered a form of money, figuring in the sale of certain services. In the same eategory are the tickets for meals or drinks issued by clubs, hotels and restaurants. Finally, we may even say that all essential elements of a monetary system are momentarily present in every ease of barter. Each participant agrees to accept one of the things in exchange for the other. 'Thus we find that there is really no sharp line of distinction to be drawn between the modern system of exchange by means of legal-tender currency and the original method of simple barter. Our most refined and complicated system of currency is but a result of gradual evolution from primitive barter and does not differ from it in its essential nature.

107. The Value of Money.-On taking up this topie, John Stuart Mill warns his readers of the confusion liable to arise from the popular phrases "money is dear" and "money is 
cheap," which are employed to describe those conditions under which money commands a high or a low rate of interest. This admonition is quite as necessary now as it was then, for those phrases are still as much misused and as much misunderstood as ever. The reason why money has the power to command interest is totally different from that which gives it the power to command commodities in exchange, and the descriptions "dear" and "cheap," as currently applied to money, are responsible for endless confusion. This confusion of ideas goes so far that many otherwise well informed men are firmly persuaded that the purchasing power of money depends entirely on its power to command interest (360). Nothing could be farther from the truth, and no better illustration of the erroneous nature of this idea can be cited than the fact that the purchasing power of money and its interest-bearing power or interest rate vary quite independently. In fact, the interest-bearing power of money is frequently high when its purchasing power is low, namely when prices are high. There is no direct relation between these two faculties of money, each being the result of a separate cause. Under the present heading we shall confine ourselves to an analysis of the exchange value, that is to say, the purchasing power of money, leaving the interest commanding faculty for future consideration.

In the development of commerce various staple commodities have been used in effecting compound exchanges and have thus performed the function of money (123). Such commodities were accepted in barter merely to be used in subsequent barter. In this way they passed from hand to hand until they happened to come into possession of some who had use for them and who accepted them for that purpose. Such media of exchange passed, as a matter of course, at their commodity value.

In the course of time only silver and gold remained in use in this manner, being for many reasons better adapted than other things for such use. In the middle ages there grew up the custom of having goldsmiths determine the weight and fineness of the silver and gold tendered by merchants in 
payment of goods. It is thus apparent that the metals passed in exchange as merchandisc performing the function of money. And when, later on, certificates of deposit of these metals, and ultimately promises to pay gold or silver, that is to say, credit, took the place of the metal itself, the value of the metal still determined the value of this medium of exchange.

This fundamental law of the value of money prevails now as it prevailed then. The value of money equals the value of that of which the money is made, be it gold or credit (125). So long as gold is the value denominator, the exchange value of the metal gold determines the purchasing power of all money which consists of gold or of credit redeemable directly or indirectly in gold.

The proposition just stated was taken for granted when we had occasion to advert to the value of money in connection with the description of the several types of currency. There is, however, yet to be considered the influence which the amount of the metal used as money has upon the market value of the metal and therefore of the money. By the use of this metal as a money substance the demand for it is correspondingly increased and its exchange value accordingly affected. ${ }^{22}$

108. The Value of Gold.-This influence can best be studicd by the aid of the graphical method, but in so doing we must temporarily adopt a value denominator other than gold, say a composite unit (31), and assume that the demand for and the supply of gold were renclered in terms of this unit.

Suppose that in Fig. 11 the curves $S S^{\prime}$ and $D D^{\prime}$ represent the supply of and the industrial demand for gold, while $O Q$ measures the total amount of gold extant. If there were no additional demand, the value of gold would adapt itself to the ordinate $q a$. But if an amount of gold equal to $O V$ is

"2 The difference slould be noted that exists between "adopting gold as a value denominator" and "using gold as a money substance." In a later chapter it will be shown that it is possible to abandon gold as a money substance without giving it up as a value denominator. Under such conditions the monetary demand for gold would become reduced to a negligible quantity. 
held apart in the channels of exchange, in the form of coin in circulation and of reserve in treasuries and banks, the supply remaining for industrial uses is reduced to $V Q$. The demand curve $D D^{\prime}$ must then be referred to this remainder alone as the available quantity, that is, the curve must be bodily shifted into the position $E E^{\prime}$; and the current value of gold, cxpressed in terms of the composite unit, will then be given by the ordinate $q^{\prime} a^{\prime}$ of the new point of intersection $a^{\prime}$ (115). While, in the absence of a demand for gold for monetary use, the quantity of the metal demanded for industrial uses would equal $O q$, the diversion of the volume $O V$ for monetary uses not only increases the value of gold, but also rednces its industrial demand to $V q^{\prime}$.

The total amount of gold $O Q$ is divided into three parts, the first, $O V$, being applied for monetary uses; the second, $V q^{\prime}$, being offered in the market in one form or another; and the third, $q^{\prime} Q$, being the quantity which exists in various forms, not offered in the market (59).

The increase of the value of gold from $q a$ to $q^{\prime} a^{\prime}$ has greatly stimulated its production. Every available source is utilized, and every new mining field is rapidly exploited.

The point $V$ that divides the amount of gold applied to financial uses from that remaining in the field of industry and otherwise extant, shifts its position under various circumstances. When brought to the mint for coinage, gold is transferred from the industrial to the financial field. When, as may happen, gold is withdrawn from monetary use and applied for industrial purposes, the relation of the respective quantities is changed in the other direction. When, for any reason, money becomes "scarce," the demand for gold for monetary use increases, entailing a transfer of the metal from the industrial to the financial field, thereby increasing the quantity $O V$, correspondingly diminishing the quantity $V Q$ and displacing the point $V$ accordingly. These changes account in part for the fluctuation of prices as the conditions of business vary from time to time.

The diagram clearly exhibits how the value of gold, and with it the purchasing power of the dollar, is affected by the 
use of gold as a money metal, and why it is that the value of gold is sustained at a higher level than it would be if large quantities of it were not used for coin and bank reserve. But it is practically certain that sooner or later methods of exchange will be developed through which credit will displace gold as a substance of money more completely than now, so that the greater portion of gold now held in treasuries and banks will be liberated, when the value of gold, no longer sustained by monetary demand, will fall and approach its natural rate $q a$, Fig. 11 (320).

rog. The Price of Gold.-Our reasoning has thus far been based on the proposition that the value of standard coin equals the value of the metal contained in it, and that the "price" of gold, expressed in "dollars," cannot change so long as gold is the current value denominator, no matter how mueh the value of gold, expressed in some other value denominator, may change.

There are what appear to be exceptions to this rule which, however, on eritical examination will be found to be fully in eonformity with it. These apparent exceptions are often improperly cited as contravening the principle in question.

There is, of course, always a difference of price between the commercial and the assayed metal. For obvious reasons gold eamnot be marketed at its coinage value unless it is assayed and the degree of fineness ascertained and guaranteed. Old jewelry usually brings a eomparatively low price, partly because of the cost of colleeting and refining the same to put it in marketable form, and partly to allow for differences due to the crudity of the assay. The same is true of the gold dust brought from mines, espeeially when brought from newly discovered fields. The cost of assaying and treating such dust is increased by the cost of earriage to the nearest aceredited refinery.

Owing to the free and gratuitous coinage of gold, whereby the owner of refined gold ean have it converted into money without cost, the differenee between wholesale and retail price exhibited by other commodities is not ordinarily observed in the gold market. It is, however, not totally alssent. In ex- 
changing foreign gold coin for domestic money, the broker cliarges a commission for the trouble and expense of again "selling" these pieces of gold, a charge which is clearly analogous to that which the retail merchant adds to the wholesale price of the goods he sells. Of a like nature is the slight premium which the seller of bar gold must generally pay when he desires money for his metal. As a matter of fact, the price of gold in the London market fluctuates and is actually quoted in market reports (122). These variations must, of course, not be confounded with those which attend the use of depreciated legal-tender credit currency (96). The real explanation is in line with that of differences in international exchange and may be more fully elaborated as follows.

Although gold is our value denominator, and gold coin can have value only because it consists of the commodity gold, yet bullion must be coined before it can legally be used for the payment of an obligation. But taking the gold to the mint involves trouble, and the coining requires time; and in the measure in which owners of gold metal desire to save this time and trouble, they are willing to make a sacrifice by offering it in the market slightly below the coinage value. The premium thus offered by sellers of gold varies according to circumstances and is usually so small that it is negligible in ordinary commercial transactions. But the fact that this varying price of gold is never above the coinage price conclusively precludes that other explanation which is offered by the adherents of the volume theory of the value of money (123).

I ro. Bimetallism.-Until a comparatively recent period, gold and silver were used independently as money. Silver, being more abundant than gold, was more largely used and naturally became the most widely accepted standard of value in trade and commerce. At the same time, gold was accepted at a varying course, according as its market value, compared with the silver standard, varied.

To avoid the complications arising from the ever changing relation in the value of silver and gold, efforts were made by 
several governments to maintain a fixed relation between the two metals by force of law. Both metals, in the form of coins of specified weights at a stated ratio, were made legal tender. Varions enactments were adopted by different countries without international coöperation. France established a system of bimetallism by decreeing $151 / 2$ weights of silver as the equivalent of one weight in gold. At about the same time the United States adopted the ratio 15 to 1 in its newly established coinage, and subsequently both countries found it necessary to change the coinage ratio so that the silver unit was 16 times as heavy as that of gold. A coin containing 4121/2 grains of silver, $\%$ fine, and one containing 25.8 grains of gold, also $\%$ fine, were each declared by the laws of the United States to be legal tender for one "dollar."

These national enactments proved unavailing to maintain gold and silver at a fixed value ratio, and efforts were put forth from time to time to establish such a ratio by international coöperation. Arguments were advanced with a view of demonstrating that a fixed value ratio conld be maintained indefinitely by admitting both metals to free coinage at that ratio. It was held that if, through any cause whatever, one of the metals composing the bimetallic system should fall below the legally fixed ratio of value, the immediate result would be that more of the metal would be coined for circulation, while coin of the other metal would be withdrawn from circulation and tumed into the market as bullion. The value of the cheapened metal would be boosted up by the reduction of its amount in the market, and, at the same time, the value of the other metal would be depressed, because the market supply would be increased through the melting down of coin. This, it was asserted, would constantly maintain the parity of the two metals at the ratio fixed by law.

It is, however, obvious that this process of equalization through free coinage must fail whenever the cost of prodncing either metal changes materially. The relatively dearer metal would continuously be withdrawn and finally disappear from circulation, leaving only the cheaper metal as currency.

IIappily, a general recognition of the impracticability of 
the double standard has led to its definite abandonment. The single gold unit has now come to be adopted as the measure of value throughout the commercial world.

The use of silver for subsidiary coin in connection with gold as the standard is sometimes mistaken for a sort of bimetallism, but this is an error, inasmuch as bimetallism requires a free and unlimited coinage of both metals.

II . Composite Value Units.-In treating the subject of the value unit ( $31 b$ ), discussion of one of the objections to composite value units was at the time deferred. This matter can now be taken up again.

The nominal value of a credit instrument-that is, an acknowledgment of debt-is fixed by the value of the things or services which the debtor promises to give. In other words, a credit instrument can have a definite value only if it is a valid promise to deliver specified things or services. For the same reason, credit money can have a value expressed in dollars only if redeemable in "dollars." In the case of a composite unit, a "dollar," instead of being so many grains of gold, would consist of a scheduled quantity of a number of commodities. Thus a ten-dollar note, to have a value corresponding with this unit, must be redeemable, not in 258 grains of standard gold, but, say, in 15 grains of gold plus 10 pounds of flour plus 25 pounds of cotton plus 200 bricks plus 20 feet of lumber and so forth, or whatever schedule may have been adopted. The impracticability of such a system of redemption is self-evident.

To obviate this difficulty of keeping the money at par with the adopted standard, the following plan has been suggested. Let the dollar of currency be redeemable in gold, the amount of which, instead of being fixed, is to be increased or reduced, according as the value of gold falls or rises in comparison with the adopted composite unit. This would require the introduction of a constantly changing "index number" with which to multiply the present weight of 25.8 grains, in order to ascertain the amount of gold in which the dollar of currency is to be redeemed.

If practical means could be devised accurately to determine 
this constantly varying index number, the total market value of the scheduled commodities would in consequence remain stationary, and, in the measure in which this aggregate of things is representative of the general market, the mean price level of all things would be approximately stable.

Whether this proposition, which has lately been championed and elaborated in detail by Irving Fisher, could be successfully carried into practice, and if it could be, whether it would have a beneficial effect commensurate with the work involved, is open to question. By whatever method the index number is to be determined from time to time, it must be through reference to market reports which are by no means proof against "manipulation" and, even apart from this, are often but crude approximations between two stated margins, an indefiniteness in part due to the difficulty of sharply defining quality $(31 a)$. Moreover, if the index number is to be corrected at frequent intervals, before previously announced changes have had their full effect upon prices generally, the market reports would continue to indicate a need for further change when no such change were really needed, and the official correction would over-reach itself. And if longer periods are chosen, the expectation of impending changes is not unlikely to be a source of business disturbance because of the sudden and intermittent effect on prices generally.

Another proposition for maintaining currency at par with a given composite unit is sometimes advanced, namely to increase or reduce the total volume of currency, as the sum total of the market value of the composite unit falls or rises, but it will be shown later (321) that every attempt along this line must prove abortive, since the proposition is based on an erroneous premise.

The fact that projects of this kind are put forth from time to time is due to the belief of many that our frequent financial upheavals result from the fluctuating value of the "dollar," manifesting itself in a corresponding but opposite fluctuation of prices. That such is not the case will become apparent in the further course of our investigation. 
II2. Depreciated Value Unit.-When depreciated legaltender notes-that is, unfulfilled promises to pay "dollars" to bearer-remain in circulation as the current money, the dollar of currency will not be equal to the dollar of the promise, whether gold or silver, but will be a certain variable percentage thereof, that percentage depending on the general appraisement of the readiness or ability of the government to ultimately fulfil its promises (76).

In the United States, from the time of the issue of the "greenbacks" up to the year 1879, the nominal unit of value, the "dollar," was 3711/4 grains of pure silver or 23.22 grains of pure gold, while the actual current unit was the depreciated value of the government's unfulfilled promises to pay such "dollars" to bearers of greenbacks. The real dollars, both gold and silver coin, were accordingly above the dollar of this currency and did not circulate (96). The former became merchandise, the value of which, expressed in terms of dollars of the currency, was regularly quoted in the market. The price of both metals went up and down as the probability of an early resumption of specie payment appeared to vary. But while the prices of both metals rose and fell concurrently, or nearly so, the price of dollars of silver was not equal to that of dollars of gold, because the prevailing ratio of exchange of the two metals was not precisely as 16 to 1 .

There were thus three legalized units of value (123), only one of which, that of the lowest value, was the customary unit of account. The fact that the dollar of account continued as such, while the dollar of gold and the dollar of silver rose and fell in market value, was by many construed as proving that the value of money had nothing to do with the value of the money metals (322).

II3. The Seignorage Theory.-Ricardo promulgated the theory that the value of coin equals the value of the metal contained therein plus the amount charged for coining (115). be this charge only the actual cost or such greater amount as the sovereign may exact for the purpose of a revenue from his prerogative of issuing currency, this charge being termed 
"seignorage" (98). The following quotation presents his view on this point:

While the state coins money, and charges no seignorage, money will be of the same value as any other piece of the same metal of equal weight and fineness; but if the state charges a seignorage for coinarge, the coined pieces of money will generally exceed the value of the uncoined pieces of metal by the whole seignorage charged, because it will require a greater quantity of labour, or, which is the same thing, the value of the produce of a greater quantity of labour, to procure it.

While the state alone coins, there can be no limit to this charge of seignorage; for by limiting the quantity of coin, it can be raised to any conceivable value.

It is on this principle that paper money eirculates. The whole charge for paper money may be considered as seignorage. Although it has no intrinsic value, yet, by limiting its quantity, its value in exchange is as great as an equal denomination of coin, or of bullion in that coin. On the same principle, too, namely, by a limitation of its quantity, a debased coin would eirculate at the value it should bear, if it were of the legal weight and fineness, and not at the value of the quantity of the metal which it actually contained.23

Upon close examination this statement is found to embrace a hazy confusion of two independent theories of the subject $(116 a)$. If the value of money is determined by the quantity of labor necessary to procure, not only the metal or paper of which the money token is made, but also that with which to pay the seignorage charged by the government for turning the metal or the paper into money, then an arbitrary limita. tion of the quantity of money so issued ean in no way affeet the value of this money. On the other hand, if an arbitrary limitation of the issue is essential to maintain the value of the money above the value of its substance, then the quantity of labor, particularly that eovering the seignorage, cannot have anything to do with the ease (116b). A seignorage charge might indeed impose some limit on the amount of money that would be issued, as this toll would naturally react on the demand, but Ricardo and his followers predicate an intentional, an arbitrary limitation of the amount to be issued, and this is something radically different from the limitation that would naturally follow as a eonsequence of the imposed toll.

23 Ricarilo, p. 213. 
I14. The Seignorage Theory Untenable.-Of the two theories which are embraced in the quoted statement we shall first take up the proposition according to which the current value of a coin equals the value of the metal plus the cost collected by the government for coinage. This theory is also put forward by John Stuart Mill, his statement, in brief, being that if the government did not coin money gratis for any one who furnishes the metal, coined money would be worth more than the bullion, for the same reason that cloth is of more value than yarn. Were the government to make a charge to cover expenses, the coin would rise to the extent of the seignorage, above the value of the bullion. ${ }^{24}$

This, manifestly set forth as a self-evident proposition, is, however, by no means an ascertained fact and, on closer examination, will be found to be not only open to question, but altogether untenable.

The use of a watch case, for instance, is to protect the works of a watch from injury, but in order to give it esthetic as well as practical utility, it is made of gold and is ornamentally engraved. The work of the goldsmith has added value to the piece of gold. According to Mill the same reasoning applies to coin. But the two cases are really quite dissimilar, since the object of coining is not to produce an olnament. From the first the stamp on coins had the object of officially vouching for correct weight and fineness, and this purpose has remained the same till now, even though art has added beauty to the piece. Surely, a stamp attesting that a piece of gold has a stated weight and is of a stated degree of fineness can add no value to this gold. We must not forget that the gold of the coin is merely a quantity of metal (93) performing the function of collateral security for the face value of the coin.

Let us suppose that the United States were to make a coinage charge of, say, 5.8 grains of gold per dollar and would collect this charge by making the coin of a weight of only 20 grains per dollar, thus returning 20 grains of coin

${ }^{24}$ Cf. Mill, 11, pp. 38-39. 
for each 25.8 grains of gold brought to the mint for eoinage. The stamp on an eagle would still be a voucher that the coin is of full weight. But is this to be understood as meaning that its weight is vonched to be 258 or 200 grains? In the first ease the voucher would be a falsehood; in the seeond, the voucher that an eagle consists of 200 grains would be a declaration that a dollar is 20 grains of standard gold, and the purehasing power of the dollar would adapt itself accordingly. ${ }^{25}$

Or suppose the government were to make coin of full weight, namely at the rate of 25.8 grains of standard gold per dollar, and would demand payment for coinage from those who bring gold to the mint. What would be the result upon the value of that coin?

Since the function of the metal in any standard coin is that of a full collateral security for the debt of which the coin is a token, and since this collateral, when applied to cancel the debt, has value only as bullion, it follows that the coined piece of gold cannot have a value exceeding its bullion value. If, then, the owner of gold who brings it to be coined must give besides the 25.8 grains per dollar some more of his gold to pay for coinage, the question arises: What would impel him to bear this charge, when he can sell his bullion at the rate of one dollar for each 25.8 grains?

If this charge for coinage were less than the cost of selling the bullion in the market, then the owners of gold would doubtless be willing to pay this charge for having their gold coined, thus sacrificing the tax so paid, since eoining would save them the eost of marketing the gold. But if the government's charge were to exceed the cost of marketing the metal, then gold would not be brought to the mint for coinage, but would go uncoined, unless the govermment itself were to buy the metal and coin it for its own requirements.

That the value of a standard coin does not exceed its bullion

${ }^{23}$ It is here assumed that the 200 grain earle would be standard coin, that is, not redeemable by the government in 258 grains of gold, for in that case the gold coin would be a credit token, like subsidiary coin. 
value is fully borne out by history. When the "pound" of silver was coined by European monarchs in pieces less than their nominal weight $(98 a)$, the coined silver did not circulate at its nominal or legal valuc, the "pound" of silver, but at a value corresponding with the precise amount of silver the coin actually contained $(98 b)$. This fact is certainly not in harmony with the seignorage theory.

Our experience with greenbacks is equally fatal to the same theory. The value of the depreciated greenbacks always reflected the average expectation of their ultimate redemption. During the civil war a battle lost by the federal troops at once advanced the price of gold; a victory gained was promptly followed by a fall of gold quotations. Since the resumption of specie payment these notes have remained at par with gold. All these facts are wholly inconsistent with the seignorage theory, namely, with the notion that the value of these notes was determined by the charge which the government made for their issue. The facts can be clearly accounted for only on the theory of currency value which we have considered in the preceding pages (107-112).

Without doubt, the seignorage theory was conceived and formulated in the endeavor to account for the phenomenon presented by subsidiary coin. It did not occur to Ricardo and his followers that such coins are in reality credit instruments which are accepted by the issuing government at their face value. Fractional coin does indeed circulate at a value exceeding its metal value, but this is so because, in the first place, fractional coin is redeemable by law in standard money, and second, because it is accepted at par in payment of taxes (96). When the subject of credit is correctly understood, the mystery attached to subsidiary coin disappears, and the seignorage theory is found to be a misconception.

\section{II5. The Volume Theory of the Value of Money.-} Among the various ideas concerning money there is none put forward more persistently than that known as the "Volume Theory of the Value of Money." According to this theory the purchasing power of the dollar depends upon the relation 
which the supply of money bears to the demand for money; it falls-that is, priees rise-as the supply of money is inereased or the demand reduced; it rises-that is, priees fall -when the demand for money is increased or the supply reduced.

This view of the relation of money to prices arises out of the use of the term "dollar"' in the sense of "money" (78, $88,95)$ which has led to the notion that the dollar is a "money unit" instead of what it really is, a value unit, consisting of a stated amount of the standard commodity. Along with other theorists on the subject John Stuart Mill appears to have believed in the existence of a unit of money the value of whieh may vary from the value of the gold contained in the standard money, when he says, apropos of conditions resulting from an increase of eurreney :

An ounce of manufactured gold will become more valuable than an ounce of gold coin, by more than the customary difference which compensates for the value of workmanship; and it will be profitable to melt the coin . . ..$^{20}$

With the introduction of a "money unit" which may differ from the gold unit we are eonfronted with a theory to aecount for the value of money which differs from that which traces the value of money to that of the standard commodity (107-112). Both cannot be correct, and in order to find which of the two actually prevails, we must subject them to a critical comparison.

According to the volume theory the value of money depends upon the quantity of money in cireulation and the demand for money (322). According to the other view, the commodity theory, it depends upon the value of that of which the money is eomposed, whether it be the commodity gold, or credit expressed in terms of that commodity, or, aecording to some, upon the value of the metal plus the cost of coining it (113). In the one case, the value of the dollar is supposed to be regulated by supply and demand of moncy, in the other by supply and demand of the metal gold. Aecording to the

2n Mill, II, p. 89. 
former theory, every change in the volume of money, other things remaining equal, is followed by a corresponding change of prices, even though the value of the metal gold remains unchanged. According to the other, a change in the volume of money affects prices only if such change reacts upon the value of gold, and even then only in the measure of such reaction; and, as we have already learned (108), this reaction is not in proportion to the change in the volume of money.

The assumption that the value of money, like the value of commodities, is determined by the supply of and the demand for money is based on an analogy, but the analogy is irrelevant. Money cannot be treated as though it were a specific commodity, like potatoes, hats, chairs. Money in itself is not useful in the sense of having the faculty of gratifying desires. Only the gold of which coin is made, or in which currency is redeemable, has this capacity. The demand for money is not a consumers' demand (58) which is reduced or satiated with continued gratification. Nor is the supply of currency a producers' supply which requires the stimulus of a recompense, for it is regulated by legislation and not by the reluctance of the producer to endure the strain of production, varying with the amount produced. Supply and demand of money eannot be represented by a rising and a falling curve, like $S S^{\prime}$ and $D D^{\prime}$ of Fig. 6, and in the absence of the features illustrated by these curves there cannot be a point where supply and demand come to a balance, that is to say, where desire is balanced by reluctance (63).

Money is not a specific commodity; its essence is that of a credit, each money token being a credit instrument, conveying a right to a stated amount of wealth (240). The value of money therefore follows the same law that determines the value of credit. And the value of credit is the amount of wealth which is specified as owing, and from this it does not differ unless the credit lacks assurance. It is the value of the metal gold, it is cost and utility as regards gold, which determines the value of money where gold is the standard of value. 
If it were asserted that the creation of new debts would. have the effeet of diminishing the value of all previously existing debts in such proportion that the old and the new debts together would have only the same value as the old debts had before, the assertion would at once be recognized as untrue. Yet, the volume theory is based on this very assumption as regards all those forms of debt which through communal agreement are made available as a medium of exchange.

As regards credit money, including bank credit over and above the metallie reserve, the real substance of that money is the miseellaneous wealth which constitutes the pledges that afford the assurance. Through the principle of eredit this wealth is made available for the purpose of a medium of exehange (69), and through the communal consensus that wealth is invested with the faculty of doing service as money. This wealth is not used bodily as money, but only through the medium of a credit conveyance, while itself continning in use for the purpose for which it was produced. The only form of wealth bodily in use as money is gold when circulating as coin, or when stored in a redemption fund or held as bank reserve.

Suppose it were true that paper tokens, upon being declared legal tender for debts, aequire value by dint of the universal demand for a medium of exchange. These tokens, in order to eirculate as money, must evidence that the holder has delivered wealth to the community and is entitled to receive an equivalent in return; in other words, they must bear witness that the holder is a creditor. Hence, if these tokens are not acknowledgments of debt, it would follow that there can be ereditors where there are no debtors $(89,92)$, and this is ineoneeivable.

But let us see what the advocates of the volume theory have to say to establish their position.

I 6. Ricardo's Statement of the Volume Theory.-It was evidently considered superfluous by Ricardo to offer any demonstration whatever of the volume theory. He merely stated the proposition as though it were self-evident. In a footnote he asserts: 
That commodities would rise or fall in price, in proportion to the increase or diminution of money, I assume as a fact which is incontrovertible. ${ }^{27}$

But the fact is that this assumption is ineonsistent with his own seignorage theory (113b). Ricardo seems to have overlooked that in explaining the value of money on the seignorage theory, and then qualifying this by adducing the volume theory, he was dealing, as already pointed out (113a), with two really incompatible propositions. As Ricardo has offered nothing to substantiate the volume theory, there is no ground for further argument regarding his assertion on the subject.

I17. Mill's Argument.-John Stuart Mill offers the following argument as a demonstration of the volume theory :

Let us suppose that to every pound, or shilling, or penny, in the possession of any one, another pound, shilling, or penny, were suddenly added. There would be an increased money demand, ${ }^{28}$ and consequently' an increased money value, or price, for things of all sorts. This increased value would do no good to any one; would make no difference, except that of having to reckon pounds, shillings, and pence in higher numbers. - . Prices would have risen in a certain ratio, and the value of money would have fallen in the same ratio.

It is to be remarked that this ratio would be precisely that in which the quantity of money had been increased. If the whole money in circulation was doubled, prices would be doubled. If it was only increased one-fourth, prices would rise one fourth. . . . The value of money, other things being the same, varies inversely as its quantity ; - . This, it must be observed, is a property peculiar to money. We did not find it to be true of commodities generally, that every diminution of supply raised the value exactly in proportion to the deficiency, or that every increase lowered it in the precise ratio of this excess. Some things are usually affected in a greater ratio than that of the excess or deficiency, others usually in a less: . . .99

These quotations are taken from the ehapter: "Of the Value of Money, as Dependent on Demand and Supply." This is immediately followed by the chapter: "Of the Value

${ }^{27}$ Ricardo, p. 326.

${ }^{28}$ The author here manifestly means "demand for other things in exchange for money."

${ }^{29}$ Mill, II, pp. $29 \mathrm{ff}$. 
of Money as Dependent on the Cost of Production," in which the author shows that the value of money, "in a state of freedom," conforms to the value of the bullion it eontains.

A pound weight of gold or silver in coin and the same weight in an ingot will precisely exchange for one another..$^{30}$

Thus he artlessly presents both the volume and the commodity theory together, although at best only one of them ean be correct. On examination it will be found that the volume theory is the one that eannot be sustained.

I 8. Mill's Reasoning Analyzed.-In the illustration in which all men are supposed to find the money in their possession suddenly doubled, the assumption that all men would thereupon pay double prices for everything they had to buy is by no means self-evident. Such is certainly not the case with people who suddenly get rich. While they may spend money more freely, buying things they would not have bought before, yet they do not usually give more money for the goods they buy than the ruling price of the goods. The question really is, what would be the ruling price of goods under the conditions which Mill suggests?

If he intended to imply that not only the quantity of all coined metal were doubled, but that the quantity of all silver and gold metal were increased two-fold, and that the mines of these metals would henceforth be twice as prolifie by the application of the same amount of labor, and furthermore, that the usefulness of two ounees of the metals for all possible uses would heneeforth equal the usefulness that formerly inhered in one ounce, then his conclusion would be sound. Priees would then promptly rise to preeisely double their former level. But since these conditions would bring about a reduction of the value of the precious metals to onehalf of what it was before, this illustration would eonfirm the commodity theory rather than the volume theory of the value of money, for in the absence of the additional conditions here enumerated, Mill's conclusion would not stand,

${ }^{30}$ Mlill, 1 I, pp. $38 \pi$. 
especially if the production of each ounce of gold and silver would still entail as much effort as before.

Those who have money to spend compare the effort to acquire the money with the gratification that can be derived from the goods to be obtained for it, and if the production of the gold or the silver of which standard coin consists continues to require the same effort as before, there is no ground for Mill's inference that the estimated worth of a coin would fall to one-half if the number of coins were doubled. No coin that is legal tender ever passed current at a value below that of the metal it contained, and there is no reason to assume that it ever will.

I I9. Newcomb's Argument.-More plausible is that attempted demonstration of the volume theory which is clothed in the garb of mathematics. This method has been adopted and elaborated by quite a number of recent writers. We shall here take up Simon Newcomb's presentation of the argument, and since that of others who accept the volume theory is virtually the same, the following discussion will apply generally.

The volume theory is held to be capable of mathematical demonstration on basis of the fact that at each sale the delivery of goods in one direction is reciprocated by the delivery of money of equal value in the other. ${ }^{32}$ An equation exists, therefore, between the flow of merchandise, or the "industrial flow," and the circulation of money, or the "monetary flow" (245).

The monetary flow is represented by the product $V \times R$, where $V$ is the volume of currency, namely the number of dollars in actual circulation, and $R$ is the average rapidity of circulation, namely, the average number of times in the year that each dollar is used as a medium of exchange.

In the algebraic representation of the industrial flow the letter $K$ was chosen for the total traffic in merchandise and services during one year, but since the total value of this traffic may rise or fall as the price level rises or falls, the quantity $K$, which is supposed to be rendered in terms of

${ }^{31}$ Cf. Newcomb, pp. 315-347. 
some invariable value unit (31), must be multiplied by the coefficient $P$ denoting the price level, in order to obtain the value of the flow in terms of dollars. The letter $P$ really represents the value of the assumed invariable unit in terms of dollars, that is, the reciprocal of the purchasing power of the dollar expressed in terms of this assumed unit. The product $P \times K$ is, accordingly, the industrial flow expressed in terms of dollars (272).

The relation of the monetary to the industrial flow is then expressed by the equation (270):

$$
V \times R=K \times P \text {. }
$$

In the application of this equation to prove the volume theory it is assumed that the annual traffic of merchandise $K$, as well as the rapidity of monetary circulation $R$, are determined by industrial conditions and eustoms and can therefore be considered as constants, leaving $V$ and $P$ the only variables. If, then, the volume $V$ is changed, it would follow that the price level $P$ must vary directly as the volume $V$ varies; otherwise the equation would not be satisfied. Newcomb therefore concludes:

that the rise in the price $P$ would be proportional to the increase in the total volume $V$ of the eurreney, ${ }^{32}$

and this leads to the proposition (351) :

When the volume of curreney fluctuates, other conditions being equal, the purchasing power of each unit of money varies inversely as the whole number of units, so that the total absolute value of curreney remains unaltered by changes in that volume.ss

This is the very essence of the volume theory. On further analysis, however, Neweomb's conclusion will be found to be invalid.

120. Newcomb's Reasoning Analyzed.-It is, of course, necessary to properly circumseribe the compass of the terms of the equation. In the industrial flow $K$ are to be included only such sales of goods and serviees as are settled sooner or

Sewcomb, p. 346. ss Ibid., p. 346. 
later through payment of money. Those sales which are never paid for must of course be excluded, and where sales and purchases are set off against one another and therefore are virtually barter, only the balance of the transactions which is settled by actual payment of money can be included in the factor $K$.

The monetary flow here considered must be regarded as consisting only of such payments as are made for goods and services, exclusive of all other monetary movements. While the volume $V$ is to consist of all the money in use in the country, including both currency and bank credit subject to check, the quantity $R$ must here be computed on basis of only those movements of money which make up the monetary flow as just defined. This precaution is necessary, as there are monetary movements which cannot be included in the present considerations. The repeated transfers of money in the form of checks from bank to bank in the course of clearance as well as the transfers of money between lenders and borrowers constitute a flow of money which is extraneous to sales or commodity exchanges of any kind and which must therefore be excluded from the monetary flow of Newcomb's equation (245).

But even with these qualifications the equation is true only if we leave out of consideration the fact that goods delivered and services rendered are to a large extent paid for at various periods after delivery (270). Only a portion of the purchases made within a given week are paid for at the time, while, on the other hand, purchases made months before may be paid within the week in question. It cannot, therefore, be said that within any one week, month or year the industrial flow must equal the monetary flow.

When taken with the qualifications above indicated, the equation itself is beyond dispute. But the same cannot be said of the conclusions derived from it. It is inadmissible to assume the quantities $K$ and $R$ to be independent of the volume $V$, for it can be shown that it is the price level $P$ which is independent of $V$.

But let us follow Newcomb's logic. 
He first argues that the rapidity $R$ of the monetary eireulation, although

not fixed by any precise law, . . . yet can only clange between very narrow limits. ${ }^{34}$

He clearly shows that, by reason of certain business eustoms and of the praetice of paying wages and salaries at stated periods, the rapidity of circulation cannot materially exceed a certain rate, and to show that it will never be much less than this rate, he says:

Every man feels that he is losing possible interest on his money by keeping it and therefore tries to pay it out for something as soon as he advantageously can..$^{30}$

This statement requires qualification. There exists a well defined and widely prevalent reluetance to pay out money, and a corresponding desire to hold on to it for use in possible emergencies. Beyond that, there is a tendency to put out money at interest, either through the purchase of bonds, mortgages and so forth, or, as is the ease with the vast number of minor traders and wage eamers, to place it at interest in savings banks. But it is only the disbursements of money for goods or services, and not the putting ont of money in any form of loan, which makes up the rapidity $R$, for, as we have just observed, the movements of money between lenders and borrowers must be excluded from consideration in Neweomb's equation. While there is unquestionably a superior limit to the rapidity of circulation, though not sharply defined, there can be no inferior limit. While the rapidity camot well exceed a certain rate, there is no obvious reason why it cannot fall considerably below this maximum. In the course of our investigation we shall learn the reason why this rapidity is at present maintained near its highest possible rate (291).

Regarding the volume of traffie, Newcomb argues in brief as follows:

The societary cireulation, or volume of traffic $h$, depends upon the volume of production, which, in turm, is limited by

* Newcomb, p. 342.

shid., 1. 324. 
the increasing irksomeness of work as the daily time of labor is increased. ${ }^{36}$

At a later point he remarks in this connection :

As a general rule the actual exchanges will not vary rapidly so long as things go on in their regular way. . . . As already shown, there is a certain amount of these transactions which is most advantageous, and in which everything goes on as nearly as possible to every one's satisfaction. ${ }^{37}$

The postulate that the volume of traffic $K$ depends on the volume of production requires qualification, inasmuch as traffic may increase or decrease independently of the amount of the goods that are produced. The same product may be sold repeatedly, entailing a corresponding increase of the traffic. Through improvements in the arts which bring about a more minute specialization in the methods of production, products will enter into traffic a greater number of times on their way to maturity, and while each transfer in the course of production adds to the volume of that traffic which entails monetary cireulation, it does not add to the volume of the final products (121). Hence there is no superior limit to this flow, unless we assume that we have reached the acme of industrial progress. Nor is there an inferior limit, for we know that during periods of business stagnation not everything is going on to every one's satisfaction, and the industrial flow is very much less than what is most desirable for the well-being of men.

It is therefore manifest that there is no valid basis for the assumption that the quantities $R$ and $K$ are constant terms of the equation and accordingly independent of the money volume $V$. Nor can the assumption that the price level $P$ is dependent on the volume $V$ be logically sustained. It is indeed wholly inconsistent with the teachings of the same author in an earlier part of his treatise. In the discussion of gold money he clearly demonstrates that the value of the gold contained in the money is that which imparts value to it. In his elaboration of the volume theory he 
reaches the conclusion that "paper" money obtains its value from a radieally different source and that it is the volume of eurreney that determines its value.

Since it is clearly improper to eonsider $R$ and $K$ to be constant factors of the equation stated, and $P$ to be a variable factor in it, the conclusions based on these assumptions are untenable.

I2 I. Valid Deductions from Newcomb's Equation.-It is to be observed that the volume theory is advanced only in diseussions of the subjeet of "paper money," and never when standard eoin is the theme. The volume theory was probably coneeived in an effort to aceount for the fact that the eurrent value of eredit money exceels the value of the substance of which the tokens are made, and sinee gold coin does not exhibit this feature, there would appear to be no need of introdueing the volume theory when the value of standard money is the subject of discussion.

But let us examine the effect which a change of the volume of gold money has on its value. Suppose that the total existing supply of gold for both industrial and monetary use be equal to $O Q$ of the diagram Fig. 11, and that the portion $O V$ of this gold had been taken for monetary use. If the volume of gold money were now to be increased, it would be neessary to transfer more gold from the industrial to the financial field, increasing the volume of gold money at the expense of the stoek of gold in the general market. The point $V$ would thereby be shifted toward the point $Q$, and the market value of gold would rise, that is to say, the general price level wonld fall, a conclusion which is in direct opposition to the volume theory. It therefore follows that this theory, if it is at all valid, can apply only to credit money.

The only logical derivations, then, to which Neweomb's equation lends itself, are the following:

Any increase of the volume of erelit money will, if anything, increase the demand for grold, beeanse of the greater quantity of the metal required in reserve. This increase of demand would maturally canse an increase in the value of 
gold, which means, of course, a fall in the general price level, instead of the rise that should take place according to the volume theory (239).

It may, however, be tentatively assumed that this influence is negligible and that the value of the precious metals remains unaffected by changes in the volume of credit money. The factor $P$ of the equation remains accordingly constant, and if the volume $V$ is changed, only the factors $R$ and $K$ can respond to such change.

Let us suppose, to begin with, that the volume $V$ is increased. The price level $P$ remaining practically unchanged, the result will be a decrease of the rapidity of circulation $R$, or an increase of the traffic $K$, or both. If the flow $K$ is not increased, then there will be more money for the same amount of business; every dollar will have less work to do and will not go round so fast. But if the traffic is increased-which does not necessarily imply an increase of the products taking part in the flow, as it may also be due to multiplied transfers in the course of increased specialization in production (120) - the rapidity $R$ may remain the same as before.

Let us suppose that on the other hand the volume $V$ is reduced. This would have the effect of either increasing the rapidity $R$ or of reducing the traffic $K$.

But the rapidity of the monetary circulation cannot be materially increased, inasmuch as under existing conditions it is always at or near its practical maximum (291). Therefore the only result which would follow a reduction of the volume $V$ would be a corresponding reduction of the flow $K$, in other words, a cutting down of the amount of business. We have indeed ample evidence on every side that, whatever the volume of traffic may be, it is rarely, if ever, up to the existing capacity of production. Not only are producers constantly seeking new markets for their surplus products and clamoring for protection of the home market against outside competition, but a condition of enforced idleness among producers is frequently manifest. The most significant conclusion derivable from Newcomb's equation is that a restriction of the volume of money, instead of preventing an inflation of prices, really 
prevents an expansion of business, and this conclusion will find confirmation from other points of view further on in our discussion (270).

The equation of industrial and monetary circulation manifestly fails to prove that prices rise or fall in the proportion in which the volume of money is inereased or reduced.

122. The Volume Theory in the Light of History.-From a purely theoretical standpoint the volume theory clearly lacks proof. But it may perhaps appear to be substantiated by experience, by history, by facts. The question to be determined is this: Is there, or has there been, a "money unit" which differs in value from the adopted "commodity unit?" With reference to standard money this question takes the form: Can the value of standard coin fall below or rise above the value of the metal it contains? And with reference to eredit money it takes this form: Can a money token redeemable in a stated amount of gold have a value different from that amount of gold? In short, can a "dollar" be anything else than the stated amount of the standard commodity?

Let us test this question in the light of history.

Since the resumption of specie payment in 1879 the value of one dollar of currency and the value of 23.22 grains of pure gold have remained equal. The trifling fluctuation of gold in the London market, in which the value of gold bullion is never above the value of the coined metal, does not prove the contrary, for reasons presented before (109). There can be no doubt that the value of the metal gold follows the same law of supply and demand that determines the value of other commodities, and if the value of the dollar were determined, not by supply and demand of gold, but by supply and demand of money, the continued parity above noted, notwithstanding the fluctuations to which both are eonstantly subjeet, would eertainly be a case of most remarkable coincidence.

However, this continued parity of curreney with gold is held to be explained on the basis of the volume theory as follows :

Suppose that in a country in which the amount of money required by its commerce is fully supplied by standard coin, 
a certain amount were added to the currency in the form of paper money. The volume of money being thereby increased, the value of the dollar would be correspondingly reduced. The value of the coined metal, in its capacity as money, being then less than the value of the same metal as a commodity, coin would be withdrawn from circulation and the gold turned into the market as merchandise. As the volume of money would thereby be reduced, the original ralue of the dollar would be restored as soon as the amount of coin withdrawn would equal the amount of paper money previonsly added, and, for the time being, a further diversion of the coined gold into the industrial market would come to a stop.

Each new addition of paper money would have a like effect, until all gold is displaced by an equal amount of paper money. Should the infiltration of paper money into the system of currency be still further continued, one of two things would happen. If the notes were of the redeemable kind, their reduced value for money purposes would result in notes being presented for redemption, and in the gold so obtained being diverted into the market where its value is greater. Hence there would again follow a reduction of the rolume of currency to the original amount, namely the amount required by the commerce of the country. But if the notes should be of the inconvertible kind, the depreciation of the dollar due to the increased volume of eurrency would persist; in other words, prices, in obedience to the volume theory, would permanently rise. ${ }^{38}$

This argument is put forth to elucidate how it is that, so long as there is no excessive issue of "inconvertible" notes, the dollar of currency is maintained at parity with 23.22 grains of pure gold, notwithstanding that the value of gold is determined by its own supply and demand, while that of the dollar is determined by the supply and demand of money. It is averred that whenever the value of the dollar of money rises above the value of 23.22 grains of gold, it would become profitable to convert gold into money by bringing it to the

${ }^{38}$ Cf. Mill, II, p. 89 ff., and Newcomb, pp. $413 \mathrm{ff}$. 
mint, until the resulting reaction would restore parity. And whenever the value of the dollar of money were to fall below the value of 23.22 grains of gold, a melting down of coin would ensue until parity is restored.

I23. The Volume Theory Inconsistent With Facts.-The above aceount of what happens when "paper money" is added to the existing eurreney is not in aceord with experience. The market price of gold bullion, if it differs at all from the coinage value of gold, is invariably below, but never above the latter (109). The assumption that the value of standard eoin ean fall below the market value of gold is totally unwarranted. A general disposition to melt down standard eoin has never been observed to attend the issue of redeemable paper money. Coin has disappeared from cireulation only when paper money was put out without provision for its redemption, resulting in its depreciation. And under these eireumstanees the eoin did not disappear gradually, as more paper money was being issued, but praetically all at once. The reason is obvious. When debtors are free to pay their debts in any of several ways, they naturally choose the easiest (112). Hence only the least valuable, the depreeiated eurreney, remains in cireulation. The oft-quoted and frequently misapplied "Gresham law" is really a formulation of the fact that debtors naturally select the easiest mode of payment, if they have the legal right to pay their debts in more than one way.

If it were true that the purehasing power of the dollar depended upon the demand for and the supply of money, there would be no need for adopting a value mit consisting of either gold or silver. ${ }^{39}$ We know, however, that every unit, whatever its origin, whether the outgrowth of eustom, the result of eonvention, or the ediet of authority, must be something more substantial than a mere name and must somehow and somewhere have its magnitude definitely and authoritatively reeorded in order that it may serve its purpose. But according to the volume theory the measure of the unit of

as 'This corollary of the volume theory has been made the basis of many schemes of fiat money, some of which, as history records, have been put in practice with disastrous consequences. 
value automatically adapts itself to circumstances, and this is unreasonable on its face. And, moreover, that theory suggests nothing to throw light on the source of the value of paper money which, so far as it exists, must be traceable to wealth held by some debtor $(68-69,92)$. It is no more reasonable to assume that value can be infused into paper money merely by the need for a medium of exchange, than it would be to suppose that utility can be developed in nature's raw products by the mere need of men for useful things. Paper money cannot acquire its value from the coin it displaces, for the metal of coins so displaced goes back into the industrial market and does not, like that underlying gold certificates, remain segregated as a pledge of the paper money.

The idea that paper money can have a value apart from the wealth or credit which underlies it is quite on a par with MacLeod's notion that wealth is created whenever a eredit instrument is issued; but, as we have seen (70), this assumption is unreasonable.

The volume theory can be scrutinized from another point of view. If the value of money is now inversely proportional to its volume, it must be possible to show how and when that relation was first developed. Our review of the evolution of money (107) is in every way borne out by historical records which show that in the early stages of that evolution the value of money was neither more nor less than the value of the commodity used as money. And when paper money, such as the certificates of the goldsmiths, came to take the place of the commodities previously in use, the value of that money was still dependent on the value of the commodity to which those paper tokens conveyed a claim. The collapse of so many historic schemes of credit money was invariably due to the failure of the issuers to recognize the moncy tokens as acknowledgments of debt which must be directly or indirectly redeemable in actual wealth or valuable services and which, in order that redemption be assured, must be fully secured by wealth possessed by the issuer.

If it were true that the value of money is now determined in some other way, there must have been some time when the 
remarkable change took place by which the value of money, instead of being dependent on the value of the metal of which it was composed, or of the wealth in which it was redeemable, became dependent on the amount of money in circulation. When did money cease to be either an already existing commodity used as a go-between, or a certificate conveying a claim against its issuer? At what point of its historic evolution did money become a specific commodity, the value of which was regulated by the supply of and the demand for a medium of exchange? Unless it can be shown how and when this metamorphosis took place, we must conclude that the volume theory of the value of money has neither an economic nor an historic basis.

The notion that the value of the "money unit" depends upon supply and demand of money is clearly traceable to a misinterpretation of the so-called "law of supply and demand," the very name of which is misleading (63).

I24. Seeming Confirmations of the Volume Theory.Whenever eredit curreney is in circulation at a depreciated value by reason of the deficient credit of the issuing power, it is easy to see that an increase of its volume will be followed by a further depreciation (239). Repeated experiences of this kind have conclusively proven the dependence of the value of such money on its volume. It is therefore not difficult to understand how men like Hume, Ricardo, Mill, Newcomb, and many others, who lived during times of such experiences, should have regarded the volume of money as one of the determinating factors of its value. They simply attributed the rise of prices following an increased issue of such notes to an increase of the volume of money as such, when it was really due to an increase of the volume of money tokens without a corresponding addition to the money substance. The result of such issue is simply that the same amount of the substance is spread ont among a greater number of claimants for it. They mistook an increase of money tokens for an inerease of money substance.

In further support of the volume theory the fact is often cited that prices have risen whenever the quantity of the 
precious metals in the markets of the world suddenly increased. Thus the epoch following the discovery of America, when large quantities of gold and silver were brought to Spain from the new world, and that following the diseovery of gold in California, were eharacterized by a general rise in priees. But these faets are in harmony with the commodity theory of the value of money and cannot, therefore, be cited as demonstrating the volume theory in particular.

I25. Minor Discrepancies of the Volume Theory.-In addition to the points already presented there are still other reasons which ean be adduced to show the unsoundness of the volume theory. With the mention of a few of them we shall conclude the discussion of this subject.

If the value of curreney tokens were in reality due to their usefulness as a medium of excliange, there would manifestly be no need to make any of the tokens of a precious metal. Since nevertheless some of those tokens are made of gold, these would naturally have a higher value than those made of baser metal, for the same reason that a wateh case of gold, although no more useful than one of brass, yet has a higher value.

Furthermore, when business becomes stagnated and traffic reduced, there is, aceording to the logic of the volume theory, a redueed demand for money. This would cause a fall in the value of money, that is, a rise in prices. But it is known from experience that the reverse is the case.

If it were true that the changes in the purchasing power of the dollar depend on nothing but the three factors: volume of money, volume of traffic and rapidity of circulation, so that the existing volume of money, through changes of the price level, always sufficed to meet the requirements of the entire traffic, in other words, if it were true that in the equation:

$$
V \times R=R \times P,
$$

the factor $P$ always automatically adjusted itself to the other three factors, the supply of money could never fall short of the demand. But it is well known that during periods of financial stringency the supply of money is decidedly below 
the demand, showing that, as a matter of faet, the priee level does not adapt itself to the needs of eommerce and that at times the demand for money to balance accounts arising from the preeeding "industrial flow" goes far beyond the supply of money (239). The very fact that there are financial crises disproves the volume theory.

It is remarkable that this untenable doetrine still exerts so potent an influence on monetary poliey. It is not that coin and eertain eredits have value beeause they are used as a medium of exchange, but, on the eontrary, they are usable as a medium of exchange because they have value. Money does not owe its value to the demand for a medium of exchange, nor to any law authorizing the issue of such medium, but exclusively to the value of that of which the money consists, be it the standard commodity gold, or credit expressed in terms of that commodity $(69,107)$. 


\section{PART II}

\section{DISTRIBUTION OF WEALTH}




\section{CHAPTER VII}

\section{THE PROCESS OF APPORTIONMENT}

126. Statement of the Problem.-In primitive society, where each man produces that which he consumes, there is no need for any apportionment; and where coöperative production exists only in the crudest forms, the fruit of labor can usually be shared directly among those who have helped. But where the processes of industry and commerce are speeialized, the division of the value produced among the various producers becomes more complicated. To be sure, the method of apportionment is simple enough, for it consists in selling the things produced and sharing the proceeds of the sale, but how the various shares are determined is the question now before us.

In the modern system of production labor is specialized to such an extent that, as a rule, any one individual performs only a small part of the work necessary to produce a given thing. The labor of many enters into the production of almost every article, and the recompense of all those so contributing must, in the last analysis, be derived from the returns received from the consumer of the final product. While the portion accruing from any one article to any one of the contributors may be very small, the volume of production readily accounts for the aggregate income of each produeer.

If we were to attempt to trace the eurrents of the distribution in cletail, we would soon be lost in a bewildering maze of ramifieations. But through it all there are apparently at work some dominant economic forees that regulate the apportionment, and it remains for us to study the aetions, reactions and interactions of these forces as they come into play in the course of the process of production and the division of the products.

127. Modern Industrial Methods.-In the processes of production practically all goods pass through a series of intermediate stages between the natural state of the materials and that of the finished products, in eaeh of which the produets 
appear as articles of merchandise, as for instance wool, yarn, cloth, coats. Each change from one stage to the next is effected by effort applied in some special process or operation, sometimes performed by a single worker, but more often by a group of coöperative workers (211).

The several processes by which production is accomplished may be consecutive or collateral. Consecutive processes may be excmplified, in the case of making a coat, by sheep raising, shearing, baling of the wool, transporting, spinning, dyeing, weaving, sewing and selling. But numerous collateral processes are equally necessary. For producing a coat the sewing thread, the buttons, the lining are required; the chemicals for dyeing must be prepared; the various machines for baling, spinning, weaving and sewing must be built; means for carrying the wool to the factory and the eloth to the tailor are also necessary. The enumeration of collateral operations might be continued almost indefinitely, and every contributing group is entitled to its share of the value of the finished product. But even so, we have not come to the end of our analysis. As already stated, each of these operations is usually effected by a group of individuals who work in coöperation toward a common end, each one performing a different task. In these groups we find employers and employed, landlords and capitalists, who, together with the contributing groups, obtain their respective incomes through the sale of the products and the sharing of the proceeds.

This analysis of the modern system of production suggests the line we must pursue in studying the apportionment of incomes. We have to learn how the proceeds from the sale of the final products are shared among the several groups which perform the various operations of production, and then, how these shares are divided within each group among its individual members $(151,154)$.

In order to clearly understand what it is that determines the relation of the respective shares we must first become acquainted with the several factors of production, with the organization of productive groups and with the principal forces which come into play. Among the factors of production, 
namely labor and capital, it is particularly the nature and function of capital with which we should make ourselves familiar. Since the organization of productive groups should here be studied in relation to the distribution of wealth, an analysis of that organization may well be preceded by a classification of the various shares into which the value of the total product is divided. A subsequent study of the forces which, as factors of competition, are active in governing the division of that value will prepare the ground for a clear understanding of the processes through which that division is effected.

I28. The Factors of Production.-Labor is the only active factor in the process of production, but it is quite generally held that land, capital goods and money are to be classed as productive factors, especially as it is known that, like labor, they command a share of the value produced. There are, however, some writers who argue that since land furnishes gratuitously the material for all our wealth, and capital goods are the result of labor applied to land, labor should be the only factor recognized as a productive agent. In view of this controversy regarding the respective functions of land, capital goods and money in the process of production, the nature and function of these factors should be subjected to full examination.

I29. What is Capital?-For the purpose of learning the precise nature of the service which capital renders in the processes of production and for which it obtains a share of the product, we must get a clear idea of what is to be defined as "capital."

As popularly applied, this term has remained comparatively free from ambiguity. It is only at the hands of academic analysts that different meanings have been attached to the term. In business parlance capital is that portion of wealth which is employed in the processes of production and exchange and so "earns" a revenue. Through being utilized by a group of workers, wealth renders a service for which it obtains a 
return, and it is this apparent earning power which distinguishes "capital" from mere wealth $(267,319)$.

This conception of "capital" is embraced in the definitions advanced by Adam Smith and by Jean Baptiste Say. According to Smith, capital is that part of a man's wealth which he expects to afford him a revenue. Say considers the term to embrace all pre-existing requisites to production.

r3o. Land, a Form of Capital.-After Ricardo had promulgated his law of rent (172), some writers thought it desirable to exclude land from the compass of the term "capital." It appeared that the line of reasoning by which the power of land to return rent was explained was not applicable to explain the power of other forms of wealth to return revenue. This led John Stuart Mill to confine the term to that portion of the accumulated produce of labor which is utilized for further production. ${ }^{40}$ When capital is so defined, land is obviously excluded, not being a product of labor.

This constitutes a departure from the popular conception of the word. The capital of a mining corporation, or of a railway company, or, indeed, of any business concern owning real estate, includes land as well as all other forms of capital owned by the company. But Mill evidently recognized that the "capital" of the business world contains various classes of things that are economically heterogeneous, and he thought it proper to separate them so as to clear the field for a theory that was to account for interest.

However, this definition did not seem to satisfy him, for he qualifies and modifies it by copious illustrations and finally concludes :

All funds from which the possessor derives an income, which income he can use without sinking and dissipating the fund itself, are to him equivalent to capital. ${ }^{41}$

This conception of capital is manifestly at variance with Mill's primary definition, for funds can be invested in land as well as in other ways. It appears that he conld not divest himself of the conviction that the faculty of wealth to earn a revenue is that which makes it "capital." 
But with land excluded from the category of "capital," the term still denotes two difierent classes of things, namely capital goods and money $(134,203)$. The essential diflerence between the two latter is seldom given due consideration, it being generally held that money eommands interest because capital goods, obtainable for the money, afford a revenue (138), while in reality the interest commanding power of money has an independent origin (188, 209-210).

I3I. The Three Forms of Capital.-The reason above adduced for excluding land from the eategory of eapital can hardly justify a departure from the current popular usage. We shall therefore adopt the customary way of considering land as being, like all other wealth that retums a revenue, a form of eapital; but at the same time we must not lose sight of what this entails, namely that "capital," under this definition, includes three classes of wealth, each of which must be considered separately when their faculty to yield revenue is to be analyzed. They are land, capital goods and money, the revenue derived from them being distinguished as rent, capital returns and money interest. Revenue-yielding rights, like franchises and certain monopolies, are generally classed as part of the capital of a business organization, but as we shall later make a special study of this kind of eapital, we shall for the present leave it out of consideration.

These three forms of capital, though deriving in totally different ways their power to afford a revenue, are nevertheless closely related, as is indicated by the fact that the rate of net returns from land, from capital goods and from money is practically the same. It is for this reason that these three forms of wealth may logically be classed as "capital."

In studying the way in which each of these forms obtains its power to command a revenue, we must accordingly seek not only for the origin of that power, but also for the reason why the rate of net returns from all of the three forms is the same $(181,185,258,267)$.

132. Classification of Capital Goods.-The seeond form of eapital, namely capital goods, may be subdivided into two classes. These are things in course of production and things which are means of production $(152,186)$. The customary 
division into "floating" and "fixed" capital is confusing, since floating capital is considered to include not only goods in course of production, but also money, and money cannot properly be classed as capital goods.

In this classification goods in course of production embrace such things as iron while being shaped into a loom, or yarns while being woven into cloth. Their value increases during the operation. Among means of production are classed the things which are being used in the process without becoming bodily incorporated in the product, like the building and equipment of a factory, the coal, gas, oil, and so forth, used in running the plant. The value of these constantly diminishes or entirely disappears. But the value so disappearing from the means of production is not lost, for it is imparted to the things in course of production, so that the collective value of means and products actually increases as the work proceeds (133). It has already been pointed out (10) how the potential utilities with which means of production have been invested by past labor are converted into actual utilities of the goods that are being advanced to completion. Figuratively speaking, goods in course of production absorb not only the labor applied to them, but also a portion of the labor previously spent in the making of the means of production. The cloth is the result, not only of the labor that produced the yarns and the labor necessary to change these into cloth, but also of a share of the labor spent in erecting the factory building, in constructing the machines, and in producing all other supplies required for carrying on the business. For the same reason that yarns are considered to be garments in course of production, a loom on which the cloth for, say 50,000 suits of clothes can be woven should be viewed as 50,000 suits of clothes in a partly finished state.

Capital goods, in whatever form they may be, are, accordingly, immature goods, namely goods which are the embodiment of past labor, to be utilized, through future labor, for producing consumable commodities (191).

I33. Active and Idle Capital.-It goes without saying that land can return rent only while in use, and that capital goods 
will yield a revenue only while being forwarded toward maturity. If they are allowed to remain unused, the "services" for which rent and eapital returns are held to be due are not rendered, and these incomes do not accrue.

As a rule, capital goods are in use only while labor is being applied to them in the process of production. This, however, is true only in a general way. In the production of many things there are periods when aetive operations must cease in order that the process may take its proper course. Wine is stored for years for the purpose of ageing. Agricultural produce in course of cultivation can be worked upon only at varying intervals, and after harvesting some of it must be kept in store so as to be available in the interval between seasons. Manufactured goods remain in store for a certain average time before they reach the consumer. During these periods all these various things are actually undergoing advancement toward ultimate use.

During the entire period required for production the things that are being forwarded toward consumption gradually increase in value. According to experience this growth of value is ordinarily such that, after the labor applied is requited, a difference still remains which in general is proportionate to the amount of eapital and to the time during which this eapital is employed (203). This remainder is the compensation that goes to eapital. Only when interruptions neeur in the maturing process, or when the time of this process is uselessly prolonged, does eapital cease to get a return. Capital is thus recognized in two states of existence; in the one case as live, cmployed or active eapital, in the other as dead, unemployed or idle capital.

In the usual course of affairs the purpose of acquiring capital goods is to "employ" them by advancing their unripe utilities toward maturity. The eloth manufacturer buys looms, yarns and other supplies to the end of produeing eloth. The merchant buys this cloth in order to retail it to his eustomers, and when he sells it, it is economically advaneed by his effort and is greater in value than when he bought it. At each successive transfer capital goods appear in a more advanced stage 
and possess a higher value (132), until, at the last exchange, they pass into the hands of the consumer as final products at their ultimate value.

I34. Money is Always Idle Capital.-In this very respect money differs absolutely from capital goods (130). Money does not undergo any transformation between exchanges (203). It remains unaltered, both in its economic condition and in its value expressed in terms of the value unit, and for this, if for no other reason, must not be confused with capital goods. It would in fact be worthless as a medium of exchange if it were otherwise. The gold which forms the reserves of banks and of the world's treasuries is locked up in vaults, thus being held from industrial fields where it could be utilized like other commodities. Unlike the value of capital goods, that of money camnot be increased by either being worked upon or put in store; it cannot bring a revenue to its actual possessor. Considered in this light, all money is manifestly idle capital, and as such must be distinguished from capital goods, if the investigation of the cause that gives to money the power to command interest is to be intelligently pursued.

This distinction has been clearly recognized by many writers who, however, have failed to realize that for this reason money is a kind of capital which is radically different in its economic aspects from capital goods (188, 267).

According to Adam Smith :

Money, the great wheel of circulation, the great instrument of commerce, like all other instruments of trade, though it makes a part, and a very valuable part, of the capital, makes no part of the revenue of the society to which it belongs. ${ }^{42}$

\section{John Stuart Mill says :}

Money cannot in itself perform any part of the office of eapital, since it can afford no assistance to production. ${ }^{4}$

According to A. F. Walker:

It is true that money does not beget money, but capital does manifestly beget capital."

$$
{ }^{42} \text { Smith, p. 220. } \quad{ }^{43} \text { Mill, I, p. } 83 . \quad * \text { Walker, p. } 96 .
$$


Simon Newcomb asserts :

The money serves the banker no useful purpose until he passes it to someone else, perhaps a customer. Everyone into whose hands it falls must be paying or losing interest on it while he keeps it, and he cannot gain the interest until he purchases an ownership in some form of actual capital. ${ }^{45}$

It is evident that these authorities clearly perceived the distinction between money and actual capital or capital goods. Nevertheless, when they come to examine the nature of interest on money loans, they quite overlook the significance of the distinction which they so clearly point out (210).

I35. The Conception of Capital as a "Fund."-The fact that eapital returns a revenue has led to the conclusion that eapital has not only the faculty of maintaining itself, but has actually a power of increase. This proposition is, however, clearly inapplieable to the individual things of which the eapital of a productive group consists. Thus, for instance, the buildings and equipments of a factory do not increase in value; on the contrary, they constantly deteriorate and accordingly become less valuable. When the power of capital to increase is in question, the term "capital" can have reference only to the things that collectively make up the capital of a productive group. This has given rise to lengthy dissertations on the diserimination that should be made between capital considered in a "concrete" and capital considered in an "abstract" sense, or, more correctly, hetween capital goods as such and capital considered as a "fund." In colloquial language the term capital is indeed used in both senses, and it may be of advantage to point out the difference so as to prepare the reader to avoid misunderstandings by confusing the two concepts.

Even when considered as a fund, it is elear that capital must at any moment consist of certain definite and tangible things. The designation "abstract" is therefore inappropriate. There is no difference, at any given moment, between capital viewed as a fund and the things constituting that capital, except as a matter of dialecties. A certain fund may

*. Neweomb, 1. :896. 
at a given time be invested in a cloth factory and thus momentarily consist of the factory building, the looms, the yarns. But at another time it may be invested otherwise and yet bc the same fund. A difference between the two ideas appears only when the identity of a given capital, in the course of its existence, is followed up either in a physical or in an economic sense.

Suppose a man owning a ranch stocked with cattle wishes to dispose of it and to invest, instead, in the fruit trade, a steamer engaged in that enterprise having been offered him. He finds a purchaser for his ranch and, with the money so obtained, he buys the steamer and engages in the fruit trade. We are here dealing with three quantities of capital of equal value: (1) a cattle ranch, (2) a sum of money, and (3) a fruit-laden ship. Viewed in a physical sense, each of these three aggregates of wealth has its independent existence. The ranch, the sum of money and the vessel remain a ranch, a sum of money and a vessel, irrespective of who owns them.

But now suppose the ranchman views his possessions as a fund. On the first day his capital consisted of a stocked ranch. On the second day he possesses in its place a certain sum of money. The third day finds him the owner of a ship. His fund of capital was twice converted. In the end the fruit vessel is to him the same fund that originally existed in the form of the ranch, only differently embodied.

Or let us consider a cloth manufacturer whose factory is stocked with the necessary machines, yarns and other supplies, and who has an adequate bank account, all of which together constitute his capital. A week later we find the yarns turned into cloth and the bank account exhausted by the payment of wages. In the place of yarns and bank balance the manufacturer possesses cloth. Upon selling this, he applies the proceeds to buy more yarns and to replenish his bank account, probably finding that he has made some profit.

Viewing the various things in their physical aspect, we observe the yarns converted into cloth and the money passed out into circulation by the payment of wages. Then we see the cloth sold for other money, some of which is passed out in 
buying a new stock of yarns. The manufacturer parts with soine capital goods and acquires others; he pays out some money and receives other money.

When eapital is viewed as a fund, its physical composition may undergo a radieal change from time to time, either by way of exchange, as in the case of the rancher, or partly through produetive processes and partly through exehange, as in the case of the cloth manufacturer. The physical identity is lost, but the fund is economically identified from day to day by the fact that in the course of production and exehange the things constituting it have taken the place of the things of which it consisted before. In the rancher's fund the ship took the place of the ranch, yet it is the same fund it was before; it is still his "capital." To the eloth manufacturer the eloth at the end of the week is the embodiment of the same fund which at the beginning consisted of yarns and a certain bank account. And after selling the cloth and buying a fresh stock of yarns, he may find his bank account to exceed that which he had at first; his fund of eapital grew as a flock of sheep might have been increased through the birth of a number of lambs.

We know from experience that capital invested in production and commerce ordinarily does increase in this manner, or, as would appear, "earns"' a revenue. In various writings J. B. Clark points to the fact that means of production, when in use, lose in value, while at the same time their owner reaps a profit from them, and that accordingly this profit is yiclded, not by capital goods, but by capital viewed in the abstract sense. He therefore coneludes that the problem of interest can find its solution only by tracing the relation of eapital, considered as a fund, to the proeess of production, and that interest consist of the earnings of the instrument procured by the employer with the final increment of borrowed capital. But a bricf survey of the subject makes it clear that the interest problem is not different whether capital is considered in the concrete or in the abstract sense. In either case the tangible wealth involved must be considered in the aggregate. In the process of production the goods that are 
being advanced toward maturity increase in value while the means of production depreciate, and the increase in value of the former exceeds the loss in value of the latter so much that the combined value shows an increase. The problem of capital interest thus resolves itself into the question: Why is it that the market value of products of labor exceeds the market value of materials, incidentals, depreciation of means of production and wages; why is it that the value of cloth exceeds the recompense of effort plus the outlay for yarns and for the maintenance of the plant?

136. Classification of Incomes.-In the modern system of production and distribution not only those who are actively engaged, but also the passive participants, those who furnish the land and other capital, share in the division of the proceeds. Incomes are therefore usually classified as wages, rent and interest; and to these some students of the subject would add business profits.

This classification of incomes has been handed down to us from the earlier economists, but is not as comprehensive as it should be. For the purpose of a more thorough examination economic returns should primarily be divided into two principal forms of income, corresponding to active and passive participation of the recipients, the one comprising wages, the other profits.

It is to be observed that these terms are here applied in a sense somewhat different from their colloquial meaning. The term "wages"' is to include all compensation for personal participation in productive effort, and "profits" is used in the sense of aequisition without such effort.

I37. Wages and Profits.-The term "wages," as. above defined, embraces every recompense for labor, whether physical or mental, direct or indirect. It includes all that a person obtains by useful work, whether he works alone or in company with others, whether he is employer or employed, artisan or merchant, lawyer or teacher. It is not restricted to what we customarily term wages, that is, the stipend allotted to manual labor; it embraces also salaries, commissions, fees, and espe- 
cially that which is so often erroneously called profit, namely the recompense for personal services rendered by the selfemploving artisan, the manufacturer, the merchant, the trader, the inventor. "Profits," on the other hand, are the acquisitions obtained in all other ways.

The merchant sometimes calls the excess of the retail over the wholesale price of his goods his profit. But from that excess he must defray the expenses ineident to his business and, in addition, must obtain something for his own work, namely his own wages; henee we must avoid eonsidering "profit" in this broad sense. Some writers, on the other hand, use the term to designate only the remainder of income after the deduction of all outlays and charges, including those for the use of capital and land. In the following pages "profits" are to be understood as exeluding all forms of compensation for personal participation and as ineluding all other forms of income, particularly rent of land, eapital returns and interest for money.

Considered in this light, wages are the recompense for active assistance in production, for "personal" services, while profits are the returns for passive participation, or for what may be termed "impersonal" serviees. The service for which wages accrue ean be rendered only by personal partieipation, while that for which profits acerue does not require personal collaboration. The absence of the personal element is exemplified notably where profits acerue to impersonal recipients, such as endowed institutions and trust estates.

138. Classification of Profits.-There are two distinet kinds of profits; the first kind are capital profits which are practically continuous or regularly recurring, while the second are chance profits, which are irregular and meertain. Capital profits are derived from the ownership of land, of capital goods, of money and of franchises, and are, respectively, rent of land, returns of capital goods, interest on money and incomes from franchises. Chance profits arise from fluctuation of prices, from incidental or accidental departures from the average condition of aflairs and from gambling in any of its forms; and they are likely to alternate with losses of like 
nature (224), in other words, they may be negative as well' as positive.

In the usual way of accounting for money interest a relation between it and capital returns is assumed which does not exist (130). It is generally held that the income which we here designate as capital returns or capital intercst is identical with money interest, on the ground that the lender of the money is virtually the lender of the capital goods obtained for it. We shall find later (209-210) that this view is untenable, and that it is necessary to distinguish capital interest from money interest and to deal with them separately in our analysis (188).

The various forms of income can accordingly be tabulated as follows (168):

Incomes.... $\left\{\begin{array}{l}\text { Wages. } \\ \text { Profits...... }\end{array}\left\{\begin{array}{l}\text { Capital Profits. } \\ \text { Chance Profits. }\end{array}\left\{\begin{array}{l}\text { Rent of Land. } \\ \text { Capital Interest. } \\ \text { Money Interest. } \\ \text { Incomes from Franchises. }\end{array}\right.\right.\right.$

I39. Gross Profits of Capital.-In common parlance the term "rent" means the stipulated charge for the lease of houses or of land, and "interest" means the stated charge for the loan of money. But if these stipulated charges are analyzed, they are found to be made up of several items, each of which is compensation for a different economic service. To avoid confusion, the common meanings of the above terms have been abandoned and the terms defined so that each shall be related to a separate cause. In discussions of economic topics the terms rent and interest are accordingly used in a more restricted sense. But as in our discussions we shall frequently have occasion to refer to economic rent and pure interest, and also to stipulated or gross rent and interest, we shall mark the distinction by these designations.

The rent agreed upon for the lease of a farm, for instance, depends not only on the location of the farm and the fertility of its soil, but also on the cost of repairs which the landlord is to make, on taxes levied on improvements, on the rate of interest as it applies to the value of the farm house or other improvements, and on other incidentals. But considered as a 
simple economic return, "rent" must be understood as meaning only those profits of the utilization of land which are derived from its inherent qualities, namely its location, its fertility and its other natural endowments (171).

We shall find that the profit derived from the use of these qualities, that is, the economic rent, while primarily obtained by the user of the land, ultimately goes to the owner. If the landowner himself is the user, he directly obtains the benefit of the rent, but if a renter uses the land, the economic rent figures as a part of the stipulated rent paid to the landowner. In general, any excess of the stipulated over the economic rent is due to conditions other than the natural endowments of the land, chiefly to improvements of whatsoever kind.

We must here not forget that all our conclusions relate to an average of general conditions. In individual cases the rent stipulated and agreed upon between owner and tenant may differ more or less, one way or the other, from that average. These variations must be regarded as being in the nature of chance profits or chance losses which are incident to all processes of production and exchange and therefore enter as items of the gross rent. Such variations of the gross rent as chance to be in favor of the landlord are tantamount to chance losses by the tenant, and vice versa, of course.

Inasmuch as these chance departures from average conditions balance each other in the grand total, they must be ignored in the discussion of general economic laws.

The income from the loan of capital goods is likewise of a composite nature. If a pleasure yacht is leased for a longer or shorter cruise, or a horse and carriage hired out for a time, the stipulated payment eovers three separate items. These are wages, compensation for depreciation and pure interest, which may be detailed as follows:

When something is leased, the lessor is usually obliged to perform some personal services. One portion of the hire constitutes the wages for such services. It covers the cost of cleaning, storing and repairing, of feeding, maintaining and housing, etc.

A second portion is to be accounted for as follows. The 
thing leased will deteriorate while in use. We know that it cannot be utilized forever, but that after a time it will wear out beyond repair. Its total capacity to yield services or to gratify desires is limited, and a portion of this capacity is consumed by the lessee. A lease virtually constitutes a partial sale of the total utilities of the object. Each lessee must therefore pay his share, so that by the time the object is worn out, taking in account its average duration, its value will have been restorcd to the owner. The second item, then, is compensation for wear and tear, also known as amortization. This portion includes the item of risk of accidental loss, which is accounted in the average durability (219). In any specific case the actual duration of a thing may be greater or less, but profits or losses due to departures from averages are to be classed as chance profits (215) and as such may be plus or minus.

The third portion of the stipulated hire is that further income, usually designated as interest, which constitutes the net return yielded by capital goods. This is the only item which constitutes a net income for impersonal services and figures as pure capital interest.

Periodic incomes, such as dividends on capital stock, which accrue to the owners of capital goods in use by productive groups apart from any personal participation of those owners in the active work of the groups, are in the main made up of two parts $(265 a)$, as follows:

First, inasmuch as capital which is in the form of means of production will deteriorate through use and so lose in value, a portion of the income returned to the furnisher of capital must cover this depreciation and also insurance against risk of its destruction, partial or complete, by accident or otherwise. Of course, if this portion, instead of being included in the periodic payments to the owner of the capital, is applied to maintain the value of the capital by repair, replacement and extraneous insurance, then the item covering depreciation will disappear from the periodic returus.

It should not be overlooked that the item of amortization is really a due payment by one group for the using up of 
capital goods that have been produeed by, and obtained from, other groups. Amortization is therefore merely a payment for material in the proeess of sharing the value of the final products among the contributing groups. It cannot be considered as value produced by the group which shares it out, and is therefore not to be counted as part of the value produced by and distributed within the group among its members $(143,265 b)$.

Second, the remainder, in point of fact, a considerable portion of the periodic capital returns, is what is known as interest yielded by eapital goods. It is only this item which can be considered as really "capital interest.",

The periodic returns accruing to money loans, namely gross interest, is also of a composite nature, being composed of three distinct items $(76,248,263 a)$. The first of these is recompense for labor and other costs involved in making and superrising loans. In the case of long-time loans, such as those on bonds and mortgages, this item is comparatively small. But in loans made by deposit banks it is considerably greater, as it must cover the expenses of carrying on the banking business, including the work of paying or clearing the ehecks through which commercial payments are effected (263b).

The second item is insurance against risk. In the case of money loans, as distinguished from loans of capital goods, the ement of deterioration is not present, since the loan must be returned by the borrower in the form of money and not in the form of a partially worn-out thing. But the element of risk of loss through shortcoming of the debtor is generally present in a greater or less degree (220), and the stipulated interest inclucles the item of insurance against such loss. It is this addition which induces the lender to assume the risk.

The third of the items which make up the compensation for the service of lending money is that which has been distinguisher as pure interest or interest-proper. 'This item is the net income of the lender, a recompense for strictly impersonal services. The origrin of the power of money to command this recompense will be fully discussed later (241-243). 
140. Gross Business Profits.-The classification of the several specific forms of income presented above in tabulated form has been made with respect to the services for which they are returns. The several forms of income may, however, occur in various combinations. A man's actual income may be composed of any or all of these specific elemental forms. Although in the case of composite incomes it is impossible to tell, in dollars and cents, just what portion is due to either of the separate kinds of services, nevertheless a dialectic separation is not only possible, but even necessary, in order rationally to analyze the distribution of incomes. A merchant, for instance, may be the owner of the lot on which his store is located, of the buildings and of all the other capital invested in his business. His annual net income will then consist of rent accruing through the more or less favorable location of his store; of interest returned by his other capital including money; of wages for supervising his business (168); and also of chance profits, which, however, are likely to alternate with similar losses. Where the element of monopoly comes into play, monopoly profits will also arise, but at the present stage of our study this element is assumed to be absent, as it will receive special attention later. Mention is sometimes made of another form of elemental income, namely "business profits," but as there is no form of economic service besides those already noted, and as there cannot be an effect without a cause, the existence of business profits, except as a composition of two or more of the elcmentary forms of income above enumerated, cannot be assumed.

That which in business parlance is usually called "profits" is, accordingly, composed of a number of items, of which only economic rent and pure interest can be specified as capital profits. A failure to recognize this has given rise to the notion that, as a rule, the rate of capital returns exceeds the rate of money interest, in other words, that money, when invested in business, generally earns more than when invested in loans, and that for this reason the borrowing of money with which to obtain capital goods, in other words, to put it in business, is profitable to the borrower. But this is true only where the 
chance profits of business exeed the chance losses, which, aeeording to the law of probabilities, happens no oftener than the reverse. This, of course, means that in the average chance profits and losses balance each other, and where there is an excess of such profits over losses, the excess must not be regarded as earnings of eapital, but merely as incidents of chance. Profits of this kind are apt to acerue most frequently during periods of general prosperity and are equally apt to be wiped out by an excess of chance losses during periods of depression. Furthermore, the belief that an excess of capital profits over eurrent money interest is the rule seems often confirmed by appearances. If a business man is unable to fully employ his ability by reason of an insufficient command of capital, an increase of sueh may render his work more produetive. Additional ineome from this eause is, however, not eapital profit, but, on the contrary, labor's earnings or wages. When all factors having bearing on the case are properly taken into account, it will be found that the average rate of returns from capital goods does not exceed the eurrent rate of interest on money loans.

I4I. Composition of Productive Groups.-The various incomes of individual members of a group are the recompense for their respective services. We have therefore next to elassify the members of the group with respect to the service or function performed by each, and unless we go into technieal details, which for our study is not necessary, the number of functions is very limited.

Inasmuch as a number of individuals are often engaged eonjointly in performing one and the same function, while, on the other hand, one or more of the members of a group frequently figure in several eapaeities, it becomes neeessary to disregard the persons and to treat only the functions as though each were performed by a distinct agent. In other words, we must personify the funetions. In this way we avoid the confusion which would ensue if we were to deal with individuals in their mixed capaeities.

Following the same line of reasoning that led us to the 
classification of incomes, we must separate the agents into two divisions, namely active and passive. The active agents are those who contribute personal services, while the passive agents are those who supply what we have termed impersonal services.

142. Active Agents.-The active agents in a productive group include the director or manager, the foremen and workmen, the clerks and salesmen. The manager organizes the enterprise, selects the methods of production, controls the purchase of the means of production and of the supplies, directs the workers and attends to the final disposition of the goods produced. The function of management frequently devolves upon a number of individuals, some of whom perform their part in the technical, the others in the commercial branch of the undertaking. In their combined capacity these represent the "manager." The workmen are specialized more or less, to suit the nature of the business. In this way the active agents are divided into two divisions, manager and workmen, though the line of separation is not always sharply defined.

The recompense of the active agents is wages, which may take the form of salaries, commissions, royalties, business incomes, or whatsoever may be the form in which personal services are compensated.

I43. Passive Agents.-As such must be considered the "capitalist" in his various phases and functions. These comprise the ownership of the land and the ownership of the capital goods and the working fund in use by the group, and also the ownership of any money that may be borrowed by the group. In addition to these we shall presently find that another function must be recognized as a passive agent, namely the "enterpriser" or "venturer" (144).

The land furnished by its owner may be a manufacturing site, a farm, a forest, an oyster bed, a mine, a waterfall, etc. The service of furnishing the land is compensated by rent (325).

The capital goods furnished by their owner consist of means of production, including all improvements on the land utilized, and all material of production and the working fund. The 
income from these capital goods, apart from the item of amortization (139), is what we have termed capital interest. When money is borrowed from a money lender, that lender becomes, for the time, a component of the capitalist (347), and in this case a portion of the capital returns goes to him in the form of money interest. In co-partnerships the function of capitalist is exercised in common by the partners. In stock companies not only the stockholders, but also the bondholders, considered together as a single economic person, constitute the capitalist.

We must here take care not to confuse the "capitalist" in the colloquial with the "capitalist"' in the economic sense (265a). Where, as frequently happens, the same individual is both capitalist and manager, we must distinguish between the two functions which he thus fulfils. As capitalist he is an investor, and as such receives capital interest; if he owns the ground, he is landlord and as such receives rent; and if he furnishes money to the enterprise, he is money lender, and as such receives money interest. On the other hand, in the eapacity of organizer or of manager he is not a capitalist, but one of the active agents of the group, and his recompense in this respect is in the nature of wages.

But the furnisher of capital fulfils still another function. The capital goods are as a rule the products of contributing groups, and when the capitalist furnishes them he is really in the position of a salesman representing these groups (265b). We have seen before that as furnisher of capital goods he obtains, generally speaking, two items, namely amortization and eapital interest, the first of which falls away if the capital goods of the group are maintained at full value by repair and replacement.

Let us take at first the case where the capital of a productive group constantly depreciates and where a corresponding amortization is due to the fumisher of the capital in addition to interest. The amortization acerues in the form of instalment payments along with other incomes from that group, so that by the time the eapital is finally used up, the entire value has been covered by the amortization items. These 
items are therefore payments for services received from extraneous groups and pertain to the apportionment of the gross income among those groups. Their recipient is in fact not a member of the group to which he has furmished capital. He becomes capitalist of that group only through his having to wait for those payments while permitting the use of his capital by the group before he is paid for it. Thus the item of interest accrues to him for the service of conceding the use of the capital while it is yet his property. Only in this capacity is he member of the group and becomes participant. in the sharing of the net income within the group.

The second case is that in which the amortization items are not withdrawn, but are applied to the maintenance of the capital by repair, replacement and full insurance against loss by accident. This case differs from the first only by an indefinite postponement of the payment of the principal. The capitalist retains ownership of the undiminished capital furnished, and he receives only capital interest. Of course, the question of chance profits or losses is here not taken into account.

I44. The Venturer.-We have already pointed out (61) that the normal market value of the products of labor equals the cost of their production, if we include in this cost not only that of labor, materials and incidentals at their market rates, but also all charges for the use of land and of other capital at market rates, and finally also the recompense of the employer's or manager's services at their market value. Thus, on an average, the gross income of a business which does not enjoy any special franchises or other monopoly advantages just covers all items of cost.

In practice, however, the actual income derived by any productive group from the sale of its products varies more or less from this average. It is sometimes greater, sometimes less than this cost, the difference being chance profits, which may be plus or minus. In every business these chances must be taken by some one who is in position to do so. A business man may acquire chance profits in addition to the wages of his own labor and the normal profits of the capital he has 
invested; or, on the other hand, he may sustain losses, and it may even happen that these are greater than his wages and capital profits combined.

In a complete analysis of the composition of an economic group we must therefore recognize, as a member of the group, one who assumes the business chances. This particular member we shall designate the "venturer"' $(143,219,224)$. It is true that in actual life this venturer has rarely a separate existence, his function being nearly always combined with that of either manager or capitalist or with both. ${ }^{40}$

If we were to single out the venturer as an individual divested of other functions, we would have to conceive him as one who, while having no capital of his own invested in the enterprise and taking no part in its management, is nevertheless its nominal owner. If the undertaking happens to have more than the usual degree of success and its income exeeeds the costs including rent and interest, the excess will go as chance profit to the venturer. But if it happens to be unsuccessful and the balance sheet shows losses instead of profits, the venturer must make good the loss.

145. Composite Agents. - We have now classified the elementary agents composing a productive group, so as to correspond with the several elementary forms of individual incomes. As already stated, some persons act in several different capacities, while some functions devolve on a number of individuals who are therefore to be considered, in an economic sense, as conjointly being a single person.

Many business men, and especially professional men, combine the position of manager, workman, landlord, capitalist and venturer in their own person. More frequently it hap-

"The terms "entrepreneur" and "enterpriser" have come into use to designate the organizer of an enterprise who also assumes the chances of success and failure and who, according to our way of analyzing the composition of productive aroups, represents two or three functions. He is organizer, venturer and usually also capitulist, at least in part. We liave chosen the term "venturer" in preference to "enterpriser" because the function we desire to desiguate is of an absolutely passive nature, while the term enterpriser is suggestive of activity and would therefore be apt to mislead the reader. 
pens that a business man, while manager and venturer, is capitalist only in part, he having borrowed part of his working capital or rented his place of business. If, in such a case, his debts equal his actual assets, he is not even capitalist in any degree. As manager and venturer his income is then confined to manager's wages and chance profits or losses, and if his business is unprofitable, his income as manager will suffer accordingly, for the loss must be made good from it.

In analyzing stock companies we find the function of manager to be held conjointly by the president and the board of directors, together with the superintendent, the foremen, etc. The "manager" is then a "person" composed of a number of individuals. The stockholders and bondholders combined constitute the "capitalist," but the function of "venturer"' is assumed only by the stockholders. The bondholders are part of the capitalist, pure and simple. If the company is solvent, they receive the stipulated interest income, no more, no less. But the share of the stockholders, taken all together, may be greater or less, according as the enterprise affords a profit over or under what would be derived from the same investment at the current rate of interest. In addition to their share as capitalist they come in for chance profits or losses, that is, for such balances as may accrue. be they plus or minus. Their minus balances may possibly wipe out or even exceed the item of normal capital returns, and in the event of adversity, they are even liable to the extent of the principal of their investment. In the liquidation of a stock company all liabilities, including the bondholders' claims, interest as well as principal, must be paid in full before any share accrues to the stockholders. In any case, such participants as are not included in the capacity of venturer will suffer loss only if the total share of those who are so included is insufficient to cover the loss. The loss, if such there be, falls primarily on those individuals who participate in the capacity of venturer, and on those otherwise interested only when the loss exceeds the holdings of the former.

146. The Employer.- We may here add a few words regarding the office assumed by the "employer." Considered in 
the economic sense, he can easily be conceived apart from the function of capitalist. But his position is inseparable from either manager or venturer. We shall, for this reason, use the term employer as embodying these two funetions com. bined. In this classification the employer as such is in no sense eapitalist, although in practice he who functionates as employer is usually also capitalist $(167,348)$.

The fact that the various funetions may oceur in various combinations offers no difficulty in the way of a separate examination of each of them in their relation to the process of production and the sharing of the value produced. We shall follow the classification already indieated, aceording to which the manager, the workman, the landlord, the capitalist and the venturer are separate and independent entities. Our purpose is to find how, and through what causes, the net income of the industrial group is divided into wages and profits, and how wages as well as profits are further divided and shared among the respective members of each group.

Nominally this division is determined by the employer. To all appearances he decides what wages to pay and what grade of goods to buy. He pays rent and interest from the funds available and fixes the priee at which the goods made are to be sold. This is, however, only apparently so. As the buyer of labor and of the supplies he must come to an agreement with the sellers. As a seller of the goods made he must meet the views of the buyers. All incomes and all expenditures of the group are in the last analysis subject to the law of supply and demand, to the inevitable action and reaction of competition.

I47. Competition, the Controlling Force-Among the forces which are active in determining the shares of the several partieipants in production, competition plays an important part.

There is prevalent a eonsiderable difference of opinion as to whether the influence of competition is wholesome or detrimental. While it is largely regarded as having the effect of hringing about an equitable distribution of the value produeed by industry, it is frequently held responsible for the fieree 
struggle between employers and employed, between capital and labor, between the rich and the poor, between the strong and the weak, giving an unfair advantage to those endowed with wealth or possessed of exceptional ability. This hostile view of competition is widespread and has given rise to volumes of legislation intended to curb the supposed undue powers of the rich and gifted. Fear of competition engenders the popular sentiment for "protective" tariff, for restriction on inmigration, for regulation of convict labor and the like.

In the face of such conflicting opinions we may well pause to inquire what the effect of competition really is, and why it is that views on this subject are so divergent (346).

Before any headway can be made in this direction, it is necessary to know precisely what competition really is. Literally it means an endeavor to obtain what others at the same time are trying to acquire. Thus, if a number of men seek to buy something of which the supply is less than the demand, there will ensue a bidding up among the buyers. On the other hand, if a number of men have for sale something of which the demand is less than the supply, each will try to sell his stock by underbidding the others. Whether the competition arises within the ranks of the buyers or of the sellers depends on the market supply of the particular thing in question in conjunction with the effective demand therefor.

Competition can be fully effective only where commercial and industrial freedom is in no way hampered or restrained; it becomes more or less inoperative where monopoly or other forms of restriction prevail. Since the effect of such restrictions will be the subject of a later chapter, we shall at present consider only such effects of competition as would follow under conditions of unrestricted production and exchange.

Under normal conditions each worker will choose that occupation which, according to his inclination, ability and opportunities, will yield him the best results. If, for any reason, the output of various occupations is not in proportion to the demand, the current prices of the varions goods will not be in proportion to the efforts of production. The desire of men to 
derive the greatest ineome from their labor will then eause an exodus of workers from the overerowded branehes leading to an adjustment, not only of the amounts produeed in all branehes, but also of the prices (343).

148. Direct Effects of Competition.-In the existing condition of any of the arts, industries or professions, the supply of its produets or serviees depends ultimately on the number of men employed in it, and this number is regulated in two ways: (1) by the enlistment of the rising generation in that particular trade or vocation and (2) by any subsequent change of oecupation, or, what we may designate as "migration" from that vocation to other's and vice versa.

So long as the recompense in all the different vocations corresponds in the main with the effort expended, there is no special inducement for workers to migrate from one to another, and although there may be some shifting of workers, the relative supply will remain unchanged. Should it happen, however, that some one field of activity appears to afford an advantage over the rest, especially if for some reason it offers more recompense in proportion to the effort required, an increased migration toward the more favored occupation will naturally ensue. On the other hand, if some one oecupation beeomes, for any reason, less remunerative than others, always considering the required effort, migration from it will predominate. The relative volume of supply in the more inviting branches will thus be inereased, while in those in which disadvantages arise to the produeer, supply will be lessened (221).

In this study the diagram may again be of assistanee. Suppose Fig. 2 be taken to represent demand and supply of a given commodity in a given market. If, then, for some reason, no more than the quantity $O q^{\prime}$ is produeed and offered in the market, the competition of the would-be buyers will raise the price to the final utility $q^{\prime} d^{\prime}$, while the marginal cost of production is $q^{\prime} s^{\prime}$. This constitutes an attraction that induees migration toward this partieular oceupation. Supply will therefore be increased until its amount reaches $O_{q}$, when marginal cost and final utility become equalized. If, on the other hand, the original supply is greater, say equal to $O q^{\prime \prime}$, 
the final utility $q^{\prime \prime} d^{\prime \prime}$ will be less than the marginal cost $q^{\prime \prime} s^{\prime \prime}$, and since a market for all of these products or services can be found only at a price equal to the final utility $q^{\prime \prime} d^{\prime \prime}$, the supply will be reduced, by migration from the respective occupation or by reduced enlistment of apprentices, until the normal amount $O q$ is reached.

The primary effect of competition is clearly a double one. In the first place, by drawing workers from one field to another, it tends to adjust the supply of each branch to accord with the relative demand (366) and, in the second place, it equalizes marginal cost of production and final utility, both becoming thereby determinators of price.

These conclusions clearly show the folly of the proposition, advocated by some socialists, to establish a statistical burean with power to regulate the amount of production in each trade, so as to avoid congestion of the market. Only free competition can properly and justly regulate the volume of production and exchange in the various branches of industry and commerce.

It will be remembered that the line $S S^{\prime}$ of Fig. 2 can appear as a rising curve only when the "sellers" price limit" is considered either from the standpoint of the land owners, or that of the capitalists, or that of the workers, whether employed or employers. In each case the curve follows a different course and has a different significance. In studying the effect of the competition of labor, in other words, the effect of the migration of workers from one occupation to another, on the volume of the supply of a given commodity, the curve $S S^{\prime}$ must be viewed as representing all the different price limits of the workers who contribute to that supply (61). The various price limits are determined by the earning capacity of the various workers in their various occupations of second choice, for it is only when the recompense afforded by different lines of employment changes so as to reverse the order of choice of some of the workers that migration from one trade to another will be prompted. The difference in the price limits of the different suppliers, represented by the various ordinates of the rising curve $S S^{\prime}$, is due to the fact that among the 
workers in the one pursuit presented by the eurve there are always some who can turn without disadvantage to some other pursuit, while the rest ean do so only with more or less diffieulty and at more or less loss. Those who are equally profieient in some other oecupation than that in question are the first to turn to that other pursuit whenever some eause for such ehange arises. It is these shifting workers who are the marginal producers in their particular pursuit.

Let us obtain a clear conception of what is really meant by the margin as regards labor.

Aecording to definition (62), the margin is where production is being continued at the greatest cost or under the most unfarorable eireumstanees; there the price limit or " cost", equals the price, as indicated at the point $a$ of the diagram. The marginal worker is he who is equally efficient in two oecupations. He was among the last of those who entered the ficld of his present employment when its advantages were rising, and is among the first to leave it when its advantages decline.

To recapitulate: Whenever the balance of advantages among the various pursuits is disturbed for any reason, only such workers as are at or near the margin are apt to turn from their oecupation to some other. Their oeeupation of first and second ehoice will have changed places. Migration from one field of effort to another takes place principally among the workers who are at or near the margin of proluction, as indieated at $a$ of the diagram, and this readjustment of workers is, as a rule, no greater than is sufficient to bring about a new balanee (223). It is through the marginal workers and those who are near the margin that the volume of supply is regulated, for it is they who shift from one oeenpation to another when the attendant circumstanees ehange.

Many economists consider that the laborers who reeeive the lowest wages are the marginal workers in all fields of production, but this is a mistake. The rate of wages per hour ol per week has no bearing on the position of the workers as regards the margin of production, for this rate measures only individual effieiency. Of two workmen in the 
sams mad one mar to quic and intelligent and mate high Teg-s. not only in that trate. but also in that wher wempaton so which be can turn. While the other, being slow and Aull. revires but low wages in that trade or in any other. Fer. buth ane at tha moroin if they can tum at will from one aremation to sume other. So are the workers who reveire high as well as thes who pecite low wages wihin the margin of the purstit in whin ther are engaged. if ther cannot turn

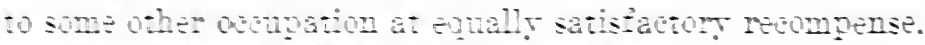

I49. Indiret Ëects of Competition.-If all men were

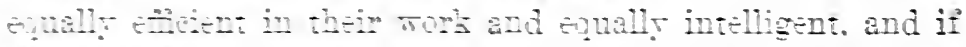

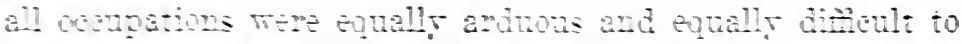
mester. In shor. if all lines of wort were alite as regards the

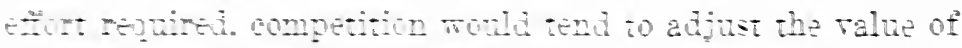
all grwuts so as to to propowionate to the time spent in pro-

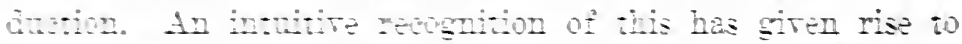
ite dowine that "labor is the real measure of value. " which was promigat:d b\% Adam smith and substuenty elaborated or Rieario. Mars. and others (30) $10 \div$.

But in premiss are not alogether in hamont with faets. Vot only are there all linds of ditterenees in the charartertites quelities and capabities of men. but in addition. some outuetions ane more irssome than others. or are more ditont to learm. or are expused to greater rish as regards sueves. on ame more dangerons io health and lite. The more arduns pursuits as mell as thos intolving greater rist are atois.j. and thos requing speial fiucation or talent are

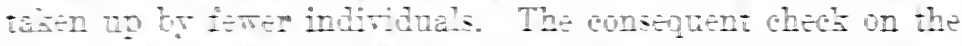
suppla of prowuts and sirvices in these pursuits tends to

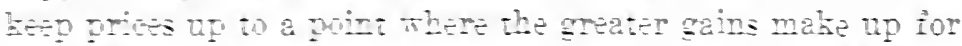

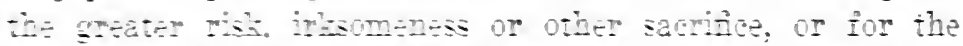

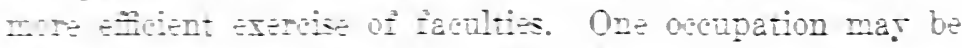
more remuneratie than another, but being more disagreecilউ. or more dengrous. or requing more time and effort For its master. a men mas turn to the less remuneratire purstit as his trst hotge 4 ). Thus it is not gain alone that is aken ints acoount in such selection. but a number of other iccors as nell. The difculty. irlsomeness and risk of any 
given occupation are reflected in the higher price of its products.

This proposition has a broad range of application, inasmuch as the difficulties in question may be of a most varying description, including even burdens of an artificial nature. If, for instance, a special tax is put on the production of a certain class of goods, their producers will naturally add this expense to the price of the products. If, then, consumers hesitate to buy at the higher price, an exodus of some of the producers from the trade will follow, resulting in a reduction of the supply, until it adapts itself to the reduced demand. When this point is reached, no further change in the volume of production will take place unless the equilibrium is again disturbed.

This process of readjustment may be illustrated by diagram. Let $S S^{\prime}$ and $D D^{\prime}$ of Fig. 12 represent the existing supply and demand of a given article. The price then equals $q a$, and the quantity supplied equals $O q$. But if to the cost of production an additional item $S T$ is added, sa by a special tax, the supply curve, which, as we have learned, depends on the cost of production, becomes bodily shifted to the highel position $T T^{\prime}$. An adjustment will then ensue so that thereafter the price will equal $q^{\prime} a^{\prime}$ and the amount produced $O q^{\prime}$.

The effect may be summarized as follows:

The producers located between the points $q^{\prime}$ and $q$ leare the trade, finding other occupations more attractive, and the quantity produced is reduced from $O q$ to $O q^{\prime}$, the intersection $a^{\prime}$ indicating the new margin. The price $q^{\prime} a^{\prime}$ will then consist of the cost of production $q^{\prime} s^{\prime}$ at the new margin, plus the tax $s^{\prime} a^{\prime}$. The quantity $q^{\prime} s^{\prime}$ being less than the original corresponding quantity $q a$, the decrease must be borne by the workers; in other words, wages in that trade are redueed in the proportion in which $q^{\prime} s^{\prime}$ is less than $q a$.

But the process of readjustment will not end there. It will be remembered that the different ordinates of the rising eurve $S S S^{\prime \prime}$ represent the earning capacity of the workers in their various occupations of second choice, that is to say, in the occupations to which they ma take recourse as an alternative, 
and that the ordinates of the branch $S a$ are less than the normal ordinate qa mainly because the respective workers are competent only in one occupation and cannot readily turn to some other. Wages in the pursuit under consideration having fallen, as shown above, the affected trade will become less inviting than other pursuits, and since fewer learners will choose it, ${ }^{47}$ the readjustment will continue and the supply will be still further reduced, until the marginal producers in that line again obtain a recompense equal to that which originally accrued to marginal producers. In other words, the curves $S S^{\prime}$ and $T T^{\prime}$ will be changed to $S S^{\prime \prime}$ and $T T^{\prime \prime}$, the price will rise to the point $a^{\prime \prime}$, and production will be reduced to the volume $O q^{\prime \prime}$. The marginal cost which determines the price $q^{\prime \prime} a^{\prime \prime}$ will then be made up of $q^{\prime \prime} s^{\prime \prime}$, equal to the former marginal cost, plus the tax $s^{\prime \prime} a^{\prime \prime}$. This shows that in the end the consumer pays the entire tax.

As it is really immaterial what kind of burden it may be that impedes production, we are justified in the following conclusion :

Whatever impedes production, whether it be the difficulties inherent in the work, or burdens imposed by law or custom, has the double effect of increasing the price and of reducing the demand for that product $(219,220)$. And in the end it is the consumer and not the producer who pays for every increase in the difficulty or in the cost of production (358).

This statement does not imply that the producer in no way suffers loss on this account, for his recompense will be reduced whenever for any reason the cost of production is increased, and his income will suffer until the market has adjusted itself to the new conditions. Of the period of transition we shall speak later (221). Moreover, the above conclusion is inapplicable when the new conditions do not uniformly affect all producers in the same line. Thus, if a tax or other exaction is unequally imposed, prices respond to the extent in which the marginal producer is affected.

${ }^{47}$ In considering the original curve $S S^{\prime \prime}$ as representing normal conditions, it is of course implied that the wage qa attracted learners to the pursuit in question in a degree equal to that of other pursuits. 
For the same reason that artificial as well as matural obstacles to the production of a given elass of things cause an increase in their prices, a removal of such impediments has the effeet of lowering prices. It is well known that whenever the difficulty of producing any given commodity is lessened, be it by the introduction of better systems in production or of new inventions, the increased supply due to these new conditions eauses a lowering of the price, which, in turn, results in an inereased demand, until a new equilibrium between supply and demand and between marginal cost and final utility becomes established. Although the producer may for a time reap an unusual profit, that advantage gradually gives way under competition, and in the end the consumers of the things of which production has been facilitated reap the entire benefit $(192,243,368)$.

This eonelusion is true with regard to all forms of eeonomic advantage. For instance, a by-product, previously valueless, may become valuable when a use is found for it. But the producer will not long reap an increased revenue, sinee the new advantage makes the business attractive to others, and the increased supply, in course of time, reacts upon the value of the total output, principal as well as by-product, whereby the benefit is again transferred from the producer to the consimer.

It is thus manifest that competition affects the value of commodities and serviees, no matter how different in kind, so as to make their values proportionate to the annount and the nature, the quantity and the quality of the efforts expended.

Efforts of the same kind are, of eourse, compared on basis of their results, and not on basis of the time expended or of the physical strength applied. And where the efforts are different in kind, as, for instance, a carpenter's, a musician's, a lawyer's, their relative market value is determined by competition, and this competition finds expression in migration of marginal workers from one oecupation to another, whenever such change holds out better prospects to the worker. The relative value of any two different forms of service is thus 
traceable to the relative estimation of the marginal workers, that is, workers equally skilled in both occupations.

Through the many workers who are in position to turn from their occupation to some other, workers who are near the margin in their present line of effort, this pursuit is brought into direct competitive relation with many other pursuits, and these being in their turn in similar relation with others, a competitive relation among all different lines of activity is established, through which the relative market value of all forms of service becomes adjusted.

Still another effect of compctition remains to be touched upon, namely its tendency to "put the right man into the right place." There is competition not only among workmen for places open to them, but also among employers for men to fill these places. Each employer must therefore pay as high wages as other employers are prepared to offer. And inasmuch as each employer naturally seeks to utilize the purchased service to the best advantage, the tendency is to place each worker into the position of his greatest efficiency. It follows that competition not only adjusts the relative pay for different kinds of work, but also assigns to each worker that place for which he is best adapted.

I50. The Law of Value Presupposes Free Competition. -In the course of our investigation (63) we found that in a normal market final utility and marginal cost of production are equal quantities and that it is competition which brings about this equalization. Where competition is obstructed (225), the law of supply and demand has not the effect of equalizing marginal cost and final utility, and prices rise above marginal cost. Only where competition is free, where there is nothing to interfere with the free choice of occupation and the freedom of exchange can it come to pass that the proceeds from the sale of coats are equitably shared among the shepherd, the spinner, the weaver, the tailor, the merchant and all those who assist in making and selling coats, and this applies with equal force to all commodities in the market (153).

We have now briefly covered the field of competition as far 
as it relates to our inquiry. The method by which we have reached our present conclusions is that of strictly logical deduction from accepted premises. These conclusions are in substantial agreement with the tenets of that school of economics which holds to the principle of laissez faire. We have not thus far turned to experience to verify our conclusions. But when we do so, we find that in practice they do not seem to be uniformly confirmed. It is therefore not surprising that the prevailing view regarding the effect of competition is by no means in harmony with the conclusions we have reached. The discrepancies call for explanation, and that explanation we shall find in the course of our further inquiry (342-346).

I5I. Apportionment of Proceeds of Production.-We are now prepared to go more fully into a detailed study of the double process of distribution, consisting of a division of the proceeds from the sale of consumption goods, first, among the contributing groups, and second, within the groups among the individual participants in production (127).

This division is effected through the various disposals of the gross income of each group. Distribution among the groups is accomplished through payments for goods or services received by one group from other groups (152), while distribution within the groups is realized through compensation to employes, whether in the form of wages, salaries or other recompense, through payment of rent to the owner of the land used if this land is rented, and through payment of interest if the capital goods are leased or if money has been borrowed. That which remains goes as a residual share to the employer or to the owner of the business. It follows, of course, that if the employer is also the owner of the land or of the other capital in use or both, the residual share will include rent or interest or both.

I52. The Function of Capital Goods in the Apportionment.-While in the modern industrial system some part of the work of production is performed years before the consumption products can become available, the workers who perform that part receive their compensation before the final disposition 
of the products. This would seem to conflict with the proposition that the recompense for this labor is derived from the proceeds of the sale of the final consumption goods. How can the proceeds be shared before they are realized?

The answer to this question is not far to seek. We are here dealing with the production of material wealth. In the course of this process the products of nature are transformed by labor into commodities which have a market value even though as yet unfit for final consumption. This applies as well to means of production, like looms which disappear by wear, as to goods in course of production, like yarns which become part of the final product (132). All these things should be looked upon as partly finished consumption goods. The looms as well as the yarns are partly finished garments. As a thing is industrially advanced from stage to stage by coöperative groups, or by workers acting as such, it enters each successive process either as a means of production or as a raw material, and emerges as the finished product of the respective group. To the spinner for whom the yarns are finished goods, the wool is the raw material. The yarns are the raw material of the weaver who finishes the cloth which, in turn, is the raw material of the tailor. The spinner, in buying the wool, pays for the work which the shepherd has performed toward the making of the coats. The weaver pays the spinner a price for the yarns that covers the recompense for the work of the shepherd as well as the spinner. The tailor, in buying the cloth, must lay out the shares which are due to shepherd, spinner and weaver. Each successive operator invests in the partly finished coats by purchasing the raw materials, expecting to be reimbursed for this outlay and for his own labor by the sale of that which he produces. The payments made to those who furnish the preceding efforts are manifestly advance payments, to be finally recovered from the price of the coats. This is true as regards all services contributing to the production of the final goods-the coats of our illustration-and applies to the earnings, not only of the shepherd, the spinner, the weaver and the tailor, but also of those who make the sewing thread and the buttons, of the iron and 
coal miners who supply the material and fuel for the machinery, of the builders of the machines, the elerks, bookkeepers, salesmen, and so forth.

We here see that the intermediate or immature products, be they means of production or supplies, perform, as earriers of value, an important part in the distribution of the proceeds from the final produets (151). Through the value which they carry the preceding efforts are paid for out of the ultimate proceeds before these proceeds are realized. The value of these unfinished products may be compared with eharges attached to a bill of lading. The charges for the earlier efforts are carried forward, in the form of "value" of the eapital goods. A study of the conditions which determine these values must furnish a clue to the rate of distribution among the several groups that perform the several operations.

I 53. The Value of Capital Goods. - If we seek to apply the law of supply and demand to the value of capital goods, we find that this law is not direetly applicable to that value. We have heretofore traced demand to a desire for gratification (58), but capital goods are ineapable in their existing form to gratify desires. They do not possess "utility" in the sense in which we have used the term, namely the utility of consumable goods. What utility they possess is only in a latent or potential state and as such is not available for gratification. We must aecordingly trace the demand for the intermediate to the demand for the final goods. So long as the tailor can sell eoats, he will buy the neeessary materials. The resulting demand for eloth engenders a demand for yarns, and this again a demand for wool. So must the demand for lnoms and other means of produeing cloth be traced to the demand for clothes. This latter is the only cause of demand for all the materials and equipments used in the production of the clothes-or whatever the final products may be-and the question of the extent to which this demand applies to each of the various materials and equipments that enter into produetion is the problem now before us.

The question of the value of immature products, and particularly of means of production, is really a problem by itself. 
The incentive that creates the demand can be traced to human desires only in an indirect way. 'The demand for looms on the part of the cloth manufacturer arises from his confidence that he will find a market for the cloth he intends to have made by their use, and the demand for cloth is ultimately due to the utility of the apparel to be made from it. The loom is the embodiment of certain of the services necessary to make the thousands of coats that will be completed through its use, and these services are gradually transferred from the loom to the cloth as the loom is utilized, at the average rate at which the loom deteriorates while being used (10). At the same time, the potential utilities of the means of production are gradually converted into the actual utilities possessed by the final products.

It is readily to be seen that the volume of demand for capital goods cannot respond to a change of the price as readily as is the case with consumption goods. This will be found especially true of the means of production and, likewise, of the goods themselves in their earlier stages. A loom, for example, may be used for weaving the cloth of many thousands of coats. For this reason an exceedingly small portion of its value will enter into the price of one coat. The demand for looms, as we have seen, is governed by the demand for clothes, and this demand would be affected very slightly indeed, if the cost of looms were doubled, as the price of coats would be but slightly affected. Nor would the demand for looms be noticeably increased if their value were reduced to one-tenth. We have clearly to deal with a product of the kind represented in Fig. 9 and must look principally to marginal cost as determinative of its value $(64,332)$. We should, accordingly, concentrate our attention on the conditions that determine the marginal cost of production. While the value of the mature product is determined miainly by final utility, the value of the intermediate products-looms, wool, yarns, cloth and so forth-is dependent principally on marginal effort. Whenever the prices of these intermediate products are such that any one of the contributing occupations affords less recompense for equal effort than others, a migration of workers from 
it to the others and a readjustment of prices will set in until the compensation of each trade is in proportion to effort put forth.

The utility theory of value is manifestly inapplicable to capital goods. Suppose we are to ascertain the value of a quantity of eloth for 100 coats, the finishing and selling of which will average 6 months. Aeeording to this theory the value of the eloth is the diseounted value of the future utility of this eloth. But what is the future utility of this quantity of cloth? The nature of this utility is certainly that of coats, but its quantity eannot reasonably be held to equal the utility of the total 100 coats. For example, suppose the value of a eoat is $\$ 20$. The value of the eloth will then surely be less than $\$ 2000$ diseounted at 6 per eent. per annum, that is, 3 per cent. for the half year required for completing the coats. If it were that amount, namely $\$ 1940$, the tailor who pays that much when he buys the eloth would, by selling the coats six months later, get back only the purehase price with interest, but nothing for his labor. The value of the eloth is therefore the discounted value of fewer than one hundred coats. But how many less? What is to determine the number? Is it 10 coats or 90 coats or some number between? There is nothing to go by unless we take cognizance of effort or labor as eo-ordinate with utility in the determination of this question. This confirms what we have heretofore noted (62), namely that the utility theory of value fails to trace value to its primary faetors.

It is now elear that so long as complete freedom of competition prevails and workers are free to choose their ceenpation, the division of the proceeds from the final products among the contributing groups-in the case of coats, among the groups represented by shepherd, spinner, weaver, tailor, merchant, ete.-will adjust itself in proportion to the relative difficulty of rendering the serviees contributed by each group $(150,267)$.

154. Apportionment within Groups.-I Let the line $A G$ of Fig. 13 represent the gross income of a group. 'This amount is divided at $B$ into two principal parts, the first of which, the "cost of supplies" $A B$, covers the payment for all services obtained from other groups in the form of raw materials, 
supplies, means of production, etc. The other part $B G$, which eonstitutes the "net income" of the group and represents the value produced by the group, is the fund from which all forms of profit and all forms of wages are ultimately shared out (127). Of this net income a portion $B C$ goes to land as rent, another portion $C E$ goes to capital goods and to money as interest, and the remaining portion $E G$ goes to labor as wages. The rate at which this division takes place varies according to circumstances, and the question now before us is: what is it that governs this division and determines the various shares that go to the various members of the group? There is here no place for chance profits, because these are in the average balanced by chance losses.

It is quite apparent that the gross income of each group, obtained from the sale of its products, is normally divided into four principal parts. Of these the portion $A B$ goes to make up the gross income of other groups, and as such is again similarly divided. But since the group which first derives the raw material from nature has no charges corresponding to $A B$ to pay, the sum total paid by the consumers for the final products is, in the last analysis, divided into rent, interest and wages, of which the first two are to be classed as capital profits.

This brings us face to face with the essence of the problem. What is it that determines this division?

We already know that the first division at $B$ is regulated by competition. But if we attempt to learn at what rate the net income $B G$ of each group is divided into capital profits and wages, we discover that the law of competition does not apply, since the services rendered by labor are radically different from those rendered by capital, the former being personal, the latter impersonal. There can be no competition between capital and labor. Industrial migration, which is the principal factor of competition, may take place between any two lines of activity. A man may be in a position to choose between teaching philosophy and laying bricks, if these happen to be his occupations of first and second choice. But between such scrvice as that rendered by labor and that rendered by capital 
there is no alternative. The sharing of the proceeds of industry between capital and labor, the division into profits and uages, cannot therefore be regulated by competition. We must look further for the eeonomic forces which determine this division, or for some eommon ground on which to compare the two kinds of service (180).

By furnishing capital to a group of workers the capitalist becomes a participant in production, and as such he is entitled to a share of the product. But to what extent does his title go?

It is self-evident that he is primarily entitled, beyond all risk, to a return of the full value which he contributes. We know, however, from experience, that the share he receives is more than the amount of the capital he has furnished. What he actually gets is (1) eompensation for wear and tear and for risk of loss, which tend to maintain undiminished the value he has furnished; and beyond these obvious items he obtains (2) compensation for the use of capital, or capital profits, the real nature of which is not so obvious. It accrues for that serviee of the capitalist which consists in surrendering the use of his wealth, whether consisting of land, of capital goods or of money (265), and this is an impersonal service. How this service of the eapitalist is to be compared with the serviee of the workers who give their labor remains to be learned.

That the division of the net income of a group into wages and capital profits does not oceur at a constant rate is plain enough. In some trades only a small amount of capital can be advantageously employed. The tools of a brieklayer are few and simple. In trades of this kind practically the entire net income becomes wages. In other enterprises a larger amount of capital is needed in proportion to labor, and in these a proportionately greater part of the net ineome goes to eapital.

I55. Economic Relations of Labor and Capital.-In view of the general uniformity of the rate of capital returus in all the ordinary fields of production there can be no doubt that certain definite forecs are at work that govern the apportionment of the net income of the produetive group between eapital and labor. What are these forces and how do they operate?

Let us turn again to the diagram Fig. 13 in which the divi- 
sion of the net income $B G$ into profits and wages is marked by the point $E$. What is it that determines the position of that point? All we know, to start with, is that profits and wages together make up the sum total $B G$ of the net income. In the terminology of mathematies, we have two unknown quantities and thus far only one equation. We are to find the quantitics $B E$ and $E G$ and as yet we know only their sum $B G$. A second equation is necessary to find how that sum is divided. We must find either what it is that determines the rate of interest and accordingly the share $B E$ of eapital, leaving the balance $E G$ to labor; or else, what it is that determines the share $E G$ of labor, leaving the balance $B E$ to capital. Is it the share of capital or that of labor which comes first $(160,267)$ ?

As a first step in this inquiry, we must find how the productivity of labor is affected by the employment of different amounts of capital.

I56. Influence of Capital on the Productivity of Labor.In producing any given kind of commodity, various methods and modifieations of methods can be adopted, some being more, others less effective $(10 a)$. It is generally found that the efficiency of labor is enhanced with the extension of specialization and with the application of more complex means of production, and that each advance in this direction is attended by the employment of a larger amount of capital.

But that the efficiency of labor inereases with the amount of capital employed is true only up to a certain point. The employer of a given amount of labor, say one liundred men, cannot indefinitely increase the output of this labor by additions to his capital, for in time he will reach a point of "diminishing returns," that is, a point beyond which a further increase of capital actually results in diminishing the productivity of the labor employed (10b). Machines may become so intrieate in the effort to make them more completely automatic that the extra cost of eonstruction, operation and repair will exceed the benefit that may be derived from the attempted improvements. Or the division of labor may be carried so far that the increased cost of handling the goods exceeds the saving of labor attained by the last step in the speeialization. 
I57. Graphical Analysis.-The relation that exists between the efficieney of labor and the amount of eapital employed may be represented graphically. The yearly production of a eertain amount of labor, say of one hundred men, working with a varying amount of capital, may be indicated by the eurve $P P^{\prime}$ of Fig. 14, in which the horizontal dimension measures the amount of capital employed, and the vertical dimension the corresponding amount produced. ${ }^{48}$

Working with praetically no tools, the efficiency $O P$ is very small. As the amount of eapital is increased, the amount produced by that labor also beeomes greater, and the graphical representation of this condition takes the form of a rising eurve. According to experienee, this rise of the eurve becomes gradually less, until, beyond the point $p$, the curve takes a downward direction. This point of the curve, which marks the point of diminishing returns, also marks the greatest possible productivity attainable through the given amount of labor, the eorresponding amount of capital being equal to $O C$.

This eurve $P P^{\prime}$ is assumed to refer to a given trade and to a given state of the art. If by further discoveries and inventions the state of the industry is advanced, the eurve will ehange its course accordingly. This contingeney is lere left out of consideration, as we must neeessarily start from some definite premise. Moreover, it is here assumed that the eapital is used intelligently and that the best method of production consistent with the amount of eapital in question is seleeted. It is obvious that an incompetent employer may, in his ignorance, increase the amount of capital, without thereby increasing the efficieney

"When we speak of the amount produced oy the efforts of a given group of producers, this loes not mean the gross value of the products turned out, but only that part of this value which is due to the services rendered by the members of that group. From the orross value is to be deducted all that is paid to contributing groups for means of production, raw material and other supplies or services. It is particu. larly to be observed that in the amount so dedueted are to be included the items which go as amortization and as insurance to the capitalist of the group. The latter, in his eapacity as supplier of the eapital produecd by other groups, is in a position outside of the group in which he is a member only as owner of the eapital goods supplied (265). 
of the employed labor. Such ineffective utilization of capital is here, of course, not to be considered.

I58. Effect of a Varying Interest Rate.-At first glance it may appear that the amount of capital most advantageously employed with the given amount of labor is $O C$ (Fig. 14), because with this combination the greatest amount of goods will be produced. A brief consideration will, however, reveal that this is not the case. Capital demands a return on the basis of the current rate of interest, and the employer has therefore to consider the cost of employing capital as well as the cost of employing labor (160).

Suppose, now, that on the basis of the current rate of interest the return demanded by an amount of capital equal to $O C$ is equal to $C i^{49}$ After deducting this amount $C i$ from the total proceeds $C p$, the employer will have left an amount equal to ip, from which he must defray the wages of the employes, the remainder being his own wages.

If a smaller amount of capital is employed, the share going to eapital is, of course, correspondingly less. The inclined line $O i$ indicates this variable share. If the employer applies an amount of capital equal to $O C^{\prime}$, the cost of the use of this capital is $C^{\prime} i^{\prime}$, and the residual share is $i^{\prime} p^{\prime}$ instead of $i p$.

A glance at the diagram shows that $i^{\prime} p^{\prime}$ exceeds $i p$, which means an increased revenue to the employer. Indeed, the income of the employer is greatest if he uses an amount of capital $O C^{\prime}$, corresponding to that point $p^{\prime}$ of the curve $P P^{\prime}$ at which the tangent is parallel to the line $O i(161)$. This, then, is the most advantageous combination of capital and labor from the standpoint of the employer, for although labor is at this point not employed at its maximum efficiency, his personal wages as manager will then be greatest $(267,347)$.

Were the rate of interest higher, so that $C I$ represented

- In order to avoid a too great elongation of the diagram, its horizontal dimension, measuring the capital employed, is on a smaller scale than the vertical, which measures the value of the products. This must be remembered in comparing the two dimensions, as otherwise the rate of interest graphically represented must appear out of proportion. 
the eharges for the use of the capital $O C$, the higher rate would eause the employer to use eapital more sparingly. His own interest would be served best by limiting the amount of eapital employed to $O C^{\prime \prime}$, the point $C^{\prime \prime}$ being found by loeating on the curve $P P^{\prime}$ that point $p^{\prime \prime}$ where the tangent is parallel to the line $O I$. The productivity of the given amount of labor would then be $C^{\prime \prime} p^{\prime \prime}$, which is divided by the point $I^{\prime \prime}$, the lower section $C^{\prime \prime} I^{\prime \prime}$ being the share due to the invested eapital, the remainder, namely $I^{\prime \prime} p^{\prime \prime}$, being available for wages, to be shared between employer and employed.

I59. Effect of Interest Rate on Wages.-These considerations point out the influence whieh the rate of interest has upon wages. A high rate of interest kecps wages at a low level for two reasons. In the first place, the more restricted use of capital entails a lessening of the amount that ean be produeed by a given amount of labor, the reduction in our illustration being from $C^{\prime} p$ to $C^{\prime \prime} p^{\prime \prime}$ (Fig. 14), which simply means a reduction of the effieiency of labor (262). In the second place, a greater proportionate share of the value produeed aecrues to capital, and a eorrespondingly smaller share to labor. A low rate of interest has, of eourse, the opposite effect (318), but the employer would not be justified in inereasing the amount of eapital to $O C$, unless the interest rate were to fall to nil, when the productivity of labor would be raised to its natural maximum $C_{p}$, and the entire produet would beeome wages.

The proposition that a ligh rate of interest means low wages, and vice versa, although repeatedly advanced, has as often been contested on the ground that in prosperous times both wages and interest are found to be high, while during periods of business depression both forms of ineome are low. From this it is inferred that the same cause which males interest high makes wages high, and vice versa. But we are here not speaking of the diflerence between good times and bad times. It is quite obvious that when through any cause the total of produetion is redueed, there is less to be divided between eapital and labor, and both must aecept correspondingly low returns. And when the amount of production is great, as is the case when times are prosperous, the greater. 
total product affords larger returns to both. We have here under consideration the effect of a varying rate of interest upon wages while all other things remain equal. The amount actually produced within a certain time being given, it is selfevident that if a greater share goes to capital, a smaller share is left for labor, and vice versa. In this division of the net income $B G$ (Fig. 13) any increase of the share $B E$ accruing as profit to capital necessarily entails a reduction of the share $E G$ accruing to labor.

I60. Effect of a Varying Wage Rate.-The foregoing examination of the effect of changes in the interest rate on the productivity of labor has brought us no nearer to the solution of our problem, which is to find the causes that determine the respective allotments to labor and to capital, for we assumed the rate of interest as given. Wages were accordingly supposed to consist of the remainder of the proceeds after capital profits had been paid, which means that capital profits come first. But at the present stage of our inquiry we have not yet found whether capital profits or wages take precedence (155).

Let us assume now that it is the share of labor $E G$ of Fig. 13 which comes first and that the wages of the one hundred men of our illustration are represented by the ordinate $O W$ of Fig. 15, in which the curve $P P^{\prime}$ is again used to represent their varying productivity, according as they work with a smaller or larger amount of capital. In this event it is the owner of the eapital who gets the residual share, and it is accordingly in the interest of that owner that only so much of capital is employed as will bring the greatest rate of returns.

The ordinate $O W$ of the horizontal line $W W^{\prime}$ indicates what portion of the total value produced must be paid to labor, only the balance remaining as profits. Hence, by employing the amount of capital $O C$, the total product will amount to $C p$, of which the share $C W^{\prime \prime}$ goes to labor and the remainder $W^{\prime \prime} p$ to capital. The rate of this profit is expressed by the ratio $W^{\prime \prime} p$ to $W W^{\prime \prime}$, and if the line $W p$ is drawn, its slope is a measure of this ratio.

In analyzing the preceding case (158), we found that it was not to the best advantage of the employer to use the amount of 
eapital $O C$, by means of which the maximum productivity $C p$ is attainable. In the present case the same is true as regards the best advantage of the eapitalist. When the lesser amount of eapital $O C^{\prime}$ is used, the rate of profit on this invested eapital is indieated by the slope of the line $W p^{\prime}$. Although the share $W^{\prime} p^{\prime}$ on the smaller investment is less than $W^{\prime \prime} p$, the rate of profits is noticeably greater.

Were the wage rate lower, so that the total wages of the labor employed would be $O w$, the eapitalist would find it most advantageous to employ no more eapital than $O C^{\prime \prime}$, for the greatest rate of profits obtainable under the eireumstances would be indicated by the inclination of the line $u p^{\prime \prime}$.

It is clear that wages vary inversely as the interest rate, whether the one or the other has the precedence; and furthermore, when interest is high, it pays best to use cheap tools and cheap labor, in other words, to adopt comparatively inefficient methods of production. On the other hand, a low interest rate and high wages are coincident with a high order of industrial development.

16r. Graphical Analysis by Differentiated Function.In Figs. 14 and 15 the curve $P P^{\prime}$ shows how the productivity of a given amount of labor depends on the amount of eapital ntilized. Productivity is there represented by the ordinates of the eurve $P P^{\prime}$, and therefore by linear dimensions. But some features of the ease can be studied to better advantage if productivity is represented in a differentiated form, in which event it is measured by an area instead of a line.

In Fig. 16 the descending curve $E E^{\prime}$ represents what is known in mathematies as the differential of the function depieted by the eurve PP' of Fig. 14. Both curves have really the same significance, but each must be interpreted in its own way.

Let us suppose that the capital is provided in instalments $O a, a b, b c$ and so forth. The curve $E E^{\prime}$ then indicates the successive increments of productivity clue to the consecutive increments of eapital, while, as will be remembered, the eurve $P P^{\prime}$ of Fig. 14 is plotted so as to show the total productivity attained by the use of the respective amounts of capital fur- 
nished. Consequently, in order to find in Fig. 16 the total annual output of the given amount of labor with any given amount of capital, it is necessary to add up the successive increments of productivity, and this sum is necessarily an area, not merely a linear measurement, as in Fig. 14.

When unaided labor is supplied with the first instalment $O a$ of capital, its efficiency is increased materially, and this increase is shown in Fig. 16 by the ordinate $a a^{\prime},{ }^{50}$ and in Fig. 14 by a very rapid rise of the curve $P P^{\prime}$ at the point $a^{\prime}$. The gain from a second equal instalment $a b$ is somewhat less, as shown by the smaller ordinate $b b^{\prime}$ in Fig. 16, and by a less rapid rise of the curve $P P^{\prime}$ of Fig. 14 at the point $b^{\prime}$. The effect of additional instalments is similarly shown by the continually decreasing ordinates of the curve $E E^{\prime}$ of Fig. 16, and by the constantly diminishing ascent of the curve $P P^{\prime}$ of Fig. 14. When the capital reaches the amount $O C$, further additions can no longer increase the output, and this is indicated in Fig. 16 by the curve $E E^{\prime}$ reaching the base line, and in Fig. 14 by the curve $P P^{\prime}$ ceasing to rise.

The difference in the way of interpreting the two diagrams can now be briefly summarized. If the one hundred men, adopted in the illustration as the given amount of labor, are provided with an amount of capital equal to $O C^{\prime \prime}$, the annual output of this labor is measured in Fig. 14 by the linear dimension $C^{\prime \prime} p^{\prime \prime}$, and in Fig. 16 by the area $O C^{\prime \prime} e^{\prime \prime} E$. Or if $O C^{\prime}$ is the amount of capital supplied, the yearly production is measured by the line $C^{\prime} p^{\prime}$ and the area $O C^{\prime} e^{\prime} E$, respectively.

When we applied the diagram Fig. 14 to an analysis of the case in which $C i$ was the interest charge for the use of the capital $O C$, we found that it would pay the employer best to use an amount of capital equal to $O C^{\prime}$ (158). This is confirmed by a study of Fig. 16. Let us suppose the employer has invested an amount of capital equal to $O C^{\prime \prime}$, while the rate of interest equals $O i$. The total annual product of labor and capital combined will then be represented by the area $O C^{\prime \prime} C^{\prime \prime} E$,

${ }^{5}$ Strictly speaking, the increase is measured by the area of the trapezoid $O a a^{\prime} E$. 
of which the area $O C^{\prime \prime} i^{\prime \prime} i$ represents the interest due on the invested capital. The portion of the total ontput represented by the area $i i^{\prime \prime} e^{\prime \prime} E$ is thus left to the employer for paying. wages and for his own recompense as manager.

When eonsidering the question of using improved machinerry, or, in other words, more capital with the same amount of labor, the employer finds that, by adding the amount $C^{\prime \prime} C^{\prime}$, production is inereased by the area $C^{\prime \prime} C^{\prime} e^{\prime} e^{\prime \prime}$, indieated by shading in Fig. 17, while the interest he must pay for the additional eapital equals the area $C^{\prime \prime} C^{\prime} e^{\prime} i^{\prime \prime}$. This addition of eapital is obviously of advantage to him, as there is a net gain equal to the area $i^{\prime \prime} e^{\prime} e^{\prime \prime}$. He accordingly finds it profitable to increase the total amount of his eapital to $O C^{\prime}$. As every sueh gain in production inereases his personal share, he naturally seeks to use the most advantageous combination of capital and labor.

When the amount of capital employed is equal to $O C^{\prime}$, the total value produced annually by the one hundred men is $O C^{\prime} e^{\prime} E$, which is divided into two parts by the line $i e^{\prime}$, the lower area being charges for the use of the eapital, the upper area being wages. This division is shown by shading in Fig. 18 .

If the employer endeavors to inerease the effieieney of the given amount of labor by yet further improvements, he finds that the additional eapital $C^{\prime} C$ would enhance production only by the amount indieated by the area $C^{\prime} C e^{\prime}$, Fig. 19 , while the eharge for this additional capital would be represented by the area $C^{\prime} C i^{\prime} e^{\prime}$. As the diagram shows, this charge would then exceed the gain, and it would manifestly be unprofitable to employ more capital than the amount $O C^{\prime}$. Of course, if he has more eapital to invest, he refrains from adding improvements that do not pay, but extends his business on the existing plan and employs more labor.

It is now elear that if the effieieney curve $E E^{\prime \prime}$, Fig. 16 , and the rate of interest $O i$ are given, then the interseetion $e^{\prime}$ of the horizontal line $\ddot{ }^{\prime}$ with the efficieney eurve $E E^{\prime}$ is the point which indicates the amount of eapital $O C^{\prime \prime}$ that can be most profitably employed with the given amount of labor.

The employer secks to establish in his works the eorre- 
sponding mode of production. At this point a small increment of capital increases production by an amount equal to the additional interest, and, for a like reason, a small addition to labor increases the output by an amount equal to its cost; in other words, one dollar spent as interest for more capital has the same effect on the output as one dollar spent as wages for more labor. However, the conditions responsible for that equality cannot be regarded as governing the rate of interest, since in the determination of this point the rate of interest was assumed.

We proceeded on the assumption that the capital is made up by adding one instalment after another. But this is frequently impracticable. Where, for instance, the capital is in the form of machinery, the addition of another instalment might mean the replacement of the machines by others which are more efficient, but also more costly, and this change cannot be effected by merely supplying an amount of money equal to the difference in cost. This would seem to invalidate our conclusions. But it must be considered that machines wear out and that the additional capital can be made use of by replacing those worn out with the improved. The problem of increasing the existing capital by an additional instalment thus becomes merely a question of time, and the conclusions deduced above remain valid, at least in the long run.

162. Final Efficiency of Capital.-In applying the diagrams Figs. 14 and 16 to the study of the relation of interest and wages to the amount of capital and labor employed, we assumed the current rate of interest to be given, and found that the interest charge makes it unprofitable to employ more than a certain proportionate amount of capital with a given amount of labor, and that, in consequence, labor fails to develop its maximum efficiency. But so far we have no clue as to why capital commands interest.

It is generally recognized that with the gradual increase of capital available for use its interest commanding power has declined. This would seem to indicate that it is an insufficiency of available capital that accounts for interest instead of interest accounting for the sparing use of capital. The fact 
that capital now commands a revenue would accordingly signify that the amount of capital now available for productive use is inadequate to employ labor at its maximum efficiency. The current interest theories take indeed this ground. Let us consider the subject in this light.

We have hitherto applied the diagrams Figs. 14 to 19 to some single commodity or trade. But for our present purpose we have to extend their application to the entire industrial domain. The diagrams are accordingly to be taken as applying not to a single line of production, but to the total of all productive labor of the community. "The dimension $O C$ " of Fig. 16 then represents the sum total of available capital, and the area $O C^{\prime} e^{\prime} E$ the yearly output of the entire labor force of the community.

Suppose that an additional amount $C^{\prime} z$ of capital becomes available and is offered for loan to whoever offers the highest returns for it. The increase of the output that may be gained by its use through an increase of labor's productivity is represented by the area $C^{\prime} z z^{\prime} e^{\prime}$, and the possibility of this increase naturally elicits a certain demand for its use. The competitors for the supply $C^{\prime} z$ being numberless and the supply being a limited quantity, the bids for its use will tend to run up to the full amount of the gain it affords. The successful bids then naturally fix the rate of capital profits for the market generally $(243,244)$. The rate of gain due to the last increment of capital is indicated by the ordinate $z z^{\prime}$ and is termed the "final efficiency of eapital" (242a) when $O z$ is the available amount. Hence, if the amount of capital is indeed limited, its final efficiency is the cardinal factor in the determination of the rate of capital returns (195).

It is now manifest that if we can find a cause for such limitation of capital which prevents the employment of labor at its maximum productivity, we will know all that is necessary to aecount for capital interest (242b). And capital interest being then ascertainable, the share of labor can likewise be ascertained, for that share is whatever remains of the net income of the productive groups. 


\section{CHAPTER VIII}

\section{LABOR AND WAGES}

I63. The "Wage Fund" Theory.-From the time of the earliest historic records on the subject of labor and wages up to the time of the inception of political economy as a branch of academic study the wages of the unskilled laborer were seldom more than enough to afford a bare subsistence for himself and his offspring. Believing this condition to be the natural order of things, the earlier exponents of the science endeavored to explain it on the basis of various theories derived from their observations. By the beginning of the nineteenth century these ideas had developed into the general conception of what has since been denominated as the "wage fund" theory, which was generally accepted up to about the middle of the nineteenth century, but has since been abandoned by almost all students of the subject.

The wage fund theory may be briefly stated as follows:

Wages depend upon the demand and supply of labor. The supply of labor depends npon the number of laborers, and the demand for labor is established and measured by that portion of capital, namely, the "wage fund," which is available for the maintenance of labor or, what amounts to the same thing, for the payment of wages. The division of this fund among the laborer fixes wages, which, accordingly, rise whenever the wage fund is increased or the number of laborers reduced, and vice versa.

When wages are less than necessary for the sustenance and perpetuation of the laboring class, those insufficiently nourished perish, so that the number of laborers is reduced, and wages rise. Conversely, if wages are higher, the propagation of the laboring class is promoted, the number of laborers increased, and wages are thereupon reduced. Wages therefore constantly tend to the bare cost of subsistence. ${ }^{51}$

as (f. Smith, pp. 49 ff.; Ricardo, pp. 50 ff.; Mill, I, pp. 420 ff.; et al. 
When this pessimistic theory, which has given to political economy its appellation as the "Dismal Science," is closely" examined, it is found that it leaves out of consideration a factor without which its conclusions remain indefinite. Supposing the wage fund and the number of laborers as given, there is nothing to indicate whether the result of the division represents the wages of a week, or of a month, or of any other definite period of time.

Any postulated wage fund must soon be exhausted unless replenished. It follows that wages are determined, not by its absolute amount, as predicated by those writers, but by the rate at which its restoration proceeds. As this fund can be replenished only by labor, an increase of the number of laborers will increase not only the amount of wages constantly to be drawn from it, but also the amount of things constantly restored to it; hence an increase of the number of laborers cannot result in a reduction of wages. The wage problem hinges on the question: what portion of the value produced by labor accrues to the wage fund? And this brings us back to the question regarding the division of the total product between labor and capital.

r64. The Wage Theory of Socialism.-Karl Marr, in his notable work "Das Kapital," published in 1867, offers another demonstration of the proposition that wages tend to the bare cost of maintenance (366), a condition which Lasalle had characterized as the "Iron Law of Wages" (Das Eherne Lohngesetz). This demonstration is founded on the general proposition that the value of a commodity is determined by the labor "socially necessary" for its production $(63,149)$, and from this predicate is derived the conclusion that the value of labor power, viewed as a commodity, depends upon the amount of labor necessary to maintain that power.

The following quotations give the gist of the value theory propounded by Marx:

A usciul article has value only because human labour in the abstract has feen embodied or materialized in it. How, then, is the magnitude of this ralue to be measured? Plainly by the quantity of the value-creating substance, the labour, coutained in the article. The 
quantity of labour, however, is measured by its duration, and labour time in its turn finds its standard in weeks, days and hours. ${ }^{52}$

Recognizing the manifest difference between the skilled and the unskilled, he explains that-

The labour that forms the substance of value, is homogeneous human labour, expenditure of one uniform labour-power. The total labour power of society, which is embodied in the sum total of the value of all commodities produced by that society, counts here as one homogeneous mass of human labour-power, composed though it be of innumerable individual units. Each of those units is the same as any other, so far as it has the character of the average labour-power of society, and takes effect as such; that is, so far as it requires for producing a commodity, no more time than is needed on an average, no more than is socially necessary..$^{53}$

Skilled labour counts only as simple labour intensified, or rather, as multiplied simple labour, a giren quantity of skilled being considered equal to a greater quantity of simple labour. Experience shows that this reduction is constantly being made. A commodity may be the product of the most skilled labour, but its value, by equating it to the product of simple unskilled labour, represents a definite quantity of the latter labour alone. . . . For simplicity's sake we shall henceforth account every kind of labour to be unskilled, simple labour; by this we can do no more than save ourselves the trouble of making the reduction. ${ }^{54}$

This proposition is defective inasmuch as labor cannot serve as a measure of value (30). The time of labor cannot be used to measure the value of labor's products, because of the vast difference of quality and quantity of the product of clifferent men's labor in any given time. Marx seeks to deal with these discrepancies by expressing the quantity of all kinds of labor in terms of the time of simple labor, and falls back on experience to obtain the rate of this reduction. He seems not to have realized that in this he was ignoring instead of solving the problem before him. Compare, for example, the work of a berry-picker with that of a watchmaker. Suppose a watch made in fifty hours is worth forty dollars, while a quart of berries picked in half an hour has a value of ten cents. Marx would explain this as follows: The berry-picker's

\footnotetext{
os Mlarx, p. 45 (13). Numbers in parentheses refer to German edition.

${ }^{53}$ Ibid., pp. $45-46$ (13-14).

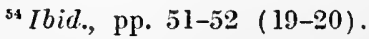


is simple, unskilled labor, hence the value of his produet is measured direetly by the hours spent in the pieking. The watehmaker's, on the other hand, is skilled labor, and his time must be multiplied by four, a faetor found by experienee. But unfortunately for Marx's reasoning, this "experienee" implies a knowledge of the aetual market value of the produets of the different workers. The value of the wateh is forty dollars, and that of a quart of berries is ten eents, while the time spent is fifty hours and one-half of an hour respeetively. The wateh is worth four hundred times as mueh as a quart of berries and requires but one hundred times the number of hours of labor. It is because the watchmaker produces four times as much value per hour as the berry-picker that in praetice his time of labor is worth four times as mueh as the berry-pieker's. If the value of the watch and that of the berries were not known from experienee, Marx's theory could not explain why the watehmaker's time should be multiplied by four or any other faetor. By turning to experience to obtain the factor of his "reduetion," he virtually assumes the value of the sundry produets of labor as known, in order to find how to "reduce" the time of skilled work to hours of simple labor. Marx's theory can be applied for finding the value of a thing only on eondition that this value is already known, a elear case of arguing in a eircle.

The wage problem is treated by Marx as a special ease of the law of value. Under the reign of eapitalistic production, he says, the workman has no choiee but to sell his "labour" power," and then he reasons as follows (207a):

The value of labour-power is determined, as in the ease of every other commodity, by the labour-time necessary for the production, and consequently also the reproduction, of this special artiele. So far ats it has value, it represents no more than a definite quantity of the average labour of society incorporated in it. Labour-power exists only as a capacity, or power of the living individual. Its production consequently presupposes his existence. Given the individual, the production of labour-power consists in his reproduction of limself or his maintenance. For his maintenance he requires a given quantity of the means of subsistrnce. Therefore the labour-time requisite for the production of labour-power reduces itself to that necessary for the pro- 
duction of those means of subsistence; in other words, the value of the labour-power is the value of the means of subsistence necessary for the maintenance of the labourer.ss

This proposition is just as illogical as his value theory. It certainly fails to explain why the watchmaker's wages should be four times the berry-picker's, the value of the means of subsistence necessary for the maintenance of both being practically the same. Moreover, labor power can be treated as a commodity only if the laborer himself is a commodity, that is, a slave. The benefits derived from any natural force, like steam, or a horse, need cost no more than the production and utilization of the steam or of the maintenance of the horse. This applies also to slave labor, and for such Marx's wage theory is correct in every particular.

But the time of chattel slavery is past. Unlike the horse or the slave, the workman of to-day is free to select his occupation and to choose between working by himself or in co-operation with others. He can leave his employer if another offers him higher wages or better treatment. When employers compete for labor's services, it is the workmen, not the masters, who get the benefit. It is only when there is not enough work to keep all workers employed that the competition among them for employment predominates and depresses wages. The workman is a free agent, except in such respects as he is bound in common with all other members of the community. Socialists may insist on calling him a wage slave, but not even to serve their theory can the wage earner be regarded as a chattel slave, to whom alone, as we have noted, Marx's theory applies. It is beyond reason to insist that the workmen's freedom can make no difference in their wages as compared with what they would obtain were they slaves. Under conditions of freedom a workman's wages are virtually the proceeds of an actual sale of the fruit of his labor. A skilful, an industrious workman obtains higher wages than one who is inexperienced or indolent, even though the cost of living be equal for both. The purchaser of slaves may reflect on the

${ }^{55}$ Marx, pp. 189-190 (155-156). 
eost of feeding and housing before buying them, but the employer, as a purehaser of the results of labor, does not inquire what a man needs for his living; he pays according to what a man ean do and how productive his services are. Wages are determined by factors fundamentally different from those which determine the cost of maintaining a horse or a slave. The socialistie wage theory is elearly untenable (207b).

165. Three Forms of Wages.-The raw products of nature are moulded by human effort into form for human needs. Nature furnishes at once the material and the forces, and human effort, direeted by human intelligence, is the agency by which these forees are direeted and applied.

In general, the products of nature ean be made available for human needs only by the application of labor, and the utilities so won are the natural recompense of labor. This has been stated by Adam Smith as follows:

The produce of labour constitutes the natural recompense or wages of labour.

But wages ean be considered in two other ways. As ordinarily understood, the term denotes "money wages," that is to say, the money paid to the worker in exchange for his share of the effort spent in obtaining the produet; and finally, the things or services bouglit by the worker with the money wages are regarded by some authorities as the "real wages" (284). Thus we have three different forms of wages, the first being the direet product of labor, the second the money obtained in exchange for that product, and the third the things or services obtained for the money.

Where industry is speeialized, the workman seldom desires a portion of the partieular things which he helps to make, but rather his share of their value. For this reason we are not so much coneerned with the first form of wages as with the seeond. Wages, in this sense, is what the worker obtains as his share of the proceeds from the sale of the product of the producing group. We are thus again brought face to face 
with the question as to what portion of the proceeds becomes allotted as wages, and how that allotment is shared out among the individual workers of the group.

r66. Wages Apportioned Through Competition.-Apparently the wages of employed workers are determined by the employer. But in reality they are the price of the workers' product and are therefore subject to the conditions of the market. The employer, in paying wages, really buys the product of the workers and therefore pays to each the market equivalent of the service received from him. Whether a workman is skilled or unskilled, his recompense is determined by supply and demand as applied to the particular service he renders. When an employer pays wages below the market value of the services rendered, the wage earners seek, and ultimately obtain, more remunerative employment clsewhere. If, on the other hand, he pays wages above the market value of the services obtained, he ultimately exhausts his resources and is compelled to reduce wages or give up his business. So long as both workmen and employers are free to accept or reject each others' terms, the force of competition regulates the distribution of the worker's' share $E F$ (Fig. 13) in accordance with services rendered. The freedom of change from one employer to another and of migration from one pursuit to another brings about among the workers in any productive group a practically just distribution of that part of the income which existing conditions allot to labor.

The psychological element which enters into the problem, namely the disinclination of both workmen and employers to change an existing situation, can only retard, but cannot prevent an ultimate adjustment.

I67. Employers' Wages.-We have seen that the employer represents two independent functions. He is both manager and venturer (146). His income as employer consists, accordingly, of two items, namely manager's wages and chance profits. At this stage of our discussion we are dealing only with the question of wages and must ignore those factors of the case which account for chance profits.

The employer does not, like the employe, receive stated 
wages or salary. His recompense is a residual share (205). The gross receipts from the sale of the products of his group are distributed by him. On the one hand he pays for all services contributed by other groups, and on the other hand he pays the wages of his employes, the rent for the land oceupied, the charges for the use of the capital goods and the interest on money borrowed. The remainder constitutes his income, the "wages" of his labor. Of course, if he happens to be the owner of the capital employed, we must here assume that he is paying the corresponding charges to himself as eapitalist or land owner.

The diagram Fig. 13 illustrates this distribution. The expenses of the employer consist of the anterior charges $A B$, the profits $B E$ due to the invested capital and the wages $E F$ of the employes, the remainder $F G$ being his wages.

When the market rate of wages is such that the share left to employers is more than their efforts are really worth, that is, when the income of employers is out of proportion to their services, some of the employed are induced to go into business for themselves, thereby becoming employers. Consequently the demand for wage workers is increased, while the supply is reduced, causing wages to rise and the share of the employers, as a whole, to fall until a proper adjustment is attained. And vice versa, when wages rule so high that the employers' share is below a proper recompense, some of them find that they ean earn more by taking employment and do so. The number of employers is thereby reduced and the ruling rate of wages for employes falls because of the redueed demand, leaving for the remaining employers a greater share. The division of labor's portion $E G$ into the shares $E F$ and $F G$, the one going to employes, the other being left for the employer, is in this way adjusted to a point where the tendeney of employes to become employers and that of employers to become employes are evenly balanced.

It is thus clear that an employer's wages, even though they accrue to him as a residual share, depending on various circumstances, are yet subject, in the last analysis, to the law of supply and demand. 
There is, in the nature of things, a difference in the capability of different employers. Some have a high order of executive ability and can successfully direct the forces of a large organization, while others reach the limit of their directive capacity in a concern employing but a snall number of men. In all cases the efficiency of the workers is, to a large extent, dependent on the efficiency of the direction. Hence a difference in directive ability accounts for a far greater difference in the net income of different groups than a like difference in the ability of other individual workers. The wages of employes being the same whatever the ability of the employer, every difference in the net income due to difference in management will appear in the employer's residual share, and a small percentage of increase in the efficiency of a group will increase the employer's share by a large percentage. This accounts for the well known fact that the share of the employer rises or falls more rapidly according to his ability than that of any other of the workers.

As in every other calling, we find among employers of labor many who obtain more than their price limit, that is, what they could earn as employes. From the highest mark the various employers' incomes grade down toward the margin, where their share is no greater than what they could earn as employes. It follows that in this relation of the employer to the employed the margin is determined by the supply of and the demand for employers' services, just as the margin in other lines is determined by supply and demand; and for the same reason that the incomes of intra-marginal employers rise rapidly, those of extra-marginal employers fall as rapidly. If those whose business ability is inferior to that of the marginal manager enter the field as employers, even under favorable auspices, they sooner or later fail in their venture. That the alluring prospects attract many is evidenced by the fact that a large proportion of those who start in business find it impossible to make a success of it. And among those who do not fail, there are many who remain at or near the margin, their incomes as employers being no more, and per- 
haps even less, than what they would get if they were to become wage earners.

I68. Merchants' Wages.-A merchant's income is really that of an employer, for he is manager of a group that forwards goods toward maturity. In the modern system of production it is neessary that the products of industry be brought within convenient reach of the consumers, and to do this is the office of the merchant.

The gross income of his business, like that of any other group, is divided into anterior charges and net income, and the latter is sub-divided into profits and wages, the profits going to the invested eapital and the wages to the active participants, including himself. From his standpoint as business manager the anterior charges $A B$, Fig. 13, paid to other groups, the profits $B E$ accruing to the invested capital and the wages $E F$ paid to elerks, salesmen and other employes, are expenditures, the remainder $F G$ being his own wages. Our conclusions regarding wages of organizers and employers are in every particular applicable to those of the merchant.

The difference between wholesale and retail price, which is frequently termed "profits," is wages, at least in part (140). Some writers on economics have decried these "profits" of the middlemen, but these deprecations are largely due to a misconception. The dealer performs one of the necessary functions in the system of modem production. So long as he is not the possessor of an exclusive right, so long as others are free to compete with him on equal terms, his income can only amount to the value of the services he renders. There is, in fact, no such thing as a "business profit" apart from the forms of income previously tabulated (138). In this list every elementary form of income is enumerated, and "business profit," which is an aggregate of various elementary ineomes, has no place in it.

An independent item of income is sometimes aceredited to what is known as the "good-will" of a business, but even the income from this source can be resolved into the elementary forms of our list. The eonditions known as "good-will" result from past endeavor and the reputation earned through it. 
Good-will therefore represents past effort and expenditure, and its proceeds are to be classed as wages and returns from capital.

I69. Adjustment of Wages.-In view of the conclusions we have reached, we may now more emphatically than before repeat that under conditions of free competition the wages portion of the net income of a group is in the main shared equitably among all the active participants, including the employer. There is no room for the supposition that the employer, or any other worker, obtains in the long run more or less than his just share. From the foregoing it necessarily follows that, contrary to a widely prevalent belief, the employer's services are not overpaid at the expense of the employed, and that the wages system has no inherent tendency toward inequity. But we have yet to analyze how the net income of a group is divided into wages and capital profits, and when we fully understand the causes which regulate this division, we shall see that it is the capitalist and not the employer who gets more than an equitable share. 


\section{CHAPTER IX}

\section{LAND AND RENT}

I70. Land the Prime Source of Wealth.-The primary source of all wealth is nature itself. The materials which are turned into commodities by the various processes of production are products of nature. The forces which become the servants of man as he utilizes them in these processes are forces of nature.

Just as all kinds of productive efforts are included in the comprehensive term "labor," so are all natural sources of the materials and of the forces requisite to production included in the term "land." This term, in the economic sense, therefore embraces much more than what is ordinarily understood by it. It embraces not only arable soil, building sites and forests, but also mines, waterfalls, fishing grounds and the like.

In order to obtain raw materials from land, it is generally necessary to perform more or less preparatory labor. Before wheat can be reaped, the land must be plowed and fertilized and the seed sown. Provision must be made to store the grain for protection against rain and storm. Coal is obtained principally by first sinking shafts and installing mining machinery. Inasmuch as most of the results of this work are inseparable from the land, those who perform the work and those who furnish the necessary appliances can be protected in the ownership of those results only by a concession of the exclusive right to the occupancy of the land. For this reason land has become private property.

I 7 I. Land Distinguished from Improvements Thereon. - I Land, as a factor of production, presents a feature which is possessed by no other form of capital. The labor required for the production of like things in different localities is not equal, but depends upon location and fertility of the land. Where these characteristies are favorable, the same results can be ob- 
tained easier than elsewhere. It is for this reason that the value of products, according as they are obtained from one or another piece of land, may exceed, or be equal to, or even fall below the normal charges for the efforts exerted and the capital goods employed in production. Of course, where it is found that the value of the products is in the average less than the cost of their production, this land will no longer be used for that particular purpose. But where the products obtained have a value exceeding this cost, the excess constitutes a profit to which the term "rent," in the sense of "economic rent" as distinguished from "gross rent," has been applied (139).

If land which yields such profit, or rent, is offered for lease, competition obliges the lessor to pay for its use a charge practically equal to this rent (323). And if it is offered for sale, competition for its ownership raises its value to a point proportionate to the profit yielded. It is the profit-yielding feature of land that gives it a market value.

In studying the nature of land values, the value of the preparations for its use, that is to say, the "improvements" made upon the land, must be considered separately from that of the land itself. The value of real estate is therefore made up of two items, namely, that of the land and that of the improvements. We are at this point concerned only with rent and with the value of land apart from that of improvements (173). The latter are to be considered as capital goods, the economic status of which will be discussed in the next chapter.

In some instances improvements become so incorporated in the land that the distinction we have here in view partly or wholly disappears. This is the case in clearing land of rocks, or reclaiming it from swamps, and so forth. We shall revert to this feature of the subject when the taxation of the land is to be considered (331).

I72. Ricardo's Law of Rent.-As regards the causes that bring about and regulate rent, there is practically no difference of opinion among modern economists. All agree upon the main points of the proposition known as "Ricardo's Law 
of Rent" (130). Since its promulgation, in the early part of the nineteenth century, only a few unavailing attempts have been made to discredit it, and these have resulted merely in confirming its truth. Such divergence of opinion as still remains relates only to minor details.

The nature of rent and the law that regulates it were recognized, in a measure, by some writers before the close of the eighteenth century, but since Ricardo was the first to propound the law in a well defined and comprehensive form, it is now distinguished by his name. A brief excerpt of his presentation is here quoted:

On the first settling of a country, in which there is an abundance of rich and fertile land, a very small portion of which is required to be cultivated for the support of the actual population, . . . there will be no rent; for no one would pay for the use of land when there is an abundant quantity not yet appropriated, and, therefore, at the disposal of whosoever might choose to cultivate it.

. . If all land had the same properties, if it were unlimited in quantity, and uniform in quality, no charge could be made for its use, unless where it possessed peeuliar advantages of situation. It is only, then, because land is not unlimited in quantity and uniform in quality, and beeause, in the progress of population, land of an inferior quality, or less advantageously situated, is ealled into cultivation, that rent is ever paid for the use of it. When, in the progress of society, land of the second degree of fertility is taken into cultivation, rent immediately commences on that of the first quality, and the amount of that rent will depend on the difterence in quality of these two portions of land.

When land of the third quality is taken into eultivation, rent immediately commenees on the second, and it is regulated us before, by the difference of their productive powers. At the same time, the rent of the first quality will rise, for that must always be above the rent of the second, by the difference between the produce which they yield with a given quantity of capital and labour. With every step in the progress of population, which shall oblige a country to have recourse to land of a worse quality, to enable it to raise its supply of food, rent on all the more fertile land, will rise.

Thus suppose land-Nos. 1, 2, 3-to yield, with an equal employment of capital and labour, a net produee of 100, 90, and 80 quarters of corn. In a new eountry, where there is an abundance of fertile land compared with the population, and where therefore it is only necessary to cultivate No. 1, the whole net produce will beloug to the cultivator, and will be the protits of the stoek which he advanees. As soon 
as population had so far increased as to make it necessary to cultivate No. 2, from which 90 quarters only can be obtained after supporting the labourers, rent would commence on No. 1, . . . In the same manner it might be shown that when No. 3 is brought into cultivation, the rent of No. 2 must be ten quarters, or the value of ten quarters, while the rent of No. 1 would rise to 20 quarters; for the cultivator of No. 3 would have the same profits whether he paid twenty quarters for the rent of No. 1, ten quarters for the rent of No. 2, or cultivated No. 3 free of all rent. .7

In following up his argument, Ricardo proceeds :

The reason, then, why raw produce rises in comparative value, is because more labour is employed in the production of the last portion obtained, and not because a rent is paid to the landlord. The value of corn is regulated by the quantity of labour bestowed on its production on that quality of land, or with that portion of capital, which pays no rent. Corn is not high because rent is paid, but a rent is paid because corn is high (359); and it has been justly observed, that no reduction would take place in the price of corn, although landlords should forego the whole of their rent. Such a measure would only enable some farmers to live like gentlemen, but would not diminish the quantity of labour necessary to raise the raw produce on the least productive land in cultivation..$^{65}$

I73. Graphical Representation of Ricardo's Law.-In the proposition so clearly stated by Ricardo the reader will readily recognize the principle which underlies the theory of value discussed in a preceding chapter (56-61). Ricardo has really paved the way for a clear understanding of the actions and reactions by which market values are regulated. He recognized the principle of the varying cost of production which forms the basis of what we called the "sellers' price limit" and represented by a rising curve. Later writers recognized a similar variation in regard to the desire for any given product and supplied the final link necessary to formulate the law of value.

If the item of rent is left out in figuring the cost of production (61), this cost becomes a varying quantity that can be represented by a rising curve, and the graphic method for illustrating the interaction of supply and demand can then be used advantageonsly to illustrate the law of rent.

or Ricardo, pp. 35-36.

- Ibid., pp. 38-39. 
The owner of a piece of land will not put it to use unless the market price of his products at least covers the three items : cost of supplies, current charges for the capital goods employed and value of his labor and that of those whom he may employ. This sum, then, is "cost of production" from the standpoint of the landowner and becomes his price limit as a seller of his products. This price limit is different for the owners of different pieces of land, for the eost of production in each case is affected by the varying fertility and loeation of the land.

Now let us suppose that the curve $S S^{\prime}$ of Fig. 20 represents the possible supply of a certain product that ean bo furnished to a given market, the elements of this supply being ordered in rising series of their respective cost or "price limit," and let us further assume that the curve $D D^{\prime}$ represents the demand for this same product. The intersection of these two curves will then locate the marginal point $a$. Accordingly, the ruling price of the entire supply of the market will adjust itself to the rate $O p$, no matter what difference there may be in the cost of producing the separate elements, and only those elements of the possible supply as are at and inside of the margin $a$ will be continuously produced and actually supplied in the market.

Coneentrating our attention on the element $q^{\prime}$, it ean be scen that the proceeds $q^{\prime} r^{\prime}$ from its" sale are divided into two parts, $q^{\prime} s^{\prime}$ and $s^{\prime} r^{\prime}$, of which the first consists of cost of supplies, returns of capital goods and wages of labor, while the second eonstitutes the "rent" afforded by the land from which the element $q^{\prime}$ is obtained (323). This profit is primarily acquired by the user or eultivator of the land when he sells his products in the market, but if tenant, ho pays it over to the landlord for the use of the land.

Land rented to a tenant usually earries improvements. If so, the landlord really supplies at least a portion of the capital goods used by the tenant in his work (171). In this case the stipulated rent paid by the tenant contains two items in addition to the economie rent, which are (1) reimbursement for deterioration of the improvements, viewed as means of pro- 
duction, and (2) current returns for the use of the improvements, viewed as capital goods. It will be recalled that the gross income $q^{\prime} r^{\prime}$ is composed of the rent $s^{\prime} r^{\prime}$ and of the cost $q^{\prime} s^{\prime}$, embracing cost of supplies, returns of capital goods and wages of labor. The first of these items, reimbursement for deterioration, is really a portion of the cost of supplies, while the second item is part of the returns of capital goods. Hence it is to be seen that after paying the stipulated rent, the tenant's residual share is composed of wages of his labor and that of his employes, and the returns due to that part of the capital which he himself furnishes.

r74. Misinterpretations of Ricardo's Law.-The objections that have been raised against Ricardo's law of rent are mostly based on a misinterpretation of his statement of the law or on a too narrow construction of it. His land No. 1 is obviously that land, whatever its area may be, from which, under the existing circumstances, the greatest amount of produce can be obtained with a given amount of labor. It is not necessarily the land which yields the greatest crop per acre.

By showing that rich land often requires great effort to clear, drain and prepare it for cultivation, and that the early settlers of a country, instead of cultivating the rich river bottoms, raised their first crops on the hillsides which have a natural drainage, Henry C. Carey attempted to refute Ricardo's law. But, as a matter of fact, this illustration constitutes a confirmation rather than a refutation. The settlers selected the land which, under the circumstances, yielded the greatest crop with the least effort.

In many respects the illustration given by Ricardo must be interpreted liberally and with due regard to general conditions. For instance, if different fields yield corn of different quality, it stands to reason that the "quarters" used for measuring the poorer grades should be conceived so much enlarged that "equivalent" rather than "equal" amounts of the different grades will be compared. Ricardo gives the gist of the law in terms which, where occasion requires, must be recast so as to be adapted to the case in question.

That the term "fertility" may have reference to mineral 
as well as agricultural land was also clearly shown by Ricardo. The cost of mining equal quantities in different mines depends on a number of conditions, all of which have some influence on the profit that may accrue to the mine owner.

Nor should fertility alone be considered. Wheat raised on more fertile land which happens to be less advantageously situated may cost more by the time it is brought to market than that obtained from less fertile land so located that less labor is required to bring it to market. In many cases location is indeed the only advantage utilized, as is the case with land in cities. In a store located in the business centre of a city more and larger sales can be effected with equal effort, or, what is the same, at equal cost, than in smaller stores in outlying districts. The labor of the salesman is more "fruitful," so to speak. So do advantages from location accrue to bankers, mannfacturers, shippers and others. "Fertility" then loses its literal significance, and commercial and industrial adrantages take the place of agricultural advantages. It matters not whether the cost of production is influenced through varying fertility or varying location, whether land is used for agriculture or for mining, for commereial or for industrial purposes, the law of rent is the same. Rent is always the value of the advantage derived from the possession of land, a value which, if the oceupant is a tenant, goes in general to the landowner with the stipulated rent.

175. The Margin of Cultivation.-The objection which has been urged most persistently against Ricardo's law is based on a denial of the existence of "no-rent" land, namely, land the use of which ean be obtained without the payment of rent, land which has not yet been brought into use becanse of the limited demand for its products. If it were true that there is no ultra-marginal land, or that there is no point of diminishing returns, Ricardo's law of rent would have no basis, for we can measure the advantages which one piece of land affords only by adopting as a stanclard of comparison some other land, the advantages of which are taken as zero.

There is no justification for denying the existence of "no- 
rent" land while there are vast tracts of land still uncultivated in various quarters of the globe, or while it is still possible to reclaim land from swamps or seas, or even as long as the intensity of cultivation of land already in use can be still further increased (178).

The denial of the existence of no-rent land is seemingly justified by the fact that land which is at the margin for some particular use is not rent-free. Thus suburban land which to all appearances is just beyond the margin of urban utility, even though at the moment lying idle, cannot be obtained without the payment of rent. We shall presently see, however, that this affords no basis for the denial, and that this condition is quite consistent with the theory of rent.

I76. Cumulative Rent.-Land is adapted for various alternate uses. It may be used for grazing, for growing wheat, for raising garden truck, for residences, or for manufacturing, bank or office buildings. These different uses range themselves in the order of their importance abont market centres. In the heart of a city the demand for land for mercantile use is greater than for any other purpose. In the zone surrounding the centre the prevailing demand is for factories and dwellings. At a still greater distance the margin for this use is passed and truck farming and other forms of intensive culture is in place. Then comes land given to extensive farming, and finally, farthest away, cattle ranges and woodlands will be found, interspersed with areas wholly unused.

In our study of this topic complications can be minimized if we at first apply the argument to a single market centre and assume that the surromnding land is throughout of equal fertility and that the cost of transportation from all directions to the centre is proportionate only to distance. Under these conditions the different uses to which the land can be put naturally range themselves in a series of concentric zones around the market. The cattle raiser occupies the most distant land, bordering on the actual margin of cultivation. Those stretches of this land which are nearest to the market centre are slightly preferable to the more outlying parts and are therefore slightly rent-bearing, hence the line where agri- 
cultural use begins is already a zone of land that can no longer be had without paying rent, and the margin of farming is not no-rent land. The marginal farmer must compete with the intra-marginal rancher. ${ }^{a}$

The farms that are nearer the market are preferred to those that are more distant and therefore yield a higher rent. Thus it happens that the marginal truck farmer must pay a rent equal to that returned by the most favorably located farm land. In short, the land lying at the margin of any one of the uses affords a rent consisting of the cumulation of the rent afforded by the less important uses of the land which lies between this margin and the outermost margin of cultivation.

But the uniformity in the characteristics of land which we have assumed in the above illustration does not really exist. The concentric arrangement of the several margins is therefore to be taken in a figurative sense. The lines by which the several uses are separated are in reality exceedingly irregular for quite obvious reasons. The markets for many products are actually outside of their margin of cultivation, as in the case of tropical fruit, spices and mineral products. We furthermore must consider that the number of markets is practically unlimited, each competing with its neighbor for the products of the adjacent lands, and that for this reason the marginal lines are completely interwoven. For all that, the general theory of rent, and, coincidently, that of cumulative rent, is not thereby vitiated, but only enveloped in a multitude of complications.

I77. Intensity of Cultivation.-The yield of any piece of land is not a fixed quantity, but depends on several conditions, among others on the amount of labor and eapital applicd to its cultivation. Land ean be eultivated with greater or less "intensity," and for each degree of cultivation its yicld is different.

For the present we shall leave out of consideration the effect of all other variable factors, such as the weather and the more or less intelligent management, by assuming these 
to be normal. The latter variations affect principally chance profits in one case, and manager's wages in the other.

The yield of land is increased with the application of more labor and capital, or, to put it briefly, of greater effort. But it does not increase in the same proportion as the effort. The productivity of land holds a relation to the intensity of cultivation similar to that existing between productivity of labor and amount of capital. The increase of productivity of land does not keep pace with that of effort applied to it, the progression in that respect being more or less similar to the curve shown in Fig. 14, illustrating the relation of capital to the productivity of labor.

In the present study, however, the diagram will be more instructive if the yield is presented, as in Fig. 16, in a differentiated instead of an integrated form. Land cultivated with little effort will bring forth little; but each additional effort will increase the output. Imagine successive instalments of effort, $O a, a b, b c$, and so forth, to be laid off on the horizontal axis of Fig. 21, and the output of each separate instalment to be laid off in the vertical direction, so that the yield of the first instalment of effort $O a$ is represented by the area $O a a^{\prime} Y$, the yield of the second instalment $a b$ by $a b b^{\prime} a^{\prime}$, etc., the curve $Y Y^{\prime}$ denoting the land's productivity.

Figuratively speaking, we may consider the piece of land under consideration to be composed of a number of superposed layers of land-successive stories, so to speak-each of which can take up no more than one of the increments of effort. The yield of the first layer, when put under cultivation, would equal the area $O a a^{\prime} Y$, that of the second $a b b^{\prime} a^{\prime}$, and so on, each succeeding layer yielding less than the preceding one.

I 78. The Point of Diminishing Returns.-Having assumed all the successive instalments of effort and, accordingly, of cost, to be equal, this cost can be represented by the ordinate of the horizontal line $C C^{\prime}$. The diagram then elucidates the fact that the instalment $c d$ is the last one which produces a yield greater than its cost. The point $d$ is manifestly the point of "diminishing returns" and delimits the most advantageous 
intensity of cultivation. The area $O d d^{\prime} C$ then represents the value of the total efforts, while the area $O d d^{\prime} Y$ measures the value of the total yield, and, accordingly, the area $C d^{\prime} Y$, which indicates the excess of the value of the product over its cost, represents the rent yielded by the piece of land.

It is now seen that the total value of the produce of the land in question, represented by the area $O d d^{\prime} Y$, is divided into two parts. Of these, the part $O d d^{\prime} C$ represents the cost of produeing the goods, comprising cost of supplies, value of labor and eharges for the use of the eapital other than land. The other part, $C d^{\prime} Y$, goes as rent to the landlord for the use of the land (185).

Now suppose that the demand for the produce of the land is increased, say through an increase of population. In consequence the value of the produce rises and is then represented by the curve $Z Z^{\prime}$. It then pays to increase the intensity of eultivation to the point $f$. To use our figure of speech, two more layers or "stories" are brought into use and the yield is inereased not only in value, but also in absolute quantity. It is also apparent that the rent of the land rises from $C^{\prime} Y$ to $C f^{\prime \prime} Z$.

Before the inerease of demand as here assumed takes place, the layers or "stories" de and of are beyond the margin of cultivation, since the value of their yield is then less than the cost of eultivation. By an increase of the demand they are brought into requisition, just as any previously existing ultramarginal land would be put to use under like eireumstances. From this viewpoint it can be seen that there is marginal land (175), at least in a figurative sense, in the midst of highly cultivated sections, nay, in the very business centres of cities, and these marginal sections are free even of cumulative rent. The erection of lofty office buikdings is nothing else than bringing into requisition the marginal layers or "stories"-an expression which in this case is literally applicable-of the land, by inereasing the "intensity of cultivation."

I79. The Personal Factor in Rent.-The yield of land, and with it the rent, is influenced not only by the intensity of 
cultivation, but also by the personal ability and foresight of the occupant, both as regards the selection of the special use to which the land is to be put and the intelligence and energy with which the productive efforts are applied.

An acre of land in the centre of the city of New York, if used for raising potatoes, would bring materially less rent than if used for office buildings or stores. An equal area of land in the country, say a hundred miles from New York, would, on the contrary, bring a higher rent as a potato patch than as a store site. And if this acre were in the north of Texas, the distance of the nearest market would even forbid the growing of potatoes, the land being available only for the lowest degree of cultivation, such as the grazing of cattle. The judicious selection of the use of any piece of land, according to circumstances, is an essential factor in obtaining the highest possible rent from it.

But even as regards a given use, the returns obtainable depend further on the personal ability of the user. Taking an acre best adapted for raising potatoes, it is found that one man is able to raise a larger crop than another, because of difference in intelligence, diligence and skill.

Among those desirous of utilizing any piece of land there are always some who can put it to better use than others, and these can always outbid their competitors. For the land of a commercial or industrial centre the banker, the merchant, the manufacturer are the highest bidders, and when these have secured their location, they are eliminated as competitors for the use of the more distant land which is open to competition among the remaining competitors. It is in this way that under the impulse of competition the occupancy of land is so adjusted among the different possible occupants that the land finds its most productive use and accordingly yields the highest rent, taking into account the different capabilities of those different occupants.

It must, of course, be understood that we are here dealing only with general tendencies. The theoretical result is not necessarily realized in each separate case. Yet, generally speaking, the facts are in accord with this theory. The most 
advantageous land returns a particularly high rent because it is being put to the most advantageous use by those most capable of doing so, the less advantageous land being left to those who, in their turn, ean get the most out of it.

180. The Source of Rent.-Rent, like wages, can be conceived in three forms. Of two settlers one may have taken up land that is more fertile than that taken up by the other, and who therefore can maintain his existenee with less effort. $\mathrm{He}$ obtains rent in the form of greater comforts of life. This may be regarded as the basic form of rent. The seeond develops when these settlers as farmers bring their produce to market. Supposing the settler on the poorer land to be at the margin of eultivation, he will obtain a price for his produce which pay's him only as mueh as he could earn at market rate of wages. His more fortunate neighbor, inasmuch as he can grow a greater quantity with the same amount of effort, can sell his produce at a price that nets him an ineome exceeding what he eould earn as a farm hand. This excess, the second form of rent, appears as a definite profit, usually in the form of money. And if the owner of the intra-marginal land leases it to a tenant, he obtains rent in its third form, namely as a stipulated periodic payment of money or its equivalent. At this point we are coneerned mainly with rent in its second form, namely in the form of a share of the gross ineome of a productive group, and with the way in whieh that share is determined.

The process by which rent, viewed as a share of the total value of the produce of land, is determined, has been elearly set forth by Ricardo. Produets obtained from intra-marginal land require less labor to prepare for the market than equal products obtained from land at the margin of production (7). But in the market equal produets, however obtained, eommand an equal price, a price determined by the marginal cost. The excess of the price over the cost of things produced on intramarginal land is rent. It is due to the advantages afforded by conditions of fertility and location of the land (154) and accrues in the first place to the user of the land. 
By way of illustration we may assume that for obtaining a given amount of produce, the cost on land No. 1 is $\$ 50$, on land No. 2 it is $\$ 60$, and on land No. 3 it is $\$ 70$. It is understood that cost is here meant to embrace all anterior charges, normal wages of labor, including that of superintendence, and current interest on the capital goods employed, but no charges for the use of land.

If now the demand for the produce of the land is such that the yields of land Nos. 1, 2 and 3 will just fully supply it, then land No. 3 is at the margin and the market price of the given amount of the produce is $\$ 70(62)$. The cultivators of land Nos. 1 and 2, in producing and selling the given amount, accordingly score a profit of $\$ 20$ and $\$ 10$, respectively.

Those who buy the produce of land No. 1 give $\$ 70$ in exchange for that which normally costs only $\$ 50$ to produce. The difference, namely, $\$ 20$, is the rent realized through the sale of the given amount of the produce of land No. 1. These $\$ 20$ represent just so much of the value of the purchaser's labor. It is therefore manifest that rent is a value furnished, not by the producers of the goods sold, but by the purchasers of those goods $(323,370)$.

Where land is used for industrial and commercial pursuits, equal amounts of effort have greater or less effect, according to location and surroundings; hence the above conclusion is true for such land as well as for agricultural land.

Reverting to diagram Fig. 20 it will be seen that by the sale of the total quantity $O q$ of the produce at the normal price $q a$, the cultivators of the land from which the various elements of the supply come receive value represented by the area Oqap, while, as will be understood by remembering that the effort of producing the element $q^{\prime}$ is represented by $q^{\prime} s^{\prime}$-they actually expend efforts of a value equal to the area $O q a S$. The sellers furnish services measured by the area $O q a S$, while the purchasers furnish services measured by the area $O$ qap, hence the difference measured by the area $S a p$ is an excess of services rendered by the purchasers, and this excess constitutes rent. Rent, then, is the result of an exchange of unequal services. It is acquired by the owners of the land, but is produced by the 
efforts of the purchasers of the products and, accordingly, by the community in general. The significance of this fact will be considered later.

I8I. Land Values.-The portion $B E$, Fig. 13, of the net income of a productive group which goes to eapital is ordinarily divided into at least two parts, namely rent $B C$ and capital interest $C E$, of which, in many cases, a portion $D E$ accrues as interest to lenders of money. The conditions which determine the first of these parts have now been fully discussed. But, as stated before (131), we must not only find why each one of the three forms of capital brings an income, but also why it is that the rate of this income is practically equal for all three forms. To elucidate this in relation to land, we must ascertain why it is that the ratio of the landowner's gains to the value of his land agrees with the current rate of interest. To this end we must now seek for the causes which determine the value of land.

Since land is not produced by labor, we cannot arrive at its value through the "marginal effort" of its production. Nor can we turn to "final utility," since land devoted to industry and commerce is not in course of consumption, and its utility exists only in a latent or potential state. We must have recourse to the method of "capitalization" (65), by comparison of land with money or with eapital goods on the basis of the one property whieh they have in common, namely the power of bringing an income (190).

It has indeed long been recognized that the value of land depends upon two items, namely, the rent it returns and the current rate of interest, and this relation is usually put in the form of the statement that the value of land equals the rent capitalized at the current rate of interest.

This statement of the case needs qualification in the light of two considerations. In the first place, experience tells that land is subject to continued changes of value, the rule being that land values steadily increase. This increase is known as the "unearned inerement." The owner of land derives a profit from this source as well as from rent. Accordingly, the 
gross gain derived from land is increment in addition to rent.

In the second place, real estate is subject to a tax, and where this tax is in proportion to the value of the estate, the rate of taxation has a reacting influence on the value of the land. The value of real estate consists of the value of the land and that of the improvements. Since the latter must be regarded as capital goods, the tax apportioned to them must here be left out of account. But that portion of the tax imposed on the value of the land has a direct bearing on the subject before us, as it reduces the profits of the landowner.

The net profits derived from land are therefore equal to rent plus unearned increment minus tax, or, putting it in algebraic form, $R+U-T$, where $R$ is the annual rent, $U$ the annual unearned increment and $T$ the annual tax assessed on the land. The landowner retains only a portion of the gross profits.

The unearned increment is governed principally by three conditions: (1) by the gradual increase of rent, for the most part due to the growth of population, to the increase of means of communication and to other conditions that make the location more advantageous; (2) by the gradual change that takes place in the rate of interest which, according to experience, has been generally falling; and (3) by a possible change in the rate of land taxation. A study of the operation of these three causes wonld lead to complications which for our purpose may be avoided by considering, in each specific case, the unearned increment as a known quantity, indicated by past experience.

There are cases of land values which are actually falling. In such cases the unearned increment has to be treated as a minus quantity.

Furthermore, it may also happen that the value of land, expressed in dollars, rises or falls as a result of changes in the value of gold in relation to other things generally. In such case a rise would be merely apparent and would not be an " "unearned" increment at all, nor would such a fall in value be other than merely nominal. 
I82. The Law of Land Value.-The proposition that land values equal the rent eapitalized at the current rate of intcrest is obviously not correct. To put it right, "net profits" must be substituted for "rent" in the statement. The owner of land will sell it only for a sum of money which, when loaned or invested, brings returns equal to these net gains.

This law of land values can be expressed algebraically. Let $V$ be the value of the land, $R$ the anmual rent, $U$ the anmual unearned increment, $T$ the annual tax, $I$ the landowner's profit, $i$ the eurrent rate per eent. of pure interest and $t$ the actual rate per cent. of land taxation $(327,328 a)$. This last rate, it should be observed, is not necessarily the nominal rate of taxation. Where it is customary to assess land a certain percentage below the actual market value, the factor $t$ should be obtained by reducing the nominal tax rate in the same proportion, so that this corrected factor represents the ratio of the tax actually assessed to the actual selling value of the land.

The value of land may then be expressed by the formula:

$$
V=100(R+U-T) \div i \text {. }
$$

By substituting for $T$ its value, $t \times V$, and solving the equation for $V$, it will be found that:

$$
V=100(R+U) \div(i+t) \text {. }
$$

This last equation may be interpreted as follows: Land values tend to equal the gross gains $R+U$, eapitalized at a rate obtained by adding the actual rate of taxation to the current rate of pure interest.

An illustration will make this elear. Suppose a piece of land to bring an annual rent of $\$ 900$, while the annual unearned inerement amounts to $\$ 300$. Let the eurrent rate $i$ of pure interest be 4 per cent. and the rate $t$ of land tax 2 per cent. Accorcling to the last equation the value of this land will be $\$ 1200$ capitalized at $4+2$, that is, at 6 per cent., which will make the value $\$ 20,000(328 b)$. The tax, at the rate of 2 per eent., will then be $\$ 400$ and the net gain aceruing to the landowner $\$ 800$, and this, in fact, represents an income of 4 per cent. on an investment of $\$ 20,000$. 
183. Speculative Land Value.-If we had assumed the simpler case, in which the land value is stationary and the rent of $\$ 900$ the only source of gain from the land, we should have found that the value of this piece of land would be $\$ 15,000$ instead of $\$ 20,000(278,328)$. The excess of the value of the first over that of the second case, namely $\$ 5000$, has been termed "speculative land value"' (361), as it cannot be accounted for by the rent alone, but is due to an expected increase of value likely to occur in the future.

It is quite consistent with the result of our analysis to consider land values as being made up of two items, namely, the value directly due to the rent and that due to the unearned increment. In the above illustration the first item would be equal to the rent of $\$ 900$ capitalized at 6 per cent., or $\$ 15,000$, while the second item would be normal increment of $\$ 300$ treated in the same way, resulting in $\$ 5000$.

184. Division of the Gross Profits Derived from Land.From formula (2) we can derive further information. The net profit $I$ of the landowner equals $i$ per cent., or $i$ onehundredths, of the value of the land, namely:

$$
I=i(R+U) \div(i+t)
$$

and the land tax equals $t$ per cent. of the same value, namely :

$$
T=t(R+U) \div(i+t),
$$

and this in our illustration yields $\$ 800$ and $\$ 400$, respectively.

We find, accordingly, that the total gross gain derived from land, namely $R+U$, is divided into two shares, $I$ and $T$, which bear the same ratio to one another as the current rate of interest $i$ bears to the rate of taxation $t$. The one constitutes the gain of the landowner, the other an income of the community. It follows that the gross profit yielded by land, namely rent plus increment, is really shared between landowner and community, the respective parts having the same ratio as that. which the current interest rate bears to the tax rate. This being true for the sum $R+U$, it is also true if the two items $R$ and $U$ are considered separately $(324,325,327)$. 
The value here discussed is, of course, the value of the land independent of the improvements that may be located on it.

It is scarcely possible to reiterate too often that our reasoning relates to general tendeneies. In individual eases exelianges may be effeeted at rates more or less departing from the results indieated by these formulas.

185. Summary.-In our quest for the causes which eontrol the division of the net income $B G$, Fig. 13, of productive groups, we have seen how one of the items of the division, namely the rent $B C$, is definitely determined. Fig. 20 clearly illustrates the process by which the net income of a group is divided into two parts. To illustrate: the net income $q^{\prime} r^{\prime}$ of the group furnishing the portion $q^{\prime}$ falls into two parts, of which $s^{\prime} r^{\prime}$ goes to the landowner (178), ${ }^{59}$ the other part, $q^{\prime} s^{\prime}$ being left to pay for the serviees of the other forms of eapital and of labor. The eeonomic forees whieh determine this division are universally recognized. Of the three shares : rent, capital returns and wages, the first, namely rent, represented by $B C$ in Fig. 13, equals the advantages which the land employed affords over marginal land, and therefore depends on relative fertility and advantages of loeation.

We have also found why it is that the rate of the total net gains of land ownership in relation to the value of the land itself is as a rule the same as the current rate of interest (131, 267 ), and that the reason lies in the fact that the value of land adapts itself to the interest rate, rising as the rate of interest falls, and vice versa. But what it is that determines the rate of interest we have yet to discover, and until this is found we eannot bring our analysis of land values to a definite conclusion (323).

so The fact that the landowner inust subsequently share his income $s^{\prime} r^{\prime}$ with the community through taxation of the hand camnot react on the division of the net income $q^{\prime} r^{\prime}$ of the group into the two shares $q^{\prime} s^{\prime}$ and $s^{\prime} r^{\prime}$. 


\section{CHAPTER X}

\section{CAPITAL GOODS AND CAPITAL RETURNS}

186. Capital Interest.-A full understanding of capital profits cannot be reached until the causes for all three forms of these profits-rent, capital interest, and money interesthave been found. The rent-producing power has been correctly traced to its origin by Ricardo's law of rent, and with a view of learning whether the power of capital goods and of money to command interest has been similarly traced, we shall now briefly review some of the principal theories that have been advanced to explain interest.

We know from experience that capital goods in productive use yield an income to their owner. The value of things produced by labor with the aid of capital commonly exceeds the cost of their production, when that cost is considered from the standpoint of the owner of the capital goods, that is, when "cost" includes all charges for supplies, for labor and for land, in short, all items of cost except charges for the use of the capital goods employed (61). The excess of the value of the product over this cost constitutes the profits or returns that accrue to capital goods (209).

In the present discourse capital goods must be understood as comprising not only means of production, but goods in course of production as well; not only looms, but yarns also $(132,191)$.

In view of the contentions which so frequently arise between labor and capital regarding the proper sharing of the value of their joint products, it is important that the cause which determines the rate of this division be thoroughly understood.

187. Distinction of Capital Interest and Rent.-The line of reasoning by which rent is explained is apparently not applicable to account for the profits that accrue to capital goods (258). Land exists in various grades-good, medium 
and poor-and the grade of land is not dependent on the efforts of the owner. No amount of cultivation, however intelligently direeted, can make an acre of land in the deserts of Arizona return as much rent as an acre in the centre of the city of New York. Capital goods, on the other hand, are neither dependent on the fickle bounty of nature, nor are they held down to a definite location. Differenees in the income obtained through their use are due principally to their more or less intelligent utilization, and such differences affeet wages of the employer rather than returns accruing to the capitalist. An analogy between eapital returns and rent would therefore seem to be out of the question.

I88. Distinction of Capital Interest and Money Interest. -It is generally taken for granted that the lender of money with which eapital goods are bought is properly entitled to the profits, or a share of the profits, obtained through the employment of those capital goods, on the ground that the lender of the money is really the lender of the capital. But when it is considered that the money itself is always idle eapital and has no capacity for production (134), the proposition that these capital returns, or any portion of them, are payable as interest to the lender of money, simply because capital goods bought with this money can be made to yield returns, is no more self-evident than would be a proposition that the profits of a factory should be turned over to the supplier of hubricating oil, because without lubrieant of some kind the machines could not be operated suecessfully. The interest commanding power of money is therefore not a conscquence of the revenue yielding power of capital goods, and the subject of money interest must be considered apart from that of capital interest (138), even though the one is closely related to the other. We shall therefore first confine our attention to the theories that seck to explain why interest accrues to capital goods employed in the processes of production, and leave the relation of money to interest for subsequent consideration (130). We camnot, however, completely (liminate referenee to money interest when reviewing these theories, for most of these do not recomize the distinction. 
189. Current Theories of Interest.-The power of money to command interest, as well as the disputes regarding the propriety of taking interest, date back to ancient history. It is, however, only in recent times that attempts have been made to explain why it is that money and capital goods possess this power. In the first attempts of this kind, among which those of Calvin and Turgot are to be counted, the power of one form of capital was attributed to the like power of another form. These explanations accordingly fail to go back to the original cause. Subsequently various theories have been advanced in the endeavor to explain the fundamental cause of interest. These theories may be divided into two eategories: first, those which assume interest to be due to natural and inevitable conditions, and second, those which assume it to arise from conditions which are purely conventional and unnatural. The first of these can be subdivided into two classes, one of which comprises those theories that attribute interest to a service rendered by the thing, namely capital, while the other includes those conceptions of the subject which consider the service as being rendered by the owner of the thing, namely, the capitalist.

We have thus altogether to deal with three distinct ideas, namely: (1) the productivity theories; (2) the abstinence theory and its variant, the "Positive Theory of Capital," and (3) the exploitation or socialistic theory.

A very comprehensive review and critical analysis of the earlier theories of the subject of interest is that published by Eugen v. Böhm-Bawerk in $1884 .^{60}$ In this work the defects of the various theories treated are exhaustively discussed, and we need therefore but briefly tonch upon these earlier theories. Böhm-Bawerk's own theory of interest, the "Positive Theory of Capital," however, calls for a more extended consideration.

190. Calvin's and Turgot's Explanation of Interest.-It was during the time of the Reformation, when so many conceptions of ethics were revolutionized, that the reformer John

${ }^{60}$ See list of authors quoted. 
Calvin, opposing the orthodox doctrine that usury should be forbidden, defended the interest of money on the ground that such interest is paid because with the borrowed money may be bought a house or a field from which profits can be derived $(204,237)$. Thus he sought to explain the interest commanding power of money by citing the rent yielding power of a house or a piece of ground. This reasoning has since been aceepted as conclusive without ever being subjected to a eritical serutiny.

Later, in the eighteenth century, Turgot, a prominent exponent of the physiocratic school of political economy, adopted practically the same line of reasoning in an effort to explain the interest commanding power of capital. He observed that capital may be invested either in land or in industrial or commereial pursuits. When invested in land it returns rent: hence nobody would make industrial or commereial investments if these would not also bring profitable returns (205). He thus sought to trace the capability of eapital goods to yield an income to the like eapability of land to return rent.

But this method of reasoning does not elear up the cause of interest. Two things will be exchanged only if both possess eertain qualities which the parties to the exchange regard as equivalent. These qualities must be possessed by the things before the parties will even consider an exchange. The exchange may therefore be accepted as evidence that the two things have equivalent qualities, but does not explain why it is that these qualities are possessed by the objects of the exchange. The money on the one hand and the house or field of Calvin on the other were exchangeable for the reason that each possessed the power of bringing a revenue (181), but the power of money to bring a revenue is not a result of the fact that money is exchangeable for land. The exchangeability is only a manifestation of the fact that both money and land have this power, but does not explain the why and whercfore. The same objection holds good against Turgot's argument, inasmuch as the interehangeability of land and capital goods as investments is accepted as a premise. 
I9I. The Productivity Theory of Interest.-The most prevalent way of accounting for capital returns is to accredit capital goods with the faculty of assisting labor. It is held that capital, by assisting labor, earns interest for its owner.

This theory receives wide acceptance because, at first sight, it appears to agree with facts and seems very plausible. Yet, on closer examination, it proves unsatisfactory. Many facts are distinctly out of harmony with this proposition. Capital goods which return profits consist not only of means of production, but also of the goods which are being forwarded to maturity (186). A productive faculty might apparently be imputed to means of production, like looms or other tools, but certainly not to the goods in process of production, like yarns that are being woven into cloth. It cannot be said of yarns that they assist the workman to weave cloth, nor can it be said that by the use of yarns the making of cloth is facilitated, so that he who furnishes the yarns should obtain more than their value by reason of the assistance which the yarns render in the making of the cloth. Yet we know from experience that profits accrue alike to means of production and to the goods in course of production. An explanation of capital returns, to be really valid, must be applicable to all forms of capital goods that actually return profits in the nature of interest.

We have already seen (132) that capital goods are immature products, the embodiment of past labor, to be utilized through future labor in the production of mature goods, and that the efficiency of modern methods of production is due to the use of preceding inventions and discoveries. The increased productivity of labor, when more efficient and incidentally more complex methods of production are employed, is usually accredited to the greater amount of capital employed. But it is by no means clear why this credit should not be given to progressive invention and improvements in methods of production. The claim that capital is producing this effieiency, or at least helping to produce it, requires to be examined. 
I92. Analysis of the Productivity Theory.-Let us assume that by a newly invented machine the cost of manufacturing stockings is materially reduced. While the inventor holds it patent, he is able, by making such machines and renting them out, to obtain an income proportionate to the benefit his invention bestows. But this is changed when the patent expires, and the right to make and sell similar maehines becomes public property. The manufacturers then bny machines instead of renting them, and at first they make a handsome profit, since they need no longer pay royalty for the use of the machines. However, the lucrative trade of making stockings attracts other manufacturers, and the increased output of these goods lowers the price, so that the consumers reap more and more of the benefit of the invention. This process takes place gradually. The profits obtained through the use of the machines gradually shrink as more machines are brought into use, and the price of their output is reduced. The question now arises, at what point will this process come to an end?

It is obvious that more capital will be invested in such machines so long as the profits that ean be derived from their use exceeds the profits which eapital invested otherwise usually brings; hence the increase of those machines will cease when profits on capital invested in them fall to the current rate of capital returns.

Thus, if capital otherwise invested did not have the power to yield an income, the number of these machines would be increased until the income on their use is reduced to the level of what other capital yields, namely to nil. We must therefore conclude that capital invested in these machines continues to retum interest, not because the machines reduce the cost of production, but because other investments afford eapital interest. The productivity theory of interest simply assumes the very thing which it undertakes to explain, namely that invested capital affords a profit in the form of interest. 'The (guestion as to why capital brings an income is not answered $(243 a)$.

According to our former study (149) one of the eflects of competition is that of conferring upon the consumers all 
benefits arising from improvements in methods of production. But according to the productivity theory of interest this is only partly true, for it is claimed that a portion of this benefit rightfully belongs and naturally goes to capital (243b). If the productivity theory were correct, it should be possible to point out the economic force which defeats the fundamental law of competition.

The endeavor of the French economist Bastiat to explain why it is that interest accrues to capital has the same shortcoming. This writer illustrates his argument by the case of James who has made a plane which he loans to William for a year, to be used in planing planks. At the end of the year the plane is worn out, and William makes a new one which he hands over to James in return for his loan, and with it he gives him a plank to pay for the advantage which the plane afforded.

Whatever it may have been that induced William to agree to pay a plank as interest, an isolated case cannot establish the rule on which the power of capital is based. William would certainly not agree to borrow the plane of James on condition of paying a plank, if John, another carpenter-who had needed for his own work a plane that would last him a year, but had made two, because he could make these in less than double the time required to make one-were to offer the loan of his second plane to William on condition of getting back a new and equally good one at the end of a year and only half a plank for the use of the one loaned. Suppose, furthermore, that there were yet others besides John who had made more planes than they had immediate use for. It is then quite conceivable that in view of saving the trouble of their storing and the risk of their shrinking or cracking or of their being stolen, competition will bring down the recompense for lending planes to the point of merely a return of a new plane in the place of the one loaned. The examination of the case must evidently be extended to the general market by assuming that the lending of planes is a business which some of the plane makers carry on in addition to making and selling planes.

So long as capital invested in the lending of planes brings 
an income exceeding the return of capital invested otherwise, the number of plane lenders inereases, and through competition the hire of planes comes down. On the other hand, when these profits are below the current rate of returns from other forms of capital, the plane makers prefer to sell the planes and to invest the money received in some other way, until the hire of planes rises again by reason of the lessening competition among plane lenders. In the end the profits from lending planes adjust themselves to the current rate of profits commanded by capital generally.

It is thus apparent that Bastiat's illustration can account for the willingness of William to pay a plank for the loan of the plane only by assuming that eapital generally has the power to command interest, and since it is wrong to assume that which is to be proven, it follows that Bastiat's illustration fails to explain interest.

I93. Interest Ascribed to Nature's Reproductive Powers. -The reproductive powers of live stock have furnished a favorite argument in accounting for interest. Thus Jeremy Bentham, in criticising Aristotle, who condemms interest on the ground that "all money is in its nature barren," argues that:

A consideration that did not happen to present itself to that great philosopher, but which, had it happened to present itself, might not have been altogether unworthy of his notice, is, that though a daric would not beget another daric, any more than it would a ram, or an ewe, yet for a daric which a man borrowed he might get a ram and a couple of ewes, and that the ewes, were the ram left with them a certain time, would probably not be barren. That then at the end of the year, he would find hinself master of his three sheep, together with two, if not three, lambs; and that, if he sold his sheep again to pay back his daric, and gave one of his lambs for the use of it in the mean time, he would be two lambs, or at least one lamb, richer than if he had made no such bargain. ${ }^{n 2}$

Bentham's illustration concedes on the one hand that money is barren and implies, on the other, that the income accuing from the vital power of the sheep is in the nature of interest. 
Yet we are told that the owner of sheep sells them for a daric. This assumption is not consistent with the premises, for no one who has a goose that lays golden eggs will give it in $\mathrm{cx}-$ change for a common goose. From the premises it would follow that the seller of the sheep, at the end of the year, would be two lambs, or at least one lamb, poorcr than he would have been, had he not made that bargain. It cannot be assumed that the seller of the sheep was a fool. There must be some flaw in Bentham's argument, for the sellers of sheep are, as a rule, as shrewd as the buyers. The fault is obviously in one of the premises. The housing, feeding and raising of the sheep and lambs require labor which the seller of the sheep desires to avoid, and without the performance of which the buyer of the sheep could not become the owner of the lambs; and under free competition the value of the accrued lambs would adjust itself to correspond with the value of this labor. The value of the lambs would therefore represent wages and not interest, and Bentham's logic falls to the ground. ${ }^{62}$

194. Interest Theory of Henry George.-No more conclusive than the foregoing is the theory of Henry George, according to whom:

Interest springs from the power of increase which the reproductive forces of nature, and the in effect analogous capacity for exchange, give to capital. ${ }^{63}$

In this statement the author refers to forces of nature which are accessible to all who choose to avail themselves of their benefit, for in another passage he speaks of them as being available at the margin of cultivation. If they were in some way limited and available only on intra-marginal land, the income they render would come under the head of rent, not of interest. On the other hand, those forces of nature which are available withont hindrance cannot be monopolized and cannot, therefore, have any value, and having no value, the value of that which is produced by their aid cannot exceed the value of the efforts necessary to utilize the forces. This value is wages, not rent nor interest. It is manifest, on examination, 
that the theory of interest advanced by Henry George is based upon a confusion of the premises.

\section{I95. Inception of the "Abstinence" Theory of Interest.} -The abstinence theory has really been evolved from the doctrine that interest depends upon the supply and demand of capital goods. According to Ricardo:

The rate of interest is not regulated by the abundance or scarcity of money, but by the abundance or scarcity of that part of eapital not consisting of money. ${ }^{\text {t }}$

This statement implies that labor employed in conjunction with capital is below its maximum efficiency because the available amount of capital is limited (162, 214, 242, 316). An increase of eapital would, accordingly, enluance labor's productivity and at the same time reduce the interest rate. This phase of the subject has been fully discussed before (157-161) and graphically illustrated in Figs. 14-19. Let us analyze Ricardo's idea more fully.

If $O C^{\prime \prime}$ of Fig. 18 represents the available amount of capital, then $C^{\prime \prime} e^{\prime \prime}$ represents its final efficiency, $O I$ the rate of interest, the area $O C^{\prime \prime} e^{\prime \prime} E$ the corresponding output of the labor employed, and the area $O C^{\prime \prime} e^{\prime \prime} I$ that portion of the output which goes to tho eapital $O C^{\prime \prime}$ as interest. Let us suppose that the ordinate $O I$ represents a rate of interest-pure interest-of 4 per cent. If now the eapital were increased by $C^{\prime \prime} C^{\prime \prime}$, the output of the same labor would be increased by the area $C^{\prime \prime} C^{\prime \prime} c^{\prime} c^{\prime \prime}$, and the rate of interest would be reduced to $O i$, say, 2 per cent. But according to Ricardo's assumption this additional output is not sufficient to induce the production and employment of the additional capital $C^{\prime \prime} C^{\prime}$, for it is plain that if an additional supply of capital were forthcoming, the rate of 4 per cent. could not be maintained, and interest would fall. 'The question thus arises, why is it that the production and employment of capital does not go beyond the point where capital brings the current rate of interest? This line of inquiry points to the existence of some impediment to the pro-

" Ricardo, p. 284. 
duction of eapital, and this impediment is currently considered to be of a psychological nature.

196. Senior's Abstinence Theory.-The above idea made its appearance among the earlier writers who held that men would have no inducement to produce and invest eapital if there were no adequate reward for their doing so. It would thus follow that interest is necessary as an incentive to industrial progress. Senior was the first to formulate this view into a definite theory. He attributed to man an inborm reluctance to save, a trait analogous to the reluetance to work. Just as the disinclination to perform work is overcome by the prospective value of the product, so is the reluctance to save overcome by the anticipated interest aecruing for deferring the enjoyment of past productions to a later time. The service for which interest is the natural recompense is "abstinenee," 65 just as labor is the service for which wages are paid (242). This reluctanee to save is supposed to fully account for that searcity of eapital through which interest can be explained.

This theory was by many considered conclusive, but its weakness has been reeognized by a gradually increasing number of students. The assumption that wealth will not be produced and saved for further use in production, unless the "abstinence" involved in such use of wealth obtains compensation in some form, is wholly inconsistent with the fact that there are times when the market supply of products of all kinds is so much greater than the demand that this condition is generally regarded as due to "overproduction." Moreover, there are other inducements besides interest for saving and investing eapital which can account for all the eapital now extant (318). A re-statement of the abstinence theory appeared to be necessary to save it from being totally discredited by the accumulating objections, and this was pre-

as It is obvious that abstinence, in this sense, is a misnomer, since the saver of wealth who permits it to be used by a productive group does not really abstain, that is, relinquish the enjoyment of his aceumulated wealth; he merely defers its nse for gratifying his own desires. For this reason the term "waiting" has been used instead by many modern writers. 
sented by Böhm-Bawerk in his "Positive Theory of Capital.", 6 In this theory the negative concept "abstinence" is replaced, as a fundamental premise, by the positive idea "evaluation," and particularly, the difference of evaluation of present as compared with future benefit.

As this is by far the best presentation, the abstinence theory must stand or fall with it. We shall therefore subject only this latest statement of the theory to a critical examination, preceded by a brief summary of the same. ${ }^{67}$

197. Böhm-Bawerk's Theory of Interest.-The "Positive Theory' 'is based on the postulate that:

Present goods are, as a rule, worth more than future goods of like kind and number. ${ }^{\text {es }}$

In this postulate the term "present goods" means goods ready for immediate consumption, and also money in hand. Among "future goods" are included not only goods and money receivable in the future, but also goods in hand which are not yet adapted for consumption, namely capital goods.

The difference in the evaluation or rating of present as against future goods is regarded as being the combined effect of a series of causes which, though of different nature, exert their influence in the same direction. Three principal causes are enumerated. The first consists of the difference of the relation of demand and supply at different periods. ${ }^{60}$ This may be excmplified in the ease of a farmer who has lost his crop and needs immediate relief, or in the case of, say, a young physician who is in need of means for his establishment and looks forward with confidence to his more prosperous future. In such eases it is less hardship to return a greater value in the future than to sufier for the want of a lesser

es See list of authors quoted.

"The argument here adduced is the same as that presented under the title: "Analysis of the Nature of Capital and Interest," by II. Bilgram, Journal of Political Economy, March, 1908.

ro Jïhm-J3awerk, 11, p. 237 (248). Numbers in parentheses refer to the German edition.

Ilide, [1]. 249 (262) $\pi$. 
value at present. The second cause adduced is of a purely psychological nature, namely the propensity of man to underrate future pleasure and pain simply because they are remote (242). ${ }^{\text {io }}$ The postulate put forth as the third cause ${ }^{i 1}$ is really an elaboration of the first and second causes in their relation to the proposition that

the roundabout ways of capital are fruitful but long, ${ }^{72}$

in the sense that the time intervening between an effort of production and the realization of the utilities resulting from the effort increases with the adoption of more complex though at the same time more efficient processes of production. Thus, if an employer has at his disposal, say, one month's labor, in other words, so much capital, he may proceed to employ it with greater or less efficiency, according as he selects a more or less complex system of production. If he wants "present goods" quickly, he obtains less goods from the same amount of capital by the use of simple methods of production than if he chooses a more efficient method that yields the finished products after a longer interval. The amount of goods obtainable from a given quantity of capital with a more complex and protracted method of production is therefore in the end greater than with a simpler and quicker one.

It is pointed out, however, that the greater quantity of goods obtainable by a more complex method, but only after a greater interval of time, has not a correspondingly greater present value, because future goods are underrated in comparison with present goods. As the lapse of time involved in the use of more complex methods of production becomes greater, there is a point of diminishing returns beyond which the gain due to the increase of the products is overbalanced by the underrating of the value on account of the greater lapse of time required for the production.

In comparing different methods of gradually increasing complexity and corresponding delay, it will be seen that the present value of the future products into which a given amount

${ }^{\text {70 }}$ Böhm-Bawerk, II, pp. 253 (266) ff.

"I I id., pp. 260 (273) ff.

Ibid., p. 82 (87). 
of capital goods is finally converted reaches a maximum at the point of diminishing returns. This highest present evaluation of the future products determines the value of the eapital goods. According to this theory the present value of capital goods equals the discounted or underrated value of the final product obtainable from the capital (198), always assuming, of course, that this latter is being employed in the most advantageous way.

Upon these propositions Böhm-Bawerk bases his theory of interest. IIis conclusions are summarized under three heads, the first relating to the subject of loans and interest on loans; the second to employed capital goods and the returns therefrom; and the third to interest derived from enduring goods, such as means of production in general, the treatment under this head being little more than an elaboration of the discourse under the second heading.

A loan is viewed as an exchange of present for future goods. ${ }^{73}$ The lender gives a present sum of money in exchange for a future sum. But money receivable at a future time being underrated as compared with the same amount in the present, it follows that a future sum of money, in order that it shall have a value equal to the present sum, must be greater in amount. In giving a greater amount of future money in exchange for a lesser amount of present money, the borrower gives equivalent for equivalent; and when the future becomes present and the debt becomes due, the debtor pays the greater amount in cancelling the debt. Where the loan is absolutely secure and all charges for risk and supervision are eliminated, the excess of the amount ultimately returned by the borrower over the amount originally advaneed by the lender is "interest."

The potential utility of eapital goods, like that of machinery that wears out, or like that of material that is used up in course of production and incorporated in the goods produced, is to be regarded as having entered, through a process of economic metamorphosis, into the final products and as composing the

73 Böhm-Bawerk, 11, pp. 28.5 (299) $/$. 
utility of the consumption goods (10). The consumption goods must accordingly be considered as an aggregation of the several different kinds of capital which, in their matured and assimilated form, have entered into the aggregation. The value of the aggregation is due to its final utility, and the value of each of its components is a part of the aggregate value.

Aecording to the undervaluation theory the value of any capital good depends upon the value of its respective part of the final product, and this being a future value, its undervalued or discounted amount is the present value of the capital good.

While capital is being forwarded and converted from its present form into its final condition as part of the final product, its present value-the discounted future valuegrows to full rate, and the inerease constitutes the interest that accrues to eapital. ${ }^{i 4}$ It goes without saying that this inerease in the value occurs only while the capital is being advanced toward its final stage, that is, while being utilized in production. While capital lies idle, while its latent utilities remain in statu quo, interest cannot arise. ${ }^{75}$

This is in substance the reasoning through which BöhmBawerk explains interest, but it is clear that his theory does not differ essentially from Senior's Abstinence Theory. Senior proceeds on the proposition that the owner of goods available at present is averse to defer their consumption-to "abstain" or "wait" - and when he does so for the benefit of others, he is entitled to compensation for so doing. BöhmBawerk proceeds on the proposition that goods available in the future are evaluated lower than the same amount of goods available now. Since it is obvious that the giving of one thing of value for another thing of less value involves a sacrifice and is contrary to human nature, it follows that both these propositions are merely different ways of expressing the same fundamental thought. Hence the "Positive Theory", cannot be valid if the "Abstinence Theory" is untenable, and that the positive as well as the negative form of the proposition is open to question will appear from the following.

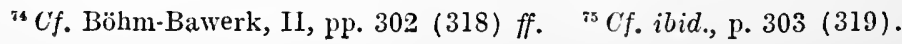


I98. Utility Theory of the Value of Capital Goods.-As we have just seen, the faculty of employed capital goods to return interest is explained on the basis of two assumptions: (1) that future goods are evaluated at less than present goods of like kind and number, and (2) that the value of eapital goods depends on the value of the final consumption goods into which they become eonverted through produetive proeesses.

Consumable goods are produced through a number of consecutive and collateral processes, in each of which a certain amount of eapital is contributed to their existence. The goods are accordingly the aggregation of all these several amounts of capital in assimilated form.

The number of operations necessary to produce consumption goods is, as a rule, indefinite, but in order to present a concrete illustration, let us assume that the making of eoats, for example, requires but four, namely those performed (1) by the maehinist, making looms, (2) by the spinner in making yarns, (3) by the weaver, turning yarns into eloth, and $(t)$ by the tailor, making the cloth into coats and selling them. The product of each operation is regarded as so much eapital. We may suppose, for the sake of argument, that, ont of 100 coats, 4 are to be eredited to the capital "loom," 30 to the capital "yarns," 26 to the eapital "weaver's effort," and 40 to the eapital "tailor's effort."

Taking these proportions as a basis, the share of the final product to be eredited to a loom on which the eloth for 20,000 coats, each worth $\$ 10$, ean be woren, amounts to 4 per eent. of the total number, namely 800 coats, and the value of this share is $\$ 8000$.

But since the life of a loom is, say, 12 years, and the conversion of the loom into cloth, and nltimately into coats, takes place gradually, the purchaser of a loom can realize its proper share only in instalments during a gradually increasing period, the average of which is 6 years. Aceording to the ntility theory, the value of the loom to the weaver becomes determined as follows. The value of the final products into which the loom can be converted is $\$ 8000$. But as this value can be realized only in the future, alter an average period of 6 years, the sum of $\$ 8000,6$ years henee, is estimated by the 
weaver at a present value of only about $\$ 6000$. Hence the value of the loom, and accordingly the machinist's share for making it, would be $\$ 6000 .^{76}$

But now comes the question which the utility theory leaves unanswered. How is the user of capital goods, through whose efforts they are forwarded toward their final condition, to know what fraction of the total value of the consumption goods that will ultimately be obtained is really to be credited to the one and to the other of the several different kinds of eapital that are being used up in making the product? In other words, what share of the total number of coats is due to the loom, what share to the yarns, and to the capital produced by the weaver's effort, and to that produced by the tailor's? The weaver, when he comes to buy a loom, knows from experience that a loom is good for 12 years' use and that in using it up the cloth woven on it will be enough to make 20,000 coats, each worth $\$ 10$ when finished. But how is he to know that the part which the loom is supposed to contribute to the ultimate product is so and so much? The determination of the value of the various items of capital making up the final product being the question at issue, it cannot be assumed that the value of any one of these items is already known. While the share of the coats which is due to the loom has here been assumed as being 4 per cent., there is nothing to show how it comes to be that percentage or any other, and the value of the product into which the loom is finally converted being unknown, it cannot be the starting point in the determination of the value of the loom itself (197). It follows that the utility theory of value is inapplicable to capital goods, such as the loom of our illustration, for if the weaver has no means of judging what portion of the final consumption goods is due to the use of the loom, he cannot gange the future utility of the loom, nor the value which, when discounted, is alleged to be the value of the loom.

${ }^{70}$ The figures here used are only for the purpose of illustration. We have assumed that only four instead of perhaps a hundred different operations go to the making of the coats, hence the sum credited to the loom appears abnormally high. 
While final utility does indeed determine the value of coats, the sharing of this value among the various agents that cooperated in their production ean be determined only on the basis of the amount of effort given by each toward the attainment of the result. In the determination of the value of eapital goods effort, or cost, is as much an essential factor as is the utility of the final produet.

I99. Time Involved in Production with Capital.-One of the essential premises of the Positive Theory of Capital, as applied to "enduring" eapital goods, is the assumption that the indirect or capitalistie methods of production, though more efficient than the primitive methods, take more time. Actual faets do not bear out this assumption, as may best be shown by a eonerete example.

Let us compare the primitive with the modern method of producing knit gloves on the following supposition.

One workman, knitting by hand, ean finish one glove per hour, or 10 per day (30). 'The modern method requires a set of four machines, each performing a different operation. Four workmen ean make these machines in 3 years and then, by their use, ean finish 160 gloves daily. In 20 years of 300 working days each, or after the eompletion of 960,000 gloves, that is, 480,000 pairs, these machines are worn out.

The modern method is of a composite nature. The first efforts toward the making of the gloves are applied to the building of the machines, which latter thereby become the embodiment of a certain part of the labor neeessary to make gloves. These maehines represent 960,000 gloves in a partly finished state, and subsequent efforts of a different nature are required for finishing the produet. These subsequent efforts are those of operating the machines, whereby the finished goods are obtained. The first one of the gloves will be finished after the expiration of 3 years, eounting from the beginning of the work; the last one 20 years later, namely at the close of the twenty-third year. From the beginning of the fourth to the elose of the twenty-third year the produetion of finished sloves will keep on at a uniform pace, hence the average time 
elapsing between the very beginning of the work and the production of completed goods is 13 years.

How does this contrast with the primitive method? The same four men, if knitting by hand, will complete 4 gloves in the first hour and will then begin another lot of 4 . In making each glove only one hour will elapse between the bcginning of the work on it and its completion, and it would appear that the reasoning of the "Positive Theory" proceeds on the basis of a comparison of this period with the average time of 13 years of the preceding case.

This comparison, however, is based on unequal premises, as the time of making 4 gloves cannot reasonably be contrasted with the time of making nearly a million. The four machines embodied part of the labor applied toward the making of 960,000 gloves. While the machines were being made, the work of producing this quantity of goods was being uniformly advanced, and even the first hour's work on the machines was as necessary for the production of the last glove as it was for that of the first one. To make the comparison reasonable, it should be based on the production of equal quantities. The period of 13 years is the average interval between the first effort and the completion of 960,000 , not of 4 gloves. To make this larger number by the primitive method, four workmen would have to work 80 years, which corresponds with an average of 40 years expiring between the beginning of the work of making this number and the producing of the finished goods. The comparison, then, is obviously in favor of the capitalistic method, in the proportion of 13 years to 40 .

At the same time, the fact must be admitted that at the beginning there is a period in which the balance is in favor of the primitive method. Should two groups, each consisting of four workmen, begin work on the same day, one group adopting the primitive, the other the capitalistic method, the first group would at once come into possession of "present goods," while the second group would not have a single glove finished until after 3 years of labor; and in addition to this time, one year more would be required by the second group to overtake the first. But thereafter the second group would 
come into possession of present goods in the form of finished gloves so rapidly that the first group would be left far behind. Even if a second period of 3 years were spent in the making of another set of machines after the first set is worn out, the second group, 26 years after the beginning of the operation, would still have, in addition to the new machines, an excess of 648,000 gloves over the production of the group that had adopted the method that brings first results quicker. Both this excess and the new machines are a clear gain, in quantity as well as in time, resulting from the adoption of the capitalistic method of produetion. After the expiration of that initial period of 4 years the second group will never again fall behind the first, but will forever remain far ahead in the possession of "present goods" which will be forthcoming more rapidly, by an equal expenditure of labor, than the first group can ever hope for. As regards the production of "present goods," the first group has an advantage over the second only for a few years after the first introduction of the improved method. It is obvious that the method which affords such an excess of products, the method by which the total time for completing an equal quantity of goods is reduced from 80 to 23 years, cannot in any sense be considered the more time-consuming one. Instead of involving sacrifice of any sort, the capitalistic method is a source of gain in time as well as in every other respect after once the initial period has been passed. Only for this period is it true that capitalistic methods of production involve a sacrifice in time.

It is to be observed that this period of 4 years falls within the time when the more productive method displaces the less productive. It is not repeated each time a new set of maehines is made, for the excess of production attained through the use of the preeding set of machines far more than covers the loss of time required for making a new set. The period duling which the first group has an advantage over the second is not a concomitant of regular capitalistic production, but attends only the process of displacing antiquated by improved processes of work.

Were a comparison made between two capitalistic methods, 
of which one is more productive than the other but requires the use of a greater amount of capital, the former, after the brief period of waiting incident to the introduction of the more productive method, would be found to be the quicker. It can therefore be definitely asserted that-barring a brief period attending the change from a less to a more efficient method-the most productive method is by all rules of logic also the quickest. Modern methods, instead of delaying production, actually hasten the same. After the period of transition is past, they invariably bring "present goods" more rapidly into the possession of the producers than do the more primitive methods.

This conclusion can be further confirmed. Suppose a community which follows the primitive method above described has on hand a supply of gloves meeting the demand for one year. Under these conditions it is immaterial, whether each glove maker continues production by fully completing one piece after another, or by simultaneously advancing his year's product of 3000 gloves, forwarding the work on all from stage to stage, so that he will have at any time the complete number of partly finished instead of a smaller number of finished gloves on hand. If then one of the glove makers, imbued with the idea that present goods are more valuable than future goods, were to complete piece after piece, he would be unable to score any gain over those who select the method of simultaneous production, as in both eases it takes 3000 hours to make as many gloves, and on account of the stock on hand the demand for the new gloves does not realize before the close of the year. But when the mode of simultaneous production is improved through the introduction of the roundabout or capitalistic method, the time of producing the goods is invariably reduced, and it is therefore unreasonable to ascribe to the use of capital the supposed disadvantage of the postponement of the completion of "present goods," which is really due to the use of the simultaneous method of production. It is the simultaneous and not the capitalistic feature which gives the method the appearance of being 
"long." When the facts are correctly analyzed, they show that the use of capital invariably hastens production.

This is in direct conflict with the proposition which forms part of the groundwork of the "Positive Theory." $\approx$ It is true, a group employing primitive methods can realize an income on the sale of their goods from the start, which a group introducing a capitalistie method cannot do. But this latter group gains a greater reeompense for their efforts after a short initial period. This greater reeompense is however uages for more efficient serviee and is not to be confounded with capital interest. The "Positive Theory" clearly fails to explain the power of capital goods to return "interest."

200. The Value of Lending.-Nor can this theory be applied with any better success to the explanation of pure interest on money loans. The diseussion of money interest should properly be deferred to the following chapter, but in order to avoid a break in the argument it is advisable to include in the present discussion also that part of the Positive Theory which relates to money interest. We shall therefore next deal with the proposition that a loan is an exchange of present for future goods and that interest accrues to the lender beeause present goods are prized higher than future goods.

It camnot be denied that it is in human nature to underrate future pleasure and pain. There are not a few who prefer present goods to those of the future and who evince their dislike for present eftort by putting off work to the last moment.

But it is equally true that there are others who prudently provide for the exigencies of the future. They recognize certain definite advantages which future goods lave for them over present goods, and therefore value those future goods

7r "The disadvantage connected with the capitalist method of production is its sacrifice of time. The roundabout ways of capital are fruitful but long; they procure us more or better consumption goods, but only at a later period of time. This proposition, no less than the former, is one of the ground pillars of the theory of capital."-Bïlnnbawerk, 11, 1, 82 (87). 
higher than the present. In other words, they save present goods for future use. Of their own accord they deprive themselves of some present pleasures in order to provide against possible want at some future time. The question therefore arises, which of the two influences is the greater economic force?

The "Positive Theory" is founded on the assumption that the under-estimation of future pleasure and pain as compared with the present is the dominant propensity, in other words, that the preference of immediate over deferred consumption and the disposition to put off exertion to the last moment predominate. A future and consequently under-estimated sum, to be equal in value to a present sum, must be greater. Hence he who gives a certain present sum in exchange for a larger future sum, the present value of which is equal to that given, and waits for the larger future sum to become present, gains the excess, which is interest. It is therefore altogether appropriate to designate the service given by the lender as "waiting," meaning by this term a putting off of the enjoyment of goods in hand for the benefit of others. The lender sells "waiting" and the borrower buys it. "Waiting" thus bccomes a service having a market value. The price which the borrower pays for the service rendered him by the lender's waiting is interest. The interest question is thus reduced to the question: What is the value of this service?

The service rendered by the lender through "waiting" may at times have a utility of the highest degree. Circumstances may arise under which it will save life, as in the case of a farmer whose erop has been destroyed by hail and who must starve if others are not willing to lend him the means of subsistence, an equivalent of which he could without difficulty return to the lender from next year's crop. From this utility of highest importance the possible utilities or advantages that may be derived from the lender's "waiting" range down through all grades of importance to the vanishing point. Therefore the value of the service of lending comes within the range of the law of value, and according to the utility theory of value it depends upon final utility. 
In his elaboration of the law of value Böhm-Bawerk has clearly shown the process by which the final utility of a commodity, and with it its market value, is determined; and his reasoning must, of course, be applicable not only to goods, but to all forms of service as well. Accordingly, the final utility, and with it the value, of "waiting" is measured by the importance of that conerete want which is least urgent among the wants that are met from the available supply of "waiting." 78

It is here where the theory elashes with facts, especially during periods of business depression, when producers, almost without exception, are encumbered by an accumulation of products for which they are unable to find a market. The supply of produced things, and the supply of labor especially, vastly exceeds the effective demand. The wheels of industry come to a partial standstill, not, however, by reason of the propensity of men to postpone productive effort, for both manufacturers and workmen are anxiously seanning the market for every opportunity to resume work that has been interrupted by an apparently occult force. If the status were reversed, if the supply of labor and its products were below the effeetive demand therefor, the hypothesis might be entertained that an underrating of the future and a consequent desire to shirk work is the prevailing eondition. But the facts are otherwise. Everywhere production has run ahear of eonsumption. Producers are foreed to make the sacrifice of "waiting" without any hope of recompense for it. On all sides the supposed benefits of "waiting" irretrievably go to waste. The supply of the service "waiting" far exeeeds the demand, for otherwise it would not be wasted. The "least urgent want met from the available stoek," that is, the final ntility, of "waiting" is at the vanishing point; hence, according to the aceepted theory of value, the value of this service, like the value of air and of water, is nil (242).

Under our existing economic conditions, in which producers are constantly looking for markets for their surplus

${ }^{74}$ Cf. Jïlum-Bawerk, II, p. 148 (157). 
productions, the conclusion which we have reached, namely that the value of "waiting" is nil, is indisputable.

But conditions can be imagined under which the final utility, and with it the market price, of "waiting" would lave a positive value, and under which the reasons advanced in support of the "Positive Theory" would be operative, so that the value of "waiting" would naturally and properly accrue to the "waiter," the lender.

Let us suppose that a number of men, shipwrecked on an island, have gathered stores of food for the winter, and that some have succeeded in accumulating more than others. Suppose, further, that the stores of the less fortunate are insuffcient to maintain them until the erop of the next season becomes available, while others have some food to spare, but not enough to supply the demand of those who need more, without stinting themselves to some degree. Since food, in this case, is the only form of wealth, buying and selling is out of the question, and those who need more food can obtain it only by borrowing. There will, accordingly, be a market demand for the borrowing of food, and only a reluctant supply for lending. The intending borrowers not only offer to return an equivalent of the borrowed amount, but are willing to pay a premium in addition, while the lenders can be induced to forego the satisfaction of full meals during the winter only through the offer of a recompense. There is an upper limit to the premium the borrowers are willing to promise, as well as a lower limit to the premium lenders require for their "waiting" and consequent loss of comfort, and these limits can be represented by curves like $D D^{\prime}$ and $S S^{\prime}$ of Fig. 6 , The market rate of the premium is then manifestly determined at the point of intersection of the two curves. In the concourse of the market, so to speak, the recompense for lending adapts itself to the point where the desire to borrow and the reluctance to lend come to equality.

It is to be observed that this limit can have a positive value only if the supply of food actually gathered is not sufficient to fully satisfy all during the time before the next season, for if any of the stores were to remain unconsumed by the time the 
next erop is gathered, the final utility of "waiting"' would be nil. ${ }^{-9}$

The above reasoning may be applied to the lending of other commodities, and of money as well. Unless the marginal lenders, the lenders who supply the least urgent want, are obliged to deprive themselves of some definite eomfort by "waiting," there ean be no final pain of abstinenee, nor ean the preference for future over present goods make itself manifest as a factor in competition. In the presence of any such eondition as that known as "overproduction," the final utility of "waiting" cannot have a positive value.

201. Relation of Money to Merchandise.-Notwithstanding that "waiting" has no positive value, manufacturers and merehants, men who have produeed goods in advance of the demand therefor, and who must therefore hold these present goods until some future time without any hope of recompense for the "waiting," are the very ones who flock to the banks and the money lenders, seeking to obtain present money in exchange for future money, seeking to buy the service of "waiting," while they themselves are forced to let their own "waiting" go to waste. In the light of the "Positive Theory" they are purchasing the service of advanee produetion, that is to say, the service of the exchange of present goods for future goods, paying a high and often ruinous price for the service, while they themselves have a surplus of present goods and are "waiting," not only without recompense, but at further cost of lieeping the present goods for the future. It is simply ineoneeivable that producers have so little understanding of their own interest as to pay other's for "waiting," while they let their own "waiting" go to waste.

When the reason which manufacturers and merehants have for borrowing money is more carefully examined, it will be seen that what they seek is not the service of "waiting," but the peculiar service that only money ean perform, namely

"We must of course assume that in this illustration the element of risk is absent, for the problem of pure interest must be viewed apart from the item of insurance. 
that of making payments in the course of business. A partiality for money can be observed not only among borrowers, but also among possessors of wealth who are offering it for sale.

What is the reason of all this desire to get money? A strongly marked demand for money in exchange for products is manifested in every province of the industrial and commercial world. The struggle of competition resolves itself into efforts to get money for merchandise (345). Vast sums are expended in the process of selling. Efficient salesmen command high salaries. Even unfair means are at times resorted to in efforts to drive competitors from the field. The ceaseless search for markets and the persistent efforts to sell are reflected in the prevailing belief that the prosperity of nations is enhanced when they export more than they import, when they send out more present goods than they receive. This belicf induces governments to encourage selling and discourage buying, promoting exportation by bounties and impeding importation by tariffs. Even wars have been waged for the purpose of securing foreign markets for the lome products. Indeed, the persistent outcry for tariffs during the so-called periods of prosperity as well as during times of depression irrefutably proves that there is a constant excess of the supply of things over the effective demand, and a constant preponderance of unrequited "waiting," not only during periods of business stagnation, but at all times. Well may we ask, why is it that the mere medium of exchange is so much more in demand than products, the very objects of exchange (204, 211)? Can the "Positive Theory" furnish an answer to this question? Since money more than any other form of wealth is sought by would-be borrowers, the theory that accounts for interest should afford light on this question. Let us see.

202. Money Never "Present Goods."-Of the goods that are offered in the market some are near the point of economic maturity, others are not. Some are practically mature or present goods, like foodstuffs, clothes, furniture, articles of luxury. Others are immature goods, such as cotton, drygoods, steel rails, machines. They require a greater or less time for their conversion, by industrial or other processes, into consumable goods or desired services. All of them are 
adapted to render gratification, directly or indirectly, sooner or later, after their sale is effected.

But what is the status of money? What gratification does it offer to the consumer? Neither borrowers who obtain money in exchange for their credit, nor manufacturers, merchants and workmen, who accept money in exchange for goods or services, do so with the intention of actually using it up. Those who accept money in exchange as well as those who borrow it expect to part with it without altering its condition. The utilization of money in the way of bodily consumption is not sought by those who acquire it; and not being adapted to be consumed by its holder, money is the most typical form of "future goods." Hence, a loan of money, instead of being an exchange of present for future goods, is an exchange of one form of future goods for another form of future goods. The borrower gives his "promise-to-pay," that is to say, his credit, in exchange for the banker's "promise-to-pay," or credit. And if the banker gives gold coin instead of mere bank credit, that which he gives, like the borrower's promissory note, consists of strictly "future goods," that is, of goods not intended for consumption, nor, indeed, so adapted except when destroyed as money by being melted down for use as gold metal.

From this it is apparent that the lending of money cannot be considered as a giving of present in exchange for future goods.

203. Money Never a Means of Production.-Nor, indeed, can money properly be classed with means of production, or capital goods (130). Such classification of money is clearly inadmissible. Although money is universally regarded as capital, it is certainly not of the kind to which the reasoning of the "Positive "Theory" can be applied, even assuming that this theory were otherwise valid. The argument adduced for classing money with goods in storage and with means of transportation as being a tool of commerce and therefore a form of capital goods ${ }^{80}$ proves on analysis to be untenable. Stored goods are goods in process of maturing, at least so long as

m) Bijhm-Bawerk, II, p. 66 (70). 
the storage is a normal part of the process of preparing the goods for the market. They are passing through the commercial stage of production, namely the process normally necessary to transfer them from the producer to the consumer. During the normal period of that storage the value of the goods increases, this increase comprising the cost of storage plus the interest supposed to accrue through the gradual growth of value, as future utilities become present ones (133). Money presents a radically different case. Turning gold from its commercial form as bullion into its conventional form as coin can in no wise be classed as a process of bringing gold nearer to its point of consumption. None of the latent and inmature utilities possessed by the gold composing the coin is ripening into consumable utilities while the coin is being used as a medium of exchange. In this respect money differs radically from stored goods. The present value of money can in no wise be regarded as the discounted estimate of its future value. The value of money does not increase while it is either stored or being utilized. On the contrary, by the act of coining the processes by which the latent utilities of gold might have been matured are positively arrested for an indefinite time, and although those utilities are likely to be brought to use only in the far distant future, if at all, their value is not discounted in consequence of the fact. Gold, when coined, is distinctly idle capital, ${ }^{81}$ for the latent utilities of coined gold remain positively in statu quo (134). Hence the "Positive Theory" cannot apply to money, even if it could satisfactorily explain the power of capital goods to bring interest.

Against this reasoning may be advanced the argument that gold, when coined, and money generally, is adapted to perform a most important commercial function, namely that of mediating exchanges and, as a commercial tool, ${ }^{82}$ should be classed with "enduring goods," 83 namely such as are capable of being utilized for an indefinite time. According to this view it would follow that just as the latent utilities of the tool of

\footnotetext{
${ }^{81}$ Cf. Böhm-Bawerk, II, p. 302 (319).

${ }^{82}$ Cf. ibid., p. 67 (il).

${ }^{63}$ Cf. ibid., pp. 339 (360) ff.
} 
production "loom" are incorporated in the product "cloth", woven on it, or those of a railroad or a steamship become incorporated in the things transported by their means, so the latent utilities of the tool of exchange, "money," become incorporated in the products exchanged by its means.

But the reasoning according to which the latent utilities of the loom, while being transferred to the cloth, grow in value by reason of the underrated future utilities becoming full rated present ones-assuming, for the sake of argument, the supposed discounting of the future to be a dominant economic factor-is not in any way applicable to money, as will presently appear.

The process through which a loom's utility is transferred to eloth requires time, during which the discounted value is supposed to grow to full value. The latent utilities of capital goods in general are brought to maturity by the more or less continuous application of labor to them, a process involving time. This is not the case with money which is of service to its possessor only for a momentary transaction; it passes out of his hands the very moment he puts it to use in effecting an exchange of any kind, whether in making a purchase or in paying an account, thus serving only in a transfer of ownership of things. How, then, ean we conceive a gradual inerease of value, as the supposed underrated future becomes fullrated present, seeing that the utilization of money is but a momentary transaction?

But there is more to be said on this point. Experience shows that when cloth is produced on a loom, the value of the cloth exceeds the value of the yarns plus the cost of weaving, the latter including wear and tear of the loom, ete. This excess is the interest accruing to the capital invested in the process of weaving. When goods are transported from one place to another, it is because they have a higher value at the point of destination than where they are produced, and here we also find that the difference of value-the price of transportation-exceeds the cost of the process inclusive of loss throngh wear of rolling stock and road bed. This excess is the interest accruing to capital invested in the means of transpor- 
tation. When wine is stored for ageing, the increase of its value exceeds cost and risk of storage, and the excess affords the interest of the capital invested. But when money is used in payment for goods purchased, neither the goods nor the money show any gain in value. Everybody realizes that "while a man keeps money, he loses interest on it." A borrower of money begins to reap interest only after he has parted with the money, and then only out of the capital goods he has obtained through it. It is thus apparent that the funetion of money is in no way analogous to that of means of production, and that the relation of money to interest is radically different from the relation of eapital goods to interest. From this it follows that the causes which compel a borrower of money to pay interest for its use are totally different from those whieh compel the borrower of capital goods to pay interest for their use.

The function of money differs radically from that of capital goods (211). Money is in no wise essential to the processes of forwarding capital goods from the immature to the mature state. These processes are those of changing the form, composition or location of things, or of proteeting them against destruction. The funetion of money is solely that of mediating changes of ownership of the things produced or in process of production. Money is not a tool of construetion, but only a tool of exchange. For constructive purposes money possesses no utility whatsoever, and for the purposes of exchange a system of bookkeeping would answer as well (90).

From whatever standpoint we approach this question, we can find no justification for classing money either with "present goods" ${ }^{84}$ or with "capital goods," ${ }^{85}$ if the latter are conceived as consisting of future goods ripening into present goods. Money as such is essentially idle or dead eapital and, like credit, must logically be classed with "future goods," and as such it is not even ripening into a present good. The supposed undervaluation of the future, therefore, cannot possibly explain why men are so anxious to get money for merchandise, and why borrowers, who have quantities of mer-

${ }^{84}$ Cf. Böhm-Bawerk, II, p. 285 (300). ${ }^{\mathrm{ss}}$ Cf. ibid., p. 66 (70). 
chandise unused on their hands, so willingly pay interest for the loan of money.

204. Calvin's Reasoning.-As already stated, John Calvin, even as far back as the sixteenth eentury, undertook to explain the willingness of borrowers to pay interest on the ground that it is not the money that brings a legitimate earning, but the house, or the field obtained in exchange for the money (190, 237). Idle money, he realized, is sterile ; but the borrower does not keep it idle; he acquires in exchange for it something that is produetive. And this is indeed the view taken by the business man generally. He borrows money beeause money is freely accepted in exehange for any form of wealth suited to his purpose. With the borrowed money he buys eapital goods, and by working with them he derives that profit which is here under consideration.

But by taking for granted that with money, which does not afford interest to the user, there may be bought any kind of eapital goods which do afford interest to the user, we are brought baek to the point from which we started (201). We started to find out why it is that there is a greater demand for the medium of exehange than there is for the objects of exchange; we were looking for the eause of the general desire of men to get money for merchandise, that is, a future good in exehange for a present good, and are brought to a point where we find that eause to be the universal readiness of men to give merchandise for money, that is, present goods for future groods. Calvin's argument, so generally aecepted, is simply a case of reasoning in a cirele (242). While there is no difficulty in explaining, consistently with the "Positive Theory," the willingness of men to give merehandise in exchange for eapital goods, that is, present goods in exchange for future goods, the value of which inereases as time advances -this value being equal to the discounted value of their future utilities-we have thus far found nothing to explain their willingness to give merchandise for money, that is, present goods in exchange for future goods, the present value of which equals the undiscounted value of their future utilities, a value which does not increase as time advanees. 
Even if it were really true that capital goods, the instruments of production, command interest because of the underrating of the value of future goods, it still would not follow that interest accrues to money for the same reason. The explanation adduced by Calvin is no more valid than that propounded by Turgot in what Böhm-Bawerk has termed the "Fruetification Theory of Interest," the fallacy of which he himself so eonclusively shows. ${ }^{80}$

205. Interest as an Inducement to Production of Capital. -On a par with the theory of the discounted future is the earlier idea, which forms the basis of 'Turgot's theory, that the power of capital to bring interest is an inducement essential to the production and investment of capital $(190,317)$.

This idea is tersely expressed by the question propounded by Böhm-Bawerk, whether-

a man of affairs would permanently continue an enterprise in which the invested capital does not earn interest. ${ }^{87}$

To be sure, no business man would do so while capital can be invested in other enterprises that do return interest. But when the nature and cause of interest are in question, it is illogical to assume that interest exists in the very nature of things. We should inquire whether a manufacturer of, say, knit gloves, having the choice between making them by hand or by machine, would really be so shortsighted as to choose the primitive method just because the machine method, although yielding more products in the end, will not do so from the beginning. The gain in productivity, and eventually in time also, through the employment of capital is in itself an indueement for the employer to apply it in production. Since the ineome of the employer as such is what is left of the value of his products after all costs have been defrayed (167), he, more than anyone else, is interested in adopting the most effieient method of production (318), and to him it is immaterial whether he gets this residual share as interest or as wages. If he does not keep up with the progress of the time, he camnot hold his own against competition. The supposition

${ }^{80}$ Bühm-Bawerk, I, pp. 61 (71) ff.

${ }^{87}$ Quarterly Journal of Economics, January, 1896, p. 141. 
that interest is necessary as an inducement to the employment of capital, whether in the starting or in the eontinuance of enterprises, is clearly without foundation.

206. Summary.-From the foregoing it follows that the premises of the "Positive 'Theory" are groundless. The indireet and complex methods of production, involving the employment of capital, instead of being protracted, are in fact expeditious when compared with simpler and more direet methods. Even though "waiting" be considered as involving effort, the waiting required by capitalistic production between the time of effort and of the consequent gratifieation is mueh more than compensated by the inerease of productivity. When compared with the time of "waiting" required by primitive methods of produetion, the period of increased waiting incident to the use of capital is terminated in a brief space of time and is therefore to be considered as a concomitant of progress and not of eapitalistic production.

But we eannot even find any facts in the business world that would justify the assumption that "waiting" is economically to be accounted as effort, or, to put it otherwise, that the preference of "present" over "future" goods is adequate to account for pure interest; and since money cannot properly be classed either with present goods or with capital goods, the theory, even if it were competent to account for the "earnings" of capital goods, eannot in any way account for the power of money to command interest. Moreover, the assumption that interest is essential as an inducement to the aceumulation of capital is, in the last analysis, found to be unwarranted. It is manifest that the phenomenon of interest is due to eeonomic forces other than those adlueed by the author of the "Positive Theory of Capital" to explain it.

207. The "Surplus Value" Theory.-The theories thus far considered are attempts to trace capital returus to natural causes and so to explain interest. On the other hand, the "Surplus Value Theory" of Karl Marx, propounded in his work "Das Kapital," ascribes these returns to some sinister influenee of the prevailing system of "capitalistic production", and a supposed exploitation of labor involved in that system. 
Capital returns and money interest are accordingly condemned as morally indefensible. The theory is substantially as follows:

Under the capitalistic system of production the workman who has no capital is compelled to sell to a capitalist his "labor power" which, as a merchandise, has a value measured by the labor time required for its "production" (164a). This value, then, is the purchase price of labor power; it is that which is called "wages." The capitalist buys labor power at this value by paying wages. It costs him only an amount measurect by the labor time required for the production of the means of subsistence and propagation of the laborer. A day's labor power costs what can be produced by, say, a half-day's labor time. But having bought it, the capitalist puts it to work for the whole day, and the value produced is greater than the cost, the difference being "surplus value" which is appropriated by the purchaser of the labor power, the capitalist.

This theory is founded on the wage theory advanced by the same author. The fallacy of the wage theory having already been pointed out (164b), this would in itself be reason enough to dismiss the matter without further comment; but as the theory itself is in conflict with every-day experience, a few more words on the subject may not be amiss.

208. The Theory Inconsistent with Facts.-According to the surplus value theory the capitalist, in order to acquire surplus value, need do nothing more than buy labor power and put it to work. If the acquisition of riches were really such a simple matter, it would be inconceivable that any of the labor power offered in the market would ever go begging for a purchaser. The demand for it would be so great that none would be left for sale.

But what do we find in reality? The question of how to provide work for the unemployed has long been a serious political and economic problem the world over. This is in direct conflict with Marx's thesis. It is true, endeavors have been made to harmonize the surplus value doctrine with these facts by pointing out that so long as the workers receive wages amounting to only a portion of the value which they produce, they are unable to buy all of their products with their wages. That portion of the remainder which is not consumed by the 
capitalists must remain unsold, and this, it is alleged, accounts for what is called "overproduction" and for the consequent lack of employment.

But this explanation conflicts with Marx's characterization of capitalists as being possessed of an insatiable greed for surplus value. Having gotten the surplus value, why should they put it on the market for sale? After purchasing the labor power, they can control production so that only part of the labor is applied to the production of the necessaries of the workers and another part to the production of those forms of wealth for which they are so greedy and which, after being appropriated by them, would not have to be put on the market and so cause an excess of supply over demand. The deplorable fact that business depressions and lack of employment are features of the present industrial system conclusively disproves the reasoning of Karl Marx.

During periods of business stagnation, whatever their cause, the competition among workmen for employment results in a reduction of wages. Low wages, then, are the result of an insufficient demand for labor. To harmonize the socialistic theory with facts it is asserted, on the contrary, that low wages are not the result, but the cause of the accumulation of unsold products and the consequent low demand for labor. This is clearly a case of "putting the cart before the horse," of confusing cause and effect.

Marx has evidently taken a one-sided view of industrial affairs. He wholly overlooked the significanee of the interminable series of failures and bankruptcies in the "capitalistic" world. Facts do not bear out the notion that employers generally are the recipients of "surplus value." Business men keenly feel the difficulty against which they must contend. It is not a rare thing that wage workers, so called "wage slaves," accumulate enough capital to become "capitalists", themselves, only to lose as employers all they had saved as employes.

The "Surplus Valuc Theory" not only lacks logical basis, but is also completely disproved by the constant ocenrrence of business failures and by the frequent recurrenec of business depression. 


\section{CHAP'TER XI}

\section{MONEY AND MONEY INTEREST}

209. Interest on Money Loans.-Up to this stage of our discussion we have used the term "capitalist" as including not only the owner or owners of the capital employed in a business, but also the lender or lenders of any money employed therein. But in examining the relation of the income of the money-lender to that of the capitalist, we must distinguish the lender of money used in a business from the "capitalist" who owns only the remaining part of the capital.

When the capital of a productive group is owned in its entirety by the capitalist of the group, its returns accrue to him alone. But when a portion of the capital is obtained by borrowing money, the capital returns are shared between the capitalist and the money-lender throngh the payment of interest on the borrowed money. In the average the sharing is about in proportion to the parts of the total capital owned by the capitalist and the money-lender respectively.

It is commonly held that when a business man borrows money to increase his working capital, he is willing to pay interest on the loan because that increase of capital affords him an increase of profits $(186,257)$. From this it would follow, as Calvin and others have insisted, that the interest is paid, not for the use of money, but for the use of the capital goods bought with the money. No business man borrows money for the purpose of keeping it; he intends to use it in payment for things or services, or in paying debts for things or services already received.

This view is clearly presented by many writers on economics. According to Simon Newcomb:

What the borrower really pays interest for is capital, not money. The borrower can gain nothing by keeping the money; all he borrows it for is to purchase some kind of eapital. . . We see then that what 
is called the rate of interest on money is not a property of the money itself, but depends upon the advantage which capital gives its owner in production. ${ }^{\mathrm{s}}$

John Stuart Mill went into greater detail in trying to show that the interest paid on borrowed money is really paid for the use of eapital goods bought with that money.

Money, which is so commonly understood as the synonyme of wealth, is more especially the term used to denote it when it is the subject of borrowing. When one person lends to another, as well as when he pays wages or rent to another, what he transfers is not the mere money, but a right to a certain value of the produce of the country to be selected at pleasure, the lender having first bought this right by giving for it a portion of his capital. What he really lends is so mueh capital; the money is the mere instrument of transfer. But the capital usually passes from the lender to the receiver through the means either of money, or of an order to receive money, and at any rate it is in money that the capital is computed and estimated. Hence borrowing capital is universally called borrowing money; the loan market is ealled the money market; those who have their capital disposable for investment on loan are called the monied class; and the equivalent given for the use of capital, or in other words, interest, is not only called the interest of money, but by a grosser perversion of terms, the value of money." so

It is manifest from the above quotation that Mill elearly distinguished between "money" and "eapital," using the term "money" as meaning a eredit instrument conveying a right to reeeive value, and the term "eapital" in the sense of eapital other than money, which cannot be anything else than capital goods.

210. Money Interest is Paid for the Use of Money.-On a close examination of the argument presented by Mill, the conclusion of which is re-stated by Neweomb and others, it will be found that this conclusion is not warranted by the premises. It is assumed in the arrument that what the borrower is seeking is capital and not money. Investigation, however, diseloses the faet that what the borrower is after is moncy and that the interest which he pays to the lender of money is paid for the use of money and not for the use of eapital. 
The hypothetical case presented by Mill is found to embrace in its scope three independent transactions effecterl between four different parties, of whom the second is the lender and the third the borrower in the case.

The first of the four is the initial owner of the money from whom, in the first transaction, the second party, our lender, obtains the money "by giving for it a part of his capital." In the second transaction the second party, the lender, loans this money to the third party, the borrower. Then comes the third transaction in which the borrower uses the money in getting actual capital from the fourth party by way of purchase.

The first transaction is a sale of capital, described by Mill as an exchange of "a portion of his capital" for a "right to a certain value of the produce of the country to be selected at pleasure." This is clearly a call loan of real capital, inasmuch as the second party can get back an equivalent of his capital "at pleasure." So long as he refrains from getting it back, he is a creditor. Does he receive interest for this call loan? By no means. The certificates which he obtained for his capital, and which prove that he is a creditor, are not merely credit instruments; they are money. But this does not change the fact that while possessing the money he is a creditor (89). He being a creditor, who is the debtor? Is it the first party to whom he gave "a portion of his capital" in exchange for the money? Not at all. Before the first transaction took place, that first party, as possessor of money, was a creditor who merely received "a certain value of the produce of the country" when he bought the eapital of the second party, the lender. The real debtor in the case is the issuer of the money who, when he issued it, received actual wealth in exchange for a mere credit instrument (92). Does the second party, while holding the money, that is, a "right to a certain value," obtain interest from that real debtor? We all know that he does not (264a). The credit instrument he received is money, something for which he can get interest if he lends it out.

In Mill's account of the case he does lend it out to our 
third party, the borrower, and takes his promissory note for it. This constitutes the second transaction. The lender, the second party, having obtained from the first party a right to a certain value, turns it over to the borrower in exchange for the latter's promise to pay. It will be observed that we have here an exchange mercly of two credit instruments, namely money on the one hand and the promissory note on the other, and that no real eapital, no eapital goods, change hands. Following this exehange the lender is still creditor. It is true, he no longer possesses a "right to a eertain value of the produee of the country to be seleeted at pleasure," but in its place he has the promissory note which eonveys a right to a certain value of the borrower's possessions (68). The borrower is now both debtor and ereditor; debtor as the maker of the promissory note, and ereditor by reason of holding a "right to a certain value," the money: But from the moment of this transaetion, in which no transfer of capital takes place and which eonsists merely of an exchange of two credit instruments, the borrower pays interest to the lender. Is this interest paid for capital reeeived? By no means, for the borrower does not receive any eapital; he receives only one kind of eredit instruments for another kind. To be sure, this kind of eredit instruments conveys a universally recognized right to a certain "value of the produce of the country," realizable at any moment; it is money, while that which he gives in exchange is but a promissory note, and as such is recognized only as a elaim to a certain value of that portion of the produce of the country whieh is in possession of the borrower, and which is realizable only at a stated future time. If the borrower pays the interest for the use of eapital and not for the use of money, as is generally held, what capital is it, and whose? According to the generally aeeepted theory, which Mill only paraphrases, the lender uses the money merely as an instrument for transferring eapital to the borrower. But the lender has already transferred the capital in question to the first party, the one to whom he sold it and from whom he got a receipt therefor in the form of money. IIe eertainly camnot transfer this eapital also to the borrower, and it is therefore certain that the bor- 
rower does not pay interest for the capital which has been furnished by the lender of the money. It is true, the borrower does ultimately get capital, but he gets it from the fourth party when, in the third transaction, he pays the money for it. Does he pay interest to the lender of the money for the use of that capital? If so, why does he begin to pay interest before he receives that capital, and why does he not pay it to this fourth party from whom he gets the actual capital?

The facts of the case cannot reasonably be interpreted otherwise than that the interest is paid for the use of the money and not for the use of the capital $(134,241,2646)$. It is counted from the moment a credit instrument which is money, is given for a credit instrument which is not money, but never from the time when actual capital, which has the capacity of being utilized in production, is given for money which has no such capacity. It is paid to the man who gives money in exchange for a promissory note, but not to the man who delivers the real capital in exchange for the credit instrument, money. The obligation to pay interest manifestly originates in transactions in which credit in the form of money is exchanged for credit that is not in the form of money, but never in those transactions in which real capital is exchanged for credit in the form of money. The only reasonable conclusion is that interest is paid for the advantage afforded by credit which is in the form of money over credit that is not in the form of money. Interest is paid for the use of money and not for the use of capital goods. The time-honored notion that interest is paid to the lender of money for the use of "capital" is groundless.

The fallacy of the idea that capital is transferred from the lender to the borrower through the medium of money (211) is the most apparent when the money loaned is in process of being issued through the agency of the lender. The money issued, say, through a national bank, has not been obtained by that bank in return for "a portion of its capital," but in return for the deposit merely of a security in the form of bonds, which security, however, remains the property of the bank together with all its usufruct. Here is plainly a case 
where the main basis of Mill's argument, namely, that money is the instrument of transferring eapital, is illusory, inasmuch as the lender has not transferred capital-that is, capital goods-in getting the money, and does not transfer capital in lending it. And yet, he gets interest.

2II. The Industrial Function of Money.-Our eonclusion that the borrower of money pays interest for the use of money and not for the use of the capital goods he buys with the money seems to conflict with the obvious fact that interest is a share of the wealth produced when labor and capital goods are eonjointly employed in the process of production. Money plays no part whatever in the wealth-producing process, its function being that of merely facilitating exchanges. Hence it is the provider of capital goods who furnishes that through which labor is enabled to create the wealth out of which interest is paid, and not the provider of money; and yet, we have here the incongruity that interest is paid to the lender of money and not to him who, when he gives goods in exchange for money, which is only a credit instrument (89), becomes the real lender of the capital goods, the lender of that which is the real embodiment of human effort.

Before we can find our way out of this labyrintl of sceming contradictions, we must learn how and why it is that capital goods, capable of yielding an income when employed, are so freely offered for money which eannot be used in the process of production (201). This we can do by carefully analyzing the real function which money performs in the industrial and commereial world.

In the modern industrial world produets are advaneed from erudest forms to the finished state by the efforts of suecessive groups of workers (127). Each group receives as its own raw materials the completed products of the preceding groups and advances them one step forward toward maturity. To illustrate, the group represented by the eloth manufaeturer obtains from other groups looms and yarns which are used in the manufacture of cloth. Although the finished produet, the eloth of our illustration, is by no means a mature commodity, the group represented by the cloth manufaeturer is 
not in a position to further advance it, for the function of this group is restricted to the forwarding of the product by that one step. The cloth manufacturer is not also a tailor. For him the cloth is idle capital (243), and in order to convert this idle capital into active capital, it must be sold and the proceeds applied to the purchase of material for producing cloth. To this end the maker of the cloth sells it off as fast as he can, and with the money obtained he pays the wages of his employes and buys' yarns and other supplies.

Here we find a leading thread in the maze. When a business man gives capital goods in exchange for money, he gives capital which has become idle for him, in exchange for money which is likewise idle for him so long as he keeps it. But although the money is idle capital, it is more useful to him than the idle capital which he gave for it, because the money is a means through which he can acquire that which to him is active capital. In the proccsses of production active capital is constantly advanced by each productive group to a stage in which it becomes idle capital for that group, and moncy is a means through which this idle capital can be exchanged for capital which is active for that group (203, 241a, 242, 245). When capital goods are sold by one group to another, the goods which are idle capital to the seller become active capital to the buyer.

The bricks in a brick-yard, the lumber in a saw-mill, the engines and the looms in the hands of the machine builders, the yarns made by the spinner and all other tools and supplies needed in the manufacture of cloth can become active capital only when these things have been assembled in the construction and equipment of the cloth factory. If a single essential element of the combination is lacking, the other factors cannot be used and are idle capital until the missing element is supplied. Considering that it would be practically impossible to bring these things together in their proper combination if we were confined to simple barter as the only method of exchange, we can clearly see that money is the only effective, the only practicable medium by which they can be assembled and turned into active capital. Without money 
in some form the things of which capital is made up might separately be brought into existence, but the peeuliar combinations by which they beeome active capital could scareely be brought about, except, perhaps, in a communistic soeiety. In an individualistic community the effective aggregation of the things of which capital is made up is possible only through the medium of money.

The illustration may be further varied. Suppose a cloth mannfacturer wants to borrow some additional capital, and a friend who is tanner offers to lend him some of his capital consisting of tanned hides. He would, of course, decline the offer. The tanned hides might be capital to a shoe manufacturer, but not to the maker of eloth. When our would-be borrower is in need of capital, he does not want an indiscriminate lot of capital goods. He wants only those particular things needed in his business, namely the things he is prepared to advance toward maturity. Since money alone will enable him to obtain, in the requisite combination, the different things he needs, he will borrow money and not eapital goods.

The specific faculty of money which accounts for the universal demand for it may be still further elucidated by the example of a cloth manufacturer who wants to get a number of additional looms and who has to borrow money to get them. Here three persons are involved: a man who has $\$ 10,000$ to lend out, ${ }^{00}$ a manufacturer who owns a factory worth, say, $\$ 50,000$, the capacity of which he desires to increase, and a machinist who has a stoek of looms worth $\$ 10,000$.

The manufacturer now borrows the $\$ 10,000$ and applies this money to the purchase of the looms. The conditions before and after this transaction are as follows.

Before the transaction the lender held a claim against the

we must always remember that money is in essence a claim against its issuer which, by communal convention, is recognized as a "right to a certain value of the produce of the country" by all who have anything for sale. Although these latter are not the debtors, they are ever ready to satisfy the claim hy giving goods in exehange for it. 
community amounting to $\$ 10,000$. The manufacturer owned a $\$ 50,000$ factory. The machinist had a stock of looms.

After the transaction the lender has a claim against the manufacturer to the amount of $\$ 10,000$ who, in turn, is in possession of a $\$ 60,000$ factory of which he owns virtually only five-sixths, the other sixth being owed to the lender. In place of his looms the machinist has nothing more than a claim against the community amounting to $\$ 10,000$. It is furthermore to be observed that from now on the manufacturer is under obligation to pay interest on $\$ 10,000$ to the lender.

We have already found that the lender receives this interest because he has given credit which is money in exchange for eredit which is not money, and that interest is paid for the advantage afforded by money. We know also that it is not paid for the loan of capital goods, for the borrower did not get the looms from the lender. The capital which the lender gave up when he himself got the money was given to another party, and when giving up his capital goods for a mere right to get their equivalent in other goods on demand, a payment of interest for this call loan was neither stipulated nor expected.

The transaction has resulted in the manufacturer increasing his active capital through the addition of looms, and, as is well known, this eapital yields returns. But it will be noted that the manufacturer received these capital goods from the machinist, and not from the lender. No one but the machinist has given up actual products of labor in the transaction. He finds it necessary to give up the looms, which are real capital, in return for money, a mere credit instrument, because in the course of specialized production his looms have become idle capital to him, while they are adapted to be active capital only to the eloth manufacturer. By means of the borrowed money the looms were transferred from the machinist to the manufacturer and have been turned from an idle into an active state, from a state in which they were unable to yield returns into a state in which they do yield returms. This conversion is effected through the peculiar faculty of money which enables the manufacturer to select from among all the products of 
the market sueh as can be ntilized by him as active capital. All this conelusively proves that interest is paid for the loan of money beeause money has the faeulty to convert idle into active capital, and not for the loan of eapital other than money. The borrowed money was not the means for transferring "real" capital from the lender to the manufacturer (210), for the lender did not have that eapital to transfer, and the looms which the manufaeturer received belonged to the machinist, hence the lender had no right to order their delivery. Nor did the machinist deliver them for the reason that the lender of the money had previously given capital goods to some one for the money. He took the money for his machines solely beeause the money possesses a certain special faculty. There is no foundation whatever for the idea that the function of the money was to transfer real eapital from the lender to the borrower. What the money did accomplish was to turn the idle eapital of the machinist into active eapital of the manufacturer through the process of seleetive exehange. The facts unmistakably indicate that interest on money loans is paid for the use of that faculty of money which enables the borrower to select in the market the particular things needed in the composition of active capital.

But here we again lose the thread that seemed likely to lead us out of the maze. In order to account for the readiness of the manufacturer to pay interest for borrowed money, we had to fall back on the experienee that aetive capital, that is, capital goods employed in productive processes, yields interest. But what it is that imparts this power to eapital is still involved in the maze, and until we recover the thread, we eannot reach a conclusive explanation of interest itself $(241 b)$.

212. Efficiency of Money.-Noney being the instrument for turning idle capital into active capital, it follows that without money the specialization of industry would be impossible, and all the advantages arising from systematized processes of industry and commeree would be unattainable.

Let us considel what would happen if we had to get along without money in any of its forms and depend for all our 
exchanges on simple barter. It can readily be seen that under such conditions practically all business must come to a standstill. Merchants could not sell their goods and manufacturers could not pay wages. All inventions of the past would become useless, and we would relapse into a state of primitive life. Men could co-operate only in those simple pursuits in which the results of labor could be shared directly among the participants, or readily exchanged by barter. A man could obtain bread from the baker or meat from the butcher only if he chanced to have something of which the baker or the butcher happened to be in need and which they are willing to accept in excliange. Since development of industry would be impossible where the method of exchange is so primitive, we would be without any of the benefits of applied science.

Suppose, now, that a small amount of money were introduced into a moneyless community. Exchanges would thereupon be somewhat facilitated and correspondingly increased, and a limited division of labor would naturally be developed. A second, a third, a fourth addition to the amount of money would permit a further increase of commerce and the extension of specialization of industry to a corresponding degree.

The first instalment of money would naturally seek those channels of production and exchange where it is most needed and most effective, and would open up opportunities for the most immediate steps in the division of labor. The second instalment, finding the channels of the first order filled, would flow in directions of less imperative necessity, or channels of the second order, permitting a further division of labor, the advantages being not quite as great as those attained through the first instalment. A further addition would similarly fill the channels of the third order, and so forth. Each successive addition would enable producers to avail themselves of more of the advantages of specialized labor, but the efficiency of each succeeding instalment, viewed by itself, would be less than that of the preceding one.

213. Final Efficiency of Money.-It is clear that in the above illustration each new addition to the volume of the medium of exchange would flow into the most important chan- 
nels yet open and would permit a corresponding degree of further development. Just as the available supply of any class of commodities is used for the most important requirements, as far as the supply goes, so the available volume of the medium of exchange would be applied, as far as it would reach, to those uses through which the most advantageous specialization of work is attainable. As the final utility of any class of goods is determined by the least urgent of the needs that can be supplied from the quantity of goods available, so is the final efficiency of money determined by the least remunerative of all the industrial developments which can be effected by means of the available supply of money. The final efficiency of money, then, is equivalent to the benefit afforded by the last of the several instalments added to the volume of money (238).

A diagram may again be used to advantage for illustrating this principle. Let the increasing volume of money be measured on the horizontal axis and the efficiency of each individual instalment on the vertical axis of Fig. 22. The gradual decrease of the efficiency of the consecutive instalments is then represented by the descending curve $E E^{\prime}$.

When the gradually increasing volume of money has reached the magnitude $O V^{\prime}$, the efficiency of the last inerement will be rated by the ordinate $V^{\prime} a^{\prime}$, while the effieiency of the total volume then in use will be represented by the area $O V^{\prime} a^{\prime} E$. A further increase of the volume to $O V$ will reduce the final efficiency to the rate $V a$ and at the same time increase the efficiency of the total volume of money to the area $O \mathrm{VaE}$.

As we have found that interest is paid for the advantages afforded by money in its capacity as a medium of exchange, it would appear, from analogy, that the rate of interest is somehow related to the final efficiency of money, but a eloser investigation of that which actually determines the interest rate must be deferred to another point of our discussion (244-256).

214. Significance of the Phrase "Efficiency of Money."In the above argument we have gauged the "efficiency of money" by the total product of industry obtained through the employment of money. But the fact is that the product is a result of several co-ordinate factors of whicl money is lont 
one. It is clearly unreasonable to give credit for the whole product to money alone, inasmuch as the other factors are at least equally indispensable. Money and capital goods are equally means to enable labor advantageously to exploit land. The phrase "efficiency of money," as we have used it, is really the measure of the productivity of land, labor, capital and money combined, and since we have yet before us the unsolved problem of the relation of capital goods and money to labor and land, the term should really be understood as meaning "efficiency of labor, capital and money applied to land."

But the final efficiency of money is only a fraction of what we have above considered as its total efficiency, and while we have as yet found no conclusive proof that it is this final efficiency of money which governs the rate at which the moneylender participates in the division of the wealth produced, it would yet appear, from analogy, that such is the case. Turning to our diagram Fig. 22, we find that if $O V$ were the volume of money, and producers were obliged to borrow all of this money from lenders, they could, by its aid, and with the total labor and capital other than money which they have at command, attain a yearly output represented by the area $O V a E$, of which output they must pay a part equal to the area $O V a i$ as interest for the money, retaining for themselves the remainder $i a E$, to be shared between labor on the one hand and employed capital other than money on the other.

However, until we make ourselves fully familiar with the forces that determine the volume of money, the problem will not have passed the indeterminate stage. We have found (195) reasons to suppose that a deficiency of available capital goods accounts for the power of capital goods to command interest income, and now we find that a deficiency of available money appears likewise to account for the similar power possessed by money. The ground is thus cleared for further inquiry into the nature of interest and into the causes which determine the division of wealth between capital and labor. 


\section{CHAPTER XII}

\section{CHANCE PROFITS AND LOSSES}

215. Chance as an Economic Factor.-When the science of economics is studied by purely analytical methods, it is necessary to leave out of account all factors of a temporary nature and to confine the inquiry to those governing forces whose influence is continuous. Reverting to our illustration of the marksman (1) as an analogy, we must leave out of account the unsteadiness of his arm and other variable influences that tend to scatter the shots. While conclusions reached in this way are not borne out in individual cases, they are nevertheless true as regards the general average. Though in following this plan we are chiefly concerned with general conditions, it is yet desirable, at this point, to give some attention to the effect of passing influences.

We have all along taken for granted a number of suppositions which are not entirely in accord with facts as we really find them. The individual has been credited with accurate knowledge and sound judgment which the real man never possesses. Every workman has been supposed to know his earning capacity, not alone in his actual occupation, but also in the occupation to which he can turn as an alternative, his occupation of second choice (61), and has always been assumed to choose that course of action which is most advantageous to him. Prices of the same kind of things at different points in the same market were considered to be equal and known to all buyers and sellers. Moreover, we have omitted to take into account numerous chance disturbances in the domain of production and exchange. Weather conditions introduce marked uncertainty into agriculture, transportation and many other pursuits, and risks in endless forms are encountered in every walk of life. Fven a mere change in fashion may boom one business and ruin another.

In the measure in which the actual conditions attending 
individual cases differ from those which we have assumed, the actual outcome of a given set of causes varies from what otherwise could be reasonably anticipated. However, as regards the entire province of production and exchange, these variations, in accordance with the law of probability, tend to balance each other in the same way as the shots of a marksman on one side of the bull's-eye are practically balanced by those on the other. These departures from the average in individual cases resnlt in chance profits or losses to individuals (139).

With a view to systematize our brief survey, we may roughly divide profits of chance-be they positive or negative, profits or losses-into those that are due (1) to fortuitous changes of value, (2) to the varying outcome of risks assumed and (3) to economic inertia.

2I6. Profits and Losses from Changes in Value.- It is a current saying that both parties to an exchange make a profit thereby. But this betokens a confusion of the idea of utility with that of value, inasmuch as each party to an exchange of things of equal market value gets only that which is more useful to him for something that is less useful to him.

According to the definition of "value" two things are economically equal if they are exchanged in the market one for the other. The fact of their being exchanged simply establishes their equality, but in no way adds anything to their existing value. The value of things may be increased by the work of carriers or merchants before or after an exchange, and this increase is often mistakenly regarded as being bronght about by the exchange itself.

Changes in the value of things may, however, take place without any effort whatever on the part of the owners of the things, and it is generally supposed that profits derived by the owners from such a change in market values are not attended by a loss to anyone.

This view is erroneous, as may be gathered from the fact that by a mere fortuitous change in the value of a thing the sum total of all wealth is neither increased nor decreased, and 
that, accordingly, any gain in wealth by one individual due merely to an increase of the value of a thing he owns must result in a loss to the rest of the community. But if there is such a loss, it should be possible to point out how it arises and whether it falls on the whole community or only on one or more of its members.

We ean here consider only gains and losses that are realized through a clouble exchange, such as buying a thing at a low price and, after its value has changed, selling it at a higher price. A man holding a thing while its value rises evidently eannot gain any advantage from the fact that its value did rise, unless he sells it after its value has risen. Where the change in value comes about without some service being rendered, it can easily be shown that a profit accruing to anyone through buying a thing eheap and selling it dear, is invariably attended by a corresponding loss to others, and, of course, vice versa.

Let us suppose, for example, that $A$ has three hats, while $B$ and $C$ have each four dollars. If, then, $C$, with his four dollars, buys the three hats from $A$ and, turning around, sells two of them to $B$ for two clollars each, he will have a hat in addition to the four dollars he had before. This hat constitutes a profit which, as we shall presently see, has entailed a loss upon others. By grouping $A$ and $B$ we find that, at the start, they owned three hats and four dollars, and subsequently only two hats and four dollars. It is therefore apparent that by the operation through which $C$ profited a hat, $A$ and $B$ conjointly have lost it $(224,277)$. It is, however, impossible from these data to determine to what extent each of them is a loser, since dollars and hats are dissimilar things.

The proposition here outlined has no bearing, of course, on cases of a possible change in the usufruet of a thing, as when the thing in question is land or invested eapital, such as stocks in some enterprise. A rise of rents or of dividends is a phenomenon that must be relegated to the problem of rent or of capital interest, and has no place in the eonsideration of chance profits. If, however, such a rise in the usufruet is attended by a rise in the value of the land or of the stocks, sueh a rise comes properly within the provinee of the present discussion, 
for any fortuitous occurrence that results in a change in the market value of anything brings that change within the scope of the above conclusion.

In these cases, however, the way in which the loss corresponding to a profit so gained becomes imposed on others is not so easy to trace. It is even held by many that by a rise in land values the wealth of a community is increased and that profits arising therefrom cannot entail losses on others. The error of this view will be shown later (329).

2r7. Profits to be Distinguished from Wages.-In the above illustration it must be understood that what $C$ gains constitutes a loss to $A$ and $B$ only if $C$, through his intermediation, has not rendered some service to the others. If $C$ is a dealer whose efforts are given to the work of transferring hats from producer to consumer, his gain is not a profit, but a wage for his labor, for he earns the difference between the purchase and the selling price.

Retailing is a necessary step in the process of production and distribution, and requires labor. Production without distribution is an incomplete process, and the work of retailing, which completes the process, is an indispensable step in the specialization of labor and must be paid for.

The middleman, so often denounced as a useless member of society, performs this important function, which certainly can be performed most economically through specialization. The mere placing of hats in a store where the customer can conveniently choose size, style and quality desired, adds to the value of the hats (12). The hats sold by $C$ to $B$ are in such case more valuable than when $C$ bought them of $A$, and the hat gained by $C$ through the transaction is his business income. So long as trade is open to competition, the business income of the dealer does not normally exceed wages for the work performed plus rent for the land occupied plus returns for the capital invested. Chance profits may or may not form part of the income, but they are likely to alternate with chance losses, and being but due to deviations from normal conditions, are negligible when general conditions are considered. 
218. Gambling.-The chanee of gaining or losing through the rise or fall of values due to adventitious eireumstanees is an unavoidable risk in the course of produetion and exchange. But there are some elasses of risks whieh are quite outside of the range of normal business. Stock speculation, gambling and taking lottery chanees are illustrations. Ventures of this nature are constantly being made, even though none of these risks affords greater chanees of gain than loss, and most of them even less, for some fixed cost must in any event be paid out of the stakes of the speculators. The faet that not a few people are constantly taking sueh ehances is widely at varianee with the assertion of some economists that men would not take risks unless the chances of gain exceed the ehances of loss.

2Ig. The Element of Risk.-We lave hitherto recognized three essential factors on which the amount of the products of industry primarily depends, namely labor, land and capital goods. There are, however, other factors that enter into the case, but these have a merely modifying effect. In agrieultural pursuits the uneertainty of the weather affects the amount produeed by a given expenditure of effort. Those who deal in perishable produets often lose a portion of their goods by deeay (58). In most industrial operations there is a greater or less amount of waste through causes which cannot be entirely eliminated (13). Large amounts of wealth may be destroyed in a few lours by fire, flood or earthquake.

Losses of this nature become virtually a tax on production and are naturally followed by a corresponding increase in the price of the commodities affected $(139,149)$. Althongh the extent of sueh losses in individual eases varies greatly, the average for different periods is approximately constant for each speeific phase of risk, and it is this average which enters as an item into the price of the product. The average losses thromgh risks in production and distribution are therefore borne by the consumers of the products.

Whenever, in any individual case, the losses aetually sustained through ordinary risks happen to be less than the average which, as we have just seen, is covered in the price and 
paid for by the consumers, a chance profit is gained by the producer; and whenever the actual losses exceed the average, a chance loss is suffered. While in individual cases either gains or losses may predominate, the general trend is to a balance.

In the ordinary course of production and distribution the workers, the landlord and the capitalist receive their respective shares at the current rate of wages, rent and interest, and any gains or losses due to chance departures from the average fall to the one who holds the position of venturer (144).

220. Insurance.-Some losses, like those from fire, hail or shipwreck, are of comparatively infrequent occurrence, but when such accidents do happen, the losses are usually heavy. For the purpose of equalizing these losses as nearly as possible among all who are exposed to the same risk, various systems of insurance have been organized. The payment for the insurance, known as the "premium," is calculated to make good the average of all losses covered by the insurance and to pay for all service required in the maintenance of the system. The cost of insurance becomes an item of the cost of production and distribution, which through competition becomes a part of the price at which the products or services are marketed and is therefore paid by the consumers (149).

It follows that whether the risk is insured or is not insured, the fact of its existence causes an increase of the market price of all products, in proportion as these products are affected.

The lending of money is subject to a risk of loss clue to the occasional failure of debtors. At a former point of our discussion (139) we have seen that this risk is usually a subject of insurance, for the interest payable on loans contains an item in the nature of an insurance premium. By receiving this premium the lender assumes the position of insurer. This applies particularly to banking institutions generally. A bank is in fact an intermediary agent between its depositors and its borrowers, and the risk involved in the lending of the depositors' money is borne by the bank. The losses arising from the failure of some of the borrowers are made good out 
of that portion of the interest paid by all borrowers which constitutes the insuranee item. The borrowers as a class have to pay for the delinquencies of those among them who fail, the bank aeting in the capacity of insurer $(102,263,290)$.

22r. Economic Inertia.-The factors which determine prices in the industrial world are subject to never-ending ehanges. Botl demand and supply are influeneed by various causes. Demand is affeeted mainly by the ineonstaney of human desires, which often change for purely psychologieal reasons, as when new fashions supplant the old. The changes in the supply are prineipally due to advances in science and the arts, whereby the efficieney of labor is inereased and the cost of production correspondingly redueed.

$\mathrm{By}$ reason of these variations in both intensity of desires and cost of production it often happens that final utility and marginal cost of production become temporarily unequal. Prices are then regulated by final utility alone, and not by cost. And owing to what is known as "ceonomic inertia," it takes more or less time for the market to become adjusted to the ehanges above indieated. The result of this inertia may be studied by diagram.

Let the curves $S S^{\prime}$ and $D D^{\prime}$ of Fig. 23 represent respectively the sellers' and the buyers' price limits at a given moment. The market having adjusted itself to these eonditions, the price will be equal to qa and the rate of production equal to $O q$. Suppose now that through an invention the cost to the producers is redueed to the level of $T T^{\prime}$ and that a ehange of fashion has stimulated the demand to the level of $E E^{\prime}$. Production being for the moment at the rate $O q$, the final utility, and henee the eurrent value, rises from $q a$ to $q b$, while the marginal eost of production falls from $q a$ to $q c$. The actual supply being $O q$, the momentary sellers' price limit cannot extend beyond the point $c$, and the priee of the commodity rises to the intersection $b$ of the sellers' price limit TCl with the luyers' priee limit $E E^{\prime}$. The price becomes equal to $q b$, while the marginal eost is only equal to $q c$. The produeers favored by this condition reap a ehanee profit, and 
this has the effect of attracting others to this occupation. Production becomes eventually increased to the rate of $O q^{\prime}$, the point of intersection $d$ becomes the new margin at which cost and utility come to a balance, and the price becomes adjusted to the ordinate $q^{\prime} d(232)$.

In the course of events changes of the opposite nature also take place, so that producers are confronted either by a falling price or by increased costs, and those near the margin suffer actual loss. They are then forced into other pursuits and the consequent decrease in the volume of production finally leads to a new balance of marginal cost and final utility.

In reviewing these ehanges of the market we may broadly distinguish three conditions. The current value of a thing, as determined by final utility, may be above, equal to, or below the marginal cost (63). In the first case production is unusually profitable and becomes increased by accessions to the ranks of the producers. In the second case final utility and marginal cost are evenly balanced, and the relative volume of production remains stationary (60). In the third case production is unprofitable and is reduced by desertion of producers to other fields (148). The normal condition is that of the second case. In the first and the third case the current value differs from the normal value, but competition tends to a readjustment in which final utility and marginal cost are equalized.

Profits and losses resulting from such conditions can arise only during a limited period, namely the period of readjustment, during which they continually tend to diminish and finally cease (149), only to reappear as new changes develop which affect the course of either or both the curves $S S^{\prime}$ and $D D^{\prime}$.

A period of readjustment may be shorter or longer, according to circumstances. There are several well defined causes that tend to prolong this period, which causes may be classed under the headings of economic inertia and economic momentum.

222. Factors of Economic Inertia.-Workers accustomed to their occupation are naturally averse to making a change and will not do so unless the disadvantages under which they 
labor, or the advantages offered by a change, overeome their reluetance. Readjustments may thereby be delayed, but they are certain to eome about in the end.

Protracted delays are apt to arise from the faet that in the production of many things a considerable interval of time elapses between the beginning of the work and its completion. Prices can, of course, be affected only after the produets are offered in the market, and this may be months or even years after the first steps toward the increased production have been taken. Agriculture furnishes an obvious example. In other cases even the first steps toward the new adjustment may be more or less delayed. When a new invention is brought out, it may often be less wasteful to eontinue the use of the old appliances, even at a disadvantage, than to "scrap" them. Those in use are then retained until practically worn out, when their replacement by improved appliances will no longer involve a loss. For this and other reasons of this nature the transferrence of capital from one channel to another is even more sluggish than the migration of labor.

223. Economic Momentum.- When, for any reason, some line of business becomes unremunerative to those engaged in it, the marginal workers will be the first to turn to other occupations, thereby lessening production in that line and gradually restoring the equilibrium between final utility and marginal eost of froduction (148). When, on the other hand, new eonditions cause some one oceupation to aftord unusual profits, the first to be attraeted are, in general, those workers who are near the margin in their respective trades and who can readily turn from that to the more remunerative field (44). A slight ehange in the price will, aceordingly, induee only a limited number of workers to change their oceupation, and the market will gradually adjust itself to the new conditions.

Sometimes, however, the adjustments are overdone, only to be followed by reaction. It often happens that some innovation opens up an unusually promising field of enterprise for both eapital and labor, with the result that more produeers are attracted to this field than are warranted by the actual demand. This situation becomes particularly aeute where 
the enterprise is of a kind which requires considerable time for preparation. Since an increase of the supply cannot make itself felt until after the finished products are offered in the market, the prospect of gain continues to be inviting, though the supply in preparation is already greater than the demand justifies. The natural result is a supply greater than the demand and a consequent more or less disastrous fall in the price of the product in question.

As a pendulum is carried by its momentum from one extreme to the other, so may the market swing from an overbalance of demand to an over-balance of supply, and some who are furnishing the supply, instead of reaping profits, suffer loss.

224. The Law of Chance Profits.-Among the profits so far considered, those of chance are the only ones that are not in the nature of recompense for some form of service. All other forms of income, namely wages, rent, capital returns and interest on money, are determined by specific economic forces, by reason of which they approximate a definite rate. Though the causes which determine the division of net incomes into wages and capital profits are yet to be examined in our further investigation, we know at least from experience that wages and capital profits have the tendency to reach a certain relative rate, however this rate may differ with time and place. But, as regards chance profits, theory as well as experience indeates that their tendency is always toward a balance with chance losses $(138,216)$.

It has been stated before that chance profits accruing to a productive group go to the venturer (144). It is however often difficult to decide whether certain items of the income of a group are due to chance or to efficient management. The impossibility of deciding whether, in any given case, a certain item should be classed as wages of the manager or as profits of the venturer cannot gainsay our conclusion that chance profits invariably tend to balance chance losses. 


\section{PART III}

\section{RESTRAINTS ON INDUSTRY}




\section{CHAPTER XIII}

\section{MONOPOLY}

225. Economic Impediments.-Of the economic factors which affect the distribution of the fruits of industry among those who participate in production, one class has so far been left out of account. To make our investigation complete, we shall now take up that remaining class. This brings us to the consideration of customs and of laws, in so far as they promote or retard the working of purely economic forces.

Our past conclusions were based in general on the assumption of a freedom of competition. But such freedom has never existed and does not now exist (150). The free play of economic forces is hampered by social conventions of all kinds, which remain with us as inherited from the ignorance, the prejudices and the superstitions of bygone times. Out of these grew various systems of caste, the traces of which are yet clearly apparent in society. We have indeed outlived the most barbarous forms of these systems, such as slavery and serfdom, but many of the economic conditions growing out of the social organization of the feudal ages continue prevalent to-day in the form of laws designed to regulate industry, commerce and exchange, as well as laws ereating monopolies through special privileges and franchises.

In current discussions the term "monopoly" has come to be used with so much looseness that we must here explain and define the sense in which it should properly be understood.

Literally the word "monopoly" signifies a sole right or sole power to sell. By most writers on economics the term is held to include all forms of economic right or power of an exclusive nature. Popularly the term is however often applied to the more or less complete control of production and exehange acquired by various industrial and commercial concerns in their respective fields, a control usually attributed to their manipulation of the market; but sueh use of the term ean only lead to confusion and should therefore be avoided. 
226. Monopoly Implies Restraint.-A monopoly is to be regarded as an exclusive economic right, the essence of which is really a special exemption from a general restraint. It is this restraint which is the positive element of monopoly (18). The power of restraint is generally exereised by the organized community through forms of law, but individuals or organized groups often seek to put it into effect with the object of acquiring a monopoly for themselves.

There are two distinct forms of monopoly, which may be designated as "personal", and "impersonal." The distinction lies in that the one depends on a restraint imposed by a controlling power upon all but a limited number of specified persons, while the other depends on a limitation placed on the production or use of certain things.

227. Ethics of Monopolies.-There is a generally prevailing idea that monopoly is, in its very nature, an injustice to the community at large. But this is by no means always the case. There are several forms of exclusive light which are fundamentally just and which, for this reason, are proper subjects of legal protection. Of this class patent and copy rights are notable examples. Monopoly in itself can do no harm; it is only when it is inequitable in its relation to the community that it becomes detrimental.

Equity is satisfied whenever an exclusive right is granted in return for the performance of an equivalent duty, or, to put it in other words, whenever that which the community receives for the grant is an equivalent of that which it gives.

Government is supposed to bestow impartially protection and rights and to impose the corresponding duties on all members of the community. But the fact is that governments have often granted, and still continue to grant to individuals or to groups rights and privileges which arc distinctly disadvantageous to the community. It is impossible under this policy to avoid the development of class distinctions and antagonisms.

228. Ownership a Form of Monopoly.-The most important of all exclusive rights is that of private ownership. This is not usually regarded as a monopoly, but since it possesses 
all the elements of monopoly, it cannot logically be excluded from that category of rights. The owner of a thing is the only one who may rightfully use it or dispose of it, and the community restrains all its other members from interfering with that right.

The nature of this right, its justice and equity, have already been amply discussed $(20,21)$.

229. Patent and Copy Rights.-Patent and copy rights differ in one essential respect from the right of ownership in things. They are not exchusive rights of possession of speeific things, but exclusive rights of producing and vending a specified kind of things.

Patents are granted to individuals who invent new means or discover new processes of production. They are enforced by the legal restraint placed upon the rest of the community against the production and sale of the thing patented. A patent is really a compact between the inventor and the community. The inventor gives to the community a full description of his invention, and in return the community pledges itsclf to protect the inventor for a certain number of years in the exclusive control of the invention. The grant of a patent is, accordingly, in the nature of a recompense for a service rendered.

The objections that have been urged from time to time against patent laws are, as a rule, clue to a widespread, though unfounded, antagonism to monopolies generally. A patent being, as already said, merely the giving of one service in exchange for another, the granting of patents is fully justified. And, moreover, the monopoly of inventions granted by the community is not only a recompense due to the inventor, but is a potent stimulus to industrial progress and thus a benefit to the community. Inventions generally require the expenditure of much labor, and frequently of labor of an exceptional quality, which should be rewarded; and the most practical as well as the most rational method of conferring this reward is to give the inventor the exclusive right, for a limited period, to exploit the invention for his individual benefit.

The time limit of a patent monopoly is an important factor 
in that exclusive right. The only matter that may be open to question is that of the duration of the patent. This, however, is only a question of expediency. If the time is too short, the inducement to invention is inadequate and progress will languish. If it is too long, the public loses by undue postponement of the time when the production of the thing invented becomes open to competition.

Copyrights on productions of art and literature are given for the same reasons as those for which patent rights are granted, the work of artists, authors and composers being essentially of a nature similar to invention.

The monopoly in trade marks is designed to protect those whose products have gained a valuable reputation. Through monopoly in the use of a name or a mark distinguishing his goods in the market, the owner of a trade mark is enabled to reap the benefit which he has earned. The propriety of granting such monopolies is self-evident.

230. Land Ownership.-The right of land ownership is in some respects essentially different from the right of ownership in the products of labor. That the producer of a thing, however it may be produced, should be the owner until he disposes of it is obvious; but such is not the case with regard to land, since land is an elementary part of nature and is not the product of labor.

It goes without saying that the cultivator of land should be protected in the ownership of the fruit of his labor. For this reason the initial ownership of land was, and in all new countries generally is, accorded to the first settlers. In the course of time, however, as population increases, the economic relation between land owners and the community becomes more and more complex. The resulting conditions will come up for consideration in connection with the land question, to be treated in a subsequent chapter (323-333).

23r. Franchises Depending on the Use of Land.-Some enterprises are of such a nature that they depend for their cconomic existence on the exclusive use of public land for specific purposes. It is impracticable, for example, to give permission to everybody indiscriminately to lay water or gas mains under the streets of a city. The convenience and com- 
fort of having water and gas in our homes is therefore dependent on what is, in its very nature, a monopoly, whether exercised by individuals or by the mumieipality or the state. Another case of the same description is that of monopoly rights to operate street cars for carrying passengers. Steam roads are monopolies in the measure in which the construction of competing roads depends on charters from the govermment which may be, and for obvious reasons in many eases should be, withheld.

Franchises of this description, being dependent on the exclusive use of land for their special purpose, are elosely related to the right of ownership in land. Their final consideration must therefore follow the discussion of the land question (334).

232. Impersonal Monopolies. - What we have denominated as "impersonal" monopoly can be brought about through impediments arbitrarily imposed on produetion, whereby the amount produeed is limited $(238,261)$. For example, eircumstances may arise under which the demand for eertain things exceeds the capacity of existing means for prodneing them, particularly if their produetion requires speeial appliances. For the time being, the price of these things is above the marginal cost of production, and profits obtained from this source are of the nature of chance profits which, as we have seen (221), tend to fall away if competition is free. But if competition is forcibly obstructed, high prices will continue, and the profits in sueh case must be elassed as monopoly profits.

As a rule, an impersonal monopoly ean be maintained only so long and so far as the obstruction to competition is effective. Any obstruction of this nature contrived by individuals for selfish curls may be snecessfully maintained for a time, but ultimately competition gains the upper hand. Only if eompetition is restrained by law or by some of her eontrollinir influence can a monopoly of any kind continue to exist indefinitely.

The workings of impersonal monopolies ean be studied by eontrasting them with monopolies of the personal type, and this may be done by referenee to the example which was illustrated by the cliagram Fig. 23. In this example we assumed 
that $S S^{\prime}$ and $D D^{\prime}$ are the initial supply and demand eurves of a given commodity and that through some change of conditions the curves $T T^{\prime}$ and $E E^{\prime}$ subsequently took the place of the initial curves. The capacity of production having before the change been adapted to an actual supply equal to $O q$, the final utility, after the change, was found to rise from $q a$ to $q b$, while the marginal cost of production fell from $q a$ to $q c$. The resulting profit $c b$ accruing to the marginal producers was recognized as an incentive to that immigration from other channels of production through which ultimately the equilibrium was restored. In this process of readjustment the amount produced was found to increase from $O q$ to $O q^{\prime}$ and the market value to fall from $q b$ to $q^{\prime} d$.

But let us assume that in this industry an increase of production is deliberately prevented and the actual supply kept at $O q$. The market value, as determined by final utility, will then remain at the rate $q b$, and the gain $c b$ of those engaged in that line will continue. In this way those profits which we have found in the natural order of things to be due to chance and subject to elimination through the effect of competition, are removed from that influence and become what are really monopoly profits.

Our study of the difference between personal and impersonal monopoly can now be completed. Let us, for illustration, compare the case where a given article is patented with that where the supply of the same article is artificially held down. In the first case the possessor of the exclusive right to produce and sell will put an arbitrary price, say $O p^{\prime}$, on the article, and the conditions of demand being represented by the curve $E E^{\prime}$, he will be able to sell, at this price, a quantity equal to $O q$. In the second case we may assume that production is deliberately limited, so that the actual supply equals $O q$, when the final utility, and with it the price, will become equal to $q b$. In the one case price determines quantity demanded, in the other quantity supplied determines price.

The effect on the market is the same, whether the price is determined under the protection of a patent or throngh deliberate limitation of the supply. In either case the price to 
the consumer is maintained above a competitive level only through prevention of competition.

233. "Cornering" the Market.-A “cornered" market is properly to be regarded as an example of a monopoly of the impersonal type, since it is brought about by an obstruction of the regular channels of supply. Such attempts at monopoly, however, meet with failure far more frequently than is generally supposed. Only under exceptional eireumstances ean such interference with the normal course of supply accomplish its purpose. Suceessful attempts of this kind are practically rare, but when they do oceur, they naturally attract a large measure of public attention, while, on the other hand, the failure of only the most widespread attempts of this class is brought to public notice. Efforts to corner the market eannot, therefore, have any more than a passing effect on economic conditions.

In so far as labor unions succeed in obstructing competition, the conditions they bring about are akin to monopoly. But monopolies of this nature eannot be diseussed intelligently until after the eause of the frequent contentions between labor and capital has been more fully discussed (268-276, 354-358).

234. Monopoly Incomes.-The essence of monopoly being the forcible suppression of competition, the holder of a monopoly is enabled to obtain higher priees than would rule in a competitive market. In granting public utility franchises it is not unusual to place some restriction on the price to be eharged for services rendered, but even where such stipulation is absent, there is a limit to what the holder of a monopoly can get.

Let us take the ease of a patented article. The patentee may over-estimate the value of his invention and set a priee on his goods which no one is willing to pay. He will then not only miss his opportunity, but will also deprive the community of any benefits which might be derived from the invention. Nor could the inventor derive any monopoly profit by selling the article at eost, that is, at a price which would obtain in the market, were the article not patented. In order 
to realize such a profit, he must therefore offer his products at a price somewhere between these limits, and there is a point at which his income will be greatest under the existing conditions (262). We may again have recourse to a graphical method for making this matter clear.

Suppose that the curve $D D^{\prime}$ of Fig. 24 represents the demand that exists for the patented article in question, while the ordinate of the horizontal line $C C^{\prime}$ represents the cost per unit of making and selling it. ${ }^{01}$ If the inventor were to sell the article at the price $O p^{\prime}$, he could sell no more than the quantity $O q^{\prime}$. The cost of making this quantity equals the quantity multiplied by the cost of each unit and is therefore represented by the area $O p^{\prime} c^{\prime} C$, while the gross receipts from the sale would amount to quantity times price, represented by the area $O q^{\prime} a^{\prime} p^{\prime}$. Hence the monopoly profits would be the area $C c^{\prime} a^{\prime} p^{\prime}$, namely the difference between cost and receipts. Had the patentee made his price equal to $O p^{\prime \prime}$, his profits would have equalled the area $C c^{\prime \prime} a^{\prime \prime} p^{\prime \prime}$. In both cases the income from the monopoly would be comparatively small. There is obviously a point in the range of prices at which the profits are at a maximum, and it can be shown that this is the point $a$ where the angle $x$ included between the line $C a$ and the horizontal line $p a$ equals the angle $y$ which is included between the same horizontal line $p a$ and the tangent to the curve $D D^{\prime}$ at the point $a$. Under these conditions the area $C$ cap measuring the monopoly profits is a maximum.

If it were possible in any specifie case to trace the actual curve of demand, or of the buyers' price limit $D D^{\prime}$, this would be a convenient method for enabling the patentee to find the most advantageous price at which to sell the patented article. But since this cannot be done, the patentee must depend upon his judgment and experience in fixing his price.

The same reasoning is of course applicable to all forms of monopoly, their economic relation to the general market being essentially alike.

When monopolies are the source of continuous incomes

${ }^{21}$ In view of the fact that the cost of producing equal quantities is usually less as the quantity produced at a time bccomes greater, the line $C C^{\prime}$ should in most cases really be a descending curve. 
throughout the duration of their existence, they are, in several respects, analogous to eapital goods. A franchise possessed by a stock company figures as one of its assets and gives a value to the stock over and above the value of the actual property of the concern.

235. The Power of Monopoly.-Judging from the various suggestions that are made from time to time for "emrbing the power of predatory wealth,' the prevailing idea of the power that can be wielded through monopoly is very much confused. The idea is no less hazy and undefined than is the popular notion as to what constitutes a monopoly. The power of the so-called trusts and other large corporations is often attributed to a monopolization of their field, while in reality it is due to an extraordinary and peculiar influence of wealth, the nature of which will be analyzed in its proper place (241$243,257-266)$. We should therefore endeavor to get a correct insight into the extent to which the power of monopoly can be carried, and the effect of this power.

With the data thus far presented we can adequately gauge the sacrifice which the community makes in granting monopoly rights, and the power which is thereby placed in the hamrls of the holder of the monopoly.

The loss which the community really sustains depends entirely on the way in which the monopoly is exploited. The case of a patented invention may again serve as an ilhstration. Should the inventor sell the artiele at the competitive price $O C$, Fig. 24, the community would obtain all the benefit as though the production of the article were not restricted at all. This benefit is represented by the area $C A D$. If, on the other hand, the article is offered at a price expal to or exceeding $O D$, so that no sales will be made, the community will for the time be deprived of any good which they might otherwise reap from the invention. At a somewhat lower price the invention is placed within the reach of a limited number of users. For example, if the sales are made at the rate of $O p$, the quantity sold will be $O q$, and the exeess of the desire for the goods sold over the price paid is rejerented by the area $\mathrm{pu} D$.

When we compare these throe eases and note the several effects on the community, wo find that in the rase where a 
prohibitive price is asked, the community loses all the benefit of the right it relinquishes, and this is the greatest privation that can possibly be incurred through the grant of the exclusive right. In no case can the grant of a monopoly deprive a community of more than the benefits it would derive from its own exercise of the right in question (262).

In confirmation of this statement illustrations could be cited by the hundreds, but one may suffice to show the principle. The company which owns the Suez Canal holds a monopoly because this artificial channel of commerce is the only waterway directly connecting the Mediterranean and the Red Sea. Nevertheless the owners cannot exact a toll higher than the cost of navigation around the Cape of Good Hope, and were they to demand so high a charge the commerce of the world would be placed on the same basis as if the canal had not been dug.

To be sure, the power of monopoly is not ordinarily pushed to a prohibitive extreme, for the simple reason that at this point no advantage can be gained by the holder. By demanding a reasonable recompense, the owner of a monopoly right shares the benefit of the monopolized object with the community. Thus, if a patentee charges a price for the patented product corresponding to $O p$, Fig. 24 , he obtains a net or monopoly income corresponding with the area Ccap, while the purchasers enjoy a benefit represented by the area $a D$.

However obvious this principle is, there are many facts which seem to be at variance with it. We hear of a tobacco, of a sugar, of a meat trust, and these are charged not only with exacting a tribute from all the users of their products, but also with crushing their competitors. Yet the community has granted to them no exclusive right to carry on their business; no specific restraint is placed on anyone to prevent him from entering into competition with them. These combinations evidently wield a power which cannot be explained by any grant of exclusive right in their favor. We are thus confronted with facts which appear to be irreconcilable with our theory, and unless this discrepancy can be cleared up, the theory cannot be verified. 


\section{CHAPTER XIV}

\section{THE MONOPOLY THEORY OF INTEREST}

236. Usury Laws.-Until less than four hundred years ago "usury," which was then the synonym of our word "interest," was regarded as morally wrong and was universally condemned as unjust and oppressive. Aristotle describes it as unnatural, the Mosaic law forbids it and in this respeet the early Christians accepted the MIosaic teachings. In the Middle Ages the doctrines of the chureh were enaeted into law, and usury was forbidden under various penalties. Even now, the taking of interest beyond a specified rate is interdieted in many states of the Union as well as in several European countries. Such laws are, however, not only ineffective, being often evaded by various subterfuges, but are also unreasonable. It is useless to repress by force that which is a natural outcome of existing economic conditions. Interest is either justifiable, or it is not so. If interest is due to the working of natural economic forces, if it is an inevitable sequence of free competition, then all laws which attempt to regulate the rate of interest are invasive and therefore unjust. On the other hand, if interest arises through an arbitrary interference with the working of natural economic forces, if it is a sequence of some distortion of the industrial and commereial order of things, the only remedy is obviously the removal of the disturbing influence. The canse, and not the result should be combated. In either case it is as futile as it is irrational to limit the rate of interest by legal proseription.

237. Distinction Between Usury and Interest.-The first effective assanlt on laws forbidding interest was made by John Calvin during the period of the Reformation. As we have had occasion to point out before $(190,204)$, he attributed the interest paid for the loan of money to the ineome derived from houses or fields bought with the money. While this reasoning does not really bring to light the cause of the interest com- 
manding power of money, it paved the way to that revision of the law through which the taking of interest, at least within certain limits, was sanctioned. A distinction was thereby established between "usury" and "interest," the former term being confined to an excessive or extortionate rate.

Calvin's explanation of the interest commanding power of money is even to-day accepted almost without challenge. We have, however, found ample evidence that this explanation is essentially unsound, and that the interest paid on money is really paid for the use of money as an instrument of exchange, and not for the use of the things that are bought with it (209211). We should, accordingly, seek to discover what it is that gives to money its singular power.

238. Money Subject to an Impersonal Monopoly.-The part which money plays in making the specialization of industry possible has already been discussed (211-213). We have also found reason to infer that the interest bearing power of money is related to the final efficiency of money, and since final efficiency can be conceived only with reference to a definitely limited quantity, we should now acquaint ourselves with the conditions that place a limit on the volume of money.

Let us make a comparison between that which limits the supply of money with that which limits the supply of any commodity. It has been shown (43) that in general the supply of commodities is limited by natural conditions, largely by the innate reluetanee of producers to exert themselves beyond a certain point. The production of any given commodity is continued only so long as the expected utility and consequent gratification is considered worth the effort. For this reason final utility, and with it the price, always tends to adapt itself to marginal cost (62-64). Does this principle also apply to money?

In speaking of effort or cost of producing money, we can here mean only the cost of eonverting into money either the substance gold through the process of coinage, or the substance of credit through the process of banking. The cost of producing the substance of which the money is constituted is not 
here in question, for this has bearing on the exchange value, the purchasing power, of money, and not on its interestbearing power. That this interest-bearing power is related to the final efficiency of money, and that this final efficiency equals the benefit afforded by the last instalment of its volume has already been shown (213). In order to understand why it is that notwithstanding the high final effieieney of money further instalments are not fortheoming, in other words, what it is that puts a limit on the volume of money, each kind of money will be taken up in turn.

Begiming with gold coin, we find that the production of such eurrency is not legally limited. All gold brought in proper quantity to the mint is eoined. The eost of doing this work is borne by the government, hence the question of cost cannot enter as a deterrent faetor. But while there are neither legal restrictions nor economic drawbacks in the form of cost, the amount of gold brought to the mint is wholly insuffieient to provide an adequate volume of eurreney. The volume of gold coin is manifestly limitcd by natural conditions. This is true even though the amount of gold produeed and utilized for money is steadily inereasing.

The seeond form of our eurreney, consisting of legal tender credit tokens, including silver dollars and subsidiary coin, is strictly limited by lax. In this ease law does that whieh, in the first case, is done by the matural seareity of the metal gold. Also in this ease there is no item of cost, since the cost of issuing that currency is borne by the govermment.

Under existing law national bank notes are ordinarily issued only against federal bonds deposited as seeurity in the national treasury. This places a limit on their use, for only a eertain, thourgh possibly variable, amount of sueh bonds is in existence. Moreover, the issue of these notes is taxed, which hats the effect of a cost that tends to restrain the issue of such notes.

The issuc of emergency mational bank notes, based on seeurity other than bonds, is indeed permitted to a limited extent, but only moler the burlen of a grachally increasing tax. This latter provision is specially designed to prevent the 
issue of these notes, except in the event of such scarcity of the circulating medium as will drive the rate of interest on money far above the usual rate.

Finally, the issue of notes by state banks is subject to a federal tax of ten per cent. per annum and is thereby practically forbidden.

From this it is apparent that the volume of our currency is arbitrarily limited by law. But our currency is not our only medium of exchange. The banking system enables business credits in the form of bank checks to serve this office (104a). It is often claimed that the check system permits an indefinite expansion of exchange facilities, enabling the total volume to adapt itself to the needs of commerce. But we have seen (104b) that, by provision of banking laws, the volume of bank credits cannot exceed more than about eight times ${ }^{92}$ the amount of legal money held as reserve in the banks, and since this reserve can, in the nature of things, be only a fraction of the total volume of legal currency, indeed, according to statistics, only about one-third of it, we find that the limitation of legal currency results in holding down the volume of bank credit within a limit which, though not sharply defined, is nevertheless positive.

This limit may vary from several causes. First, the total volume of currency in the country, applicable for bank reserve, is variable, principally by reason of the variable amount of gold in the country. Second, the ratio of the currency held in bank reserves to the total volume of the currency is variable, depending largely on the changing phases of business activity. This causes a fluctuation in the volume of bank credit, even while the volume of currency remains unchanged.

It is held by some that the field of exchange facilities is further broadened by the use of promissory notes given in payment of accounts. But this is not so, since promissory notes do not take the place of money in the sense in which bank credit does. They are not adapted for general circulation and

${ }^{03}$ This ratio may be affected by changes in our currency laws or banking practice. 
cannot, for this reason, facilitate exchanges to any great extent. As an addition to the volume of the medium of exchange they are a negligible quantity.

These considerations plainly show that while the volume of gold money is limited by natural conditions, the volume of credit money is limited by certain legal enactments, through which the issne of eurreney is specifically restricted, on the assumption that such limitation is necessary for the protection of the note holders $(264,270)$.

We have here the fundamental difference between the supply of commodities and that of money. While the production of those commodities that are not monopolized in any way is regulated by purely economic forees, by conditions which naturally arise under the influence of free eompetition, the production of money is circumseribed by legal enactments. By this arbitrary regulation there is created an impersonal monopoly (232), the effect of which we shall presently analyze. While, in the case of commodities, the production of which is open to free competition, final utility and marginal cost are normally equal, there is no corresponding equality between the final efficieney of money and the marginal effort or cost of converting gold or credit into money.

239. The Supposed Danger of “Inflation."-The legal restriction of the amount of currency is prompted by the fear of grave consequenees supposed to follow enlarged issues of curreney $(320 a)$. The supposed effects of this so-called "inflation" are deseribed by John Stuart Mill as follows (285, 308, 3206) :

There is no way in which a general and permanent rise of prices, or, in other words, depreciation of money, ean benefit anybody, except at the expense of somebody else. The substitution of paper for metallic currency is a national gain; any further increase of paper beyond this is but a form of robbery.

An inerease of notes is a manifest gain to the issuers, who, until the notes are returned for payment, obtain the use of them as if they were a real capital: and so long as the notes are no permanent addition to the curreney, but merely supersede gold or silver to the same amount, the gain of the issuer is a loss to no one; it is obtained by saving to the community the expense of the more costly material. But if thero 
is no gold or silver to be superseded-if the notes are added to the currency, instead of being substituted for the metallic part of it-all holders of the curreney lose, by the depreciation of its value, the exact equivalent of what the issuer gains. A tax is virtually levied on them for his benefit. ${ }^{3}$

This argument is founded on the theory that an increase of the volume of eurrency, other conditions remaining unchanged, is attended by a depreciation of the currency already existing (115-125). According to this theory the additional currency notes obtain their value by robbing the previously issued notes of a portion of theirs.

Such is really the case when a note issue is increased without making provision for the redemption of the added notes, for in such ease depreciation does inevitably ensue (124). The charge of robbery against the issuer is then justified, not, however, because of an increase of the issue, but because of the absence of provision for redeeming the notes. Depreciation will not follow when the added eurrency is adequately secured by existing wealth, and is redeemable in the commodity constituting the value unit. Mill and his fellow disciples of the earlier school erred in assuming that the value of currency notes is subject to an economic law different from that which controls the value of all other credit instruments. They failed to realize that the value of eurrency notes is really derived from the wealth which is pledged for their redemption and that it is measured by their face value stated in terms of the mivil in which they are redeemable. Why, then, expect +.1em to depreciate? Indeed, the value of notes which are adequately secured and redeemable in gold can change only if the value of the metal changes; and since an increase of fully secured notes redeemable in the standard metal is likely to be attended by an increase of the demand for the redemption medium, the value of the metal will rise rather than fall in consequence $(121,320 c)$. The fear of depreciation is groundless, and to denounce an increase of eurrency as "inflation" and "robbery" is wholly unwarranted. 
As above stated, the danger of depreciation exists only when redemption is jeopardized. But Mill and his school warn against any increase of currency beyond the volume already in existence, however completely redemption may be guaranteed. What reason is there for thinking that the volume now in use is the proper amount? Who can point out when money has attained the limit of its usefulness? The very fact that periods of finaneial stringeney do oceur proves that the value of the dollar does not adapt itself to the demand for money (125), and to advocate emergency issues for meeting temporary money stringencies is to admit the fallacy of the volume theory. No law has ever been proposed to prevent an inflation of looms, or of locomotives, or of other tools of production and transportation, lest the value of the looms and the locomotives already in use should thereby suffer. In the production of commodities we have learned to let free competition have its way. Why should the most important tool of trade, the medium of exchange, be treated as an exception? There is certainly no more danger in increasing the facilities of exchange than there is in increasing the facilities of production. On the contrary, every impediment to exchange is at the same time an impediment to production.

240. Interest on Money Due to Competition for Money. -If we had no money at all, a specialization of the proeesses of production would be impossible, since specialization requires that the goods, while being advanced toward maturity, be transferred from group to group and subjected to repeated rearrangement. This fully explains the existing demand for money.

It follows that if the total demand for money is not supplied, competition will tend to put a premium on its use (242, 348). Interest is accordingly paid on money because of its inadequacy to meet the demand of those who need it for the exchange of their products or services, and, as we shall see later (256), this competition raises the rate of interest as high as the market will bear, indeed, so high as to exert a destructive effect upon the market (276). 
It is of course only the borrowers' demand for money while the money in circulation is inadequate to cover the requirements of business that ean account for interest, and this demand arises generally from the exigencies of business, such as the employment of labor, or the purchase of material on credit. Thus money is usually borrowed to pay debts so incurred or to be incurred. As we here deal with the question of pure interest apart from the wage and insurance items of gross interest, we must here assume that risk is absent, in other words, that the borrowers have adequate eredit which they pledge for the loans.

But why, it may be asked, should it be held that the demand for money accounts for the interest commanding power of money, and not for its purchasing power, as is supposed by economists generally?

Because, in the first place, owners of money would have no inducement to loan it to borrowers if the borrowers' demand for it would result only in maintaining its purchasing power. In the absence of interest the lending of money would bring no recompense to the lender, for there is no reason to assume that money, when the loan is returned, would as a rule have a greater purchasing power than when the loan was advanced.

In the second place, money is not in itself a specific commodity, but consists of credit, the amount of which is expressed in terms of the adopted standard commodity (115). Its substance is therefore the wealth which constitutes the security of the credit, and its value is measured by the amount and value of the commodity in which it is redeemable. Only when that redemption is not provided for, is the money subject to depreciation from its nominal value. An excessive demand for a medium of exchange can affect the purchasing power of money only in the measure in which that demand reacts upon the value of the standard commodity, and this reaction has been analyzed heretofore (107-108). Demand, therefore, does not affect the purchasing power of money in the manner in which it affects the market value of commodities.

How an insufficient supply of the medium of exchange gives it the power to command interest will next be considered. 
241. Cause of the Inadequacy of Capital.-In dealing with the subject of money interest it was shown (210) that the borrower of money pays interest for the use of the money and not for the use of the capital goods bought with it, even though money is always idle capital incapable of yielding a revenue to its holder (133-134). Borrower's of money pay interest rather than go withont it by reason of the faculty exclusively possessed by money, the faculty of making possible that aggregation of capital goods which is indispensable in the process of produetion (211a). But even then we had to fall back on experience for the fact that capital employed in production returns a revenue $(211 b)$, and an adequate explanation of this fact is yet wanting.

We have already obscrved how goods in course of production pass from group to group. When the appropriate material is acquired by a group, this material is live capital until, in the process of production, it is advanced toward maturity. Thereupon, as far as that group is concerned, it becomes a finished product, or idle capital, which can become live capital, either as raw material or as means of production, of the next group only through the process of exchange. The goods thus become alternately active and idle capital. It is through production that capital goods are advanced from the active to the idle state, and through exchange that they are turned from an idle to an active state. From this it is at onee apparent that with the process of production going on, and with the process of exchange held back through the arbitrary limitation of the means of cxchange, the conversion of capital from the active to the idle state takes place more freely than the conversion from the idle to the active state. Consequently, the quantity of idle capital, in the form of goods awaiting exchange, tends to increase, while the quantity of active capital tends to diminish (266). In this lies the reason for the cbbing of capital in actual cmployment, and, at the same time, for that flood of things in the marlict known as "overproduction."

242. Key to the Theory of Capital Interest.-We have heretofore had occassion to advert to the relation which exists between the faculty of employed capital to "earn" a profit, 
and the limitation of capital in actual use (162b), but could not at that point trace the cause which determines the amount of employed capital, nor the reason for the experienced fact that capital is not put to use to the extent which would enable labor to be employed at its maximum efficiency. Later we found that the interest commanding power of capital has been almost universally attributed to a scarcity of capital, or to some psychological factor that could readily account for the undersupply. We found that Ricardo simply took this scarcity as a matter of fact (195) and argued on that basis; Senior assumed that men are naturally averse to defer the consumption of what they have produced, and introduced the term "abstinence" to designate self-imposed delay of consumption (196); while Böhm-Bawerk presents the same idea in the form of an hypothetical underestimation of future pleasure and pain as compared with the present (197). The disinclination to "abstain" or "wait," as well as the assumed underestimation of future values would take the form of an unwillingness to produce capital, the benefit of which can be enjoyed only in the future, unless that future benefit is greater than can be obtained through the same amount of effort in the present; and this unwillingness to produce things which will bring benefit only in the future would in turn account for that comparative dearth of capital by which capital interest is explained. But we have found (200) that in the economic world the final utility, and hence the value of this waiting, is nil, and that accordingly these psychological factors cannot be made to account for the faculty of capital to yield returns.

However, these theories may now be definitely set aside. Our inquiry has brought us to a point where the scarcity of capital can be explained by causes of a positive and objective instead of a negative and subjective nature (347). The undersupply of money required for the purpose of mediating the transfer of capital goods from group to group fully accounts for the scarcity of active capital, and at the same time explains why there is a superabundance of idle capital, or unsold goods, generally attributed to "overproduction," a condition which is in irreconcilable conflict with every one of the above cited 
theories. That the power of active capital to return an income is due to a searcity of such eapital is quite true, but the reason for this shortage has not been correctly diagnosed by any of the generally accepted authorities on the subject. We have found that the formation of active eapital is impeded by needless legal restriction, not by psychological restraints, such as a disinelination to produce or save capital, or an aversion to produce for future use, that can be overcome only by an accretion to the value of the future product. These needless restrictions imposed by law impede the free interchange by which idle capital is made active. This fully accounts for that undersupply of active capital which imparts to it an "earning power" approximating its final efficiency (162a), a power which it does not of itself possess.

We can here go one step further in our conclusions. Since idle capital can be made active only through the use of money, the last increment of active capital is made active through the last increment of the supply of money. Hence the efficiency of the last increment of active capital, in othcr words, the final efficiency of capital, is equal to the efficiency of the last increment of the supply of money, in other words, to the final efficiency of money. It would follow from this that the rate of interest on money should determine the rate of capital returns.

This completely reverses the usual explanation, according to which interest is paid for money because capital goods bought with the money bring returns. The connection of cause and effect is really as follows. 'The deficiency of money is the cause of the deficiency of active eapital, as just explained. And in the same way in which the demand for money, in connection with its scarcity, gives to money a command of interest (240), so does the need of capital for produetive processes, in conjunction with its deficiency, impart to eapital groods, when productively employed, the faculty of returning an income.

Summing up, the lack of money has two direct effects, of which the one is a lack of capital goods for productive processes, and the other is the interest commanding power of money. It has also an indirect effect, growing out of the lack of active 
capital, namely the faculty of capital goods to return an income when employed in production.

The borrower of money, when he invests it in active capital, is accordingly not a loser, for the returns derived from this form of capital compensate him for his outlay of interest. To him money is the instrument by means of which idle and therefore unremunerative capital goods are converted into such as afford returns (211). It is to be observed that this presentation of the matter differs from that of Calvin in that it is not a case of reasoning in a circle, but traces interest to a primary cause (204).

243. The Missing Link in the Productivity Theory.-We have now been led to what is virtually a confirmation of the productivity theory of interest. Returns accrue to invested capital goods by reason of the advantage afforded by the last addition of active capital to that in use before (162). While the capital in use is limited to the amount $O C^{\prime}$, Fig. 18, the last increment of this capital affords an increase, at the rate $C^{\prime} e^{\prime}$, in the amount of products obtainable by the given amount of labor. Competition for the use of this last increment of capital, therefore, naturally tends to raise the price of this use to that rate.

But the productivity theory of interest remains incomplete until the limitation of active capital is explained. When the capital in active use equals $O C^{\prime}$, and labor's productivity is represented by the area $O C^{\prime} e^{\prime} E$, an addition of $C^{\prime} C$ to the capital would increase the output to the maximum $O C E$. This addition of capital would therefore yield a positive advantage, and we can discover no other reason why it is not made than the impossibility of converting idle into active capital through the process of exchange as rapidly as is necessary to keep pace with the conversion of active into idlc capital through the process of production (211). This impossibility has been traced to the insufficiency of the medium of exchange.

At a former stage (149) we were brought to the conclusion that unhampered competition would result in ultimately conferring upon consumers all of the advantage derived from improved methods of production, and further on (192b) we also found that, in point of fact, the consumers do not reap all of 
this advantage, but that the owners of capital receive a share. This incongruity has now been traced to the existence of an impersonal monopoly through which the proper assembling of capital goods for productive use is impeded and competition correspondingly hampered.

There is a close similarity in the play of economic forces which determines prices and that which determines interest. In both cases two forees are in operation, one an impelling, the other a restraining force. In the production of commodities the impelling force is the desire for the utilities of the product, while the restraining foree is the reluctance to put forth effort, which places a limit on the amount produced. In the use of wealth for further production, that is to say, in the application of wealth as capital, the advantage afforded by capitalistic production is the impelling force, while whatever holds back the setting apart and utilizing of products of past labor for purposes of further production constitutes the restraining force, the force that puts a limit on the amount of capital actively employed. In both cases the recompensevalue in the one and interest in the other-becomes adjusted to the point where a balance between the impelling and the restraining force is established.

A corresponding similarity exists between the various theories that have been advanced to account for value and for interest. Each of the two sets of theories can be divided into two classes, according as they give prominence to the impelling or to the restraining forces. In the utility theory of value the restraining force, effort or cost, is subordinated, and predominance is aseribed to the impelling force, namely desire induced by utility. The labor or cost theory, on the contrary, neglects the impelling force and gives undue prominenee to the restraining one, namely effort or cost. So, likewise, do we find in the productivity theory of interest an absenee of due regard for the conditions that restrain the conversion of idle into aetive capital, while in the abstinence theory and in the "P'ositive Theory of Capital" the impelling foree, the effieiency of eapital, is not recognized as a factor coequal in importance with the one that restrains.

It is singular that in his theory of rahue Böhm-Bawerk 
gives prominence to the impelling force, the desire to utilize things, while in his theory of interest he reverses his position by giving prominence to a restraining force, a dislike for waiting, an unwillingness to accept future gratification in place of an equal gratification now. In the one theory he minimizes the importance of the dislike for putting forth effort, the force that restrains production; while in elaborating the other he is imbued with the idea that the productivity of capital, the force that impels the utilization of wealth for purposes of further production, cannot account for interest. On the one hand he considers "utility," the impelling principle, to be the causation of value; on the other he regards the "underestimation of future goods," a principle restraining the utilization of present goods for future purposes, of wealth as capital, to be the causation of interest.

In point of fact, however, that restraining force which he thus adduces as the dominant factor in the causation of interest is really not such at all. The truth is that it is not the psychological factor adduced by Böhm-Bawerk, but the existing restraint on the facilities of exchange, that is the real cause of the insufficiency of active capital and consequently the cause of interest. If this restraining factor were removed, the amount of capital used productively would rise to a point where there is no advantage to be gained by any further addition to it, and at this vanishing point the impelling and the restraining forces would naturally come to a balance.

The promulgators and adherents of the various forms of the abstinence theory of interest do not seem to realize the close relation that exists between it and the productivity theory. It is invariably true that capital interest, wherever it exists, is due to the advantage which the last available increment of capital affords in productive use; in other words, to the final efficiency of capital, just as the value of commodities is related to their final utility. But considering that the "final efficiency" of capital can be greater than nothing only so long as the available amount of capital is not enough to employ labor at its maximum efficiency, the productivity theory, to be complete, must, as already stated, point out why 
the available capital is not enough. The abstinence theory and the "Positive Theory" are simply efforts to supply the missing link in the produetivity theory, although their authors seem not to have been aware of this; and that even these efforts are founded on defective premises has been shown above.

When we found (192a) that the produetivity theory is ineompetent to explain the phenomenon of interest, it was on the assumption that production and exchange were not in any way impeded, but this, as we now find, is not the case. The arguments advaneed by such authorities as Böhm-Bawerk, with the objeet of refuting the various productivity theories, proceed likewise on the assumption of complete industrial and commercial freedom, and although the conelusions are valid on basis of this premise, they do not disprove that eapital interest, under existing conditions, is due to the advantage afforded by the last available addition to capital, that is, to the final effieieney of eapital, for the simple reason that those arguments assume conditions which do not at present exist.

The lack of eapital is not due to natural eauses, hence the power of eapital to eommand a share in the distribution of the results of effort is not a natural attribute, but is aequired through the effect of restrietions now in foree. While eapital is indeed a necessary link in the processes of produetion, it is not an aetive factor, any more than a belt that transmits power from pulley to pulley is productive of power. Just as the belt is a mere transmitter of energy, so is capital but a passive factor in the productive processes, a mere vehiele of efiort. It does not "earn" the profits which it gets.

244. The Law of Interest.-Before proceeding to deduce from the theory of interest the economic law by which the rate of interest is determined, we may well pause brieily to review the conclusions thus far reached. 'The factors of the problem become more numerous as we proceed; their relations become more complicated. 'l'o avoid the danger of getting on the wrong traek, we must earefully keep in close touch with our present line of incuiry, namely that regarding the ad- 
vantages afforded by the application of capital and money in the processes of production.

The effective utilization of the discoveries and inventions of the past, through which the productivity of labor is increased, is generally coincident with the employment of an increased amount of capital, but since the amount of eapital available for productive use is inadequate to employ labor at its maximum efficiency, capital acquires the power to exact a portion of the value produced, at a rate depending on its final efficiency.

This final efficiency can become a positive quantity only when the amount of capital in productive use is insufficient to employ labor at its maximum efficiency. Reverting to the diagram Fig. 18, if the capital in productive use is limited to $O C^{\prime}$, the final efficiency is equal to $O i$ and the rate of interest tends to this ordinate (162). The total value produced, which is represented by the area $O C^{\prime} e^{\prime} E$, is then divided into two parts by the horizontal line $i e^{\prime}$, the quantity above this line accruing to labor, that below to eapital.

If an employer borrows money, it is either to buy additional capital goods and employ additional labor, thus increasing his output, or to pay debts incurred by having previously done so. For the purpose of our present analysis we may apply the diagram Fig. 18 to that part of his business only which has been added through the borrowed money. The area $O C^{\prime} e^{\prime} E$ then represents the amount produced by the additional labor in conjunction with the additional capital represented by $O C^{\prime}$. The rate of interest payable on the borrowed money being $O i$, the above output is divided by the line $i e^{\prime}$ into two parts, of which the one, $O C^{\prime} e^{\prime} i$, must be devoted to the payment of interest on the loan, while the other, $i e^{\prime} E$, represents the part which accrues to the additional employes for their labor and to the employer for the additional service rendered by him. The efforts of the employer becoming more efficient by such investment of the borrowed money, his wage income is increased, and this is the only substantial inducement to borrow.

It is now to be observed that the area $O C^{\prime} e^{\prime} E$ represents 
products which, having to be marketed, are idle capital until sold. If the borrower now could hand over to the lender that portion of his produets which, as stated above, must be devoted to the payment of interest, the transaction would find its conclusion in the division of the products between labor and capital in the proportion in which the line $i e^{\prime}$ divided the total area $O C^{\prime} e^{\prime} E$ into two parts.

But the lenders of money do not agree to any such proposition. While their money enables the borrowers to increase the quantity of their output of products, they require the interest to be paid in money, not in kind. While the advantage of the hat manufacturer, as borrower, acerues to him in the form of more hats, or that of the shoe manufacturer in the form of more shoes, the lender will not aceept his share of the profits in the form of hats or of shoes. Before the borrower can apply his increased produets to the payment of interest, he must sell his goods and get money for them (345).

At first glanee it would appear that this has no bearing on the problem itself, but upon closer examination it will be found that the process of selling his goods introduces complications which must be taken into account, and this can be done only by an exhaustive study of the cirenlation of money.

245. The Barren Circulation of Money. ${ }^{04}$-When money performs its normal function of mediating exchanges, its flow from the buyer to the seller is attended by an opposite and equivalent flow of goods from the seller to the buyer. This flow of goods embraces the process by which idle capital is made active (211). But in the world of affairs there are also found currents of money which flow independently of any flow of goods. Money passes not only from consumer to merchant, and from merchant to produeer (120), but also between lender and borrower. The flow or "circulation" of

The analysis here following is in part a re-statement of an article by 11 . Bilgram, entitled "The Cause of Business Stagnation," published in the Annals of the American Academy of Politieal and Social Seicnee, January, 1905. An outline of the same subject had previously been published in the Appendix to "Involuntary Idleness," by the same author. 
money through which exchanges of goods and services are effected may be termed the efficient or fruitful flow, in contradistinetion to that flow in which it does not mediate the exchange of goods or services. While money, in the process of lending, passes from hand to hand, it does not perform its normal function, it is not given in exchange for goods. Nor is an exchange of goods involved when money is used in the payment of a loan. Such flow of money as is not effective in the exchange of goods may appropriately be termed inefficient or barren flow. While modern economists have given attention to the efficient circulation, showing that normally the monetary flow equals the industrial flow of goods and services (119), the study of the barren flow has been entirely neglected, although, as we shall learn, it is only through this study that the law of interest can be learned. Our next inquiry will therefore be centred on that flow of money which results from the process of issuing and retiring money, as well as from the lending of money and its return.

For the same reason as that which requires us to distinguish between the efficient and the barren flow of money, we must also distinguish between debts arising from the delivery of goods or the rendering of services and those arising from money loans. The former result from a temporary excess of the industrial flow over the effective monetary flow (270), while the latter are incidental to those monetary movements which take place apart from distinctively industrial transactions. As it is of vital importance to make this distinction, we shall select the terms "business debts" and "loan debts" to differentiate the same.

246. The Growth of Loan Debts. - When a debtor pays a loan, the amount returned exceeds the amount borrowed by the interest paid for the loan. The return flow of money to the lenders is therefore greater than the outflow from the lenders.

Since lenders who make a business of lending usually apply not only the principal, but also more or less of the interest received by them for further loans, it follows that the indebtedness of the borrowers to the lenders must constantly increase. 
Furthermore, since with every inerease of the sum total of loan debts the amount of interest thereon increases correspondingly, this increase of loan debts takes place in what is virtually a geometric progression, at least so long as the debtors continue to keep the money in active cireulation by borrowing. It is however plain enough that a geometric progression will in time rise to practically impossible amounts. A stage will therefore be reached, sooner or later, when this process camnot go on any further. The debtor class will then be unable to meet its obligations, and a financial " crash" ensues.

This is but a bare statement of what really goes on. The money-lenders spend part of their ineome for purposes other than lending, thus returning some money to active circulation without adding to the sum-total of loan debts. On the other hand, some workmen place part of their wages in saving banks, and some business men apply part of their earnings to loans, thereby bringing about an increase of the amount of loan debts. We have accordingly to subject these conditions to a closer serutiny.

247. Differentiating the Financial from the Industrial World.-We have spoken of the cireulation of money as being divided into a fruitful and a barren flow, and have indieated in general the processes of the latter. For a more detailed study of this phase of our problem let us consider the lenders of money and the users of money as being embraced in two separate categories. These we will denominate the "financial " and the " industrial" division, it being understood, of course, that the term " industrial " ineludes eommercial functions as well. 'These two eategories aceordingly embrace the entire range of the eeonomic world. The first elass comprises the lenders of money and the agents of money issues; the second the buyers and sellers of both eapital goods and consumption goods in all the various channels of production and exchange. Having reeognized this distinction, let us carefully observe the flow of money passing between the two classes, and espeeially the effect of this process upon the volume of money in the active ficld and upon the volume of loan debts. 
It may well be asked whether we can reasonably assume such a division of the economic world. The fact that any one individual may use some of his money as a medium of exchange for the purchase of things or services and some as capital for loans, and thus at once functionate in both the industrial and the financial sense, may be considered as making such a division logically unassumable. But we are here dealing with economic functions rather than with the men who perform them. We have already pointed out (16) that an individual may perform various separate economic functions and may thus have a correspondingly multiple existence in the economic sense. Every man who uses money both for buying things and for lending is identified with both the industrial and the financial class in the measure in which he is a buyer or a lender respectively. He simply performs the part of two distinct economic persons.

Inasmuch as the difference of functions relates to the two different uses of money, the sum total of money falls into two distinct divisions. When money is on hand for buying things or services, it is in position to perform its normal function as a medium of exchange; it is in an active state, as it were. But when money is on hand for lending, it is not in position to perform its normal function as a medium of exchange and is accordingly in a passive state.

A graphical representation may again facilitate our study. Let us assume all money to be contained within an inclosure, Fig. 25, which is divided, by a partition, into two compartments or fields, the one containing the active, the other the passive funds. The field of the passive funds pertains to the lenders of money and the agents of money issues, in short, to the financial class. The field of the active funds includes the users of money, the producers and consumers, in short, the industrial class. All money transactions making up the efficient circulation, comprising all kinds of sales and purchases, take place within this field. By thus eliminating that circulation of money which mediates the industrial flow, we can confine our study to the barren circulation, namely that flow of money which does not mediate exchanges and which passes between the 
financial and the industrial classes. The partition which in the diagram separates the active from the passive field is represented as having openings or channels through which the currents of this circulation flow.

248. The Several Barren Currents.-At first we can discern three barren currents passing between the two fields. One of these, flowing from the passive to the active division, is that which results from the borrowing and lending of money. ${ }^{95}$ This current has the double effect of increasing both the volume of active funds and the total sum of loan debts. The other two currents flow in the opposite direction. The one is the payment of loans and the other the payment of interest. Both bring about a diminution of active funds, but the first of the two has the additional effect of reducing the loan debts.

It has been pointed out before (139) that gross interest really consists of three items : first, compensation for labor and other costs connected with the business of lending; second, insurance on the risk assumed by lending; and third, pure interest, the net profit on money loans. The first of these three items is a payment for personal services and is therefore a transaction that is to be classed as part of the fruitful circulation of money, taking place within the division of active funds. Only the second and third items are really to be included in the stream of payments passing as interest on loan debts from one division to the other.$^{98}$ For this reason only two items, insurance on risk and interest proper, can, in our present consideration, be included in the tcrm "gross interest." The interest with which we are here dealing is

When notes are discounted, we can, of course, consider only the discounted amount as constituting the aetual loan.

* When the business of lending is transacted through an agent, this agent usually deducts his commission and other expenses, the cost of his services, and pays to his client the gross interest minus that cost. If the lender himself attends to that business, the item cost acerues to him as wages and expenses, and these he receives as member of the industrial elass. Only the remainder goes to him as member of the finaneial class. 
therefore only that portion of the gross interest which is not in any way a recompense for personal service.

The eurrents thus far discussed may be designated by the letters $L$ (Loans), $P$ (Payment of Loans) and $G$ (Gross Interest, consisting of $R$ plins $I$, Risk Insurance plus Pure Interest).

In the long rum the current $P$, namely payments on loan debts, will not fully balance the current $L$, bceause some debtors default in their parments. But the resulting losses are made good by that portion $R$ of the gross interest $G$ which is deroted to risk insurance (251). For this reason the sum $P+R$ will in the end equal the loan current $L$. The effect of this system of insurance is the same as though the current $R$ were applied to pay off that portion of the debts which the delinquent debtors fail to pay. The branch $R$ of the current $G$ must therefore be regarded as having the effeet of reducing the volume of loan debts, while, on the other hand, the braneh $I$ has no such effect.

249. Preparatory Currents.-In tracing the circulation of money, as it passes to and fro between the passive and the active fields, it will be found necessary to recognize two additional currents.

The field of passive funds contains all of that money, including, of course, all of that bank eredit, which, after having been put into circulation, has found its way back into the passive field through either the channel $P$ or $G$. If there were only the three channels $L, P$, and $G$ available, this money could not go into cireulation except through lending, in other words, hy passing through the channel $L$. But some of this money is constantly being put to use for purposes other than lending, for instance, for personal requirements, or for investment in industrial or commercial pursuits (275). Inasmuch as it is only when money is in the active field that it can be put to active use, we must needs assume that any money of the passive field which is to be put to active use must first be transferred into that field. We have accordingly to provide in our diagram a channel through which this transfer takes place, and this channel is indicated in Fig. 25 at $E$ (Expenditures). Such use of part of the passive funds must therefore 
be considered as a double transaction; first, as a barren flow of money through the channel $E$ from the passive to the active field, and seeond, as a fruitful cireulation of money within the active field, where it performs its normal function of mediating the exchange of goods and services.

Conversely, money which is circulating in the active field may be withdrawn from further active cireulation and applied to lending. It is thereby directed into the current $L$, but before it can join that current, it must be regarded as having been transferred from the field of active to that of passive funds. Hence, in the process of lending out money from the active field, it undergoes a double transfer; first, a preparatory transfer through the channel designated $S$ (Savings), and seeond, the subsequent flow through the channel $L$.

In one respect the terms " expenditures " and " savings," selected to denominate the currents $E$ and $S$, are not properly descriptive. These currents should be conceived as being distinct from the suceeding transactions to which they are merely preparatory. The current $E$ does not represent the aet of giving money in exchange for things, the act of spending it, for that pertains to the efficient circulation. It is made up only of those transfers of money from the passive to the active field which must be presupposed when money which is in the passive field is to be used in the active field. Similarly, the current $S$ is made up of those transfers that must be assumed as preceding the act of lending whenever money which is in the active field is being diverted from active use and made the subject of lending.

These preparatory transfer's consist of nothing but a change in the status of money while in the owner's hands. There is no bodily transfer, but only a shifting in the direction of its use. We may view this shifting as though the owner, in his capacity of member of the financial class, hands over this money to his other economic self, member of the industrial class, or vice versa. The money is merely transferred, by the will of the owner, from one field to the other. While we must regard these transfers as currents, they are currents only in a figurative sense. 
In another respect, however, the above nomenclature is justified. The current $E$, although representing only a preparatory change in the direction of the money before it is expended, actually measures the amount of money expended by the members of the financial group in the industrial market, while the current $S$ measures the amount of money withdrawn from the active field through its being put out at interest; or, if viewed in connection with the attendant angmentation of the current $L$, whereby it is returned to the active field, the current $S$ measures an increase of the volume of money debts unattended by any increase of active funds.

The five currents above described, one of which is a composite current, together constitute the barren circulation, and each of them has a specific bearing on our problem regarding the volume of active funds and the sum of loan debts. Their effect may be tabulated as follows:

Current $L$ Increases Active Funds and Increases Loan Debts.

$P$ Decreases Active Funds and Decreases Loan Debts.

$G\left\{\begin{array}{l}R \text { Decreases Active Funds and Decreases Loan Debts. } \\ I \text { Decreases Active Funds and has no Effect on Loan Debts. }\end{array}\right.$

$E$ Increases Active Funds and has no Effect on Loan Debts.

$S$ Decreases Active Funds and has no Effect on Loan Debts.

250. The Volume of Active Funds.-A glance at the diagram Fig. 25 shows that all changes in the volume of money in active circulation are determined wholly by the volume of the several currents just described. Whenever the currents flowing toward the field of active funds predominate, the volume of active funds is increased, and when the reverse condition prevails, this volume is reduced. Passive funds can go into circulation only by passing throngh either of the channels $L$ or $E$. On the other hand, money can be removed from active circulation only by passing through either of the channels $P, G$ or $S .^{97}$

If we denote by the letter $V$ the volume of funds eirculating in the active field, and by $d V$ the change or differential of

${ }^{97}$ Money which is hoarded is virtually not in active use, but for our present inquiry it may be considered as remaining in the division of active funds, as long is it is merely hoarded. 
this volume within a given period, the extent of this change ean be found from the volume of the various eurrents during the same period. This relation can be expressed in the form of the equation.

$$
d V=L-P-R-I+E-S .
$$

This equation will be used below for further deductions.

251. The Volume of Loan Debts.-As we have seen, these eurrents affeet not only the volume of money cireulating in the active field, but also the volume of loan debts, that is, the total indebtedness of the industrial to the finaneial world.

The volume of loan debts is inereased by the current $L$ and is reduced by the opposite eurrent $P$. There is, however, another factor, already adverted to (248), which reduces the volume of debts, namely the oceasional insolvency of debtors. A rast amount of loan debts is annually written off to loss on this account. But, in the aggregate, this loss is made good by that portion of the gross interest $G$, which constitutes the insuranee against risk and whieh we have designated $R$, the portion through which the solvent borrowers are virtually made to pay the debts of the insolvent ones (289). It follows, then, that $L, P$ and $R$ are the three items governing the volume of loan debts.

As stated before, the loan debts here under consideration inelude only the debts direetly ineurred by the borrowing of money, but not industrial or business debts arising from the delivery of goods or serviees, sinee the latter transactions are clearly snch as take place within the active field.

If now the letter $D$ is used to designate the volume of loan debts, and $d D$ the ehange or differential of this volume during a given period, it is evident that:

$$
d D=L-P-R \text {. }
$$

Substituting in equation (1) for $L-P-R$ its equal $d D$, as per equation (2) and solving for $I$, we obtain:

$$
I=E-S+d D-d V .
$$

This formula presents the conditions which determine the total amount of net interest reeeived by the lenders as a class 
during any given period. It applies to short as well as to long periods, but when long periods are in consideration, the differential terms are insignificant as compared with the other terms and, accordingly, become negligible. The equation will then assume the form:

$$
I=E-S \text {. }
$$

The two quantities $E$ and $S$ are what we have termed "preparatory " currents. Of these the current $S$ flows opposite to the current $E$, and since the latter measures the expenditure of money by the lender class in the industrial market, while the current $S$ measures the withdrawal of money from the industrial market for the purpose of lending, we can regard the difference $E-S$ as measuring the "net-expenditures" by the lenders (272).

Equation (4) is to be interpreted to the effect that in the long run the total interest $I$ received by the lending class equals the net-expenditures of that class in the industrial market.

Applied to a static business condition (252) in which both the volume of money in circulation and the total volume of loan debts remain unchanged, this equation is, indeed, strictly true for both short and long periods. The sum total of loan debts can remain stationary only while the currents $L, P$ and $R$ of Fig. 25 balance each other, and if the volume of money in the active divirion is also to remain unchanged, the three remaining currents $I, E$ and $S$ must likewise balance, and this is expressed by formula (4).

The business world is, however, not in such static condition. Changes constantly oceur which affect both the volume of loan debts and the volume of money in actual use. But ncither the one nor the other can be increased or reduced indefinitely, and for this reason the equation (4), although but an approximation, is practically true in the long run. This means that the total net-interest $I$, accruing to the lenders of money, cannot indefinitely exceed the difference between $E$ and $S$, nor can it be indefinitely less (274). There are periods in which the volume $I$ exceeds the difference $E-S$, but such periods must necessarily be succeeded by other periods in which the condi- 
tions are reversed, $E-S$ then exceeding the volume of $I$. For the study of these periodic changes, which we shall take up in the next chapter (271), we must have recourse to the unabbreviated equation (3), which is correct under all conditions. In the present chapter we shall confine our investigation principally to the proposition that the volume of $I$ cannot continuously exceed the difference $E-S$ on the ground that equation (4) is substantially true, although temporary departures on either side may occur. ${ }^{98}$

252. The Rate of Interest.-If $I$, the total net income accruing as interest, and $D$, the sum total of loan debts, are given, the determination of the rate of interest is a question of simple arithmetic. Suppose we could obtain the respective data covering the period of one year, the rate $i$ of interest would be found as follows:

$$
i=100 \times I \div D \text {. }
$$

Since the value of $D$ is unavoidably variable during the period, the value of $i$ should really be obtained by a process of integration, but for our purpose it will suffice to assume that the corresponding average of $D$ is given.

By inserting the value of $I$ from formula (3), we obtain (267) :

$$
i=100 \times(E-S+d D-d V) \div D,
$$

or, by applying the abbreviated equation (4), we obtain the

${ }^{88}$ It is a fact that in long periods the total volume $V$ of our money, including bank eredit, slowly increases, principally because of the slow increase of our stock of gold and the coincident expansion of the system of bank credit. But the same is also true for the total volume $D$ of the indebtedness of the industrial to the financial world. In assuming that the difference $d D-d V$ ean be neglceted, we not only ignore the periodic fluctuations of the quantities $D$ and $V$, but we also take for granted, in considering long periods, either that both do not change at all, or, if they do change, that the change is equal for both. This is indeed nearly the case, for every increase of bank credit is attended by a nearly equal increase of business debts. But while there is some difference, formula (4), though true in the main, is not mathematically correct. On the other hand, all deductions based on formula(3) are accurate throughout. 
rate of interest prevailing under static conditions (251) as follows :

$$
i=100 \times(E-S) \div D \text {. }
$$

This last formula also represents the general average rate of interest in the actual business world.

The volume of the currents $E$ and $S$, which we termed preparatory currents, depends solely on the option of those who have the money to spend. They are free to make such use of it as seems fitting to them. Their motives for using it in one way or another are not within the scope of our present inquiry. $E$ and $S$ are accordingly quantities which are independent of other economic factors and, like the quantity $D$, must be accepted as economically fundamental data. Hence the formulas (5) and (6) express the law of interest, at least as regards money loans.

253. A Seeming Contradiction.-This law appears to be inconsistent with our earlier conclusions, according to which the rate of interest depends on the final efficiency of money (242-244). There can be no possible relationship between the productivity of the last increment of capital made available by the last increment of the volume of money on the one hand and the quantities $E, S$, and $D$ on the other. But the reason of this manifest discrepancy is not far to seek. Let us for the moment take recourse to an analogy in dynamies.

Isaac Newton showed that the velocity of a falling body constantly increases and, at any moment, is proportional to the time of the fall, or to the square root of the height through which the body has fallen. This law is, however, not verified in the descent of a drop of water falling through the air from a great elevation. At the start it has indeed an accelerated motion in accordance with Newton's law, but presently the acceleration becomes less, and finally the drop continues its downward course with a nearly uniform instead of an accelerated motion.

This fact is strikingly illustrated in nature by a number of high waterfalls, among them that of the Staubbach near Lanterbrumnen, Switzerland. This stream descends the upper 
slope of the mountain in large irregular billows which, upon breaking over the brink of the fall, partake at first of an aceelerated motion. But after descending through a small part of their plunge they break into spray and continue to fall in curtain-like festoons at a speed which is quite uniform, as far as the eye ean judge.

Why is it that thesc descending drops fail to follow the universal law of falling bodies? For the simple reason that an interfering factor, the resistanee of the air, modifies the motion and finally develops a reaeting force equal to the weight of the drop, when acceleration eeases and the motion beeomes uniform. The velocity of the falling drop is ruled by a law radically different from the law of falling bodies which Newton traced to the primary cause, gravity. The final velocity of the drop depends neither on the time nor on the height of its descent, but on its weight and size, on the density of the air and on the law of the resistanee of bodies moving in fluids. Yet, this fact in no sense contrarenes Newton's law of falling bodies. In like manner, with regard to the law of interest, if it is possible to discover an interfering force analogous to the resistance which the air presents to the falling drop, a force which prevents the rate of interest from becoming adjusted to the final efficiency of money or of capital goods, the cause of the discrepancy between our recent conclusion and the previous one will have been brought to light.

254. Effect of the Interest Power of Money.-The fact that money loaned at interest renders an income without further labor on the part of the lender is a powerful incentive to withhold money from the channels of exchange and to direct it into the ehannel of loans. Lenders not only endeavor to lend out again the prineipal of the loans returned to them by borrowers, but they also offer part of their interest ineome to further increase their loans. They naturally strive to expend less than their income from interest, and this constitutes a tendency to keep the current $E$ below the eurrent $I$. Thus only a portion of their income is restored to circulation by passing through the channel $E$, while the remainder, namely, $I-E$, goes into circulation by passing through the channel 
$L$, and this causes an increase of loan debts. The fact that some men actually spend more than their income, dissipating a portion or even all of their means, is here negligible, since we survey the community as a whole. The desire to increase loan investments obviously predominates so that $E$ is naturally less than $I$, at least while " business is good."

Members of the industrial group are likewise intent on saving money for lending. Merchants and manufacturers frequently invest their money savings in bonds and mortgages, and many of the workmen whose wages little more than suffice for the necessaries of life take what they can spare to savings banks. Thus the current $S$ springs from a natural desire of men to put out money at interest.

If, then, $E$ tends to be less than $I$, the difference $E-S$ must be still less, and the natural tendency is that equation (4), $I=E-S$, will not be satisfied.

255. Inevitable Consequence.-It is not difficult to foresee what must be the consequence. Let us assume that the difference $E-S$ is really less than $I$, in other words, that $I-E$ $+S$ is a positive quantity. Since formula (3) can be presented in the form

$$
I-E+S=d D-d V,
$$

a glance will show that $I-E+S$ can be positive only if either $d D$ is positive or $d V$ is negative. A positive $d D$ indicates a constantly increasing indebtedness, while a negative $d V$ signifies a constantly decreasing volume of money in circulation. Hence the business world must submit to the one or the other of these two evils, and since money is imperatively needed for the transaction of business, an indefinite reduction of money in use cannot be supposed. The business world has practically no choice but to borrow as much as possible of the money offered for loan in the money market, and a gradual increase of the volume of loan debts is the unavoidable consequence (281). But with every increase of these debts the payment of interest increases, and the process described accelerates until debts become overwhelming and bankruptcy ensues. If the whole in. dustrial world were consolidated into one company which still 
remained under the necessity of borrowing money on interest from the financial world, this company could not possibly escape ultimate bankruptey.

This statement must not be misunderstood. It does not mean that every independent business man is approaching ruin, nor even that a large percentage of them are in this condition. The conclusion must be interpreted as follows:

The active field embraces the debtor class, for a large number of business men are working in part with borrowed capital. The faet that the sum total of these debts goes on increasing, as just shown, together with the fact that some business men suceed in lessening their debts, simply implies that the debts of others are more than correspondingly increasing. The vietims of this fateful condition find that in the so-called " competitive struggle" their gross ineome is insufficient to eorer expenses. In the vain hope of making good the deficit, they continue to produce, struggling under overpowering disadvantages and hoping for better times, until their debts equal and finally exceed the eapital they employ. In the end they must suceumb to the inevitable; they fail $(257,280,304,340$, 345 ).

The eonclusion that the sum total of loan debts tends steadily to increase, especially in years of prosperity, is fully confirmed by established facts (344). The eonstantly increasing public indebtedness, partieularly in Europe, is viewed by many with foreboding. The growth of bonded debts of railroad eompanies and other industrial and eommereial corporations, partieularly in Ameriea, is still more alarming. The expansion of bank deposits is usually heralded as an evidence of prosperity, but under existing conditions it has also its dark side, which is rarely noted. Since about seven-eighths of all bank deposits represent commercial loan debts (104), it is obvious that every increase of bank deposits means a positive increase of interest-bearing loan debts.

Still more positive confirmation of our theory is furnished by the fact that there are always numbers of business men who are on the verge of bankruptey, brought there, not for lack of a nolmally remunerative business, but because of the long- 
continued and constantly increasing drain upon their business incomes by the payment of interest on a constantly increasing debt. In fact, business failures are reported by mercantile agencies without intermission. It is now generally assumed that commercial failures which are not positively fraudulent or traceable to evident lack of business capacity are due to economic reactions for which bankrupts cannot be held responsible and which must be considered as an unavoidable concomitant of business activity.

256. Effect of Business Failures on Pure Interest.-The delinquency of borrowers puts on the lenders a loss which must be covered out of the gross interest. In other words, a greater or less portion of the gross interest is to cover losses involved in lending. This latter item is what we have designated by the letter $R$. Any increase of these losses, while the gross interest $G$ remains unchanged, implies a corresponding reduction of the net interest $I$ (274). This reduction is imposed by conditions which the lenders cannot control. By increasing the item $R$, business failures cause a reduction of the item $I$ of the gross interest until it falls below the difference $E-S$, whether or not the quantities $E$ and $S$ are affected at the same time. The preceding excess of $I$ over that difference is then reversed, so that in the long run the equation $I=E-S$ is satisfied.

While a falling drop of water, in its descent, has a tendency to follow Newton's law of falling bodies, it is prevented from exceeding a certain velocity by the resistance of the air. In like manner, while the rate of interest tends to adapt itself to the final efficiency of money, the total amount of net interest $I$ is prevented from indefinitely exceeding the difference $E-S$ by the physical impossibility of the industrial world continuously returning to the financial world more money through the channels $I$ and $S$ than it receives through the channel $E$. This is the interfering factor in our present case; the analogy with the falling rain drop is in fact complete. The conflict between final efficiency of money on the one hand, and the impossibility of continuously giving more money than is received on the other, results in the constant recurrence of failures in the business world. The rate of interest is as high as the market 
can bear and camnot, for this reason, rise to the rate that would correspond to the final efficiency of money (240). The equations (5) and (6) must therefore finally be aceepted as expressing the law of interest in its relation to money loans, the first being a precise statement, the second an approximation, giving the average rate.

257. Rate of Capital Interest.-For reasons just explained (255) there are at all times and in all trades producers who are in debt to the extent of the capital they employ. From the capitalist's standpoint these are obviously the marginal producers, namely, those who, as regards the use of eapital, are working under the most unfavorable circumstances under which production is being continued $(62,348)$. The interest paid on money loans by the marginal producers, that is, by the producers who are indebted to the limit of their capital, is an expense whieh they cannot escape under present conditions. Their expense in producing the goods is equal to the cost (61) of conducting the business plus the interest paid on the borrowed moncy. The more fortunate business man who owns the capital employed by him and who, therefore, is not under obligation to pay interest, can produce the same goods at the mere cost of conducting the busincss. But whatever it may cost the different produeers to make the goods, the selling price is the same for all, and this price is established by what it costs the marginal producer to make the goods. Hence those who own the eapital they employ reap a profit on their sales equal to the money interest which the completely indebted producer must pay, and this profit is what constitutes capital returns (265). It is in this way that capital goods acquire what appears to be an earning power, the rate of which is the same as that of money interest (209).

Referring to Fig. 13, the business man who is indebted to the extent of his entire capital must pay money interest equal to $C E$, hence the eost of production to him, counting the value $F G$ of his own services at market rates, is made up of cost of supplies $A B$, rent $B C$, interest $C E$ and wages $E G$. He being the marginal producer, this cost determines the market value 
of the products, and he gets only the value $F G$ of his own services as net income from his business. The capitalist who owns all his capital, except the land, can produce at a cost equal to $A B+B C+E G$, and his profits from the sale of his products, apart from his wages $F G$, are equal to $C E$. Or if he is partially indebted and must pay money interest to the amount of $D E$, his capital profits are represented by $C D$.

258. Capital Interest an Intra-Marginal Profit.-We are now brought to a recognition of the fact that the interest supposed to be earned by capital goods is after all analogous to the rent of land (187), at least in that both are intra-marginal profits. These profits accrue to the owner of capital goods by virtue of his advantage over the marginal producer, who must pay interest on an amount of money equal to the capital employed. This advantage being equal to the interest paid by the marginal producer accounts for the fact that the rate of interest returned by capital goods equals the rate of interest on money $(131,267)$.

This appears to conflict with a former conclusion to the effect that the rate of capital interest tends to rise to the final efficiency of capital, while, according to the above, it rises only to the aetnal rate of money interest, which we found to be below the final efficiency of money. This discrepancy is explained by the recurrence of periods of business stagnation, when a portion of eapital is eondemned to idleness. Capital returns are correspondingly reduced and do not rise above the rate of money interest.

The reason why capital has the power to "earn" an income is due to the fact that money has the power to command interest. To summarize: (1) the power of money to command interest is due to the inadequacy of its volume to mediate all the exchanges necessary to permit the free development of industry; (2) the power of capital goods to yield "earnings" is due to the advantage possessed by the intra-marginal producer who owns his capital over the marginal producer who is in debt for all his capital and must pay interest on that debt.

259. Currency Laws Examined.-Having found that the power of money to command interest is due to the limitation 
of the volume of money, and that this limitation results from the operation of prevailing eurrency laws, we have next to determine in what way and to what extent that limitation is justified. To this end we may here apply the test of equity proposed in an earlier ehapter (20) and analyze the process by which money is prodneed, with a view of learning the nature of the rights granted and the duties imposed by curreney laws.

Money is an instrument of exchange by the use of which simple barter becomes expanded into complex barter, into exchange through purchase and sale (83). In the process of simple barter the exchange of one thing for another is effeeted by one reciprocal transaction, while in the process of exchange through sale two transactions are required: first, a giving of goods for money, and then a giving of money for other goods. These two transactions or sales are separated by a sensible period of time, and during this time the money serves as an evidence that the holder has given goods before receiving goods. He is ereditor of the money system to the extent of the money which he holds (89). But this necessarily implies that someone else has received goods before giving goods, thereby becoming debtor of the money system (92).

In any system of eredit money those who have the right to issne either curreney or bank eredit acquire through such issue the means wherewith to buy before they need sell, and thus to receive before giving; they have the right to become debtors of the money system and to remain possessors of wealth they do not own so long as the eurrency issued by them remains in circulation. We must, of course, not confuse the giving of goods with the mere pledging of goods. The issuer must give security when he obtains the eurrency. But since he retains possession of the wealth pledged, or at least continues to enjoy the usufruct of the pledge, he eannot be regarded as having parted with wealth, so that the first time the money is given for goods or serviees, the giver of the money, who thus becomes its issuer, reccives goods without having given goods.

On the other hand, the nembers of the eommunity who 
have consented to use these notes as money have thereby taken upon themselves the obligation or duty to give before receiving, in short, to become and remain lenders of wealth, or creditors, to the extent of the eurrency which they individually hold and whieh, as a eommunity, they maintain in eirculation. This clearly outlines the nature of the rights and duties embraeed in any eurrency system.

These considerations do not strictly apply to the issuers of gold coin. In this case the giving and receiving of actual wealth are coincident. It is therefore neeessary to consider the right and duty involved in the coinage system from another point of view.

Ordinarily a person can obtain money for merchandise only when he succeeds in finding a purehaser for his goods. The issuer of gold coin, on the contrary, obtains money without going to this trouble. He need only take the gold to the mint and have it converted into money instead of selling it as merchandise (93). In this way the owner of gold is saved the necessity of doing the merehant's work. Gold is therefore a merchandise which can be converted into money without the effort and uncertainties attending the finding of a purchaser; its market is assured. The value of all other merchandise can become realized only through the efforts of the merehant to find a purchaser, and in this respect that value is precarious. Such is not the case with any metal admitted to free coinage. This unique position of the money metals misled those economists of the eighteenth century known as the Mercantilists into the belief that nothing but gold and silver constitute the wealth of a country.

It is thus clear that the owner of goods in the form of gold metal is aecorded by law the right to have his goods coined into money, while, on the other hand, the owners of all other goods are not only under the necessity of first finding a purchaser for them before they can get money, but are furthermore in duty bound to accept the proffer of the gold metal in coined form as money in exchange for their goods. This elearly presents the correlative conditions of right and duty embraced in the coinage system. 
260. Existing Currency Laws Inequitable.-It may seem strange to describe the consent of sellers to aceept money in exchange for goods as a duty or obligation, in the face of the fact that all are really striving to make such exchange. But we must remember that coin and currency notes can become money only by virtue of the general consent to accept them in trade. This is really an agreement to give actual wealth in exchange for a mere credit instrument (93), and such accept. ance of the money in accordance with the agreement is manifestly in the nature of an obligation or duty. Though this duty is not usually regarded as onerous, it still remains a duty, and the question before us is whether those upon whom that duty is imposed are accorded a corresponding right (20).

To be sure, a right to issue currency cannot be granted unconditionally; certain provisions must be observed without which a sound currency is impossible. Chief among these is the obligation to pledge security, for without security there can be no eredit in the economic sense. Making the right to issue currency contingent on furnishing adequate security is therefore not an undue requirement. But in so far as additional and arbitrary eonditions are imposed by law, all who must needs submit to the obligation of accepting the currency are unduly restricted in the exercise of the corresponding right of issuing it (261). And such is indeed the effect of present eurrency laws.

Arbitrary restrictions on the right to issue currency are imposed in three different ways: (1) by specifically limiting the maximum amount of currency to be issued; (2) by too narrowly prescribing the kind of security acceptable as a basis for eurrency; and (3) by imposing a tax on the issue of currency excecding insurance against risk of loss through depreciation of the security.

Let us more closely consider the nature of these restrictions in their order.

First: When laws establish a definite limitation to the amount of currency that may be issued, applicants for additional issues must be refused, even though they offer to 
comply with all economically necessary conditions. Such laws are an arbitrary denial of a right to which all are justly entitled who submit to the corresponding duty of accepting the currency as a medium of exchange. The laws which prescribe that banks must hold a certain reserve of lawful money, while yet the amount of lawful money is arbitrarily limited by law, belong to this category.

Second: The securities acceptable under the law as a basis for currency issues may exist in quantities insufficient to cover the need for currency. That such is now the case in regard to national bank currency, for which only national bonds are acceptable as security, is shown by the fact that these bonds, though bearing a very low rate of interest, have all along been at a premium.

The claim that this limit is imposed in order to make the currency safe cannot be sustained, for the routine of deposit banking demonstrates conclusively that carefully scrutinized and assured business credits can be used as money with safety. About seven eighths of the assets upon which bank credit rests consist of business credits, and bank credit is constantly doing the work of money. While business credits are not well adapted for acceptance as security by the government, there are other securities, like real estate, available in abundance. It is decidedly a violation of justice to confine the kind of wcalth acceptable as security for the issue of currency to one or a few forms of property, unless there exists so much of this property that its use for the purpose will engage but a fraction of the supply and therefore will not cause an appreciation of its value. That federal bonds do not conform to this condition is indicated above.

Third: The imposition of any tax beyond necessary insurance on the right to use eredit as a medium of exchange is virtually an arbitrary limitation of a right which in justice inheres to all who submit to the corresponding obligation. A tax covering insurance against default of the credit cannot be viewed as a tax on the conversion of assured credit into money. But every additional tax is indefensible. It has the same effect that a specific limitation of the volume of currency 
would have. This can be elucidated by the diagram Fig. 22, where the curve $E E^{\prime}$ represents the deereasing efficiency of consecutive inerements of money. It is manifest that a tax equal to $O i$ has the effect of forbidding the issue of that portion of curreney which lies beyond the point $V$, since the efficiency of the inerements loeated between $V$ and $E^{\prime}$ is not enough to cover the tax. The same labor that under the fullest freedom of exchange would produce an amount represented by the area $O E^{\prime} E$, cannot economically produce more than an amount corresponding to $O V a E$ (262). Labor is foreibly prevented from using the most advantageous methods of production; nature's forces are not utilized to the best advantage known in the arts. Moreover, of the reduced product an amount equal to the area $O V$ Vi must be devoted to the payment of interest to the money-lender, and the produeer has only the remainder $i a E$ out of which to eover all other costs, including his own wages and those of his employes.

So long as any of these three impediments are placed in the way of freedom of exchange, the publie, bound by the duties imposed by the eurrency laws, is deprived of the corresponding rights, and the laws are to that extent inequitable.

26r. Pure Interest a Monopoly Tax.--The advocates of laws obstructing the issue of eurreney do not deny that the purpose of such laws is to limit the volume of money. They believe that the stability of curreney requires this limitation. But they fail to realize that this constitutes an interference with the freedom of exchange, whereby a monopoly of the impersonal type (232) is ereated, which has a twofold effect. On the one hand it restricts the right of the producers of wealth freely to exchange the products of their labor, and sinee exehanges are indispensable to modern produetion, it virtually constitutes a restriction of the right to work (291,347). On the other hand, it imparts to money direetly, and to capital goods indireetly, the power of returning continuous unearned incomes to lenders of money and to owners of capital. That this monopoly is sustained by laws that are essentially inequitable has been demonstrated above (260). The right to 
use assurcd credit as a medium of exchange has been transformed into a privilege. It is this privilege which gives to money its interest commanding power. Interest is clearly traceable to a monopoly upheld by law.

At first glance it may appear that this conclusion is inconsistent with the fact that interest was paid for the use of money in ancient times, when currency laws were yet unknown. But a closer examination of the subject will clear away this apparent inconsistency.

In the earlier stages of civilization the risk assumed by the lender of money was much greater than it is to-day, and the main item of the interest charge was insurance against risk. Such portion of that charge as constituted pure interest was doubtless due to the general scarcity of money which, in the absence of the use of credit as a medium of exchange, was confined to the precious metals, of which but very limited quantities were used as money (329). In the course of time the precious metals have been supplemented and to some extent displaced by the application of eredit as a substance of money, but while the natural cause of the insufficiency of money has thus been removed, another cause to the same effect has come into force, namely, the arbitrary limitation of the circulating medium by law.

262. The Power of the Money Monopoly.-In the light of these conclusions it becomes possible to survey the extent of the harm which the money monopoly is capable of inflicting upon the community (235). The greatest injury the public could possibly suffer in this direction is that which would result from a total abolition of money in all its various forms. This would manifestly reduce the community to that primitive state in which each individual must make with his own hands that which he wants.

But forcing the scarcity of money to the extreme of its total elimination would benefit no one. In the money monopoly, as in all others, a certain degree of moderation of its exercise affords a maximum benefit to those who are in position to gain profit from it (234). How nearly this degree is approached under the prevailing limitations of the curreney 
camnot be judged. At all events, the volume of money permitted to the community by our laws is such that industrial progress is only obstructed, not prevented, but to whatever extent the monopoly is operative, the country's industries suffer thereby.

Every branch of industry and commerce feels the evil influence of this monopoly. It ramifies through every province of activity, because every branch of industry, every channel of commerce, depends on exchanges, and so far as this monopoly restricts exchanges, it has the effect of hampering all productive efforts. It causes a certain amount of labor to go to waste, partly by reason of labor's inefficient utilization $(159,260)$, and partly through the enforced idleness of some labor (270). It is impossible to conceive of any other form of monopoly which has so potent and at the same time so injurious an influence on every individual, every community, every nation and on the whole economic world.

263. Service Rendered by the Lender of Money.-The gross income from money loans, the return commonly called "interest," accrues to the lender of money in return for three different services rendered by him, corresponding to the three items of which gross interest consists (139a).

The first is the service of attending to the business of lending. If the loan is one of long time, like a mortgage or a bonded loan, this item makes a very small part of the whole. Those who make a business of negotiating such loans and attending to their details, usually obtain a compensation which, being determined by competition, represents the average value of this service. If the lender himself does this work instead of hiring an agent for the purpose, he may be considered as having earned this portion by his personal effort.

The service so rendered has a specific usefulness. Whatever the method of its issue, the currency must be directed into the ehannels where it is needed. This is the normal function of the banker and the money-lender, who thus perform a definite service to the eommunity.

In the case of discounts by deposit banks, the work done for 
the borrower incidentally inclucles various services in addition to that of attending to the details of the loan proper, services which are not entailed in the case of ordinary long-time loans. The work of effecting the elearance of exchanges through the check system, the collection of notes, drafts, etc., may be cited as the most important of these extraneous services, and the payment for these is taken out of the discounts (139b).

The second form of service is that of iusuring the credit of the borrowers. Money-lenders invariably run some risk of having clifficulty and possible expense in the ultimate collection of their dues, or of losing a part or all of the sum loaned, and according as the risk appears greater or less, lenders of money are correspondingly reluctant to lend, and the borrowers have accordingly to pay the second item of interest, the insurance premium, to overcome this reluctance. In the concourse of the money market this premium is such that, in the general average, losses of this nature are covered by this second item (220). The payment of this item on the part of the borrowers virtually places the lenders in the position of insurers of the borrowers' eredit, these payments by all borrowers in general covering the losses sustained by the lenders in individual cases.

264. The Third Item of Gross Interest.-It is generally held that the service for which pure interest, the third item of the gross interest, is paid to the lender, consists in furnishing capital to the borrower. That this view is erroneous has been proven above $(210 b)$.

The real nature of the service which lenders render to borrowers, apart from the services already mentioned, can best be studied by considering a loan as being what it really is, namely, an exchange of two credits, and then carefully comparing that which is given by the lenders with that which is given by the borrowers.

When a borrower obtains a loan, he gives his promise to pay, his credit, and gets in return money, which is but another form of credit. Our inquiry is therefore narrowed down to the question as to what it is that distinguishes the credit given by the borrower from that given by the lender, for in that 
distinction we must look for the real nature of the service for which the third item of interest is demanded by the lender and paid by the borrower.

The lender may give lawful money, or bank notes, or some form of bank credit, that is, an order on a bank to transfer bank credit from the lender to the borrower. That which is furnished by the lender is either a credit authorized as a medium of exchange by law, or, in case he gives nonlegal-tender notes or bank checks, a credit permitted to be used as a medium of exchange under the law. The credit given by the borrower must be presumed to be as sound as that given by the lender, inasmuch as a premium for its insurance is being paid to the lender. The only difference between the two credits exchanged is that the eredit furnished by the lender is monetized credit, that is to say, credit placed within the range of that communal agreement that makes it acceptable as a medium of exchange, while that furnished by the borrower is not monetized credit (238).

There is no good reason why the borrower's credit, properly secured and insured, cannot be put into a form in which it can be utilized as a medium of exchange (103) without the payment of more than the cost of the labor involved and of insurance. There is nothing to prevent it but the restraint of law. The business man in need of a medium of exchange must turn to the money lender for help and pay him interest for a service which consists of nothing more than an intermediation in the monetization of credit. The labor of this intermediation is naturally paid for by the first item of gross interest, and there would be no additional cost but for the provisions of law which obstruct the monetization of eredit (341). This third item of gross interest, usually the largest fraction of that charge, is in fact due wholly to misdirected interference of law with the freedom of exchange.

If the case is viewed from still another standpoint, our conclusions are further verified.

Although bank credit as such is no more reliable than any other credit that is equally assured, it is specially privileged, within certain limitations of law, to be used as money. The 
transformation of bank credit into money is effected through the general consent of the community to accept notes issued by the bank and checks drawn on the bank in payment for goods sold or for services rendered. It is the community which converts bank credit into money. It is the people who perform that service for which the banker obtains the third item of the gross interest. Indeed, those very members of the community who play the largest part in the performance of that service, the business men, must, when they become borrowers, buy back at a price the very service which they, in common with others, have performed gratuitously. The business men who borrow are the real issuers of bank notes (102) and bank credit (105). They are the debtors in regard to the currency and bank credit issued through them, while the people who accept the currency and the bank credit become thereby the creditors of these money systems, the lenders of the actual capital. The bank is merely an intermediary agent in the process of issue. The issuers or debtors do inleed pay interest on these debts, but they pay it to the intermediaries of the issue and not to the creditors, the holders of the notes or the owners of the bank credit. The banker earns only the "cost" and the "risk" items of the gross interest, in that he performs the agent's work and effects the insurance of the possible risk attached to the real issuer's security. But he gets more than what he earns; he retains all three items of interest. The users of the currency, those who are the real creditors of the case, the lenders of the real capital, and to whom pure interest, the third item of the gross interest, should properly go, if it were true that the lender of capital goods is entitled to interest, do not receive it and do not even expect it $(210 a)$. Through the limitation of money by provision of law, which results in the impersonal monopoly of money, the borrower of money must pay to the dealer in money not only his proper earnings, but also the third item of gross interest in the form of interest proper. It is clear that the payment of the third item of interest is in the nature of a tax paid by those who work for the privilege of using their own credit as a medium for exchanging their products, 
a tax imposed through the operation of law-protected impersonal and inequitable monopoly.

265. Service Rendered by the Capitalist.-Generally speaking, that portion of the income of an industrial group which goes to the owner of the capital goods employed consists of two items (139a), namely (1) amortization, that is to say, compensation for the wear and tear and consequent depreciation of his capital, and (2) compcnsation for the use of that capital. Personal services cannot be considered here since these are excluded from the function of the capitalist by our definition of that function (143a).

In the first capacity the capitalist is either a contributor of the capital goods utilized by the industrial group, or, more frequently, a contributor of the money with which those goods are bought and aggregated to the end in view. His position differs, however, from that of a money-lender in that he is not entitled to receive a stated amount of money at a given future time, but is the owner of the capital goods bought with his money. Being the owner of that eapital, there accrues to him, in the average, insurance in the measure in which he runs the risk of losing it, and amortization, as the goods deteriorate. Usually these items are not paid to the capitalist, but are applied to make good the deterioration of the capital by insurance, repair and replacement, in order that its value may remain intact. Thus, in this capacity the capitalist either receives in instalments, or retains undiminished as owner, the equivalent of what he gives, nothing more. Indeed, as supplicr of the capital goods and eventually recipient of amortization, he is not to be regarded as a member of the group, being in this respect nothing more than an agent in the purchase of the capital goods from other groups (139b, 1436,157 ).

When we come to consider the "eapitalist" in his second capacity, that of owner of the capital employed by a given group, his position must be carefully distinguished from that of the employer, with which it is often crroneously confused. The income that normally accrues to the employer consists of wages which are the recompense for the work involved in 
managing the business. The capitalist as such is a passive agent, one who simply leaves the use of his eapital to the productive group (154), without doing any work himself.

Examining the position of the capitalist, we find that he replaces the money-lender, by enabling the group to do its work of production without having recourse to borrowed money. His service is therefore analogous to that of the money-lender, and his recompense for that service can have no other basis than has the recompense paid for the service of the money-lender (257). The capitalist's claim to recompense is in fact on a par with the money-lender's claim to interest, and pure money interest being due, as we have found, to the operation of the impersonal money monopoly, pure capital interest must be traced to the same origin (348).

The processes of exchange, absolutely nccessary to the modern processes of production, are hampered by legal obstacles, which the services of the money-lender and of the capitalist help to overcome. So long as these legal obstacles exist, and only so long, do the money-lender and the capitalist render a service for which there accrues to them an income not earned by them, but gained for them through the complex workings of the existing monetary system.

266. Abundance of Real Capital. - While the inadequacy of capital to employ labor at its maximum efficiency is that which accounts for the power of active capital to bring a revenue, this inadequacy is in striking contrast with the fact that the products of labor from which capital can be aggregated are so plentifully offered in the market that the difficulty of finding purchasers for them is commonly ascribed to "overproduction" (241) and that the opening of new markets for surplus products is regarded as essential to national prosperity. Moreover, unemployed labor, able and willing to produce still more, is so abundant that the problem of providing employment for idle workmen is forcing itself upon the attention of the whole world. Insurance against unemployment has not only been proposed, but in some countries has been actually put into practice. What is it that prevents the surplus of goods in the market, and the 
labor erying for employment, from being utilized to supply the defieiency of capital? What else than the inadequacy of the medium of exehange, without which neither the capital goods already produced, nor the labor with which to produce more, can be made available in the process of production.

The most convineing proof of the superabundanee of existing capital goods is the universal willingness of their owners to give them up in return for money. In selling things for the credit instrument money, the producers part with present goods in exchange for a right to obtain goods in the future, and for this virtual loan of material wealth the holder of the right receives no interest. The total amount of actual wealth so loaned without interest by the community equals the volume of all money in use, and that the members of the community are willing to lend out still more wealth on the same terms is shown by the eagerness of manufacturers and merchants to give up their goods for money, and by their endearors to find new markets.

Those who really receive interest, the lenders of money, are not lenders of capital goods when they lend money. They only give eredit in the form of money in exchange for an equivalent credit in the form of the borrower's security, the only difference being that the latter, though equal in value to the former, is disqualified by law from being used as a medinm of exchange. These facts clearly show that it is not the real capital, the goods already produced by labor, but the medium of exehange, which is scaree, and that money interest is not paid for the giving up of present in return for future goods, but for the loan of an instrument which is privileged to effect exchanges.

It is an error to assume that the lender of moncy surrenders eapital to the borrower; it is an error to say that the lender of money praetises "abstinence" or "waiting," or that he agrees to take "future goods" in return for "present goods." There is a flaw in this reasoning, for if the lender has given present goods in return for future goods, he has done so when he acquired the money in the process of selling his goods, and if there were really an ceonomic force which tends 
to accord a recompense to him who gives present goods in exchange for future goods, the owner of money should and would obtain interest until he gets the goods to which he is entitled in exchange for the money.

The current academic explanations of interest which assume, directly or indirectly, a scarcity of capital, fail for two reasons. In the first place, it is not true that there is a scarcity of capital goods, the fact being that such goods can be obtained in abundance without the payment of interest in exchange for mere evidences of debt, provided only that these evidences are acceptable as a medium of exchange. In the second place, the lending of money is not a lending of goods, but merely an exchange of a credit which is qualified by law or convention to circulate as money for a credit which is not so qualified.

267. Summary.-Our investigation has now led us to an understanding of how and why the net income from production is divided into wages and capital profits, the latter comprising rent, capital interest and money interest. We have also found why it is that the rate of interest on money, the rate of profits afforded by land and the rate of gains returned by invested capital are practically equal (131, 185, 258). That the three forms of capital are competitively related has thus been fully demonstrated.

At an earlier stage of our investigation (155), when considering the division of the net income of productive groups into wages and profits, we had before us nothing that would indicate whether labor or capital has the prior claim. The data requisite for a complete answer to this question are however now fully before us.

Production being effected by the co-operation of various specialized groups, the revenue derived from the sale of the finished products has first to be divided among these groups. This division is made through the payments for raw materials, means of production and other services bought by each group from its predecessors. That this sharing is governed by competition has been fully shown (153). 
The part whieh is retained by each group, namely, its net income, measures in the average the value of the services rendered by all its various partieipants, and this value is shared among them.

Dealing with averages, we may distinguish three principal shares, namely, wages for work done, rent for the use of the land, and eapital interest, the whole or part of which may take the form of money interest, if the capital goods used by the group are wholly or in part bought with borrowed money.

The division is determined by certain economic forces, but it is elear that only two shares require speeific determination, the remainder making up the third share.

The first part segregated from the total is rent. The operation of the economic forces through which rent acerues to the owner of the land has been sufficiently diseussed before (170-180). In regarding the sum total $O q$ of a given kind of products that is brought to a given market, Fig. 20 represents the process of the division, which is determined by two primary factors. One of them eomprises the various natural qualities of all the land used for the purpose, as they affeet the effort required for the production of the different elements making up the supply. They find expression in the supply eurve $S S^{\prime}$. The other comprises the aggregate of those conditions which govern the demand and which are represented by the demand eurve $D D^{\prime}$. The margin of eultivation becomes located at the intersection $a$, the ordinate $q a$ of which determines the price of the product. The total product having a market value represented by the area Oqap, and the cost of producing it being represented by the area $O q a S$, the rent which acerues to the owners of the land utilized is proportionate to the area Sap.

The share of the net income which accrues to the capitalist and the money-lender eombined depends upon the current rate of interest and on the amount of capital that can be employed advantageously. Both these factors are determined in their own way. How the rate of interest is dependent on the balance of the two currents $E$ and $S$, Fig. 25, flowing be- 
tween the financial and the industrial field, and representing cxpenditures and savings respectively, has been fully shown and formulated in the equations (5) and (6) (252), and how the interest rate determines the amount of capital that can be employed advantageously has likewise been pointed out (158). The share going to capital and money combined is equal to the product of the above amount of capital multiplied by the interest rate.

The share going to labor as wages is really determined at the margin of the employment of capital, namely, where all capital goods needed are obtained through borrowed money. The share going to land as rent and that going to money as interest being predetermined, the amount going to labor as wages is the residual share of the group's net income. The intra-marginal capitalist purchases labor at the same price as that which labor commands at this margin, and, after paying rent and wages, he retains as income an amount equal to the money interest paid by the marginal capitalist, and this income is capital interest. It would appear from this that capital interest is the final residual share, but since capital interest equals the money interest paid by the marginal capitalist to the lender of money, it is really, like money interest, a predetermined share. Labor cannot employ itself without the use of land and cannot therefore shirk the payment of rent. Nor can it make itself independent of the charges for the use of capital so long as the means of exchange command an item of pure interest. Labor must therefore take what is left after rent and interest are paid.

Our investigation has also laid bare the source and the nature of the peculiar power which money possesses under existing conditions. Under these conditions money possesses two distinct capacities, only one of which is inherent and essential, while the other is extraneous and unessential. Each of these faculties is due to a separate and independent cause.

In the first place, money has capacity as a medium of exchange. This faculty is imparted to it by the social compact through which coined gold and certain credits acquire current acceptability in the market. Through the use of this 
eapacity producers are enabled to specialize their work and to employ the best methods of produetion. But in this eapaeity money merely faeilitates exchanges, and sinee produets do not inerease in value merely through being exchanged, the use of money as a medium of exehange cannot afford either profit or revenue (13t). In this eapacity, therefore, money cannot be elassed as eapital (129).

But, as stated above, money possesses another eapaeity, namely that of commanding a revenue when loaned. It is only through lending that money develops a power eharacteristie of capital. This power becomes attached to money through the operation of legal hindranees to the free use of seeured credit as a medium of exchange and is aceordingly extraneous to the essential funetion of money, being imparted to it through the operation of an impersonal monopoly (259261).

We must, however, avoid the error of eharging these conditions to machinations of any speeial class of the eommunity. Although we have found that interest is not really earned by the owners of either money or eapital, these latter eannot be justly aceused of aequiring it by nefarions or by coereive means. They are no more responsible for the existing conditions than the victims of the system (336).

It may be in order to reiterate that it is only the unearned portion of gross interest which is here in question. That portion of the current interest which eompensates the lender for personal services and eovers the risk entailed is, of course, altogether reasonable and just. What we have yet to learn is how money can be deprived of its present power to eommand a return exceeding the value of the services rendered by the lender. This cannot be done by legal limitation of the rate of interest, as is abundantly shown by experience. But it ean be done by doing away with the legal limitation of the use of eredit as a medium of exehange which prevents the supply of money from meeting the demand. A practicable method to this end will be elaborated in a later ehapter. 


\section{CHAPTER XV}

\section{BUSINESS STAGNATION}

268. Involuntary Idleness.-As stated at the beginning, the present inquiry was started for the purpose of discovering, if possible, the cause or causes of financial crises and of the recurring periods of business stagnation. In the light of our preceding investigation this question finds a conclusive answer. A few additional deductions from the data at hand will bring us to an understanding of why it is that the processes of production and exchange are subject to periodical disturbances, and why it is that in times of business stagnation the pressing demand by unemployed workers for the means of livelihood is not supplied in spite of their readiness to give their labor in exchange. This labor could collectively produce the very things which the idle workers need, yet, through some eause they seek employment in vain, while others remain but partially employed. This condition cannot be ascribed to any lack of natural resources, for there is land in plenty from which to obtain the raw products that need only be worked into the things required. It cannot be attributed to a scarcity of industrial and commercial facilities, for in times of business depression the means of production and transportation are in part idle, and their owners are constantly on the lookout to put them to use. Nor can it be said that energy and enterprise are wanting, for everywhere both employers and workmen are anxious to resume work. It is manifest that these conditions are not inherent in the nature of things, but that they result from some existing defects in the existing economic system which cannot but be susceptible of correction in some practicable way.

269. Excess of Supply Over Demand.-The most conspicuous feature of business stagnation is the excess of the supply of labor and its products over the effective demand for them. This would appear to conflict with the well recog- 
nized fact that the supply of any one thing in the market constitutes a demand for some other thing of equal value, and that for this reason the total of all supply and the total of all demand are always equal (34). But it must be remembered that this is true only of the sum total of supply and demand, and is not necessarily true as regards the supply and demand of particular commodities or services. It simply means that if at any time there is an excess of the supply of some goods or services in the market, this inequality is necessarily balanced by an equal deficiency of the supply in some other direction.

But even this does not seem to be borne out in the actual business world. It is the universal experience that there are times when all kinds of goods and services are offered in the market in excess of the effective demand. At such times there are workers in practically every branch of industry who seek employment in vain and producers in practically every line whose goods accumulate in the market because of a general lack of effective demand.

If it is indeed a fact that total supply and total demand are necessarily equal, it must be possible to point out some product of which the supply is less than the demand during those periods in which the supply of both labor and merchandise generally is greater than the demand.

270. Insufficient Supply of Money the Cause.--Since practically all exchanges are mediated through money, each offer of goods or services primarily constitutes a demand for money, and it follows that if the supply of this medium is deficient, the demand for things and services offered for money is correspondingly deficient. The general oversupply of things and services offered for exchange can be accounted for only by an equal under-supply of the medium of exchange. In our preceding investigation we lave found that there is actually an under-supply of the medium of exchange (238), and that this condition imparts to both money and capital goods the power to command an unearned income. The arbitrary control of the volume of currency, accordingly, is 
not only the cause of the predatory power of wealth, but also the cause of industrial stagnation.

In the equation of monetary circulation (119)

$$
V \times R=K \times P
$$

the letter $K$ represents the yearly traffic of goods and services, and the product $K \times P$ is the same traffic expressed in terms of dollars. The monetary flow $V \times R$ measures the volume of money payments. If, then, by an undue limitation of the volume $V$ this flow is constrained, the volume of exchanges is thereby correspondingly restricted. This demonstrates what has been stated above, that stagnation of business with its coincident lack of employment is due to the inadequacy of the medium of exchange $(121,262)$.

This explanation of the lack of employment has often been advanced, but has been persistently rejected by many economists, principally for the following reason.

It is known that periods of business stagnation alternate with periods of business activity, though the volume of money is practically the same during both periods. If it is sufficient luring prosperous periods, why should it not also suffice during times when business is depressed? Indeed, during periods of protracted business stagnation money accumulates in banks and is offered for loan at reduced rates of interest. This fact is generally held to indicate that we are actually suffering from a plethora of money. Let us examine how far this argument is valid.

When a steady wind blows against a tree, it alternately bends down and rises up again, swaying to and fro. When bent down as far as it will go, it remains for a moment almost stationary before it rises again, and after assuming its upright position, it remains practically upright for a seeond or so before bending down again.

But who would construe these facts as demonstrating that the swaying of the tree cannot be caused by the wind, on the ground that if the tree can maintain an upright position for a moment in the face of the wind, this wind cannot be regarded as the cause of the bent position of the tree at another 
moment. Yet, this is in substance the contention of those who insist that the accumulation in banks during periods of business stagnation is proof that there is not only an abundance, but even a plethora of money, and that accordingly the recurring periods of business stagnation cannot be due to an insufficient volume of currency. As a matter of fact, the obstructions placed in the way of freedom of exchange by our currency laws are the cause not only of a holding back of the processes of production and exchange, but also of the alternations of periods of depression with periods of prosperity, just as the action of the wind really causes the bending and alternate swaying of the tree.

If the tree were absolutely rigid, if the element of elasticity were totally absent, the wind could not possibly sway it. It would resist the wind until the force increases to the point of breaking. Some reactive force like that of elasticity which increases as the tree is bent, or like that of gravity which acts on an increasing leverage as a pendulum swings from its central position, must be present in order to bring about alternation of movement.

That such a factor is present in the existing conditions of commerce and industry can easily be shown. The element of credit is to business conditions what elasticity is to the tree. It is through the system of credit that debts accumulate and exert an increasing pressure upon business conditions generally.

A community can be imagined in which commercial credit is unknown. Its money would consist of a standard commodity exclusively; every purchase would immediately be settled by the payment of money; there would be no debts, no lending of money. If under these conditions the volume of money were inadequate to mediate all those exchanges which would be required in order to keep all workers fully employed, the industrial flow would correspondingly be restricted. An unvarying amount of unemployed labor, a practically uniform degree of "lack of work," would prevail in this community. The extremes of prosperous and dull times would never be 
observed. Crises would never oceur. The equation of monetary circulation

$$
K \times P=V \times R
$$

would be constantly satisfied.

But credit, as a factor of our commercial system, permits a departure from this uniform state of things. 'The industrial flow $K \times P$ may for a time exceed the compensating monetary flow $V \times R$, and during this time the inadequacy of the volume $V$ cannot manifest itself as an obstruction. Since the delivery of goods is not at once followed by paynient, the above equation is not applicable to definite periods (120) and should be modified.

If $B$ is the sum of business debts and $d B$ is the differential, that is, the increase of these debts within a given period, ${ }^{99}$ the equation should be written $(245,272)$ :

$$
K \times P=V \times R+d B .
$$

While business is prosperous and the industrial flow $K \times P$ exceeds the monetary flow $V \times R$, credit is freely extended and business debts gradually increase. But ere long payments are more and more postponed, collections become slower and slower, and increasingly long credits are demanded on every side (273). The monetary flow is inadequate to fully balance the industrial flow (291), but for a time the inevitable result is staved off.

So, too, those currents which make up the barren circulation of money do not balance. As long as the flow I, Fig. 25, exceeds the difference $E-S$, a reactive force, like that of the elastic force of the bending tree, will develop in the form of increasing money debts, and since these debts cannot indefinitely increase, a reaction must finally set in. The period of increasing debt and the period of inevitable reaction alternate like the oscillations of the tree, these changes taking the form of recurring business fluctuations. But let us look more elosely into the details of this process.

${ }^{29}$ If business debts should decrease during any period, the differential $d B$ becomes, of course, a negative quantity. 
27I. The Cycle of Industrial Activity. ${ }^{100}$-In our conelusions regarding the law of interest (251) we limited our considerations principally to long periods of time, taking no aecount of fluetuations from the average. We reasoned from the formula :

$$
I=E-S,
$$

whieh is wholly valid only with reference to average eonditions. But when we come to study periodic ehanges, we eannot ignore the quantities $d D$ and $d V$ and must therefore have recourse to the strietly eorrect formula:

$$
I=E-S+d D-d V \text {. }
$$

The differential quantities $d D$ and $d V$ nave a distinet significance in the eycle of industrial aetivity. In this cycle there ean be distinguished four periods, according as the predominating features are successively (1) a positive $d D$, (2) a negative $d V,(3)$ a negative $d D$, and (4) a positive $d V$; or, to put it in ordinary phrase, first, an increasing volume of of loan debts, attended, as we have seen before, by a similar inerease of business debts; second, a deereasing volume of active funds; third, a decreasing volume of debts; and fourth, an increasing volume of aetive funds. In the first and second periods the flow $I$ exceeds the difference $E-S$ of the preparatory currents, in other words, the total net interest reeeived by the finaneial class is more than their net expenditures. In the third and fourth periods the reverse is the case. As a rule these periods merge gradually into each other. Only exceptionally can a rapid change from one to the other be observed. In Fig. 26 in which the line $D D$ represents the varying volume of loan debts, and the line $V V$ the varying volume of money in actual use, this eycle is graphically depicted.

272. First Period.-In times of industrial activity, when business is "brisk," all industries are fully employed and goods are sold as rapidly as they ean be made. The industrial 
flow is at its height. Though all available money is drawn into circulation and the rapidity of circulation is greater than at any other time, yet the monetary flow $V \times R$ does not keep pace with the industrial flow $K \times P$ (119), and the active demand for money finds expression in a high rate of interest. In the above equation (270) the differential $d B$ is accordingly a positive quantity, which means that busincss debts are on the increase. But just as the resistance of the swaying tree against the wind, when it begins an oscillation downward, is at first but slight, so is the effect of accumulating business debts upon industry and commerce at first but imperceptible.

Meanwhile debts for money loans are also increasing, and interest payments likewise. The current $I$ now exceeds the difference $E-S(251)$, and therefore the balance of the three currents $I, E$ and $S$ of Fig. 25 is in favor of the passive funds. This excess is returned into the field of active funds through the loan channel $L$, hence that current exceeds the sum of the currents $P$ and $R$. The volume $V$ is not reduced, despite the excess of $I$ over $E-S$, but this excess, being added to the current $L$, causes an increase of the volume of loan debts, an increase of the indebtedness of the business world to the financial world.

At this stage three factors come into play which hasten the coming reaction. First, the prices of both goods and labor go up, and the corresponding lise of the price level $P$ swells the excess of the flow $K \times P$ over the flow $V \times R$. At this higher price level the capacity of money to perform its work as a medium of exchange is reduced, hence the same amount of money can no longer compass the same volume of traffic. Second, through steady employment wage-earners are enabled to lay aside more of their earnings than before. An increasing fraction of the total money is being withheld from circulation, and the current $S$, Fig. 25, is increased. Third, borrowers of money reach the limit of their credit, and the payments of business debts become increasingly deferred. The excess of $I$ over $E-S$ is no longer fully restored to circulation, hence the volume of active funds begins to shrink. Thus the first period of the cycle, characterized by an increasing 
indebtedness, a practically stationary voume of active funds and an excess of the current $I$ over the difference $E-S$, gradually merges into the seeond period, characterized by a steady diminntion of the volume of active funds.

273. Second Period.-The diffieulty experienced in colleeting outstanding aecounts now increases, as the monetary flow lags more and more behind the industrial flow of goods (270). Payments are received more slowly than counted upon; the risks of selling on credit become more and more marked. Lack of funds on the one hand, and considerations of safety on the other, now compel retrenchment. Preparations made for a continuous and inereasing run of business activity now become unavailing, and business failures increase in number. Money has become "tight" and is held back for possible emergencies. Hoarding becomes a eommon practice $(282,303)$, and less money is brought to the banks, henee bank reserves diminish. The dearth of money becomes acute, and the unusual demand for gold, the only medium through which the shrinking bank reserves ean be replenished, causes its value to rise, and in consequenee prices tend to go down (345). Since banks are eonstrained to eurtail loans and to call in or reduce those already granted (2i7), the volume of that part of the medium of exchange which consists of bank credit is contracted (281). A financial panic is imminent. The swaying tree has bent before the wind to its lowest position and its resistance is strained to the utmost.

At this stage of the cycle the financial conditions in the United States present a feature which, by reason of the extensive use of bank eredit as a means of payment, is peenliar to this country. Over two-thirds of the available means of exchange normally consist of bank credit which has but a limited range of circulation. Only abont one-third, or even less, of the means of payment eonsists of eurrency which is adapted to pass from hand to hand, and the money which is withheld from the banks by hoarding is taken exclusively from this latter portion. The banks receive too little currency to meet their requirements. They are therefore unable to furnish currency as it may be called for by depositors, 
and these are accordingly unable to make payments requiring currency. At such a juncture even wages have largely to be paid by check. To meet the emergency as it develops in the great centres of exchange, recourse is taken to extraordinary means of filling the gap in the means of payment, by creating the medium of exchange known as "clearing house certificates." In countries where payment by check is not so prevalent as in the United States, financial crises do not take the acute form of a marked disappearance of currency from circulation.

The distinctive features of this second period of the cycle are a practically stationary volume of loan debts, since bank reserves are at a minimum, and a diminishing volume of active funds, resulting from an overbalance of the currents that flow out from the active into the passive field, accentuated in the early stages of the period by a general tendency to hold on to money in apprehension of its increasing scarcity. The quantity $d D$ is practically nil, $d V$ is negative and $I$ still exceeds $E-S$.

274. Third Period.-Owing to the lack of money in the active field and the consequent stagnation in business, many debtors are unable to meet their obligations, and the third period is ushered in. Business men who can do so pay off at least part of their loan debts, since a smaller working capital suffices for the reduced volume of business. But the sum total of collectible debts is furthermore reduced by reason of business failures which at this period become increasingly numerous, and since for this reason a greater portion of the gross interest goes to cover losses, that portion of the remainder which constitutes pure interest is materially reduced (256). This is the typical period of business depression with its widespread business disasters and the prevailing stagnation of industry and commerce. It has been currently but erroneously assumed that these conditions are but a manifestation of the process of "weeding out financially weak business concerns" and putting a stop to "heedless overproduction of things." 
The eeonomic law expressed by the formula:

$$
I=E-S,
$$

which we have found to mean that the net income $I$ from money loans cannot indefinitely exceed the net expenditures $E-S$ of the lenders (251) now asserts itself. The sum of net interest on loans falls below the net expenditures of the lenders to the extent to which it formerly exceeded the latter. Money is now freely offered for loan on approved security at low rates of interest, but would-be borrowers who are already deeply indebted eannot give acceptable security for further loans, and the possessors of good security who have but few or no debts have no need to borrow for the purpose of payment, and no occasion to borrow for the purpose of increasing business facilities which are already more than adequate under the existing conditions. Money accumulates in banks, which would seem to indicate that it is not needed in business. This accumulation is often adduced as proving that there is a plethora of money, while in reality it is a natural and inevitable result of excessive interest rates due to the insufficiency of money.

The features of this, the third period, are a diminishing volume of debts, in part due to the many failures by which debts become invalid and must be charged to loss, a small volume of active funds, an accumulation of money in banks, and a low rate of net interest, so low, indeed, that it is insufficient to cover the expenditures $E$ of lenders, while the current $S$ shrinks to almost nothing. The current $I$ is now less than the difference $E-S$.

275. Fourth Period.-Finally the third period of this business fluctuation merges into the fourth, as the money in the aetive field slowly increases by reason of the excess of $E$ over $I$. The differential $d V$ is positive, and this Ieads to a gradual recovery. The net income $I$ of lenders is still low, principally for two reasons. In the first place, most of the remaining debts have been renewed at a lower rate of interest and, in the second place, the volume of indeltedness is at an ebb, while, at the same time, business is so dull that those 
who are in position to borrow money have no inducement to do so. By the excess of the current $E$ over the currents $I$ and $S$ of Fig. 25 the passive funds are finally, though slowly, restored to activity. It should be remembered that the current $E$ includes not only the expenditures of passive funds for personal use, but also their investment in industrial enterprises (249). The money that has accumulated through the current $I$ is now being put out in "reorganizing" business concerns that had become "embarrassed," in starting anew enterprises that had been halted and in investments in new undertakings. It is by this process that the ownership of all larger industries is being gradually acquired by the "Napoleons of Finance." We shall hereafter have more to say on this feature of our industrial system (338).

In this period the volume $D$ of debts is low and practically stationary, but the volume $V$ increases, as indicated in Fig. 26, while the current $I$ remains less than $E-S$.

276. Succession of Cause and Effect.-In the foregoing presentation of the cycle of industrial activity we have found an explanation of all the developments of the successive periods by tracing their causal relations. The characteristic features of each period result from those of the preceding one and become in their turn the immediate causes of those of the succeeding period.

The underlying cause of this succession of events is tne need of the business world for a medium of exchange coming in conflict with the forces that constrain the supply. Money thereby obtains the power to command pure interest which gives preponderancy to the monetary flow from the active to the passive field. In the first period the money so withdrawn from circulation is restored to activity through loans, entailing an increase of the volume of loan debts. In the second period the volume of debts has grown to a point beyond which they cannot increase, and the industrial field becomes depleted of money through the interest flow being no longer returned through loans. This leads to the third period, a time of general stagnation of business, of business failures (240) and of reduced interest rates. And this is followed by a reaction which starts the fourth period, a time of readjustment, charac- 
terized principally by a gradual restoration of the locked-up currency to circulation.

Cause and effect are thus seen to follow in their natural sequence, in a cycle of four periods. In actual affairs, to be sure, the successive periods do not follow each other as rlythmically as plotted in the diagram Fig. 26. The ranifications of business are such that at times the extent of fluctuation is less than at others, the interval between extremes being then marked by minor disturbances, just as in a stormy sea the depression between two high waves is marked by smaller ones.

\section{Current Explanations of Business Stagnation.-} Various theories have been advanced by writers on economics and are constantly echoed by the periodical press, to explain the phenomenon of business stagnation. Financial crises are usually attributed to causes within the control of individuals, such as reckless or even dishonest pursuit of gain, to misdirection of large industrial enterprises, to designedly cornering the money market, and so forth. Our investigation points indeed to an enforced constriction of the currency, effected, however, not through a scheming by financiers supposed to have control of the money market, but through the operation of our currency and banking laws. These laws have persistently been framed in the light of the supposition that the rolume of the medium of exclange must be guarded against so-called inflation; and the fear of "inflation" is born of a theory which, unfortunately, has too long been prevalent, principally by reason of the support given to it through incorrect reasoning by academic authorities.

There is a widespread disposition to blame "spcenlation" for industrial disturbances, and since this term is largely applied to transactions which are really nothing but gambling and which are therefore popularly condemned, this explanation, though incorrect, is apt to pass unchallenged.

Stock speculation has much the same kind of attraction as all other forms of gambling. 'The prospect of gain by a lucky venture is so alluring that the chances of loss are disregarded, and hazards of this nature are often carried to a point where the gambler is finally engulfed in ruin. But there is no reason 
whatever why this should lead to general disaster. No actual wealth is either gained or lost by the community as a result of such ventures. Some people thereby become richer, others poorer (216), and since no one can foresee the future, no one can have more than a temporary advantage over others in the field of speculation, except where the "insiders" are playing the game with loaded dice. An industrial depression of a general nature cannot result from this eause.

The widespread belief that stock speculation is one of the causes of financial crises is strengthened by the fact that such crises are invariably attended by a general fall in the value of stocks. But this can readily be explained. When in the second period of the cycle of business fluctuation (273) the banks are obliged to call in loans, those debtors who possess stocks or bonds find these assets most easily marketable for paying off their loans, and such certificates of value being put upon the market in unusual amounts, their value naturally declines. A break in the value of stocks is therefore often a first indication, but not a cause of the coming storm, the real cause being the accumulated overwhelming indebtedness of the business world.

278. Over-trading.-The impulse to speculate finds expression in various ways. Instead of gambling in stocks, business men may, in a purely speculative spirit, buy goods in expectation of a rise in the market. Crises have often been ascribed to the failure of such expectations, as may be seen from the following condensed abstract from John Stuart Mill:

When there is a general impression that the price of some commodity is likely to rise, there is a disposition among dealers to increase their stock of goods in order to profit by the expected rise. This disposition tends in itself to produce a rise of price. Other speculators are attracted who, by further purchases, produce a further advance. After a time the price ceases to rise and the dealers, thinking it time to realize their gains, are anxious to sell. The price begins to decline, the dealers rush into the market to avoid a still greater loss, and finding but few purchasers willing to buy in a falling market, the price falls much more suddenly than it rose.

In a community in which credit was unknown, this will be 
confined to one or a few commodities. But when people go into the market and purchase with the money they hope to receive hereafter, this form of speculation may be going on in all commodities at once. All prices will then rise enormously by the mere extension of purchases on book credits. After a time those who had bought would wish to sell and prices would collapse, thus bringing about a commercial crisis. ${ }^{101}$

This argument is founded on unwarranted assumptions. A rising or falling of market values cannot as a rule be foreseen. But even if there are reasons to expect the price of some goods to rise, and these reasons are generally known, those who have such goods for sale will not sell unless they get a price that includes the expected increase. Hence a general rush to buy in a rising market will at once be checked by an increase of the price. To be sure, it may happen that some individuals gain insight into causes that may affect prices before others do, and may use this insight to reap speculative gains, but since, in the nature of things, these happenings are but of comparatively rare occurrence and may be on the side of either buyer or seller, their influence on general business conditions is negligible.

But even if a rise in price had induced dealers to lay in a large stock of the goods, there is no reason to assume that the first manifestation of a decline in prices would cause a rush to sell, such as described by Mill. Prices in general are known to be subject to irregular minor fluctuations (60), hence a turn in the movement of prices is never accepted as certain indication of a continued advance or decline. The conclusion that a first indication of a fall in prices will frighten the holders of the goods into selling and will keep people from buying, thus causing a collapse, does not agree with observed conditions. In point of fact, a demoralized market is one of the incidents and not the cause of commercial crises.

Although a rising or falling of market prices can be foreseen only in sporadic instances, theories have nevertheless been elaborated regarding the effect of a rising or a falling market on the state of business, on the current rate of interest, on the 
stock market and on other economic conditions. Theories of this kind are applicable to such cases only where a continued rise or fall can be foreseen with tolerable certainty, as for example to land values. How the expected annual increment affects the value of land has been fully discussed (183) and will be the subject of further consideration (327-329). As a special exception to the rule that an impending change of prices cannot be foreseen may be mentioned the peculiar conditions prevailing during the time following the passage of the law, in 1875 , providing that specie payment should be resumed on the first of January, 1879. During the intervening period the value of the dollar was predetermined to rise from its depreciated level to parity with gold, and a general fall of prices, as measured in the current dollar, could accordingly be foretold. In this extraordinary instance the certainty of a continued fall of prices was presumably responsible for the prolongation of the business depression throughout that period.

279. Improvident Investments.-Somewhat more plausible than the attempted explanation just discussed is that which attributes stagnation of industry to the investment of large amounts of capital in undertakings, such as the building of railroads, which eventually turn out to be unremunerative.

Similar in purport is the proposition that crises result from an "undue conversion of floating into fixed capital." 102 This statement can have reference only to the investment of money in some form of enterprise, and since money, whether in the form of currency or of bank credit, when invested, simply changes hands and does not disappear from the community, this "undue conversion" can only be understood as meaning that too much money has been spent on the production of fixed capital, in other words, that too much effort has been diverted from the production of consumable things to that of means of further production, and that this "fixed" capital turns out to be less remunerative than expected.

In order to account for business stagnation on this ground it would be necessary to assume that the extent of ill-directed

${ }^{103} C f$. Walker, p. 473; MacLeod, I, p. 214; ct al. 
investments fluctuates in more or less regularly successive periods. But even conceding this assumption, the suggested explanation would not aceount for the phenomenon. Even though expectations that the products or services to be rendered through the investments would find a profitable market are not realized; even though the capital so "fixed" proves unremunerative or a total loss; why should this cause a general stagnation of business and a paralysis of enterprise? The owners of the capital that has been misapplied have simply lost a part or the whole of it and are that much poorer for their venture. To some extent this loss may spread beyond the immediate losers and may be shifted upon others. But all this affords no reason why production and exchange in general should be arrested in their course. The fact that some energy has been wasted is no cause for the paralysis of energy in general. It is manifest that this affords no explanation for business depressions.

280. Undue Expansion of Credit.-An approach to the true explanation of commercial erises is the theory which attributes these disturbances to an undue expansion of eredit. It is accepted by many writers on the subject and is formulated by Perry as follows:

The cause of commercial crises is, in general, an undue expansion of credit; or, to use an equivalent expression, a disproportion between the amount of debts and the available eapital in the loan-market, or elsewhere, to meet those debts. ${ }^{103}$

But this explanation is vague. In order distinctly to express the eondition, the statement should read that there is a disproportion between the amount of debts and the available means of payment to meet these debts. Where Perry fails, as do all others of his school, is to explain how this "undue expansion of eredit" comes about, for it is in this dircetion that the real cause of commercial crises is to be looked for. The fact is that bank currency and bank credit, making up together the indispensable medium of commercial exchange, are put into circulation almost entirely through the proeess of lending, and so long as the borrower must pay interest at a 
rate which includes a toll in addition to due compensation for the work and the risk of the lender, the debts which are contracted in the process of issuing currency and bank credit, namely the debts of the industrial to the financial class, must constantly increase, which means that the debtors as a class are thereby compelled to "an undue expansion of credit" to such an extent as must inevitably result in an overwhelming "disproportion between the amount of debts and the available 'capital' " with which to pay them (255).

281. Loss of Confidence.-Another widely accepted explanation of business depressions is that which attributes them to a general loss of confidence. Loss of confidence in what? Evidently in the ability of debtors to pay their debts or in the likelihood of business continuing to pay. But why this loss of confidence? Evidently because debts have grown, payments are put off and orders are getting less. The bare statement that confidence has been lost is not an explanation, inasmuch as the reason why confidence has been lost remains to be explained.

Quite often the explanation is sought in a general shrinkage of credit. What credit? The wealth in existence, the very basis of credit, has not shrunken, but, on the contrary, has been steadily increasing during the period of prosperity preceding a commercial crisis, and is at a maximum at that very juncture. The phrase is obviously meaningless, unless "credit" is to be understood in the sense of monetized credit, in other words, money. What really takes place and is erroneously regarded as a "shrinkage of credit" is, in the first place, the growth of indebtedness beyond the means of payment (255), and, in the second place, a diminution of the means of payment through a reduction of bank eredit by a calling in of loans (273), in other words, a reduction of the extent to which existing wealth is monetized (104). This is not a shrinkage of credit, but a demonetization of credits, and this, in turn, is a result of our defective and ill-considered currency laws.

282. Hoarding of Money.-Considering that commercial crises have their primary cause in the inadequacy of the volume of currency, it is not surprising that one of the incidents of such disturbances, the hoarding of money, should 
be mistaken by many observers for the cause of the crisis instead of one of its accompaniments. That the hoarding of money toward the close of the second period actually plays a certain part in hastening the transition from the second to the third period of the cycle of business fluctuation has been shown above (273).

When we consider that money, whether gold or paper, is in reality an evidence that the owner, when he obtained the money, gave real wealth in exchange for it, and by hoarding the money allows this real capital to be used without himself getting interest (80), the question immediately arises, why should the hoarding of money be deprecated, and why is it considered a detriment to the community?

It is clear that a withdrawal of money from circulation can be harmful to a community only if it causes such a reduction of the active funds as to impede the processes of active business. And this can come abont only through the mistaken limitations on the issue of money imposed by our currency laws.

By many it is regarded desirable that the rich should spend their money freely, even thongh extravagantly, in order that it be put into eirculation and so "make business." A business system in which extravagant consumption of wealth becomes a desirable factor of business activity is manifestly bad.

283. Extravagance.-If further proof were needed of the hopeless confusion that has arisen in the discussion of the eauses of business disturbances than those above adduced, it would be afforded by the divergent opinions and conflicting theories on the subject of saving and spending money. It happens very often that those who regard the extravagant spending of money by the rich as being beneficial because money is thus brought into circulation, turn about to admonish wage earners to save their money, overlooking the fact that this very saving would in the same sense take money out of circulation.

Extravagance, profligacy, intemperance and other vices may indeed deprive their victims of the means of support in time of need, but cannot result in a condition of affairs in 
which production and exchange are brought to a standstill and in which men able and willing to work seek for employment in vain. On the contrary, it is but too frequently true that the victims of business depression turn to intemperance and to crime as a result of their inability to honestly gain their livelihood.

There is manifestly no better ground for this explanation of economic crises than for the various other current theories on the subject. These superficial explanations of business stagnation may be dismissed from further consideration, inasmuch as the real cause of the trouble has already been pointed out in the course of our inquiry.

284. Effect of Tariff on General Business Conditions.The very term "protective" tariff reflects the widespread notion that a high tax on imports has the effect of making it possible to give employment in the home market to workmen who otherwise would be left unemployed because of foreign competition. But we have already found, in the course of our inquiry, that the real cause of unemployment lies in our irrational currency laws, and that competition, in and for itself, cannot account for lack of employment.

It cannot be denied that changes in tariff schedules have the effect of disturbing the existing equilibrium between the trades affected on the one hand and all other trades on the other; and, moreover, that they have an influcnce, one way or another, on the cycle of business activity.

The high wages prevailing in this country are usually credited to high tariff. This, of course, can refer only to wages as measured in dollars and cents. It will appear later (353) that a tariff has also the effect of keeping the general price level up, or, which is the same, of keeping the purchasing power of money down. Hence such increase in wages as is due to tariff, while apparent in the number of dollars and cents, is only in a minor degree an increase of real wages (165). A high tariff is therefore not as much of a boon to labor as it would appear to be. That it is a partial palliative of the ill effects of our monetary system will be shown in the last chapter (351-353). 


\section{PART IV \\ CONCLUSIONS}




\section{CHAPTER XVI}

\section{CURRENCY REFORM}

285. Essentials of a Sound Currency.--In view of the numerous disastrous failures of curreney schemes recorded in history, any proposal for a radical change in the existing eurreney system is generally regarded with distrust. The prevailing tendeney is to "let well enough alone." This is strengthened by the widespread aceeptance of the volume theory of the value of money, aceording to which any change in the volume of money will be balaneed by an opposite ehange in the value of the unit, and ean only derange the seale of priees, resulting in more harm than good (239). For this reason ehanges in the laws regulating the eurrency have been made only under the stress of urgent necessity, and generally against mueh opposition.

But there is ample reason, as we have seen in the course of this inquiry, for a thoroughgoing reform, looking to a material inerease in the volume of money. What is required is a medium of exchange that will be ample in quantity for all emergencies, and sound in quality under all eonditions. We have therefore to find, if possible, a practieable way of meeting these requirements. The faults of the various eurreney systems which have proved defective ean be avoided by bearing eonstantly in mind that every piece of money is essentially a eredit instrument, an aeknowledgment of debt, aecepted in the market as a medium of exchange, and that its value depends solely on the value of the credit on whieh it is based.

An indispensable requisite of money is therefore the substantial seeurity on which it is based, the wealth which is the foundation of the eredit which money represents. $A$ further requisite is that the amount of the eredit, the value of the money, be definitely stated in terms of the adopted standard eommodity and that the stated amount of that eommodity shall be obtainable for it, directly or indireetly; in other 
words, that it shall be redeemable at its stated value. Still another requisite is that there shall be a communal agreement, expressed or implied, to accept the tokens of the credit, the acknowledgments of debt, as money (85).

286. The Security of Money.-Just as the value of a credit is derived from the debtor's wealth that is subject to seizure and sale for the debt, so is the value of money derived from the wealth that is pledged to secure its redemption. This wealth is the real substance of the money. The token is merely the evidence that its bearer is part owner-or rather lessor of this wealth to the extent of the face value of the token.

In the case of currency issued by the government and based on its "credit," the community is the debtor, and the payment of the debt created by the issue of the currency is assured by the gorernment's taxing power, the property of the tax payers becoming the substance of this money.

In the case of bank currency the desirability of a double security-the issuers' and the agents' pledges (102)-has already been adverted to; and, in addition, mutual insurance of the currency among the agents of issue is necessary where the security is not absolutely free of risk.

In the case of gold coin and gold certificates, the security consists of gold, and since this security is itself also the commodity of redemption, a further security is not necessary (94).

But the case is different if the security consists of wealth which cannot be used directly for redemption. Such wealth is subject to price fluctuation, and possible loss from this cause must be completely guarded against by ample margin and insurance (289).

287. The Issuer's Pledge.-Since currency is needed for no other purpose than that of exchanging goods and services, the objects of exchange, the goods themselves (87), would seem the most natural security for the currency. Imagine a hatter needing shoes, a shoemaker desiring to buy a lot of groceries, and a grocer wanting a hat. These wants could be supplied by exchanges, if a medium of exchange were issued, 
let us say, to the hatter on the security of his stoek of goods (301). He could then use this money to buy shoes. With the same money the seller of the shoes would be enabled to buy groceries, and then, with the same money, the grocer could buy a hat. After the money is returned to the hatter and the circuit of exchanges is completed, the money would have served its purpose as curreney and might be retired.

This illustration shows the function of money and the propriety and feasibility of employing business assets, like merchandise, as issuer's security. As a matter of fact, the transaction is typical of modern deposit banking in which, as we have seen (105), the real issuer of the medium of exchange is the borrower who obtains bank eredit upon furnishing security to the bank in the form of pledges of business assets (104).

288. The Agent's Pledge.-When curreney is emitted by the government through the agency of a bank, the latter, as intermediary agent (105), becomes eustodian of the issuers' pledges, namely, the promissory notes or other evidences of indebtedness furnished by the real issuers. But since the people look to the government for the guarantee of the curreney notes, the government naturally requires some adequate pledge on the part of the banks, and this pledge, in whatever form it may be given, constitutes the agents' pledge of the currency (102).

While business eredits may properly be accepted by banks as security, they are not well adapted to be so accepted by the government. The uncertainty of busincss credits makes it necessary to subject them to repeated scrutiny, and while local banks can easily keep in touch with the business standing of their customers, it would be impracticable to burden the goverument with this duty. Even securities like stoeks and bonds of various enterprises are too unstable to be accepted and looked after by a central authority.

At first glance the securities now received for the issue of national bank notes, namely, federal bonds, would seem to be ideal for this purpose. But apart from the inadequacy of the volume of these bonds, and even if state and municipal bonds 
were to be accepted in addition, there is a fundamental objection that will be discussed later $(333,341)$.

There can, however, be no such objection to the acceptance of real estate security. Liens on real property not exceeding, say, one-half of the assessed value ${ }^{104}$ would furnish a sound foundation for currency, as there would be ample margin in the value of the property (302). Such security would require at most an annual revision (303).

Proposals to use land as security for credit currency have been opposed by pointing to the historic failures of Law's "Louisiana Bubble" and of the assignats and mandats of the French Revolution. But the real trouble in those instances was the fact that the notes were not redeemable in a specified quantity of a specified standard commodity. An assignat note for 100 livres had back of it ostensibly the security of real estate, but as the security was not specified either in amount or location, it was practically no security at all. The denomination was in terms of "livres" which, at the time, were silver coins weighing about one-fifth of an ounce, but as such real livres could not be had for the notes from the issuer, their value was only that of an indefinite piece of land, nowhere definitely located, which, of course, was nothing.

If a debt secured by land or real estate is redeemable at its face value in the commodity adopted as the value denominator or its market equivalent, it cannot possibly share the fate of the assignats. This is proven by the general preference for' mortgages over most other forms of security.

The expectation that land values will ultimately vanish on the introduction of the single-tax reform might be advanced by some as a more formidable objection to the use of liens on land as a security for currency, but it will be shown later (329) that this objection also does not hold good.

289. Insurance of Currency.-Despite all possible precaution, and even though the margin of security may be ample for all contingencies that may be foreseen, an occa-

${ }^{104}$ One-half of the lowest assessed value of the estate during the last five or ten years would, perhaps, be safer as a limit, in order to avoid the risk arising from short-lived land booms. 
sional depreciation of some of the securities beyond the margin is still within the scope of possibility. In order to be prepared for such contingency, an additional measure of safety, in the form of insurance, is desirable (286).

As regards the issuers' pledges-the borrowers' promissory notes-such insurance is in vogue in the present general banking system. Though these pledges are not at all free from the danger of depreciation, the banks are practically assured against loss from this source through what is virtually an insurance premium (102). This premium is collected by the banks from all borrowers as that part of the interest or discount charged on loans which constitutes payment for insurance. In this way the borrowers collectively make good the losses which the banks suffer through the occasional failure of some of their borrowers (251). Of course, only that portion of interest which in the average covers the losses arising in the business of money lending constitutes the insurance item. As some loans are more risky than others, the banker adjusts the insurance charges accordingly, by varying either the rate of discount or interest, or by imposing other conditions (290).

The security which is now required of the banks as agents in the issue of currency-and which we have called the "'agents' pledge" - being bonds of the United States, is practically free from any risk of depreciation, and therefore requires no insurance. When, however, securities are accepted by the government which are even remotely subject to depreciation beyond the margin, it becomes necessary to adopt some system of insurance to cover any possible losses from this source.

290. Insurance of Bank Credit.-To make currency absolutely safe is undeniably of paramount importance. For this reason ample safeguards are now adopted to assure the redeemability of every national bank note. No one would for a moment question the propriety of the government insisting on all reasonable measures requisite for this purpose.

Since bank credit transferable by check constitutes the largest item in the aggregate of our means of exchange, the very same reasons which exist for effectively assuring the 
credit represented by national bank currency also apply to the assurance of bank credit subject to check $(304 a)$. The bank's depositors-the holders of bank eredit-are in a measure insured against loss from the partial or total failure of some of the real issuers of the bank credit, the borrowers from the bank, as above explained. But this insurance is incomplete, as it does not secure the depositors against a partial or total failure of the bank itself. There are many reasons why the system of insurance, mutual as regards the depositors of each individual bank, should be amplified through a mutual insurance system embracing all the banks of a country, or at least of a district. Nevertheless, such insurance has not even been seriously considered until within recent years, and owing to the fear that this measure would foster reckless banking, but few attempts to put it into practice have thus far been made $(304 b)$.

The opposition to this proposition is neither reasonable nor wise, since all concerned would be benefited, the banks as well as the depositors. When fire insurance was first preached, similar antagonism was encountered on the ground that it would encourage arson, and although it is much easier to conceal arson than bank fraud, the expediency of fire insurance is now generally recognized. The danger of a run on a bank, often caused by some unfounded rumor, would be completely removed by insurance. Numerous hoards of money, now hidden away, would be brought to the banks. It is not unlikely that in this way the cash reserves would be increased ten per cent. or more, resulting in a proportionate extension of banking facilities. These obvious advantages would more than counterbalance such losses as might be entailed upon careful and conservative bankers through the assumption of unwarranted risks by those less conscientious. It is only a question of formulating and enacting an effective system of bank examination and of imposing such obligations on the stockholders, and particularly the directors, of a defaulting bank that only in rare and exceptional cases a contribution from other banks would be required. Through such a system the danger of improper banking and consequent losses would be 
so far eliminated that every objection to a system of insuring bank deposits would be removed. As it is, each bank now protects itself against loss from defaulting borrowers by charging all borrowers with the insurance item of interest, and there is certainly no adequate reason why depositors of banks should not be similarly protected against loss from the failure of a bank by a system of insurance among the banks themselves $(220,289,304 c)$.

\section{I. The Natural Limit of the Volume of Currency.-} The question regarding the amount of eurrency that should be issued may here be briefly touched upon. There is no reason for restrictions apart from those which are neeessary to insure the redeemability of all notes in the standard commodity (302). So long as proper security is furnished and deposited with the govermment-the only agency to whom the people can confidently look for the requisite guarantee of the validity of the currency notes-the issue of notes may be safely extended, since the value of such notes eannot vary from the gold in which they are redeemable. Abundance of such currency cannot have any but a beneficial effect upon commerce and industry.

Nor is there any real danger involved in an issue of more money than is actually required for the processes of production and exchange. No one possessing monetizable eredit will have it monetized merely for the sake of doing so, and whenever there is a real need for more money, every obstacle to its issue is a restraint upon commerce. Every such restraint diminishes the amount of work that ean be done and abridges the right of men to work (261). In the absence of undue restrictions the volume of money would simply adapt itself to the demand, the natural limit of which is reached when there is no advantage to be gained by any possessor of eredit in having it monetized. And should it happen that the curreney increases to an amount more than enough to satisfy this demand, the only result would be that each dollar would, in the average, be used less frequently. At present, there being not enough of the cireulating medium, the rapiclity of eirculation is close to the maximum $(120,121)$, and yet the monetary flow 
cannot keep pace with the industrial flow (270). Under present conditions commercial debts are always, even in the "prosperous" period of the cycle of business activity, much greater than need be, and they call for an excessive extension of business credits and a prolonged postponement of payments as the cycle approaches the critical period. A superabundance of properly secured currency, even if more than sufficient to meet all the requirements of the industrial flow, far from causing a depreciation of money, would simply result in relieving the unhealthy business conditions which now prevail.

292. Currency Redemption.-As we have mentioned repeatedly, credit currency, in order to circulate at par with gold, must be either redeemable in gold, or accepted by its issuer in payment at par with gold.

Although under the present banking laws of the United States national banks may refuse to redeem their notes in gold and proffer legal-tender notes instead (295a), redemption in gold can be effected, at least in an indirect manner, inasmuch as legal-tender notes are redeemed by the government in gold on demand. In a similar roundabout way bani checks are also redeemable in gold, apart from the fact that banks generally pay checks in gold when requested.

If our present patchwork currency is to be replaced by a single, uniform issue (2956), that currency must be directly redeemable. To this end a certain amount of gold would be required as reserve. This condition would seem to impose an effective limitation on the volume of notes that can be issued, the extent of which must depend on the ratio which the gold reserve is to bear to the volume of the note issue. The next question, then, is, how far this ratio can be reduced with due regard to the requirement of redemption.

Experience has shown that the demand for redemption varies between wide limits at different times, and unless provision is made to meet the greatest demand that is likely to arise, redemption on demand will fail at times. Suppose it could be shown that the gold reserve may not be less than 
twenty per cent. of the total issue without jeopardizing the parity of currency, then the amount of currency cannot safely exceed five times the amount of gold held for its redemption.

The diffieulty thus presented may be stated as follows. $A$ large proportion of reserve is necessary if currency is to be redecmable in gold on demand under all praetical conditions. In fact, unless the gold held for redemption fully equals the issue, as is the case with gold eertifieates, redemption on demand is subjeet to the proviso that notes will not be presented for redemption faster than the stock of gold can be replenished before it is exhausted. On the other hand, an expansion of the issue is possible only by reducing the ratio of gold reserve. What ratio, then, can be safely adopted? The same problem exists with regard to bank credit subject to eheck. All bank depositors have the right to withdraw their deposits in cash, but it is well understood that banks never have on hand as much cash as their liabilities to depositors aggregate.

The present system is really a compromise between the two extremes. A reserve fund amounting to from 15 to $25 \mathrm{per}$ cent. of the deposit liabilities has eome to be considered sufficient under ordinary conditions to enable the banks to meet all current demands for eash (104), and national banks are therefore required by law to maintain reserves of that amount. This proportion of cash reserve is however reduced to less than one-eighth through the operation of the banking laws which permit deposits in certain specified banks to be counted as part of the reserve by the banks making the deposits, a condition which, however, is not permitted to those specified banks.

And yet, with all these provisions, there are times when banks, throughout the country, are unable to meet the demands of their depositors for eash. The existing compromise is manifestly inadequate to prevent financial crises. To compel banks to have a larger amount of eash to meet the demand of depositors, it has been proposed that they should be required to hold a large percentage of their liabilities in the form of gold eoin or bullion. But this would infallibly bring about a contraction, not only of the currency, but also of bank credit, to 
the great detriment of industrial welfare. If it were possible to reduce the present demand for gold, the proportion of that metal held in reserve might be redueed materially, and to find whether this is possible, the nature of the present demand for gold requires to be analyzed.

293. The Demand for Gold.-Modern processes of mining gold have made it possible to obtain the metal on a commercial scale from more extensive deposits than ever before, and the output has attained unpreedented proportions. Of this continuous supply a portion is used in the arts, another portion is hoarded, still another portion is put into eirculation as coin, and the remainder goes to swell the tons upon tons already lying idle in treasuries and bank vaults, where the gold is used as reserve for credit currency and bank eredit. The bulk of the metal is thus dug out of mines, only to be buried in costly fire and burglar proof vaults.

The demand for gold in the arts and industries is engendered by the faculty of the metal directly or indirectly to satisfy desires, just as the demand for any other commodity is induced by its usefulness to man. Although that usefulness alone can explain the desire for, and hence the value of gold, only a part of the output is absorbed in the industrial channels. The remainder is applied for monetary purposes, for which the metal gold is adapted not so much on aecount of its specific properties, as principally because of its generally accepted value.

The use of gold, or, for that matter, of silver, as currency is to be traced to the widely aecepted but erroneous idea that standard coin alone is real, or, as it is frequently termed, "basic" money, and that all other devices for mediating exchanges are only "money substitutes" (88).

The use of gold as reserve in banks has grown up with the modern system of banking. As has already been shown in an earlier ehapter (103), the original gold and silver notes were storage receipts, the amount of metal in store having been equal to the sum of the outstanding notes. Subsequently the amount of the outstanding notes was gradually increased, the added notes having been secured by pledges of other wealth. 
But in order to be prepared at any time to give "real money" for any of the outstanding "money substitutes" that might be presented for exchange, that is, for "redemption," the issuers of the notes found it neeessary to retain on hand an amount of the metal equal to about one-quarter of the ontstanding notes. This experience has prompted the present laws which require banks to maintain a reserve amounting to a certain fractional part of the deposits, with this difference, that other forms of eurrency, and even their own deposits in certain other banks, may be counted as reserve in addition to gold.

Oring to these regulations the total lending eapacity of all banks of the country -in other words, the possible volume of bank credit subject to check-is about eight times the actual amount of gold and lawful money held in reserve by all these banks (10t). It follows, then, that for each dollar of gold bullion or lawful money added to the sum total of bank reserves the lending capacity of all the banks of the country is increased not only by that one dollar, but by about seven dollars more.

Of the stock of money available for bank reserve under present laws, standard coin is the only form which is not limited by law, and the supply of gold is therefore the only source available for a general inerease of banking reserves. Every dollar's worth, that is to say, every 23.22 grains of pure gold, added to bank reserves, permits the lending out of about eight dollars at interest. It is not surprising, then, that banks are so eager to accumulate gold, and that their rivalry for its possession reaches a world-wide seope. As a result of this competition vast amounts of gold are shipped from time to time one way or another between the financial centres of the world.

It is often said that these shipments are made to settle the balances of intermational commerce; but while this may be true in some cases, it is eertainly not in all. The shipment of some eighty million dollars' worth of gold from London to New York in the fall of 1907 was described in the daily press at the time as a master stroke of finance to break the force of the panic of that year. But what office did this gold perform? There was no abnormal demand for industrial purposes, nor 
was there any excessive call for redeeming legal-tender notes, nor was this gold needed for currency, for practically none of it found its way into circulation. It remained in the vaults of banks and of the New York sub-treasury. The only use to which this gold was put was to amplify the reserves of banks which had fallen off because less cash was being returned to the banks than was checked out. It served the purpose of maintaining legal bank reserves-nothing else.

The question naturally arises: Why were not other forms of security applied for this purpose? Surely there was ample wealth at the command of the bankers to supply the needed security. The fact is, the law required that bank reserves shall consist of lawful money, and since, for some reason, lawful money was not being returned to the banks as fast as it was being drawn out, the banks were obliged to replenish the depleted reserves in the only way left open to them by our laws, namely, by importing gold.

As far as the economic requirements of the case are concerned, any adequate security would have served the same purpose as the gold itself. But existing law made a distinction, and the law had to be complied with. What, it may be asked, is the intent of such law?

According to many prominent writers on the subject, standard coin alone is "real" or "basic" money, on which all "money substitutes" must be founded; hence it is held that cvery system of currency must be supported by an ample quantity of basic money to guard it against collapse. The prevalence of this belief accounts for the extensive use of gold for currency, and particularly for the laws which restrict bank reserves to "lawful" money, while at the same time precluding the increase of "lawful" money beyond such additions as may be afforded through the mining of gold. Thus we observe two causes of demand for gold as money, in that it is used as currency in the form of coin, and as bank reserve in the form of bullion or of coin.

294. Can the Monetary Demand for Gold be Reduced?When we consider that gold, when put in the form of coin, or held in place of coin in the form of bullion as bank reserve, 
is put out of use entirely, except as a form of collateral security, the question forcibly obtrudes itself whether there is not some way of organizing a money system with gold as a standard of value, but without having to use the gold itself as a collateral seeurity.

As regards the use of gold for currency, we lhave before us the fact that almost all over the United States and Canada, and to a large extent in Europe generally, it is already practically displaced by eredit currency of one form or another. Yet, notwithstanding this substitution, gold has remained the standard of value. There is no reason why this process should not be carried to its logical conclusion.

Inasmuch as credit currency fulfils all the requirements of a medium of exchange, there is really no need for coining the metal gold. The work of the mint might therefore be confined to preparing bars of refined gold to be used instead of coin for redeeming eredit currency (302). Gold would then cease to be used as a money substance, but would remain the redemption substance. With gold eurrency completely replaced by credit currency, the quantity of the metal available for purposes of redemption wonld be correspondingly increased.

This would really amount to a demonetization of gold without, however, abandoning gold as our measure of value. The unit of value, the dollar, would still be 23.22 grains of pure gold, currency being redeemable in gold metal at that rate. But the call for redemption, the demand for gold in exchange for currency, would be reduced to the demand for industrial purposes, for the metal tendered in redemption would be merchandise and not money. Gold would thus be in the same eategory with all other forms of merchandise, its holder having to find a purchaser for it if he wants money in its place.

As regards the use of gold for bank reserves, it has been noted that in this capacity the metal serves two purposes which must be considered separately. In one capacity it is part of the security for the bank notes and bank eredit in circulation. When so employed, not all of it is held by the banks, but a large portion is stored in the vaults of the United States treasury and sub-treasuries and is represented in the banks in 
the form of gold certificates and gold deposit receipts. In the other capacity it scrves as a store from which redemption of the outstanding notes of the banks is effected.

Viewing the gold held in reserve in its capacity as security, it is plainly to be seen that it can be replaced by pledges of other forms of wealth (69). Gold has no inherent advantage in this capacity over other forms of wealth, when the latter is pledged in quantity ample for the purpose. So far as concerms the making of the circulating medium secure, there is absolutely no need of a definite store of the metal gold, and therefore no need for legislative provision to that end.

But in its second capacity, namely, in that of serving as a medium of redemption, it cannot, so long as gold is the value denominator, be replaced by any other form of wealth, however amply pledged, nor by currency notes of any kind. The necessity of providing for redemption requires absolutely that gold be held in reserve. The only question in this regard is the quantity required for this purpose.

295. Centralized Redemption.-National banks, when called upon to redeem any of their notes, may do so with legaltender notes instead of gold (292a). If they do supply gold, it is accommodation, not obligation. This exchange of legaltender notes for bank notes cannot really be considered an act of redemption, for it is merely an exchange of one credit instrument for another of essentially equal import. The main distinction between legal-tender notes and bank notes is that which is arbitrarily made by legislation. From an economic standpoint both are virtually identical. If there is a difference, it is rather in favor of the national bank notes, these being secured by the assets of the issuing banks as well as by national credit. The law that makes it appear that this exchange of one credit instrument for another is an act of redemption really provides that the process of redeeming shall be an indirect one, involving a double operation, namely first, the exchange of national bank notes for legal-tender notes, and then the exchange of the latter for gold.

In a project of currency, such as it is our purpose to present, there is of course no room for the multifarious forms 
of our present complicated system. The elimination of standard coin, as above suggested, would go far toward effecting a much desired simplification. Besides subsidiary coin nothing more would be needed than one single kind of bank notes of various denominations, issued on the general principle of those of the national banks (292b), admitting as security for the notes not only obligations of the government, but also other obligations of unquestionable value; the notes to be redeemable in gold, and to be issued in quantity limited only by demand conditioned on compliance with the indispensable requirements of security and redemption.

With notes issued on such a plan, their redemption would serve no real purpose except when the gold is needed as merchandise, either in the industries or for adjusting international balances. This would be especially the case if the gold given in redemption of the notes were furnished, as here proposed, in the form of bullion. Only those holders of notes requiring gold as such would have occasion to present notes for redemption, henee to obligate banks to give gold for their notes on demand, would really be to compel them to become gold merchants to that extent. Such a requirement would place the banks at a marked disadvantage as compared with other merchants, for if a dealer's stock of goods runs short, so that he eannot serve his customers at a moment's notice, his standing as a merchant does not thereby suffer, while if a bank were under legal obligation to supply a customer with gold on demand, its failure to do so would under the law constitute an act of bankruptey.

This danger is obviated in the present national banking system by the expedient of relegating to the national treasury the duty of gold redemption, which is accomplished in the way above described. The individual banks are thereby freed from the obligation of maintaining a gold reserve to meet the local demands. But this system of centralized redemption puts upon the federal government the onerous duty of maintaining the gold reserve. In the case of the issue of a uniform eurreney through national banks, the system of having the government redeem the notes may be eontinued, but the duty 
of keeping the central gold reserve unimpaired should then logically be imposed on the banks, and this could be done through a system of assessments as occasion requires.

Under this system the holders of notes would have the right to demand gold in exchange for the notes only from the government, just as is the case under the present system; but the redemption fund would be kept up by the banks, which is not the case at present. However, while the banks would not be under the additional obligation to furnish gold for notes over the counter, any more than they are under the existing system, there would be nothing to prevent them from accommodating their customers, as they do now, when they can conveniently do so.

296. Deferred Redemption.-If the greatest possible freedom of expansion and consequent accommodation of the medium of exchange to the requirements of commerce is to be attained, we must find how small a proportion of gold metal would suffice as a redemption fund for an issue of currency notes redeemable in gold. Whatever system of note issue and redemption may be adopted in which the issue is greater in amount than the gold held for its redemption, there always remains the possibility that at some time the demand for redemption may exceed the reserve held for that purpose. A system of centralized redemption would doubtless have the effect of reducing this danger, but could not wholly remove it.

Experience has proved that at critical junctures of business disturbance banks are unable to meet their obligations to pay cash to their depositors on demand. As is well known, the drain upon banks during a crisis is so persistent that even some of the most thoroughly solvent institutions cannot keep up their reserves. Ordinarily this condition would mean bankruptey, but at such periods banking laws are in a measure held in abeyance, if only for the reason that their enforcement would but intensify the prevailing distress.

This at once suggests a simple arrangement by which a small gold reserve would amply suffice. We need only enact into law in regard to gold redemption that which has heretofore been permitted in contravention of the law in regard to 
cash obligations of banks. In other words, disaster due to a possible exhaustion of the gold reserve can be met by a legalized postponement of actual gold redemption, that is to say, by allowing redemption to be deferred for a limited period when, and only when, occasion absolutely requires (303a). The time limit would have to be determined by the exigencies of the occasion and with regard to the methods adopted for replenishing the redemption store of gold.

This proposition should not be misunderstood. It does not include giving a bank the right to defer the cashing of checks of its depositors. On the contrary, the object is to facilitate the issue of currency so that the supply of cash will always be sufficient. It is only to the redemption of the currency in gold that the proposed delay would apply.

Under this system the notes would ordinarily be redeemable in gold on demand, but in case of emergency that redemption would be subject to a postponement for a time sufficient to replenish the redemption fund. This would be but a limited period under any possible circumstances.

It is of course clear enough that this is directly opposed to the frequently propounded doctrine that no monetary system on a gold basis can be safe and sound, unless the currency is redeemable in gold on demand. Let us more closely examine whether this condition is really indispensable.

Apart from the use of gold for currency and bank reserves, its use in the industries is the only reason for its demand. In the field of industry gold is merchandise, just as pig iron is to the founder, and wool or yarn is to the cloth manufacturer. When these business men find their respective sources of supply in the market temporarily exhausted, in other words, when the goods they need are not to be found in stock, they must needs await their turn to be supplied. A similar shortage of gold for redeeming notes would simply mean that the stock of gold on hand has run short and needs replenishing.

The holder of money has been described by John Stuart Mill as one possessing "a right to a certain value of the produce of the country, to be selected at pleasure." But this statement of the right is too broad. The holder of money 
cannot command with it any produce of the country, unless the same is being offered in the market, even though such produce may exist in abundance. Mill's statement should therefore be amended to read: "a right to a certain value of such produce of the country as is offered in the market." Accordingly, a holder of currency, having a right to gold in exchange for it, should have this right subject to the supply of gold in the market, and if the market supply of gold falls short of the demand in the same market, a delay of the supply would be a natural consequence, just as would be the case if the supply of any other product were momentarily insufficient. What reason have we for requiring a supply of gold to be kept in store to meet on the instant every possible demand for it? No one would expect this with regard to any other merchandise. The adoption of the gold standard does not and cannot involve the obligation of maintaining an inexhaustible supply of gold for purposes of redemption, if for no other reason than that such a supply is physically impossible. As a matter of fact, repeated experiences have demonstrated conelusively that an immediate redemption in gold is not necessary to keep notes at par. Among these experiences may be cited several noted instances.

After the Bank of England, in February of 1797, was granted the right to temporarily suspend specie payment, its notes continued to circulate at par. Depreciation ensued only at a later period, when it became apparent that resumption of specie payment might be delayed indefinitely.

From the time, in 1875, when the Congress of the United States provided for the resumption of specie payment, the value of the then depreciated greenbacks steadily rose and attained parity with gold some time before the first of January, 1879 , the date set for resumption. Moreover, the depreciation of the notes during the period preceding the date of resumption was much less than the then eurrent rate of discount on first class obligations payable on that date.

As already noted, the so-called "redemption" of bank notes in legal-tender notes cannot be considered as actual redemption. Under our present laws bank notes are not really 
redeemable in gold on demand, yet they are accepted in the commercial world without hesitation at par with gold.

Furthermore, legal-tender notes are legally redeemable only at the treasury and sub-treasuries of the United States. Such notes, when eirculating at a distance from the nearest point of redemption, are by no means immediately convertible into gold, yet they have remained at par with gold since the time when specie payment was resumed in 1879 .

During the period before subsidiary coin was made redeemable in standard coin, and while it was aceepted by the government at par only when tendered in limited quantity, it yet freely circulated at par with standard eoin.

During monetary panies like those of 1893 and 1907 it was the scarcity of eurrency as a medium of exchange, and not the scarcity of gold as a medium of redemption which characterized the situation. Nobody objeeted to any of the currency, whether legal-tender notes, bank notes, silver dollars or silver certificates. Because of the lack of currency, clearing house certificates had to be issued and were freely accepted as means of payment. The question was not one of a demand for gold, but of a demand for curreney. The fact that in 1907 many millions of dollars' worth of gold was imported only proved the great demand for a medium of exchange, for there was no unusual demand for a medium of redemption. The supply of available money for bank reserve was cut off by the general resort to hoarding, and no other source of supply was open under the existing laws except the gold market abroad. If legal eurrency could have been issued freely on security of actual wealth other than gold, there would have been no lack of eurrency, and consequently no panic; and the importation of gold would not have been necessary.

All these instances elearly prove that the immediate convertibility of eurreney into gold is not necessary to keep it at par with gold. An assured eertainty of redemption within a limited space of time has proved to be amply sufficient (315).

As already stated, this discussion has bearing only on the redemption of eurreney in gold, but not on the eashing of valid checks. Were such a measure as that here proposed 
once adopted, any bank could obtain eurrency on terms which would leave it no valid excuse for failure to provide all the cash that may be legitimately demanded. The suggested postponement has reference only to the furnishing of gold metal in exchange for currency, and while such a postponement might affect the activity of workers in gold, just as a partial failure of the cotton crop interferes with the cotton industry, the business activity of the whole community could not possibly suffer, as it suffers now in consequence of money panics.

If our eurrency system were reformed on these lines, the question of the ratio of the gold reserve would offer no diffculty. Since banks would not need to keep gold as cash reserve, the demand for this metal would be so greatly reduced that a temporary exhaustion of the central gold reserve would be but remotely possible (320), even were the legal rate of gold reserve reduced to but a small fraction of the present requirement, especially as the only natural demand, that of the gold industry, would be far more than covered by the current output of gold from the mines. It is quite possible that a gold reserve of only one per cent. of the amount of currency issued would ultimately be found to cover fully every demand made on the redemption fund without undue strain on the system of its replenishment (303b).

297. Procuring Gold for Redemption.-As already stated, the gold needed for redemption is to be furnished by the banks through whose agency the notes are issued. Whenever the gold in the redemption fund falls below the amount corresponding to the legal rate of gold reserve, the deficit would have to be covered by the banks of issue, each to supply the share assessed against it and to receive in exchange for this gold an equivalent of notes from the redemption fund. The notification to furnish gold would be sent to the banks at stated periods, let us say, monthly. The rate of assessment would accordingly be computed at the close of each month, and the banks be required to supply their respective amounts of gold within the succeeding month. Under this rule the amount of gold in the redemption fund would never be much less than the amount prescribed for it, unless, indeed, the 
demand during the current month happens to be extraordinarily large.

Should this reserve become exhausted, then those who would next apply to have notes redeemed, that is to say, those who would want to buy gold from the reserve fund, would simply have to await their turn (320). Some assurance of the good faith of those applying would of course be necessary to preelude an abuse of the system by speculators. If at the end of any month there were still a deficiency, the rate of gold assessment against the banks for the following month would have to be computed to meet the deficit and also to restore the normal ratio.

A frequent recurrence of such deficits would show that the adopted ratio of reserve is too low, and its increase would accordingly be indicated. On the other hand, were the monthly demand for gold never to exceed a small fraction of this fund, a reduction of the ratio would be admissible.

It is, of course, not impossible that the demand for gold may, under some abnormal condition, rise to a point where it would be impracticable for the banks to meet during the ensuing month the assessment called for by the proposed rule. In view of this contingency the law might be made to provide that, when the assessment for gold in any one month were to exceed, say, two per cent., the time allowed for the banks to turn in the gold shall be extended for a limited period (303).

There is no reason to fear that the possibility of a postponed gold redemption would be a source of weakness. When considered in the light of existing conditions, all such apprehension will be found groundless. Under the present system a simultaneous demand on all banks for cash amounting to only ten per cent. of their deposits would exhaust nearly every bank reserve and most likely precipitate a financial crisis, while under the system here outlined a similar demand for gold in exchange for curreney notes, if clistributed over a few months, would be met with hardly any effeet on general business conditions. 
298. The Communal Agreement.-However valid and sound may be the credit which a credit instrument represents, it is not eurrency, unless it is brought within the scope of that social compact through which it becomes accepted in the market (85). This is done by giving the credit instrument the legal form of eurrency notes. Beyond this, a well grounded public confidence in the soundness of the credit, coupled with assurance of redeemability, is all that is economically necessary to give the notes currency as money. This confidence is at present imparted through the governmental control of the issue and custody of the agents' security; and, indeed, the government is the only authority to which the people can look with entire conficlence for the necessary assurance.

From a strictly economic standpoint the monetization of valid credit is a very simple process. Ever since credit money has come into use, it has been unhesitatingly accepted as a medium of exchange, whenever its security was regarded as adequate, its redeemability unquestioned and its circulation legally permitted. As a matter of fact, governments have had little trouble in forcing even inadequately secured notes into use by declaring them legal tender, and such currency has continued to circulate for long periods of time, though usually in varying degrees of depreciation. These facts prove that there is no inherent difficulty in the way of converting valid credit into valid money. Such conversion, however, is now regulated by laws through which the issuc of currency is restricted, although the restriction itself cannot be justified by sound economic considerations (238-239).

There is a popular notion that the creation of money is possible only through some mysterious power possessed by government. According to this idea nothing can be money that is not legal tender. This opinion has no foundation in fact, for both bank notes and bank checks constantly perform the function of money. It is not the government's "fiat," but the certainty of redemption, that prompts the common consent to accept the notes in the market, and it is this acceptability that gives the notes their money quality. An authoritative control of currency issues is indeed desirable for several reasons, but it is not indispensable. 
But, however exercised, this control should not go beyond the enforcement of such regulations as are necessary to make certain of the security and to assure redemption. It should not go to the length of arbitrarily limiting or in any other way needlessly hampering the issue of currency.

299. The Process of Issuing Currency.-The process of issuing bank currency really consists of three successive operations. The govermment, having manufactured the notes which are to serve as money tokens, delivers them to the issuing bank in exchange for a security sufficient to guarantec the return of the notes or their equivalent to the government. The bank, in due course, delivers the currency notes to its customers in exchange for promissory notes or other security through which the return of the currency or its equivalent to the bank is assured. And, finally, the customers use the notes as a medium of exchange in purchasing things or services. Thereupon, and not until then, do the bank notes become current money.

It will be remembered that credit is ownership of wealth in possession of the debtor (68), just as a debt is possession of wealth owned by the creditor. Considered in this light, the third transaction alone constitutes a lending of actual wealth, or the creation of a real credit relation. The first transaction, like the second, is merely an exchange of.credit instruments. Both transactions are part of the process by which government exereises control over the issue of currency and is put in position to warrant the validity of the notes. The first transaction is related to the second as wholesaling is to retailing. Otherwise there is no essential differenee between the two. The bank is debtor to the government in the same sense in which the borrower is debtor to the bank.

300. Money Tokens.-A money token is simply an evidence of debt by the issuer, emitted in a form which is accepted in the market as money to the amount betokened. The material of which money tokens are made must not be mistaken for the substance of the moncy itself. That substance consists of the wealth which is pledged as sceurity for the issue, and this is true even of standard coin, in which the security is borne by the token itself. 'The paper, bronze, niekel 
or silver of which money tokens other than standard coin are made have no influence on the value of the money as such. At the same time, due care must be bestowed on the preparation of the tokens, so that they may be properly adapted for their function as currency. The notes now in use fully meet this requirement. They are generally given such form as to be practically safe against falsification, and in their usual shape and size are sufficiently characteristic to be readily recognized as money.

For various reasons it is desirable that the tokens pe prepared by the government, or at least under its supervision and control, and that the government guarantee the value of the security (92). In this way the issue may be maintained in uniformity, and abuses in the issue most effectively guarded against. Moreover, there is naturally a preference for guarantee by the community over that by any other anthority.

30r. The Cost of Issuing Currency.-When the government undertakes the administration of the currency system, including the printing of the notes and their distribution to the agents of issue, the question arises whether the expense of this work should be borne by the state or be collected from the issuers through the agents of the issue.

In the illustration of the hatter, the shoemaker and the grocer (287) we assumed that the hatter became the issuer of the notes through which the exchanges were mediated. Is it just to make him pay the cost of the issue? The three men of the illustration were equally benefited by this method of exchange, hence it does not seem right to expect any one of them to bear the total expense of the system. So likewise, in the real world, the benefit of the currency system is shared by the community in general. There is every reason why the cost of making and distributing the notes and of replacing the worn ones should be paid by the people as a whole, that is, out of the public treasury. It would be unjust to place upon a limited number-represented by the hatter of our illustration -the burden of this cost $(310)$. For the same reason it is improper that banks of issue should be taxed to meet this expense. Nor would any other tax on the issue of notes be 
justifiable, just as neither of the three men of our illustration should be muleted for doing that which benefits all alike (303).

302. Plan of Currency Reform.-The proposal presented in the following pages is worked out in detail merely to show that on the general principle already stated a practicable plan can be elaborated. It is quite possible that some experiences of the past and others of the future may point out various modifications as regards the details, and even different ways of reaching the same end. The purpose is to remove those restrictions on the utilization of credit as a medium of exchange which are not only needless, but positively harmful.

A currency reform with this end in view may be effected without any disturbance of business conditions and could be realized with but few changes in the details of the present national banking system.

The principal change is one which is in line with the frequently proposed issue of "asset currency." It consists essentially in broadening the range of securities acceptable from the agents of issue by the treasury as a basis for bank notes. But in view of the continuous scrutiny required and of other complications incident to the use of ordinary commercial paper as a security to be held by the government for the issue of currency, the proposition already indicated (288) would appear to be decidedly preferable.

In the plan here proposed the "assets" to be accepted as a basis for currency, besides national, state and municipal bonds, are to be real estate liens, of which there is undoubtedly an ample supply obtainable to cover every possible demand for curreney. In this way it would not be necessary to have recourse to ephemeral business paper to supply that security for the issue which is placed in custody of the government.

Notes so issued should be redeemable in gold from a redemption fund in custody of the govermment. It may suffice to confine the offices of redemption to the treasury and the sub-treasuries of the United States, but if found expedient, additional branches could be opened, say, in the principal post offices. As under this system the coinage of gold could be dis- 
continued, a demand for redemption would be honored only in amounts of, say, $\$ 100$ and multiples, adapted to the sizes of the bars of bullion in which redemption would be effected (294).

Since redemption could be demanded only from the government, banks being relieved of the obligation to hand out the metal over their counters on demand, there would be no need for distinguishing the notes issued througl one bank from those issued through another, hence all notes of equal denomination could be made alike in all details. This would not only simplify the present cumbersome and costly method of issuing special notes to each bank, but would also facilitate the detection of counterfeits, if such came into circulation. The chief object of this reform being the removal of all unnecessary restrictions to the volume of currency (291), the production of notes should be continued, and the demand for notes supplied, so long as those conditions are complied with which would assure that every note issued is regularly redeemable in the value denominator. Since currency can be used only for mediating exchanges, every call for additional currency indicates that there is further need for means of exchange, and every refusal to issue currency in response to such call is a restraint of the right to make exchanges.

These notes would readily take the place of all forms of currency now in use, with the exception of fractional currency which, in its present form, leaves practically nothing to be desired.

The banks through which this currency is to be issued would use it as they now employ national bank notes. By the process of discounting promissory notes, business credits would, as now, be turned into bank credit and made available for mediating exchanges, through either currency or checks. Such amounts of notes as would not be put into actual circulation would constitute the reserve.

303. Organization of Banks of Issue.-Whether we view a bank as an intermediary agent between the real issuer of currency and the government that controls the issue (102), or as the retail distributer of the money tokens furnished in gross quantity by the government, its function is that of con- 
verting ordinary credit into money, or, as it nay be termed, of monetizing or mobilizing credit.

It follows that, in the last analysis, the raw material of banks of issue is not money, but credit, and for this reason the prerequisites for their establishment need be nothing more than valid eredit. Upon handing the instruments of this credit to the government as security, the banks would obtain from the government other credit instruments, namely currency notes, whereby that credit would be monetized. It is therefore quite feasible to organize banks on the basis of stock issued, not against cash, but against certain specified forms of credit, such as bonds of the federal, state and perhaps municipal governments, and recorded real estate liens (288), which, in turn, are to be accepted by the government as security for the currency issued to the banks. In this way the banks would obtain their working funds.

Should any of the securities furnished by a bank as basis for currency depreciate below the legally prescribed limit of margin, the bank would be required to make good the shortage, either by furnishing more security, or by reducing its issue.

Inasmuch as it is conceivable that notwithstanding all these precautions a bank may become insolvent to such a degree that it cannot redeem the full amount of the currency issued through its agency, the provision should be made that in such case a proportionate tax would be imposed on all other banks of issuc to cover the deficicncy. This should be the only tax imposed on the issue of currency, apart from the obligations of furnishing security and of providing and main. taining the redemption fund (301).

The gold for this latter fund could be obtained by requiring every bank applying for currency to furnish not only the prescribed amount of securities, but also gold to the amount of such percentage of the currency issued as expcrience indicated as sufficient. To begin with, it might be advisable that a rate of ten or fiftecn per cent. be adopted, this rate to be afterwards reduced to a point indicated by experience as being entirely safe. It is probable, as already noted (296b), that a rate as low as one per cent. may in the end be found to be fully adequate. 
When currency notes are presented for redemption, they would be turned into this fund in exchange for gold taken from it. While this fund would thus remain unimpaired, its metal portion would be reduced, and in order to restore normal conditions, monthly assessments would be made on all banks of issue for gold in exchange for the notes in that fund. The comptroller of the currency might be empowered to replenish the stock of gold by using currency from the redemption fund for the purchase of gold metal in the market at a price not more than the legal rate-23.22 grains of pure gold per dollar -and thus avoid the necessity of calling on the banks for it. Since gold would no longer be coined, the possessors of the metal would find its sale to the treasury a means of converting it into money, just as the same result is now obtained by bringing the gold to be coined, the only difference being that the amount so converted would not depend on the supply of the metal, but on the demand for it by the redemption fund.

Should at any time and for any reason the redemption fund become entirely depleted of gold, applicants for the metal would simply have to wait for the stock to be replenished (296a). As all applicants for gold in redemption of notes would get the metal in turn as fast as it came in from the sources provided, there could never be anything in the nature of an actual suspension of gold redemption. The delay would merely take the form of a time of grace. If such conditions were to prevail at the close of a month, the assessments on the banks of issue would naturally have to cover not only the amount awaiting redemption, but also an amount restoring the redemption fund to its normal status.

In view of the possibility that the demand on the banks for gold in any one montli may be more than the banks can supply within that period without excessive pressure on the market for that metal, provision should be made for shifting at least a part of the assessments on the succeeding month or months (297).

If such a plan were universally adopted, there would be no demand for gold save for industrial purposes. That demand would readily be covered by the new gold coming into the market, and it would therefore be out of reasonable prob- 
ability that the call for gold upon the redemption fund would ever amount to much $(320 a)$. The likelihood is rather that gold would always be freely offered in the market, since the metal would no longer be admitted to coinage.

But supposing the plan to be adopted only in one country, one of the effects would doubtless be a tendency to the exportation of gold and a possible demand for gold in redemption of notes to the extent of exhausting the redemption fund of its metal reserve (320b). However, since a delay of gold redemption would be legally admissible, a temporary exhaustion of the gold of this fund could not of itself react upon the general status of the currency. To guard against merely speculative or wanton calls for gold in exchange for notes, it might be expedient to require with each eall for redemption a deposit of, say five or ten per cent. of the amount, this deposit to be forfeited if the demand is not made effective when the supply is offered.

The reasons above adduced for reducing the gold redemption fund to a small percentage of the currency issue do not hold good as regards the reserve fund of banks. Experience has shown that banks should maintain a substantial reserve fund of actual currency, and there are good reasons why this fund should not be less than about 15 per cent. of the deposit liabilities. This is true even though we have repcatedly pointed out that the requirement of a large reserve fund is objectionable, in so far as the expansion of bank credit is thereby hampered, making it often impossible for banks, espeeially when the cycle of business activity reaches the hoarding stage (273), to mect all demands of legitimate business for "money." But once the needless limitations on the issue of currency are removed, this objeetion falls away.

304. Deposit Insurance.-The desirability of mutual insurance of deposits has already been adverted to (290a). An insuranee fund may be ereated by requiring all banks to make a deposit equal to, say, two per cent. of their capital and surplus, and to maintain that proportion as their capital and surplus is increased or decreased.

Assuming that a bank becomes insolvent, the winding up of its affairs would require (1) that the payment of the checks 
of depositors be continued to the extent of their balances, utilizing for this purpose the available assets of the bank and drawing on the insurance fund for such additional amount as may be needed; (2) that, also by drawing on the insurance fund as may be necessary, an amount of currency equal to the sum issued through the insolvent bank be paid to the government to be retired, and that the stock securities held by the government be thereupon tumed over to the receiver of the bank; (3) that the other assets of the bank be realized upon as promptly as possible. From these collections the insurance fund is to be reimbursed as far as possible for the drafts made upon it. If these drafts cannot be repaid in full from the collections, the deficit is to be charged against the stockholders' securities which had been turned over to the receiver, and assessed on the stockholders pro rata. In the case that some of the stockholders fail to pay that assessment, the amount is to be obtained by selling their respective securities, the balance, if any, to be returned to them. But it may happen that the stockholders' securities are inadequate to cover the deficit due to the insurance fund, and in this case the remaining deficit is to be made up by assessment on all banks in proportion to the sum of their deposits and their currency issue $(290 c)$.

The following additional rule should in justice to all concerned become a part of the plan whenever a system of deposit insurance is adopted.

It is clear that the insurance fund cannot lose through the failure of a bank unless its assets fall short of its liabilities for currency issued and for deposits. The stock of a bank and its surplus, if there be any, is accordingly the margin of safety as regards a possible loss to the insurance fund (104). In fairness to all banks embraced in the insurance system, this margin of safety should not in any bank be less than a certain proportion of the total liabilities. It would be advisable to require each bank to deposit in the insurance fund an amount of stockholders' securities, over and above those deposited in the treasury for currency issued, of a given proportion, say one-fourth, of the deposit liabilities, to be utilized as receiver's assets if the respective bank fails. Each bank should accord- 
ingly be required to inerease its capital stock whenever its deposit liabilities increase beyond the proportionate amount of the securities already furnished, and to deposit in the insurance fund the securities on which the new stock is issued. The stockholders being the first and principal losers in the event of a failure of the bank, this will go far towards putting a stop to imprudent and unsound banking.

Bank failures of the past with attending losses to depositors prove that the present means for the protection of bank credit are not as efficacious as they should be. It would therefore seem that the insurance fund would frequently be called into requisition. But it should be remembered that the conditions which are at the root of most bank failures-apart from those which arise through sheer mismanagement or eriminality-would undergo a wholesome ehange by currency reform on the line proposed. From the moment that the cause which entails an endless succession of business failures (255) is removed, the risk now inherent in the business of deposit banking would be so largely reduced that bank failures due to the failures of customers would become comparatively rare. The system of deposit insurance would therefore become little more than a formality.

It has been only of late that mutual insurance of deposits has been put in practice (290b). This has been done in some western states of the Union under provisions of law making such insurance obligatory on state banks. But the enactments appear to have been formulated without proper precaution against loose praetiees, and the experiment has been disappointing. The system is nevertheless likely to be more generally introduced after experience has indieated the remedies for such defects as have shown themselves.

305. Missing or Lost Notes.-Currency notes, when in eirculation, are liable to be lost or destroyed, and it may be desirable that an approximate accounting of these notes be effected.

This could be done by periodically changing the design, or at least a serial letter or other mark, say every ten or twenty years, and as worn notes are returned and cancelled, keep 
account of their series. If after the lapse of such a period the notes of the preceding series have not all come back and been cancelled, it may be assumed that the notes remaining out have been lost. An amount of new notes equal to that of the supposedly lost notes could then be turned into the national treasury, and if subsequently any of the missing notes should be received for cancellation, they would be exchanged for other notes out of that treasury and thereupon cancelled.

The rationale of this procedure will be readily understood. If notes are accidentally destroyed or lost, the amount in existence will of course be less than that issued. Since for every note issued there is a corresponding security on deposit with the government, there would be an excess of the debtors' over the creditors' account in the money system. In the way here suggested the discrepancy would be eliminated and the proper balance between securities covering the debts and the actual volume of currency, the credits, could be maintained close enough for all practical purposes.

306. The Legal-tender Quality.-The question arises as to whether or not this proposed currency should be made legal tender. In the ordinary course of business such a provision would be superfluous, just as it is found unnecessary as regards bank checks and national bank notes. Like these, the currency here proposed would naturally circulate on its merits. The principal function of the banks being that of monetizing the credit of their customers, the means of that monetization, the currency notes, would naturally be legal tender as between them. No other form of currency outside of minor coin being in use, it would also, of course, be legal tender for all debts, public or private, expressed in terms of dollars. While it would thus be really unnecessary, there would, on the other hand, be no objection to expressly declaring the notes to be legal tender (99).

307. The Function of Banks of Issue.-The expediency of issuing the stock of banking institutions against securities and liens instead of money may appear questionable. Yet there is nothing improper or unreasonable in it. From a purely economic standpoint there is no difference of value be- 
tween fully assured credit and money. The difference is of a merely conventional nature, and being due exclusively to statutory enactment, it can be eliminated by statutory provision. The subject resolves itself into a question of dealing with conventional prejudiees, such as fell away when the public became educated to the use of bank notes and ehecks in lieu of specie. As a matter of fact, ehecks constitute a money system based on business credits and are, in a sense, a prototype of the currency notes here proposed. There is absolutely no reason why this eurrency should be any less effective for the purpose of mediating exchanges than the national bank notes of the present banking system.

As already stated, banks of issue perform the function of distributing the eurreney into its proper ehannels, or, looking at it in another way, of mediating the monetization of business credits. The examination and insurance of the securities representing these credits are the proper function of the local banks, which would monetize those eredits as they do now, by diseounting promissory notes and other credit instruments.

Banking institutions would also eontinue to perform that function of modern banks whieh eonsists in effecting the clearance of business accounts by eheck. But since the diseounts from loans would no longer suffice to cover the clerieal expenses of this work, the banks would have to look for an income from those to whom they render this service. This income could be obtained by the banks charging a certain amount for each check made out by a depositor and passed back to him through the bank. Business men would then be paying directly for the labor involved in mediating their payments instead of indirectly, as under the present system.

308. Summary.-The principal aim of the eurrency system here proposed is the removal of that impediment which now prevents the volume of eurrency from adapting itself to the effective demand for money. This means a complete reversal of the prevailing policy of finance which has grown up on the fallacious theory that the value of the "money unit" depends on the volume of money, and that therefore every increase of the volume is attended by a corresponding increase 
of the price level, and vice versa. Imbued with this theory, John Stuart Mill (239) and others of that school came to believe that every permanent increase of currency results in a loss to the holders of existing notes and a corresponding gain to the issuers of the new notes. This misconception still remains an obstacle to the institution of a rational reform of the currency.

The present proposition is based on the self-evident fact that currency notes redeemable in gold have the same value as the gold in which they are redeemable. Being freed from arbitrary restrictions, the volume of currency would automatically adjust itself to the requirements of commerce, expanding and contracting where and when the demands of business dictate. Currency notes issued under the proposed rules would possess all the various requisites of a perfect medium of exchange. They would be fully secured and, being redeemable in gold, would be on a par with gold.

Notwithstanding the increased currency issue, there would be no danger of a shortage of gold for purposes of redemption. The demand for the metal would no longer include a demand for banking purposes and would subside to the level of its industrial requirements. The demand for its use as currency and bank reserve being practically done away with, the gold now locked up in treasuries for redemption purposes, and in bank vaults as reserve, would, at least in part, find its way into the market as metal, so that the supply of gold to meet all market demands for the metal would never fall short. It is only because consideration should always be given to every possible contingency, however remote, that some provision, as already suggested (296-297), should be made to meet a possible temporary exhaustion of the redemption fund, though such an exhaustion under the proposed system is almost inconceivable.

309. A Credit Clearance System.-Herbert Spencer has pointed out that legislation generally follows rather than leads in the march of progress. Legislators are presumed to represent their electorate and therefore rarely feel justified in 
advocating a reform which has not the sanction of a prevailing public opinion.

The volume theory of the value of money having long been preached by economists of standing and reputation, and taken as the keynote of currency legislation, there may be need of some practical demonstration of the fallacy of the old idea and of the validity of the proposition on which alone an effective reform of the eurrency can be based.

Were a number of business men to combine for the purpose of organizing a system of exchange, effective among themselves, they could clearly demonstrate how simple the money system can really be made. The greater the number of business men that would thus co-operate, the more complete would be their own emancipation from the obstruction to commerce and industry which existing currency laws impose.

A practicable plan for employing any sound business credit as a medium of exchange may be outlined as follows:

For the purpose of settling business accounts through a system of mutual clearance, societies of business men can be formed in their respective localities, and these bodies federated in a larger organization. The method of clearing accounts among members of these societics need differ in but a few details from the method at present employed by deposit banks for clearing checks. Each society would open an account with every one of its members, and any member desiring to use his own credit as a medium of exchange would, first of all, furnish thoroughly acceptable and amply adequate security for the amount of eredit he desires to have mobilized.

Neither the amount of this security nor any part of it is to be credited to the account of the respective member, but is to be held by the society as a pledge to cover "credit checks" which he is to be entitled to draw on the society in excess of any deposits that he may make to the credit of his account.

Even though he makes no deposit of funds of any kind, but has furmished only the security above indicated, he is to be entitled to draw, within the limit of the amount for which his security has been accepted, credit checks which would be substantially of the following form and tenor: 
The Credit Clearing Society of $\ldots \ldots \ldots \ldots$

Credit..............John Smith............. or order with .One II undred..................Dollars.

and charge to the Account of

\section{William Brown.}

Such checks would be accepted by all members of the federated societies in payment of business accounts, and when deposited, would be duly credited to the depositors' and charged to the drawers' account.

Besides credit checks, bankable funds, such as bank notes and bank checks, are to be accepted for deposit, but when so deposited, the checks drawn against the account are to be only in the form of credit checks of the above description, to be used by the drawer in paying accounts due by him to other members of any of the federated societies.

Since all business men have upon their books both accounts payable and accounts receivable, a clearance of the greater part, if not all, of this mutual indebtedness could readily be achieved by an extended application of this method. It is only necessary to follow the customary method of clearing bank checks.

A brief illustration may conduce to a better understanding of the idea. A depositor, after furnishing acceptable security adequate to cover the eredit he purposes to use, might during the first month pay out eredit checks to the amount of, say, $\$ 3000$, and receive in payment, in the course of business, a number of similar checks to the amount of $\$ 2500$, which he deposits at his society. At the end of the month his account would be overdrawn to the amount of $\$ 500$. He would have drawn against his security to that extent, and thus, for the time being, be debtor for that amount to his society, and incidentally to the entire clearance system.

During the succeeding month he might send out checks to the amount of $\$ 3500$ and receive $\$ 4200$ in the form of similar checks from his customers. On depositing these, he would have a balance of $\$ 200$ in his favor and thus be a creditor of this clearing system. If the bulk of his business had been transacted with members of the federated societies who had 
given and received such checks in payment, he would have needed in his business but little eash and would have been to that extent independent of the money market.

It is manifest that under these rules a member could check out more than he deposits and thus become debtor of the clearing system, but this only up to the amount for which the security he furnished had been accepted. His credit is monetized or " mobilized" through the over-drafts of his account with the society, and to that extent addition has been made to the exchange medium of this system. As issuer of this additional exchange medium he became to that extent a debtor to the system. Upon subsequently reducing his indebtedness by the deposit of credit checks received from other members, or of current funds, he correspondingly reduces the volume of his own mobilized credit and incidentally his indebtedness to the system. A member depositing more credit checks than he has issued has evidently made no draft against any security he may have furnished and is, in fact, a creditor of the clearance system to the extent of his balance.

The total volume of this medium of exchange, that is to say, of the credit so mobilized, would automatically adapt itself to the business requirements of its members. It would expand whenever a member overdraws his account-within the limits of his security, of course-and it would contract whenever an indebted member reduces his indebtedness by deposits.

It is obvious that such a system could easily be inaugurated with but a few provisions for its maintenance and to guard against abuse.

310. Ways and Means of the System.-The cost of conducting such a business would be mainly that of the services of its employes and of such incidentals as are requisite to the conduct of the business. Another item to be considered would be the possible losses through exceptional deprceiation of some of the securities. To cover these requirements, monthly assessments would be made on the members of the association which, at least at the beginning, should be proportionate to the amount of their indebtedness to the society, in other words, 
in proportion to the extent to which their individual credit has been monetized for them by the association. ${ }^{105}$

The rate of these assessments should at first be rather in excess of the estimated requirement, with a view of gradually accumulating a reasonable surplus fund in preparation for contingencies. This rate should be revised from time to time so as to adjust the income to the necessary outgo. Inasmuch as the object of the societies would be the facilitating of exchanges and not the making of profits, it would naturally be undesirable as well as unnecessary to accumulate more than a limited surplus fund.

Inasmuch as the assessments on the debtors of each society are to be adjusted to cover not only necessary expenses, but also any losses arising through exceptional depreciation of pledged securities, it follows that each society would be incidentally a mutual credit insurance company. The solidarity of responsibility thus effected would maintain the credit of the societies upon the highest plane at all times.

The various local associations would naturally accept all credit checks issued by members of any of the federated societies and would clear them as checks are cleared by deposit banks. Unauthorized credit checks, or checks exceeding the credit of the drawer would, of course, be treated as unauthorized bank checks and overdrafts are now treated by deposit banks.

3II. Payment of Individual Balances.-In the practical working of a system such as here proposed, the process of clearance cannot be expected to work out to exact balances. Some members will receive a larger amount in credit checks than they can use in payments to their fellow members, and their credit balances will correspondingly increase. Others will pay out more credit checks than they receive and accord-

${ }^{105}$ In the light of former conclusions (301) it would appear improper that the cost of conducting the business should be borne by those alone who are drawing upon their credit in the operation of the system, inasmuch as those who, for the time being, are not using their own credit, are getting the benefit of the clearance system as well as the others. But so long as bank depositors generally get their checks cleared without cost to them, those members of the clearance system who would have no occasion to have their own credit monctized should be given the same advantage. 
ingly have an increased debtor balance. To adjust these differences, some such means as the following would be required.

The creditor members, namely, those whose deposits of credit checks exceed their drafts, must be entitled to obtain cash from the society to the extent of their credit balances. The cash necessary for this purpose has naturally to be looked for from those who issued more credit cheeks than they deposited and who, through the monetization of their credit, have become debtors to the system. In order that this cash may come in systematically, the debtors would be required to deposit, within stated intervals, say monthly, a certain amount of cash proportionate to the amount of their overdrafts. Thus a member whose debtor balance at the end of a month amounts to, say, $\$ 2000$, when the monthly assessment of cash required to meet the ealls for payment of eredit balances is twenty per cent., would have to deposit at least $\$ 400$ in eash during the ensuing month.

These cash deposits would virtually constitute instalment payments of the indebtedness incurred, but this indebtedness could of course be renewed through a further issue of eredit checks within the eredit limit of the issuer. The rate of assessment, or "cash rate," would be adjusted from time to time to correspond with the demand for cash payment of credit balances. But while this rate may readily be adjusted so that in the average the amount of cash received meets the calls for payment of balances, these reeeipts might at times beeome inadequate, and this contingency must also be provided for.

3r2. Deferred Payments.-In ease that demands for cash payments of eredit balances surpass the amount of cash on hand, a temporary postponement of the payments can be provided for in a way similar to that suggested in the ease of gold redemption (296-297). Accordingly, a member who deposits a larger amount of checks than he pays ont in the course of his business and who desires his eredit balance, or a portion of it, paid in eash, might have to wait some days after entering his demand, before it could be met. In such an event the monthly call on debtors for cash, that is, the "eash rate," would be increased to a point which would adjust the eash income to the required anount, and so enable a resumption 
of balance payments on demand. But, on the other hand, the debtors should be protected against an unexpectedly heary demand for cash. If the rule were made that the monthly cash rate shall never exceed 50 per cent. of the debt balance, the delay of payment, in the event of a simultaneous presentation of all outstanding eredits, would amount to somewhat over two months. A limit of, say, three months for the maximum delay of balance payments could be adopted to surely cover the theoretically most unfavorable case, a case corresponding in the present banking system with a simultaneous demand for withdrawal of all deposits, which, as is well known, could never be met, and is never taken into account as even a possibility.

Members having credit balances would, accordingly, have the right to demand payment of those balances, with the understanding that, if need be, the society may avail itself of a period of grace never exceeding three months. In practice such occasion would rarely, if ever, arise, and if it did, the delay would probably never exceed one or two weeks, except, perhaps, during the initial stage of the organization. Those accepting payment in credit checks would, of course, do so with a full knowledge of this provision.

Such possible delays in the payment of credit balances may appear, at first sight, to be a serious objection to such a system. But upon further consideration it will be found to be of trifling consequence, as compared with the conditions now actually prevalent in business. Members accepting credit checks would, as a rule, be able to use the credit they represent for paying some of their accounts, and only exceptionally would they require their balances exchanged for currency. Moreover, once the system is more or less extensively adopted, any delay in balance payment that might arise would seldom exceed a week, and as it would be perfectly reasonable for members to insist on payment of their invoices within ten days of their date if paid by credit checks (340), and equally feasible for debtors to pay by credit checks within that time, this period, added to the possible delay of balance payment, would probably never exceed one month, a time which is now customary in business generally. Anyway, the likelihood of 
such delay would fall away entirely soon after the system was fairly in operation.

313. Issue of Notes.-Nor can there be any objection to broadening the scope of the system by having the federated associations issue notes for eireulation among the members, thus taking the place of eurreney. These notes would be issued to any member in exchange for credit cheeks at the office where he deposits, and if presented for redemption by a creditor member of any of the societies, at the place where he is a depositor, would be redeemable in actual eurrency on the same conditions on which eredit balances are eashed.

Inasmuch as redemption could be demanded, not by any bearer of the notes, but only by a member who is himself at once a depositor and a creditor of the system, and furthermore, inasmuch as redemption would not be specifically promised on demand, but be subject to eertain limitation as to time, these notes would not be money in the legal sense of the term and would therefore not be subject to the present prohibitory tax, but would nevertheless serve all the purposes of a medium of exchange within the cirele of the association membership.

In order that the field in which these notes can be utilized may be still further enlarged, the various societies might accept non-depositors as "associate members" on a stated initiation fee. These assoeiate members would then be in a position to aecept such notes and pass them to other members, although they could not have them redeemed, except through a regular ereditor member. In this way even wage earners could use these notes. This would materially inerease the chance of cancellation of accounts and would correspondingly decrease the need for eash for the clearance of credit balances.

314. Advantages of the System.-While the system of clearing aceounts herc proposed would reach its fullest efficieney only when employed by the business world in general, it yet could easily be inaugurated with advantage through the co-operation of a comparatively small number of business houses. Such an institution, when once in operation, would afford advantages to its members which would sooner or later induce all progressive business men to join. The advantages in question may be briefly recapitulated. 
The most obvious benefit would be the greater facility afforded for the settlement of business accounts. Through the medium of the institution the credit of the individual business man could be utilized as though it were money, so far at least as relates to dealings with members of the affiliated societies, and no arbitrary regulation could put a limit to this use of credit. And yet an undue expansion of this medium of exchange could not occur, as its volume would depend on the willingness and consent of creditor members to carry balances. Whenever the balance of a creditor member of any of the societies exceeds the amount he can use in his business, he would naturally hare the excess redeemed in currency. In this way debtor members would be brought to reduce their indebtedness by cash deposits. The volume of this medium of exchange would thus automatically adapt itself to the needs of business.

The system would, of course, not be free from all cost to the participants. It would cost something to keep the organization going, and, as has been shown before, this cost would be collected in the form of charges against the debtor members. But though these charges would be analogous to interest, their amount would be below the current interest rate, at least to the extent of the item of pure interest now paid as part of the charge for current interest or discount.

Other advantages would follow incidentally. Under such a system of clearanec prompt payment of accounts by eredit checks could reasonably be demanded by every member from every other (340). Any delay in such payment would be an acknowledgment of lack of resources, and being thus virtually an admission of financial weakness, would be a warning against a further extension of eredit to the delinquent. Questionable debts would not accumulate; the current custom of extending credits on the basis of supposed assets would cease, and the present method of settling accounts with promissory notes, when the amount of such notes already afloat is known only to the maker, would become obsolete. The conduct of business with an excessive proportion of liabilities would become almost impossible, and disastrous business failures, which are the consequences of excessive liabilities, would be correspondingly reduced. 


\section{CHAPTER XVII}

\section{EFFECTS OF CURRENCY REFORM}

3I5. Direct Results.-The eurreney system proposed in the foregoing ehapter eannot be said to be a radieal departure from well established prineiples. There is not a single feature among the proposed details that has not in some way or other stood the test of time. Under this system every currency note would remain, as it is now, an acknowledgment of debt, doubly secured. The gold standard would eontinue to be maintained through redeemability of the notes in gold (292_ 297). The use of bullion instead of specie as money is even now the current practice in international settlements (85). A temporary delay in gold redemption in ease of emergency is nothing new, and past experience has proved it to have no influence on the value of the notes if the postponement is not of an indefinite period (296). The purpose of the proposed reform is the removal of that obstruction to the freedom of exchange which is being maintained because of the fear of an inaginary danger (239-240).

The proposed alternative in the form of a system of mutual elearance of commercial accounts differs from the present bank eheek system only in a few details and, regarded from a simply eeonomie standpoint, the differences are merely in degree. The principal change is that of materially reducing the proportion of the reserve fund of legal money, made feasible by the provision for a brief postponement, in ease of emergency, of the exchange of legal money for credit cheeks.

But as regards the effect which the proposed curreney reform would doubtless have upon the industrial world, and upon society generally, far-reaching changes for the better would certainly follow. When the supply of curreney is allowed freely to respond to every demand that is supported by the tender of adequate security, and the issue is not hampered by a needless tax, competition among lenders will bring 
about a reduction of the interest rate to a point where this rate will cover only the value of actual services rendered. The item of pure interest will be practically eliminated from gross interest (327), as a natural consequence of the freedom of competition and the doing away with the impersonal monopoly of money. This condition would be realized as rapidly as the currency reform is put in operation and the additional currency brought into circulation. The beneficial effects that such a change would bring about in the general constitution of society can scarcely be estimated, but a few of the more salient results may be fairly prognosticated.

316. Indirect Results. -When once money lias lost its power to command pure interest, possessors of money or of credit capable of being monetized will naturally seek to invest their means in such industrial and commereial pursuits as still afford capital interest. These investments would take the form not only of enlargement of existing establishments, the starting of new enterprises and the full employment of all available labor, but also of such improvements in the methods of production as will enable labor to achieve its maximum efficieney. In consequence of that increase of capital by which the efficiency of labor is enhanced, the final efficiency of eapital, and hence also its power to command an unearned income, will become lessened (195).

Tinese investments would naturally continue until the diminishing capital returns cease to offer suffieient inducements for the further monetization of credit and its investment in business. At what point will this be the ease? When, as we have heretofore found, the current rate of pure interest on money loans equals, say, $C^{\prime} e^{\prime}$, Fig. 18, the amount of capital an employer can use to his best advantage is no greater than $O C^{\prime}$, and the amount of goods produced by a given amount of labor is represented by the area $O C^{\prime} e^{\prime} E$. But when the item of pure interest on money loans falls to a nominal rate, there need be no stint in the employment of capital goods, and the amount of capital that can be most advantageously employed will be increased to the point at which labor attains its maximum efficieney, the point indicated at $C$ in the diagram, the 
productivity being represented by the area $O C E$. At the same time, the final efficiency of capital, and accordingly also the rate of unearned returns of capital, finds its natural level at, or at least near, the vanishing point $C$.

If the prevailing theories regarding interest were correct, this result would not obtain. According to these theories man is naturally averse to producing things in advance of his requirements. It is immaterial whether this aversion is explained by regarding "abstinence" or "waiting" as an irksome effort, or by assuming that the strain of future productive effort is underestimated. This aversion, if it were as potent an economic factor as is assumed by these theories, would indeed account for that insufficiency of capital which makes it impossible to employ labor at its maximum efficiency. And if it were true that the insufficiency of live capital could be traced to the insufficiency of capital goods in existence, a mere addition to the volume of money could not possibly supply more capital.

The idea of an insufficiency of capital goods is however plainly at variance with actual facts. Why is it that the industrial world is so anxiously seeking for new markets for its excess productions? Why is it that the business world is striving to prevent, through the imposition of tariffs, the importation of that supply of capital goods which would supplement their supposed insufficiency? Why are we periodically visited by conditions to which the term "overproduction" has been applied? Why is it that there is the great trouble of the unemployed? If employers could readily obtain money at an interest rate that does not include a monopoly tribute, their demand for capital goods with which to increase labor's efficiency would become effective, and it is quite manifest that such demand would be duly supplied. Producers would no longer have any need to hunt for distant markets, as the home market would readily absorb all their productions, and uninterrupted prosperity would follow.

With the increase of capital employed in production, its final effieiency and, accordingly, its power of returning unearned revenue, would diminish, as already stated, and with 
the consequent reduction of the incomes of the passive participants in production a greater portion of the value gained in the process of production must accrue to the active participants. At first the increase would go to the employer alone, but this would induce a number of workers to compete by becoming employers. The demand for labor would correspondingly increase, with the result that wages would rise, so that in the end all active participants would obtain their shares according to the proportionate value of their respective services.

This higher level of wages would be brought about by competition, the very factor to which low wages are erroneously ascribed by the socialistic school of economists, and would be permanent, for with the disappearance of the item $I$ in the barren circulation of money (245-249), the cause of monetary crises and business depressions (271-276) would be removed once and for all.

3I7. Unfounded Apprehensions.-A reform of the currency system in the direction of greater freedom cannot be staved off indefinitely, since the fallacy of that theory of economics on which the prevailing objection to a natural expansion of the currency is based, is gradually being recognized and must ultimately give way to the truth. But the inevitable outcome of such a reform, the practical disappearance of pure interest, however salutary and beneficial to the community at large, will naturally be contemplated with alarm by many of those for whom the present system affords unearned gains. It has often been asserted that no one would save, if savings, when invested, would not return an income (205). In their effort to show that pure interest, the unearned profit of capital, is both just and necessary, leading economists have even declared that in the event of eapital ceasing to obtain that profit, it would not be invested, but would be held back, leaving labor unemployed. They maintain that lack of employment would result from those very conditions which, according to our conclusions, would definitely put an end to unemployment. However, it is not difficult to show that their assumption is totally groundless. 
318. Natural Inducements to Save.-Is it really true that the saving of wealth will eease when capital no longer yields a revenue to its owner? This supposition is certainly not confirmed by the conclusions to which our investigation points. Aceording to these conclusions an inereasing amount of means of production will be brought into use as the rate of interest on money loans falls (159). And were the rate of pure interest on money to vanish, the amount of capital employed would be increased to the point where labor attains its maximum efficiency. The employer would certainly seek to use that method of production which, under the existing conditions, yields the greatest returns with the least cost (205), and it is only the insufficient supply of money and consequent high rate of interest that now prevents the employment of that full complement of capital which enables labor to work to the best advantage. The desire to benefit from the increased efficiency of labor, the endeavor of the employer to increase the recompense for lis own efforts, is an inducement to produce capital far more potent than the desire to get interest on capital; and since the production of capital is possible only by the performance of work long before the fruit of that work becomes available for consumption, the inducement to produce capital is also an inducement to save.

But apart from the advantage afforded by the use of capital, there are yet other inducements to the accumulation of wealth (196). Men of prudent disposition seek to provide not only for their declining year's, but also for unforeseen emergencies. They make provision for their families both by accumulating savings and by insuring their lives. The growth of the system of life insurance is a significant commentary on the theory that men prefer present to future wealth. Here we actually see men saving wealth which will never become "present" wealth for themselves, but only for their heirs.

319. Inducements to Invest Savings.-The assumption of some economists that if it should come to pass that capital no longer commands pure interest, such savings as are made will not be invested in production, is also groundless. It is plain enough that capital goods in productive use would not be withdrawn therefrom, if for no other reason than that such 
withdrawal would of itself render them worthless. A selling of the plant or equipment of a business is, of course, not a withdrawal of capital, but only a change of ownership. A withdrawal would ensue only if the owner of capital should use up in his living and thus dissipate the income he receives as recompense for the depreciation of the capital goods. If the income so received is not used up, but is saved and stored in the form of money instead of being applied to restore the capital as it wears out, this money, it will be remembered, has value only because it constitutes a claim to actual wealth which is in possession of the issuer of the money and which is presumed to be in use as capital. The capital represented by that money is accordingly invested capital, and the withholding of the money from use does not constitute a withholding of capital from active employment.

It is true that under present conditions the hoarding of money has the effect of restricting the activity of labor; not, however, through a withdrawal of capital, as it is usually designated, but by diminishing the medium of commerce which, as it is, exists in insufficient quantity. Hoarding of money simply aggravates the evil effects of our faulty currency laws. Once the undue limitation on the use of credit as a medium of exchange is removed, the hoarding of money would be of no consequence to the community at large, as the present hindrance to the turning of idle into active capital would no longer exist.

The apprehension that unemployment would follow the shrinking of pure interest is to be traced to a prevailing misconception as to the causes of involuntary idleness. We need only place before our mind the process by which invested capital would lose its power to command pure interest. The first effect of a thoroughgoing currency reform being a reduction of the interest commanding power of money, the investment of money in industrial undertakings would be stimulated, as already said (155-162), and this would in turn result in a reduction of the interest commanding power of capital goods used in production. An increase of the amount of capital in productive use would accordingly precede, in fact, be the 
eause of, the decline of the interest commanding power of capital goods. This again brings up the question as to how low the rate of capital interest is likely to fall before it ceases to be an inducement for further investments.

The investor naturally takes into consideration the risk he runs of losing a part or all of what he ventures. This risk exists in endless forms. Articles of manufacture may become obsolete. Maehines not only wear out, but may be superseded by new inventions. Insurance in its various phases does not afford complete assurance against possible losses in business. The reluctance to assume such risks accounts for a limitation of capital investments and prevents capital returns from falling below the point where these contingencies are fully covered.

Whether this point will ever be reached in practice, or whether an increase of investments will be halted before it is reached, leaving the chances of gain still to overbalance the ehances of loss, must be left for the future to determine. It is not inconceivable that the impulse to the making of further investments would cease before returns from invested capital fall to the point of its mere insurance and maintenance, so that an item of pure capital interest would still be left as part of the average income from invested capital. But so long as there remains an average profit, however small, it is more likely that the investment of savings would continue in preference to keeping them idle, and that in the end this remaining profit, namely, the item of pure capital interest, would entirely disappear. The investor's recompense would then be the costless conservation of his savings, coupled with the chance of gain attended by an equal chance of loss. The getting of a regular unearned income out of aceumulated savings would thus naturally come to an end, and the owner of wealth who does not work would simply have to draw on that wealth for his living.

These conclusions apply of course only to purely passive investors. To the investor who is at the same time actively engaged in the work of organizing or managing the enterprise, or who applies in his investment more than ordinary judgment and foresight, there would naturally accrue a due return. But 
such return would be in the nature of wages rather than of capital interest.

When the normal return of invested capital is reduced to its mere maintenance, and capital has no longer the power to gain for its owner a regular income not earned by him, students of economics will be relieved of one of the vexing problems on which the authorities are at odds, namely, the proper definition of "capital"' (129). 'There would be no need for considering capital a distinct category of wealth. "Capital" and "wealth" would then be recognized as synonyms, and the use of the word in equivocal and misleading meanings would soon fall away, especially where the term is used virtually in the sense of "medium of exchange." This is the case when it is said that "capital" is needed for carrying out a certain enterprise, such as the building of a railroad or the development of natural resources. It is well known that the "capital" required in such cases is money, and that this money is furnished almost entirely in the form of bank credit.

Suppose a community requires a market-house and wants to build it without calling on capitalists for the means. If the work were undertaken by the community itself, the value created as the work proceeds could be applied as basis for an issue of currency, duly redeemable, with which to pay the workers. The community could thus effectively "finance" the enterprise, while at the same time the members of the community would be supplied with a medium of exchange that goes into circulation without the intervention of an agency to which a toll in the form of pure interest must be paid, not only at the start, but continuously thereafter. This has actually been done in the well-known and often quoted case of the Guernsey market-house; and why the example there set has not been generally adopted is indeed difficult to understand.

320. Opposition to Currency Reform.-There can be no question that a currency reform admitting of such an increase of the currency issue as will adapt exchange facilities to the effective demand would encounter opposition on the ground that it would work an injustice to the investor of capital. But such opposition can logically proceed only from one or the 
other of two standpoints. The pure interest which capital now commands is either natural and just, or it is unnatural and unjust.

Let us first take the standpoint that pure capital interest is something natural, on the ground that:

the rate of interest is not regulated by the abundance or scarcity of money, but by the abundance or scarcity of that part of capital not consisting of money ${ }^{108}$

or that capital interest is the reward of "abstinence" or is due to a natural undervaluation of future as compared with present goods. In either case no change in the currency system could possibly affect the interest commanding power of capital, and opposition to currency reform on the ground that it would work injustice to capital would be illogical.

On the other hand, to concede that through a liberal reform of the currency system capital would be divested of its power to command pure interest would be tantamount to an admission that this power of capital is unnatural and unjust, and opposition to such reform would be worse than illogical.

Opposition may, however, proceed on still other grounds. There is a prevailing opinion that the only effect of an increase of currency would be that of deranging prices. This question has been discussed before (239a), but since the succeeding developments of our inquiry have thrown further light on the subject, we may briefly resume its consideration.

So long as currency is redeemable in gold, the purchasing power of money can fall only by a lowering of the value of gold metal. The question therefore resolves itself into this: Would the proposed money reform have the effect of making the metal gold cheaper in comparison with other things generally?

When banks, by furnishing security to the government, can obtain, without eharge or other limitation, money with which to replenish their necessary reserves, and so be independent of either the uncertain current of deposits, or the alternative of getting gold for the purpose, it is altogether reasonable to expect that quantities of that metal, now held

s's Ricardo, P. 284. 
in banks and treasury vaults, will be put upon the market. That this increase of its market supply would result in a fall of its value is self-evident and is illustrated in diagram Fig. 11. As the amount $O V$ becomes less, the value of gold will not remain equal to $q^{\prime} a^{\prime}$, but will approach the rate $q a$ (108). In other words, prices will rise. This can, however, have no worse effect upon business than does the rise of prices usually observed when activity returns after a spell of business stagnation. Moreover, as this fall in the value of gold would be coincident with an abundant supply of gold in the market, an emergency requiring a delay of gold redemption under our proposed currency reform would hardly ever arise (296, 297, $303 a$ ). It should be borne in mind that this fall in the value of gold would be due to the liberation of gold metal now stored as reserve fund, and not to any increase of the volume of currency $(239 c)$. The value would therefore not fall in the same ratio in which the currency is increased, as the advocates of the volume theory maintain, but only to about the value that gold would naturally have, were it not used for monetary purposes. This rate is shown by the ordinate qa of Fig. 11.

Those authorities who insist that a material increase of currency, regarded by them as "inflation" (341), must lead to a proportional increase of prices, reason on the theory that the value of money is governed by its volume, a theory which we have found to be baseless. The followers of this theory, propounded by classic authority, have endeavored to elaborate and fortify it without eritically scrutinizing the premises on which it is founded. Under the influence of this school of economists this doctrine has been kept constantly in view in the enactment of our currency laws. The natural growth of commerce has been hindered through allowing ourselves to be guided by this misleading theory, whereby it is made to appear, as John Stuart Mill implies (2396), that an increase of the volume of currency would enrich the issuers of the additional notes at the expense of the holders of the previous issues. In reality, the prevailing laws, instead of preventing "robbery," as Mill puts it, actually gives to possessors of money and other capital the power to "levy a tax" on industry and commerce. 
To the end of meeting every objection that may be urged against the introduction of the proposed currency reform we should also carefully consider the question whether this reform can be introduced without harmful effects in one country, while the present system of limitation is retained elsewhere. The first result would naturally be an extraordinary development of industrial activity, shortly followed by a rise of wages and a fall in the rate of capital returns. This reduction of profits would furnish an impulse to the investment of capital abroad where higher interest rates prevail. Foreign exchange would rise as a result to a point where the exportation of gold would become remunerative, and this would tend to deplete the country of its stock of gold (303b). This would seem to endanger the stability of the currency redeemable in gold. There need, however, be no fear of such a result, because the low interest rate that impels the exportation of gold would at the same time favor the exportation of goods to such an extent that the payments for the excess of exported goods would soon reverse the flow of gold.

The financial history of Great Britain during the nineteenth century fully bears out this view. The rate of interest in that country was lower than in any other, and its export trade grew to unparalleled proportions, so that in consequence the gold market of the world became centred in the British metropolis. A relatively low interest rate was throughout that period coincident with an influx of gold.

32 I. The Increasing Cost of Living.-For some time past the conviction has been growing in the public mind that many of the existing industrial ills are traceable to defects of our monetary system. Many observers have become persuaded that the fault lies mainly in the instability of the value unit. The universal rise of the "cost of living" has of late attracted much attention and widespread discussion.

While a number of contributory eauses have been at work to raise the cost of living, the principal eause is no doubt to be found in the vast improvements made in the metallurgy of gold. Through the introduction of the eyanide process gold is now obtained with less labor and cost than formerly. The consequent lowering of the supply curve $S S^{\prime}$ of Fig. 11 accounts 
at once for a lowering of the value of gold. Where gold is the standard commodity, a general rise of prices is the inevitable consequence.

Among the various propositions directed toward establishing a value unit that shall be practically independent of the value fluctuation of any single commodity, the one most frequently considered is the establishment of a composite unit (31). In discussing the difficulties of introducing such a unit (111), we had not yet reached a point where we could properly deal with a project based on the idea that the value of money varies inversely as its volume, other things remaining equal. That project has been devised with the idea of maintaining the markct value of the schedule of commodities composing the standard at a designated sum, say, one hundred dollars, by the following method. The comptroller of the currency, or some like authority, is to compute, from the daily market reports, the current price of the schedule list of goods. Whenever this total shall be found to be greater or less than the prescribed sum, he is to withdraw or to emit currency, as the case may be. It is supposed that prices will thereupon obediently fall or rise, as the volume of outstanding notes is reduced or increased, restoring the value of the scheduled list of commodities to its prescribed sum. But, as we have learned (115125 ), this result would not ensue; hence the experiment would necessarily end in failure.

322. A Real Source of Danger.-The desire to establish an invariable standard of value takes a more dangerous turn in the proposal to establish a value unit that shall be independent of any commodity whatever. For some reason, the belief that legal-tender notes need not be redeemable at all, but that they are invested with value by the fiat of government, has gained considerable acceptance $(97 b)$. The advocates of this notion propose to issue legal-tender notes and simultaneously to abolish any and every commodity standard, maintaining that in this way an invariable value unit can be established. But as such notes would not be redeemable in any definite quantity of a specified commodity, they could not be certificates of a definite debt, and accordingly could not possess any 
definite value (97a). Any attempt to put this idea into practice would surely add another to the many failures of projeets of this kind recorded in history.

When men like Law and Mirabeau obtained the power to carry out their schemes, they flooded their country with fiat notes which at first circulated on basis of the popular belief in their validity. But they soon depreciated, and finally their worthlessness became generally reeognized, precipitating the country into ruin and misery. Instead of a blessing, these issues beeame a curse.

These and similar failures are frequently ascribed to "inflation," that is, to the issue of more money than was needed, while in reality they were due to the fact that these notes were in no way redeemable. Whenever eurrency notes are put into eirculation, the issuing power obtains things or services for mere pieces of paper, or at most mere promises to pay. The issuing authority should therefore be considered as having obtained a loan, and unless it is made responsible to pay this debt in the end, no one else can be expeeted to do so in its behalf.

The "fiat" notion of the value of money is a twin brother of the volume theory. Both ideas are based on the untenable proposition that the value of money is due to the demand that exists for a medium of exehange (115). The disastrous experienee of "wild-cat banking" (103b) is no doubt to be attributed principally to the prevalent aceeptation of the fiat theory. The Ameriean bankers of the middle of the nineteenth century misinterpreted the expcrience of the goldsmiths of past eenturies (103a). Imbued with the notion that the notes they were issuing possessed value because they supplied a demand, these bankers eonsidered that nothing more than a small eoin reserve was necessary to sustain their value. Under this erroneous impression many banks dissipated their assets, and when the time of reckoning eame they were unable to meet their obligations and failed.

The advocates of both the volume and the fiat theories often point to our past experienee with greenbacks and the similar experience of a number of European nations with depreciated 
eurrency as a proof that the value of the "money unit" is independent of the value of either gold or silver or any other commodity that may be adopted as a standard of value (112), taking as evidence the fact that specie rose to a premium during the period of the irredeemable greenbacks and disappeared from circulation. That the phenomenon can be satisfactorily explained without recourse to the phantastic notion that value can inhere in money consisting of nothing more than pieces of paper legalized to serve as money has been shown before (96).

323. The Land Question.-In our analysis of the factors which come into play in the determination of land values we were unable to bring the study to a final conclusion (185), since at that point the causes of the interest-returning power of money and capital had not been traced. In the light of our subsequent conelusions we may now proceed to give the land question final consideration.

Rent, in the economic sense, being the share of the net income of productive groups which normally accrues for the use of the land, is determined, as will be remembered, by deducting from the market value of the produce of a productive group all costs of production apart from any eharge for the use of the land (173). The process by which rent is determined was illustrated by the diagram Fig. 20, and may be briefly revicwed as follows:

Since the different elements making up the total supply of a given commodity are produeed in different localities, their production and transportation to the market require varying expenditure of labor and capital. By arranging the different elements of the supply in a rising series of cost, we obtained the curve $S S^{\prime}$. The conditions of demand being represented by the curve $D D^{\prime}$, it was shown that normally the quantity brought to market equals $O q$, and the value adapts itself to the ordinate $q a$. The element $q^{\prime}$, for instance, is produced at a cost equal to $q^{\prime} s^{\prime}$ and has a market price equal to $q^{\prime} r^{\prime}$. The user of the land from which this element comes is therefore able to obtain in the market a service equal to $q^{\prime} r^{\prime}$ in exchange for a serviee equal to $q^{\prime} s^{\prime}$, gaining a profit equal to $s^{\prime} r^{\prime}$, which is "rent." 
When the diagram was applied to the question of wages, and the curve $S S^{\prime}$ represented the price limit from the standpoint of the workman, that is, his earning capacity in his alternative occupation, that of his second choice, the fact that the limit of any one of the intra-marginal producers was below that of the marginal one did not and could not imply that the personal service rendered by this intra-marginal producer was less than that rendered by the marginal one. It only indicated that the degree of his capacity in his occupation of first choice materially exceeded his capacity in his occupation of second ehoice. But when the diagram is applied to the question of rent, the differenees between the varions ordinates represent actual differences in the measure of effort expended, or of serviec rendered, by the users of the different plots of land in the production of equal quantities of produce. Any user of intramarginal land, say of the land which yields the element loeated at $q^{\prime}$, when he sells his produce obtains in the market the greater service $q^{\prime} r^{\prime}$ in exchange for something which requires for its production the lesser service $q^{\prime} s^{\prime}$, and the excess $s^{\prime} r^{\prime}$ namely, the rent-is furnished by those who, owing to the circumstances of the case, must produce and pay this excess (180, 329).

That the surplus $s^{\prime} r^{\prime}$ is primarily acquired by the user of the land, and, if the user is not also the owner, subsequently by the owner, has been shown before (171).

324. The Right of Land Ownership.-The right to acquire the rent is universally coneeded to the landowner. There is, however, a duty imposed upon him, namely that of paying the land tax, and, as we have already seen (184), through this tax he is obliged to share the rent with the community in a certain proportion. But he retains the greater share for himself, and our next task is to find the basis of his right to that share. We know that he is the owner of the land by virtue of a communal concession. But what is he doing to earn the share of the rent which he retains? Is he returning an equivalent service? IIas he done aught that justly entitles him to this revenue, or is the community making him a gift of it?

Falling back on fundamental premises (21), we must re- 
gard the right of private ownership of land as a right of exclusive possession or control which exists by virtue (1) of the tacit consent of the community to leave the owner in possession, and (2) of the effective protection of that possession by the community. The owner of land thereby acquires an advantage, in so far as the products of intra-marginal land have a value that yields not only a return for the effort of production, but also a further return in the shape of rent.

325. Land Laws Examined.- Whether the right of private land ownership is equitable or otherwise may be examined through a comparison of the rights and duties involved (20).

The benefit which the landowner derives from the ownership of land is rent. This being primarily derived from the community at large, the only return required of the landowner which can be considered as a duty is his obligation to pay such tax as the community levies on the land. The right and duty can be contrasted as follows:

The right of the landlord accords him the rent, while his duty is measured by the land tax he is obliged to pay. Conversely, the right of the community consists in realizing the tax, and its duty consists in protecting the owner's exclusive right of possession and use, which includes the right to sell the products of the land at their market value. Since the value of products obtained on intra-marginal land exceeds the costin other words, the value of the service-of their production, it follows that the eommunity, in buying those products, gives a creater service, represented by $q^{\prime} r^{\prime}$ (Fig. 20) in exchange for a lesser service, measured by $q^{\prime} s^{\prime}$, the excess $s^{\prime} r^{\prime}$ being rent.

In our former analysis (184) we found that the tax levied on land is but a comparatively small portion of the rent. Accordingly, the landlord obtains from the community something of which he gives only a fractional part in return. The community gives something for which it obtains less than an equivalent. This is true whether the rent is of agricultural, of commereial, or of industrial origin. The principle remains the same. It follows that the service obtained by the landowner by virtue of his right has a value greater than the 
service rendered by him as a duty. Conversely, the service which the community renders to the landlord as a duty has a value greater than the service which it obtains as a right. Right and cuty, in the case of land ownership, are not evenly balanced. Hence the present form of land ownership, in so far as it embraces the right of the owner to keep for his own use a portion of the economic rent, is in principle clearly inequitable.

This inequity becomes strikingly apparent where the land is leased to a tenant. In that case the landowner ceases to be the user of the land, but still gets the surplus of the service rendered by the community over the service rendered by the tenant. Although doing nothing more towards establishing and maintaining the right exereised by the tenant than any other member of the community, he yet continues to get the difference between the value of the right-the rent-and the cost of the duty-the tax.

In studying the composition of productive groups (143) we considered the owner of the land which was used by such group to be one of its members, performing a service for which he receives the rent. We now find that this service is not really performed by the landowner, but by the community in general. In an equitable state of affairs this rent should, aceordingly, go to the community and not to the landowner (368). There is evidently a certain measure of inequity involved in the present system of land tenure.

326. Land Ownership a Vested Right.--That the system of absolute land ownership is essentially inequitable has been recognized by various thinkers since the time of Moses, whose ordinance of the Jubilee Year was ealeulated to remedy the injustice. Similar considerations form the basis of the plan of land tenure known as the "single tax" system. However, this plan is regarded by many as embracing an element of injustice similar to that which it is intended to eorreet. The imposition of a tax on land equal to the economic rent would, according to Henry George, have the effect of reducing land values to nil, or, as he puts it, confiseating land values (359360). A reform entailing such loss on landowners would 
naturally be resisted by them. Land ownership is a vested right acquired by owners from the community and assured to them by law. When land first became private property, it was in most cases no-rent land, and as such had practically no value. The value which land now possesses, apart from the value of the improvements produced by labor, has been acquired by land in the course of time. Why, it may be asked, should the present owner be deprived of the value which the land has acquired throngh centuries, when this value has arisen without cost to anybody?

It is this last supposition which is open to question. While it is indeed true that land value has arisen without a direct cost to anybody, this increase of value has been coincident with and due to a burden which the community has taken upon itself. Land has acquired its value only as it has acquired the capability of yielding rent, and, as we have seen, rent is what is left of the value obtainable from the land after all costs of producing this value has been covered. This rent is paid by the community, whether through payment for cabbages produced on the land, or for convenience of shopping in the centre of a business district, or for the luxury of a seat in a theatre. Through the purchase of the products of intra-marginal land the community contributes to the owner of the land a revenue which he gets without returning to the community more than a portion in the form of land tax. That which remains to him, when capitalized at the prevailing interest rate, stands as the value of land. The community is in fact paying what is analogous to interest on a debt equal to the value of the land (329). The right of land ownership, as it stands now, is clearly a remnant of the feudal ages which enables the landowner to obtain from the community an income which he does not earn.

It is, however, easier to point out the inequity of the cxisting system of land tenure than it is to formulate a practicable plan for correcting the injustice. The right to the exclusive possession of land is necessary to induce men to cultivate it, to improve it, to place buildings on it. It often takes years before the full benefit of labor bestowed on land can be realized. Justice demands that this benefit be assured to those who make 
the improvements. Unless he who eultivates or otherwise improves the land is proteeted in the ownership of the fruit of his labor, our civilization must fail. Unless a reasonable remedy is instituted, the cure may be worse than the evil. Such remedy must have the effect of depriving the landowner of the right to get something for nothing, but must leave to him the full benefit of his own effort in utilizing the land.

327. Bearing of Currency Reform on the Land Question. -However involved the problem may appear at first glance, it will be found, upon closer examination, that with the money monopoly abolished, no radical change in the system of land tenure would be necessary to work it out.

Our analysis of the eauses that determine the value of land shows that the yearly gain yielded by land, consisting of rent plus increment, $R+U$, is divided into two parts, $T$ and $I$, of which $T$ goes to the community in the form of land tax, while the remainder $I$ is retained by the landowner. We also found that these two parts are related to each other in the proportion which the actual rate of taxation $t$ (182) bears to the eurrent rate of interest $i$ (184).

It has been shown (315) that with the removal of existing monetary restrictions the eurrent rate of pure interest would fall to nil, and, according to the rule by which the division of the gain derived from the ownership of land is determined, as stated above, the land $\operatorname{tax} T$ paid to the eommunity would increase until it equals the entire gain $R+U$ yielded by the land. The portion $I$ left to the landowner would accordingly diminish to the vanishing point. Thus, with the abolition of the money monopoly the inequitable feature of the present system of land tenure would automatically fall away, inasmuch as that whieh would be returned to the community in the shape of tax would fully balanee that which the landowner gets without earning it (371).

328. A Concrete Illustration.-The process by which these results would come to pass may be readily understood if presented in the form of a concrete illustration.

Let us first take the case of a piece of land whieh has been returning an annual rent of $\$ 900$, and the value of which has 
remained unchanged during a number of years. Let us also assume that the actual tax rate $(182 a)$ is 2 per cent.

Supposing that the current rate of interest on fully secured loans had been 4 per cent., the value of this piece of land would have been $\$ 900$ capitalized at $4+2$, that is, 6 per cent., which would come to $\$ 15,000$ (183). The tax was accordingly $\$ 300$ and the landowner's share $\$ 600$. This land therefore represented an investment returning a net income of 4 per cent.

This would not continue under the operation of a currency system by which money and eapital goods would lose their power to command pure interest. It is clear that the demand for land as an investment would then be greater than the supply, for land would be in demand as the only form of capital bringing a net return, while the supply would eease, since the landowners would not exchange their paying investment in land for money or capital goods that do not bring a net return. This exeess of demand would naturally cause land values to rise $(360)$. But how far would they rise?

Let us assume that as much as $\$ 30,000$ was bid for the piece of land in question. In the ease of a sale at that price this would be followed by a eorresponding increase of its assessment. The annual tax would then amount to $\$ 600$, leaving for the owner of the land a clear profit of $\$ 300$. This land would then still be a profitable investment, while money and capital goods would not command pure interest, and consequently no unearned profit. Competition for the possession of this land would then tend to raise the value still higher. Since competition for the possession of land would continue as long as it affords a revenue not afforded by money or by capital goods, the bidding would go up as high as $\$ \pm 5,000$, when the 2 per cent. tax would absorb the entire economie rent of $\$ 900$, bringing the income from investments in land to a par with that from other capital investments.

Now let us suppose furthermore that the piece of land in question not only returns an eeonomie rent of $\$ 900$, but has, for some years past, shown a yearly increment in value of $\$ 300$. This will make the expected gross gain $\$ 1200$, and the value of the land would naturally be greater than in the preceding 
ease. Beginning again with an initial eondition of current interest at 4 per cent., a tax rate of 2 per eent. and the value of the land at $\$ 20,000$ (182b), the $\operatorname{tax} T$ would be $\$ 400$ and the net income $I$ of the landowner $\$ 800$, or 4 per cent. of the investment. With the elimination of pure interest from the returns of other forms of capital, competition for the land in question would raise its value, and thereupon the tax on it, until the value reaches $\$ 60,000$, making the $\operatorname{tax} \$ 1200$ and leaving no net gain to the landowner.

We have here been basing our deductions on the assumption that the increment as well as the rent is a given quantity. But our figuring shows that under the assumed circumstances the increase of land value would go on very much faster than the rate assumed. We had assumed $\$ 300$ to be the normal yearly increment of the value of the land in question, assumed to be lue to an increase of rent, and our illustration shows that within a comparatively brief period the value of this land would rise from $\$ 20,000$ to $\$ 60,000$, and this even independent of that increase of rent which is ordinarily the cause of the unearned increment. But this phenomenal advanee in the value of land would be the outcome of extraordinary economic changes, characterized by the gradual disappearance of pure interest. This rise of value would come to a halt when the period of transition is past, and a further inerease would thereafter take place only if the rent or the normal inerement were greater than above assumed, or the rate of taxation were to be reduced.

The results shown in the above illustrations do not conflict with the law of land value heretofore stated, our deduetion of that law having necessarily proceeded without taking into consideration possible extraneous influences, such as a fall in the rate of interest to the point of disappearance of the pure interest item.

It is of course altogether probable that an extraordinary increase of land values would be attended by great speculative activity which might even enhance them beyond the level of the final adjustment. In that event a reaction would set in after the current rate of interest has found its lowest level. It 
can safely be predicted that when land values have become finally adjusted, the tax on land would have risen to a point where rent plus increment, $R+U$, goes to the community, supposing, of course, the assessment of land values being properly made. Such return of rent is the principal aim of the single-tax propaganda, but would be brought about automatically by the far more comprehensive reform of removing the existing arbitrary impediment to the freedom of production and exchange (364).

329. Land Values Tantamount to a Public Debt.-From the above it is plain that a reform of the currency in the direction here proposed would have a controlling influence on the conditions of land tenure, inasmuch as it would have the effect of equalizing the duty of the landowner with the right enjoyed by him. Such land as has a comparatively stable value and which promises no unearned increment would normally have a value on which the land tax equals the economic rent; and where there is reason to expect the value to rise or to fall, this expectation would be reflected in the value of the land being greater or less than the rent capitalized at the rate of taxation, so that the amount of the annual tax would be above or below that of the economic rent to the extent of the expected annual increase or decrease of the value of the land.

We may again reiterate that where actual facts are at variance with the theoretical conclusions derived from economic laws, these variations are to be attributed to chance factors, just as the scattering of the shots of our illustration (1) is due to the unsteadiness of the marksman's aim. We have found that land values exceed the capitalized rent only if a rise in the value of the land is anticipated by the competitors for the purchase of the land, hence the tax would in general differ from the rent by the anticipated advance or decline of land value. If through some unlooked-for occurrence the actual increase or decline in value is greater or less than expected, our conclusion that the difference between tax and rent equals the increment or decrement, as the case may be, would to that extent be at variance with facts. Where there is a uniform change of conditions, such as a gradual rise of the rent due 
to a steady increase of population, or to a gradual diminution of the current interest rate, the increase of land values from year to year is correspondingly uniform, and the expectation of that increase, based on past experience, is usually realized. But if changes out of the ordinary take place, the actual advance or decline of land values will not agree with the anticipation. It is reasonable to assume that ordinarily such adventitious influences are as likely to affect land values one way as another and that, with rare exceptions, their effect in the long run tends to balance.

Supposing that there had never been an actual scarcity of money, and that money would therefore never have had the power to command interest; supposing also that land ownership had always been conditional on the payment of a tax, at a fixed rate $(332 a)$, on the value of the land: it would follow from what we have learned above that the taxes paid on land would always have been about as much as the rent derived from the land plus the increment of its value. The community would then not only have been paid for what it furnished in the form of rent (323), but would also have gotten the value of the attendant increments. The owners of the land would therefore be justly entitled to all the increments which make up its full value, having paid that much to the community for the right of owning the land (288). This value would virtually represent a debt due to the landowners by the community, payable whenever the community requires to get possession of the land $(326,334)$.

But the actual cconomic conditions differ from those of this hypothetical case. Monetary systems everywhere are defective and have always been so (261), and the item of pure interest has therefore always been a potent factor in determining the apportionment of incomes. With competition hampered through restriction of the freedom of exchange, land ownership has not been eonditional on the payment by the landowner to the community of a tax equal to the economie rent plus the increment of land value. As the case stands, the community has all along not only, as it were, released the landowner from the payment of a full equivalent for the protection 
and benefit rendered him by the community, but also left to him the greater part of the increment of the land value, thus incidentally saddling itself with what is tantamount to an obligation to the landowner, to the extent of the value of the land. Hence it will be readily understood that any increase of the value of land, in excess of the tax paid on account of that increase, is a direct and unearned gain to the landowner which virtually takes the form of a debt owing to him by the community, and which is thus correspondingly a loss to the community (216).

That the value of land is in the nature of a debt owed by the community to the landowner is plain enough from the fact that the public is now constantly providing what amounts to an interest charge, accruing to the landowner as "rent."

The adoption of a measure of currency reform that would remove the restrictions on the freedom of exchange would not be followed by an increase in the market value of land, if coincidently with that reform the tax rate on land would be increased in the same measure as the current rate of pure interest falls, thus leaving the sum $t+i$ unchanged. But such a constant adaptation of the tax rate to the falling interest rate being obviously impracticable, a rise of land values resulting from the fall of the interest rate is inevitable. Such an increase would of course be an unearned gain to the landowner at the expense of the community (332b). But whatever loss this might entail on the community, it would be of trifling moment as compared with the cost of trying to attain social justice on the plan of either socialism or the single-tax, only to find that the one is impracticable (365-367) and the other inadequate to effect a just distribution of wealth (364).

Our successive deductions have enforced the conclusion that a removal of the existing restrictions on the medium of exchange would bring the market value of land to a higher figure than at present, notwithstanding that the owner of land could no longer derive from its ownership anything more than what would be the wages of his own labor applied to it, since he would be paying a tax amounting to the sum of rent and increment, $R+U$, which the land affords. 
This is directly opposed to the eonclusion reached by Henry George and accepted by his followers, that land would no longer have any market value if the tax were suffieiently high to absorb the entire economic rent. In the absence of land value, an inerement of such value would, of course, be preeluded.

Land values would eertainly vanish if no net return could be gotten from land, while eapital goods and money continued to afford such revenue. If, however, pure interest could no longer be obtained from money or capital goods, the conclusion that land values will disappear does not neeessarily follow. Were the community to continue to impose a tax on land at a given percentage of its value, such value would necessarily continue, and its amount would be determined by competition for the possession of the land as outlined above (327-328). The value would go up to the point where the land would cease to bring to its owner a net return, for so long as it yields such return, while other forms of eapital do not, competition for its possession would drive up its value until the value reaches that point.

The value of land which afforded no unearned gain to the owner would be quite analogous to the value of treasury notes which afford no interest to their holder, both alike representing a debt owing by the community.

330. Assessment of Land Values.-If a tax is to be inlposed on the value of land, that value would have to be determined for purposes of taxation in some manner preseribed by law. The rise of land values which, as we have seen, would follow the institution of a proper eurreney reform, would require a re-assessment, from time to time, and with any delay of this re-assessment the amount of the tax would remain below the amount of the economic rent and inerement, leaving an unearned income to the owner of the land.

So long as this appraisement of land is delegated to men eleeted or appointed to office, their determination is likely in numerous instances to be more or less inaccurate. There are, however, ways in which it may be possible to ascertain the 
market value of land with reasonable accuracy, and this with less expense than by official appraisement.

Suppose provision were made to let every owner of real estate be his own assessor and to levy the tax on his appraisement. Undervaluation could be guarded against by providing that if either the government or any individual should offer to purchase the property at a price exceeding this assessment by more than, say, ten per cent., the owner must either raise his assessment to within the ten per cent. of the offered price, or sell at that price. Under such rule each property owner would find it to his interest to record a fair value, for if he were to assess the property at too low a figure, some one would sooner or later bid high enough to compel increase of assessment or sale. To meet cases where sentimental or other psychological considerations come into play, as in the case of homestead holdings, or in the case of a business having a "goodwill" value, or to guard against spite work, adequate regulations would of course have to be provided.

331. Exemption of Fixed Improvements from Taxation. -Under such a method of assessment as above outlined, the tax would evidently be levied not merely on the value of the land, but on that of all fixed improvements as well, for a sale would inevitably include these improvements. Any plan of taxing land by which not more than its economic rent and its normal increment of value is to go to the community must logically exclude improvements from taxation. This is quite in conformity with the single-tax idea generally. It would accordingly be necessary to deduct the estimated value of the improvements from the total, in order to exempt from taxation those improvements, whether they be in the form of buildings erected on the land, or of woodland or fruit trees planted upon it, or of clearing, of draining, of irrigation. Where the improvements are naturally subject to deterioration, the value of the estate and that of the improvements shrink together, leaving the value of the land unaffected, unless the factors which determine land values have changed at the same time. In the case of such improvements as become incorporated in the land (171), as in levelling it for cultivation and clearing it of 
rocks, the improvement should be given consideration in the assessment, at least for a number of years, on the same principle as that on which invention is protected by letters patent.

The importance of exempting fixed improvements on land from taxation is generally overestimated. It is often said that a tax on that part of real estate which is produeed by labor is a tax on industry ; but this view can hardly be sustained. Only where the improvements consist of dwellings, gardens, private parks, etc., and are used and occupied by the owner, will the tax have to be borne by the owner; and apportionment of the eost of public protection in proportion to the requirement for that protection is not inconsistent with fair play. Where, on the other hand, land is used for industrial or commercial purposes, a tax assessed on the value of buildings and other appurtenances of the business, unlike that assessed on the value of land, bears on marginal producers as well as on all others, and for this reason must be borne in the end by the consumers of the products of the industry. It is therefore by no means a tax on industry, but rather a tax on the community, inasmuch as the consumers of the products of industry are distributed throughout the community.

However, since the tax on land values alone would probably yield a public income fully adequate to meet all legitimate requirements of government, it may be found expedient to take the measures above suggested for reducing the tax on real estate to one on land values alone.

332. The Tax Rate.-In reaching the conclusion that the tax on land values would absorb eeonomic rent and normal increment if the eurrent rate of pure interest falls to nil, no specific rate of taxation was required to be assumed. No matter what the rate of taxation might be, rent plus increment would go to the community. If the tax rate were low, land values would rule at a higher figure; with a higher tax rate they would be correspondingly lower. In short, the value of land independent of improvements would tend to become equal to rent plus increment eapitalized at the rate of taxation, and assuming that value to be correctly appraised, the total land 
tax would ultimately equal the economic rent plus the expected increment.

This line of reasoning does not apply to a tax on improvements, since their value is determined by the marginal cost of their production (153), which, apart from incidents of chance, is not affected by the rate of land taxation. Moreover, the proposition that land values would equal the sum of the excess of taxes paid on land over rent, if pure interest had never come into play, is true only on the supposition that the tax rate had never been changed (329a), for otherwise the value of land would not agree with the excess of taxes paid.

If the tax rate were changed any time, injustice would be done either to the landowners or to the community. Suppose that from the first institution of private land ownership the rate of taxation had been fixed and that the currency system had always afforded full freedom of exchange, so that now land values, generally speaking, really equalled the excess of taxes over the rent derived from the land, then a raising of the tax rate, in depressing land values, would be an injustice to landowners equivalent to a partial repudiation of a public debt due to them; and, vice versa, a lowering of the tax rate would increase land values and would thus without cause increase the quasi public debt due to landowners, and this would be unjust to the community. An invariable and permanently fixed tax rate on land would therefore be one of the essential conditions of just land laws, and such rate should ultimately be established once for all.

In the adoption of this tax rate the interests of both landowner and community would have to be duly considered. As it is impossible, by any plan whatever, sharply to separate the value of land from that of its improvements, it may often hap. pen that the value subjected to taxation actually includes part of the improvements, and in order to minimize such injustice as might thus arise, the tax rate should be low. But, on the other hand, a low tax rate, entailing a corresponding rise in land values, would materially increase the unearned advantages which, through a falling interest rate, landowners would obtain at the expense of the community (329b). 
Suppose a rate of 2 per cent. to be adopted, land values would rise to fifty times the annual rent plus inerement. But as this quasi debt of the community to the landowners would be free of interest charge, it would not be felt by the community, but would have to be met by future purchasers of land.

333. Land Tax Ample for Public Needs.- When the public revenue from land taxation takes in the sum-total of all rent plus increment, as it would through an effective currency reform-and no change in the tax rate could more than temporarily affect this revenue-the public receipts from this source would greatly exceed the sum of all taxes now collected by towns, counties, states and nation. All other taxes could therefore be dispensed with and the entire system of taxation simplified. The towns or counties might collect the land tax and transfer a certain portion to the states, and these, in turn, a due proportion to the national treasury. The total income may reasonably be expected to be so great as to make bonded public debts wholly unnecessary, and those existing could be paid off as rapidly as they mature $(288,341)$.

It would probably come to pass under such a system of taxation that the revenue would exceed the necessary expenses of government, and the question of how equitably to dispose of the balance would thus arise. A similar problem has been met in some German towns which own land, the income of which exceeds municipal requirements, by returning the excess to the citizens in the form of dividends. Whether such a system would be practicable generally can only be determined by experience. It would certainly have a salutary effect on voters, every one of whom would have a tangible interest in the honest and economic application of the public funds. But be this as it may, there are many other ways in which any excess of public revenue over the immediate costs of administration might properly be expended. Schools, hospitals, libraries and other similar institutions which now depend on endowment incomes that would practically cease with the elimination of pure interest, could easily be supported from this tax, and a system of pensions for old age and other disability could be 
instituted. In short, numerous social problems could be rationally and effectively solved.

334. Exclusive Rights or Franchises.-The greater number, if not all, of the public service franchises granted by municipal, county and state governments, involving exclusive rights to construct and operate railways, to lay gas, water or electric conduits, to run overhead wires, and so forth, assume more or less the character of exclusive rights to the use of land and may therefore properly be treated as a modified form of land ownership (231). All that has been said regarding land values fully applies to the value of such franchises. As in the case of land, distinction is to be made between the value of the mere franchise and the value of the improvements which are essential to its utilization. The former may be traced to a "rent," namely, to net profits derived from the utilization of the franchise; and in addition to this there is also generally an "unearned increment."

Whenever the value of a franchise exceeds the value of the capital invested in its utilization, in other words, whenever a franchise as such has a market value, it is generally supposed that this value is a creation of law. This view is, of course, erroneous, for law cannot create value. Men can get richer through the mere operation of law only at the expense of other men or of the community. What was said in regard to the nature of land values (329) is equally true as regards the value of franchises.

It has been the practice to grant franchises for periods of 99 , or even 999 years, notwithstanding that our descendants may refuse to be bound by our extravagance in this respect. A number of these franchises have attained a value many times exceeding the total capital invested in the necessary improvements. Some even now return an annual income exceeding the total capital really invested, and are likely to return a constantly increasing revenue.

A franchise once granted cannot be annulled by the courts on the ground that it was injudiciously granted, without resorting to revolutionary methods. For this reason the power 
ereated by these grants is viewed with serious misgiving by many observers who realize the gravity of the blunders committed in giving away these exclusive rights. Yet these rights are not any more detrimental to the community than the present system of land ownership, and far less so than the present eurrency system, under which there is created what is practically a monopoly of the medium of exchange.

The injustice to the publie interests arising from improvident grants of franchises can be corrected by a system of taxation, on the same plan on which the land question may be solved. All unearned acquisition through public-service rights may thus in the end be effeetually stopped. A tax analogous to the land tax could reasonably be assessed on the value of franchises, the owner or owners to report the value, or, if the franchise is held by a stock company, to report the value of the stock, with the proviso that any bona fide offer for the franchise exceeding the assessed value more than, say, ten per cent. will be the basis of a new assessment within the ten per cent. of the offered price. If a two per cent. tax were adopted, our penalty for corrupt or shortsighted grants of franchises would then be reduced to a quasi public debt equalling the profits due exclusively to the franchise itself for a period of fifty years.

An equitable solution of the currency question would thus at once limit the harm resulting from past mismanagement of public trusts and at the same time put an end to the acquisition of unearned values by owners of land and holders of franehises. 


\section{CHAPTER XVIII}

\section{OLD PROBLEMS IN A NEW LIGHT}

335. Diagnosis of the Economic Disorder.-The task of a physician in treating a patient is of a threefold nature. $\mathrm{He}$ has first to examine the patient's condition to learn the symptoms by which the disorder manifests itself. On the basis of this information he then determines the source of the trouble, and finally he preseribes the remedy in accordance with his diagnosis. If his treatment is to work a cure, he must make sure that his diagnosis is correct, for unskilled experimenting might be the undoing of the patient.

Just as symptoms of congestion of one organ, or emaciation of another, point to a diseased condition of the patient's system, so the accumulation of enormous wealth in the hands of a few, while vast numbers of the real wealth producers obtain but a bare subsistence, and in times of industrial stagmation face even the lack of that, points to a similar morbid condition of the economic system. Whatever course of treatment is to be undertaken to eure the ills of the body social must, as in the case of the body physical, be based on a rational examination, lest the "cure be worse than the disease."

The strictly deductive line of investigation pursued in the foregoing pages has consistently led ns to the conclusion that the underlying cause of the economic disorder is the legalized restriction of the right to use credit as a medium of exchange, a conclusion which, though confirmed by all the symptoms of the social disease, is not in agreement with the accepted tenets of the modern school of economics. According to these tenets money and capital are justly entitled to pure interest, although all of the several theories on which this claim is based are controvertible. According to one theory, wealth employed in the processes of production earns a share of the proceeds by the assistance it renders to labor. According to another, the reluctance of men to save what they have produced, in order 
to use it for purposes of further production, can be overcome only through the payment of a recompense. According to a third, future goods are underrated as compared with the present, and the waiting attending the growth of future into present goods is rewarded by a corresponding "agio" or increase. Labor's recompense is supposed to be subject to an economic law which eauses it to tend to the minimum necessary for subsistence. Books upon books are written, and theories of wages and theories of interest are invented in the attempt to prove that things cannot be otherwise than they are. Sociologists in the halls of learning are teaching, and legislators in congresses and parliaments are formulating into law, the misconceptions of economic principles and the misinterpretations of economic history which have come down to us from the past. The economic disorder which becomes manifest as business stagnation is variously diagnosed as due to overproduction, to speculation, to bad investments, to hoarding of money, to tinkering with tariff laws, to an undue expansion of eredit, to loss of confidence, to extravagance, and to any and every other imaginable cause. Industrial depression, with its attendant evil of widespread enforced idleness, is regarded by not a few serious thinkers as an unavoidable ineident of industrial progress. By others, again, the avarice of employers is regarded as the nltimate cause of low wages, and under this misconception workmen are urged to organize in order to overcome this supposed avarice by "collective bargaining" and to enforce their demands by means of strikes and boycotts. Still others hold that the existing system of land tenure is the principal cause of economic injustice and see in the reform of that system, through taxing land to the extent of the entire rent, a cure for the poverty of the masses. There are also many who look upon competition as the one great bane of the social system, to remove which it is proposed to "socialize" all proeesses of industry and commerce under a system of communal ownership of all means of production.

Whether the present currency system, which we have found to be the seat of the social caneer, is based on rational or irrational theories, whether the laws which put them in practice 
are just or unjust, the fact remains that these theories are generally regarded as true and the laws as proper and right. Just as the slave accepted his condition as a matter of course, just as the serf of the feudal ages bowed submissively to the laws which constrained his liberty, just as the people of the Orient, and in a measure those of contemporary Europe, regard the differences of easte as being in the natural order of things, so is governmental restriction of the medium of exchange looked upon as a measure necessary to protect its value. Our investigation, however, has made it plain that through the operation of this restriction, enforced by law, industry and commerce are subjected to an exaction as arbitrary and unjust as that imposed in the middle ages by robber barons on merchants passing their strongholds. The modern way of collecting this impost is more subtle, more refined than that of former times, but the result, the acquisition of unearned revenues by some at the expense of others, is as indefensible in the one case as in the other.

336. Capital Not Productive.-Physicists have long recognized the impossibility of devising a "perpetual motion." Chemists no longer seek for a "philosopher's stone." But in the field of economics capital is yet supposed to have the power to propagate itself through the operation of natural causes, notwithstanding that a self-creating power of capital is inconceivable. The fact is that the apparent power of capital to grow is really a power to acquire an unearned share of the results of labor performed by those who work.

The human race cannot continue to consume more than is produced. It follows that no one individual can consume more than he produces, unless some one else produces more than he consumes. Yet it is taken as a matter of course that wealth, once acquired, returns a continuous income.

Suppose a man to work until he is 50 years old and to produce wealth, all told, amounting to $\$ 40,000$. Suppose that during this time he consumes the equivalent of $\$ 20,000$ and. on retiring, invests his savings of $\$ 20,000$ at the rate of 5 per cent. Suppose, furthermore, that the yearly income from this 
investment, amounting to $\$ 1000$, supplies his subsequent needs, and that he dies when 75 years old, leaving the principal of $\$ 20,000$ to his heirs. Summing up, this man will have produced wealth to the amount of $\$ 40,000$, and after using up $\$ 20,000$ before he retires and $\$ 25,000$ after that, a total of $\$ 45,000$, there is still left $\$ 20,000$ to be shared among his heirs.

Existing economic conditions have enabled him to acquire $\$ 25,000$ more than he produced. How did this come about? That capital has no creative power and therefore cannot add value to itself has been amply demonstrated in our previous analysis (191-194, 257-267). The inevitable conclusion is that the $\$ 25,000$ received by him in excess of what he has produced represents wealth produced by others who, by the existing economic conditions, were deprived of it.

In this way many receive unearned incomes through the power of money. The fact that most of these are at the same time employed in productive pursuits and thus obtain earned wages as well as unearned gains only serves to obscure the fact that their capital profits are unearned.

It must, however, not be left out of sight that the owners of capital cannot be held individually responsible for these conditions, except in so far as they, as members of the community, are responsible for the perpetuation of the existing inequitable monetary system (267). It is the system which is at fault, and no altruistic capitalist, nor any number of them, can do more than sporadically alleviate the evil effect of the system. While the practice of the "Golden Rule" may result in ameliorating conditions here and there, it cannot stay the recurrence of financial crises and the consequent industrial and commercial disturbances.

In our various references to the "efficiency" or "productivity" of capital there would appear to be implied the assumption that capital in and for itself is productive. The fact that capital brings an income to its owner appears to afford an all-sufficient basis for that assumption. But our investigation has led us to the conclusion that the power of capital under existing conditions to command a profit for itself is not traceable to any quality or faculty inherent in it, 
but to extraneous conditions, namely, to restrictions placed on the freedom of exchange. It is through these restrictions that money is given the power to impose a toll on exchange and that capital acquires the power to impose a toll on production. If capital were really productive, we would let capital do all our producing and so escape the necessity of doing any kind of work.

337. The "Almighty" Dollar.-Since money and wealth have the power to bring to their owner a perpetual income, it is not surprising that the desire for wealth is uppermost in the minds of all, with the exception, perhaps, of here and there some altruistic idealist. The idea that the power to earn interest is a natural attribute of money and of capital is so thoroughly rooted in the minds of men that it is generally accepted as a matter of course. Everyone is striving to obtain a "competency," and only few stop to analyze this power of money and to trace it to its ultimate cause. The influence of this peculiar power permeates our entire social system, and the worship of money manifests itself in all details of every-day life. When a merchant sells his goods, he exchanges with his customer equivalent for cquivalent; yet when he is handed that equivalent in money, he is by custom impelled to acknowledge its receipt with a humble "thank you," although, in point of fact, the purchaser has more reason to be thankful, inasmuch as the merchant supplies some particular product which his customer wants and in return accepts a mere certificate of credit.

338. The Concentration of Wealth.-The singular power of money, without which neither economic rent, nor capital returns, nor pure interest could be acquired by the owners of land, of capital goods or of money, is directly responsible for the tendency of wealth to become concentrated in the possession of a comparatively small class of the community. Bacon already observed this tendency, for he characterizes usury as that which "bringeth the treasure of the realm into few hands."

We have already described (244-255) how it comes about that the indebtedness of the industrial to the financial world 
is constantly increasing and how numerous business undertakings are gradually forced toward bankruptcy. This process is a slow one, to be sure, and only comparatively few concerns become seriously involved, but the fact remains that the process is continually going on, carrying one business after another to the brink of bankruptcy, and not a few of them over it.

Some of these concerns, especially if extensive and normally prosperous, are saved from extinction through "reorganization," and in that case "financiers" generally gain control.

Owing to the restraint enforced through the existing currency and banking laws, banks are unable to supply all the facilities of exchange normally required for the conduct of business, and it is quite natural that those concerns which come into the control of banking interests are favored. The brunt of the system therefore falls most heavily on those who are not identified with financial agencies, and who, having to work without adequate facilities of exchange, are handicapped in competition and are finally driven from the field. The inability of such concerns to hold their ground is generally attributed to the operations of the financed concerns which go under the name of "trusts" and which are supposed to gain or to seek a monopoly power by "pushing their competitors to the wall." This, however, is simply a phase of the process by which wealth is concentrated and through which the most important industries gradually pass into the control of a comparatively few "captains of finance" (275, 364).

The so-called "trusts" are accordingly the natural and inevitable outcome of the money monopoly. They are usually regarded as being themselves monopolies, or attempts at monopoly, but they cannot properly be classed as such, except as they are in possession of special privileges. Apart from such privileges they are not legally protected against competition in their respective ficlds, but rather the contrary, and if they develop monopolistic power, they obtain it indirectly through their ownership or control of money or of land, especially mineral lands, or both. The oppressive power of "trusts" has its ultimate source and stronghold in the 
money monopoly, and only with the ending of that monopoly will those trade combinations which now wield a power akin to monopoly lose this power.

339. Efforts to Curb the Concentration of Wealth.-The steady growth of enormous fortunes in the hands of a comparatively few individuals, which has become so marked a feature of our industrial system, has come to be regarded with apprehension lest the continuance of this growth lead to intolerable conditions. Out of this apprehension has arisen a disposition to counteract this growth through legal measures. Although the idea of definitely limiting the wealth of individuals, while not without advocates, is nowhere seriously entertained, methods liaving the same tendency, such as graduated inheritance and income taxes, have been enacted into law.

Such measures are, however, inadequate to establish justice or to prevent the accumulation of unearned fortunes. Graduated taxation is imposed equally upon wealth acquired through labor and upon that acquired through the operation of unjust laws. On the one hand such taxation penalizes industry and thrift, while, on the other, it recovers only a small share of the unearned incomes. Moreover, this share goes to the community without affording redress to those who have been deprived of the full fruit of their labor.

340. Corporation and Bankruptcy Laws.-Statistics show that a very large percentage of all business undertakings meet with failure within the first one or two decades of their existence. Of these failures some are doubtless due to misjudgment or incompetency. Others are due to losses sustained through unforeseen causes, and a number are fraudulent. But over and above all these there is a long and continuous list of business failures which are due to the general financial stress (255). Numerous concerns which are staggering under the burden imposed on industry by the faults of our financial system are precipitated into bankruptcy through no fault of theirs, but through the disastrous working of that system.

It has been in recognition of the blamelessness of such bankrupts that laws imposing imprisonment for debt have been abolished, and in their place provision has been made 
for the release of bankrupts from all debt remaining after bankruptcy proceedings have been consummated. And if an ineorporated company becomes bankrupt, the claims of its creditors are limited to the actual assets of the corporation. By virtue of this limitation the claims of creditors cannot be extended to the individual members of the corporation, and the creditors lose more or less of their elaims, notwithstanding that the individual members of the company may be possessed of ample wealth.

Such protection is apt to be abused. It presents a temptation to the undertaking of speculative ventures whose promoter's have everything to gain from success, while in the event of failure the loss falls, at least in part, on others. Although the intent of the law is good, it has the effect of affording undue protection to unserupulous men.

A reform of the money system that would permit sound business credit to be monetized without the inequitable tribute of pure interest (246-255) would result in a condition where no business man entitled to credit need lack money. A delay in the payment of accounts would be elear evidence that the debtor is not entitled to further trust. Inasmuch as the same reform would remove the present ineubus on business, the temptation to take risks in selling goods on eredit would be lessened, and unpaid accounts would not pile up as now (312, 314). Thus the one great cause of bankrupteies would be removed, and the legalized limitation of liabilities would no longer be found necessary for the protection of legitimate business.

341. Public Debts.-When interest-bearing publie debts are contracted, it is generally held that the borrowed money should be used only for permanent improvements, and that all current public requirements should be covered by taxation. Inasmuch as permaneut improvements will inure to the benefit of suceeding generations, it seems proper that they should bear a share of the cost of the work, and it is generally supposed that through going into debt for the improvements and leaving it for posterity to pay the debt, we make them 
bear a share of that cost. But when critically examined, this supposition is found to be a mistake.

One thing is certain. We cannot in any way make posterity help us to do the work of making those improvements. Such public property as national defences, roads, bridges, waterworks, public buildings, sewers, etc., must be completed before we ourselves can reap any benefit from them, and the future generations cannot help us to complete them.

If, then, they cannot lend us any help in this direction, in what other way can we make them assist us? Can we really do so by going into debt?

Posterity inherits from preceding generations all wealth which these have produced over and above that which was consumed or destroyed; no more, no less. Debts transmitted cannot affect the total inheritance of succeeding generations for the simple reason that the inheritance includes the credits as well as the debts, and the sum of all credits necessarily equals the sum of all debts. And if the future generation gets from its predecessor neither more nor less, whether or not it inherits a public debt, it would seem that the present generation can in no way be benefited by incurring such a debt.

When public improvements are undertaken, as when a system of sewers is being built, the workers must be compensated for their services, and this is ordinarily done with money. This money can be obtained by the community in three different ways: (1) through taxation; (2) through the creation of a funded debt-by an issue of bonds; and (3) through the creation of an unfunded debt-by the issue of currency notes.

If, in the first place, the money is raised by taxation, and the taxpayer's are determined to let a future generation "do the paying," they must create debts to be paid by the future generation, and this they can only do by individually borrowing the money required and securing the debts by their property. The improvements paid for by the taxes so raised become the property of the community, while the corresponding debit stands against the property of the taxpayers. 
If, in the seeond plaee, the money is raised through an issue of bonds, the improvements beeome the property of the community, while the publie bonded debt constitutes a corresponding debit against the property of the taxpayers.

If, in the third place, the money is obtained through an issue of curreney notes instead of bonds, the improvements beeome the property of the community, while the notes emitted by the government constitute a corresponding debit against the property of the taxpayers.

This shows that in either ease the taxpayers contraet a debt equal to the cost of the improvements. In this respeet the result is the same in the three cases. But in respeet to the interest involved there is a marked differenee.

In the first case it is the taxpayers individually who must pay the interest on their respective shares of the debt.

In the second case it is the community as a whole whieh pays the interest on the debt, but inasmueh as interest on public debts is one of the current public requirements, the money to pay it must be obtained through taxation. It follows that, as in the first case, the interest is paid by the taxpayers.

In the third case, however, the payment of interest falls away altogether.

The notion that we ean make our deseendants pay for publie improvements and thereby make it easier for ourselves is due to the lack of a proper understanding of the nature of money. We have found that there is a distinetion between an eeonomie caneellation and a legal payment of a debt $(75,95)$. An eeonomie caneellation embraces the delivery of aetual wealth, while a legal payment of a debt is not a cancellation at all, but consists in giving one eredit instrument for another one. Even the payment of a debt with gold coin is not a eancellation of the debt, unless the recipient intends using the metal of the gold eoin as such. If he does not do so, if he subsequently expends the coin as money, he uses it in its capaeity as a credit instrument of which the gold is merely a collateral seeurity, as an instrument eonveying a claim to merchandise, and not as merchandise itself. 
Inasmuch as public debts are payable in money, they are payable in credit instruments. Money represents an acknowledgment of debt which is accepted as money by virtue of a communal agreement. And there is no reason, ontside of our unreasonable banking laws, why monetized public credit, adequately assured and redeemable in gold, should not be used in place of the monetized credit of some banker in making payments for public improvements as the sundry payments become due during the progress of the work. If currency notes issued on public credit were used for such payments instead of the money borrowed on interest-bearing bonds, the debt would readily be carried by the public in the form of a medium of exchange without interest.

When, as is now the practice, public improvements are financed through the creation of an interest-bearing debt, the interest is not paid for any actual service of the financiers, but merely because the community has placed artificial obstructions in the way of the process of exchange (264). The payment of interest does not arise from economic exigencies, but only from artificial conditions created by law.

Whenever the proposition is advanced to save the payment of the interest charge on public debts by monetizing the public credit through the issue of currency notes, the cry of "inflation" and "fiat money" is raised (320), and the attending increase of exchange facilities is branded as a danger to industry and commerce. The issue of non-interest-bearing currency is condemned on the basis of a supposed danger of an over-supply of money, and on the plea that government should not go into the banking business, as that would mean socialism, but should leave that to private enterprise. The issue of interest-bearing bonds is accordingly urged as the only safe alternative. Furthermore, it is often insisted that whenever a government issues bonds, they should be sold for "real money," namely, gold, and not for "money substitutes." It is, however, a fact that bonds have all along been sold for money other than gold, and there is no cogent reason for insisting on gold at any time. Stamped pieces of gold used as money offer no advantage whatever over sound credit cur- 
rency. When governments issue bonds, they do so because they are in need of money for purposes of payment, and since any valid credit monetized through the issue of currency notes, if fully secured and regularly redeemable in gold, serves in the channels of exchange the same purpose as gold coin, there is no reason for the discrimination. Money-lenders demand the same amount of interest, whether they loan "real money," "money substitutes," or only "bank credit." In their dealings with borrowers they make no distinction between the various forms of the medium of exchange. Why, then, should it be assumed that the govermment must have gold for the purpose of paying its obligations? Gold is needed only for the purpose of redemption, and currency issued on the same credit as that on which bonds are now issued must of course be as good as the bonds. If currency were issued in place of interest-bearing bonds, the small amount of gold requisite to make these notes redeemable in bullion could be obtained by the government from the same source from which bankers now obtain it. There is clearly no excuse for the issue of interestbearing government bonds. As a matter of fact, there is not even any real necessity for monetizing the public credit as suggested above. If we had a system of currency free from needless limitations imposed by law, the public income from the land $\operatorname{tax}(288,333)$ would fully suffice for all public requirements, including the costs of permanent improvements, hence there would be no occasion for incurring public debts of any kind whatsoever.

342. The Strife of Competition.-There is a prevailing idea that it is competition which makes it so difficult, and frequently impossible, for a small business, however capably it may be conducted, to maintain itself in the market alongside larger competitors. Competition is sometimes likened to warfare in which those engaged in business strive for the mastery, the defeated being compelled to give up. But competition, in and by itself, cannot have a destructive effect. Under natural conditions a capable but small competitor ought to be able to obtain his due share of the market, and 
where and when this is not the case, we must look to find the cause that produces this effect. The following homely example will be found fully to confirm a number of our deductions.

343. Competition in a Moneyless Community.-Let us imagine a primitive community in which simple barter answer's all the purposes of exchange, and in which a medium of exchange is as yet unknown. In such a community the principal products would doubtless be things to eat and things to wear, and our attention may therefore be concentrated on two classes of producers: the makers of bread and the makers of clothes. For the sake of argument let us assume that the effort required in making a set of apparel is as much as the effort of making 500 loaves of bread, and that, accordingly, through the operation of competition, 500 loaves will normally exchange for one set of apparel.

Suppose now that the more ambitious tradesmen get the notion that through underbidding their fellow tradesmen they can do more business, and that smaller profits on bigger business bring more wealth. Some of the bakers would accordingly offer, say, 550 loaves of bread for a suit of clothes, and others, apprehending a loss of trade, would fall in line and do likewise. But a similar rivalry must be supposed to spring up among the tailors also. Imagine one of the tailors to underbid the others by offering a suit of clothes for, say, 450 loaves, and the others to follow his example for fear of losing custom. We would then have the spectacle of the tailors offering a suit of clothes for 450 loaves, while the bakers insist upon giving 550. Such competition is, of course, unthinkable, nor does it illustrate the process by which, in the real world, even capable competitors are eliminated from the field. What is there, then, in industrial competition that has this effect?

It may be held that competition is destructive only to the less capable competitors. If that were the case both the bakers who cannot make bread as fast or as good as others, and the tailors who are slower and less skilled than others, would have to get out of business. But what is it that prevents the less skilled of both trades from going on prodncing and exchanging their products to the extent of their capacity? 
It is, of course, plain enough that conditions may arise which prompt underbidding. Suppose that in our primitive community there are too many bakers in proportion to the tailors, so that more bread is made with a view of getting clothes than there are clothes being offered in exchange for bread. Since the bakers cannot all be supplied with the clothes they want for their bread, they will compete among themselves for the clothes, and the price of bread will go down; in other words, 550 instead of 500 loaves will be paid for a suit. This, of course, means a rise in the value of clothes, the tailors having in this case no reason to compete against each other. But since, as we have assumed, it takes as much labor to produce a suit of clothes as to make 500 loaves of bread, the tailor trade would be more attractive than that of baking, and the most versatile of the bakers would learn tailoring and become tailors. Underbidding among the tailors would thereupon begin, and a readjustment of the exchange rate would proceed until the normal ratio of 500 to 1 is re-established.

It is thus apparent that competition is the prime factor in the process by which the relative quantities of the various things produced for the market are regulated in proportion to the demand, and their exchange rates adjusted to correspond with the effort required in their production (147).

In this last phase of our illustration we had assumed that over-production of bread is coincident with under-production of clothes. But, it may be asked, what will happen if both the bakers and the tailors produce more goods than they can dispose of? It is clear, of course, that the bakers would have no difficulty in exchanging part of their over-produced bread for part of the over-produced clothes, resulting in both bakers and tailors being well supplied with food and clothing; in other words, all would be rich and could afford to stop work for a time. But how can this lead to either of them being driven out of the market? In our moneyless community competition could never degenerate into a semblance of warfare through which competitors are driven from the field and 
deprived of their chance to earn a livelihood. Something else than competition must obviously enter into the problem.

344. The Advent of Money.-This moneyless method of trading has its disadvantages. When a tailor sells a suit of elothes and accepts 500 loaves of bread in exchange, a portion of this bread will become stale, and some will perhaps even spoil before it can be consumed. And when the baker needs a suit of clothes, he must work day and night to produce 500 fresh loaves for the occasion, while ordinarily he needs but a fraction of that number for his daily requirements. But these disadvantages are not insurmountable, as we shall presently see.

One of the townsmen becomes possessor of a quantity of silver which, by reason of its utility for ornaments, is highly prized in the community. A part of this he cuts into pieces, some large, some small. The small ones he makes of such a size that each evenly exchanges for a loaf of bread, and calls them dimes. The large ones he makes ten times as heavy, so that 50 of them will buy a suit of clothes, and he calls them dollars.

When he needs bread or clothes, he offers in exchange such silver pieces, which both bakers and tailors readily accept, seeing that they can make similar use of them among themselves. When the tailor wants a loaf of bread, he gives a dime pieee in exchange for it and is thus easily enabled to get fresh bread as he wants it, while the baker, in turn, when he wants a suit of clothes, finds the tailor ready to accept 50 of the dollar pieces in return. The silver pieces have become a medium of exchange-money.

All the tradesmen of the community soon realize the advantages of these pieces of silver as a medium of exchange, and as such they are sought after by all who have things to exchange. Since, however, the owner of the silver has no occasion to use more than a small portion of it for his own purchases, all of it does not find its way into circulation, and a number of the tradesmen seek to borrow some of the silver from its owner. Seeing this demand for his silver, he offers to lend it in return for a recompense, the amount of which 
is to be determined by competition. In the end he agrees to give it over to the borrowers on eondition that they return it to him at the end of a year, with the addition of one dime for each dollar of the borrowed silver.

Let us suppose that after supplying the demand for silver to be used for ornaments, the owner of the silver has enough left to make 105,000 dollar piees. The greater portion of this he now makes up into pieces of that size, and the remainder into dime pieces. Reserving 5000 dollars for his own use, he proceeds to lend out the balanee. Some men borrow 100 dollars, others more, others less.

During the year the lender spends his 5000 dollars, giving some of it in alms to the poor, and at the end of the year the entire amount of eoined silver is in cirenlation.

The borrowers, finding it diffieult to get along without money in their business, now seek renewal of their loans. This being granted, they pay nothing more than the stipulated recompense, amounting to 10,000 dollars. This leaves them indebted to the amount of 100,000 dollars, while the amount in cireulation is 95,000 .

Of his income the lender now again reserves for his own use 5000 dollars and offers the other 5000 to the borrowers, who, needing as much as before, and having only 95,000, all told, are glad to avail themselves of the offer and borrow the tendered sum on the same terms as before. They now owe to the lender 105,000 dollars.

When the seeond year expires and the total amount of silver is again in eireulation, they eompensate the lender for the loan of 105,000 dollars, by paying him 10,500. This leaves only 94,500 in eireulation. As the silver pieces have now become a necessity, the borrowers ask for a renewal of the old loans, and the lender not only agrees to this, but lends out 5500 of his ineome in addition, retaining, as before, 5000 lollars for personal expenses. The loans now amount to 110,500 dollars.

This process eontinues. In the conrse of each year the lender expends 5000 dollars of his ineome and lends ont the remainder, and each sueceeding year his claim upon the eom- 
munity increases more rapidly, so that during the eighteenth year the debts owing him exceed 300,000 dollars, although all the money in existence is not more than 105,000 (255).

345. The Real Battle-Ground.-The lender now gives notice that at the end of the year he desires to collect one-half his loans. In preparing themselves for the occasion, the debtors begin to retain the money as it comes into their hands, instead of spending it, and even turn a quantity of the silver intended for ornaments into coin. Although the total amount of money is thus actually increased, it gradually disappears from circulation. The war of competition, as we know it, now sets in. But it is evidently a competition for money (201). In this struggle the only recourse open to the debtors is the underselling of their competitors. The bakers offer 11 loaves for a dollar, while the tailors reduce the price of their suits to 45 dollars (273). It will be observed that, while both bread and clothes are reduced in price, their relative value remains as 1 to 500, or nearly so. The absurd condition which resulted when the moneyless community was seized with the spirit of underbidding is not present here. We have not here the case of the bakers offering more bread for a suit of clothes and the tailors offering to take less. What they both want now is silver, the only thing with which they can pay their debts.

It will be observed that if the townsmen had originally agreed to pay the interest with the produce of their labor, namely, with bread and clothes (244), there would have been no occasion to increase their debts in the effort of keeping all money in circulation, and the indebtedness would not have grown to proportions which made ultimate payment impossible. The underselling was prompted, not by a demand for a medium of exchange, but by the demand for the stipulated means of paying debts. Hence the fall in prices was not due to the demand for money for purposes of exchange, but to a struggle to escape the consequences of a failure to meet the stipulated obligations.

The sequel of this war is a foregone conclusion. The reluctance to part with money and its withdrawal from circula- 
tion result in a general reduction of business, and eonsequently in a general restriction of production. And when the time of settlement is at hand, there being not enough silver in existenee to meet even one-half the obligations of the debtors, many must fail (255).

346. Significance of the Illustration.-The main features presented by our illustration have their parallels in the aetual world. Bank note eurrency, like the silver pieees of our eommunity, gets into eireulation mainly through loans on which interest must be paid, and bank credit is issued in the same way.

As shown in our illustration, these loans gradually and persistently grow through the addition of interest, and since this has been going on through generations past, the sumtotal of loan debts now exceeds many times the total volume of money. An indefinite inerease of the volume of debt is prevented only through the interminable succession of business failures which is so eonstant a feature of the commereial world and which at intervals, when the volume of debt has become excessive, are preeipitated in a mass. In our modern era, eompetition, which normally should have the effeet of regulating the exchange of services, is transformed into a contention for the means of exchange, and the natural course of trade is distorted into a scramble for money. The eagerness to obtain money and the reluetanee to part with it have become seeond nature to us all, and a large amount of effort that should go to produetion is wasted in hunting for trade.

When aceumulated debts eause an exeessive demand for means of payment, all possible resourees are drawn upon to obtain these means. Under this pressure all available money metal is turned from the ficld of industry into the field of exchange. 'The point $V$ of Fig. 11 is moved toward the right, and the value of the money metal rises. This explains the fall of prices during periods of business crises.

However eritically we analyze the effects of free eompetition, only salutary results ean be traced to it. When competition is characterized as destructive (147), it is beeause of a misunderstanding of its essence. The war of competition 
is a fight for the possession of something the production of which is arbitrarily restricted, namely, that which enables producer's to exchange the fruit of their labor. In short, it is a struggle for freedom to do business, for the right to work. Not competition that regulates the exchange of services, but competition for the only means through which such exchange can be effected, is at the foundation of the strife that now pervades the economic world (354).

347. The Iron Law of Wages.-Our earlier deliberations (151-162) failed to show the causes which in the modern industrial world decide the division of incomes between capital and labor. It was made clear that competition takes no part in this apportionment. Later (186-208) we found that the accepted theories of capital interest are defective and fail to point out the forces which govern the division. Ultimately it was found (236-267) that capital obtains its power to acquire profits for its owner through the working of an irrational currency system maintained by irrational laws.

Briefly reviewed, the law, by restricting the production of the needed medium of exchange, obstructs those exchanges which are necessary for the aggregation of capital goods as they are needed in the process of production (242), with the effect of keeping down the amount of capital in productive use. In diagram Fig. 18 it has been graphically shown that if the capital employed is limited to $O C^{\prime}$, the corresponding productivity of labor employing this capital is represented by the area $O C^{\prime} e^{\prime} E$, which is less than the natural maximum productivity $O C E$ of this same labor. Of the amount so produced the portion $O C^{\prime} e^{\prime} i$ accrues to the owner of the capital employed (143), leaving to the active agents of the productive group an amount represented by the area $i e^{\prime} E$.

If exchanges were not obstructed, labor's productivity would rise to its maximum $O C E$, of which no portion need be paid to capital as pure interest. This has been amply demonstrated in the preceding chapter. It follows that under present conditions labor is deprived of the amount $C^{\prime} C e^{\prime}$ by being unable to employ the most efficient mode of production 
(158), and is despoiled of the share $O C^{\prime} e^{\prime} i$, which amount is given to eapital for nothing else than for the right to work (261). These losses to labor can be avoided through rational eurrency reform (302-308).

When it is considered that under the reign of equitable laws the area $O C E$ would represent wages, while under present conditions wages are represented by the area $i e^{\prime} E$, it is easy to see that to-day wages equal the reduced productivity of labor $O C^{\prime} e^{\prime} E$, less the portion $O C^{\prime} e^{\prime} i$, which is diverted from wages and improperly allotted to capital (358).

348. The Employer's Part in the Process of Apportionment.-The sharing of the gross income of a group is effected by the employer. Out of the gross income he pays the value $A B$, Fig. 13, of all services contributed by other groups; the rent $B C$ for the use of the land employed; the interest $C E$ for the use of all capital goods and ready money needed; and finally the wages $E F$ of the employes, retaining for himself the residual share $F G$ as his wages.

If part of the working capital has been obtained through borrowed money, a corresponding share $D E$ of the interest $C E$ accrues as money interest to the lender.

The share $A B$ is similarly shared out by the several groups who receive it; hence the value of the final consumption goods is, in the last analysis, divided into rent, interest, and wages. When consumption goods are sold in the market, the purchasers must pay a price that comprises rent, interest, and wages. But for produeing these goods the active agents of production receive only wages. When they collectively buy back their own productions, they must pay more than they received for producing them. It is by this process that the workers, as consumers, furnish the unearned ineomes of landlords, capitalists, and money-lenders. They clearly recognize that collectively they pay for the things they buy more than what they collectively have received for producing them. As far as they can see, the employer is the agent intervening between the producing and the marketing. It is therefore not unnatural for the workmen to come to the conclusion that the 
employer gets the excess of what they pay for the things over what they receive for producing them.

But does the employer as such really get the items of rent and interest, or any part of them?

Rent arises from the fact that the amount of effort necessary to produce and bring to market equal quantities of a given commodity is greater or less according as these are produced on more or less fertile land or on land more or less favorably located. Competition for the possession and use of the different degrees of advantage thus inherent in land enforces on the employer occupying it the payment of rent (172-174, 371), and through the rent, which amounts to more or less according as the land used offers more or less advantages, the cost of producing equal quantities is practically equalized. But we have also found that the rent would go to the community through taxation, if our currency laws were reasonably amended (323-328). The unavoidable addition of the item "rent" to the other items of cast determining the value of the final consumption goods would then constitute an indirect tax, relieving the community of all other taxes. At any rate, the employer derives no benefit from the addition of the rent item to the value of the consumption goods, whether the landowner retains the greater part of the rent, as now, or turns the entire rent over to the community in compensation for his right of owning the land.

If the employer is not also capitalist, if he is at the margin as regards the use of capital (257), having obtained the capital goods employed by him through borrowed money, he cannot escape the payment of interest on the loan (240) which, as an item of the cost of production, is added to the other items of cost which together make up the market value of the goods produced. Here also the employer cannot be held responsible for that addition to the market value of the goods through which the consumers are made to provide the income of pure interest to the money-lenders, nor does he derive any benefit therefrom.

If the employer is owner of a portion or all of the capital employed, he gains an unearned profit through the fact that 
the market value of the product includes pure interest as an item of its composition. But he acquires this unearned gain (265) in the capacity of capitalist and not as employer (146); nor is he responsible for the fact that this profit accrues to him, for he gets it without any deliberate aetion on his part. Again, we must not only absolve the employer from all blame for this unjust distribution of ineomes, but must also reiterate that in the capacity of employer he does not receive interest.

While the employer indeed effeets the distribution, he does so under the dominance of eeonomic forees. While he divides the net income of his group into rent, interest and wages, he is powerless to do otherwise. IIe is a mere tool, a "cat's paw" (358), in the process by which the landlord, the eapitalist, and the money-lender are accorded their unearned shares.

349. The Downward Tendency of Wages.--Wages being what is left of the market value of the product of labor paid by the consumer, after rent and interest have been taken therefrom in the proeess of distribution, it remains for us to learn to what extent capital gains at the expense of labor.

Under given conditions the share aequired by the landlord is definitely determinable. The margin of the use of land is determined by the quantity of land required for the production of all that is called for by the existing demand; and intra-marginal land cannot return to its owner more than the value of the advantage which its use affords over that of marginal land.

Interest, however, is determined in a different way. Its primary tendency is to adjust itself to the final efficiency of capital, and this has a positive value only on account of the insufficiency of the medium of exchange. But as a result of the ever-increasing indebtedness the sum-total of the interest toll gradually increases until it exceeds what the "traffic can bear," leading to the well-known periodic exhaustion of the business world and consequent stagnation of business, when industry comes to a partial standstill, and all workmen cannot be employed. The rate of interest is then depressed below the rate corresponding to the final efficiency of capital, just as a falling rain drop is restrained by the resistance of the air from 
attaining the speed that it should have according to Newton's law of falling bodies.

So long as there are workers vainly seeking employment, they naturally offer their services for less than their fellows are getting, with the consequent tendency of wages to a lower level. When the number of workers seeking to dispose of their services is at all considerable, the tendency of wages is toward a minimum of subsistence, and at times even to a point below it. This is what has been termed the "Iron Law of Wages." The least capable workers are thus forced to take for their share scarcely enough to meet their needs and the needs of their children who are later to take their places. These workers are indeed victims of a grievous condition which is often, through ignorance of the true state of affairs, ascribed to the greed of employers and stigmatized as "exploitation." The ultimate cause of the inadequate returns to the workers, the real reason of low wages, is not to be found in the struggle of competition, as economists of the socialistic school imagine, but in the insufficient demand for labor, which, in turn, is due to the operation of our currency laws (268-270). The tendency of wages to go below the current cost of subsistence must inevitably continue as long as through needless restriction of the issue of currency the freedom of exchange is in any way obstructed.

Meanwhile the army of the unemployed will vary in numbers with the alternations in the cycle of business activity, and the downward tendency of wages will come intermittently into play. In many countries involuntary idleness of large numbers of workers has become a chronic disorder of the social organism, but periodically it is manifest throughout the world. Some of the workers perish for lack of adequate means of subsistence, or through sickness caused by anxiety and want, and charity, organized or unorganized, can do but little more than ameliorate this condition. Many of the unemployed become beggars and ultimately confirmed paupers. It is undoubtedly true that the dearth of employment is largely responsible for the tramp evil, partly because the difficulty of finding employment develops the habit of idleness, and partly because some individuals have learned how 
to live without work through appeals to charity on the plausible pretext of being unable to find employment. And from habitual idleness there is but a short step to crime. Thus the system that is responsible for unemployment is also responsible for much of the criminality of our time. Criminal traits lave indeed become so rooted in some classes of society by centuries of oppression that criminologists liave come to consider the propensity to erime an hereditary disease.

350. Effect of Proposed Currency Reform on Wages.To the workman a money reform having in view the elimination of pure interest may seem to benefit only borrowers of money, and thus leave out the mass of wage-workers from any share of its advantages. It would appear as though the only ones among the wage-workers to benefit by such a reform are the few who ultimately work their way into the class of employer's.

Nevertheless, the wage-earners would be the chief gainers; the gain would come to them in the form of increased wages.

Our original inquiry was directed toward finding the cause of business depressions, with a view to discover a remedy for these economic disturbances. The relation of these causes to the level of wages has coincidently been brought to view. When business is depressed, wages are low because the supply of labor is in marked excess of the demand. Competition for employment is excessive, and with two workers competing for one job, wages necessarily go down. Conversely, in periods of business activity, when the demand for workers increases, wages naturally rise. But our investigation has traeed the excess of the supply of labor over the demand to undue restrictions in the issue of eurreney (268-270). Through the removal of these restrictions, as here suggested (302-308), business activity would be promoted to such an extent that even that portion of the product which now gocs as pure interest to eapital and to money, would go to wages instead. Henee the workers would be getting all that is really due them, and the universal dissatisfaction over the present manifestly unjust distribution of ineomes would no longer have any reasonable ground.

The income of the employer, as manager of the business, 
would likewise be increased with the general increase in wages. In many cases the incrcase of his wages would even more than balance the disappearance of capital returns from his income, so that both workmen and employers would have every cause to welcome the change. Only the unearned profits of capital would disappear.

351. Protective Tariff,-In the effort to maintain a high level of wages, most industrial countries have adopted the policy of "protection," consisting of a tax on imports designed to impede competition from abroad.

This method of keeping wages up is like an attempt to cure a disease by merely symptomatic treatment. Instead of freeing commerce from the shackles imposed upon it through the restriction of the medium of exchange, whereby a portion of labor's wages is diverted from the natural channel, a protective tariff adds but another restriction to the freedom of exchange. The periodic inability of a large number of workers to find employment is looked upon as an unavoidable concomitant of our modern industrial life, being regarded as the result of "overproduction" due to the great increase of labor's productivity through advances in the industrial arts. Most countrics, therefore, strive to hold for their industries the largest possible share of the inadequate demand by reducing the supply from abroad. To this end tariffs are imposed with the object of closing the home market as far as possible to foreign products, and all sorts of expedients are resorted to in the effort to gain foreign markets for the home products. This has led to the system of paying bounties on the exportation of certain products, and of subsidies to transportation and other agencies. Each nation seeks to increase its exports and to diminish its imports, and an excess of exports over imports is regarded as a favorable "balance of trade."

To export more goods than are imported obviously reduces the amount of wealth in a country. It is therefore by no means self-evident why such a policy is regarded as beneficial. But the popular faith in protection finds explanation in the fact that commerce is carried on by exchanging goods for 
money. The policy of protection is not to prevent international trade, but to permit, or by bounties even to promote, selling abroad, and to restrain buying abroad. It favors exchanges of home products for money and hinders exchanges of money for foreign products. It is therefore clear that the real effect of tariffs and bounties is to prevent the exportation of money and to increase the home stock by drawing upon the supply abroad. Tariffs and bounties are, in fact, formidable weapons used in the international warfare for the possession of money.

The underlying motive for this contest is the same as that which, during the eighteenth century, prompted some European states to forbid the exportation of gold and silver. It would therefore seem natural that with the decadence of the Mercantile school of economists, who urged this prohibition, and with the rise of the school which promulgates the volume theory of the value of money, the policy of protection would have been abandoned. Yet, such has not been the case. It is to be noted that if the volume theory were true, the exportation of goods for money would be a losing proposition, because the amount of goods possessed by a nation is reduced by exportation, while the value of all the money in the country would, according to the volume theory, remain the same in spite of all the additional money received through commerce (119).

But in the light of our investigation and conclusions the reason for the widespread popular approval of the policy of protection is not far to seek. Experience has indeed proved what we have found true in theory, namely that an increase of the amount of available money is coincident with an increase of industrial activity. A reduction of imports has the effect of keeping money from going out of the country, and in the measure in which tariff brings about an cxcess of exports over imports, it has the effect of bringing money into the country (353). And even if the money due on exported goods is not brought home, but instead is invested in the importing country, an advantage accrues to the exporting country, because through the obligation to pay interest or dividends on the in- 
vestment the country that imports becomes tributary to the country that exports. A so-called favorable balance of trade results either in the importation of money, or in the acquisition of a continuous revenue payable in money.

352. Balance of Trade Co-related to Rate of Interest.A difference in the current rate of interest prevailing in any two countries has a direct bearing on the balance of trade between them. There is a natural tendency to the investment of capital where its returns are greatest. When in any country the rate of interest is low, there is a tendency of money to go abroad, where interest is higher. A transfer of money is generally effected by transfer of bank credit through bills of exchange. While the trade between two countries is even, the demand in both for such bills in payment of imports balances the supply, so that in reality no money need be sent either way, the imports paying for the exports. But when in one of the countries the importers' demand for exchange is augmented by the demand of investors, the exchange rate goes up. This adds to the cost of importing into low-interest countries and, of course, vice versa, and affords an impulse toward exportation of goods from low-interest countries, while, on the other hand, in high-interest countries the impulse is toward importation.

A difference in the rate of interest is, of course, only one of the several factors which affect international trade balances. Where other factors of opposite tendency predominate, they may overbalance the normal effect of a difference of prevailing interest rates.

353. Advantages of a Tariff.-The primary effect of a tariff is that of lessening foreign competition in the home market, and, as a result, the prices of the goods affected are higher than they would be otherwise. The increased price of such goods tends to stimulate their home production and correspondingly to stimulate the demand for labor. This is followed in normal sequence by a rise in the price of labor, in other words, by an advance of wages. But this stimulus continues only to a point where the rise of wages corresponds to the rise of the general price level. In this respect the wage 
earners, although getting higher wages, gain no advantage thereby (284).

But there is another effeet of a tariff which affords an aetual gain to the wage earners. Through impeding the importation of goods it helps to that extent in produeing a socalled "favorable" balanee of trade, which simply means that the money resources of the country, instead of being lessened through remittance abroad to pay for goods imported, are really increased through receipts of money in payment of goods exported (351). As a result, the monetary strain whieh depresses industrial activity is to that extent relieved and the demand for labor correspondingly augmented. This eauses an inerease of wages independent of that due to the rise of priees, and this item of the inerease beeomes a real gain to the wage earners of the country.

It is thus apparent that the sole advantage of the tariff is but in the nature of a partial offset against the disadvantages resulting from the existing seareity of the medium of exchange. With the currency system so organized as to permit the amount of currency automatieally to adjust itself to the aetual needs of industry and eommeree, the demand for labor would beeome equal to its supply, tariff or no tariff. "Proteetion" would then become useless as well as needless, and free trade would be to the interest of all.

354. Trade Unions.-Quite on a par with the policy of placing obstructions on international commeree as a means of promoting domestic prosperity is the effort of trade unions to restriet the employment of labor as a means of benefiting the laborers. Both measures are resorted to as protection against what is supposed to be the effect of competition (346). In both cases the objeet is to raise wages; in the one case by increasing the demand for labor and in the other by keeping down its supply. With this latter objeet in view, trade unions constantly strive for a reduction of working hours, resist in various ways the introduetion of labor-saving devices, urge for the arbitrary restriction of immigration, insist on the limitation of the number of apprentices and endeavor to ex- 
clude from employment all who are opposed to these measures.

The justification of this policy is based on the mistaken idea, prevalent among wage earners, that it is the selfishness and greed of employers which is responsible for the existing unsatisfactory wage rates and the manifestly unjust distribution of wealth. It is argued that employers obtain undue advantage by reason of the competition of workers for em. ployment, and that all measures for overcoming this advantage are justifiable.

355. Labor Legislation.-It is quite natural that trade unions, in their effort to obtain for their members redress of those grievances which they consider to be due to the selfishness of employers, should endeavor to accomplish the end through legislation.

Prominent among the statutes that have been enacted principally through these endeavors are laws limiting the working hours, not only of minors and of women, but also of men, laws eliminating or restricting the competition of convict labor with free labor, laws restricting immigration with the view of protecting workers already on the ground from the competition of others from elsewhere.

While some of these measures are humanitarian in their tendency, the one common effect of all is that of extending opportunity of earning a living to workers who otherwise cannot find employment. But these measures, whether they limit the employment of minors, of foreigners or of convicts, or the hours of labor, cannot remove the cause which limits the employment of workers generally, and cannot therefore do more than better the condition of some workers at the expense of others.

While a reduction of the time of labor is not only desirable, but should be the natural result of the constantly increasing facilities of production, it is nevertheless futile to attempt to raise the wage level through a reduction of the hours of labor. A lasting improvement can be attained only by removing, through rational currency reform, the existing obstacle to the full employment of labor, so that the fear of 
being left unemployed will no longer compel men to submit to unfair conditions.

356. Arbitration of Labor Disputes.-Differences often arise between workmen and employer, as in questions of wages or of conditions of employment, which are not properly susceptible of adjustment by law, and in the effort to bring such disputes to an amicable conclusion, resort is often had to arbitration. This method is gaining ground to such an extent that the propriety of making it compulsory has many advocates. Yet, when closely examined, arbitration in such cases is essentially irrational.

Arbitration is quite in place in the case of international differences, or when a dispute arises over an existing agreement which admits of varied interpretation, or when, for inherent reasons, the original agreement cannot be specific as to certain details, as in the case of fire insurance adjustments. In fact, the mediation of the courts in civil suits is essentially an act of compulsory arbitration. But when two parties are about to enter into an agreement regarding their future relations, such as an agreement regarding the rate of wages, it would seem to be most unreasonable to give to a third party the power to decide the terms of this agreement.

The wage worker is really a seller of his services which the employer buys. His position is analogous to that of the merchant who offers his goods for sale, while the employer corresponds to the merchant's customer. Suppose, now, that a merchant raises the price of his goods, and an old customer, considering the increased price too high, takes steps to transfer his patronage to the merchant's competitor. And suppose further that the merchant seeks to coerce the customer to continue his patronage and proposes that a third party decide the price to be paid. This would no doubt be considered a very absurd proceeding. Yet, it is precisely parallel to a demand by workmen to have the rate of wages or some other grievance adjusted by arbitration. Those who advocate arbitration for fixing the terms of a contract regarding future relations of employer and employed are evidently at their wits' end in an 
effort to correct an evil, the cause of which they do not understand.

357. Strikes and Boycotts.-When differences arising in labor disputes cannot be settled by conciliatory measures, and arbitration is not acceptable to both parties involved, organized workers frequently seek to enforce their demands by striking. Besides refusing to continue working on their employers' terms, they endeavor in various ways to keep others from doing so. Failing in this, they sometimes attempt to deprive the employer of a market for his products through concerted measures, known as "boycotting."

Such proceedings, even if successful, cannot, however, permanently benefit the workers as a class. If they succeed in raising wages above the competitive level, the increase becomes an addition to the cost of production and must therefore in the end fall on the workers themselves as consumers of the products, through a corresponding rise of prices (358). The condition which is the ultimate cause of low wages remains unchanged, and though the nominal rate of wages be sustained at a higher level by these means, the actual rate of wages remains the same, the rise in the nominal rate of wages being balanced by a general rise in prices.

A permanent cure for the prevailing industrial discontent can be hoped for only through the removal of its fundamental cause. When capital has no longer the power to command an unearned revenue, it will become generally recognized that all measures which in any way restrict industrial freedom are inherently wrong, and this applies not only to laws restricting the processes of exchange, but likewise to strikes and boycotts which interfere with the natural processes of production and distribution.

358. What Trade Unions Accomplish.-Trade unions have their prototype in the trade guilds of the Middle Ages, which were originally organized to protect their members against the encroachments of their overlords. But in course of time, after overcoming fendal oppression, they became oppressive in their turn. Having acquired certain privileges, they so regulated admission to their ranks that the number of 
"masters" that might establish themselves in business was rigorously limited, and in this way they restrained competition in their respective fields.

In the development of trade unions we have a striking example of history repeating itself. In the early stages of modern industrialism, following the invention of the steam engine, wages were at the starvation point and the hours of labor so long as to leave barely time for needed sleep. Under the stress and burden of the abject condition to which the masses of the working class were thus reduced, the workers strove to obtain justice by united action, but their efforts were at first obstructed by the enactment of laws forbidding the formation of labor unions. Through persistent agitation against this despotism the working classes succeeded in the course of the nineteenth century in having these legal obstacles to their organized efforts completely removed.

It was not long, however, before success in this direction was followed by a change in the attitude of the trade unions, from a striving for greater freedom for themselves to a striving for lessening the freedom of others. From a position of justifiable defence and insistence on equal rights, these unions have gone to the length of subverting equal rights, not only of employers, but of fellow workers as well. Having gained freedom for themselves, they have in their turn become oppressors through placing obstructions against industry, in the vain belief that they can thereby be permanently advantaged.

Trade unions are considered by many who have the wellbeing of wage earners at heart as necessary to conserve their rights. This conviction, however, rests on a misinterpretation of certain facts.

Since the beginning of the nineteenth century the economic and social eonditions of wage earners have been vastly improved. Wages have been increased, the time of labor shortened and the social standing of workmen greatly enhanced. The same period also marks the rise of labor unions. Moreover, wages in well organized trades are, as a general rule, higher, and the time of labor shorter, than in trades and oceupations which are not so well organized, This is claimed to 
prove that the betterment in the position of the wage earners has been due to the efforts of trade unions, and that these bodies are necessary to maintain the economic advantages which labor has gained. And yet, this inference is not justifiable and rests on a mere coincidence of facts.

We have found (347) that wages equal the value of the product of labor less that quotum which is acquired by capital. It follows, then, that wages can be permanently increased only in two ways, namely by increasing labor's productivity, or by reducing the quotum which goes to capital, or, of course, by both processes combined.

Now, it is clear that the increase in the productivity of labor which has taken place in the course of modern industrial development has been due entirely to inventions and discoveries, and the processes through which these were made available. It is through progress in this line that the worker is enabled to produce far more goods with less labor than ever before. But what have labor unions done? They have persistently opposed, both actively and passively, the introduction of devices and methods for increasing the output of labor. Trade unions certainly cannot claim to have increased wages through increasing the productive capacity of labor.

Nor have they done aught to reduce the quotum which capital obtains through its grip on the industrial world. Instead of aiding the employer to overcome the handicap which makes him a tool in the process through which capital obtains an undue share of the products of labor (348), these unions have actually added to the difficulties of the employer and strengthened the power of capital. Although it is not improper for them to insist on the enactment of laws compelling payment of wages in legal money, these laws act as a boomerang in the absence of such additional measures as are necessary to make the volume of currency adequate for the purpose. Without these additional measures the domination of the financier over the industrial world is only strengthened by laws which, however desirable and proper, like those forbidding payment of wages in store orders, add to the demand for currency. The truth is that the increase of wages and the betterment of 
the condition of the wage earning elass which has come with the progress of modern invention has been brought about, not through trade unions, but in spite of them. While the progress of invention has tended to increase the purchasing power of wages, the effort of trade unions has tended to inerease prices in the same proportion in which it has suceeded in raising money wages.

It is true, as above noted, that, as a rule, wages in strongly organized trades are higher than in those of less complete organization, assuming, of course, that the trades compared are those in which wages would otherwise be equal. Where the unionizing of a trade is incomplete, those employers upon whom its forces are effective must ultimately throw off this burden or go down under the competition of other employers who are not under trade union restrictions. It is only in trades where all employers are affected alike, and where competition is therefore equalized, that an artificially raised level of wages can be maintained. But in this case the marginal cost of production is correspondingly increased, and the price of the product rises accordingly. It follows that not employers nor capitalists, but only consumers, including all classes, pay the inerease in the end $(149,357)$.

So long as the wage level of only certain trades, and with it the price of their products, is held up through the efforts of trade unions, the workers in those trades will gain more as producers than they lose as consumers. The reason is elear. While the wages in their own trade are held up to an artificial level, the prices of only some of the products of which they are themselves consumers are being similarly held up. On the other hand, the workers in the ununionized trades are suffering a disadvantage through having to pay a higher price for the products of the unionized trades out of the merely normal wages of their own trade.

It is therefore apparent that wage earners would not gain anything, were all trades completely unionized and the wage level thus artificially raised throughout. The natural result would be that all products of labor wonld rise in price in full proportion to the rise in wages. And this is all that eould be 
accomplished in this direction by the complete organization of labor for which labor unions are striving. The increase in money wages being attended by a proportional increase in prices, the purchasing power of wages would in the end be the same as before. The efforts of the trade unions cannot permanently bring to the wage earner a larger share of the products of labor than he would otherwise obtain.

Only for a short period following an increase of wages that has been brought about through the concerted efforts of trade unions can wage earners as a class be gainers. Employers who before such raise of wages could just make ends meet are thereafter forced either to raise the price of their goods or quit business. In the latter case a rise of the price would naturally follow by reason of the reduction of the supply. While the employer has to make good the excess of wages for a while, the ultimate effect upon the market is that the consumers pay the advance in wages, and capital gets as much and labor as little as before.

The restraint of competition by a combination of wage earners as a means of increasing wages appeals to wage workers as very promising. But far from being an antidote or cure for the prevailing injustice in the distribution of wealth, it is only a "will o' the wisp" which the wage earner pursues in the vain hope that it will lead him out of the "slough of despond" in which he fincls himself bemired. Not until both workmen and employers come to understand that the underlying cause of the prevailing economic injustice is the arbitrary limitation of the volume of currency and the consequent creation of the abnormal power of money, will they see their way to the proper remedy. As it is, and as it has been through generations past, employers see no other way than to combine to restrict competition for their own benefit, and workmen see no other way than to combine for the like end. While they waste their energy in endless contentions, each side seeking to combat force with force, monopoly with monopoly, they continue to be an easy prey to their common enemy, the unnatural power of money. This they can overcome only by obtaining for themselves the right of free exchange, a right for which 
they are now eompelled to pay to the money power a toll which continually inereases until, through the exhaustion of exehange faeilities and the overwhelming aeeumulation of debt, industry is brought to a halt.

359. The Single Tax.-The proposition to abolish all taxes save that on land, urged by various thinkers at various times, has been made the central idea of the so-ealled "single tax" propaganda, popularized by Henry George and formulated in his noteworthy work "Progress and Poverty." During George's lifetime this movement made rapid strides and gained many followers, but sinee his death its progress has been slow. This is no doubt due to the fact that the reasoning by which he seeks to prove that the measure which he proposes as a remedy for low wages is open to question. The main line of his thesis is sound and the faults of the present system of land tenure are clearly set forth; but at the same time the nature of both capital and interest is wholly misconceived. Nevertheless, the work of Henry George has borne good fruit. His presentation of the land tax doetrine has left an indelible impression on modern eeonomie thought. In various eountries, as in Australia and New Zealand, and in individual localities, as in parts of Germany and of British Columbia, some initial steps have been taken toward incorporating the tenets of the single tax into law. The effect of these measures on industrial conditions has, however, fallen far short of those benefits that must have acerued if the single tax were indeed a cure for poverty, as George and his followers have maintained.

The aim of the single tax proposition, briefly stated, is the absorption of the entire economie rent by the state through taxation, leaving to the owner of the land no portion of the rent as such, but only a due eompensation for his serviees as agent in the process of colleeting the rent for the government. All other taxes would then beeome superfluous and would eonsequently be abolished. It is proposed to start by taxing only the land and not the improvements thereon, and to gradually inerease the tax until the value of the land disappears.

This measure is advoeated on the ground that the value of 
land is not due to any effort on part of the landowner, but arises from the growth of population and from the improvements made on the surrounding land. Land has not been produced by labor and, being the inheritance of all alike, it cannot rightfully become private property.

Henry George recognized that his proposed remedy would be of no avail if the landlord, on being called upon to pay a tax equal to the economic rent, could add this charge to the price of the produce of the land in case he cultivates it himself, or to the stipulated rent in case the land is let to a tenant. This author therefore reiterated Ricardo's demonstration that the imposition of this tax could not affect the value of the things produced on the land, nor could the landlord raise the rent on the tenant. The rent depends on the price of the produce and not vice versa (172). By the confiscation of the rent no burden is placed on the marginal producer, for he gains no rent and pays no tax, and the price of the product is determined by cost at the margin.

This proposition can be illustrated by the diagram Fig. 20 . Let us single out the element $q^{\prime}$, which is produced at a cost equal to $q^{\prime} s^{\prime}$. By imposing a tax equal to $s^{\prime} r^{\prime}$ on the production of this element, the gross eost of its production rises to $q^{\prime} r^{\prime}$. Treating every element in the same way, the effect will be that the gross cost of all elements is equalized, and the price $q a$ remains unaffected.

360. Ethical Status of Land Ownership.-That the economic rent of land should properly accrue to the community through taxation is confirmed by our investigation, although we reached the conclusion by a distinctly different line of reasoning. But the inference that, as a result of such taxation, the value of land would shrink to the vanishing point does not agree with our conclusion on the subject and is evidently derived from the erroneous assumption that land can have a market value only if it returns a continuous income, an assumption which is on a par with the unwarranted supposition, sometimes set forth, that money has a value only by reason of its power to command interest $(65,107)$.

In view of the fact that the author of "Progress and Pov- 
erty" considers capital interest as altogether right and proper, it was but natural that he believed the value of land would disappear through taxing it to the extent of the entire economic rent. According to his premises the proposed reform would be not only a confiscation of the rent, but of the value of the land as well. Recognizing that this outcome of the proposed measure has the appearance of injustice, especially to those landowners who acquired their title by purchase, he proceeds to justify his proposition as follows:

Beginning with the premise that land is not a product of labor, but a gift of the Creator to the entire community of mankind, he argues that land cannot, in the nature of things, rightfully become private property. Those who first obtained control of the land as private property virtually robbed the community of it. Applying the same rule as that which gives to the original owner of a stolen thing the right of recovery, even from an innocent purchaser, George concludes that depriving land of its market value through the appropriation of the economic rent by the community is but a restoration of the value of the land to the community and therefore not in conflict with justice.

But this is not a true parallel. The holders of land have not obtained their possessions by way of theft or robbery, but by preëmption or by way of gift from the controlling power. In either case the ownership of land must be viewed as resulting through an agreement between the land holder and the state, taking the form of law. Whether the state exists in the form of an autocracy, an aristocracy or a democracy is here immaterial. That these agreements and the laws which define them have developed inequitable features, unforeseen at first, is no reason for proceeding, at a later date, to confiscate whatever value the land may have acquired. The fact remains that our ancestors, in their ignorance of what the future had in store, have permitted some individuals to acquire private ownership of land withont imposing such conditions as alone would make such ownership equitable, and we are bound by their action, morally as well as legally. $A$ bargain made in good faith, however unwise it may be, must stand; that it 
subsequently is found to have been ill advised affords no right to repudiate it. All that may reasonably be done is to allow the landowners to keep the value that has legally become theirs and to take such measures as will for the future deprive land ownership of its present power to bring unearned incomes to the owners.

We have already observed that Henry George considered the interest-bearing power of capital as natural and just. For this reason he did not realize that the absorption of the entire rent through taxation can be brought about by a reform of the currency, and this without the elimination of the value of land (328).

36r. Henry George's Theory of Business Fluctuation.Convinced that the existing system of private land ownership is the prime cause of all the greater evils that afflict the social organism, it was but natural that Henry George should have proposed the single tax as a cure for business depression and as a means for raising wages to the highest possible level. $\mathrm{He}$ therefore felt impelled to trace business depressions to the present system of land tenure, and here follows in brief what he says on this subject:

As a rule, the current value of land is in excess of what can be accounted for by the present capacity of the land for returning rent. This excess is the speculative value which is due to the expectation of a future increase of its rent (183), an expectation based on general experience. In anticipation of this future development, land which is not yet within the margin of cultivation is appropriated and held for the rise.

As population increases, the man who sets out in search for the margin must therefore pass for long distances through halftilled farms before he reaches a point where land can be had free of rent. When he settles, he will in turn take up land, and those who follow are forced farther on, carrying the margin of cultivation to still more remote points. Through these speculative appropriations the margin is pushed out and the rent thus increased, crowding down wages and interest to a point below which labor cannot exist nor capital be maintained. Production, therefore, begins to stop and the paralysis is com- 
municated through all the interlacings of industry and commerce.

The period of depression thus ensuing will continue until either (1) the speculative advance in rent has been lost; or (2) the increase in the efficiency of labor, owing to progress of improvement, has enabled the normal rent line to overtake the speculative rent line; or (3) labor and capital become reconciled to smaller returns. The rent will begin to advance again, a speculative advance will again take place, production will be cheeked, and the same round be gone over. ${ }^{107}$

362. Analysis of This Theory.-This explanation of business fluctuation is based upon premises which cannot be sustained. The assertion that land is deliberately held out of use by the landowner while he is waiting for a rise is not generally true. The display of human nature as here presented is unnatural and unreal.

There can be no question but that it is the desire for acquiring wealth which impels the aequisition of land by those who do not purpose using it themselves. In view of the fact that land yields gains in two ways, namely through rent and through increase of its value, it would obviously be to the interest of landowners to make both sources of gain available. But in George's theory it is assumed that the average landowner will neglect getting the rent, while his heart is set on getting the increment. This assumption is manifestly not tenable as a basis of economic theory. It is not necessary to hold land out of use for the purpose of gaining the unearned inerement; nor will this increment become greater by allowing the land to lie idle. The landowner has in fact no inducement to hold the land out of use; on the contrary, he has every reason for putting it to the best possible use under the circumstances, so as to obtain the rent in addition to the increment. Even though land has been appropriated, it is not for that reason held idle, but is generally obtainable for use in return for the economie rent, that is, in return for a rent which the highest bidder is willing to pay. Nor could these terms of

${ }^{100}$ Cf. George, pp. 184 ff. 
occupancy be improved by enacting the single tax proposition into law, for land could not be obtained for use on more farorable terms under that system.

In all these considerations we can deal only with general tendencies, to which, in the nature of things, exceptions constantly occur. These exceptions afforded Henry George occasion copiously to illustrate his thesis. But the comparatively few instances of land being held out of use for speculative reasons are far outnumbered by the many in which the landowners strive to put their holdings to the best possible use, either through their own efforts or through leasing it to others. It is therefore illogical to conclude, as he does, that the speculative holding of land has a tendency to remore the margin of used land beyond the normal rent line. That there is always some unused land within the margin and some used land beyond is inevitable in the course of things. But the average condition is not affected by such instances, which are comparable to the crests and troughs of the waves in a stormtossed sea. There are rises and falls on the surface of the water, but its average level is not affected by the storm.

Where large tracts of land are used as private preserves, the conclusion that the actual margin is thereby pushed out is undoubtedly correct. But such abstraction of land from economic use is not due to speculation, and it is safe to say that it occurs mainly where the owner derives unearned income from other land rented to tenants, or from capital in some other form. Such abstraction of land will therefore come to an end when capital loses its power to command an unearned income.

It often happens that in the midst of highly cultivated surroundings or in central locations of cities some plots of land are put to a less adrantageous use than the situation would warrant, and it appears that Henry George, observing such cases and thinking that they confirmed his theory, attributed them to sheer speculation on the part of the owners. An illustration will suffice to show that such cases are unavoidable in the normal course of erents, especially in rapidly progressing communities. 
Let us imagine a block of buildings near the eentre of a growing eity, buildings which were ereeted when the eity was vet but a town and which are little more than shanties. The growth of population ealls for better and more commodious buildings, and such are growing up in the new sections of the eity. Many smaller houses in the old parts of the town are still in use, and for the time it pays better to build new residences on the outlying empty lots than to demolish the older dwellings nearer the centre and replace them by more modern struetures. Meantime the business centre of the city expands. In some streets stores appear with attractive show windows. In other quarters factories spring up. Here large office buildings arise, and there theatres or bank buildings make their appearanee.

Returning to our bloek of antiquated buildings, we find their owner observing the changes going on in all directions. He also desires to improve his lots, but how? He may be ready to meet any real demand for improvements, but who nows whether the location, in the midst of progressive changes, will warrant the ereetion of dwellings, or of stores, or of factories? A mistake of judgment in this respeet might entail a loss far exeeeding the loss of rent while waiting for development. Thus the old buildings remain standing in and about the eentre section of the eity for an indefinite space of time, only to give way finally to buildings which will put the various sites to their most eeonomic use.

There is every reason to suppose that similar eonditions would prevail under any proposed applieation of the single tax principle. The assumption that land which is not put to its most economic use is being deliberately held down by the owner in ealm anticipation of the unearned inerement is largely a figment of the imagination, and while there are indeed here and there exceptional instances of such holdings, these exceptions are too insignificant to make the explanation of business stagnation offered by Henry George at all reasonable.

363. Discrepancy between that Theory and Facts.-The inadequacy of the theory on which business depressions are 
traced to the private ownership of land is further apparent from the discrepancy between the theory and the facts. If it were true that it is the holding of land out of use that hampers business, then periods of depression would be marked by the impossibility of obtaining raw material in sufficient quantity to meet the demand. We know, however, that this is not the ease.

While Henry George realizes that-

All trade is the exchange of commodities for commodities, and hence the cessation of demand for some commodities, which marks the depression of trade, is really a cessation of the supply of other commodities, ${ }^{108}$

he fails to point out any commodity of which, as he says, the supply has ceased. Surely, there are no facts to indicate that the supply of products obtained directly from land is insufficient during periods of industrial depression. On the contrary, as noted above, there is no scarcity of raw products generally during such periods. If there were such scarcity, the excessive demand would at once drive up the prices of these raw products, stimulate the eultivation of land and increase rent. Landowners would eagerly put their land to profitable use, and stagnation could not drag on for years, as it does. Obviously, the theory does not agree with the facts of the case.

Suppose the water supply in some one quarter of a town is deficient. An expert, seeking to locate and correct the trouble, examines the pressure of water at a number of accessible points in the locality and finds the water pressure high at one point and low at the next. He therefore naturally concludes that the conduit is choked somewhere between. I t us apply this test to trade stagnation. In the hands of the manufacturers and merchants we find the supply of goods congested to such a degree that the condition is generally designated as "overproduction." They all want to sell. The obstruction which we are to locate is not to be looked for at an earlier point in the process of production. It must be at a point beyond. 
On the other hand, the consumers, particularly the workmen, are in need because they cannot buy. There are too many sellers and too few buyers. On the one side of the point of sale we find congestion or excessive accumulation; on the other side we find deficiency and want. Evidently, the obstruction lies somewhere between; the impediment is in the channels of exchange. The commodity, in the supply of which a "cessation" has occurred, is not, as Henry George supposed, the produce of land, but something very different, namely the medium of exchange. And so long as the law puts arbitrary limitations on the use of assured credit as a medium of exchange, the under-supply cannot be remedied, and numbers of workmen must remain unemployed.

364. Single Tax not a Remedy.-While the fundamental object of the single tax, namely the acquisition of the economic rent by the community instead of by the individual landowner, is justifiable in every respect, the measure would be practically useless as a means of correcting the most serious of our industrial ills. The power of money to acquire unearned wealth, the power without which land ownership could not afford unearned acquisitions, would still remain in force. Experience shows plainly that the landowner as well as the producer is subject to the dominance of this power. Business enterprises, especially those of large magnitude, fall gradually under the control, not of the owners of land, but of so-called "financiers," manipulators of money and monetized credit (338). If the tax on land were to replace all other taxes, and the ideal of the advocates of the single tax were realized, it would soon become apparent that the economic evils from which we are suffering had not thereby been cured, and that the working classes had not been benefited. Another reform would still be needed, namely that of doing away with the existing obstacles in the process of exchange (329). On the other hand, were these obstacles first overeome, the landowners would find themselves unable, under the dominance of competition, to retain any portion of the economic rent (328), and the aim of the single tax would thus be incidentally attained. 
365. Socialism.-Discussion of socialism is beset with peculiar difficulties, chiefly because of the fact that the leading authorities on the subject do not agree in their statements of its propositions. There is so wide a divergence in the various programs advanced in the name of socialism that it would be practically impossible to review them all. We shall here confine ourselves to a consideration of that plan of social reorganization which is most generally advocated by socialists and through which equity in the reward of labor is to be attained, namely the "common ownership of all means of production," including, of course, land, so that only consumption products become subject to private property. Through that common ownership it is assumed that "the modern wage system will be abolished" and "competition will be replaced by co-operation."

None of the schemes of so-called socialism is even reasonably definite as to the ways and means of inaugurating and maintaining the proposed socialistic state. Its authoritative exponents insist that no one can be expected to know the future, and that the details of the process will naturally develop in practice. They propose, in effect, to cross the bridge which spans the chasm between the present world and their Utopia when they come to it, failing to realize, in their enthusiasm, not only that there is no such bridge, but also that they have not even planned out a way of building one.

The advocates of socialism are, however, to be credited with a realizing sense of the fact that the present social order is somehow out of joint. To recognize the existence of a wrong is the first step towards reform.

As a physician, when called to a patient, has first to observe the symptoms before he can diagnose the case and prescribe the correct treatment, so must reformers first observe those facts which reveal the morbid condition of the social organism. This first step the socialists have correctly taken. But in the next step, in the diagnosis, they have erred, and consequently in their prescription they have gone amiss.

366. Theory of Socialism.-The theory presented by Karl Marx in his work "Das Kapital" is the only thoroughgoing attempt to propound a scientific basis for the proposition of 
socialism. His theories of value, of wages and of "surplus value" or interest, have been diseussed at some length in our earlier chapters $(164,207-208)$ and have been found to be unsound. It is therefore not necessary to repeat these arguments here.

Were the reasoning of Karl Marx correct, the abolition of the private ownership of capital would indeed be the only effective remedy for the present industrial ills. Aecording to his thesis nothing short of collective ownership of the means of production can prevent the acquisition of "surplus value" by the individual owners of eapital and make it possible for the workers to get the full reward of their labor. That reward can come to them only through the institution of the " $\mathrm{Co}$ operative Commonwealth." Competition, whieh charaeterizes the individualistie system, is eonsidered to be the means through which eapital is enabled to aequire the "surplus value." This competition is branded as the weapon of the strong in the everlasting warfare of commeree. Production and exehange, it is maintained, instead of being carried on to provide the requirements of life, develop into a scramble in the market, in which the insatiable hunger of the possessors of eapital for "surplus value" is the sole incentive to production. More things are accordingly produced than required, and the market becomes overstocked with produets for which there is no demand. It is urged that the "competitive" system must give way to a "eo-operative" system of production, which is to be directed and regulated by competent authority, so that production shall be adapted to demand. Some socialists go even so far as to dissuade wage earners from saving, and rather to cultivate a higher standard of living, so that the amount of labor "socially neeessary" for the maintenance of "labor power" shall be increased, and with it the wages of labor, while the share going as "surplus value" to capital is correspondingly reduced.

These and other similar arguments indicate the confusion of ideas upon whieh the reasoning of socialism is based. First and foremost, we have the fact that competition and co-operation are not antithetical, as soeialism assumes. They are in 
reality complementary, inasmuch as freedom of competition develops co-operation. Competition can be regarded as baneful only by those whose diagnosis of existing conditions fails to go below the surface. The regulation of production, so that supply shall be properly adapted to demand, never can be effected through prescribed regulation so well as through the processes of untrammeled competition (148). The notion that the level of wages can be raised by deliberately raising the standard of living is a palpable case of putting the cart before the horse and, at the same time, directly conflicts with the socialistic theory that under the individualistic system the wages of the least skilled laborer are held down to the point of bare subsistence.

367. Impracticability of Socialism.-The various efforts to give a coherent foundation to the propositions of socialism have all failed. As to the ways and means of carrying the idea into practice, no definite proposition has yet been generally agreed upon by its advocates.

The problem which confronts socialism is of a twofold nature. In the first place, it is necessary that some practicable plan be devised for turning the present industrial system into a socialistic one. And that once done, there must be mapped out some way of maintaining the new order of things.

It is manifest that the transition can be effected only in two ways, namely, either by turning one enterprise after another through private initiative from a competitive to a co-operative organization, or through the acquisition of all means of production by the community at large.

Of these two methods the first is elearly in the direction of least resistance and therefore the most practicable course. There is nothing whatever in the way of turning an existing industrial enterprise from a competitive into a co-operative organization, or of establishing a new one upon this basis.

Suppose that a number of workers acquire or establish and operate a manufacturing or distributing business with capital of their own. They may then agree that the entire net income shall be distributed among themselves as compensation for their services. Whatever "surplus value" there might be, 
would thus go to them and increase their wages. It is plain that if the theory of socialism had any validity, such cooperatice organization would easily overcome the competition of institutions organized on the competitive or so-called capitalistic plan, and the socialistic régime would thus come about in a normal sequence by way of gradual evolution.

It may be alleged that this plan of socializing industry is fraught with difficulty, inasmuch as workers generally are not possessors of capital and therefore cannot successfully carry out this plan. But this objection is not valid. Workmen banded in unions do not hesitate to enter into a conflict with the competitive system by striking, thus deliberately sacrificing their income and drawing upon their capital previously saved from their wages. Why not use this capital in the formation of co-operative organizations which shall own the capital they use, and let these gradually displace the capitalistic concerns which continue to compete with them? This done, the establishment of the socialistic state could be effected by amalgamation of all co-operative organizations into one.

The fact, however, is that while co-operative enterprises have been actually established time and again, and while some of them have measurably prospered and continue in existence, they have failed to convert the industrial world to their methods.

The alternative course is to substitute communal action for private initiative and to obtain the end through the acquisition of all means of production by the community. It is often pointed out by advocates of socialism that much has already been done in this direction. The postal system, the highways, some canals, the public schools and numerous waterworks and gasworks are owned and operated by the community. From this it would appear that the conversion of our social system into a socialistic state is actually in progress. The next step would seem to be the acquisition and operation of the entirc transportation, telegraph and telephone systems by the government, and eventually of all means of production used in industry and commerce.

If this scheme of socialization could really avail to improve 
the condition of the masses of the people, and particularly the industrial classes, then the extensive nationalization of the means of transportation and communication which has already taken place in various European states should have proven of marked benefit to the wage carners.

These expectations, however, have not been realized; the condition of European workers has not been bettered by this policy in a manner or degree that would tend to confirm the socialistic theory. Its defenders have therefore taken the ground that such governmental ownership of industries as has hitherto been exercised is not socialism, but merely a form of capitalistic or plutocratic monopoly. But in the absence of any explanation of the difference between this government ownership and icleal socialism, it can only be inferred that the refusal to recognize the former as essentially socialistic is simply due to the fact that the expected results have not been realized.

One other way of reaching the goal of socialism has been suggested here and there as the final necessity of the situation. It is the forcible expropriation and confiscation of all individually owned capital by the community. A serious consideration of this proposition need not detain us.

It is to be observed at this point that while there is no law forbidding the formation of co-operative enterprises with the view of realizing the dream of socialism, the free utilization of eredit as a medium of exchange, to which our investigation points as the only way to attain social justice, is effectually prevented by legal obstacles. Were the theory of socialism correct, the socialistic state would naturally evolve under the operation of the law of the survival of the fittest. But the free monetization of credit is made impossible by the provisions of our monetary laws.

The second problem that confronts socialism is that of maintaining the socialistic order after it is inaugurated. A number of questions must be satisfactorily dealt with, if the socialistic state is to endure.

It is of course assumed that all men physically able would be engaged in some work. But putting aside all questions as 
to how the work is to be organized and the various tasks allotted, the manner as to how, and in what quota, the produets are to be distributed must be definitely worked out. There are manifestly but two alternatives. Either the workers must be paid wages, whether in money or in orders of some kind, with which to obtain from the general store what they clesire, or some other plan of sharing the products on the basis of communal ownership must be put in practice.

If the distribution is to be effected through some medium of exchange given in return for service, in other words, through payment of wages, the amount of the wage must be determined somehow. If that amount is to be decided by official rule, how is that rule to be applied? Is a distinction to be made between the skilled and the unskilled, the intelligent and the stupid, the diligent and the lazy? If so, who is to be the judge? Furthermore, how and by whom are the prices of the products to be regulated? And if the prices are to be regulated by official action, how is that action to be determined?

Whatever might be the details of the system, these must be in harmony with the fundamental principle of socialism, namely communal ownership of all means of production, transportation and communication, which necessarily implies that all products of industry shall primarily belong to the eommunity, from which the individual is to obtain what he wants in exchange for his wages, and that these wages shall in some way be decreed by the state. The state being the sole employer, the individual worker can have no alternative but to be employed by the state, and from the decree of the state he can have no appeal but to the state itself. The principlc of individualism that everyone shall have the right to dispose of the products of his own labor is to be abolished in the system of soeialism. If it is nevertheless proposed that the products shall be shared out in proportion to merit; if the principle of socialism is to be: "From each according to his ability and to each according to his merit," the advocates of socialism have failed to point out a reasonable plan for gauging individual merit, especially as regards efforts which are essentially different in their nature. 
368. Communism.-The other alternative in the distribution of the products of labor would be a system in which all forms of private ownership are to be abolished and all forms of wealth owned in common. Under this system every member of the community is to do some share of the work, and in return each is to have a share of the things produced. The general idea of communism, as distinguished from socialism, appears to be expressed in the motto usually put forth by its advocates: "From each according to his ability, to each according to his needs."

To persons of an emotional nature, whose feelings go deeper than their reasoning, this proposition is so attractive that innumerable attempts have been made to put it in practice. But so far, all experiments of this kind have ended in failure. The various enterprises started on this plan that lasted any length of time gradually abandoned the principle of communism and ultimately developed into some form of joint stock organization.

The cause of the failure of communism is not far to seek. The existing supply of the things produced being open to all comers, according to their individual needs, the first question that comes up is as to who is to determine those needs, and how. The next question is, how is each member of the community to be brought to do that which is needed to be done for the community at large, in other words, how can the supply of products be adjusted to meet the call for them? For instance, suppose the members of the community who have chosen to be shoemakers is only lialf enough to meet the call for shoes, are they to work double time to make up for the lack of their numbers? Under the individualistic system the insufficient supply of shoes would cause a rise in their price and so increase the recompense of shoemakers above the average. This would attract new workers to their ranks and so bring down the price to the general level. The economic force that tends to adjust recompense to effort is absent in every plan of communistic organization. The communistic system requires of the individual practically total self-effacement and the abandonment of all expectation of material reward for 
exceptional services. Experience has amply proved that while men may consider themselves in some measure requited by honors and distinction for some signal service rendered the community, continued efforts of an exceptional nature cannot be looked for unless there is present the further incentive of a material reward.

Nevertheless, the idealist finds himself constantly obsessed by the question as to why should a man whom nature has endowed with more than average intelligence enjoy more comforts and luxuries than his less talented fellow man? It is not a man's fault that he lacks talent; it is his misfortune. If it is proper, as we have found (325), that the advantages which nature has bestowed upon land should belong to the community, why should not also the talents which nature has bestowed on individuals belong to the community?

When closely examined, the two cases are found to be essentially dissimilar. Land is held in private ownership by virtue of a social compact through which the owner acquires the exclusive right to the land and its usufruct. He gets the latter, whether he himself utilizes the land or transfers its occupancy under lease to another.

The natural endowments of an individual, on the other hand, are not held by virtue of any concession, communal or otherwise, nor can they be put to use by anyone but the individual himself. The protection which the community affords him through the operation of law is only such as it accords to every other individual. The community cannot endow a man with talent, and no law is needed to protect him in its possession. Besides, exceptional skill may be acquired through patient and long continued effort, instead of being a manifestation of natural endowment. Is it proper that a man who diligently attends to his work should be made to share with the man who slights it? To insist on such sharing would be putting a premium on indolence.

Furthermore, the less gifted always derive more or less benefit from the achievements of the more gifted. Every advance in the methods of production benefits in the end all consumers of the products (149). The less gifted cannot demand, either as a matter of justice or of expedicney, more 
than what accrues to them in the natural course of free and untrammeled competition.

When this course is not subject to interference through class privilege, nor through unjustifiable restrictions on industrial and commercial freedom, all will be better circumstanced under the individualistic system than under any possible form of communism. Under the one system progress is fostercd and production continually facilitated through the incentive given to ambition and achievement by the prospect of substantial reward, while under any other system ambition would become atrophied, achievement diminished and progress brought to a stop.

369. Anarchism.-It is perhaps superfluous to state that by "anarchism" is here to be understood, not the idea of lawlessness and terrorism which it usually connotes in the public mind, but that propaganda, often called "philosophic" anarchism, which is based on the idea that the source of the disorders of the social organism is to be found in the institution of government, which, it is asserted, is essentially an invasion of the natural freedom of the individual. The theory assumes that the individual, if free from coercion or control by government, would naturally rule his conduct through an inborm sense of justice and an instinctive respect for the rights of others.

According to the tenets of anarchism, the community has no right to levy taxes, nor to enforce in any way the collection of debts. Nor has it any right to impose legal obligations or restrictions of any kind. No one should own land unless he occupies and uses it. It is supposed that competition, when freed from all obstacles, will naturally adjust the price of the products of industry to cost.

Anarchism, like socialism, is proposed as a means for correcting such injustice as exists in the present social system, but it is diametrically opposed to socialism, both in its diagnosis of the disorder and in the remedy prescribed. As already stated, the ailments of society are regarded as due to the invasive interference of government through law. But instead of distinguishing between laws which conserve the 
natural rights of individuals and those which infringe them, all are condemned indiscriminately, and the concepts of government and of invasion are confused. Under this delusion it is concluded that the only way to avoid the invasion of natural rights is to abolish all government. The avowed aim of anarchism is "equal freedom" for every individual.

But equality of freedom necessarily imposes a limit on freedom by its very qualification. That limit is at the point where invasion begins, and this point must in some way be determined. Is that determination to be made by each individual for himself? Is each man to define what constitutes invasion and to decide how far his rights go without intruding on the equal rights of another? Even as between the most intelligent and conscientious of men, differences of opinion and conviction continually arise as to how far their respective natural rights extend. Cases are bound to arise in which such differences lead to contentions. Where the individuals involved fail to reach a mutual understanding, their differences must be adjusted by some extraneous agency, and to be effective, the decision of this agency must be capable of enforcement. The process of the decision and the manner of the enforcment become naturally a matter of general agreement, in other words, of a social compact. Thus we have law and government in the very nature of any conceivable system of anarchism. Equal freedom can prevail only by virtue of government.

The necessity of an organized social body is yet otherwise implied in the very fundamentals of anarchism. A right of ownership in products of labor, which is one of the tencts of the anarchistic school, can exist only by virtue of a social compact, expressed or implied, and which can endure only where there is a supreme power ready to protect that right when neeessary.

Opposition to government can be justified only so far as it is dirceted against such enaetments of law as violate the principles of equity and invade the natural right of the individual. Because some laws are incquitable and therefore invasive is no reason for overturning all. It is in the ignoring of this 
truth that the proposition of anarchism is fundamentally defective.

370. Land Tenure Under Anarchism.-The proposition of anarehism in relation to land is that occupaney and use alone shall confer the right of possession, and that land shall not be taxed. This principle, however, could be put in practice only under conditions which are tantamount, not to anarchism, but to its antithesis, namely communism.

Anarchism proposes to concede the right of ownership in products of labor, such as houses. Suppose, now, the owner of a house has cause to change his residence and offers his vacated house for rent. The house would continue to remain his property, and the rent which he obtains under free competition would naturally include, not only recompense for wear and tear, but also the rent of the land due to location. This means that the owner of the house would remain virtually the owner of the land on which the house is located and that he would continue to get the economic rent, even though he ceases to occupy that land.

In any system of land tenure based on occupancy and use, as proposed in the anarchistic system, the entire rent of all land would accrue to only a portion of the community, as it does under the existing system. But since the rent which land yields is really produced by the community at large (180), the only just disposition of the rent is that to which we have already pointed, namely its appropriation by the community through taxation.

371. Theory of Anarchism Regarding Price.-The supposition that under an anarchistic system the price of products would be at the point of cost could not be realized if occupancy and use of land conveyed an otherwise unconditional right of exclusive possession. It is a fully recognized fact that most things can be produced at a lower cost in some places than in others, and it has already been shown by Ricardo (172-173) that the ruling price equals the normal cost of production at the margin, that is, where production is carried on under the most unfavorable conditions under which it is still being continued. Equality of price and cost would therefore obtain only in the case of things produced at the margin of pro- 
duction, and the owners of intra-marginal advantages, who can produce at a less cost, would continue to reap unearned profits. Land tenure based on occupancy and use would therefore effectually defeat the fundamental aim of philosophic anarchism, namely the elimination of unearned gains.

To bring about that ideal eondition under which price will tend to equal cost, not only at the margin of cultivation, but under every degree of natural advantage, it is necessary that the economic rent become an item of the cost of production (348); and unless this item accrues to the community at large, it must accrue as an unearned profit to somebody. Since our investigation has made it clear (327) that when money and capital are deprived of their monopoly power the owner of land will be obliged, under the working of purely economic forces, to pay this rent to the community in the form of tax, it follows that the ideal aim of anarehism can be realized, not through the abolition of government, but simply through the abolition of the monopoly power of money.

372. Conclusion.-We started out to learn, if possible, why it is that coincident with the enormous increase in the facilities of production brought about by modern advances in science and the arts, there are frequently recurring intervals of industrial depression, when workers in many fields of industry are thrown out of employment and brought to suffering for want of the very things of which the production has been so greatly facilitated.

In the course of this investigation we have been brought to the conclusion that the recurring economic paroxysms, known as financial crises, which are followed by periods of industrial depression, are the inevitable outcome of the arbitrary limitation of the volume of the currency. We have found that every symptom of the disorder, every successive feature of the industrial disturbance, is clearly and unmistakably traceable to that one prime cause.

But in addition to that we have also found that this same cause gives rise to the most grievous of the many forms of social and conomic injustice that are so loudly erying for redress throughout the modern world. It is the extrinsic 
power of money, that power whereby the owner of money is enabled to "make money" without doing anything, that power whereby the owner of wealth is enabled to acquire more wealth without producing anything, that power of money which is due to its being the subject of an impersonal monopoly. We have seen how it is that we are actually fostering this monopoly without realizing our error, misled by academic misconceptions that have been handed down to us from the past. We have found what it is that gives reason to the discontent of wage earners throughout the industrial world. But we have also learned to understand that, while it is true that the wage earner is bereft of a portion of his earnings to the benefit of the wealth owner, the "capitalist," it is not because of the greed or wickedness of the wealth owner, as is but too often preached to the wage earner, but because this injustice is inherent in our existing economic system, and more particularly because of the constriction of the facilities of exchange.

It is through the restriction of the freedom of exchange that money and capital have obtained that extraordinary power through which industry is periodically paralyzed and the producers are shorn of the full benefit of their own exertion. Is this process to go on unchecked until it perhaps reaches the vitals of the social system? Or is the body social to be given over to be experimented on with the crude and merely temporizing remedy of trade unionism, or with one or another of the numerous schemes of socialism, all under a misunderstanding of the real cause of the trouble? Or shall it be that, with that cause elearly recognized, we remedy the trouble by some method that is at once rational, simple and safe?

But for the prevalence of groundless economic doctrines inherited from past generations, and the tenacity with which these are adhered to by present-day leaders in economic science, this necessary remedy would before now have been applied, by removing all arbitrary restrictions on the natural expansion of the means of exchange. Every step in this direction has been persistently opposed on the ground that the unrestricted monetization of credit, even though that credit be completely assured, is fraught with danger to society 
and replete with wrong to individuals. As we have shown in the foregoing pages, these fear's and anticipations are wholly imaginary. It is the existing currency system that is fraught with danger to society and injustice to individuals. This system must therefore be reformed. Will it be necessary to have this reform inaugurated through private initiative, by the formation of loeal and federated institutions for the clearanee of commercial accounts, so as to overcome the existing limitation of the medium of exehange by lessening the need for curreney, or shall the facilities of exchange be inereased through reform of our currency laws in the direetion of permitting the volume of the curreney to be determined by the exigeneies of business instead of through arbitrary legal limitation or other obstruction?

As regards general objections that can possibly be raised against a reform of this nature, none appears to be really tenable. There is scarcely one among all the numerous other remedies proposed for the existing social and economic disorders that does not, or would not, in one way or another result injuriously to some members of the community, or to the community at large. The several measures now adopted by governments to "eurb the predatory power of wealth," like graduated taxation, discriminate against the industrious and competent members of the community. Trade unions, in their effort to increase the recompense of underpaid labor through eoercive measures directed against both their employers and their fellow workers, invade the freedom of all concemed. The Single-Tax proposition, if enacted into law, would work injustice to a large elass of the community. On the contrary, the reform of the currency on the lines proposed in the preceding chapters would not work injustice in any way whatever. No one would be deprived of anything belonging to him, and only the abnormal power of capital would eome to an end. The effect on society generally would be to free the worker's in cvery ficld of industry and commerce, employers and wage carners alike, from the incubus imposed by the existing money system and to bring about an equitable distribution of the products of labor, thus putting an end to the discords which make of our modern economic world a babel of contention. 


\section{APPENDIX}

\section{COMMENTS ON THE UNITED STATES BANKING AND CURRENCY'}

\section{LAT, APPROVED DECEMBER 23, 1913}

WHILE the present work was going through the press, a reform of the banking and currency system of the United States along lines widely discussed for several years past was enacted into law. As regards general principles, the currency to be issued under the new system does not differ from the existing national bank currency. The changes relate only to certain details.

In the first place, the machinery through which the currency is to be put into circulation is more complicated. The "Federal Reserve Board" is a newly created organ of the government through which the issue of the new currency is to be supervised and regulated; and a system of "Federal reserve banks" constitutes a new agency in the process of issuing currency notes, interposed between the government and the individual banks. The reserve banks are to be organized as stock companies of which the national banks are obligated, and under certain conditions state banks, trust companies and even individuals are permitted, to become stockholders. With certain exceptions these reserve banks can do business only witl each other and with the member banks. The principal exceptions are that they shall act as depositories and fiscal agents of the government and may engage in certain foreign banking operations.

In the second place, the provisions for insuring the redeemability of the currency notes are changed. The "Federal reserve notes" are government obligations, redecmable by the reserve banks in gold or lawful money, and by the United States Treasury in gold to be furnished by the reserve banks. No specific limit is placed on the amount of these notes that may be issued. This currency is to be advanced by the Reserve Board to the reserve banks against collateral sccurity in the form of commercial paper previously discounted by the menber banks and rediscounted by the reserve banks. The latter are to pay such rate of interest on these advances as may be established by the Feleral Reserve Board, and are to maintain a gold reserve of 40 per cent. of the amount of the issued currency remaining in circulation.

The Federal reserve banks receive deposits from the member banks and also from the government. These deposits are available for the rediscounting of the paper presented by the member banks, but a reserve of 35 per cent. of the deposits, in gold or lawful money, must 
be maintained. Each member bank is to maintain a reserve of 12,15 or 18 per cent. of its deposits, according to location, this reserve to consist in part of currency and in part of deposits in the Federal reserve bank of its district.

The principal feature of this system making for greater freedom of exchange is the provision for the use as a basis for currency of a form of credit having much greater compass than that provided under the previous system. But the possible benefits of this provision are in part, if not entirely, neutralized by other features.

The machinery for distributing the currency is unduly complicated by the interposition of the Federal reserve banks between the government and the individual banks. In the previous system the national banks were the direct agents between the government as guarantor and the people as users of the currency.

Although the law does not specify a definite limit to the amount of the reserve notes, there is nevertheless imposed indirectly a limitation that tends to prevent the issue from becoming adequate to the real needs of commerce.

The provision requiring the reserve banks to maintain 40 per cent. gold reserve has this effect. It is apparent that under this condition the amount of the currency issued cannot exceed two and one-half times the amount of gold held as rescrve for the issue. And inasmuch as the amount of gold available is limited, the amount of notes that can be issued is thereby restricted.

This restriction is partially relieved by the reduction of the reserve previously required of national banks, this reduction permitting a corresponding expansion of bank credit.

There is, however, another obstruction to the note issue, namely, the greater cost of bringing the notes into circulation, as compared with that under the old national bank system. This cost embraces several items. To begin with, the reserve banks are to pay on the reserve notes advanced to them such rate of interest as may be established by the Federal Reserve Board. Let us suppose that the Board determines it at 2 per cent. To this each reserve bank must add something to cover its expenses and an amount calculated to afford dividends on the 40 per cent. gold reserve supplied by the stockholders and lying idle in the bank. The stock being expected to return a dividend of 6 per cent., the discount rate of the reserve bank must yield for the reserve alone 2.4 per cent. of the amount of its note issue. Should then the annual cost of conducting the reserve bank, including the current assessment for the requirements of the Reserve Board, amount to, say, 1 per cent., the discount rate of the reserve bank cannot be less than 5.4 per cent. And if the member banks must pay this rate for the money, they eannot afford to lend it to borrowers at 6 per cent., the legal limit of interest in many states of the Union. The demand for Federal reserve 
notes by member banks would in that case be so low that very little of that currency would be called for, unless, indeed, the interest charged by the Reserve Board is kept down to practically nil, and the dividends of the reserve banks are made up in part from other sources, such as the loaning out of the deposits received from the member banks and the government. Some additional income is calculated to accrue from international transactions, but this cannot be accounted as an important factor of the case.

As regards security, the national bank currency is, if anything, better safeguarded than the new eurrency. The former is doubly secured; first, by the borrowers' pledges held by the banks of issue, and second, by Federal bonds, the property of the banks. Of these two securities the more reliable, consisting of the bonds, is placed in custody of the government, which, in turn, guarantees the validity of the notes. In the new system the security consists of the borrowers' pledges and the assets of the reserve banks, including the required gold reserve. Of these the less reliable, the pledges of the borrowers, are placed constructively in custody of the government. But these securities require frequent renewal and recurring scrutiny, involving an added complication and a corresponding cost.

Should it bappen that commercial paper, rediscounted by a reserve bank for one of its member banks, becomes uncollectible, and the bank that had it rediscounted is unable to replace it by valid pledges, being itself bankrupt, the deposit of the defaulting bank is applied to cover the deficit. And if this deposit should be insufficient, the reserve bank must make good the balance. Such loss, accordingly, falls on the remaining stockbolding banks. In this way the reserve bank becomes an insurance agency through which any loss caused to the reserve system by a defaulting bank is distributed among all other banks of the district. This is the only valid justification for the creation of an agency intervening between the government and the individual banks. Complete security of the currency is thereby assured, but this desideratum is attained in a much more cumbrous manner than under the former system.

In the conflict of opposing views on the general subject of banking and currency the law, as finally passed by Congress and approved by the President, came to include some provisions which, on close examination, would appear to be in conflict with the main purpose of the law.

In the rediscounting of commercial paper each Federal reserve bank is restricted to dealings with its member banks. The profits out of which to pay dividends to the member banks as stockholders must therefore be made out of them as borrowers. If every stoekholding bank were to borrow in proportion to the stock it holds, it would be immaterial whether the discount rate be so high as to afford normal dividends, or so low as to afford none at all. What the member banks 
would lose on one hand, they would gain on the other. A high rate of discount churged and correspondingly high dividends paid by the reserve bank would accordingly be of advantage only to those stockholding banks which do but little discounting, while those that discount more than a proportionate share would be benefited through a low rate of discount, even though the rate of dividends would thereby by diminished. If the reserve banks are to be enabled to pay dividends of 6 per cent. on the paid-in capital, as indicated in the law, their discount rates must, as observed above, be so high as to deter the member banks from having their commercial papers discounted, a condition which obviously militates against the volume of currency responding to the needs of commerce.

With the view of ereating an elastic currency, commercial paper, of which there is an abundance, is to be utilized instead of Federal bonds as that security for the currency which is to be held by the government. But it is the use of this very kind of security which introduces an element of incongruity. Currency is an instrument with which to make payment for goods delivered or services rendered by one to another, while commercial paper is an instrument through which such payment is postponed. It follows that under this plan the means for making payment are obtainable only through a system of postponing payment. A currency system requiring as an essential of its existence an indefinite perpetuation of the practice of deferring the payment of debts through promises to pay them in the future cannot be regarded as a rational solution of the currency problem.

While the Federal reserve currency system is a step in the right direction, inasmuch as it affords the possibility of a much needed expansion of the currency without jeopardizing its soundness, the shortcomings of the system are such as to make the process of issuing the currency so costly that the intention of the law, that of rendering the business world independent of financial disturbances, can at best be but partially realized. Commerce and industry can be benefited by the Federal reserve system only in the measure in which it will afford the business world a lower rate of interest and discount than ruled before. 


\section{LIST OF AUTHORS QUOTED}

Bexthas: "Defense of Usury," by Jeremy Bentham, London, 1790.

Bilgibam: "Involuntary Idleness," by Hugo Bilgram, Philadelphia, J. B.

Lippincott Company, 1889.

BöHM-BAWERK: "Capital and Interest." (Kapital und Kapitalzins, von

Eugen v. Böhm-Bawerk. I Abteilung: Geschichte und Kritik der

Kapitalzins Thecrien. Innsbruck, 1884.) Translated by William Smart, London and New York, 1890.

"Positive Theory of Capital." (Kapital und Kapitalzins, von Eugen v. Böhm-Bawerk. II Abteilung: Positive Theorie des Kapitales. Innsbruck, 1889.) Translated by William Smart, London and New York, 1891.

"The Positive Theory of Capital and its Critics," by E. v. BöhmBawerk, Quarterly Journal of Economics, January, 1896.

Conaxt: "The Principles of Money and Banking," by Charles A.

Conant. In two rolumes. New York and London, Harper Brothers, 1905.

George: "Progress and Poverty," by Henry George, New York, Joln

IV. Lovell \& Co., 1883.

MACLEOD: "Elements of Economics," by Henry Dunning MacLeod. In two volumes. New York, D. Appleton \& Co., 1881.

Marx: "Capital." (Das Kapital, von Karl Marx, Hamburg, Otto Meissner, 1872.) Translated by Samuel Moore and Edward Aveling, Chicago, Charles H. Kerr \& Co., 1906.

MiLL: "Principles of Political Economy," by John Stuart Mill. In two rolumes. New York, D. Appleton \& Co., 1884.

Newcomb: "Principles of Political Economy," by Simon Newcomb, New York, IIarper Brothers, 1886.

Perry: "Elements of Political Econony," by Arthur Latham Perry, New York, Charles Scribner \& Co., 1866.

Ricardo: "The Works of David Ricardo," by J. R. MeCulloch, London, Jolin Murray, 1886.

Stager: "l'rinciples of Economies," by Henry Rogers Seager, New York, Henry Holt \& Co., 1913.

Surtir: "Wealth of Nations," by Adam Smith, London, George Routledge \& Sons.

Siencer: “Social Staties," by Herbert Spencer, New York, 1). Appleton $\&$ Co., 1888.

Walker: "Mloney," by Francis A. Walker, New York, Henry IIolt \& Co., 1883. 


\section{OUTLINE OF INDEX}

Abstinence. See Theories. Anarchism. See Theories. Arbitration. See Trade Unions.

1. Bank Credit.

Bank Notes. See Currency.

2. Banks of Issue.

Barter. See Distribution of Products.

3. Business Stagnation.

4. Capital.

5. Capital Goods.

6. Chance.

Checks. See Bank Credit.

Commerce. See Distribution of Products.

Commercial Clearance. See

Currency Reform.

Communism. See Theories.

7. Competition.

8. Cost of Production.

9. Credit.

10. Currency.

11. Currency Reform.

12. Debts and Debtors.

13. Definitiuns.

Demand. See Supply and Demand.

14. Diagrams.

15. Diminishing Returns.

16. Distribution of Products.

17. Distribution of Wealth. Dollar. Sce Unit of Value.

18. Economic Forces.

Effort. See Labor.

19. Employment.
20. Equity.

Exchange. See Distribution of Products.

21. Gold.

Groups. See Productive Groups.

Income. See Distribution of Wealth.

Industrial Flow. See Monetary Flow.

Inertia. See Economic Forces. Inflation. See Currency Reform.

22. Insurance.

23. Interest.

24. Labor and Industry.

Labor Legislation. See Tracle Unions.

25. Land.

26. Land Values.

27. Laws.

Market. See Distribution of Products.

Means of Production. See Production.

28. Monetary Flow.

29. Money.

30. Monopoly.

Ownership. See Rights.

31. Price and Price Limits.

32. Production and Consumption.

33. Productive Groups.

34. Profits.

Redemption. See Currency.

35. Rent. 
36. Rights.

Risk. See Chance.

Saving. See Economic Forces. Seignorage. See Value of Money.

Single Tax. See Theories.

Socialism. See Theories.

Speculation. See Chance.

37. Supply and Demand.

38. Tariff.

39. Taxes.

40. Theories.
41. Theory.

42. Trade Unions.

Unemployment. See Employment.

43. Unit of Value.

44. Utility.

45. Value.

46. Value of Money.

4i. Wages.

Waste. See Chance.

Wealth. See Distribution of Wealth. 


\section{INDEX}

[NUMBERS REFER TO PARAGRAPHS, NOT TO PAGES.]

1. Bank Credit, 104, 105

Bank Checks, 104

Limitation of Bank Credit, 104, 238

Bank Reserves, 104, 292-294, 303

Margin of Security of Bank Credit, 104, 304

The Real Issuers of Bank Credit, 105

Deposit lnsurance, 220, 263, $289,290,304$

2. BaNks of Issue, 101, 302304,307

Evolution of Modern Banking, 103

"Wild-cat" Banking, 103, 322

3. Busivess Stagnation, 1, 121, 268-2S4

Cycle of Industrial Activity, 271-276

Current Attempts to Account for Stagnation, $277-284$, 361-363

4. Capital, 129-135, 197. See also (5) Capital Coods.

Distinction Between Capital and Wealth, 129, 319

All Forms of Capital Have Equal Rates of Income, $131,185,258,267$

"Fixed" and "Floating" Capital, 13Z

Aetive and Idle Capital, 133, 203, 211, 241, 242

Capital Viewed as a Fund, 135
4. Capital-Continued.

Efliciency of Capital, 155-162

Relation of Capital to Labor, $155-162,191,243$

Final Efficiency of Capital, $162,195,196,205,241,242$

The Aggregation of Capital, 211

Abundance of Real Capital, 266

Capital Not Productive, 336

5. Capital Goons, 129-134, 186$208,210,211$

Classification of Capital Goods, 132

Value of Capital Goods, 132, $133,152,153,197,198$

6. Chance, 1, 13, 14, 215-224

Risk, 13, 14, $72,76,96,112$, $139,219,263$

Waste Attending Production, $13,58,219$

Gambling and Speculation, 218, 277-280

The Law of Chance Profits, 224

7. Competition, 147-150

Competition Equalizes Marginal cost and Final Utility. $148,150,221$

The Law of Value Contingent on Free Competition, 150. 243

Relation of Wages to Profits Not Governed by Competi. tion, 154

The Strife of Competition, 3.42346 
8. Cost of Production, 61

Cost Determines Sellers' Price Limit, 61

Cost Theory of Value, 62, 63

Marginal Cost, 62

Marginal Cost Normally Equals Final Utility, 63, $148,150,221$

9. Credir, 66-76

Three Forms of Credit, 69

Divergent Conceptions of Credit, 70

The Substance of Credit, 72

Superposed Credits, 73, 100

Public Credit, 74, 341

The Value of Credit, 75,76

Depreciated Credit, 76, 96

10. Currency, 77-125, 285-314. See also (11) Currency Reform; (29) Money

Currency Laws, 85-87, 95, 98, $99,256,260,302-308$

Issuer of Currency is Debtor, $92,210,259,260,263$

The Substance of Currency, 92, 102, 115, 286-289

Redemption of Currency, 95, $101,292,295-297,302,303$

Depreciated Currency, 96, 112 , 114, 123, 124, 322

"Inconvertible" Currency, 90 Subsidiary Coin, 100

Bank Note Currency, 101, 102 The Real Issuers of Bank Cur. rency, 102

Restraints on the Issue of Currency, 103, 238, 260, 261, 264

Currency Laws Examined, 259, 260

Natural Limits to the Issue of Currency, 291, 292

The Process of Issuing Currency, 299
10. Currency-Continued

Money Tokens, 300, 301

Cost of Issuing Currency, 301

Missing or Lost Notes, 305

11. Currency Reform, 285-314

Volume Theory a Bar to Currency Reform, 239, 308, 322

"Inflation," 239,320

Commercial Clearing Institutions, 309-314

Results of Currency Reform, 315,316

Unfounded Apprehensions and Objections, 317-320

Effect of Proposed Currency Reform on Wages, 350

12. Debts and Debrors, 66, 68

Debt the Correlative of Credit, 66,68

Public Debt, 74, 341

Economic vs. Legal Payment of Debt, 75, 95, 341

Loan Debts Distinguished from Business Debts, 245

Growtl of Debts, 246, 255, 270, $272,344,346$

The Volume of Loan Debts. 251, 271-276, 344-346

13. Definitions and ExplanaTIONS :

Economics, 4

Utility, 6, 24

Immature Products, 6, 132

Production, 7

Labor, 8

Means of Production, 10, 132

Consumption, 14

Economic Groups, 15, 16

Rights, 17, 18

Laws, 17, 22

Right of Ownership, 18, 20, 21

Right and Duty, 19

Equity, 20 
13. Definitions, etc.-Continued. Value and Price, 23-25, 29

Unit of Value, 28

Dollar, 28

Standard Commodity, 29

Supply and Demand, 34

Price Limits, 48, 49, 56, 61

Current Price, 59

Normal Price, 60

Cost of Production, 61

Marginal Efiort or Cost, 62

linal Ltility, $6: 2$

Margin of Production, 62

Capitalized Values, 65

Credit and Debt, 66, 68

Money, s3, 88, s9

Currency, ss

"Inconvertible" Currency, 96

"Fiat" Money, 97

Seignorage, 97, 113

Subsidiary Coin, 100

Issuers' and Agents' Pledges, 102

Bank Credit, 104

Bimetallisn, 110

Monetary and Industrial Flow, 119

Capital, 129-132, 135, 197

Active and Idle Capital, 133

Wages, 137

Profits, 137

Personal and Impersonal Services, 137

Rent, 138, 139, 186

Cliance Profits, 138, 215

Amortization, 139

Capitalist, 143

Venturer, 144

Einployer, 146

Competition, 147

Final Efficiency of Capital, 162

Land, 170

Margin of Cultivation, 175

Cimmlative Rent, 176

Unearned Inerement, 181
13. Definitioxs, Etc.-Continued. Actual Rate of Land Tax, 182 Speculative Land Values, 183

Present and Future Goods, 197

Waiting, 200

Surplus Value, 207

Insurance, 220

Economic Inertia and Momentun, 221-223

Monopoly, 225, 226

Impersonal Monopoly, 226, 232

The Barren Circulation of Nonev, 245, 248, 249

Loan and Business Debts, 245

Money in Active and Passive State, 247

Socialism, Communism, Anarehism, 365, 368, 369

14. Diagrams :

Fig. $\quad 1-39,40$

Fig. $2-42,43,46,148$

Fig. $3-45$

Fig. $4-46$

Fig. $\quad 5-48-50,56$

Fig. 6-56-64, 115, 200

Fig. $7-59$

Fig. 8-64

Fig. $9-64,153$

Fig. 10-64

Fig. 11-108, 121, 320, 321, 346

Fig. 12-149

Fig. 13-154, 155, 159, 160, 166-168, 181, 185, 257,348

Fig. $14-157-159,161,162,177$

Fig. 15-160, 161

Fig. $16-161,162,177$

Fig. 17-161

Fig. 18-161, 195, 243, 244, 316,347

Fig. 19-161

Fig. 20-173, 180, 185, 267 , $323,325,359$ 
14. Diagrams-Continued.

Fig. 21-177, 178

Fig. 22-213, 214, 260

Fig. 23-221, 232

Fig. 24-234, 235

Fig. 25-247-256, 267,270-275

Fig. 26-271-276

15. Diminising Returis:

In the Use of Capital, 10, 156

In the Use of Land, 175

In the Intensity of Cultivation, 178

In Discounting the Future, 197

16. Distribution of Products, 12 , 83, 127, 217

Advertising, 12

Work of Distribution Indispensable, 12, 217

Buying and Selling are Reciprocal, $34,51,52$

Barter, 47-50

Complex Barter, 52, 83, 295

17. Distribution of Wealti, 126162,267 . See also (23) Interest; (34) Profits; (35)

Rent; (47) Wages.

Classification of Incomes, 136140

Wages, the Recompense for Personal Services, 137

Profits, the Recompense for Impersonal Services, 137

Apportionment between Labor and Capital, 137, 151, 154$162,267,347,348$

Classification of Profits, 138140

Composite Nature of Gross Incomes, 139, 140, 154, 248, 263,264

Amortization is Part of Cost of Supplies, 139, 143, 157, 265
17. Distribution of WealthContinued.

The Capitalist's Recompense, 139, 143, 157, 265

The Venturer's Income, 144, 219,224

Wages Vary Inversely as Interest, 159

Gross and Net Proceeds from Land, 181, 182

Division of Gross Proceeds from Land, 184

Monopoly Incomes, 231

Concentration of Wealth, 338

Efforts to Curb the Concentra. tion of Wealth, 339

18. Economic Forces:

Desire, the Impelling Force, 5, $35-41,43$

Aversion or Reluctance, the Restraining Force, 35, 41-43

Evaluation, 48-50, 54

Competition, 147-150

Abstinence or Waiting, 195, 196,200

Inducements to Save, 196, 200, $205,254,318$

Inertia and Momentum, 221223

Economic and Legal Impediments, 225

Monopoly, 225-235

19. EMrloyment :

Choice of Occupation, 44, 61, 149

The Problem of Unemployment, 268-270

Remedy for Unemployment, 316

20. EQUTTT, 20

Equity a Test of Just Laws, $22,259,260,325$

Ethics of Monopolies, 227 
21. GowD :

Gold the Adopted Standard of Value, 28

Gold Coin a Credit Instrument, 93, 94

Gold Reserve, 103, 292-297

The Value of Gold, 108, 109, 320

The Standard Commodity has an Assured Market, 259

The Demand for Gold, 293, 294

Reducing the Monetary Demand for Gold, 294

Exportation of Gold, 320, 351

22. Insurance, 139, 220

Insurance Item of Gross Interest. 139, 220, 248, 263

Deposit Insurance, 220, 263, $289,290,304$

23. INTEREST, 133, 138, 139, 186214, 236-267. See also (17) Distribution of Wealtl.

Interest Cannot Accrue to Idle Capital, 133, 197

Capital Interest, 138, 139, 186$208,242,257,258,265$

Money Interest, 138, 139, 188, 200-204, 209-214, 240

Composite Nature of Gross Interest, 139, 248, 263, 264

Capital Interest Compared with Rent, 187, 258

Capital Interest Compared with Money Interest, 188

Calvin's Explanation of $1 n$ terest, 190, 204, 237

Interest Theories, $190-208$, 236-267

Interest as an Inducement to Save, 196, 205, 254

Final Utility of Waiting, 200

Money Interest is Paid for the Use of Money, 210, 211, 240, 242
23. INTEREST-Continued.

Ineflicacy of Usury Laws, 236

Capital Keturns Accrue in the Form of Idle Capital, 244

The Rate of Interest, 252-256

Interest is a Monopoly Tax. 261

Interest a Toll on the Right to Work, 261, 291, 347

24. LABor AND INDUSTrY, 8, 9

Efliciency of Labor, 10, 1I, 155-161

Specialization of Labor, 11

Co-operation, 11

25. LAND, 130, 170-185

Land Distinguished from Im. provements Thereon, $17 \mathrm{I}$

Net Proceeds from Land, 181, 184

The Land Question, 323-334

26. Land Values, 181-185

The Unearned Increment, 181184

The Law of Land Values, 182, 183

Speculative Land Values, 183

Land Values, Tantamount to a Public Debt, 326, 329

Assessment of Land Values, 330,331

27. LAws :

(A) Economic Laws, 17

The Law of Equal Freedon, 22

The Law of Value, 30, 55, 58, 64,150

The Law of Supply and Demand, 58, 150

The Law of Competition, 147150

The Law of Wages, 166,347 350

Ricardo's Jaw of Rent, 179 174 
27. Laws-Continued.

The Law of Land Values, 182, 183

The Law of Chance Profits, 224 The Law of Interest, 244-256

(B) Statutory Laws, 17, 22

Exclusive Rights Due to Law, 18

Currency Laws, 85-87, 95, 98, $99,259,260,302-308$

Legal-tender Laws, 86, 95, 96, 98, 99, 306

Inefficacy of Usury Laws, 236

Corporation and Bankruptcy Laws, 340

Protective Tariff, 351-353

Labor Legislation, 355

28. Monetary and Industrial FLow, 119-121, 270

Rapidity of Circulation, 119, 120, 291

Impediments to Industrial Flow, 121, 241, 270

Flow of Products in Course of Production, 153, 241

The Barren Flow of Money, 245-249

29. Money, 77-125, 285-314. See also (10) Currency; (46) Value of Money

Complex or Indirect Barter, $52,83,259$

Money not a Value Denominator, $78,79,115,122,123$

"Money," “Dollar," a n d “Gold" often Confused, 78, $79,88,95,115$

Gold the International Money, 79

The Function of Money, 83, 88, 211,241
29. Money-Continued.

The Essence of Money, 84, 85, 298

The Right Conveyed by Money, 87

Theory of Money, 89-92

Money Tokens are Credit Instruments, 89, 93, 202, 210, 300

Owner of Money is Lender of Goods, 89-92, 209-211, 259

Credits and Debits of the Money System, 91, 92

The Issuer of Money is Debtor, $92,210,259,260,263$

The Substance of Money, 92, $102,115,286-289$

Standard or "Basic" Money, 93, 94, 293

Acceptance of Coin is not a Purchase of Gold, 93, 259

"Fiat" Money, 97, 322

Subordinate Money Systems, 106

Money not a Specific Commodity, 115, 123, 240

Money vs. Capital Goods, 131, 132, 134, 138, 188, 202, 203, 210,211

Money Never "Present" Goods, 202

Money Never a Means of Production, 203, 209

Efficiency of Money, 212-214, 238, 242

Money in Active and Passive State, 247

The Twofold Capacity of Money, 267

Over-supply of Goods Due to Under-supply of Money, 269, 270

Apparent Plethora of Money, 274 
30. MoNopoly, 18, 225-235

Monopoly Implies Restraint, 18,226

Franchises, 65, 231, 334

Impersonal Monopoly, 226, 232

Ethies of Mronopolies, 227

Monopoly lncomes, 234, 235

The Power of Monopoly, 235

Power of the Money Monopoly, 262,345

31. Price and Price limits, 24. $48,49,56$

Price Determination, 55-61

Puyers' Price Limit is Measure of Utility, 56

Sellers' Price Limit is Measure of Eliort, 56,61

Price Fluch uations, 58, 60, 108, $221,278,346$

Current rs. Normal Price, 5!, 60

Factors Accounting for Tariable Sellers' Price Limit, 61

32. Production and Consumption, $5-14$

Means of Production, 10, 14, $132,152,153,197$

Speeialized Production, 11, 126

Waste Attending Production, $13,58,219$

Margin of Produetion, 62. 17.;

33. l'ronuctive Groups, 15, 16, $127,141$.

Funetions Personified, 15, 16, 141-146

Aetive and Passive Agents, 142, 143

Manager and WVorkmen, 142

C'apitalist, 143

Venturer, 144

Composite Agrents, 145

Fimployer, 146
34. Profits, 137-140. See also (17) Distribution of Wealth

Chance Profits, 138, 144, 215224

Composite Nature of Business Profits, 140

35. ReNT, 138, 139, 170-185, 348

Composite Nature of Gross Rent, 139

Rent Accrues to Landowner, $139,171,324$

Ricardo's Law of Rent, 172174

Margin of Cultivation, 175

Cumulative Rent, 176

Intensity of Cultivation, 177

l'ersonal Factor in Rent, 179

The Source of Rent, 180, 323

Abrorption of Rent by Taxation, 325-32?, 348

36. Rigints, 17

Exclusive Rights Due to Law, 18

The Riglit of Ownership, 18, $20,21,67-69,71,228$

Right and Duty, 19

The Right of Land Ownership, 21. $170,230,324-330,360$, 370

The Right Conveyed by Money, 87

37. Supply and Demand, 34-43, 56-58

Total Supply Equals Total Demand, 34, 269, 270

Equilibration of Supply and Demand, 43, 56, 58, 63

Relation of Supply and Demand to Price, 57, 153

The Law of Supply and Demand, 58, 150 
37. Supply and Demand-Conta. Demand for Money Exceeds Demand for Merchandise, 201,270

Apparent Excess of Supply over Demand, 269-270

38. TARIFF, 284, 351-353

Tariff Theory in Conflict with

Volume Theory, 351

Balance of Trade Co-related to

Rate of lnterest, 352

Advantages of a Tariff, 353

39. TAXes, 19

Taxes on Issue of Currency, $103,238,303$

Tax on Land, 181-184, 325-333, 359

Graduated Taxation, 339

40. Theories:

Cause of Business Stagnation, $1,121,268-284$

Theory of Value, 33-65, 153

Theory of Money, 89-92

Seignorage Theory of the Value of Money, 113, 114

Volume Theory of the Value of Money, 115-125, 239, 320, 322

Commodity Theory of the Value of Money, 115-125, 239

Wage Theories, 163, 164, 166$169,347-350$

Interest Theories, $190-208$, 236-267

The Productivity Theory of Interest, 191-194, 243

The Abstinenee Theory of Interest, 195, 196

The "Positive Theory of Capital,” 197-206
40. Theories-Continued.

The "Surplus Value" Theory of Interest, 207, 208

The Monopoly Theory of Interest, 236-267

Current Theories of Business Stagnation, 277-284, 361363

Single Tax, 359-364

Socialism, 164, 207, 208, 365368

Communism, 368

Anarchism, 369-371

41. Theory, 1-3

Departure from Averages, 1, $43,58,215-224$

Induction and Deduction, 3

Multiple Funetion of Individuals, 16, 56, 247, 249

Adrantages of Graphieal Methods of Study, 46

42. Trade Unions, 354-358

Labor Legislation, 355

Arbitration in Labor Disputes, 356

Strikes and Boycotts, 357

What Trade Unions Aceom. plish, 358

43. Unit of Value, 28-32, 53, 54 . See also (2l) Gold

Dollar, the Value Unit of the United States, 28

Labor Cannot Serve as a Value Unit, 30, 164

Idealistic and Composite Units, 31, 32, 111, 119, 32]

Evaluation of the Current Unit, 54

Moncy not a Value Denominator, $78,79,115,122,123$

Bimetallism, 110

Depreciated Value Unit, 112 
44. Utilits, $6,7,9,24$

Potential Ltility, 10, 14, 132, 153,197

Utility in a Product is Limited, 14, 139

Utility Theory of Yalue, 62, 63

Final or Marginal Utility, 62 , 63,221

45. Valle, 23-65. See also (26) Land Valnes; (43) Unit of Value; (46) Value of Money

Exchange the Criterion of Value, $\mathbf{2 3}, \mathbf{2 5 - 2 7}$

Value Distinct from Utility, 24 Dual Meaning of the Term "Valne," 24, 25

Market Value is Estimated Value, 26

How Values are Measured, $2-$ Law of Value, $30,55,58,64$, 150

Theory of Value, 38-65, 153

Excliange Rate in Barter, 4750

Capitalized Values, 65

Valne of Products Independent of Interest Rate, $\mathbf{6 5}$

Value of Franchises Dependent on Interest Rate, 65

Value Cannot be Created by Law, 70, 125, 334

The Valne of Credit, 75, 76

The Value of Ciold, 108, 109, 320

The Value of Capital Goods, $132,133,152,153,197,198$

The Value of lending, 200

"Surplus Vahe," 207, 208

Exchange Cannot lin hance Values, 216
46. Value of Money, 94, 96, 98, $100,10 \overline{7}-125,239,240$

The Value of Standard Money, 94, 98, 114

The Valne of Credit Money, $95,66,101$

Value of Money not Due to Demand for Money, 97, 115, 123

Value of Money Measured by Conventional Unit, 107

Seignorage Theory of the Value of Money, 113, 114

Volume Theory of the Value of Money, 115-125, 239, 320, 322

Commodity Theory of the Value of Money, 115-125, 239

Greshamis Law, 123

Value of Money not Altered Between Exchanges, 134

47. WaGEs, 137, 163-169. (See also (17) Distribution of Wealth

The Sharing of Wages, 149, $165-169$

Wage Theories, 163, 164, 166$169,347-350$

Three Forms of Wages, 165

The Law of Wages, 166,347 350

Employers' Wages, 167, 168, 205,217

Competition Tends to Distribute Wages Equitably, 169

Wages a Residnal Share, 267

Effect of Proposed Curreney heform on Wages, 350 
Figs.1-2-3
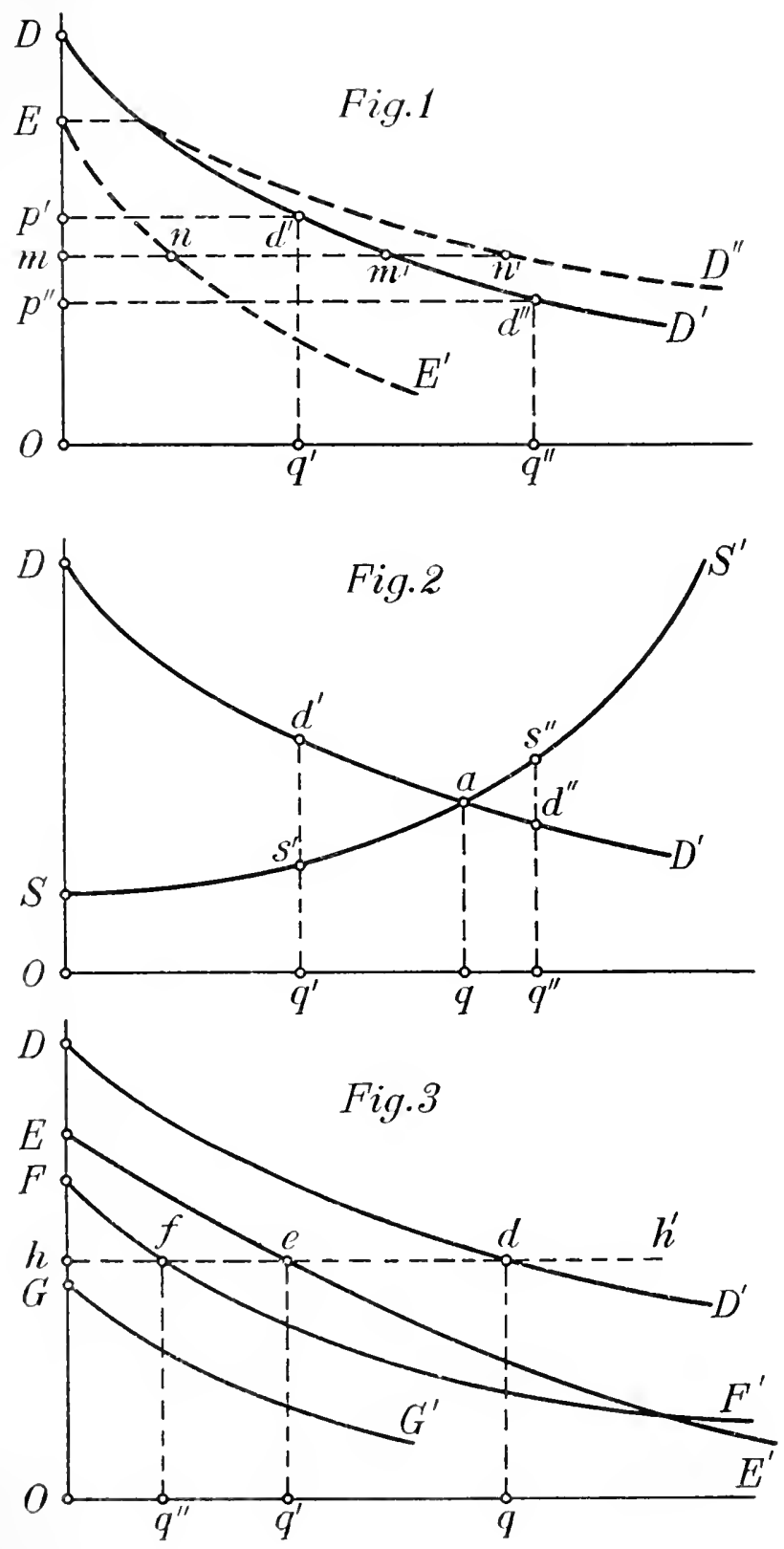
Figs.4-5-6
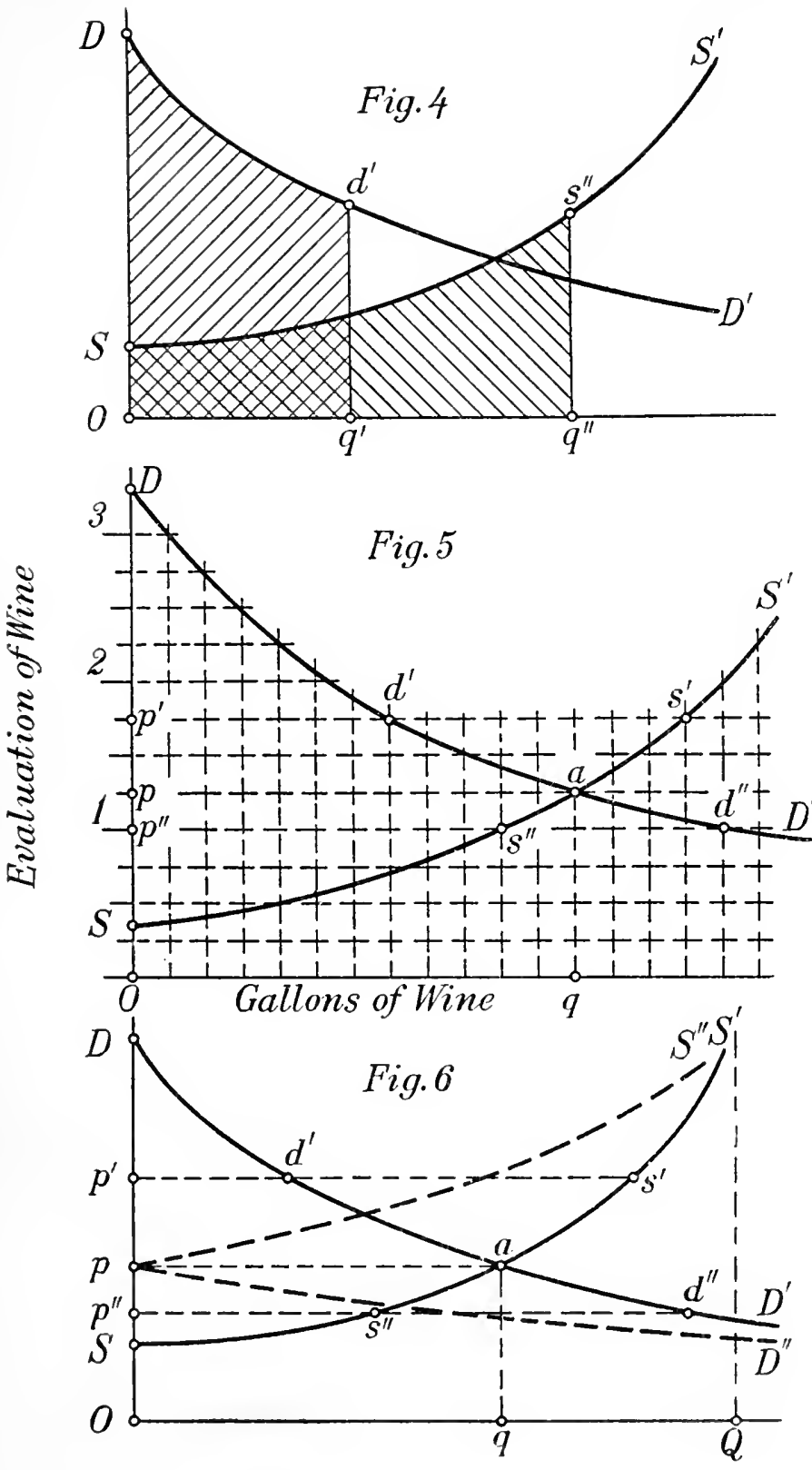
Figs.7-8-9-10
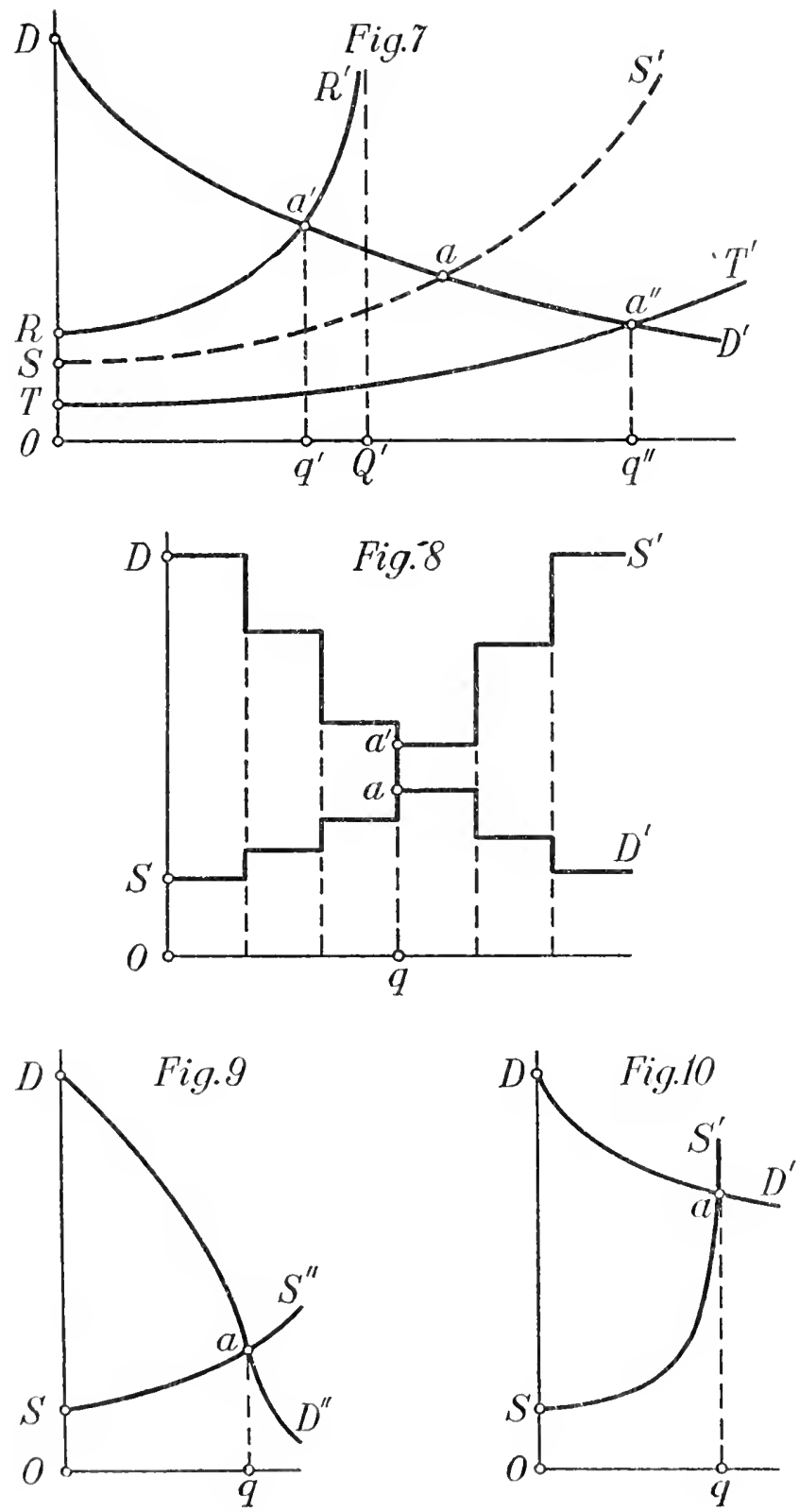

Figs.11-12-13
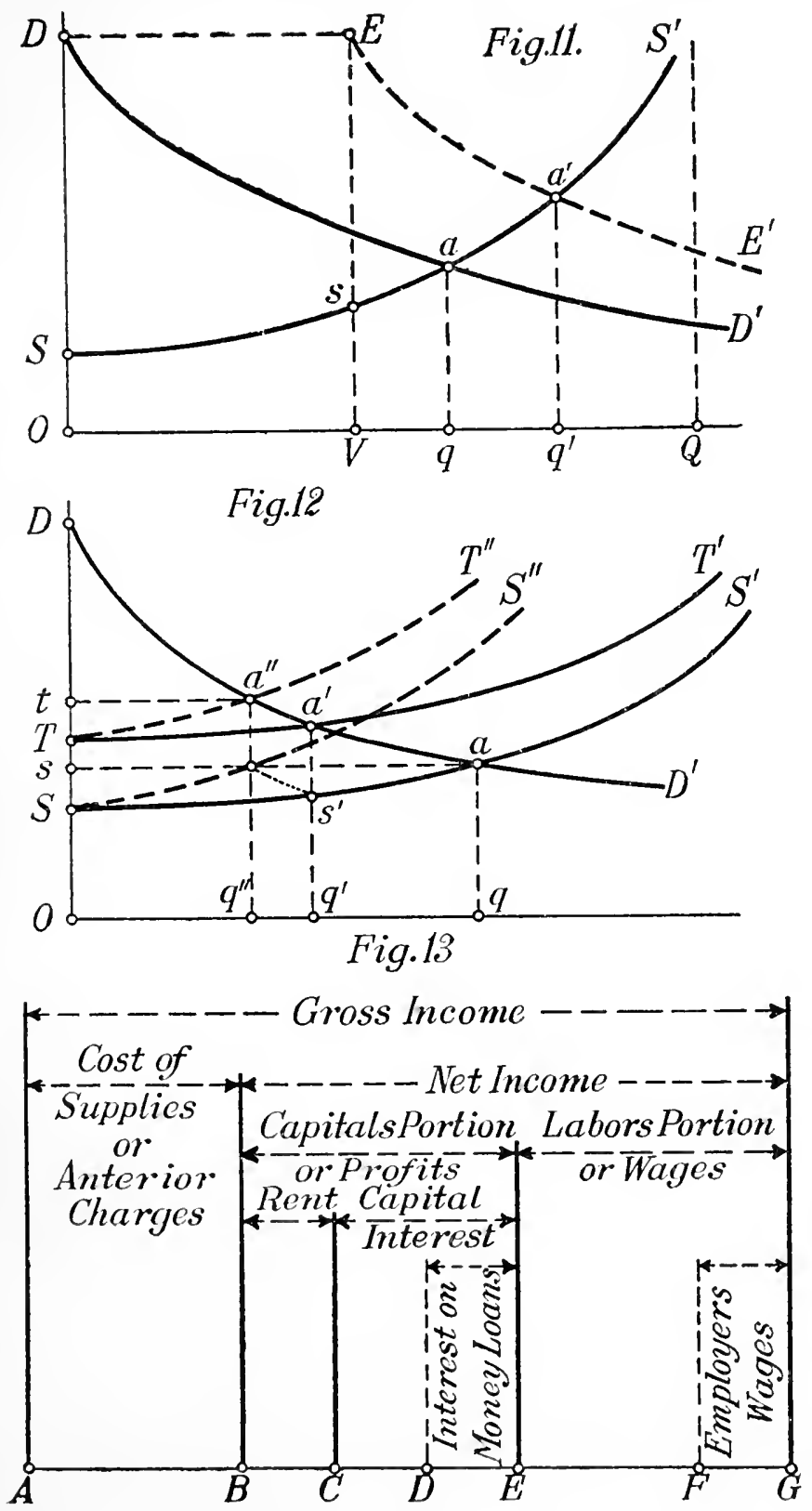


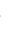


Figs.14 -15-16
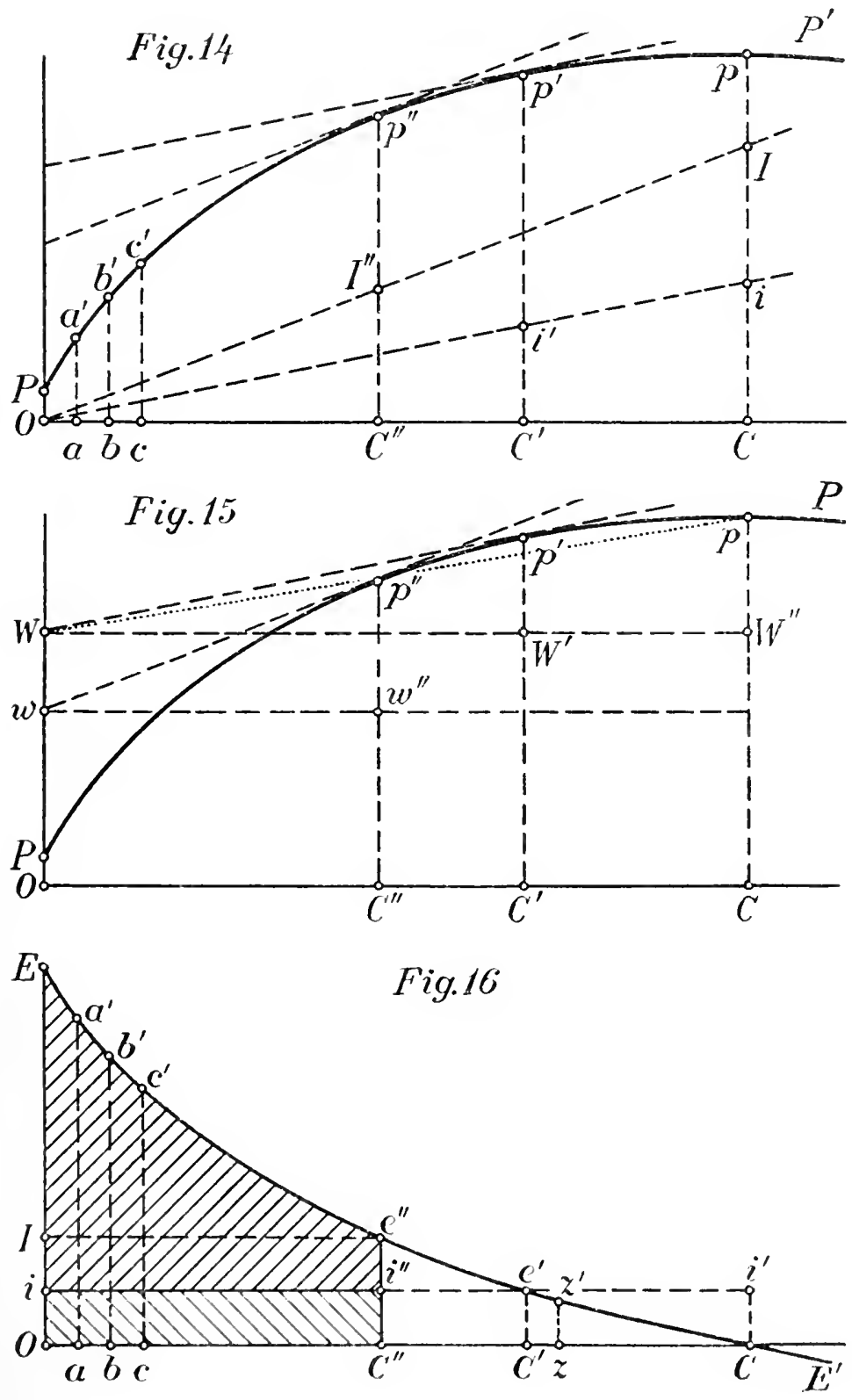


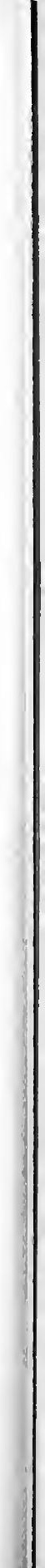



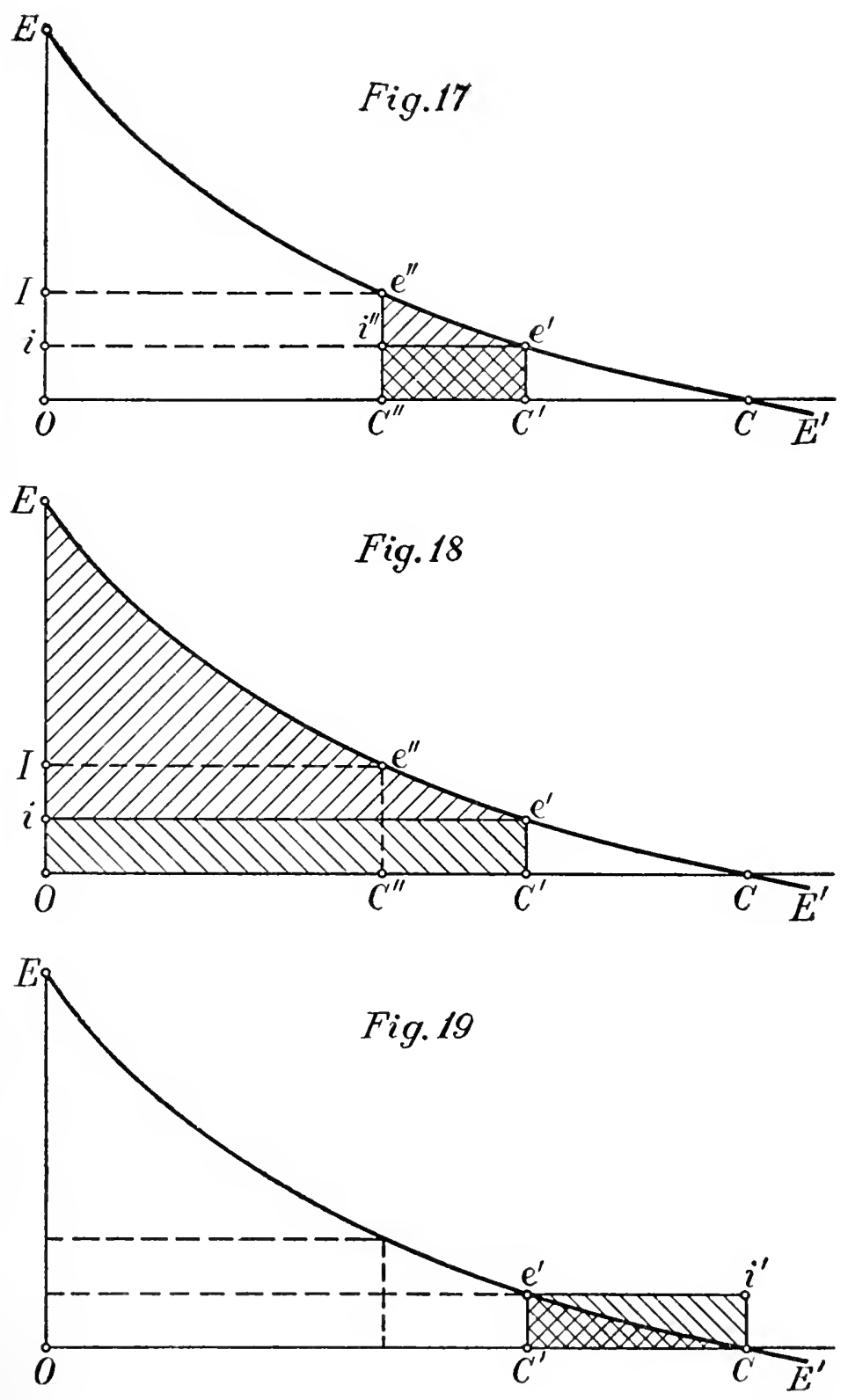
Figs.20-21-22
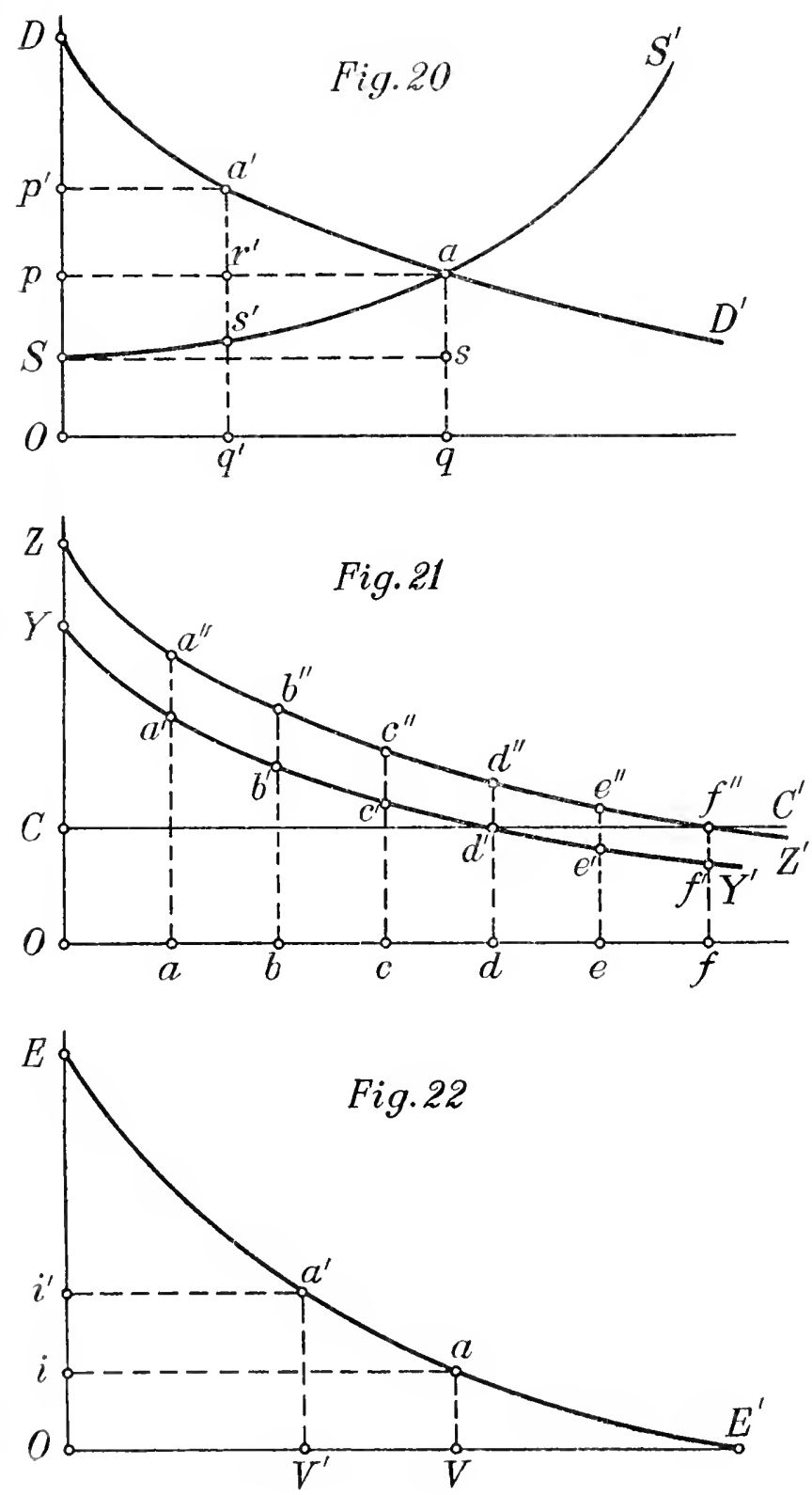

Figs. 23-24
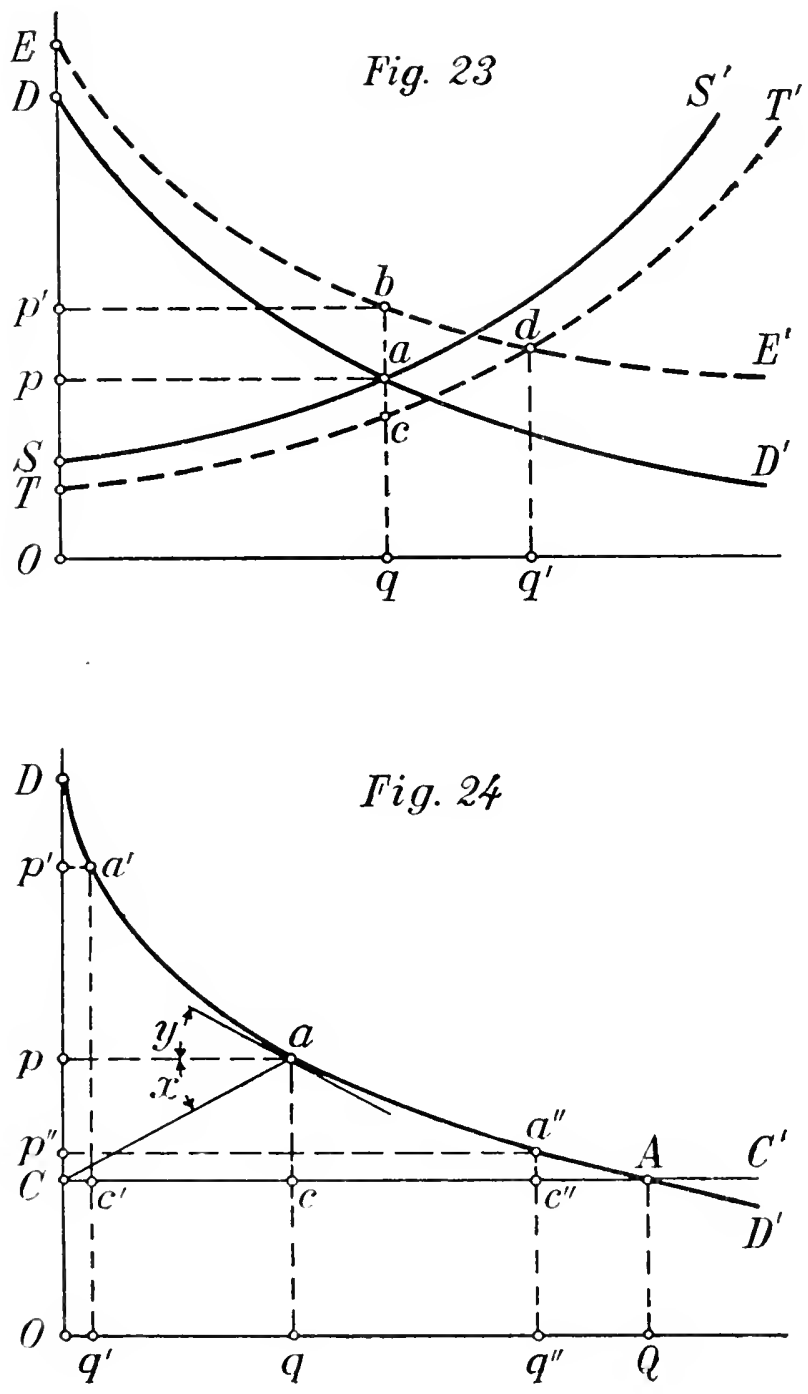
Fig. 25

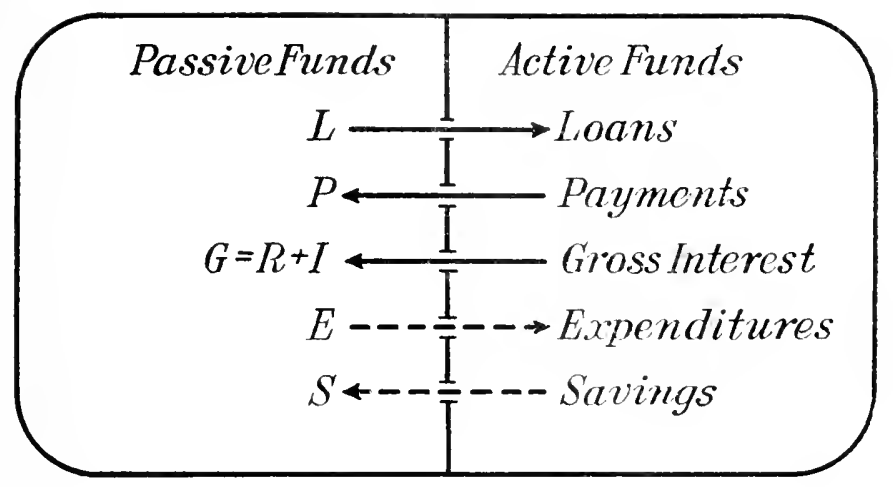

Fig. 26

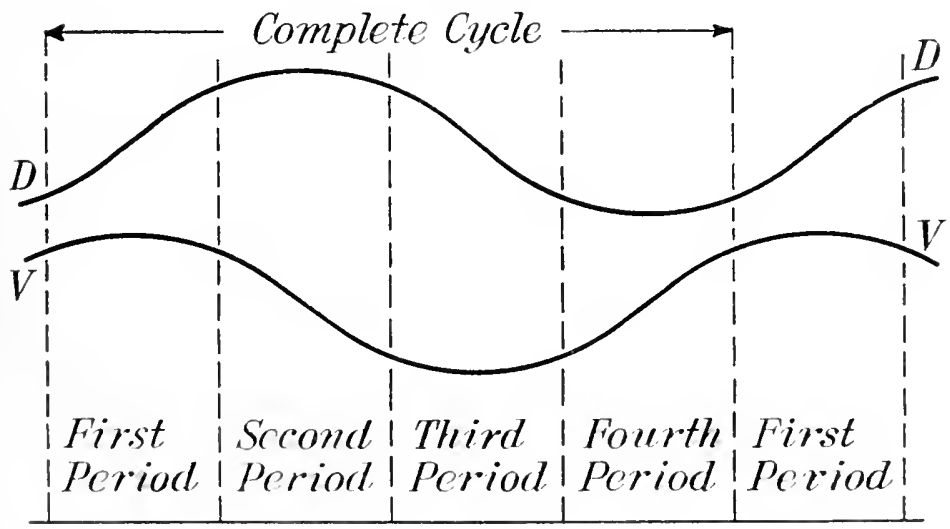




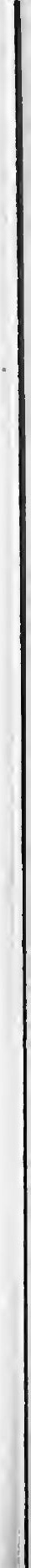


THE UNIVERSITY LIBRAD

AT
LOS ANGELES
LIBRARY




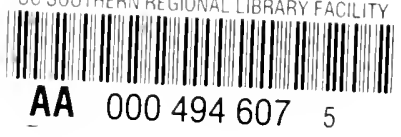




\section{(bitinflysts
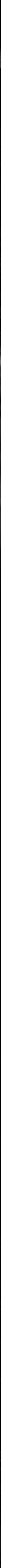